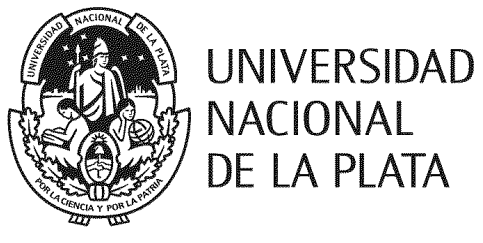

Tesis Doctoral

\title{
PROCESOS DE RECARGA/DESCARGA EN ACUÍFEROS SOMEROS DE LA REGIÓN COSTERA EN LA PROVINCIA DE BUENOS AIRES
}

Lucía Gómez

Directores:

Dr. Eduardo Kruse y Dra. Silvina Carretero 


\section{Agradecimientos}

Mi mayor agradecimiento es para Silvina Carretero y Eduardo Kruse por todo su apoyo y dedicación.

A la Dra. Cristina Dapeña por sus correcciones en la interpretación isotópica.

A las Cooperativas de Obras Sanitarias de San Clemente de Tuyú y de Santa Teresita por su ayuda en la construcción de la red de monitoreo de Mar del Tuyú.

A Dardo Guaraglia por sus enseñanzas en el cálculo de difusividad hidráulica.

A Santiago Perdomo y Javier Gomez por la geoeléctrica realizada.

A John Rapaglia por su ayuda en la medición de radón.

A Cesar Marcomini, Julieta Galliari por ayudarme y acompañarme en los relevamientos de campo.

A Renzo Guerrero de la Municipalidad de La Costa por los trabajos de nivelación.

A mis compañeros Marta, Patricia, Leandro, Juan, Maximiliano.

$Y$ todos aquellos que contribuyeron de alguna manera durante este tiempo. 
ÍNDICE

RESUMEN

$\begin{array}{ll}\text { ABSTRACT } & 9\end{array}$

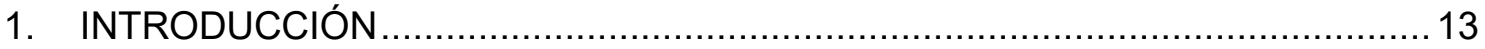

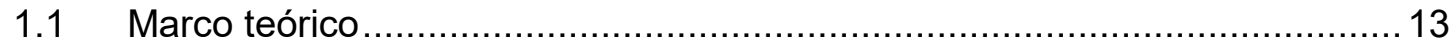

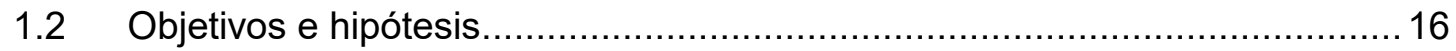

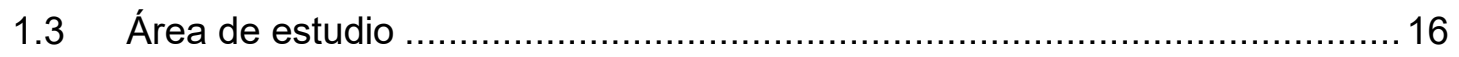

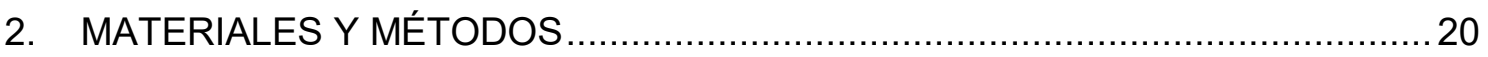

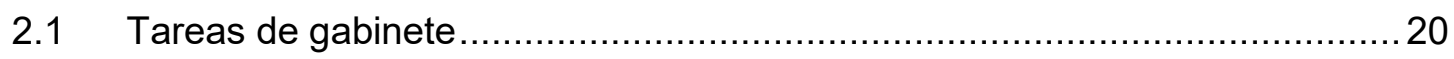

2.1.1 Recopilación bibliográfica e información antecedente............................20

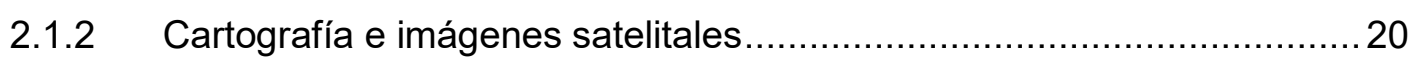

2.1.3 Uso de suelo y modificaciones en la recarga ........................................ 21

2.1.4 Datos climáticos y balances hídricos ................................................... 21

2.1.5 Elaboración e interpretación de los relevamientos hidrogeológicos .......24

2.1.6 Elaboración e interpretación hidroquímica ...........................................24

2.1.7 Elaboración e interpretación de datos de isótopos estables...................25

2.1.8 Sistema de Información Geográfica (SIG) …………........................26

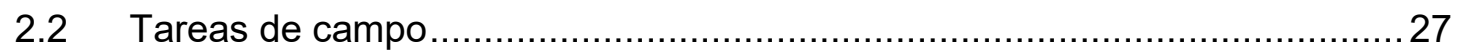

2.2.1 Instalación de redes de monitoreo ................................................ 27

2.2.2 Monitoreo periódico de niveles freáticos (mediciones manuales)...........29

2.2.3 Monitoreo continuo de niveles freáticos (sensores de presión)...............30

2.2.4 Extracción de muestras de agua subterránea.........................................31

2.2.5 Medición de la infiltración en el suelo mediante infiltrómetro de doble

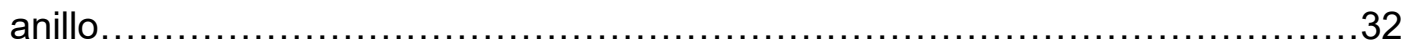

2.2.6 Determinación de humedad del suelo................................................ 35

2.2.7 Medidas puntuales de permeabilidad: Ensayos Slug Test .......................35

2.2.8 Cálculo de la difusividad hidráulica .................................................... 37

2.2.9 Relevamientos geoeléctricos ............................................................. 40

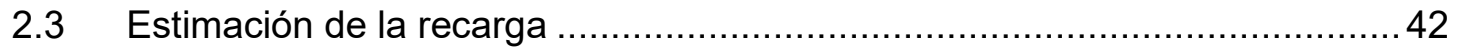

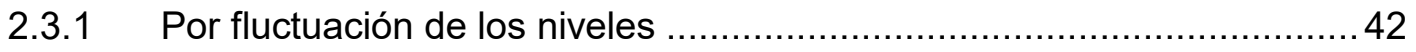

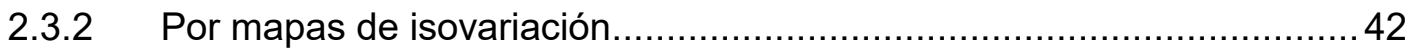

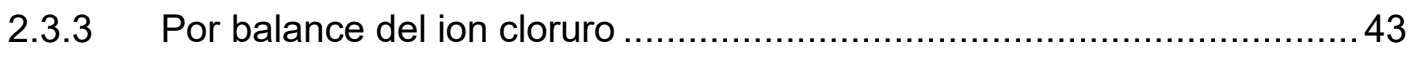

2.4 Determinación de la descarga submarina (SGD: submarine groundwater

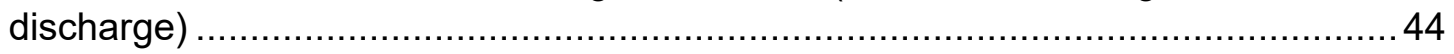




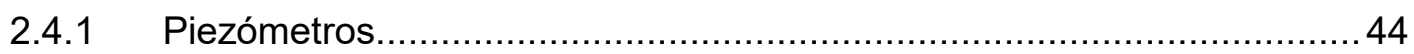

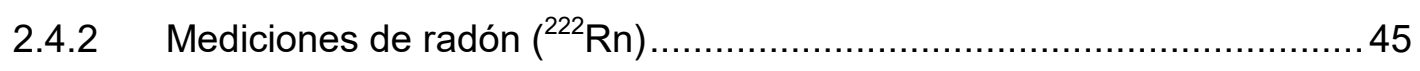

2.4.3 Tomografía de resistividad eléctrica (ERT) .....................................4 47

2.5 Efecto de las mareas del Río de La Plata sobre el agua subterránea en la

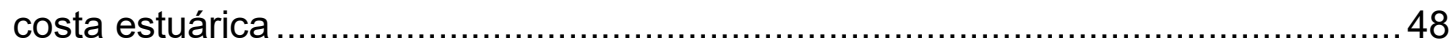

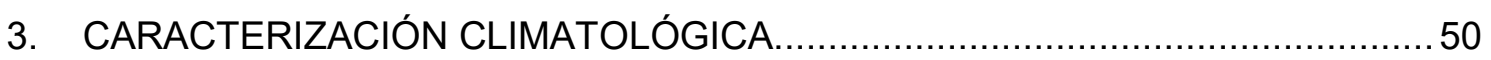

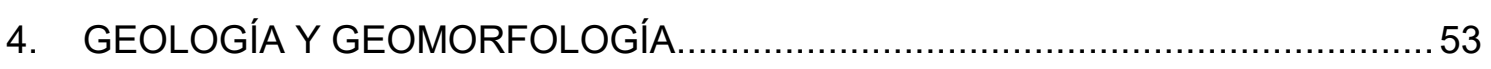

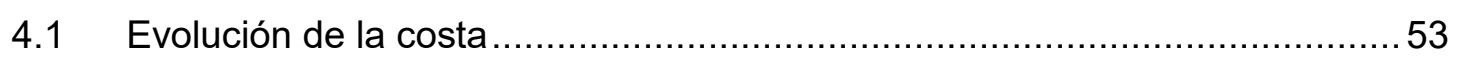

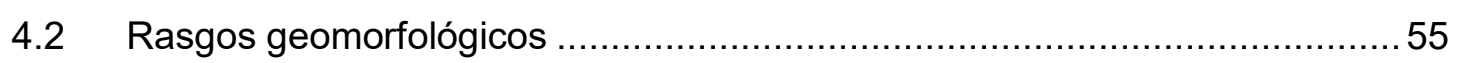

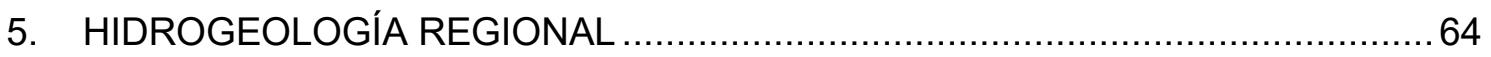

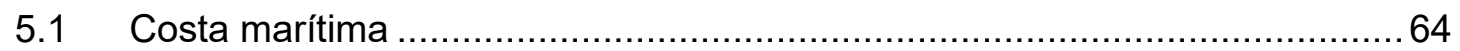

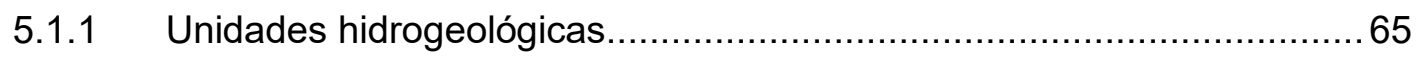

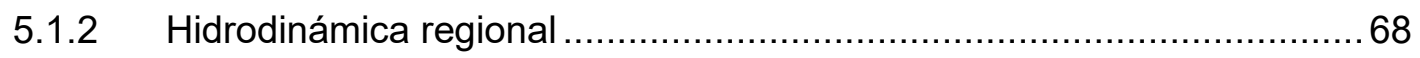

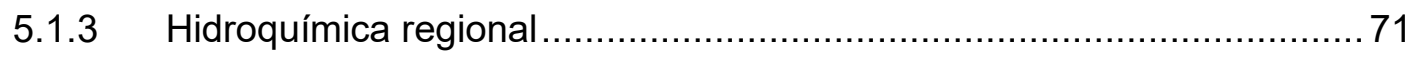

5.2 Costa estuárica (Río de la Plata) ....................................................... 71

6. CONDICIONES HIDROGEOLÓGICAS A ESCALA LOCAL ................................76

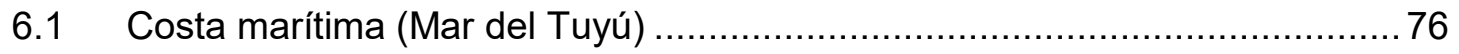

6.1.1 Caracterización del acuífero freático...............................................76

6.1.2 Estimación de la conductividad hidráulica $(\mathrm{K})$.................................. 78

6.1.3 Estimación de la velocidad de infiltración........................................... 79

6.1.4 Estimación de difusividad hidráulica en el acuífero freático ....................8 88

6.2 Costa estuárica (Río de La Plata) ......................................................... 91

6.2.1 Características del acuífero freático ................................................ 91

6.2.2 Estimación de la velocidad de infiltración.............................................95

7. BALANCES HÍDRICOS DURANTE LOS RELEVAMIENTOS ........................... 101

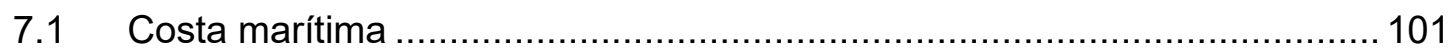

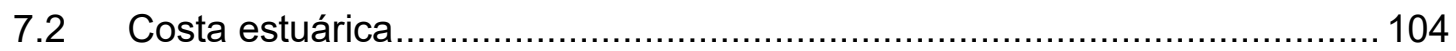

8. RECARGA / DESCARGA DEL AGUA SUBTERRÁNEA ............................... 107

8.1 Condiciones hidrodinámicas en la costa marítima (Mar del Tuyú) .............. 107

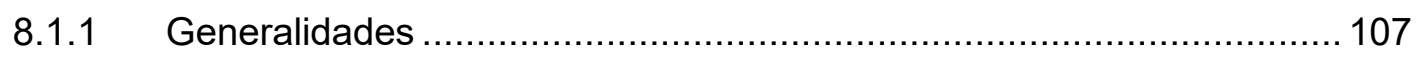

8.1.2 Índice de variación nivel freático / precipitaciones .............................. 115

8.2 Condiciones hidrodinámicas en la costa estuárica (Berisso)....................... 118

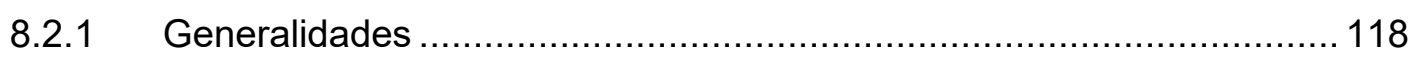

8.2.2 Efecto de las mareas del Río de la Plata sobre el agua subterránea en la

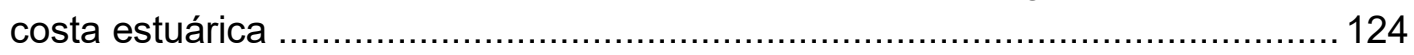

8.3 Condiciones hidroquímicas en la costa marítima (Mar del Tuyú) ................. 131

8.3.1 Características generales ..................................................... 131 


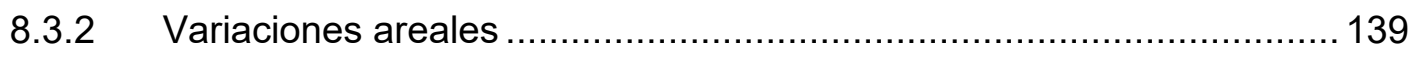

8.3.3 Variaciones temporales ..................................................... 146

8.4 Condiciones hidroquímicas en la costa estuárica (Berisso) ….................... 150

8.4.1 Características generales .......................................................... 150

8.4.2 Variaciones areales ................................................................. 156

8.5 Caracterización de isótopos estables (Deuterio y Oxígeno-18) del agua

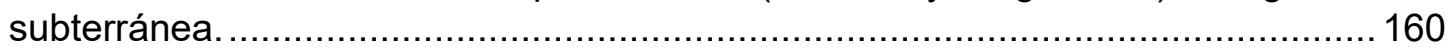

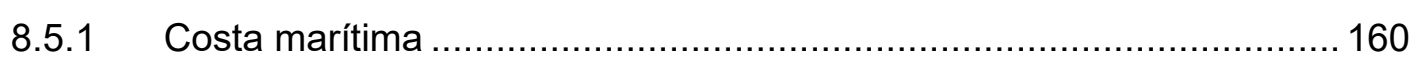

8.5.2 Costa estuárica.................................................................. 163

8.6 Relación recarga / conductividad eléctrica del agua subterránea................. 168

8.6.1 Costa marítima ....................................................................... 168

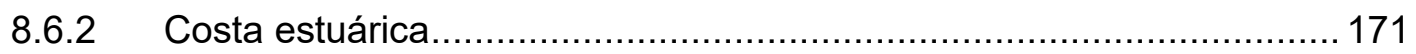

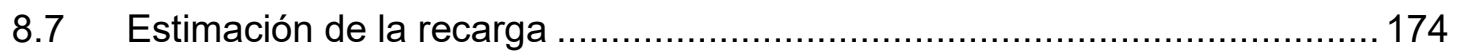

8.7.1 Estimación de la recarga por método de fluctuaciones de niveles

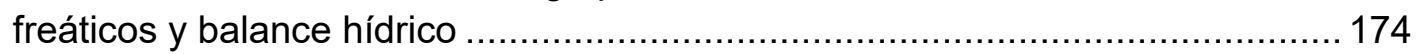

8.7.2 Estimación de la recarga por el método de balance de cloruros ...........177

8.7.3 Comparación entre métodos...................................................... 177

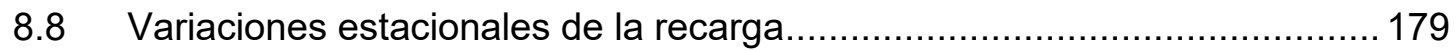

8.8.1 Recarga: Condiciones climáticas / Niveles freáticos ........................... 180

8.9 Cambios en el uso del suelo y modificaciones en las reservas .................... 186

8.9.1 Respuesta de los niveles freáticos en un sector de duna urbanizada y

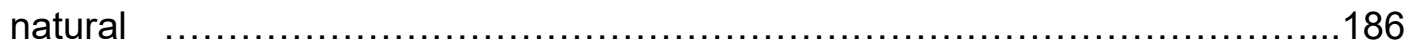

8.9.2 Análisis periodo (1955 - 2017) mediante el uso de imágenes.............. 189

8.10 Análisis mediante mapas de flujo (1987-2016) …................................... 194

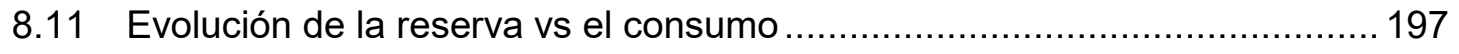

8.12 Comparación entre metodologías y otros sitios del cordón costero .............. 198

8.13 Detección de la descarga del agua subterránea al mar .............................. 199

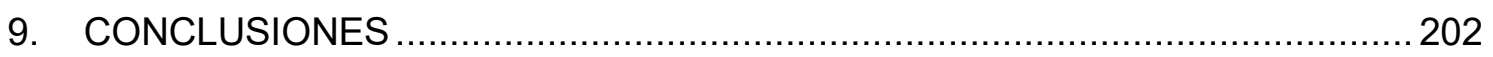

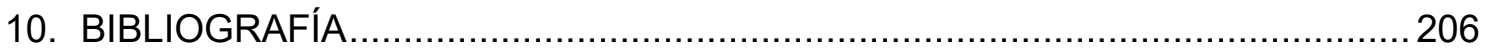

$\begin{array}{ll}\text { ANEXOS } & 221\end{array}$ 


\section{Resumen}

El acceso al agua dulce es el principal factor relacionado con el crecimiento económico y el desarrollo social de una región. En muchas zonas litorales los acuíferos costeros son la principal y única fuente de agua dulce apta para consumo humano. Los procesos de recarga/descarga en los acuíferos someros costeros representan a fenómenos complejos en cuanto a su interrelación con otras fases del ciclo hidrológico.

El objetivo general fue evaluar los procesos de recarga/descarga que actúan en el acuífero costero somero ubicado en forma paralela a la costa de la provincia de Buenos Aires.

En el sector oriental de la provincia de Buenos Aires se destaca al norte, la costa del Río de la Plata (zona estuárica intermedia); en la parte central, la Bahía de Samborombón (zona estuárica exterior); y al sur, el litoral atlántico (costa marítima). Para este estudio se seleccionó un sector de la costa atlántica y en forma complementaria se incluyeron algunas experiencias en la costa del Río de la Plata. En el primer caso corresponde a la zona identificada por la localidad de Mar del Tuyú (Partido de La Costa) y en el segundo la localidad de Los Talas (Partido de Berisso).

Las actividades desarrolladas incluyeron tareas de gabinete, campo y evaluación de los procesos de recarga y descarga. En la primera se efectuó la recopilación bibliográfica nacional e internacional, el estudio de imágenes satelitales acompañado del análisis de usos de suelo, cálculo de balances hídricos, elaboración e interpretación de los relevamientos hidrogeológicos, hidroquímicos e isotópicos. Se utilizó un sistema de información geográfica (SIG) como plataforma de mapeo. El trabajo de campo incluyó la instalación de redes de monitoreo del agua subterránea, el monitoreo periódico de niveles freáticos (mediciones manuales y automáticas), así como la extracción de muestras de agua para análisis químicos. Se realizaron ensayos de estimación de la velocidad de infiltración, determinación de humedad del suelo, cálculo de la difusividad hidráulica a partir de las mediciones de niveles, y relevamientos geoeléctricos. Para estimar la recarga se aplicaron metodologías a partir de la fluctuación de los niveles freáticos, mapas de isovariación y balance del ion cloruro. También se han estimado valores de descarga utilizando tres métodos de estudio: piezómetros, ${ }^{222} \mathrm{Rn}$ como trazador y tomografía de resistividad eléctrica. El estudio del efecto de las mareas del Río de la Plata sobre el agua subterránea en el humedal costero de Berisso también fue abordado.

La costa marítima está constituida por dunas de arena que conforman un cordón paralelo a la costa. A su vez para el sector específico de estudio se distinguen, de 
oeste a este: cordones litorales; campo de dunas inactivo vegetado; dunas semiactivas con crestas sin vegetación y con espacios interdunales totalmente vegetados y, dunas activas. Las características geológicas y geomorfológicas de este cordón costero facilitan la recarga del agua subterránea a partir del agua infiltrada de las precipitaciones, almacenándose en forma de lente de agua dulce, los cuales limitan tanto al este como al oeste con agua de elevada salinidad. En la costa estuárica se reconocen rasgos geomorfológicos relacionados a la planicie de marea relictual, cordones litorales conchiles y llanura estuárica. Los sedimentos que conforman estas unidades son holocenos de origen marino y fluvio-estuárico, los más recientes. En estas geoformas también las condiciones geológicas y geomorfológicas favorecen el predominio de la recarga de agua subterránea a partir de la infiltración de los excesos de las precipitaciones, formándose lentes de agua dulce, por encima de aguas de mayor salinidad y que la limitan al oeste y por debajo. Hacia el este, el límite lo constituye el agua dulce del Río de la Plata. En este caso la aplicación de métodos geoeléctricos permitió determinar la profundidad y distribución de los sedimentos en el subsuelo, así como delimitar la geometría y el contenido de agua dulce en el sector del cordón litoral.

En cuanto a las condiciones climáticas para el periodo estudiado, en general, las precipitaciones oscilaron en una media anual de 1000 y $1100 \mathrm{~mm}$ en ambos casos. La evapotranspiración real (ETR) en condiciones medias estaría en el orden del $65 \%$ de las precipitaciones y los excesos del $34 \%$ para la costa marítima y del 70 / 30\% para la costa estuárica del Río de la Plata. Los mayores excesos se registran entre marzo y octubre, no reconociéndose una variabilidad regional marcada, así como tampoco en la relación ETR - excesos.

En la costa marítima se define que el acuífero freático tiene una forma elongada en sentido norte-sur, donde las mayores alturas se encuentran en el sector central (área de recarga) y disminuyen hacia el este y oeste (áreas de descarga). El flujo subterráneo es divergente desde la zona de recarga con dos direcciones opuestas de descarga una hacia el continente y otra al mar. El flujo subterráneo en la costa estuárica indica un movimiento del agua en dirección SO - NE, produciéndose la descarga local y regional en el Río de la Plata. Localmente se manifiesta una morfología positiva en la capa freática con forma de lente debido al agua dulce contenida en los cordones litorales de conchillas.

En la costa marítima existe una relación directa entre las fluctuaciones de los niveles freáticos y los excesos del balance que se han transformado en recarga al acuífero. Si las precipitaciones acumuladas entre las fechas de relevamientos (aproximadamente 
30 días) son inferiores a $70 \mathrm{~mm}$, no se registra una elevación en los niveles freáticos. Se observa un comportamiento diferencial según la época del año en cuanto a la respuesta de los niveles freáticos. A igual cantidad de precipitaciones los mayores ascensos se obtienen en el semestre frío. En la costa estuárica de Berisso en periodos con excesos nulos o menores a $26 \mathrm{~mm}$ los niveles se profundizan, por lo cual se define que es necesaria una mayor contribución para producir la elevación de los niveles freáticos en este ambiente. En la llanura estuárica, esta relación no es tan clara ya que existiría una influencia de las mareas del Río de la Plata que enmascara la relación entre la variación de niveles freáticos y la recarga.

Los gradientes hidráulicos, velocidades de flujo y consiguiente valor de descarga en la costa marítima son mayores que en la costa estuárica debido a las características de los sedimentos.

En la costa marítima existe una variabilidad en la conductividad eléctrica (CE) del agua subterránea en función de la recarga (a mayor recarga menor $\mathrm{CE}$ ) aunque en términos generales, la correlación no presenta un buen ajuste en este área. En cambio, para la costa estuárica se verifica una relación inversa entre las alturas de los niveles freáticos y este parámetro.

Las mayores velocidades de infiltración para las dunas de la costa marítima se estimaron en el sector representativo de las condiciones naturales de la duna activa y disminuye bajo condiciones de compactación del terreno. Si bien en los cordones litorales (conchillas) de la costa estuárica los valores son altos, en la costa marítima son superiores indicando mayores posibilidades de recarga al sistema subterráneo. En ambos casos las reservas de agua almacenada dependen de la recarga natural a partir de la infiltración, siendo la fuente de abastecimiento a la población y cuya explotación se efectúa mediante pozos individuales.

Existe una relación entre el tipo de agua subterránea, el ambiente geomorfológico y el comportamiento hidráulico en ambos sistemas. En la costa marítima, la zona de recarga principal del cordón costero y la de descarga al mar, en su mayoría, presentan aguas bicarbonatadas sódicas, de baja salinidad, con valores aceptables para consumo humano. El sector de descarga al oeste se caracteriza por aguas con mayor contenido salino, siendo cloruradas sódicas y bicarbonatadas sódicas, con contenidos no aceptables para bebida, especialmente por la presencia de Fe y Mn. En la costa estuárica, el agua de los cordones litorales es bicarbonatada cálcica. En la planicie de marea relictual y en la llanura estuárica el agua se clasifica de tipo cloruradas y/o sulfatadas sódicas, salvo el pozo que presenta influencia del Río de la Plata y es 
bicarbonatada cálcica. El agua apta para consumo, excepto por el contenido elevado de Mn, sólo se alojaría en el cordón litoral.

Los análisis de isótopos de ${ }^{18} \mathrm{O},{ }^{2} \mathrm{H}$ y exceso de deuterio $(d)$ para la costa marítima indican que el agua de las precipitaciones se infiltra rápidamente alcanzando el nivel freático sin modificaciones en su composición isotópica. No se han detectado indicios de intrusión marina ni otros procesos de mezcla. En la costa estuárica también se indica que la lluvia es la principal recarga del sistema. Aunque existen pozos ubicados en la llanura estuárica y sometidos a la influencia de las mareas del Río de la Plata donde se registran procesos particulares.

A partir de estudios más específicos realizados en la costa marítima se observó que los cálculos de recarga mediante las fluctuaciones de los niveles freáticos y balance hídrico muestran que existe una correlación entre los meses con excesos y la respuesta de los niveles freáticos ante la recarga. El método por balance de cloruros es el que menores el valor de la recarga arrojó y podría deberse al corto periodo de muestreo utilizado.

También se detectó que existe una relación entre los cambios en el uso del suelo y modificaciones en la recarga, evidenciado por las variaciones en los valores de infiltración en las arenas del cordón costero.

La descarga de agua dulce subterránea en el mar (SGD) fue evaluada. La hidrodinámica y el uso de ${ }^{222} \mathrm{Rn}$ permitieron realizar una cuantificación, mientras que el método geofísico resultó más cualitativo y mostró la distribución areal de la SGD a lo largo de la línea de la costa atlántica.

Los resultados obtenidos para el cálculo de la difusividad hidráulica del acuífero son concordantes con los estimados a partir de ensayos de bombeo, por lo que la metodología propuesta sería aplicable a esta zona costera. A su vez se ha observado que la conductividad hidráulica presenta fuertes heterogeneidades en el área.

Las diferentes actividades socioeconómicas que se desarrollan en cada sector costero determinan que existan distintos usos y demandas de agua subterránea. En la costa marítima los requerimientos de agua dulce para consumo humano son especialmente altos durante los meses de verano debido al turismo. Por el contrario, en la costa estuárica se realizan distintos cultivos (entre ellos la vid) y la explotación de conchilla, por lo que existen canteras abandonadas y en actividad. En ambos casos el agua dulce almacenada en los acuíferos someros costeros representa la única fuente de abastecimiento a la población. La información obtenida resulta de utilidad para el manejo del recurso hídrico de ambas regiones. 


\section{Abstract}

Access to fresh water is the main factor related to economic growth and social development of a region. In many littoral zones, coastal aquifers are the main and only freshwater source for human consumption. Recharge/discharge processes in shallow coastal aquifers represent complex phenomena regarding its relationship with other phases of the hydrological cycle.

The aim of this thesis was to evaluate recharge/discharge processes acting in the coastal aquifer located parallel to Buenos Aires province coast.

In the western sector of the province of Buenos Aires it is possible to distinguish, in the northern area, the Río de la Plata coast (upper estuarine coast); in the central area, the Samborombón Bay (external estuarine coast) and; in the southern area, the Atlantic littoral (seacoast). For this study a sector of the Atlantic coast and, as a complementary study, some experiences in the Rio de la Plata coast were selected. The first case corresponds to the zone identified as Mar del Tuyú district (Partido de La Costa) and in the second, Los Talas district (Partido de Berisso).

Office, field work and recharge/discharge processes evaluation were developed. The first activity includes national and international bibliographic compilation, satellite imageries along with the evolution and land-use changes analysis, hydrological balances calculation, elaboration and interpretation of hydrological, hydrochemical and isotopic data. A Geographic Information System (GIS) was used as a mapping tool. Field work included groundwater monitoring networks installation, phreatic level measurements (manual and automatic), and groundwater sampling for chemical analysis. Infiltration velocity tests, soil moisture tests, hydraulic diffusivity calculation from groundwater level measurements and geoelectric campaigns were carried out. For recharge calculation, water-level fluctuation, water-level change maps and chloride mass balance methods were applied. Discharge was also calculated applying tree methods: piezometers, ${ }^{222} \mathrm{Rn}$ as a tracer and electrical resistivity imaging. Río de la Plata tides effect on the groundwater of the coastal wetland in Berisso was also studied.

The seacoast area is constituted by sand dunes that form a fringe parallel to the coastline (sand-dune barrier). In turn, for the specific study area it is possible to distinguish, from west to east: beach ridges, inactive field dune with vegetation; semi active dunes with crests with no vegetation and interdune areas totally vegetated and; active dunes. The geological and geomorphological characteristics of the sand-dune 
barrier facilitate groundwater recharge from infiltration of the precipitation, accumulating as a groundwater lens which is limited to the east and west with high salinity water In the estuarine coast it is possible to identify geomorphological environments as the relict tidal plain, shell ridge and estuarine plain. The sediment forming these units are marine Holocene and fluvial-estuarine, the latest. In these geoforms, geological and geomorphological conditions favor groundwater recharge from infiltration of the water surplus from precipitation, forming freshwater lenses over the high salinity groundwater which limits the lens on the west and below. Towards the east, the limit is constituted by the Río de la Plata freshwater. In this case geoelectrical methods allowed to determine the depth and distribution of the sediments underground and, in addition, to define the geometry and freshwater content in the shell ridge sector.

Regarding the climatic conditions for the studied period, in general, the precipitations annual average varied between 1000 and $1100 \mathrm{~mm}$ in both cases. The mean actual evapotranspiration (AET) is in the order of $65 \%$ of the precipitations and the water surplus of the $34 \%$ for the seacoast and of $70 / 30 \%$ for the estuarine coast of the Río de la Plata. The highest water surplus occurs between March and October, and it was not recognized a regional variability and either in the relationship AET- surplus.

In the seacoast the phreatic aquifer is defined by an elongated shape in direction northsouth where the maximum topographic heigh coincides with the central sector of the dune (recharge area) and it decreases towards the east and west (discharge areas). From the divide, groundwater flows into two opposite directions, towards the continent and towards the sea. Groundwater flow in the estuarine coast indicates a water flow in SW-NE direction producing local and regional discharge towards the Río de la Plata. Locally, due to freshwater storage in the shell ridge, a positive morphology in the phreatic level on a lens shape is shown.

In the seacoast there is a direct relationship between groundwater level fluctuations and water surplus which—through infiltration-constitute the recharge to the aquifer. If accumulated precipitation between surveys (circa 30 days) is lower than $70 \mathrm{~mm}$ the rise in the phreatic level is not detected. A different behavior of the groundwater level was observed according to the season. Given the same amount of precipitation the highest rise in the groundwater level were observed in the cold season. In the estuarine coast of Berisso in periods with surplus equal to zero or lower than $26 \mathrm{~mm}$ groundwater level decrease, therefore it is defined that is necessary a higher water surplus to produce a groundwater rise in this environment. In the estuarine plain, this 
relationship is not that clear because of the influence of the Río de la Plata tides which mask the relationship between the phreatic level fluctuations and recharge.

Hydraulic gradients, flux velocities and therefore, recharge values in the seacoast are higher than in the estuarine coast due to the sediment characteristics.

There is a variability in the groundwater electrical conductivity according to the recharge in the seacoast, although in general terms, the relationship is not clear in this area. In turn, in the estuarine coast, an inverse correlation between the phreatic levels and this parameter was verified.

In the sand dune of the seacoast, the highest infiltration velocities were obtained in the sector representing the natural conditions of the active dune. These velocities are reduced under soil compaction conditions. In the shell ridge of the estuarine coast, infiltration velocity values are also high, but in the seacoast are higher, indicating higher possibilities of recharge to the groundwater system. In both cases groundwater reserves depend on the natural recharge from infiltration, being the source of supply to the population and which exploitation is conducted by individual wells.

There is a relationship between groundwater type, the geomorphological environment and the hydraulic behavior in both systems. In the seacoast, in the sand dune barrier main recharge area, and the discharge towards the sea area, for the most part, present sodium-bicarbonate water with low salinity and acceptable concentrations for human consumption. The discharge towards the sea area is characterized by water with higher salt concentration being sodium-chloride and sodium-bicarbonate types with nonacceptable concentrations for drinking water, especially because the presence of $\mathrm{Fe}$ and $\mathrm{Mn}$. In the estuarine coast, groundwater in the shell ridge is calcium-bicarbonate type. In the relic tidal plain and the estuarine plain, groundwater is classified as sodiumchloride and/or sodium-sulphate types, except for the well which shows an influence from the Río de la Plata and presents calcium-bicarbonate water type. Drinking water, except for the high concentration of $\mathrm{Mn}$, would be only stored in the shell ridge.

Isotopes of ${ }^{18} \mathrm{O},{ }^{2} \mathrm{H}$ and deuterium excess $(d)$ analysis for the seacoast indicate that water from precipitation quickly infiltrates reaching the phreatic level with no modification in the isotopic composition. Saltwater intrusion or other mixing processes were not detected. In the estuarine coast it is also indicated that precipitation is the main recharge to the system. Although there are wells located in the estuarine plain and affected by the tides of the Río de la Plata where particular processes were noticed. 
From specific investigations conducted in the seacoast, recharge calculation via waterlever fluctuation method and the water balance show a correlation between months with water surplus and the groundwater level response to the recharge. The chloride mass balance method seems to underestimate the recharge value and it would not be recommended in the coastal area.

There was also detected that there is a relationship between land-use changes and modifications in the recharge, demonstrated by variations in infiltration values in the sand-dune barrier.

Submarine groundwater discharge (SGD) was assessed. The hydrodynamics and the use of ${ }^{222} \mathrm{Rn}$ allowed to make a quantification while the geophysical method was qualitative and shows the spatial distribution of the SGD along the Atlantic coastline.

The results obtain for the aquifer hydraulic diffusivity calculation are in agreement with the values calculated from pumping test, for this reason the proposed method would be applicable in this coastal area. Also, in this area, an important heterogeneity in the hydraulic conductivity values were observed.

The different economical activities developed in each coastal area determine the existence of different water demand and uses. In the seacoast, drinking water demand is especially high during summer months due to tourism. On the other hand, in the estuarine coast there are different kinds of farming (grapevine among others) and extraction of shell with abandoned and active quarries. In both cases freshwater stored in the shallow coastal aquifers represents the only source for water supply to the population. The obtained information is useful for the water resources management in both regions. 


\section{INTRODUCCIÓN}

\subsection{Marco teórico}

A nivel mundial las zonas costeras son sitios que albergan las mayores densidades poblacionales. El acceso a agua dulce es el principal factor relacionado con el crecimiento económico y el desarrollo social de una región. En muchas zonas litorales los acuíferos costeros son la principal y única fuente de agua dulce apta para consumo humano.

En el ambiente litoral los acuíferos costeros se encuentran alojados frecuentemente en depósitos sedimentarios tales como cordones litorales, y dunas que son las geoformas típicas de hallar en las llanuras costeras. Para poder hacer un uso sustentable del recurso hídrico es necesario establecer un modelo conceptual del funcionamiento del sistema acuífero. Entender sus dimensiones y su capacidad para almacenar agua nos dará idea de las reservas de agua disponible. La hidrodinámica e hidroquímica del acuífero no solo depende de sus características intrínsecas, sino también de la interacción con el medio físico que lo rodea. Las características geológicas, geomorfológicas, estratigráficas, edáficas e hidrometereológicas del área influyen en la dinámica del acuífero. El establecimiento de un modelo conceptual de funcionamiento facilita la identificación de las entradas y salidas del agua es decir la recarga y descarga al sistema acuífero.

Estos procesos de recarga/descarga en los acuíferos someros costeros representan a fenómenos complejos en cuanto a su interrelación con otras fases del ciclo hidrológico. Para lograr resultados aplicados a los problemas relacionados con estos procesos es necesario considerarlos en forma simplificada según las escalas espaciales y temporales requeridas teniendo como base las características particulares del medio físico en el caso de estudio.

Esta complejidad conlleva una incertidumbre, a la que se le debe adicionar la escasez de datos en las observaciones y mediciones. Es importante reconocer dicha incertidumbre para aplicar los resultados que se obtengan y así, a partir de la comparación de los métodos utilizados, minimizar los errores en su aplicación.

Los principales controles sobre la recarga son el clima, hidrología, geomorfología y geología (Scanlon et al., 2002). Entre las variables propias del ambiente físico, que afectan al proceso de recarga se encuentran la humedad antecedente del suelo y el espesor de la zona no saturada (ZNS) (Sophocleus y Perry, 1985). Las propiedades del suelo y del acuífero varían de un lugar a otro tanto lateral y como verticalmente. Muchos métodos eliminan esta variabilidad espacial utilizando variables regionalizadas 
a través de promedios de datos o la generalización de medidas puntuales. El tiempo involucrado en el proceso determinará si se trata de una recarga a corto plazo, recarga estacional, recarga perenne o recarga histórica. La variabilidad temporal a corto plazo ocurre después de una lluvia, la recarga estacional durante periodos húmedos, la recarga perenne donde el flujo descendente es casi permanente y la recarga es continua (Simmers, 1988). Además, la recarga puede clasificarse como difusa o localizada. Si la infiltración es continua a lo largo de toda la superficie del terreno durante determinados periodos de tiempo, lo que implica una recarga distribuida espacialmente, es un proceso difuso. Si el flujo se concentra por vías o canales preferenciales causando flujos rápidos, la recarga es localizada.

Las fuentes de recarga y los principales procesos (recarga directa, indirecta y localizada) de los sistemas hídricos han sido objeto de investigación de diversos autores.

Algunos autores centran su investigación en las metodologías utilizadas en la estimación de recarga y los factores que promueven o limitan el uso de cada técnica. (Sharma, 1989; Lerner et al., 1990; Simmers, 1998; De Vries y Simmers, 2002).

Scanlon et al. (2002) presentan una clasificación de las diferentes metodologías para estimar la recarga a los acuíferos. Las técnicas ya sean físicas, trazadores o modelos matemáticos difieren en los rangos de tasas de recarga que estiman y de las escalas espacio temporales que representan. Los enfoques de los métodos a utilizar dependerán de las características del sitio donde se producirá la recarga. Climas áridos y húmedos requieren enfoques diferentes para cuantificarla.

Distintos autores (Samper, 1997; Custodio, 1998; Simmers, 1998; Scalon et al., 2002) sugieren la aplicación y comparación de diferentes procedimientos metodológicos corroborados por mediciones de campo de las diferentes variables involucradas para aumentar la confiabilidad de las estimaciones de la recarga. El método del balance es la forma más común de estimar recarga de manera indirecta debido a que todas las variables se pueden medir excepto la recarga, que se obtiene por diferencia o valor residual. La precisión del resultado va a depender de la precisión con que se midieron los demás componentes.

Las zonas templadas y húmedas se caracterizan por aguas subterráneas con los niveles freáticos menos profundos siendo la recarga principalmente de tipo autóctona y directa. La tasa de recarga está limitada por la capacidad de almacenar y transmitir agua, lo que está condicionado por las características geológicas y geomorfológicas. En estas áreas son aplicables metodologías basadas en estudios de la zona saturada. 
La evaluación de recarga de acuíferos es crucial para determinar la disponibilidad de recursos hídricos y el establecimiento de los caudales ambientales, aspecto de especial relevancia en sistemas en los que existen relaciones con los cauces superficiales, con zonas húmedas, y/o relaciones agua dulce/salada (García-Aróstegui et al., 2017). Los acuíferos freáticos son los más susceptibles a la contaminación, y la tasa de recarga puede dar un orden de su nivel de vulnerabilidad (Simmers, 1997). Una explotación intensiva de acuíferos costeros puede provocar descensos de niveles y agotamiento del acuífero, el deterioro de la calidad por mezclas con aguas salinas, por ejemplo, por intrusión marina o mezclas con acuíferos subyacentes o adyacentes de mala calidad.

Los estudios de recarga de acuíferos costeros de la costa atlántica bonaerense son los realizados por Carretero y Kruse (2014) quienes analizaron las variaciones en el uso del suelo entre 1973 y 2010 utilizando imágenes Landsat, y evaluaron las modificaciones en la recarga del acuífero como consecuencia de la urbanización en el Partido de La Costa. Se reconoció una reducción del volumen de recarga, que en condiciones naturales se estima en el orden 440 mm ( 40\% de la precipitación anual) en un $10 \%$ debido a las modificaciones en el uso del suelo donde la duna se vio reemplazada por superficies urbanizadas mayormente impermeables. Pero si se tiene en cuenta cada núcleo urbano la reducción de la recarga va desde el 18 al 25\%. En otros trabajos Carretero et al. (2013c) analizaron las variaciones de la recarga asociadas al uso del suelo entre 1987 y 2012 resultando en valores entre el $21 \%$ en San Clemente y el $30 \%$ en Las Toninas-Santa Teresita. En el trabajo efectuado por Carretero et al. (2021) donde se analiza la variación de la recarga entre 1957 y 2016 , fundamentalmente como consecuencia de la forestación, se observó una reducción en la recarga del $19 \%$ en Punta Médanos y un $24 \%$ en Pinamar.

Rodrigues Capítulo et al. (2018) comparan la recarga producida en dos sectores diferentes de la costa atlántica (San Clemente y Pinamar). Se verifica la variabilidad en las posibilidades de recarga en zonas forestadas (bosques de Coníferas, Acacias, Tamariscos) y no forestadas (duna sin cobertura vegetal). Ambos estudios se efectuaron sobre el mismo cordón costero. En un caso, la reducción en la recarga se relaciona con el avance de la urbanización, en cambio en el otro como consecuencia de la implantación de forestación no nativa que ha sustituido al suelo desnudo. Se deduce que el efecto de la forestación sobre el ciclo hidrológico es mucho mayor que el producido por el crecimiento de las urbes. 


\subsection{Objetivos e hipótesis}

El objetivo general fue reconocer los principales procesos de recarga/descarga que caracterizan el acuífero costero somero alojado en forma paralela a la costa de la provincia de Buenos Aires.

Para cumplir con el objetivo general se presentan los siguientes objetivos específicos:

- Definir particularidades de la recarga y descarga del agua subterránea en base a las condiciones hidrodinámicas, hidroquímicas e isotópicas.

Se postula que en condiciones naturales, geoformas positivas y de litología permeable, constituyen reservorios lentiformes de agua dulce cuyo volumen está fuertemente influenciado por las posibilidades de infiltración de los excesos de agua del balance hidrológico. Para poder estimar la recarga es necesario conocer el acuífero, sus características y sus mecanismos de recarga y descarga.

- Evaluar las modificaciones que influyen en el comportamiento del acuífero somero como consecuencia de cambios en el uso del suelo y su posible afectación en la recarga del agua subterránea.

Se plantea que en la región costera, con excesos de agua en el balance hídrico, los procesos de recarga y la explotación de las aguas subterráneas están condicionados por los cambios en los usos del suelo, incidiendo en las posibilidades futuras de abastecimiento de agua.

- Identificar los factores hidrológicos que influyen en las variaciones de la recarga de los acuíferos someros, para que puedan ser utilizados como herramienta de gestión.

El conocimiento del medio físico, del clima y de los procesos de recarga y descarga del acuífero posibilitan un entendimiento global del funcionamiento del sistema. La cantidad y calidad de agua subterránea que se almacene en los acuíferos también dependerá de la acción antrópica en la región costera a estudiar. Por esta razón es necesario un tratamiento integrado del ciclo hidrológico para la aplicación de acciones que permitan alcanzar un equilibrio entre el desarrollo socioeconómico sustentable, las necesidades de agua y la protección del ambiente en las regiones costeras.

\section{3 Área de estudio}

La provincia de Buenos Aires posee $1200 \mathrm{~km}$ de costa. A lo largo de toda su extensión se desarrollan ambientes litorales y paisajes sumamente diversos, resultantes de una gran heterogeneidad geológica, geomorfológica, climática y ecológica. En el sector oriental de la provincia de Buenos Aires se destaca, al norte, el estuario del Río de la 
Plata que se subdivide en tres zonas superior, intermedia y externa (Difrieri 1982) y al sur, el litoral atlántico (costa marítima).

Para este estudio se seleccionó un sector de la costa atlántica (marítima) y en forma complementaria se incluyeron algunas experiencias en la costa estuárica del Río de La Plata (Figura 1.1). En el primer caso corresponde a la zona identificada por la localidad de Mar del Tuyú (Partido de La Costa) y en el segundo la localidad de Los Talas (Partido de Berisso).

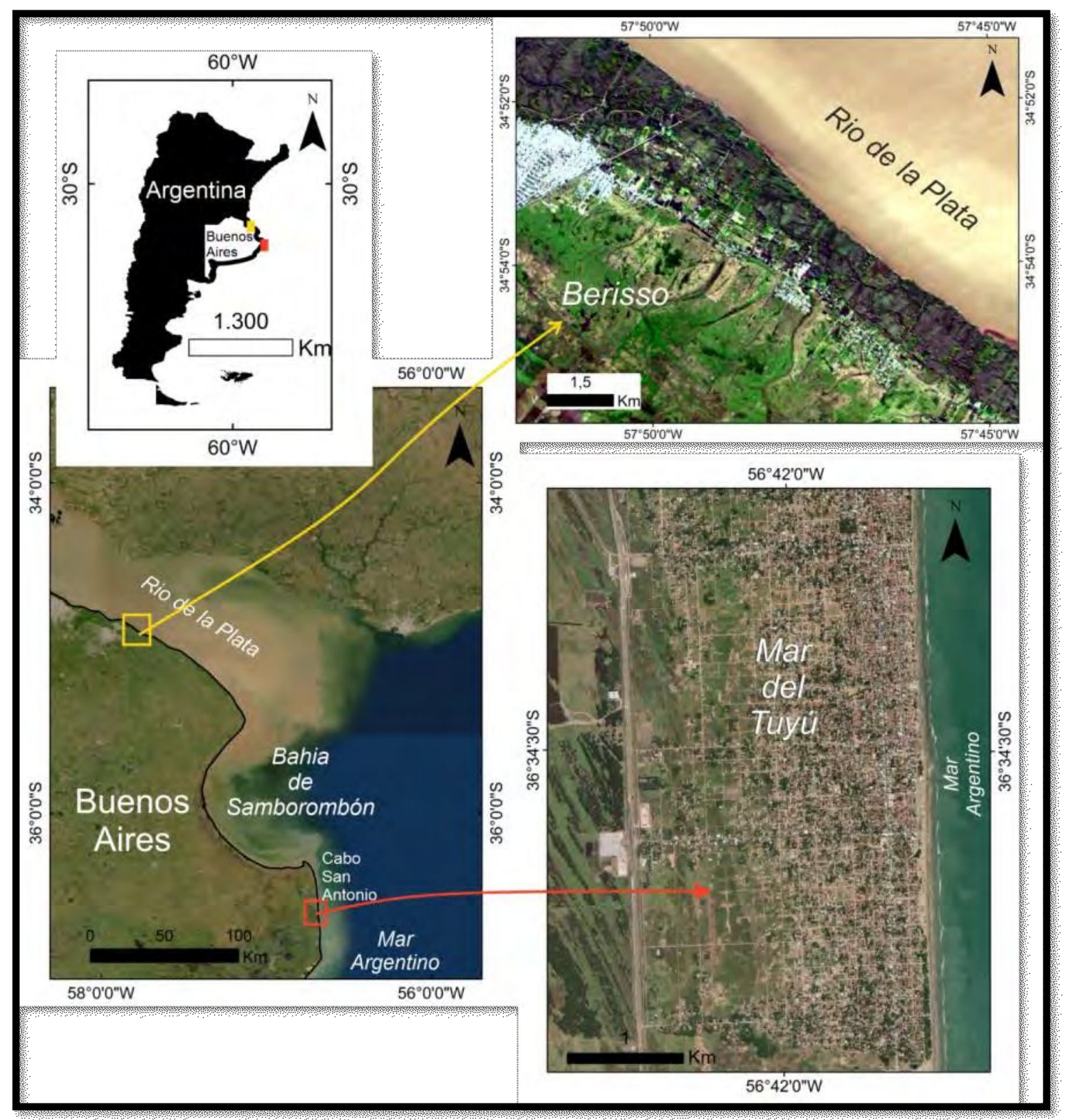

Figura 1.1 Área de estudio.

El sector principal de esta investigación corresponde a una franja costera ubicada en la parte central del Cabo San Antonio, entre los $36^{\circ} 33^{\prime}$ y $36^{\circ} 36^{\prime}$ de latitud sur y los $56^{\circ} 41^{\prime}$ y $56^{\circ} 42^{\prime}$ de longitud oeste. En este sector se encuentra la localidad de Mar del 
Tuyú, partido de La Costa. Su extensión alcanza los 2,5 km de ancho por $4 \mathrm{~km}$ de largo (Figura 1.2). La explotación del recurso hídrico es a través de perforaciones domiciliarias, ya que la localidad no cuenta con servicio de red de agua potable. Existe servicio de red cloacal lo cual es un paso importante en la preservación de calidad química de las aguas subterráneas. La población estable se encuentra en el orden de los 8000 habitantes (INDEC, 2010) pero por tratarse de una zona cuya única actividad económica es el turismo, durante el verano este número puede llegar a quintuplicarse.

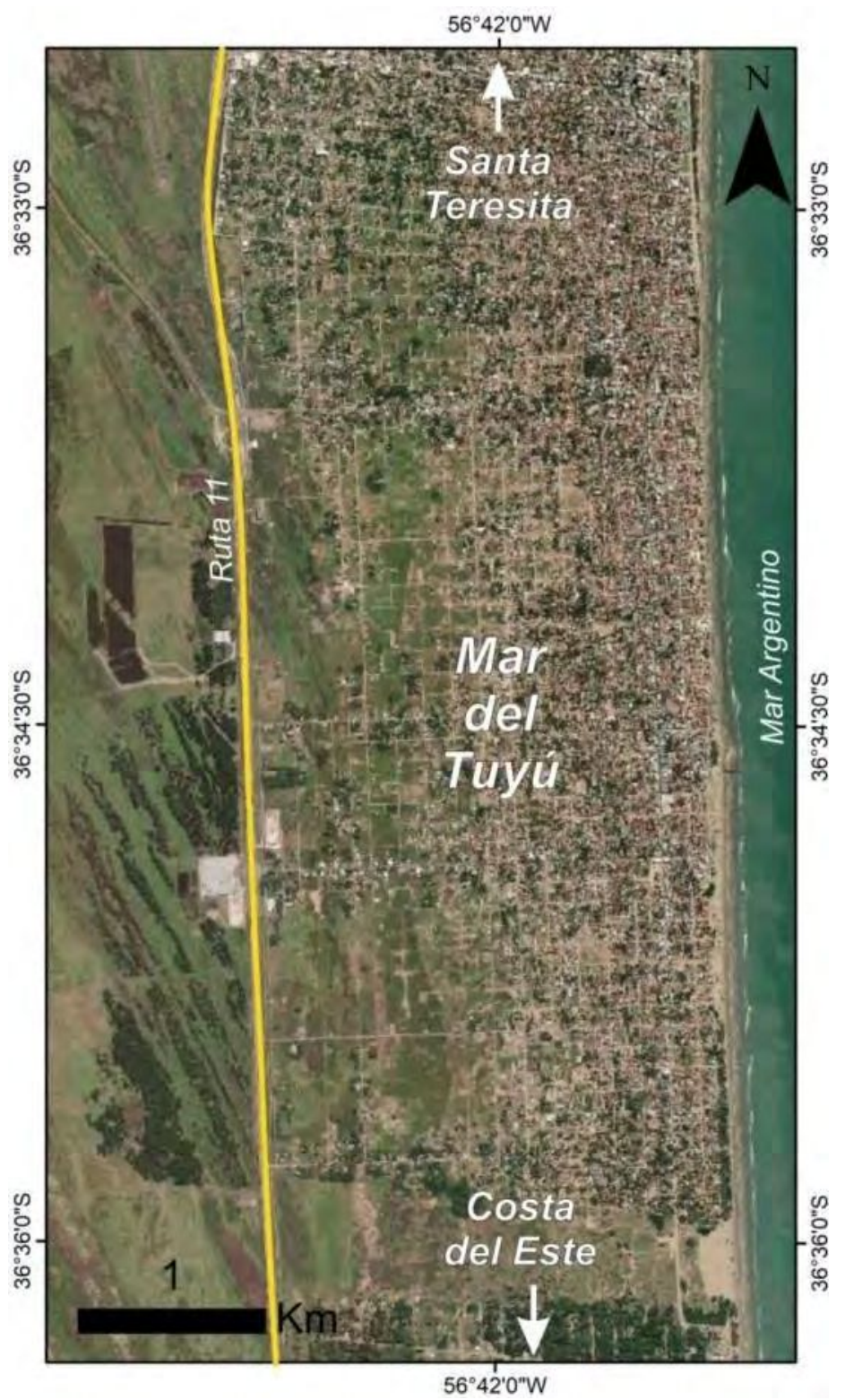

Figura 1.2 Localidad de Mar del Tuyú, partido de La Costa (costa marítima).

El área complementaria de este estudio, correspondiente al borde sur del Río de la Plata, se circunscribe entre las coordenadas $34^{\circ} 52^{\prime}$ y $34^{\circ} 56^{\prime}$ de latitud sur y $57^{\circ} 43^{\prime}$ y $57^{\circ} 50^{\prime}$ de longitud oeste, ocupa una franja costera de $12 \mathrm{~km}$ de largo por $2 \mathrm{~km}$ de ancho dentro del Partido de Berisso. Esta franja se encuentra limitada al este por el 
Río de la Plata y al oeste por la Avenida Montevideo (Figura 1.3). Esta zona se caracteriza por ser un área rural muy poco poblada (INDEC, 2001) con 494 habitantes. Cabe señalar que el sitio no cuenta con servicio cloacal y el sistema de red de agua potable se restringe a las viviendas aledañas a la Avenida Montevideo. El resto de la población se abastece de agua potable a través del servicio municipal de reparto de agua (carro hidrante que suministra agua a los tanques de PVC domiciliarios una vez por semana). Una pequeña parte opta por una alternativa natural de recolección, almacenamiento y uso del agua de lluvia como fuente de consumo para las familias y demás usanzas (doméstico, productivo, etc.).

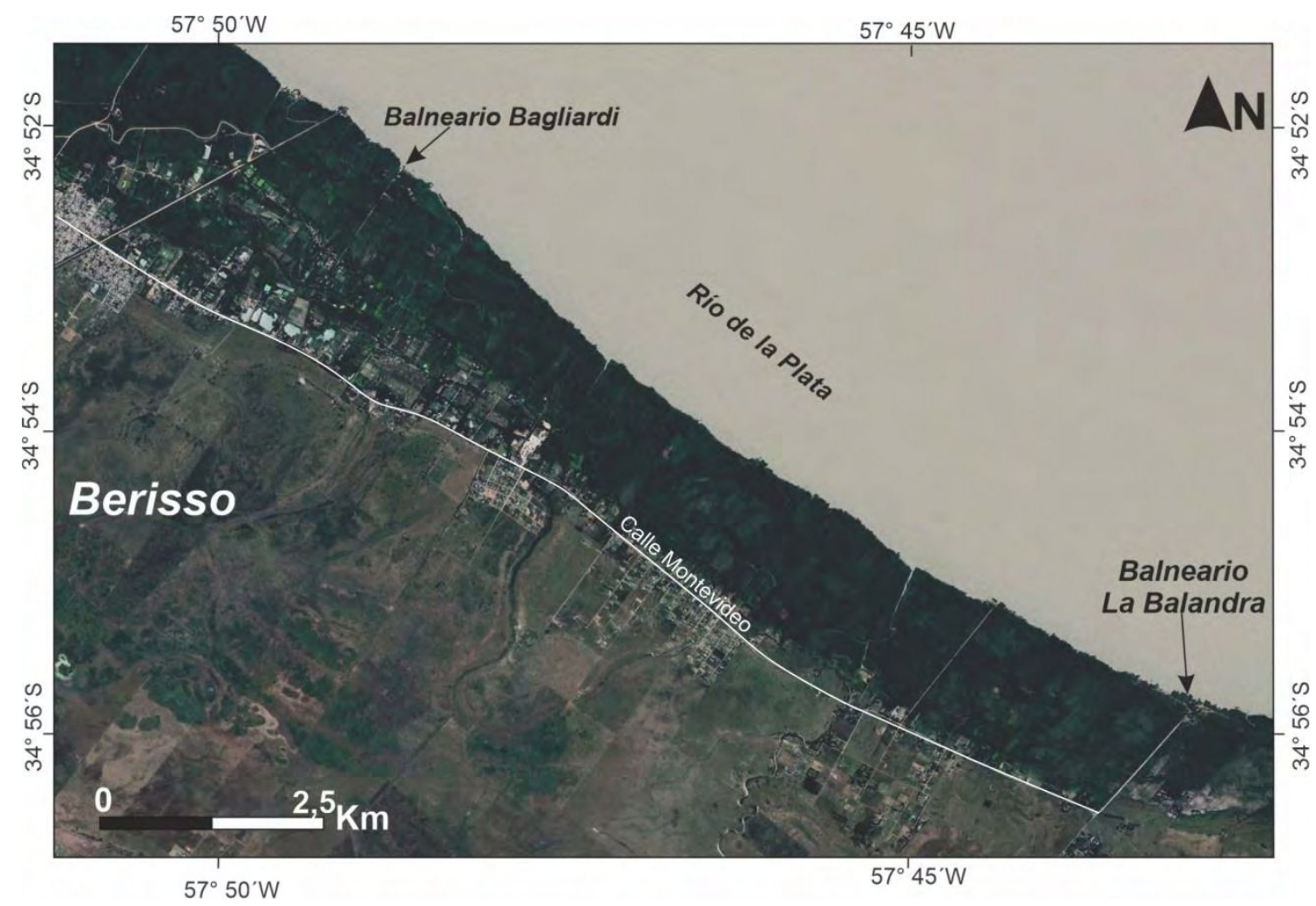

Figura 1.3 Borde sur del Río de la Plata localidad de Los Talas, partido de Berisso (costa estuárica). 


\section{MATERIALES Y MÉTODOS}

En este capítulo se presenta en forma amplia las actividades realizadas y su asociación con las distintas técnicas empleadas para alcanzar los resultados obtenidos.

Por esa razón se incluyen no sólo los métodos tradicionales de la estimación de la recarga / descarga sino también aquellas actividades desarrolladas, que incluyeron tareas de campo, gabinete y laboratorio, los cuales condujeron a la recolección de datos básicos para la caracterización del área de estudio y el establecimiento de un modelo conceptual del comportamiento del agua subterránea. Además, se mencionan los procedimientos utilizados en la adquisición de datos y análisis para la estimación de parámetros hidráulicos del acuífero y también para la evaluación de la recarga.

\subsection{Tareas de gabinete}

\subsubsection{Recopilación bibliográfica e información antecedente}

La primera tarea consistió en la recopilación bibliográfica para enmarcar y caracterizar la región estudiada. La información antecedente sobre la geología, geomorfología, hidrogeología regional ha sido relevada de numerosas y variadas fuentes de información, las cuales han sido utilizadas como base y serán citadas al realizarse la referencia en el texto.

La consulta de bibliografía internacional sobre la temática de acuíferos costeros, interfase agua dulce-agua salada, intrusión salina, antropización, y sobre todo lo relativo al proceso de recarga, entre otros, ha sido considerada como referencia siendo mencionada en el desarrollo la tesis.

\subsubsection{Cartografía e imágenes satelitales}

La interpretación de imágenes satelitales y fotografías aéreas permitió el mapeo de unidades geológicas y geomorfológicas de la región, que fueron reconocidas y caracterizadas en los trabajos de campo.

Fotografías aéreas del año 1955 del Ministerio de Obras Públicas de la Provincia de Buenos Aires permitieron el mapeo de la geomorfología ya que al no existir casi población solo se observa el paisaje natural. En las imágenes satelitales recientes perteneciente a Digital Globe, Google Earth se pudo observar la configuración actual y el trazado urbano que cubre en gran parte la geomorfología natural de dunas. Las fotos fueron georreferenciadas utilizando un Sistema de Información Geográfica. 


\subsubsection{Uso de suelo y modificaciones en la recarga}

Se ha realizado un análisis de la distribución territorial, para lo cual se han digitalizado diferentes zonas de acuerdo a las características observadas en las fotos, imágenes y trabajo de campo.

También se efectuaron clasificaciones supervisadas de imágenes y fotografías aéreas de diferentes años con el objetivo de evaluar los cambios de uso de suelo. Asociados a esos cambios se han evaluado las modificaciones en la recarga

\subsubsection{Datos climáticos y balances hídricos}

Dada la existencia de información climatológica regional antecedente ya publicada en informes realizados por CFI (1990, a) y de investigaciones actuales realizadas por Carretero (2011) en esta tesis se analizan fenómenos climáticos locales.

El análisis climatológico a escala local se realizó analizando e interpretando los datos aportados por la estación meteorológica ubicada en Santa Teresita (Lat. 36³2'24.30" S; Long. 56² $43^{\prime} 13.15^{\prime \prime}$ W) a $3 \mathrm{~km}$ del área de estudio (Figura 2.1). Esta estación proporciona un registro continuo cada 15 minutos de la lluvia (mm) y presión atmosférica $(\mathrm{hPa})$.

La estación permite recuperar los datos online y se pueden descargar en formato Excel que facilita su manipulación. Al obtenerse un dato cada quince minutos en un mes se registran alrededor de 2900 datos. Desde enero de 2015 a diciembre de 2018 se fueron acumulando datos diarios de precipitación, pudiéndose obtener los valores diarios, mensuales y anuales que caracterizan al área de estudio. La precipitación representa la única entrada de agua al sistema acuífero. 


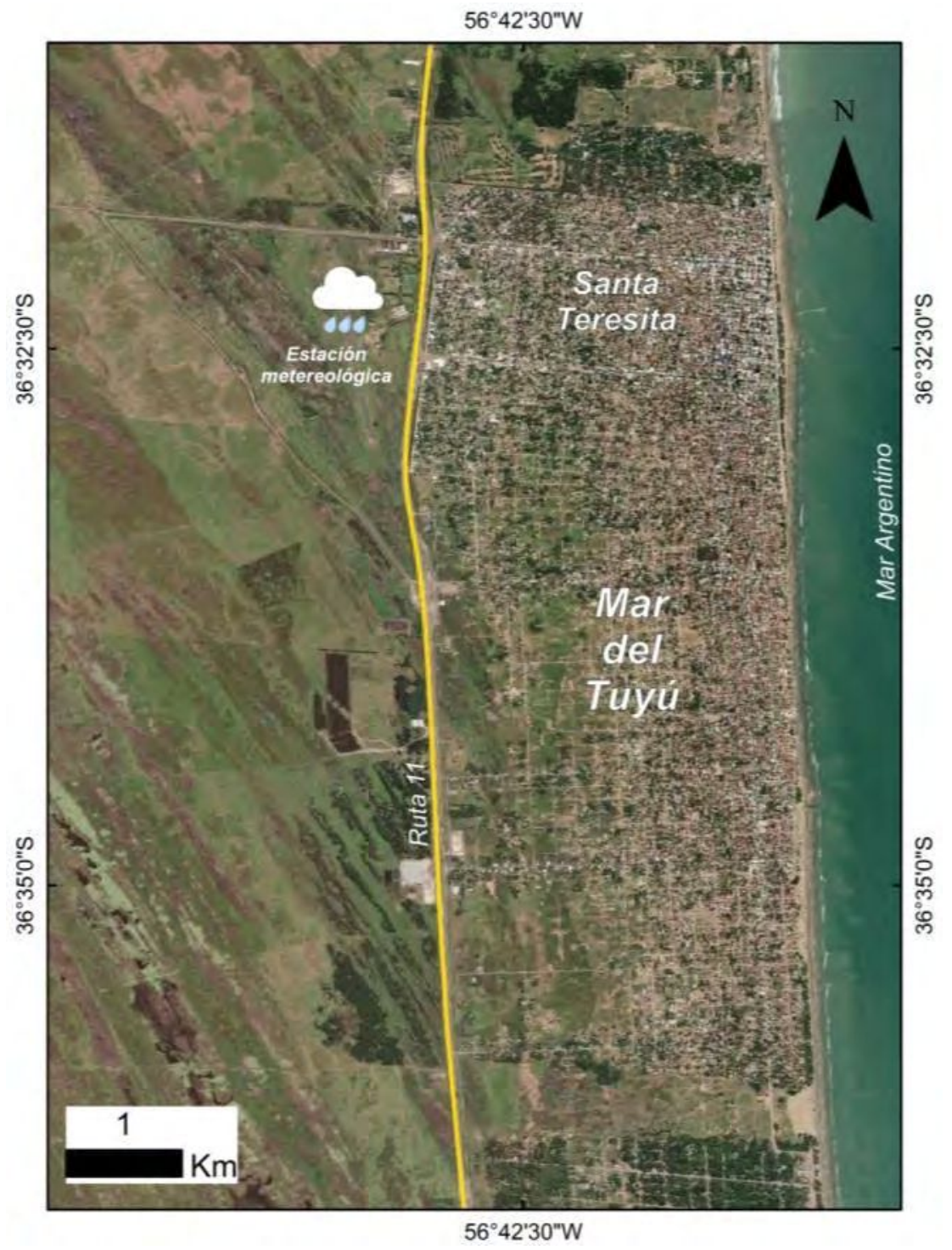

Figura 2.1 Ubicación de estación meteorológica.

Una de las experiencias de campo realizadas para analizar la recarga a escala de detalle requirió de la instalación de 4 pluviómetros (Figura 2.2) los cuales fueron instalados en las cercanías de cuatro freatímetros en los cuales, a su vez, se instalaron registradores de nivel continuos. Los cuatro pozos seleccionados se ubican en la unidad geomorfológica campo de dunas semiactivas que corresponde hidrodinámicamente a la zona principal de recarga. Los pozos MT6 y MT11 se ubican en el sector urbanizado y los dos restantes MT7 y MT10 se ubican más al oeste donde prevalecen las características naturales. La finalidad fue obtener un detalle de los ascensos de niveles luego de un evento de lluvia, además de comparar la respuesta de los cuatro pozos frente al mismo evento de precipitación. También se analiza la existencia de cambios en la infiltración de las arenas del cordón costero como consecuencia de las actividades antrópicas. 


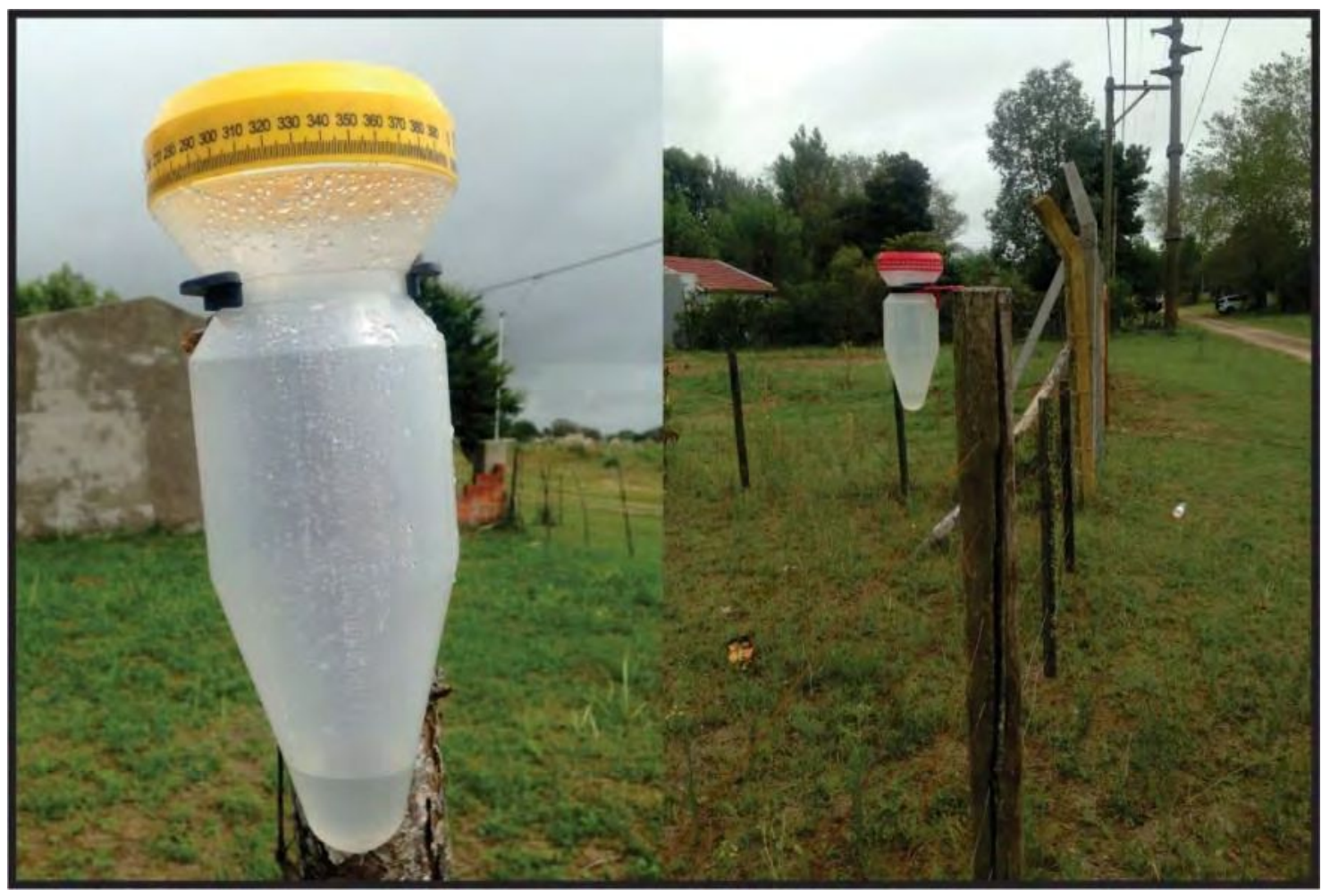

Figura 2.2 Pluviómetros instalados para analizar la recarga a escala de detalle.

Se calcularon balances mensuales para ambos sectores del área de estudio según la metodología de Thornthwaite y Mather (1955). Para la costa estuárica (Berisso) los datos de precipitaciones fueron obtenidos de la estación La Plata Observatorio y para la costa marítima, de la estación previamente mencionada.

Para la determinación de los excesos de agua en la zona de Mar del Tuyú se efectuaron balances hídricos diarios de acuerdo a los datos de precipitación disponibles y los valores de $\mathrm{ET}_{0}$ (Evapotranspiración potencial diaria, $\mathrm{mm} / \mathrm{d}$ ) estimados con la fórmula de Hargreaves (Hargreaves y Samani, 1985). Esta fórmula utiliza como insumos la temperatura y radiación solar extraterrestre. La primera se ha obtenido de la plataforma Windgurú y la segunda de tablas.

$$
E T_{0}=0,0023\left(t_{\text {med }}+17,78\right) R_{0} *\left(t_{\text {max }}-t_{\text {min }}\right)^{0,5}
$$

$E T_{0}=$ evapotranspiración potencial diaria, $\mathrm{mm} / \mathrm{d}$.

$t_{\text {med }}=$ temperatura media diaria, ${ }^{\circ} \mathrm{C}$.

$R_{0}=$ radiación solar extraterrestre, en $\mathrm{mm} / \mathrm{d}$ (tabulada).

$t_{\max }=$ temperatura máxima diaria, ${ }^{\circ} \mathrm{C}$.

$t_{\min }=$ temperatura mínima diaria, ${ }^{\circ} \mathrm{C}$. 
En el balance hídrico a nivel diario, se generan excesos de agua que formarían parte de la recarga de los acuíferos. Utilizando el programa Balshort (Carrica, 1993) para el período 2015 - 2018 se obtuvieron evapotranspiración real (ETR) diaria, excesos y déficit a nivel diario. El sistema requiere la carga de precipitación diaria, la evapotranspiración potencial mensual (calculada previamente) y la capacidad de campo. Por las características litológicas de los sedimentos superficiales se escogió como más representativo el resultado obtenido a partir del valor de capacidad de campo de 50 mm (Falasca y Forte Lay, 2006; Forte Lay y Spescha, 2001).

Es de gran relevancia aclarar que la costa marítima debido al gran dinamismo del sistema subterráneo en las dunas costeras se han considerado los valores de precipitaciones y sus correspondientes excesos como ingreso al sistema entre fechas de mediciones. Es decir que, por ejemplo, los excesos tomados para el mes de julio no corresponden al mes calendario sino a aproximadamente 30 días entre mediciones que, por ejemplo, pueden ser del 25 de junio al 25 de julio. Se realiza esta aclaración porque en el análisis climático local se considera a los balances de acuerdo a los meses calendarios, pero para el análisis detallado y el estudio de la respuesta de los niveles freáticos vs los excesos se suman los excesos diarios entre mediciones de nivel.

\subsubsection{Elaboración e interpretación de los relevamientos hidrogeológicos}

La información obtenida tanto en las mediciones manuales como continuas fueron utilizadas para la construcción de mapas de flujo y gráficos de fluctuaciones de niveles freáticos, entre otros. Los gráficos de fluctuaciones vs los excesos permitieron analizar la respuesta de la capa freática ante la recarga. Los gráficos de CE vs excesos hicieron posible evaluar la relación entre la recarga y este parámetro químico. Se han evaluado situaciones de condiciones climáticas promedio y contrastantes. También se han evaluado el comportamiento según los ambientes geomorfológicos y las zonas de recarga principal y descarga.

\subsubsection{Elaboración e interpretación hidroquímica}

Se construyeron mapas de isocontenido en base a los datos de los muestreos realizados. Existiendo datos de censos previos del Consejo Federal de Inversiones en agosto de 1987 (CFI, 1990 b) para Mar del Tuyú, se evaluó el comportamiento de los iones comunes en ambos muestreos para reconocer la variación de concentración a través del tiempo y su calidad para consumo humano. 
A partir de la utilización de un SIG, se construyeron mapas de isocontenidos de las variables disponibles: bicarbonatos, sulfatos, cloruros, total de sólidos disueltos (TSD), dureza total, y conductividad.

Se clasificó el agua mediante diagramas de Piper, Schoeller-Berkaloff (Schoeller, 1962) para confirmar la relación entre la química y la geomorfología. Los gráficos se realizaron con el software Easy Quim (Vázquez y Serrano, 2012). También se analizó la aptitud química de acuerdo al Código Alimentario Argentino (A.N.M.A.T., 2007). La variable alcalinidad (Alc) se calculó aplicando la relación estequiométrica:

$\mathrm{HCO}_{3}(\mathrm{mg} / \mathrm{L})=1,22 \times$ alcalinidad $\left(\mathrm{mg} / \mathrm{L} \mathrm{CaCO}{ }_{3}\right)$

Así como la dureza total utilizando la ecuación:

$\mathrm{D}(\mathrm{ppm})=((\mathrm{Ca} \mathrm{ppm} / 20)+(\mathrm{Mg} \mathrm{ppm} / 12))^{*} 50$

Los métodos analíticos empleados por el laboratorio G.E.M.A. Estudios Ambientales pueden observarse en la Tabla 1 y los protocolos en el Anexo 1.

Tabla 1 Técnicas analíticas empleadas por el laboratorio G.E.M.A. Estudios Ambientales.

\begin{tabular}{|c|c|}
\hline Determinación & Método \\
\hline Solidos disueltos totales & SM 2540 C \\
\hline $\mathrm{pH}$ & SM 4500-H+B \\
\hline Calcio & EPA 7140-EAA \\
\hline Magnesio & EPA 7450- EAA \\
\hline Sodio & EPA 7770-EAA \\
\hline Potasio & EPA 7610-EAA \\
\hline Hierro & EPA 7380-EAA \\
\hline Manganeso & EPA 7460-EAA \\
\hline Cloruros & SM 4500 Cl- \\
\hline Sulfatos & SM 4500-E \\
\hline Bicarbonatos & SM 2320 B \\
\hline Nitratos & SM 4500 NO3 E \\
\hline Nitritos & SM 4500 NO2 B \\
\hline
\end{tabular}

\subsubsection{Elaboración e interpretación de datos de isótopos estables}

En coincidencia con el muestreo para cationes y aniones se recolectaron muestras para la realización de análisis isotópicos de oxígeno-18 $\left(\delta^{18} \mathrm{O} \%\right)$ y deuterio $\left(\delta^{2} \mathrm{H} \%\right.$ ). 
Las muestras de agua fueron analizadas para determinar su composición isotópica mediante un espectrómetro de anillo de cavidad (CRDS, L2120-i, Picarro, USA), unido a un módulo de vaporizador (A0211 high-precision vaporizer) y un módulo de autoanalizador (A0325). Las determinaciones de isótopos de agua fueron realizadas en el laboratorio del Grupo de Estudios Ambientales, IMASL (CONICET-Universidad Nacional de San Luis), San Luis, Argentina. La calibración se realizó utilizando tres referencias internas del laboratorio y dos estándares internacionales de la IAEA (VSMOW2 y SLAP2). Cada muestra fue medida ocho veces, de las cuales se utilizaron solamente las últimas tres mediciones para la estimación final de la señal isotópica de la muestra analizada evitando así el efecto memoria de la muestra anterior. La precisión de medición del CRDS es $<0.1 \%$ y $<0.5 \%$ para $\delta^{18} \mathrm{O}$ y $\delta^{2} \mathrm{H}$, respectivamente. Todos los valores isotópicos están expresados relativos a VSMOW y se presentan en valores por mil (\%).

Los resultados de $\delta{ }^{18} \mathrm{O}$ vs $\delta{ }^{2} \mathrm{H}$ se han representado en un gráfico junto a la Línea Meteórica Local y también se ha dibujado un gráfico $\delta^{2} \mathrm{H} \%$ vs cloruros para analizar la existencia o no de intrusión salina. En Berisso además se graficó la relación $\mathrm{SO}_{4}{ }^{{ }^{2}}$ vs $\delta^{18} \mathrm{O} \%$.

\subsubsection{Sistema de Información Geográfica (SIG)}

La utilización de imágenes satelitales y de un sistema de información geográfica (SIG) facilita la sistematización de factores que intervienen en la hidrogeología de un área particular. A través de un SIG se reúne, organiza, maneja, analiza, combina, elabora y presenta datos geográficamente localizados a partir de diferentes fuentes y contribuye en un particular al manejo del espacio.

A partir de esta herramienta se confeccionaron capas temáticas tanto de la geomorfología, geología, uso del suelo y mapas de flujo subterráneo. La integración de estas capas permitió el mapeo de áreas de recarga y descarga. No existe en la práctica un estándar de datos a analizar para la delimitación de potenciales zonas de recarga (Acharya et al., 2019). Los factores que más peso tendrán en la afectación a la recarga dependerán de las condiciones locales, teniendo en cuenta el tipo de litología, geomorfología, cobertura de suelos y precipitaciones (Chowdhury et al., 2010).

La interpolación de datos hidrodinámicos e hidroquímicos para obtener mapas de curvas de igual valor se realizó mediante la operación del SIG a partir de la metodología de tipo vecino próximo, por tratarse de la que mejor representa el comportamiento de las variables en la región. 
Posteriormente, los mapas se han corregido manualmente realizando ajustes de acuerdo a interpretación propia y conocimiento del sistema. Según el objetivo planteado se llevó a cabo una reclasificación según las necesidades de cada análisis, obteniéndose mapas isofreáticos y de isoconcentraciones químicos. Con otras herramientas de análisis espacial se han realizado operaciones entre mapas resultando mapas de isovariaciones de niveles freáticos para distintas fechas. Se procedió de igual manera con las variables hidroquímicas. A partir de los mapas de flujo se calcularon los gradientes hidráulicos, valores de descarga y recarga.

\subsection{Tareas de campo}

\subsubsection{Instalación de redes de monitoreo}

Una vez reconocida las áreas se planteó una red de monitoreo de aguas subterráneas. Los freatímetros se dispusieron en las diferentes unidades geomorfológicas, con el objetivo de determinar la hidrodinámica e hidroquímica del acuífero freático en los diferentes sectores del área de estudio.

Con el apoyo de las Cooperativas de aguas de San Clemente (COS) y de Santa Teresita que proporcionaron la logística, se concretó la realización de una red de monitoreo de aguas subterráneas en la costa marítima (Mar del Tuyú).

En diciembre de 2015 se finalizó la instalación de dicha red conformada por 18 perforaciones (Figura 2.3) las cuales abarcan los diferentes ambientes geomorfológicos y distintos usos de suelo. 


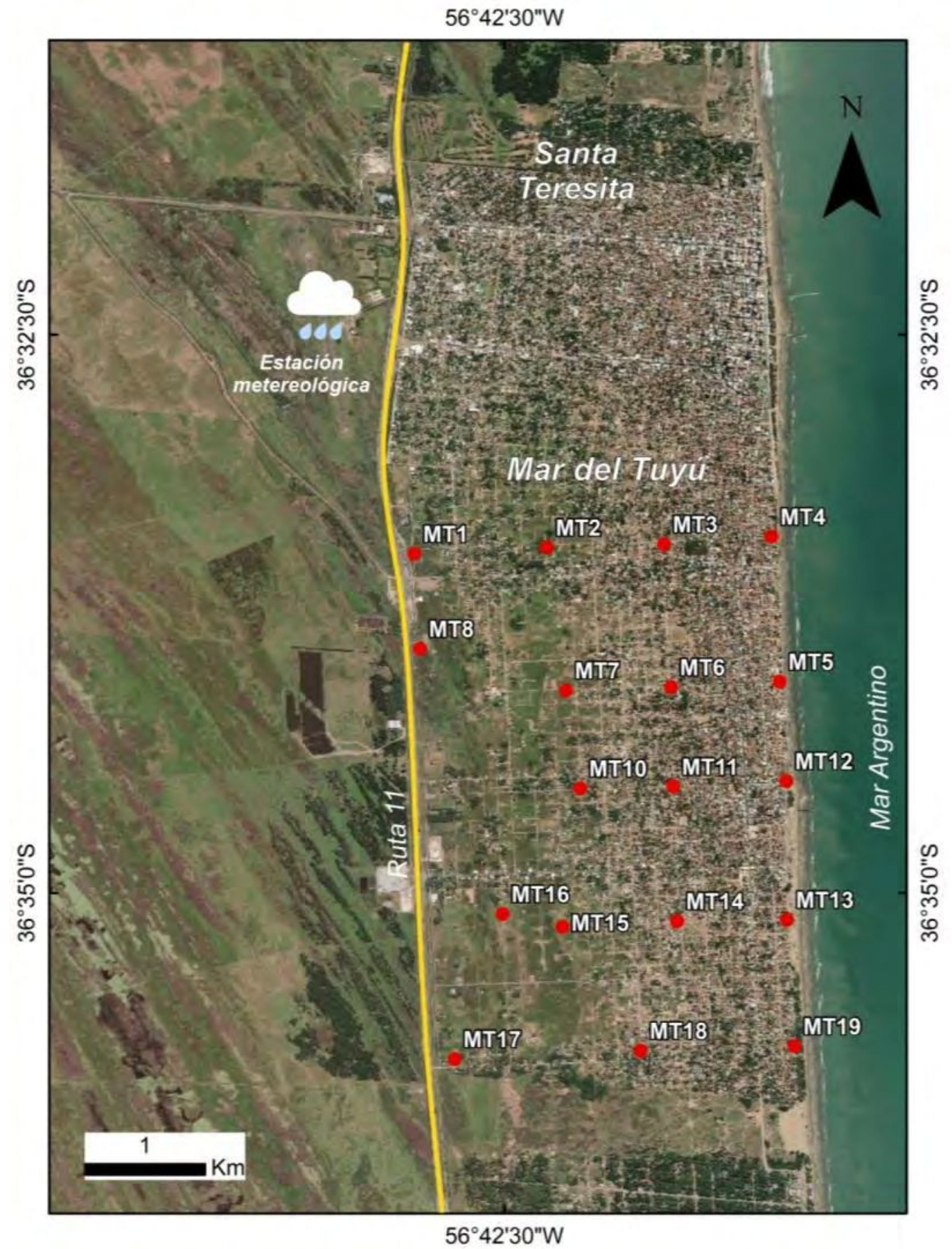

Figura 2.3 Red de monitoreo en Mar del Tuyú. También se observa la localización de la estación meteorológica.

La profundidad de las perforaciones promedia los 4 a $5 \mathrm{~m}$, con filtros ranurados de 1,5" de diámetro y se encuentran distribuidos de manera equidistante a lo largo de la zona de estudio.

En diciembre de 2016 personal de la Municipalidad de La Costa llevó a cabo la nivelación de las bocas de pozos mediante el empleo de un nivel óptico marca Topcon modelo AT-B3. 
A partir de la instalación de la red se efectuaron mediciones de nivel freático con periodicidad mensual (Anexo 2).

En la costa estuárica (Berisso) las perforaciones se realizaron manualmente con barreno helicoidal. La profundidad máxima alcanzada varía según la litología atravesada y la profundidad del nivel freático, ya que al encontrarse arena y agua la perforación se desmorona y no es posible continuar. Por lo tanto, hay sectores donde se alcanzan $3 \mathrm{~m}$ y en otro $1,5 \mathrm{~m}$ de profundidad máxima. La localización de los 12 freatímetros incluye las tres geoformas existentes (planicie de marea relictual, cordón litoral y llanura estuárica) en este sector (Figura 2.4).

En mayo de 2017 se llevó a cabo la nivelación de las bocas de pozos mediante el empleo de un GPS Diferencial modelo South Vector 86/88.

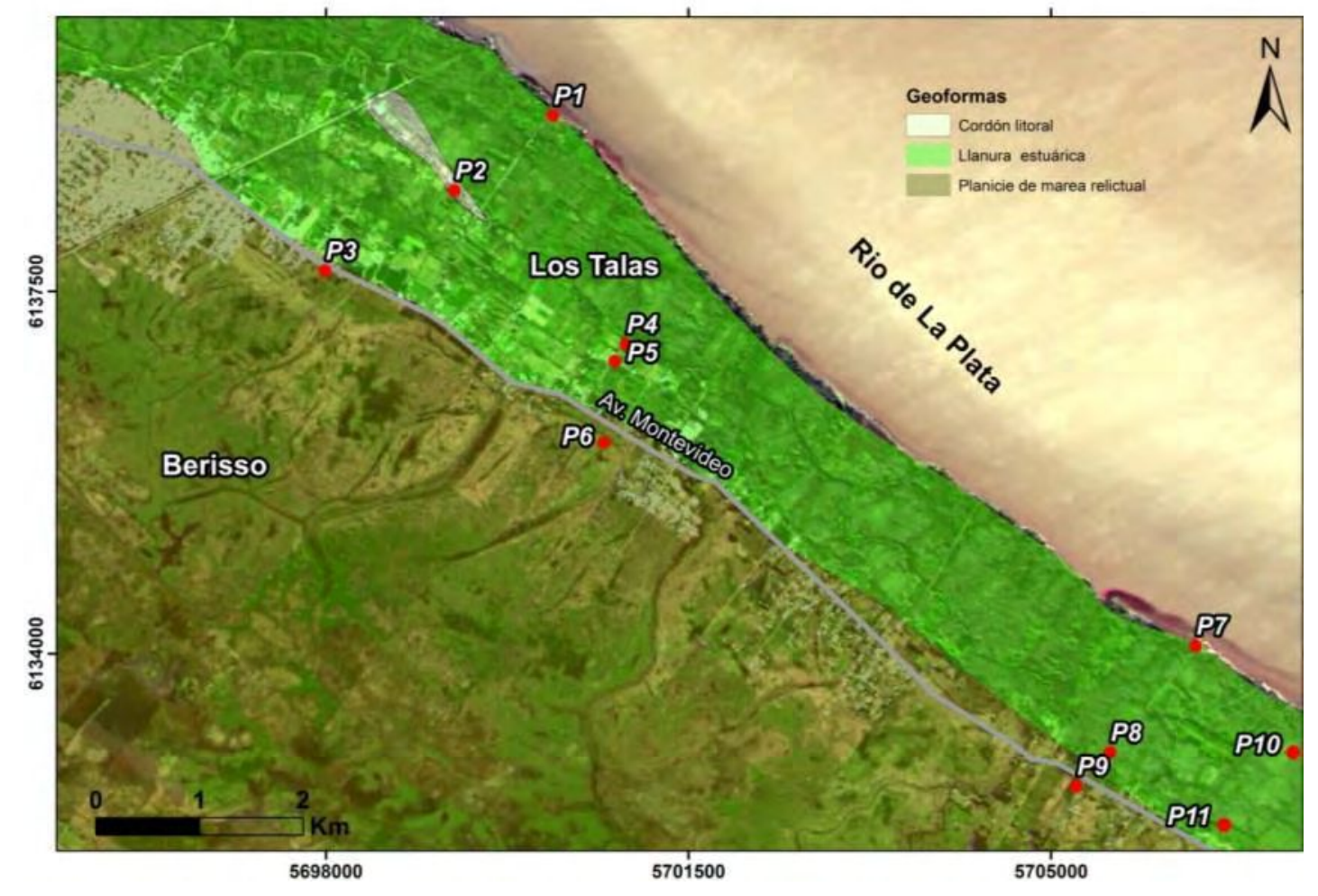

Figura 2.4 Red de monitoreo en la costa estuárica (Berisso).

\subsubsection{Monitoreo periódico de niveles freáticos (mediciones manuales)}

Se realizaron mediciones manuales de profundidad y conductividad eléctrica del agua subterránea. El instrumental empleado consta de una sonda de nivel y un conductímetro marca Lutron (Figura 2.5). Las mediciones se realizaron entre los meses de enero 2016 a diciembre 2018. Durante 2016 en la costa marítima la frecuencia de mediciones fue mensual y se realizó en forma más espaciada en los 
otros años. En la costa estuárica el trabajo de campo se efectuó, en general, cada 2 o 3 meses.

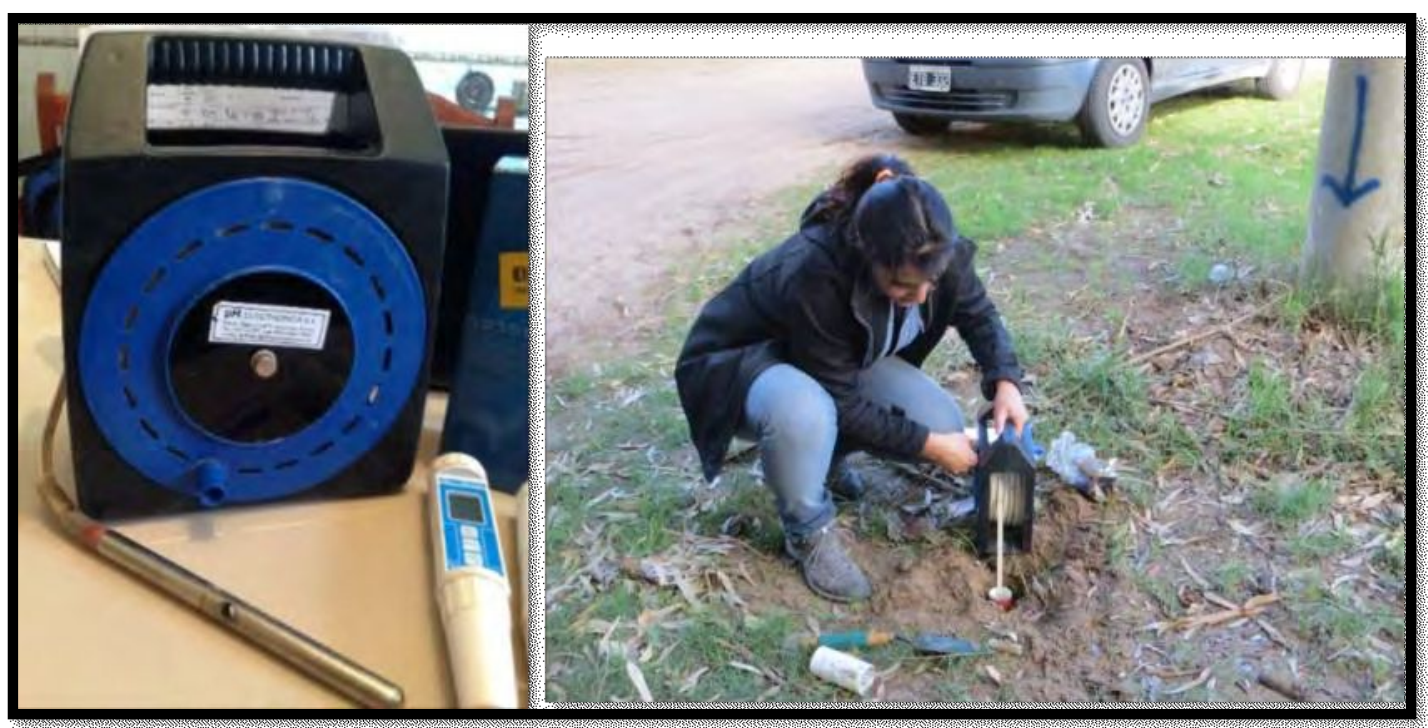

Figura 2.5 Instrumental utilizado en el campo.

\subsubsection{Monitoreo continuo de niveles freáticos (sensores de presión)}

Un diver puede registrar niveles y temperatura del agua subterránea de manera continua gracias a los sensores que tiene incorporados. Se debe colocar el diver en el interior de un pozo suspendido a través de un hilo o cable que no se estire para mantener una profundidad constante.

Lo que mide el sensor es tanto la presión que ejerce la atmósfera como la columna de agua que está por encima del sensor. Si el diver no está sumergido en el agua, mide solo la presión atmosférica como si fuera un barómetro. Una vez sumergido el dispositivo mide ambas presiones. Para obtener solo la presión ejercida por la columna de agua se debe realizar una compensación barométrica. Los valores compensados se pueden relacionar con un punto de referencia, como la parte superior del pozo de monitoreo, o con un nivel de referencia vertical. Las lecturas de presión barométrica son consistentes en una región (excepto durante eventos climáticos rápidos), por lo tanto, pueden utilizarse datos de una estación meteorológica cercana, dentro de un radio de $15 \mathrm{~km}$ del registrador o más sin degradar significativamente la precisión de la compensación en caso de no contar con un sensor en el pozo.

Para el caso de los divers marca Hobo, utilizados para esta tesis, para bajar los datos de la memoria, el software solicita que se introduzca un valor de nivel de agua de referencia. Se debe por lo tanto contar con este valor tomado con sonda manual, 
registrando a su vez el día y horario que luego permitirá correlacionar los valores correctamente.

Para el trabajo de campo y obtener mediciones continuas de nivel freático se utilizaron sensores de presión de la marca HOBO modelo U20L-02 cuyas características de fábrica se pueden ver en la Tabla 2. Estos registradores para conectarse a la computadora requieren de la utilización del software HOBOware Pro, de un acoplador (COUPLER2-C) y de una estación base óptica (BASE-U-4). La compatibilidad con puerto USB permite una configuración fácil y descargas rápidas.

Tabla 2 Especificaciones de fábrica del sensor HOBO

\begin{tabular}{|l|}
\hline Especificaciones del producto U20L-02 \\
\hline Rango de operación de 0 a $400 \mathrm{kPa}$; aproximadamente de 0 a $30,6 \mathrm{~m}$ de profundidad. \\
\hline Rango de calibración de fábrica de 69 a $400 \mathrm{kPa}, 0^{\circ}$ a $40^{\circ} \mathrm{C}$. \\
\hline Presión de estallido $500 \mathrm{kPa}$ o $40,8 \mathrm{~m}$ de profundidad. \\
\hline Precisión del nivel de agua ${ }^{*}$ Error típico: $\pm 3,0 \mathrm{~cm}$ de agua. \\
\hline Error máximo: $\pm 6.0 \mathrm{~cm}$ de agua. \\
\hline Precisión de la presión bruta ${ }^{* *} \pm 1,20 \mathrm{kPa}$ error máximo. \\
\hline Resolución $<0.04 \mathrm{kPa} 0,41 \mathrm{~cm}$ de agua \\
\hline $\begin{array}{l}\text { Tiempo de respuesta de presión }(90 \%) \\
\text { de medición también depende del tiempo de respuesta de la temperatura. }\end{array}$ \\
\hline
\end{tabular}

La instalación de estos dispositivos se realizó en repetidas oportunidades a lo largo del periodo estudiado de acuerdo al objetivo específico planteado.

\subsubsection{Extracción de muestras de agua subterránea}

El muestreo para la realización de análisis químicos se llevó a cabo durante el mes de septiembre de 2016 en la costa marítima y octubre del mismo año en la costa estuárica. En laboratorio se determinaron los cationes y aniones mayoritarios del agua subterránea y en campo se midió la conductividad eléctrica de las muestras.

En coincidencia con el muestreo para cationes y aniones se recolectaron muestras para la realización de análisis isotópicos de oxígeno-18 $\left(\delta^{18} \mathrm{O} \%\right.$ ) y deuterio $\left(\delta^{2} \mathrm{H} \%\right.$ ). 
Para la toma de muestras de agua subterránea se utilizó un muestreador Bailer. La obtención de muestras representativas requiere que los pozos se purguen extrayendo de éstos un volumen de agua equivalente a 3 o 5 veces el almacenado en el pozo y tomando la muestra al día siguiente, luego de la recuperación del nivel freático (U.S. Geological Survey, 2006). El agua fue recolectada en botellas de plástico de 2 litros, tapadas y rotuladas. Las determinaciones fueron realizadas por el laboratorio certificado GEMA SRL.

\subsubsection{Medición de la infiltración en el suelo mediante infiltrómetro de doble anillo}

Esta metodología se basa en la saturación de una porción de suelo delimitada por dos anillos de acero, uno interior pequeño y uno exterior de mayor tamaño (Figura 2.6). Estos se hincan en el suelo $(5 \mathrm{a} 10 \mathrm{~cm})$ sin alterar el terreno que queda en su interior. Se disponen de manera concéntrica, se procede al llenado con agua hasta alcanzar una altura de al menos $3 \mathrm{~cm}$ en ambos anillos. La medición consiste en medir el tiempo y mantener una altura de agua constante en ambos anillos. El agua va descendiendo al infiltrarse a través de la porosidad del suelo. El ensayo consiste en la medición del tiempo que transcurre entre cada llenado necesario para mantener la altura de agua en el cilindro interior. Se procede enrasando a $3 \mathrm{~cm}$ cada vez que el nivel baje $0,5 \mathrm{~cm}$.

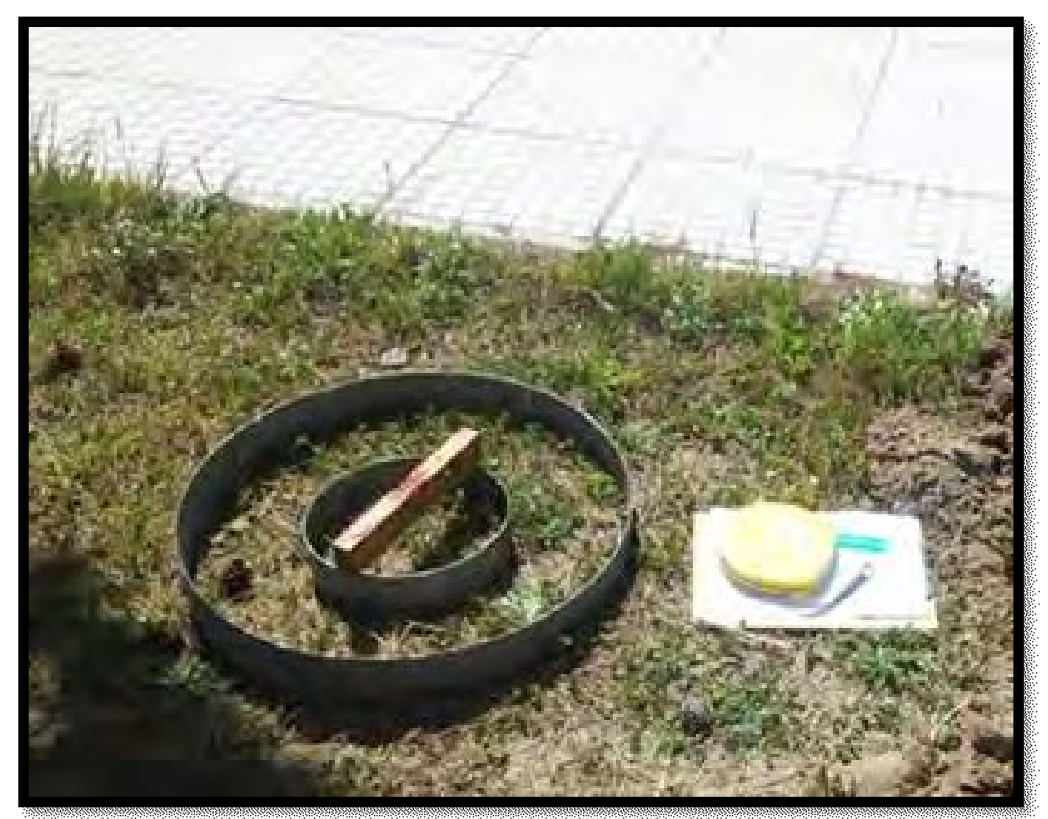

Figura 2.6 Infiltrómetro de doble anillo.

La capacidad de absorción del suelo y la velocidad con la que el agua se infiltre a través del suelo dependerá de las condiciones de saturación previas. En un suelo seco 
los valores iniciales son elevados y van descendiendo hasta llegar a un estado final de saturación donde la velocidad de infiltración es constante. Tanto la humedad como las características propias del suelo (textura, estructura, tamaño de las partículas) impactan directamente en el tiempo transcurrido para alcanzar el estado de saturación.

La tasa o velocidad de infiltración es la velocidad con la que el agua penetra en el suelo a través de su superficie. Normalmente se expresa en $\mathrm{mm} / \mathrm{h}$ y su valor máximo coincide con la conductividad hidráulica del suelo saturado (Figura 2.7).

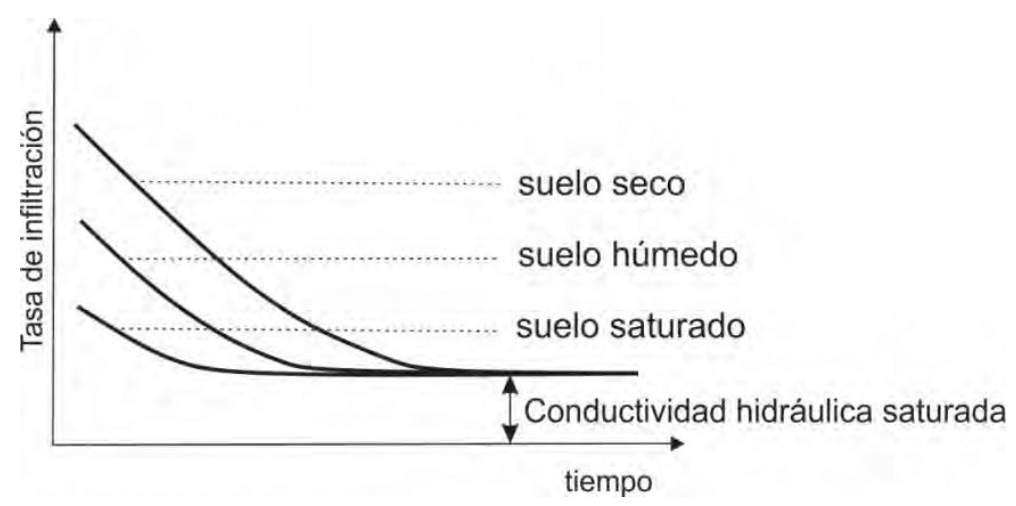

Figura 2.7 Tasas de infiltración según estado del suelo; tomado y modificado de instructivo R014 de Programa de Servicios Agrícolas Provinciales (PROSAP, 2009).

Una de las condiciones necesarias para la obtención de buenos resultados es la de no provocar flujos de entrada ni de salida entre los anillos exterior e interior (Figura 2.8 a y b). Esto se logra evitando desniveles de agua entre anillos.

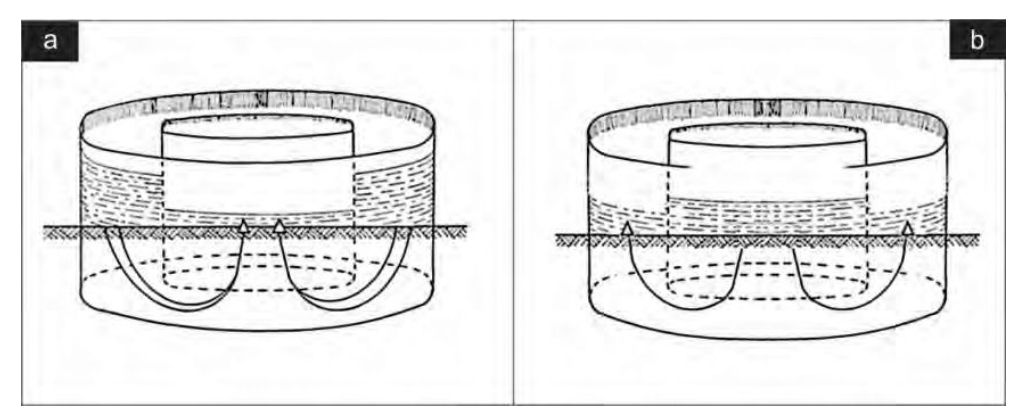

Figura 2.8 Colocación de los anillos.

Manteniendo un desnivel relativamente pequeño entre ambos anillos se logra que el flujo sea vertical. El anillo exterior tiene por función evitar la infiltración horizontal del agua por debajo del cilindro interior, de tal forma que las medidas se correspondan con seguridad al flujo vertical (Figura 2.9). 


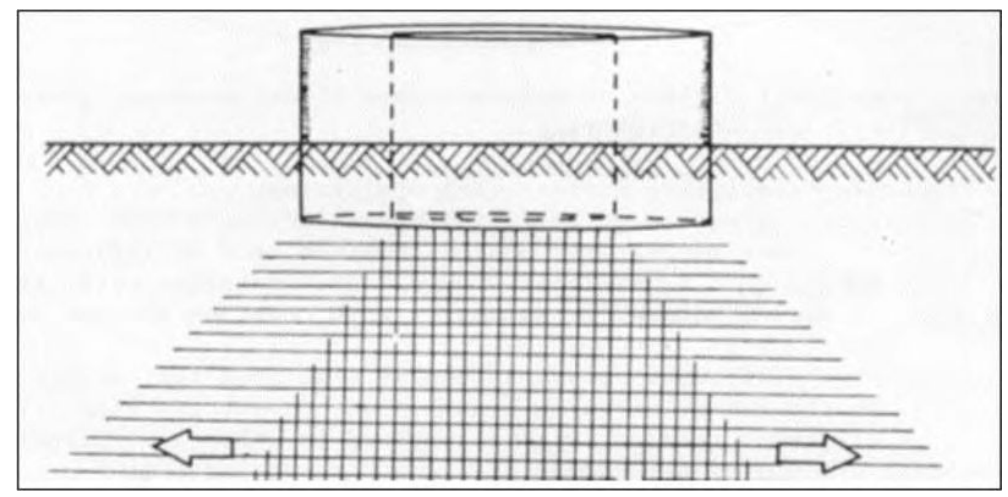

Figura 2.9 Flujo de agua en el suelo generado por el doble anillo.

Los datos obtenidos en cada ensayo de campo se procesan utilizando el método de Kostiakov (1932)

$$
\boldsymbol{d}=\boldsymbol{K} * \boldsymbol{t}^{\boldsymbol{m}}
$$

Donde:

d=infiltración acumulada en el tiempo t $(\mathrm{mm})$.

$\mathrm{K}=$ constante que depende de la estructura y la condición inicial del suelo (seco).

$\mathrm{m}=$ constante que depende de la estabilidad de la estructura del suelo frente al agua, 0 $>\mathrm{m}<1$.

$\mathrm{t}=$ tiempo

Se aplica función logarítmica a la ecuación de Kostiakov

$$
\log d=\log K+m \log t
$$

De esta forma se ha transformado la ecuación exponencial a una recta, cuya pendiente es $\mathrm{m}$ y ordenada al origen es log $\mathrm{K}$. Como sólo se tienen los valores obtenidos del campo se debe ajustar esos puntos a una recta de regresión (mínimos cuadrados). Una vez realizada la recta de regresión se obtienen en forma gráfica o analítica las constantes $\mathrm{K}$ y $\mathrm{m}$. Derivando la ecuación de Kostiakov en función del tiempo obtenemos la expresión correspondiente a la velocidad de infiltración o infiltración promedio:

$$
I P=K * 60 * t^{-n}
$$

Donde:

$\mathrm{IP}=$ infiltración promedio en $\mathrm{mm} / \mathrm{h}$

$\mathrm{K}$ y $\mathrm{m}=$ constantes de cada suelo

$-n=m^{-1}$ 
$\mathrm{t}=$ tiempo

A esta ecuación se la transforma en logarítmica lo cual permite calcular la velocidad de infiltración a través del tiempo:

$$
\log I P=\log K-(n * \log t)
$$

Los ensayos se realizaron en lugares cercanos a los pozos de monitoreo de agua subterránea. Se dispusieron zonas diferentes con el objetivo de evaluar la velocidad de infiltración en los diferentes sectores según la geomorfología y el uso del suelo.

\subsubsection{Determinación de humedad del suelo}

Conjuntamente con el ensayo para determinar velocidades de infiltración se realizaron medidas de humedad a distintas profundidades dentro del perfil de suelo.

Los pozos o calicatas se realizaron a pala, en aproximadamente 1 metro de profundidad. Se utilizó un sensor de humedad marca Lutron que se fue hincando cada $10 \mathrm{~cm}$ a lo largo del perfil (Figura 2.10). Los datos se graficaron en diagramas \% humedad vs profundidad.

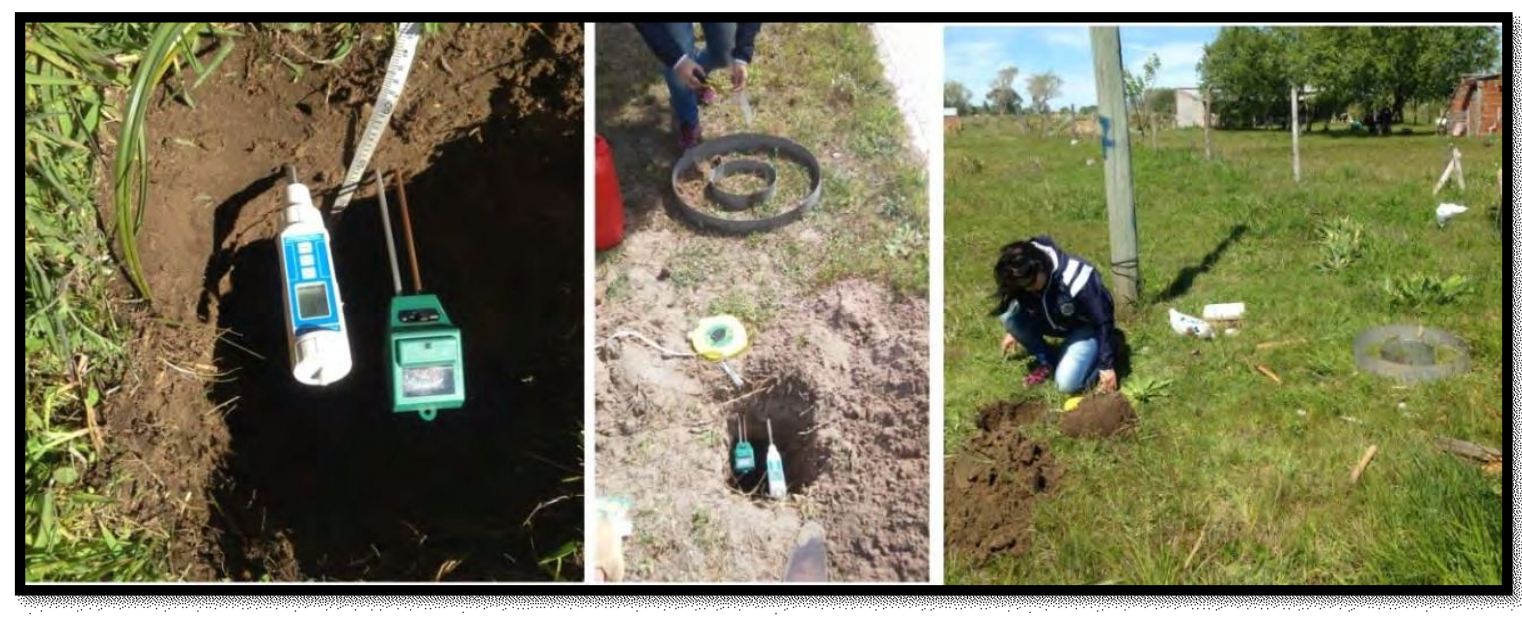

Figura 2.10 Ensayos de infiltración y de humedad del suelo.

\subsubsection{Medidas puntuales de permeabilidad: Ensayos Slug Test}

Medidas puntuales de permeabilidad se realizaron a través de ensayos slug test por el método de Hvorslev (1951) para acuíferos libres.

$$
K=\frac{r_{t u}^{2} \ln \left(\frac{L}{r_{f}}\right)}{2 L t_{37}}
$$

Dónde (Figura 2.11): 
$\mathrm{K}=$ permeabilidad $\mathrm{o}$ conductividad hidráulica

$r_{\mathrm{tu}}=$ radio de la entubación

$\mathrm{L}=$ longitud de la rejilla o parte ranurada de la perforación

$r_{f}=$ radio de la zona filtrante

$t_{37}=$ tiempo en el que aún perdura el $37 \%$ del ascenso instantáneo inicial. El $37 \%$ aparece en la deducción de la fórmula debido a que: In $(1 / 0,37)=1$, o lo que es lo mismo: $1 / \mathrm{e}=0,37$.

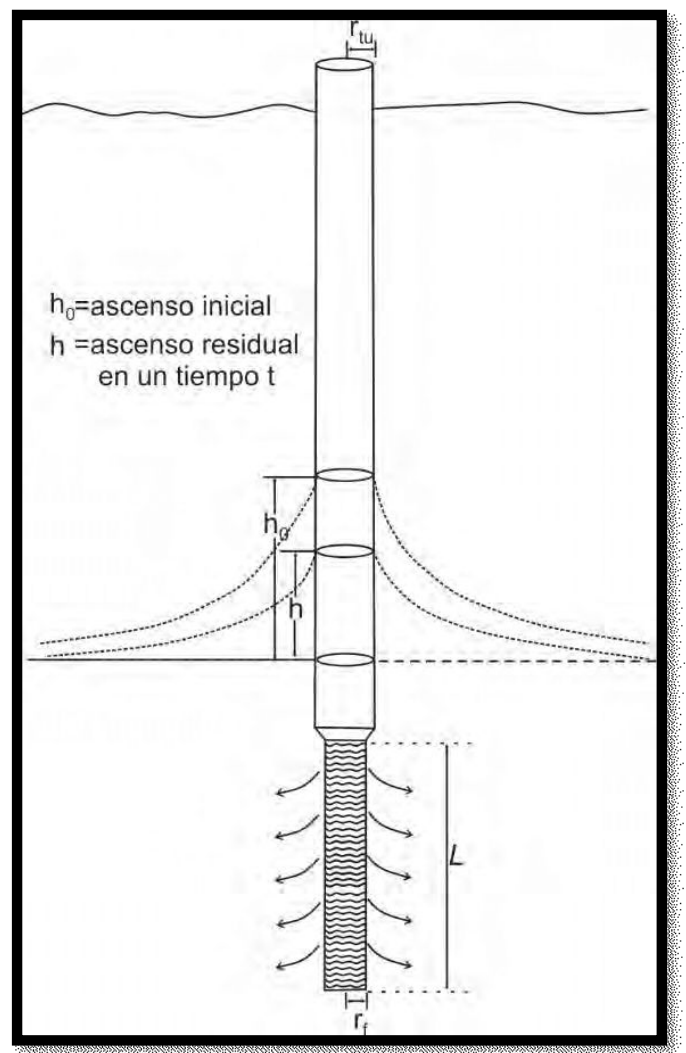

Figura 2.11 Diseño del ensayo slug test.

El método consiste en generar un ascenso inicial del nivel al introducir agua en el pozo y se miden los niveles en función del tiempo. Debido a que se trata de sedimentos arenosos, tanto el ascenso como el descenso se producen de manera muy rápida, en escala de segundos. Para una medición precisa del nivel se utilizaron sensores de presión de medición continua (divers) instalados en cada pozo ensayado con una frecuencia de registro de datos cada 1 segundo.

Los pozos tienen características comunes son de 1,5“de diámetro. La profundidad de los pozos coincide con la longitud de la zona filtrante ya que estos están ranurados en toda su longitud. 
Al introducir un volumen de agua se produce un ascenso rápido del nivel desde la posición inicial hasta la boca de pozo (nivel máximo). Una vez alcanzado el máximo se deja recuperar el nivel a su posición inicial. Se registran los descensos de nivel en función del tiempo:

$$
\mathrm{h}_{0}=\text { nivel máximo - nivel inicial }
$$

Se calculan los ascensos parciales o residuales (h) para cada tiempo:

$$
\mathrm{h}=\text { nivel alcanzado en el tiempo }(\mathrm{t})-\text { nivel inicial }
$$

Luego se divide $h / h_{0}$ y se representa el $\ln h / h_{0}$ respecto al tiempo. Los puntos deberían quedar aproximadamente alineados. De los gráficos se obtiene $t_{37}$ que es el tiempo en el que aún perdura el $37 \%$ del ascenso instantáneo inicial. Se busca en el eje vertical el valor 0,37 y se obtiene el tiempo correspondiente (Figura 2.12). Se han aplicado el radio y la longitud en metros y el tiempo en días, de modo que la $\mathrm{K}$ se obtuvo en $\mathrm{m} / \mathrm{d}$.

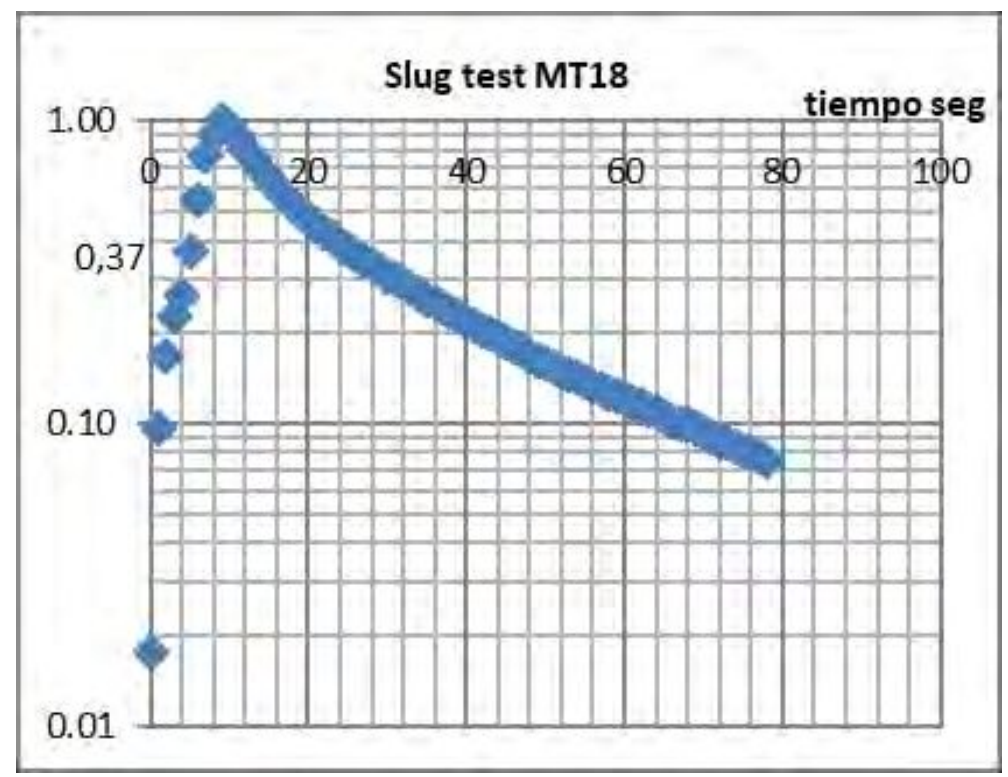

Figura 2.12 Ejemplo del gráfico para obtener $\mathrm{t}_{37}$

\subsubsection{Cálculo de la difusividad hidráulica}

Las fluctuaciones de nivel de agua subterránea generadas por excitación de las mareas marinas se utilizan en acuíferos costeros e islas para la estimación de la difusividad hidráulica (D). Siendo $D=T / S$, donde $S$ es el coeficiente de almacenamiento y $T$ es la transmisividad del acuífero. $D$ es un parámetro que indica la sensibilidad o comportamiento de un acuífero ante una acción externa, por ejemplo, un bombeo, o en este caso la propagación de la onda de marea. 
Jacob (1950) y Ferris (1951) presentaron una solución analítica para la propagación de una onda oscilatoria en un acuífero isótropo y homogéneo. De esas fórmulas originarias surgen dos fórmulas para calcular la difusividad hidráulica (D). La primera está basada en la eficiencia de marea (TE) y la segunda utiliza el tiempo de retardo (TL). A partir del análisis de las series temporales de marea y nivel de agua subterránea, se pueden estimar estos dos factores (TE) y (TL). En los trabajos de Erskine, (1991), Trefry y Bekele (2004), Rotzoll y El-Kadi (2008), Rotzoll et al. (2013), Xun et al. (2014), Shirahata et al. (2014), Shirahata et al. (2016) se presentan diversas formas de obtener TE y TL.

Jacob (1950) y Ferris (1951) utilizan en sus ecuaciones el factor de eficiencia de la marea (TE) y el retardo de fase (TL) para obtener la difusividad hidráulica (D) de un acuífero.

Ecuación 1:

$$
\begin{gathered}
\frac{h}{h 0}=\exp \left(-x \sqrt{\frac{\omega S}{2 T}}\right) \sin \left(\omega t-\sqrt{\frac{\omega S}{2 T}}\right)(a) \\
\left(\sin \left(\omega\left(t-\frac{x}{\omega}() \sqrt{\frac{\omega S}{2 T}}\right)\right)=\sin \left(\omega\left(t-t_{1}\right)\right) ; \text { donde }_{1}=\frac{x}{\omega} \sqrt{\frac{\omega S}{2 T}}\right.
\end{gathered}
$$

Retardo de fase ( $T L \circ t_{1}$ ): Es el retardo en el tiempo de la aparición de una cresta de máxima altura de agua subterránea generada luego de una cresta de máxima altura de marea. A partir de la Ecuación. 1, introduciendo $\omega=2 \pi / t_{0}$ queda:

Ecuación 2:

$$
\begin{gathered}
T L=t_{1}=-x \sqrt{\frac{t_{0} S}{4 \pi T}}(a) \\
\frac{S}{T}=\left(-\frac{T L}{x}\right)^{2} \frac{4 \pi}{t_{0}}(b)
\end{gathered}
$$

Atenuación de amplitud (TE): Es la relación entre las alturas hidráulicas en dos piezómetros o en un piezómetro y un nivel de superficie como el nivel del mar.

Ecuación 3: 


$$
\begin{gathered}
T E=\frac{h}{h_{0}}=\exp \left(-x \sqrt{\frac{\pi S}{t_{0} T}}\right)(a) \\
\frac{S}{T}=\frac{t_{0}}{\pi}\left(-\frac{1}{x} \ln (T E)\right)^{2}(b)
\end{gathered}
$$

Dónde:

$t_{0}$ : período de la excitación, frecuencia de excitación $f_{0}=1 / t 0$.

$\mathbf{h}_{0}$ : amplitud de la excitación.

h: altura de la componente f0 en el pozo de observación.

x: distancia de la excitación al pozo de observación.

$\mathbf{t}_{1}$ : retardo de fase.

T: transmisividad del acuífero.

S: coeficiente de almacenamiento del acuífero.

Existen dos fórmulas para estimar $\mathrm{D}=\mathrm{T} / \mathrm{S}$ presentadas en la Ec. 2 b y Ec. 3 b. Para aplicar estas fórmulas es necesario calcular previamente TE y TL. Para ello se aplican los métodos de Erskine, (1991), Trefry y Bekele, (2004), Rotzoll et al., (2013), Xun, et al. (2014) y Shirahata et al. (2016).

En un freatímetro ubicado en la costa marítima (Mar del Tuyú) a x=50 m del mar se colocó un sensor de presión, a partir del cual se obtuvieron los niveles horarios en forma continua. La marea horaria se obtuvo de los registros del Servicio de Hidrografía Naval (SHN). Los datos recolectados entre junio y octubre de 2017, constan de 3492 horas y son adecuados para ser utilizados en estos cálculos.

También se utilizó un método de análisis visual que consiste en estimar TL y TE a partir de los gráficos de la onda de marea y la onda de nivel en el pozo de observación. Se seleccionaron tramos cortos (aproximadamente 24 hs). TL se estima midiendo el tiempo que transcurre desde un pico máximo de marea y el pico máximo de nivel freático generado por esa excitación. La atenuación (TE) se calcula como:

$$
T E=h / h_{0}=(\text { cresta }- \text { valle })_{\text {nivel }} /(\text { cresta }- \text { valle })_{\text {marea }}
$$


Se descartan las variaciones debidas a recarga por lluvia.

Para calcular las variaciones de nivel, se realiza primero un filtrado de datos donde se calcula el valor medio y se resta ese valor de todo el tramo. Luego se le aplica una ventana deslizante de 2 hs. Para descontar los efectos de recarga y descarga, se calcula la tendencia lineal de cada señal y se resta del tramo.

Una vez obtenidos TE y TL por los diferentes métodos se reemplazan en las dos ecuaciones independientes Ec. 2 b y Ec. 3 b. TE también se calculó matemáticamente por desviación estándar.

Tradicionalmente la estimación de las propiedades hidráulicas de un acuífero se realiza a partir de ensayos de bombeo. En el caso de la presencia de agua salada a escasa profundidad el bombeo puede deteriorar la calidad del agua dulce sobrepuesta y por esa razón conviene analizar la posibilidad de utilizar otros métodos. En una zona costera se pueden utilizar las fluctuaciones del nivel del agua subterránea en un pozo, originadas por las mareas marinas para la estimación de $\mathrm{D}=\mathrm{S} / \mathrm{T}$ del acuífero freático.

De acuerdo a los datos antecedentes en la región, los parámetros hidráulicos provienen de ensayos de bombeo realizados en localidades cercanas. Se indica una transmisividad $(\mathrm{T})$ del orden de $100-200 \mathrm{~m} 2 / \mathrm{d}$ y un coeficiente de almacenamiento (S) de 0,10 (CFI 1990b, Carretero, 2011). Es decir que S/T varía entre 0,001 y 0,0005.

Se ha aplicado esta metodología para obtener parámetros hidráulicos del acuífero sin la necesidad de realizar ensayos de bombeo.

\subsubsection{Relevamientos geoeléctricos}

En la localidad de Los Talas (Berisso) en la costa estuárica, se llevó a cabo una campaña de prospección geoeléctrica con la Facultad de Ciencias Astronómicas y Geofísicas de La Plata en el año 2016. La caracterización geoeléctrica se realizó a partir de métodos eléctricos $2 \mathrm{D}$, más precisamente tomografías de resistividad eléctrica. El sitio seleccionado para el estudio corresponde a un cordón de conchilla que debido a su geología altamente permeable conforma un acuífero freático de buena calidad de agua subterránea. A partir de la información geológica, geomorfológica e hidroquímica se reconoce a este cordón de conchilla como un cuerpo 3D cuyo ancho en dirección E-O es de aproximadamente $30 \mathrm{~m}$. El largo horizontal en dirección NO-SE es de 500 metros y su espesor máximo aproximado es de $10 \mathrm{~m}$. La base de estos cordones corresponde a sedimentos arcillosos con agua subterránea de elevada salinidad por lo que se esperaría obtener baja resistividad en ese sector. 
La principal aplicación de esta metodología es la identificación de la interfase agua dulce-agua salada. En la localidad de Los Talas será necesario reconocer este límite para poder efectuar una correcta estimación de la subsuperficie del lugar, permitiendo de esta manera conocer las posibles profundidades de explotación del acuífero de agua dulce.

El instrumental que se utilizó para este estudio se compone de:

1. Sistema automático de resistividad (ARES II).

2. Batería de auto de $12 \mathrm{~V}$.

3. Cable con 28 electrodos separados entre sí por 5 metros de distancia.

4. Cable con 32 electrodos separados entre sí por 2,5 metros de distancia. Los instrumentos mencionados se pueden apreciar en la Figura 2.13.

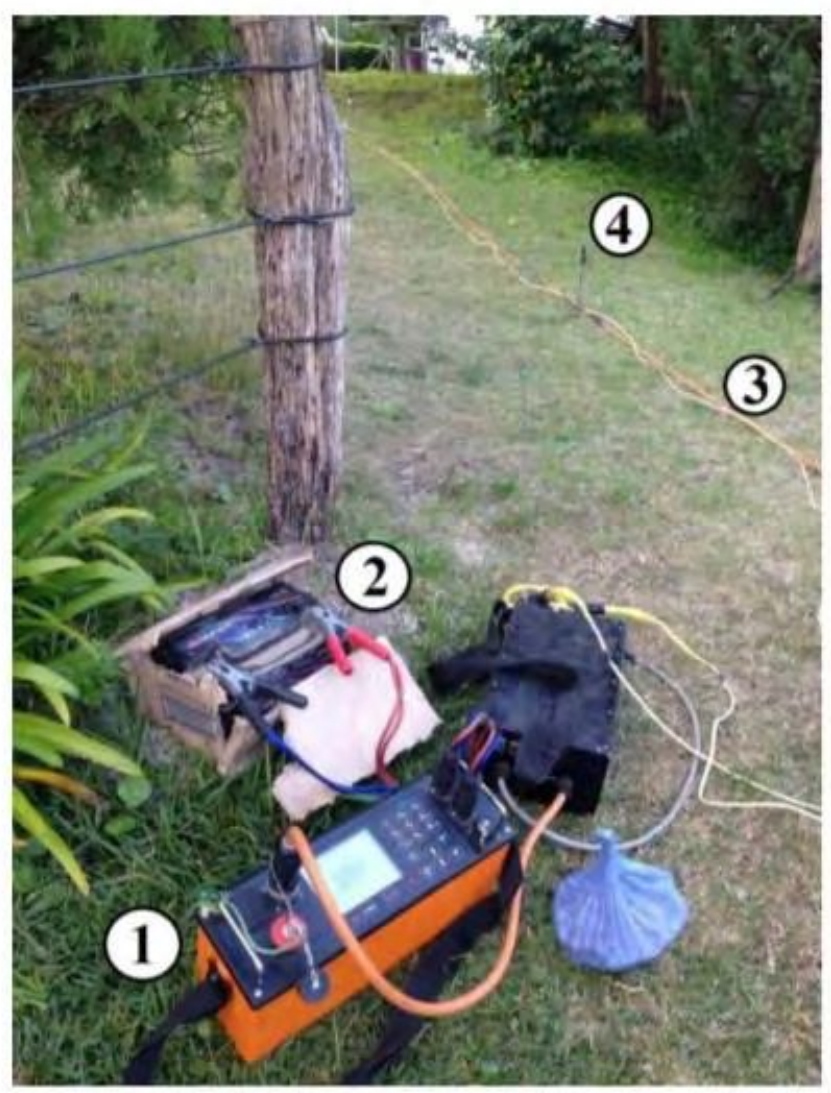

Figura 2.13 Instrumental utilizado para las tomografías.

Teniendo en cuenta las características del área de estudio, se optó por utilizar el dispositivo Wenner-Schlumberger, con una separación mínima de 5 metros y una máxima de 30 metros. La elección de este dispositivo se debe principalmente a su sensibilidad tanto a los cambios verticales como a los horizontales. Además, este tipo de arreglo conserva la forma de la estructura, respetando con gran exactitud los cambios de resistividad. La profundidad de exploración que se maneja utilizando este 
dispositivo es adecuada para los objetivos del trabajo, ya que permite explorar los cordones y alcanzar los niveles salobres, obteniendo un contraste marcado entre resistividades. Luego de hacer reconocimientos en la zona, se midieron dos transectas de resistividad en $2 \mathrm{D}$ usando el instrumental antes mencionado.

\subsection{Estimación de la recarga}

La estimación de la recarga puede tratarse de diferentes formas, entre otras: determinación directa, métodos de balance de agua, métodos hidrodinámicos y en las fluctuaciones freáticas, estudio de las variaciones naturales y ambientales de la composición química e isotópica, técnicas de trazadores: químico e isotópico artificial.

Un especial tratamiento en este trabajo se le da a las metodologías que incluyen la estimación de la recarga a partir de la fluctuación de los niveles freáticos, mapas de isovariación y balance del ion cloruro.

\subsubsection{Por fluctuación de los niveles}

La recarga puntual puede estimarse a partir del método de las fluctuaciones del nivel freático (Healy y Cook, 2002) calculándose como:

$R=S_{y}(\Delta \mathrm{h} / \Delta \mathrm{t})$

Donde Sy es porosidad efectiva, $\mathrm{h}$ altura del nivel freático y t el tiempo. Se considera un valor de porosidad efectiva $\left(S_{y}\right)$ en las arenas del acuífero freático de 0,10 (CFI, 1990b; Carretero, 2011).

El agua infiltrada luego de la precipitación provoca una variación del nivel freático $(\Delta h)$ en un determinado periodo de tiempo $(\Delta t)$ que multiplicado por la porosidad efectiva del acuífero es igual a la tasa de recarga de ese momento.

Con los datos obtenidos en cada evento de precipitación se calcularon tasas de recarga (intensidad o valor por unidad de tiempo). Se define como tasa de recarga al flujo unitario, en volumen por unidad de tiempo $\left(\mathrm{L}^{3} / \mathrm{T}\right)$ o también es frecuente expresarla como volumen por unidad de superficie y unidad de tiempo o altura por unidad de tiempo (L/T) (Custodio, 1998).

\subsubsection{Por mapas de isovariación}

Para estimar los valores de recarga se construyeron mapas isofreáticos mensuales. Con la herramienta de análisis espacial del SIG, calculadora raster, se realizó la resta entre mapas mensuales consecutivos y se obtuvieron mapas de isovariación mes a mes. Se llevó a cabo una reclasificación, se extraen las curvas de isovariacion y 
posteriormente, se ha corregido manualmente realizando ajustes de acuerdo a interpretación propia y conocimiento del sistema. Luego se pasa del formato raster al formato vectorial para obtener polígonos. A cada polígono se le asigna el valor medio entre las dos curvas de isovariacion que lo cierran. Para determinar la variación del volumen de agua dulce almacenada por encima de $0 \mathrm{~m} \mathrm{~s}$. n. m. para ese momento se multiplica el área de cada polígono por el valor medio de variación asignado a cada polígono y por la porosidad efectiva del acuífero.

Dicha estimación se realizó utilizando el valor medio de las curvas de isovariación, una porosidad efectiva del acuífero del $10 \%$ y el área estimada para cada rango de variaciones.

Este método es aplicable a toda el área donde las variaciones de nivel son solo atribuibles a recarga por lluvia. Cabe aclarar que no se ha detectado una influencia mareal significativa en los freatímetros de la zona costanera. Por otro lado, en los sectores de descarga, si bien existe un flujo lateral desde el sector más alto de la duna, también se produce recarga in situ por tratarse de un material altamente permeable como son las arenas.

\subsubsection{Por balance del ion cloruro}

El método de balance del ion cloruro ha sido desarrollado por Eriksson y Khunakasem (1969), y compara la deposición total de cloruro en la superficie con la concentración en el agua del suelo por debajo de la zona activa de las raíces o con la concentración en el agua del acuífero.

Es un método muy difundido para el cálculo de la recarga debido a que las determinaciones son rápidas y de bajo costo y es utilizado tanto en zonas áridas y semiáridas más frecuentemente, aunque también se lo ha aplicado en zonas húmedas (Edmunds et al., 2002; Scanlon et al., 2002; Custodio, 2010; Nolan et al., 2007, Alcalá y Custodio, 2014).

Suponiendo que el aporte de cloruros tomados del suelo o aportados de forma artificial es nulo y que la retención de cloruros por parte de la vegetación es igual a la liberación de los mismos al morir dicha vegetación, se obtiene:

$R / C_{A s}=P / C_{p}-E_{S} C_{e}$

Donde $\mathrm{R}$ es la recarga, $\mathrm{C}_{\mathrm{As}}$ es el contenido medio de cloruros de agua subterránea, $\mathrm{P}$ es la precipitación, $C_{P}$ representan la concentración de cloruros en la precipitación y su cociente representa el aporte de cloruro atmosférico. $C_{e}$ es la concentración de 
cloruros en el escurrimiento superficial. Las concentraciones están expresadas en $\mathrm{mg} / \mathrm{L}$ y la precipitación en litros.

Esta ecuación puede simplificarse asumiendo que el ion cloruro, no es aportado por el terreno, y que dadas las características del suelo como la alta permeabilidad y geomorfología existente, el escurrimiento superficial $\left(E_{S}\right)$ es nulo y por lo tanto despreciable por lo que se puede desechar los términos $E_{s}$ y $C_{e}$.

La ecuación simplificada queda de esta manera:

$R=C_{P} / C_{A S} * P$

Donde $\mathrm{R}$ es la recarga, $\mathrm{P}$ la precipitación, $\mathrm{C}_{\mathrm{p}}$ y $\mathrm{C}_{\mathrm{AS}}$ representan la concentración de cloruros en la precipitación y en el agua subterránea respectivamente y su cociente representa el coeficiente de recarga medio.

Se estimó la recarga a partir de este método en la costa marítima considerando los valores medios de concentraciones de cloruros en el agua subterránea muestreadas en la localidad de Mar del Tuyú en septiembre de 2016. Las concentraciones de cloruro en las precipitaciones corresponden a las recolectadas en un pluviómetro en San Clemente del Tuyú entre abril-2015 y octubre-2016. Se consideran representativas de la región para ser aplicadas a este método.

\subsection{Determinación de la descarga submarina (SGD: submarine groundwater discharge)}

En marzo de 2016 se llevó a cabo una campaña en el Partido de La Costa (PDLC) para estudiar la SGD. La localidad de Mar del Tuyú se encuentra incluida en este estudio y se presentarán los datos correspondientes a ese sector de la costa marítima.

Se han utilizado tres métodos de estudio: piezómetros, ${ }^{222} \mathrm{Rn}$ como trazador $\mathrm{y}$ tomografía de resistividad eléctrica. Con los dos primeros es posible realizar una cuantificación mientras que el último es cualitativo y muestra la distribución areal.

\subsubsection{Piezómetros}

Se utilizaron los piezómetros distribuidos a lo largo del cordón costero, los cuales constituyen una red de monitoreo que abarca desde San Clemente hasta Mar del Tuyú $\left(90 \mathrm{~km}^{2}\right)$. Se midieron los pozos y se confeccionaron los mapas de flujo correspondientes a cada sector a partir de los cuales se calculó la descarga hacia el mar. 
Burnett et al. (2006) mencionan el método de los piezómetros como una de las metodologías para el cálculo de la SGD, teniendo en cuenta y considerando constante el valor de conductividad hidráulica del acuífero, utilizando la ley de Darcy de acuerdo a la ecuación:

$$
Q=-K d h / d L
$$

donde $Q$ es el flujo de Darcy (volumen de agua subterránea descargada por unidad de área por unidad de tiempo), $\mathrm{K}$ es la conductividad hidráulica y $\mathrm{dh} / \mathrm{dL}$ es el gradiente hidráulico, en donde $\mathrm{h}$ es la altura hidráulica y $\mathrm{L}$ la distancia. Para el área de estudio se ha considerado una K de 20 m/d tomado de bibliografía. El informe de CFI (1990,b) menciona diferentes valores de $\mathrm{K}$ a lo largo del cordón costero y para la zona de Mar del Tuyú correspondería este valor. Por otro lado, Carretero y Kruse (2015a) han calculado este parámetro en la zona sur de San Clemente del Tuyú con valores medios de 20-22 m/d mediante ensayos de bombeo.

\subsubsection{Mediciones de radón $\left({ }^{222} \mathrm{Rn}\right)$}

La medición de radón-222 en el agua de zonas costeras es una técnica para localizar potenciales fuentes de SGD (Stieglitz, 2005, Rapaglia et al., 2015). Se midió el ${ }^{222} \mathrm{Rn}$ en forma constante utilizando un sistema de detección de ${ }^{222} \mathrm{Rn}$ en el aire (RAD7), modificado para medir agua vía intercambio a través de un mini-módulo con filtro de membrana (Liqui-Cel). Se navegó en una embarcación de pequeño porte en forma paralela a la costa desde Punta Rasa hasta Costa del Este $(30 \mathrm{~km})$ a una velocidad promedio de 3 nudos, tratando de mantener una distancia menor a $500 \mathrm{~m}$ de la costa. Se bombeó el agua al mini-módulo utilizando una bomba peristáltica a una tasa de 0,50,8 L/min, devolviendo el excedente al mar. La actividad del ${ }^{222} \mathrm{Rn}$ fue continuamente medida por el RAD7 según la técnica descripta por Burnett y Dulaiova (2003). Simultáneamente se midió temperatura y salinidad utilizando un conductívímetro eléctrico marca YSI ProODO. En tres ocasiones el sistema cerrado estalló debido a la carga de sedimentos en suspensión proveniente de la descarga del Río de la Plata. En cada oportunidad el bote se detuvo hasta que el equilibrio fue alcanzado nuevamente. Desafortunadamente no se tomaron muestras para obtener la concentración de los sedimentos en suspensión. La velocidad del viento fue muy baja ( 1-3 m/s) y la temperatura del aire fluctuó entre $15^{\circ} \mathrm{C}$ en la mañana y $28^{\circ} \mathrm{C}$ en la tarde. La actividad del ${ }^{222} \mathrm{Rn}$ fue posteriormente corregida por desgasificación debido a estos dos factores. También se midió la conductividad eléctrica in situ y la actividad del ${ }^{222} \mathrm{Rn}$ directamente en la playa, tanto en la zona intermareal como en la zona de surf y en varias perforaciones lo largo del PDLC. El agua de las perforaciones fue bombeada a través 
del mini-modulo hasta que se alcanzó la concentración en equilibrio en el detector (aproximadamente 35 minutos).

Resulta complejo cuantificar la SGD utilizando la actividad del ${ }^{222} \mathrm{Rn}$ a lo largo de la costa, debido a que la mezcla de aguas es difícil de caracterizar y el componente de entrada en el balance de masas no es tan claro como sería en el caso, por ejemplo, de una laguna costera (Stieglitz et al., 2010). Sin embargo, asumiendo que el aporte de ${ }^{222} \mathrm{Rn}$ desde mar abierto sea despreciable, se puede calcular un balance de masas para intentar una cuantificación.

Las fuentes y sumideros de ${ }^{222} \mathrm{Rn}$ en aguas costeras puede representarse por el modelo de balance de masas de Burnett y Dulaiova (2003)

$F_{S G D}+F_{\text {Diff }}+F_{\text {Riv }}=F_{a t m}+F_{\text {dec }}+F_{\text {mix }}$

Donde FSGD = flujo de ${ }^{222} \mathrm{Rn}$ desde la SGD $\left(\mathrm{dpm} / \mathrm{m}^{2} / \mathrm{d}\right)$, Fdiff $=$ flujo de ${ }^{222} \mathrm{Rn}$ por difusión desde los sedimentos, FRiv $={ }^{222} \mathrm{Rn}$ aportado desde el río; Fatm = pérdida de ${ }^{222} \mathrm{Rn}$ por difusión atmosférica; Fdec = desintegración del ${ }^{222} \mathrm{Rn}$ en la columna de agua; Fmix = pérdida de ${ }^{222} \mathrm{Rn}$ debido a la mezcla.

Se asume que Fdiff no presenta una importancia significativa de acuerdo a las diferencias regionales en la distribución del ${ }^{222} \mathrm{Rn}$ que se observaron. El aporte desde el río debería ser también despreciable, sin embargo, debido a la carga de sedimentos en suspensión no sería el caso. El problema es que este factor no es posible de cuantificar por falta de datos, por lo tanto, no se considerará en la ecuación. De todas maneras, hay que tener en cuenta que este factor sobreestima el rol de la SGD en el área. La mezcla es otro factor que resulta dificultoso de cuantificar en una costa abierta y también se desprecia. Como una primera aproximación de los cálculos, la Ec. 1 se simplifica en:

$$
F_{S G D}=F_{a t m}+F_{d e c}
$$

La difusión atmosférica se calcula multiplicando el coeficiente de transferencia del gas por la concentración promedio de radón en aguas abiertas. Este valor sería insignificante ya que depende de la velocidad del viento, la cual fue muy baja durante el muestreo. Por lo tanto, el mayor factor que determina el balance de masas es el decaimiento, el cual depende de la profundidad del agua y la concentración de radón en la superficie. El flujo de ${ }^{222} \mathrm{Rn}$ por SGD puede ser dividido por la actividad del ${ }^{222} \mathrm{Rn}$ en los pozos para determinar el flujo en $\mathrm{m}^{3} / \mathrm{m} / \mathrm{d}$. 
Usando el promedio de la actividad del ${ }^{222} \mathrm{Rn}$ en la transecta $(7,3 \mathrm{dpm} / \mathrm{L})$ y el promedio de los pozos (130 dpm/L) como valor extremo, se ha intentado calcular el flujo de descarga.

\subsubsection{Tomografía de resistividad eléctrica (ERT)}

La tomografía de resistividad eléctrica, también conocida por el acrónimo ERT por denominación en inglés (electrical resistivity tomography) resulta una herramienta eficaz y expeditiva para estudiar el subsuelo. En particular se ha utilizado exitosamente en diversos trabajos para la caracterización de la relación agua dulceagua salada (Perdomo et al., 2013a; Perdomo et al., 2013b) y la identificación de la descarga de agua dulce (Andersen et al., 2007). Las mediciones de resistividad se integran en un perfil de $2 \mathrm{D}$, por lo que permite estudiar variaciones laterales $y$ verticales de esta propiedad en el subsuelo, que pueden ser causadas por cambios en la litología, granulometría e incluso en las características químicas del agua subterránea.

Las determinaciones de la resistividad se realizaron con un resistivímetro de corriente continua conectado a un navegador GPS para georreferenciar cada medida. Se utilizó un cable multinúcleo arrastrado desde el bote, lastrado y compuesto por cinco electrodos metálicos de acero inoxidable que estuvieran en contacto con el fondo marino. y se materializó un dispositivo electródico polo-dipolo con una distancia mínima entre electrodos de $5 \mathrm{~m}$ (Figura 2.14). El electrodo de infinito se ubicó cerca del bote a $40 \mathrm{~m}$ de distancia del arreglo, las distancias reales fueron consideradas para el cálculo de las constantes geométricas.

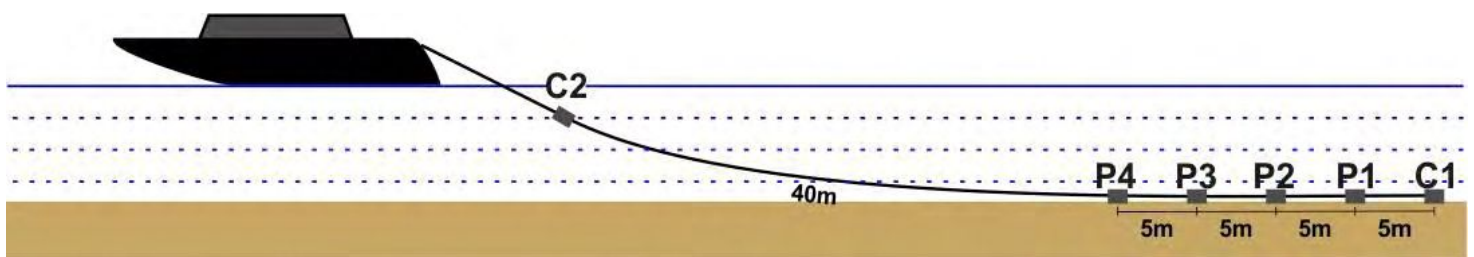

Figura 2.14 Disposición de los electrodos para el arreglo Polo-Dipolo.

Se registraron 11607 datos de resistividad aparente a lo largo de un perfil de aproximadamente $35 \mathrm{~km}$, hasta 3 niveles de medición y un espaciado aproximado de $10 \mathrm{~m}$ entre mediciones consecutivas. Las medidas de resistividad aparente fueron procesadas con el software Res2dInv (Loke et al., 2015). En primera instancia se consideraron secciones de $3 \mathrm{~km}$ de largo donde la distancia a la costa había sido constante, y también reducir los tiempos de inversión. En la etapa de procesamiento se consideró el efecto de la capa de agua de mar por encima de los electrodos de 
medición, incorporando la batimetría del fondo marino y la conductividad eléctrica medida in situ. La rutina de inversión utilizada por el programa se basa en el método de mínimos cuadrados suavizados restringidos (DeGroot-Hedlin y Constable, 1990; Sasaki, 1992), y básicamente el algoritmo trata de reducir la diferencia entre los valores de resistividad aparente medidos y calculados mediante el ajuste de la resistividad del modelo. La medida de esta diferencia viene dada por el error medio cuadrático (RMS) que en inversiones de datos experimentales se acepta un 5\% como error máximo tolerable. El detalle del procesamiento de los datos puede consultarse en Albino Martínez (2017).

\subsection{Efecto de las mareas del Río de La Plata sobre el agua subterránea en la costa estuárica}

Se seleccionaron tres sitios correspondientes a diferentes unidades geomorfológicas donde estaban ya colocados los freatímetros P1, P2 y P3 (Figura 2.15) ubicados en una transecta perpendicular al Río de la Plata a diferentes distancias de la línea de la costa estuárica.

Se analizó el comportamiento del agua freática en relación a las variaciones de altura del Río de la Plata, para lo cual se instalaron sensores de nivel con frecuencia de medición horaria, durante el período diciembre-2015 a marzo-2016. En el pozo ubicado más próximo al río ( $\mathrm{P} 1)$, se instaló, a su vez, un sensor con registro de temperatura y conductividad eléctrica del agua subterránea.

Para completar este análisis se incluyeron datos de las variaciones del nivel del río provistas por el Servicio de Hidrografía Naval y de las precipitaciones de la estación meteorológica La Plata - Observatorio (UNLP). 


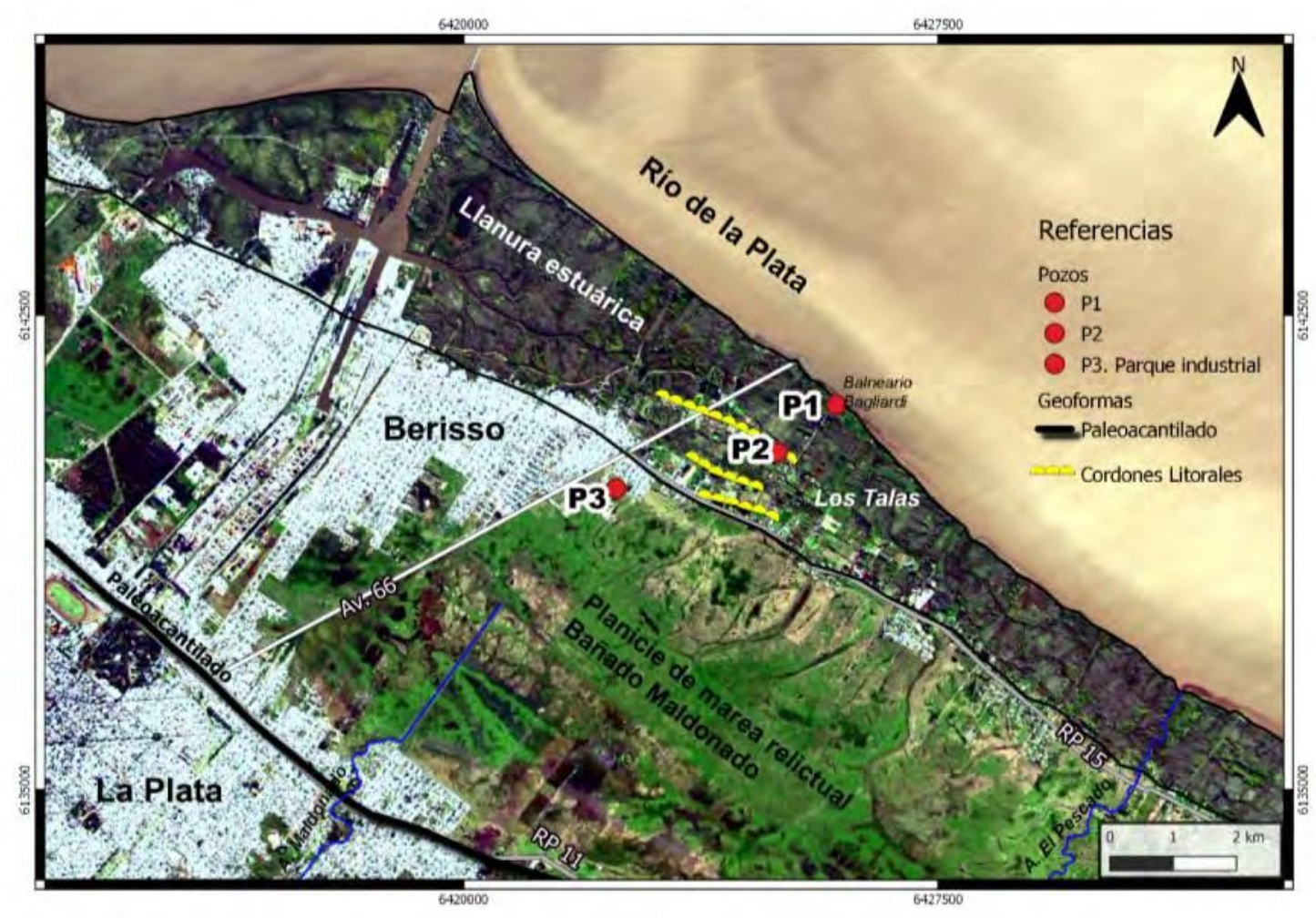

Figura 2.15 Localización de los freatímetros analizados. 


\section{CARACTERIZACIÓN CLIMATOLÓGICA}

En este capítulo se presentan las características climáticas de ambas áreas de estudio analizadas sobre la base de estudios antecedentes.

\section{Costa marítima}

El clima de la región es templado húmedo. Según la clasificación de Thornthwaite es B1B'2 r a', donde B1 es húmedo, B'2 es mesotermal (templado), r representa un nulo a pequeño déficit de agua, y a una concentración estival de la eficiencia térmica menor del $48 \%$ (CFI, 1990a).

Según las estadísticas del Servicio Meteorológico Nacional, para el periodo (19511980) la precipitación media anual para San Clemente del Tuyú de orden de $1034 \mathrm{~mm}$ con una distribución relativamente homogénea a lo largo del año (Figura 3.1).

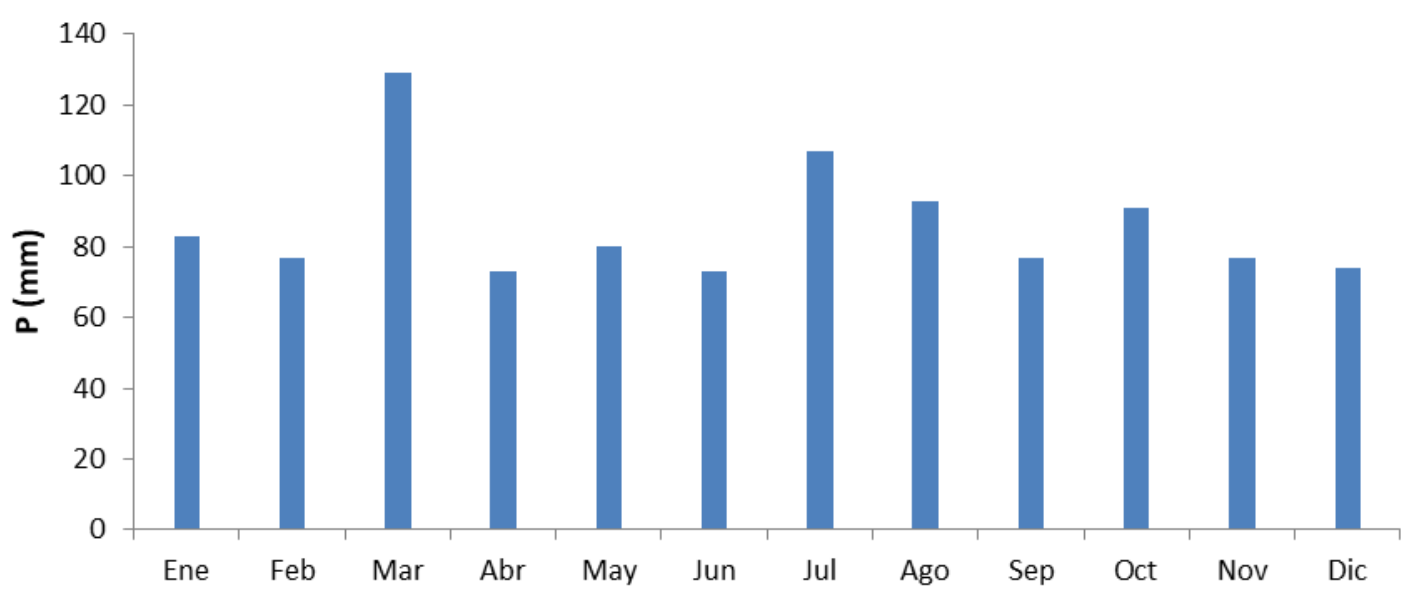

Figura 3.1 Precipitaciones medias mensuales en San Clemente del Tuyú (Período 1951-1980).

Estacionalmente el verano (diciembre, enero y febrero) representa el 22,6\% del total anual. Para el otoño (marzo, abril, mayo) un $27,3 \%$, en primavera (septiembre, octubre y noviembre) un $23,7 \%$ mientras que la estación invernal (junio, julio, agosto) constituye el $26,4 \%$.

El mes más lluvioso es marzo con un promedio mensual de $129 \mathrm{~mm}$ y el mes menos lluvioso es junio con $73 \mathrm{~mm}$.

En la Tabla 3 se presentan los valores de precipitación medios máximos y mínimos de dos localidades del Partido de La Costa. 
Tabla 3 Precipitación media máxima y mínima de dos localidades del Partido de La Costa.

\begin{tabular}{|c|c|c|c|}
\hline & Media anual & $\begin{array}{c}\text { Máxima anual } \\
(\mathrm{mm})\end{array}$ & $\begin{array}{c}\text { Mínima anual } \\
(\mathrm{mm})\end{array}$ \\
\hline $\begin{array}{c}\text { San Clemente del } \\
\text { Tuyú (1951-1980) }\end{array}$ & 1034 & $1380(1993)$ & $773(2004)$ \\
\hline $\begin{array}{c}\text { Santa Teresita } \\
(1990-2006)\end{array}$ & 1001 & $1174(2012)$ & $457(2013)$ \\
\hline $\begin{array}{c}\text { San Clemente del } \\
\text { Tuyú (2003-2014) }\end{array}$ & 871 & & \\
\hline
\end{tabular}

La temperatura media anual para la región es de $14,6^{\circ} \mathrm{C}$, con influencia directa por la distancia al mar (Carretero, 2011). Las temperaturas medias del verano $\left(20,4^{\circ} \mathrm{C}\right)$ y del invierno $\left(8,6^{\circ} \mathrm{C}\right)$ se mantienen constantes en toda el área (SMN, 2007).

\section{Costa estuárica}

El clima es templado - húmedo, con una precipitación media anual es de 1049 mm/año. Según la clasificación de Thornthwaite es B2C"2"r"a"), correspondiente a un clima húmedo (B2), microtermal (C"2), lo que indica que posee valores de evapotranspiración mayores a $570 \mathrm{~mm}$, con nula o pequeño deficiencia de agua ("r") y porcentaje de la concentración estival de la eficiencia termal inferior a 33.9 \% (a") (Kruse et al. 2014)

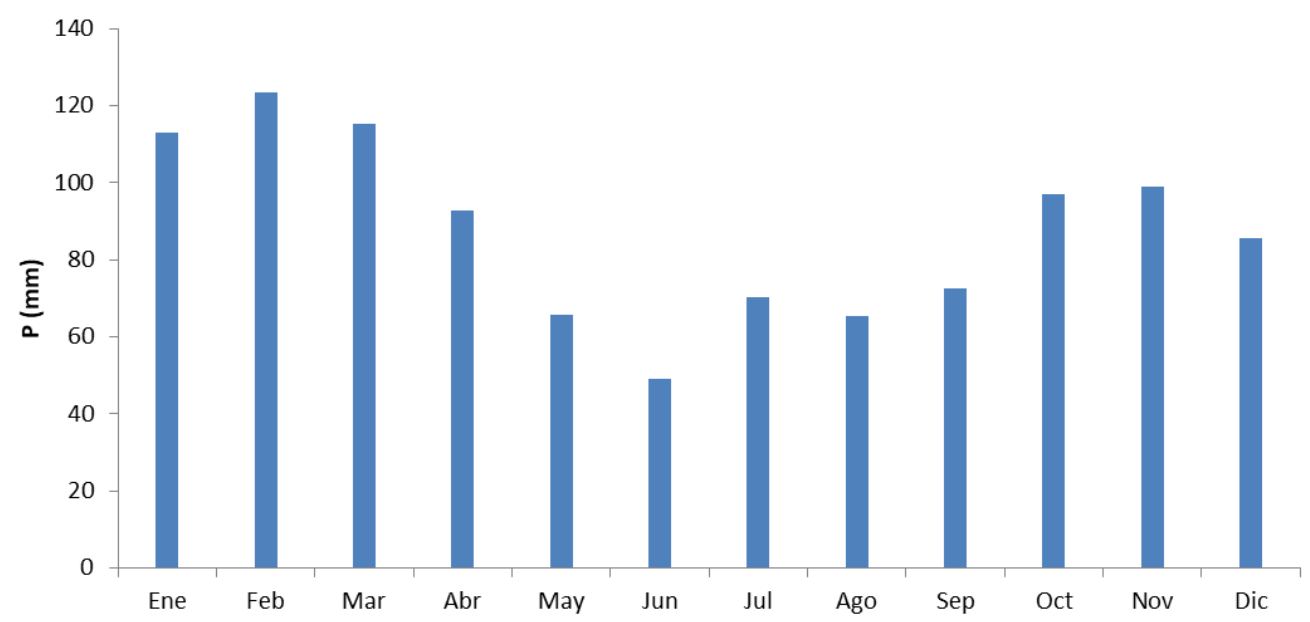

Figura 3.2 Precipitación media mensual (periodo 1995-2005), estación meteorológica La Plata Aero.

Estacionalmente el verano (diciembre, enero y febrero) representa el 30,7\% del total anual. Para el otoño (marzo, abril, mayo) un $26,1 \%$, en primavera (septiembre, octubre 
y noviembre) un $25,6 \%$ mientras que la estación invernal (junio, julio, agosto) constituye el $17,5 \%$.

El mes más lluvioso es febrero con un promedio mensual de $123 \mathrm{~mm}$ y el mes menos lluvioso es junio con 49 mm (Figura 3.2).

Se puede observar que el periodo más lluvioso transcurre de octubre a abril concentrando el $69 \%$ del monto anual. El periodo menos lluvioso se corresponde con los meses de mayo a septiembre representando el $31 \%$ del total anual.

La temperatura media anual es de $16,1^{\circ} \mathrm{C}$, con enero como el mes más cálido $\left(22,7^{\circ} \mathrm{C}\right)$ y julio como el más frío con $9,8^{\circ} \mathrm{C}$ (Auge, 2005). 


\section{GEOLOGÍA Y GEOMORFOLOGÍA}

\subsection{Evolución de la costa}

Distintos autores han descripto la evolución de la llanura costera durante el Holoceno, lo cual adquiere importancia en el comportamiento hidrológico regional. Si bien se considera la llanura costera como una unidad, los procesos y rasgos locales quedan expresados en la geología de cada sitio.

Se ha propuesto que las fluctuaciones del nivel del mar por efecto glacioeustático y la transgresión posterior al último máximo glacial (post-LGM), fueron el principal condicionante de la evolución. Se menciona que a los 18/20.000 años AP el nivel del mar presentó su posición más baja -105 metros (Guilderson et al., 2000), a partir de donde comenzó a ascender nuevamente durante la transgresión holocena. Como consecuencia de este evento, grandes extensiones de terreno se vieron afectadas por los procesos costeros dando origen a las llanuras costeras.

De acuerdo a los trabajos de Violante et al. (2001) las llanuras costeras bonaerenses constituyen los registros sedimentarios litorales del holoceno. Su extensión indica el máximo alcance que tuvo el mar sobre el continente, quedando expresado este límite como un escalón o paleoacantilado no mayor a 1 metro de desnivel, indicando el máximo alcance del mar durante la transgresión holocena Figura 4.1. 


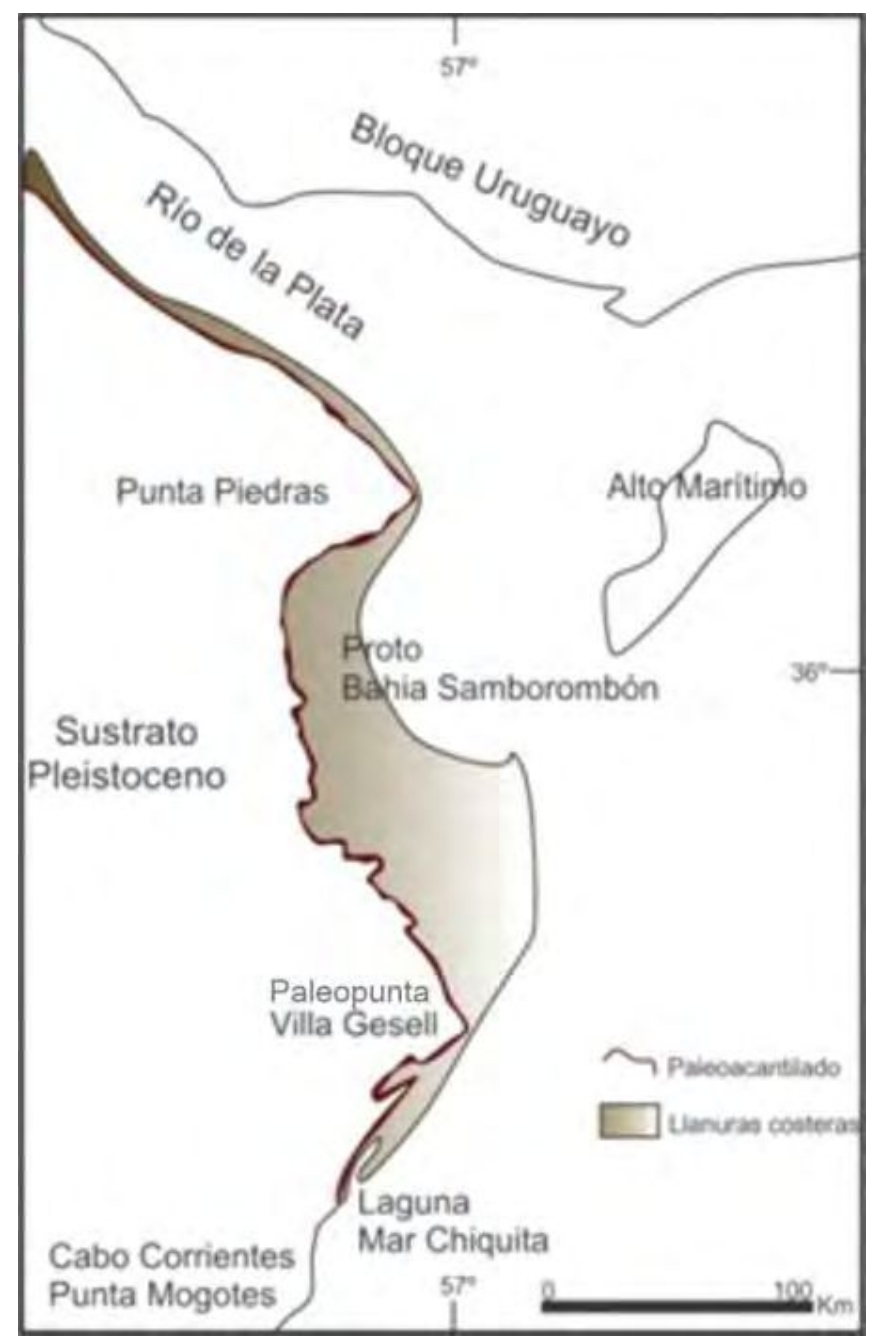

Figura 4.1 Tomado y modificado de Violante et al. 2001.

La importante acumulación y preservación de las secuencias estratigráficas se relaciona con la presencia de un relieve bajo predominante y una intensa dinámica sedimentaria producto de altas descargas del Río de la Plata y por el transporte litoral. Esta dinámica fue promovida por las fluctuaciones del nivel del mar ocurridas con posterioridad al último máximo glacial (18000 años).

Los sedimentos de las llanuras costeras se distribuyeron en ambientes de barreras litorales, cordones de playa, llanuras de mareas y albuferas (Violante et al., 2001). El sustrato pleistoceno (sedimentos Pampeanos) se encontraba bajo condiciones subaéreas al inicio de la última glaciación. La sedimentación holocena se ajustó al paleorelieve de este sustrato, el mismo contaba con relieves alto (salientes topográficos) y relieves bajos (bahías) (Figura 4.1) 
Los altos topográficos se prolongaban hacia el mar quedando expuestos a la acción de las olas de mar abierto bajo condiciones de alta energía quedando representados por la Punta Piedras - Alto Marítimo, la paleopunta Villa Gesell y por el extremo oriental de Tandilia que conformaba el sector cabo Corrientes- Punta Mogotes.

En cuanto a las zonas bajas, caracterizadas por ser sitios de baja energía protegidas de la acción de las olas, se encontraban la proto - bahía Samborombón y la depresión Mar Chiquita (Violante et al., 2001). El desarrollo geomorfológico del área controló la distribución y extensión de los depósitos holocenos.

Las variaciones del mar por efecto glacioeustático ocurren a partir del último máximo glacial, hace aproximadamente 15000 a 18000 años. En ese momento la posición del mar estaba situada 120-150 m por debajo del nivel actual, en coincidencia con el actual borde exterior de la plataforma continental. La transgresion holocena comienza con un ascenso rápido antes de los 8600 años A.P. Luego el mar tomó una posición semejante a la actual hace unos 7000 años. Llega a su nivel más alto a los 6000 años A.P. con una altura de $6,5 \mathrm{~m}$ por encima del nivel presente. La regresión marina subsiguiente comenzó entre los 6000 y 5000 años A.P., ocurre una relativa estabilidad entre los 5000 y 3500 años A.P., luego un descenso rápido que llevo el nivel de 5 a 2,5 m sobre el actual entre los 3500 y 2900 años y un final con descenso lento en los últimos 2900 años hasta que el mar alcanzo su posición presente (Violante et al., 2001).

\subsection{Rasgos geomorfológicos}

En la región se distinguen dos rasgos del paisaje principales, la llanura continental y la llanura costera.

La llanura continental, terraza alta o llanura pampeana, está conformada por sedimentos pleistocenos y holocenos, es la superficie situada en cotas superiores a los $5 \mathrm{~m} \mathrm{~s}$. n. m. El límite con la llanura costera es un paleoacantilado o escalón de no más de $1 \mathrm{~m}$ de altura que representa un resalto de pendiente, formado por erosión de olas en el máximo nivel del mar del Holoceno. Se caracteriza por un diseño irregular, constituye la línea de costa al momento del máximo transgresivo holoceno.

La composición litológica de la planicie continental está conformada por los depósitos loéssicos atribuidos a la Fm. Pampeano (González Bonorino, 1965) o Sedimentos Pampeanos (Fidalgo et al. 1975) o Formaciones Ensenada y Buenos Aires (Riggi et al., 1986). Constituye, por su espesor y amplia distribución, la unidad litológica que 
caracteriza la llanura pampeana y representa el sustrato donde se desarrollan los procesos generadores de muchos rasgos del actual paisaje (Fucks et al., 2017).

La llanura costera es el ámbito que se desarrolla al pie de la llanura pampeana, conformado por la cuña de sedimentos litorales del Holoceno. Si bien las llanuras costeras tienen en común haber sido generadas durante la transgresión holocena, las particularidades de cada zona, ya sea el relieve del sustrato sobre el cual sobre el cual se acumulan los sedimentos que la integran, la energía de olas, dirección de corrientes, la presencia de altos topográficos etc. condiciona y caracteriza la geomorfología local de cada ambiente.

Con respecto a las particularidades geomorfológicas de la llanura costera, en el litoral marítimo se debe señalar que la caracterización regional de CFI $(1989$,a) considera a la llanura deprimida y el cordón costero como geoformas principales del paisaje Figura 4.2.

La llanura deprimida está definida entre el cordón costero al este y la terraza alta y cordones litorales al oeste (CFI, 1989a). Existe un declive hacia el centro y norte de la cuenca del Salado. Presenta geoformas menores de relieve positivo y negativo. Las de relieve positivo no exceden de 1,5 m sobre el relieve circundante y bordean el eje deprimido central desde Gral. Lavalle al sur Figura 4.2. Las formas son médanos arcillosos (lúnulas) al suroeste, médanos arenosos (mantos) al este y noreste, y crestas de playa, ubicados al oeste de los médanos costeros. Las de relieve negativo incluyen a los canales de marea, los cuales definen una red de cursos irregulares que convergen hacia el norte al Río Ajó con drenaje muy lento conformando cañadas con vegetación. Cerca de la Bahía de Samborombón y el Río Ajó son verdaderos canales de marea en donde se forman cangrejales.

El cordón costero se desarrolla sobre una espiga del Holoceno inferior, que ha progradado hacia el norte durante los últimos 5000 años (Violante et al., 2001). Se desarrolla sin interrupciones desde Punta Rasa hasta la desembocadura de la laguna Mar Chiquita, tiene un ancho de 2-4 km con mayor desarrollo en la zona de Punta Médanos.

Presenta dos unidades geomorfológicas de menor jerarquía, playas y médano. Las playas son rectilíneas, con anchos entre 50 y $150 \mathrm{~m}$ y pendientes suaves, de arenas finas a medias, excepcionalmente gruesas. Son del tipo costas en construcción, sin barrancas, con playa arenosa. Las condiciones oceanográficas indican un transporte neto de sedimentos hacia el norte. 
Los médanos están ubicados al oeste de la playa que les da origen. Entre Cabo San Antonio y Punta Médanos son bajos y fijados por la vegetación. A veces es difícil identificar formas definidas. El balance según la cantidad de arena movida por el viento es positivo hacia el continente. La deriva litoral coincide con el transporte neto por el viento en dirección norte y se observa una pérdida de áreas de la playa que se van incorporando a los médanos.

La deriva litoral es la principal fuente de aportes de sedimentos de la playa y el campo de dunas, sin embargo, las condiciones aerodinámicas son un factor limitante en el desarrollo de las dunas costeras y en el aporte de sedimentos desde el sector continental a la playa (Marcomini, 2002). En el contexto geomorfológico de la región (Figura 4.2) los rasgos que presentan una litología arenosa, entre ellos el cordón costero, revisten una especial importancia y adquieren relevancia en la caracterización hidrogeológica. La infiltración favorecida en estos ambientes indicaría puntos de interés en donde se produciría el potencial almacenamiento de las aguas subterráneas. 


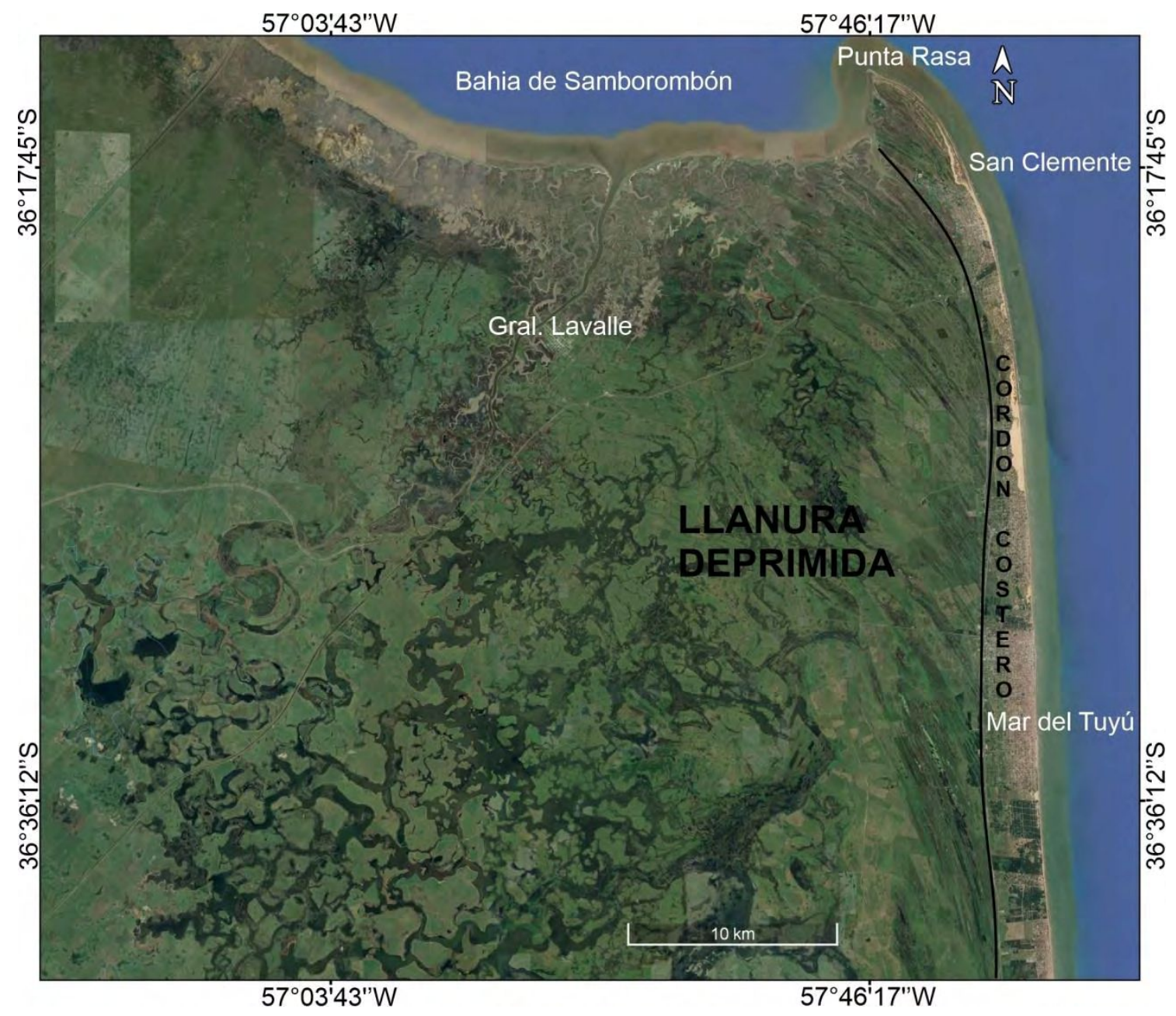

Figura 4.2 Contexto geomorfológico regional.

Además de la caracterización geomorfológica regional de CFI (1989a) donde se considera a la llanura deprimida y el cordón costero como geoformas principales del paisaje, Marcomini y López (2010) han definido para el sector de Mar del Tuyú otras subunidades geomorfológicas (Figura 4.3). Se distinguen de oeste a este: cordones litorales de rumbo NO hacia el oeste $(A)$, luego un campo de dunas inactivo (B) formado por mantos de arena vegetados debido a las mayores condiciones de humedad. Hacia el este continúan las dunas semiactivas (C) donde se distinguen crestas de dunas con espacios interdunales totalmente vegetados. Por último, las dunas activas (D), que se desarrollan en contacto con la playa. Estos rasgos se ven desdibujados por el ejido urbano tal como se observa en la Figura 4.3.

Ambas clasificaciones serán utilizadas de acuerdo a la necesidad del grado de detalle para los distintos análisis expuestos en el desarrollo de la tesis. 


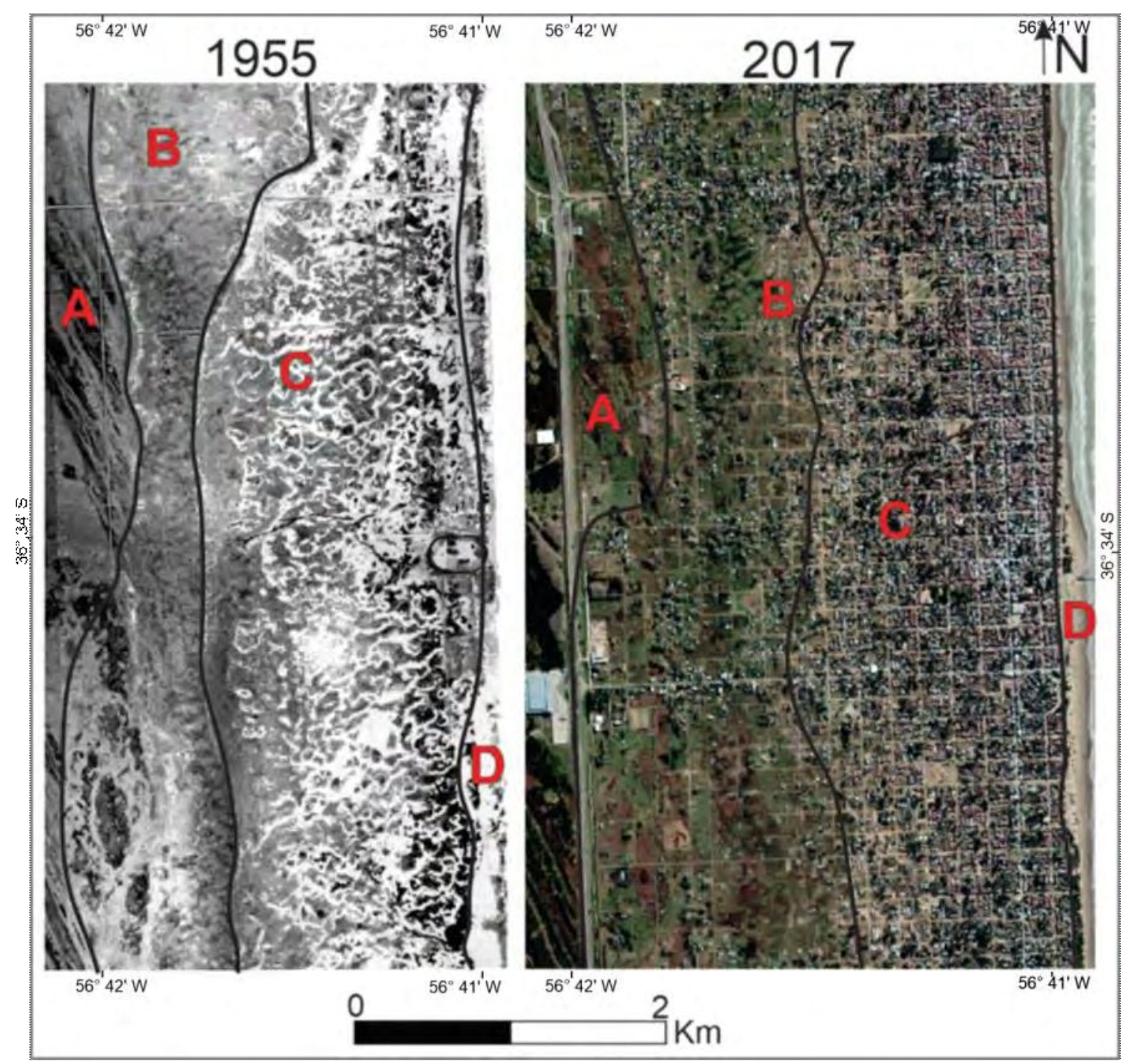

Figura 4.3 Ambientes geomorfológicos. De oeste a este se describen A: cordones litorales de rumbo NO; B: campo de dunas inactivo; C: dunas semiactivas; D: dunas activas.

En la región costera del Río de la Plata (costa estuárica, Berisso) también se reconocen dos ámbitos geomorfológicos contrastantes: la planicie continental y la llanura costera Figura 4.4. El límite entre estas dos formas principales se sitúa aproximadamente a los $5 \mathrm{~m} \mathrm{~s}$. n. m. representado por un acantilado relicto (Fucks et al., 2010; Prieto et al., 2016). 


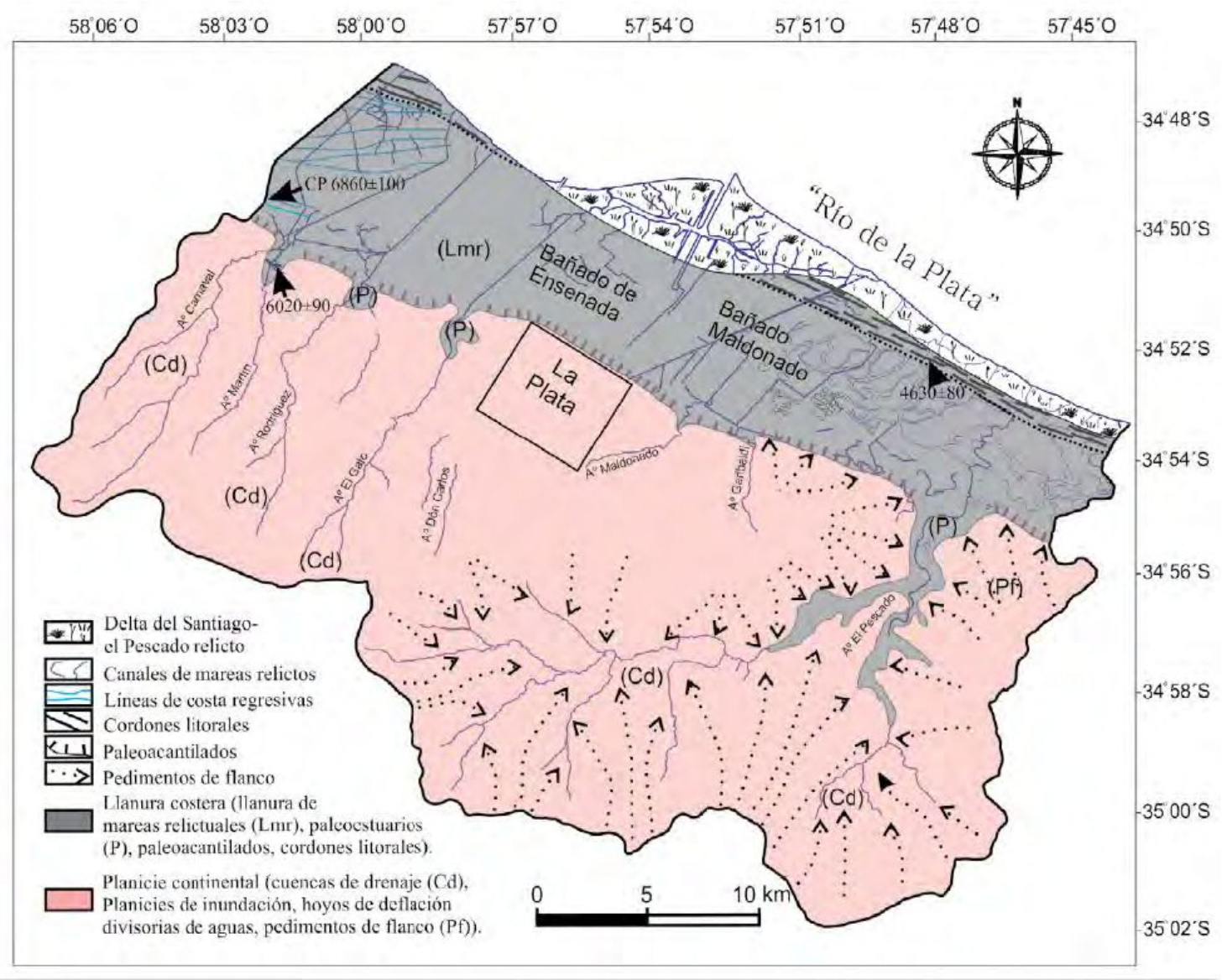

Figura 4.4 Características geomorfológicas tomado de Fucks et al. 2014.

La llanura costera desarrollada en la margen sur del estuario del Río de la Plata constituye una franja de unos 4 a $8 \mathrm{~km}$ de ancho, con una pendiente imperceptible (entre 0,06 a $0,1 \%$ ), sobre la cual se han desarrollado redes anárquicas y amplios bañados.

Esta unidad mayor puede subdividirse en geoformas menores: planicie de marea relictual, cordones litorales y llanura estuárica (Figura 4.5). Los sedimentos que conforman estas unidades son holocenos de origen marino y fluvio-estuárico, los más recientes (Fucks et al., 2017). 


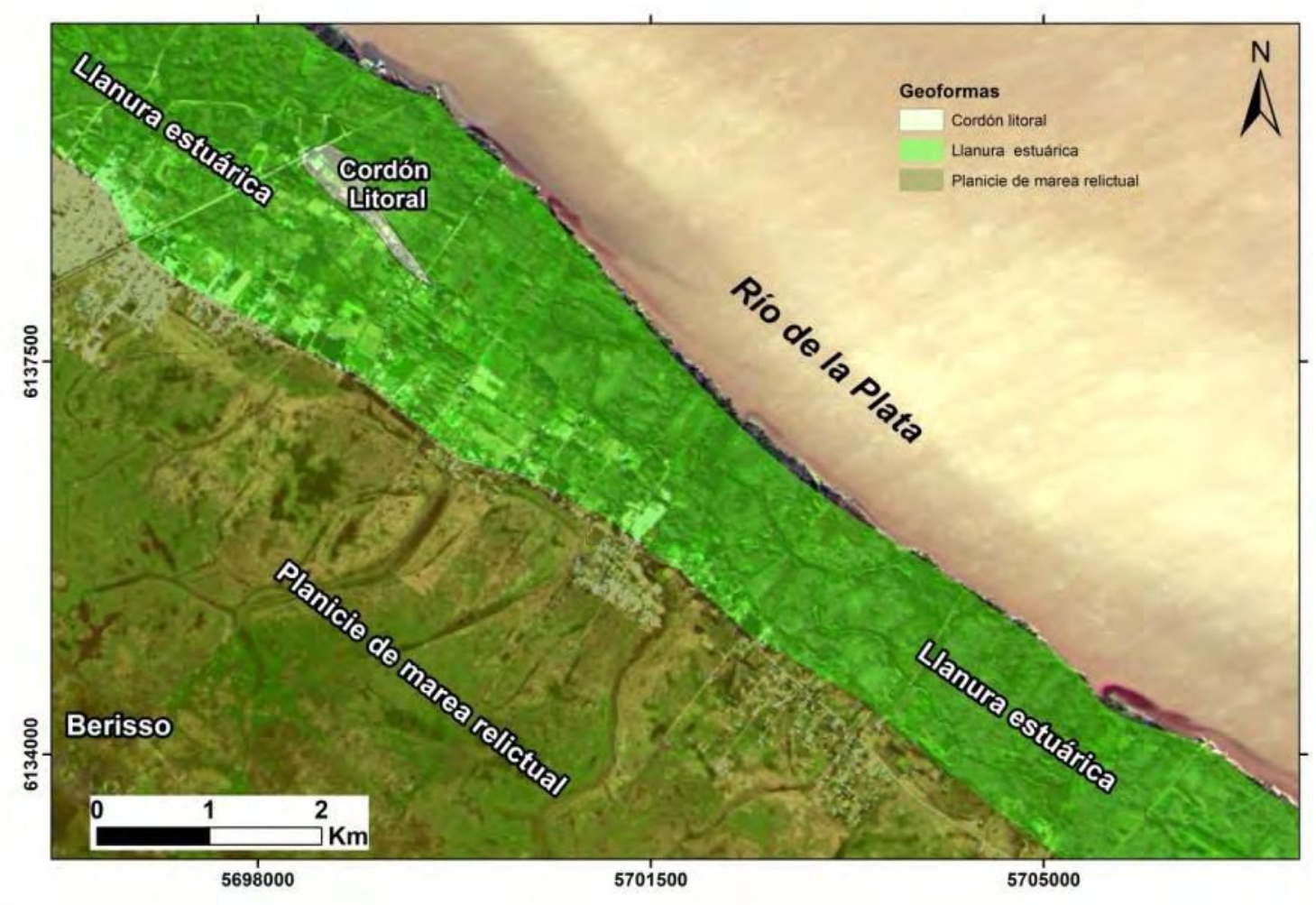

Figura 4.5 Mapa geomorfológico costa estuárica.

La unidad más antigua es la planicie de marea relictual integrada por sedimentos limo arcillosos a arcillas limosas de muy baja permeabilidad $(1 \mathrm{~m} / \mathrm{d})$. Presenta una forma plano cóncava cuyos límites son el paleoacantilado y la unidad conformada por los cordones litorales hacia la costa. Para el área se reconocen tres ingresiones marinas, la máxima tiene su expresión en el paleoacantilado que alcanza una cota de $5 \mathrm{~m}$ s.n.m Formación Puente de Pascua (Fidalgo et al., 1973, Fucks et al., 2010).

Los cordones litorales están integrados por gravas, arenas y conchillas con escaso porcentaje de limos, siendo frecuente las intercalaciones con arenas y limos. Los cordones ocupan una posición topográfica más elevada con respecto a las unidades adyacentes, con cotas medias de $3 \mathrm{~m} \mathrm{~s}$. n. m. Estos sedimentos corresponden a facies (Fc. Cerro de la Gloria) de alta energía de la Fm. Las Escobas (Fidalgo et al., 1973) y almacenan, en forma muy restringida, agua dulce. En la zona de Berisso, el material calcáreo de los cordones ha sido explotado en gran parte y en la actualidad se encuentran canteras abandonadas donde aflora el nivel freático y algunos sectores con relictos de esta geoforma conservada (Figura 4.6). 


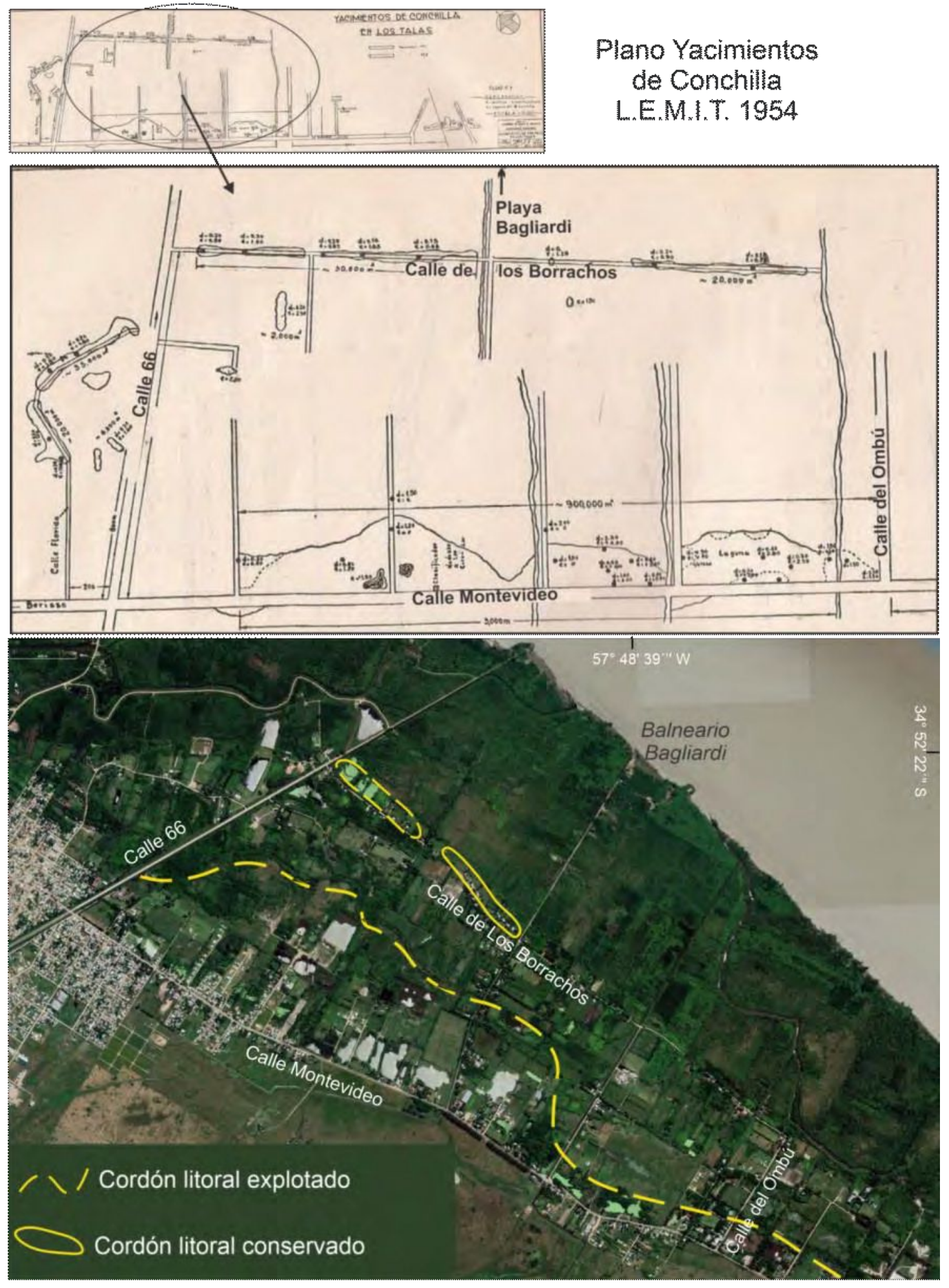

Figura 4.6 Plano de los yacimientos de conchilla para el año 1954 en Los Talas, Berisso. La imagen actual muestra las canteras producto de la explotación de las conchillas.

La llanura estuárica se extiende desde los cordones litorales hacia la playa actual del Río de la Plata (Figura 4.5), los sedimentos que ocupan esta franja costera son limos y arenas, con intercalaciones de arcillas. Representan los depósitos del río Santiago-El 
Pescado que, por efecto de la deriva litoral, han formado un delta paralelo a la costa y cuyos sedimentos son retrabajados por el Rio de la Plata (Fucks et al. 2014). Esta geoforma se encuentra expuesta a las mareas e inundaciones por sudestadas y es el ámbito donde se desarrollan las actividades forestales y vitivinícolas. 


\section{HIDROGEOLOGÍA REGIONAL}

En la caracterización geológica regional se plantea un sistema compuesto por distintas unidades hidrolitológicas. Se reconoce una secuencia sedimentaria psamítico-pelítica originada por sucesivos desplazamientos de la línea de costa durante el Pleistoceno y el Holoceno. También se identifica un sistema hidrogeológico profundo cuyo origen estaría vinculado al relleno en una cuenca sedimentaria.

Se realiza una descripción más detallada del ambiente de la costa marítima, en relación con el área complementaria de estudio situada en la costa estuárica del Río de la Plata. La secuencia profunda muestra una configuración relativamente similar. Las diferencias existen en la parte superior de la secuencia (Plioceno a reciente), en que se debe resaltar la mayor cantidad de información existente de la costa marítima.

\subsection{Costa marítima}

El sistema hidrogeológico de la costa marítima se detalla en la Tabla 4, indicándose para cada unidad la litología, los nombres formacionales que reciben, el ambiente de depositación y su edad.

Tabla 4 Sistema hidrogeológico. Modificado de Carretero (2011).

\begin{tabular}{|c|c|c|c|c|c|c|}
\hline Litología & \multicolumn{2}{|c|}{$\begin{array}{l}\text { Comportamiento } \\
\text { hidrolitológico }\end{array}$} & \multirow{2}{*}{$\begin{array}{c}\text { Formación } \\
\text { Punta Médanos }\end{array}$} & \multirow{2}{*}{$\begin{array}{c}\text { Ambiente } \\
\begin{array}{c}\text { Continental origen } \\
\text { eólico }\end{array} \\
\text { (cordón costero) }\end{array}$} & \multicolumn{2}{|c|}{ Edad } \\
\hline $\begin{array}{l}\text { Arenas finas a medianas } \\
\text { castaño amarillentas }\end{array}$ & \multirow{3}{*}{$\begin{array}{l}\text { Acuífero } \\
\text { freático }\end{array}$} & \multirow{6}{*}{$\frac{\frac{C}{D}}{C}$} & & & \multirow{3}{*}{ 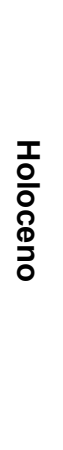 } & $\frac{\text { 음 }}{\frac{\pi}{6}}$ \\
\hline Arenas conchilíferas & & & Pozo N¹7 & $\begin{array}{c}\text { Marino } \\
\text { (barrera litoral) }\end{array}$ & & \multirow{2}{*}{$\frac{\stackrel{\circ}{\frac{\pi}{0}}}{\text { के }}$} \\
\hline $\begin{array}{c}\text { Arenas finas y arenas } \\
\text { arcillosas }\end{array}$ & & & \multirow{2}{*}{ Pozo N8 } & $\begin{array}{l}\text { Marino } \\
\text { (playa-barrera } \\
\text { litoral) }\end{array}$ & & \\
\hline $\begin{array}{c}\text { Arcillas y arcillas arenosas } \\
\text { verde grisáceas con valvas } \\
\text { enteras }\end{array}$ & $\begin{array}{l}\text { Acuitardo - } \\
\text { acuícludo }\end{array}$ & & & Albufera & \multirow{3}{*}{$\begin{array}{l}\frac{0}{D} \\
\frac{D}{0} \\
\frac{0}{0} \\
\stackrel{\cap}{D} \\
\frac{D}{2} \\
0\end{array}$} & \multirow{3}{*}{$\frac{ㅇ}{\frac{0}{0}}$} \\
\hline $\begin{array}{c}\text { Limos arenosos y arenas } \\
\text { limosas castaño } \\
\text { amarillentas, } \\
\text { friables }\end{array}$ & \multirow[t]{2}{*}{$\begin{array}{c}\text { Complejo } \\
\text { Acuífero } \\
\text { Semiconfinado }\end{array}$} & & $\begin{array}{l}\text { Buenos } \\
\text { Aires }\end{array}$ & Continental & & \\
\hline $\begin{array}{c}\text { Arenas y arenas limo } \\
\text { arcillosas } \\
\text { castaño a amarillento }\end{array}$ & & & Pozo N¹0 & $\begin{array}{c}\text { Marino } \\
\text { (litoral a } \\
\text { plataforma } \\
\end{array}$ & & \\
\hline
\end{tabular}




\begin{tabular}{|c|c|c|c|c|c|}
\hline Arcilla hacia la base & & & interior) & & \\
\hline $\begin{array}{c}\text { Arcillas plásticas verde-gris } \\
\text { con valvas gruesas y } \\
\text { moteados férricos }\end{array}$ & $\begin{array}{l}\text { Acuitardo- } \\
\text { Acuícludo }\end{array}$ & Pozo No 4 & $\begin{array}{c}\text { Marino } \\
\text { (plataforma } \\
\text { interior) } \\
\end{array}$ & & $\sum^{\frac{0}{2}}$ \\
\hline $\begin{array}{c}\text { Arenas cuarzosas, claras y } \\
\text { pardo amarillentas }\end{array}$ & \multirow{3}{*}{$\begin{array}{l}\text { Sistema } \\
\text { profundo }\end{array}$} & $\begin{array}{l}\text { "Arenas } \\
\text { Puelches" }\end{array}$ & $\begin{array}{l}\text { Continental } \\
\text { (fluvial) }\end{array}$ & $\begin{array}{l}z \\
\mathbf{0} \\
8 \\
0 \\
\mathbb{0} \\
0\end{array}$ & $\begin{array}{l}\stackrel{\circ}{\Phi} \\
\stackrel{0}{0} \\
\stackrel{0}{\bar{\alpha}}\end{array}$ \\
\hline $\begin{array}{l}\text { Limos y arcillas con } \\
\text { intercalaciones psamíticas }\end{array}$ & & $\begin{array}{l}\text { Paraná } \\
\text { (“Verde") }\end{array}$ & $\begin{array}{c}\text { Marino } \\
\text { (transgresivo) }\end{array}$ & & 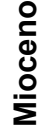 \\
\hline Areniscas y arcillas rojas & & $\begin{array}{l}\text { Olivos } \\
\text { ("Rojo") }\end{array}$ & $\begin{array}{l}\text { Continental } \\
\text { (regresivo) }\end{array}$ & 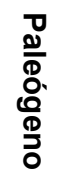 & \\
\hline
\end{tabular}

\subsubsection{Unidades hidrogeológicas}

En la región es posible reconocer un sistema somero y uno profundo. En el primero se puede identificar el acuífero freático.

El sistema somero incluye a las siguientes unidades: acuífero freático, unidad acuitarda, complejo acuífero semiconfinado (CAS) y unidad acuitarda - acuícluda.

\section{- Acuífero freático}

El acuífero freático está compuesto por una secuencia de arenas finas a medianas con un contenido variable de fragmentos de valvas y detritos vegetales que pertenecen a la Fm. Punta Médanos y la facies Mar de Ajó de la Fm. Pozo n¹7.

El espesor ha sido señalado a partir de dos perforaciones antecedentes realizadas por el Consejo Federal de Inversiones (CFI, 1989b). En el perfil hidrolitológico de orientación N-S paralelo a la costa se reconoce un espesor de $13 \mathrm{~m}$ en Mar del Tuyú, donde estas arenas se apoyan directamente sobre un nivel de arcillas verdes de comportamiento acuitardo.

En San Clemente del Tuyú, Las Toninas y Santa Teresita existen perforaciones más recientes (Carretero et al., 2016) que abarcan el espesor total del acuífero. Un perfil estratigráfico tipo comprende hasta los 3,5 $\mathrm{m}$ de profundidad una arena clara, de origen eólico, con fragmentos de conchillas que corresponde a la Fm. Punta Médanos. Por debajo y hasta los $8 \mathrm{~m}$, arenas más oscuras las cuales se correlacionan con el ambiente de barrera de la Facies Mar de Ajó (Fm. Pozo n¹7). En adelante y hasta los 
$11 \mathrm{~m}$ se describe una arena más oscura y fina, muy arcillosa con fragmentos de conchillas. Luego de los $11 \mathrm{~m}$ la litología cambia a arcillas arenosas con conchillas que gradan a arcilla gris con fragmentos de conchillas gruesas $(5 \mathrm{~mm})$ lo cual constituye la Facies Destacamento Río Salado de la Fm. Pozo n8 (Tabla 5).

Tabla 5 Descripción del perfil estratigráfico tipo (Tomado de Carretero et al., 2016).

\begin{tabular}{|c|c|c|c|c|c|}
\hline $\begin{array}{c}\mathrm{N}^{\circ} \\
\text { muestra }\end{array}$ & $\begin{array}{l}\text { Prof. } \\
\text { (m) }\end{array}$ & Litología & Estratigrafía & Ambiente & $\begin{array}{l}\text { Comportamiento } \\
\text { hidrológico }\end{array}$ \\
\hline 1 & 2 & $\begin{array}{l}\text { arena clara con } \\
\text { fragmentos de } \\
\text { conchillas }\end{array}$ & \multirow{2}{*}{$\begin{array}{l}\text { Fm Punta } \\
\text { Médanos }\end{array}$} & \multirow{2}{*}{ Médanos actuales } & \multirow{6}{*}{ Acuífero } \\
\hline 2 & 3,5 & $\begin{array}{l}\text { arena clara con } \\
\text { fragmentos de } \\
\text { conchillas } \\
\end{array}$ & & & \\
\hline 3 & 5 & $\begin{array}{c}\text { arena más } \\
\text { oscura con } \\
\text { fragmento de } \\
\text { conchillas }\end{array}$ & \multirow{3}{*}{$\begin{array}{c}\text { Fm Pozo } \\
N^{\circ} 17 \text { Facies } \\
\text { Mar de Ajó }\end{array}$} & \multirow{3}{*}{$\begin{array}{l}\text { Barrera por acreción } \\
\text { de espiga de playas }\end{array}$} & \\
\hline 4 & 6,5 & $\begin{array}{l}\text { arena más } \\
\text { oscura con } \\
\text { fragmento de } \\
\text { conchillas }\end{array}$ & & & \\
\hline 5 & 8 & $\begin{array}{c}\text { arena más } \\
\text { oscura con } \\
\text { fragmento de } \\
\text { conchillas } \\
\end{array}$ & & & \\
\hline 6 & 9,5 & $\begin{array}{c}\text { arena más } \\
\text { oscura más } \\
\text { fina, muy } \\
\text { arcillosa con } \\
\text { fragmentos de } \\
\text { conchillas fina }\end{array}$ & \multirow{3}{*}{$\begin{array}{c}\text { (Fm Pozo n8) } \\
\text { Facies } \\
\text { Destacamento } \\
\text { Río Salado/La } \\
\text { Victoria }\end{array}$} & \multirow{3}{*}{$\begin{array}{c}\text { Llanura de mareas y } \\
\text { cangrejales/depósitos } \\
\text { de albufera }\end{array}$} & \\
\hline 7 & 11 & $\begin{array}{l}\text { arcilla arenosa } \\
\text { con conchillas }\end{array}$ & & & \\
\hline 8 & $>11$ & $\begin{array}{l}\text { arcilla gris con } \\
\text { fragmentos } \\
\text { chicos de } \\
\text { conchillas } \\
\text { gruesas }(5 \mathrm{~mm})\end{array}$ & & & $\begin{array}{l}\text { Acuitardo/ } \\
\text { acuícludo }\end{array}$ \\
\hline
\end{tabular}

En la Tabla 6 se resumen los parámetros hidrogeológicos definidos para el acuífero freático según las distintas fuentes de información. 
Tabla 6 Parámetros hidrogeológicos.

\begin{tabular}{|c|c|c|c|c|c|}
\hline Locación & Fuente & Método & $\begin{array}{c}\mathbf{T} \\
\left(\mathrm{m}^{2} / \mathrm{d}\right)\end{array}$ & $\mathbf{S}$ & $\begin{array}{c}\mathbf{K} \\
(\mathrm{m} / \mathrm{d})\end{array}$ \\
\hline \multirow{5}{*}{ San Clemente } & DIGMAS (1985) & & $110-150$ & 0,12 & 7,1 \\
\hline & UNLP (1976) & & 200 & 0,10 & 20 \\
\hline & Carretero (2011) & & 101 & & \\
\hline & $\begin{array}{c}\text { Carretero y } \\
\text { Kruse (2015a) }\end{array}$ & $\begin{array}{c}\text { Theis, } \\
\text { Recuperación } \\
\text { Theis }\end{array}$ & $116-266$ & 0,10 & $16-26$ \\
\hline & Perdomo (2015) & $\begin{array}{c}\text { Tomografía } \\
\text { eléctrica }\end{array}$ & 106 & & \\
\hline $\begin{array}{l}\text { Las Toninas en } \\
\text { Costa Chica }\end{array}$ & DOSBA (1980) & & 544 & 0,14 & 47 \\
\hline $\begin{array}{c}\text { Área al norte de Sta. } \\
\text { Teresita y las } \\
\text { Toninas }\end{array}$ & $\begin{array}{c}\text { Namen SRL } \\
\text { (1983) }\end{array}$ & & 90 & & $7,3-10,1$ \\
\hline Costa del Este & Perdomo (2015) & $\begin{array}{c}\text { Tomografía } \\
\text { eléctrica }\end{array}$ & 211 & & \\
\hline Mar de Ajó & DOSBA (1980) & & 513 & 0,07 & 42 \\
\hline $\begin{array}{c}\text { Extremo sur, zona } \\
\text { de acuífero con } \\
\text { mayor espesor }\end{array}$ & COPUAP (1982) & Jacob & 1265 & 0,025 & 80 \\
\hline \multirow{3}{*}{ Ea. Rincón de Cobo } & \multirow{3}{*}{ CFI $(1990, b)$} & Jacob & $460-485$ & $\begin{array}{l}0,001- \\
0,012\end{array}$ & $25-27$ \\
\hline & & Theis & $>650$ & 0,001 & \\
\hline & & Chow & \multicolumn{3}{|c|}{ valores similares a los de Jacob } \\
\hline Sur de Mar de Ajó & $\begin{array}{l}\text { Santa Cruz y } \\
\text { Silva Busso } \\
\text { (2001) }\end{array}$ & Neuman & $217-354$ & 0,05 & \\
\hline Punta Médanos & Perdomo (2015) & $\begin{array}{c}\text { Tomografía } \\
\text { eléctrica }\end{array}$ & 350 & & \\
\hline
\end{tabular}




\section{- Unidad acuitarda}

Compuesta por arcillas y arcillas arenosas verde grisáceas con valvas enteras, con un espesor de 2,5 a $5 \mathrm{~m}$ que presenta un techo casi horizontal con suave pendiente al sur, situándose entre 8 y $9 \mathrm{~m}$ debajo del nivel del mar. Originados en un ambiente de depositación del tipo albuférico. Los valores de $\mathrm{T}^{\prime}$ y $\mathrm{K}^{\prime}$ son de $1 \times 10^{-5} \mathrm{~d}^{-1}$ y de $1 \times 10^{-4}$ $\mathrm{m} / \mathrm{d}$ respectivamente $(\mathrm{CFI}, 1990 \mathrm{~b})$.

\section{- Complejo acuífero semiconfinado (CAS)}

Incluye a limos arenosos y arenas limosas castaño amarillentas friables con propiedades más arcillosas en la base. Las arenas medias relacionadas con el segundo evento transgresivo-regresivo ocurrido durante el Holoceno, que se caracterizó por la acreción de las barreras areno-conchiliferas, representa a una unidad acuífera.

En el área de Punta Médanos presenta características netamente acuíferas y aguas de baja salinidad. Los ensayos a caudal constante mencionados por CFI (1990b) para la zona de Ea. Rincón de Cobo indican una T de $182 \mathrm{~m}^{2} / \mathrm{d}$ y S de $3,8 \times 10^{-4}$ (método de Walton) y $\mathrm{T}$ de $224 \mathrm{~m}^{2} / \mathrm{d}$ y $\mathrm{S}$ de $10^{-4}-10^{-5}$ (Hantush), generalizándose para el acuífero una $\mathrm{T}$ de $180-220 \mathrm{~m}^{2} / \mathrm{d}$ y un $\mathrm{S}$ del orden de $10^{-4}$.

\section{- Unidad acuitarda - acuícluda}

Compuesto de arcillas plásticas verde-gris con valvas gruesas y moteados férricos

\section{- Sistema profundo}

El sistema profundo está integrado por sedimentos más antiguos que pertenecen al relleno de la Cuenca del Salado, comenzando con un depósito de arenas cuarzosas, claras y pardo amarillentas, de carácter acuífero, que se localiza entre los 90 y $120 \mathrm{~m}$ de profundidad. Continúa la secuencia limos y arcillas con intercalaciones psamíticas acuíferas hasta los $800 \mathrm{~m}$. Sigue un depósito con areniscas y arcillas rojas hasta los 1200 m, que presenta niveles acuíferos, acuícludos y acuitardos. Las capas acuíferas del sistema profundo se caracterizan por aguas de elevada salinidad.

\subsubsection{Hidrodinámica regional}

De acuerdo con los relevamientos efectuados asociados a la geomorfología surge el modelo hidrodinámico (Figura 5.1), así el cordón costero es la zona de recarga principal, luego un corto tramo es de conducción, y se da la descarga en dos direcciones opuestas, una hacia el mar y la otra al oeste, en la llanura deprimida. 
El esquema general está limitado por dos interfases, hacia el continente agua dulceagua salobre y hacia el mar, agua dulce-agua salada.

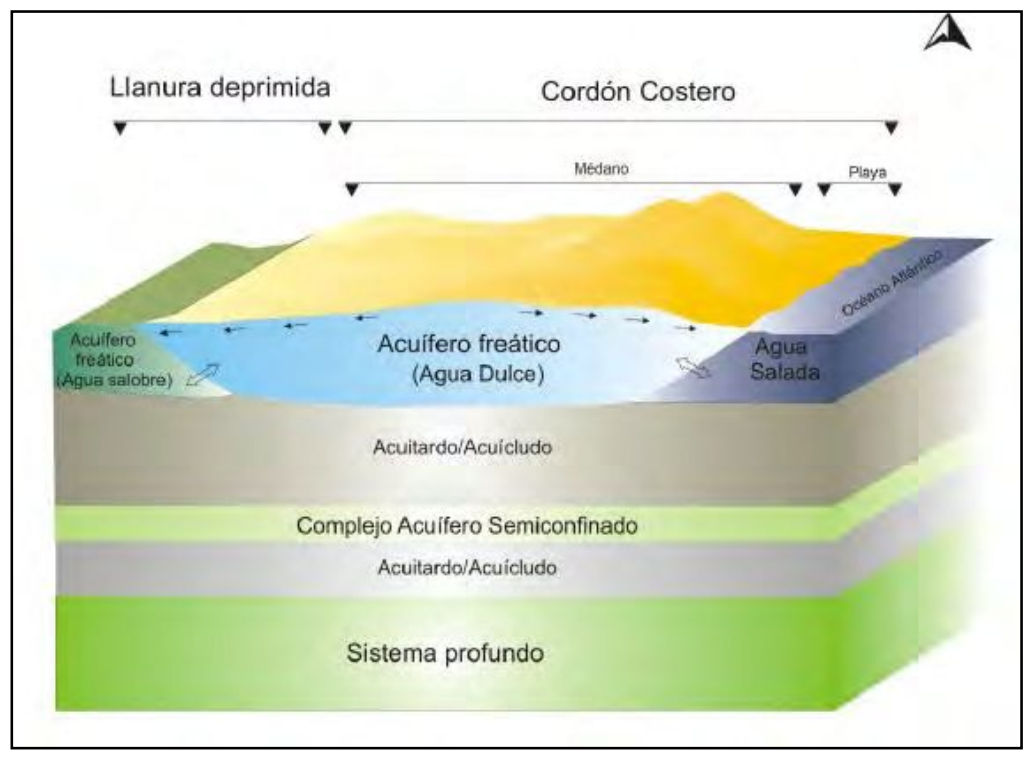

Figura 5.1 Esquema hidrodinámico. Tomado de Carretero (2011).

La divisoria de aguas subterráneas de dirección general N-S, tuerce levemente al SO a partir de Mar de Ajó, coincidente con las mayores alturas del cordón costero.

Las curvas isofreáticas aumentan de norte a sur siguiendo la topografía del cordón costero, con valores de 0,5-2 m s. n. m. en San Clemente y 8 m s. n. m. en Punta Médanos (Figura 5.2). El flujo se desplaza al este y oeste con una componente N-S de menor importancia. El escurrimiento subterráneo se da en dirección al mar con un gradiente hidráulico de 0,004 entre San Clemente y Mar de Ajó, llegando hasta 0,008. Al sur de Nueva Atlantis es de 0,002 y en Punta Médanos 0,001-0,0015. Hacia el oeste, con mayor uniformidad, el valor es de 0,001 y 0,002, salvo en el sector rural de San Bernardo, Mar de Ajó y Nueva Atlantis, que es de 0,0005 (CFI, 1990b). 


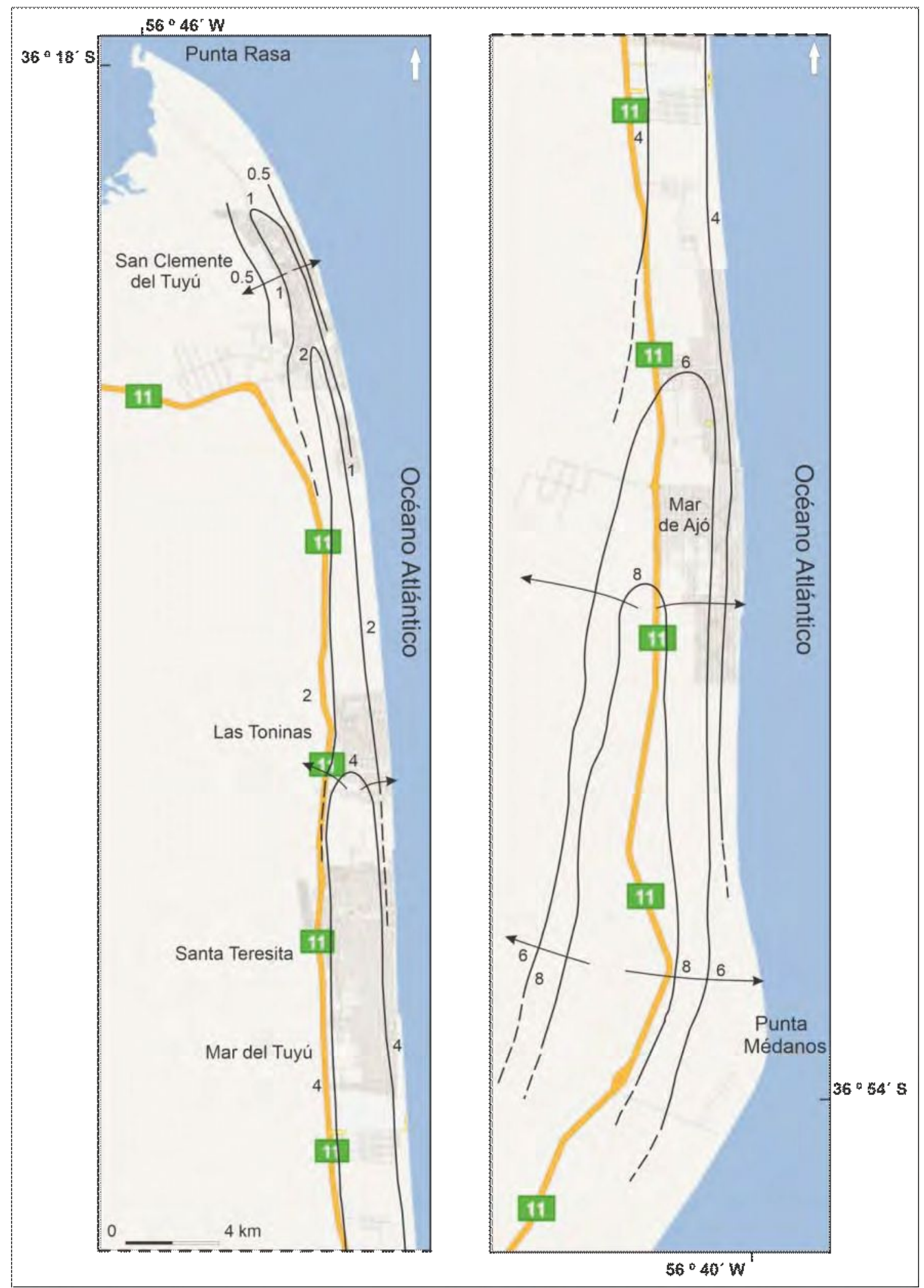

Figura 5.2. Curvas isofreáticas del cordón costero desde San Clemente a Punta Médanos, tomado y modificado de CFI 1990b.

De acuerdo con CFI (1990b) las mediciones del nivel freático entre abril y noviembre de 1987 permitieron determinar el espesor saturado total (EST), y el espesor saturado total sobre el nivel del mar (ESM), definiendo a este último como el límite de la 
depresión por explotación. Se reconoce un aumento del EST de norte a sur de 5 a $7 \mathrm{~m}$ en San Clemente pasando a 11-16 m en Punta Médanos. Una disminución del EST al este y oeste a partir del sector más elevado. Idéntico es el comportamiento del ESM con 0,7- 0,8 m en San Clemente a 1,5 -7,5 m en Punta Médanos.

\subsubsection{Hidroquímica regional}

El acuífero freático se caracteriza por presentar en general bajo contenido de cationes y aniones en el cordón costero, observándose un desmejoramiento de la calidad química hacia la llanura deprimida.

El diagnóstico hidroquímico regional (CFI, 1990b) indica que el cordón costero presenta bajos tenores en las áreas centrales (divisoria subterránea) que aumentan en ambos sentidos de escurrimiento. De acuerdo con la evolución vertical, aumentan las concentraciones en profundidad, lo cual es más notorio en el área de San Clemente Mar del Tuyú con una secuencia bicarbonatada cálcica, bicarbonatada sódica, clorurada sódica. En el resto del cordón es bicarbonatada cálcica con pasajes a bicarbonatada sódica en el contacto con el acuífero semiconfinado.

En la llanura deprimida empeora la calidad del agua asociado a que es zona de descarga del cordón costero, y por su lento drenaje debido a la morfología y presencia de sedimentos arcillosos que producen un aumento de los contenidos respecto al cordón.

Este sistema geohidrológico se caracteriza por su continuidad hidráulica, con una variada conexión entre los niveles acuíferos, la cual es función de la presencia y variaciones en el espesor de los niveles acuitardos.

\subsection{Costa estuárica (Río de la Plata)}

En la costa del Río de la Plata (Berisso) se destaca la importancia hidrogeológica de la secuencia superior del sistema que incluye al acuífero Puelche y al acuífero Pampeano / Pospampeano.

Las arenas Puelches (Plioceno - Pleistoceno) constituyen una unidad acuífera de importancia compuesta por una sucesión de arenas cuarzosas, de grano medio a fino, con coloración amarillenta y blanquecina. Son de origen fluvial y se apoyan en discordancia erosiva a las arcillas de la Fm. Paraná.

Los Sedimentos Pampeanos (Pleistoceno Medio - Superior) incluyen a sedimentos limo-arenosos de origen eólico y fluvial, mientras que los sedimentos Postpampeanos (Groeber, 1945) (Pleistoceno superior - Holoceno) están compuestos por sedimentos 
limo-arcillosos y arenosos de variado origen. Los sedimentos Postpampeanos dan origen en la zona de Berisso a la Planicie Costera entre los $5 \mathrm{~m} \mathrm{~s}$. n. m. y la ribera del Río de la Plata (0 m s. n. m.) y conforman una cuña sedimentaria cuyo espesor pasa de unos pocos centímetros en el límite con Llanura Alta aumentando gradualmente hasta llegar a un máximo de $25 \mathrm{~m}$ hacia el río.

Desde un punto de vista práctico, las secciones del subsuelo menos profundo (Postpampeano, Pampeano y Puelche) resultan las más conocidas ya que constituyen las unidades acuíferas actualmente en explotación. Estas unidades presentan una alternancia de secciones productivas separadas por sedimentos de menor permeabilidad. A pesar de las diferencias verticales de permeabilidad, existe una continuidad hidráulica por lo que se considera un acuífero multiunitario (Varela, 2002). Dada la vinculación hidráulica existente la explotación y generación de conos de depresión puede generar cambios en la hidrodinámica natural del sistema.

En el perfil hidrogeológico (Figura 5.3) desarrollado desde el casco urbano de La Plata (Llanura Alta), pasando por la ciudad Berisso (Planicie Costera) hasta la llegar a la costa del Río de la Plata, se grafican las unidades acuíferas presentes en cada sitio. 


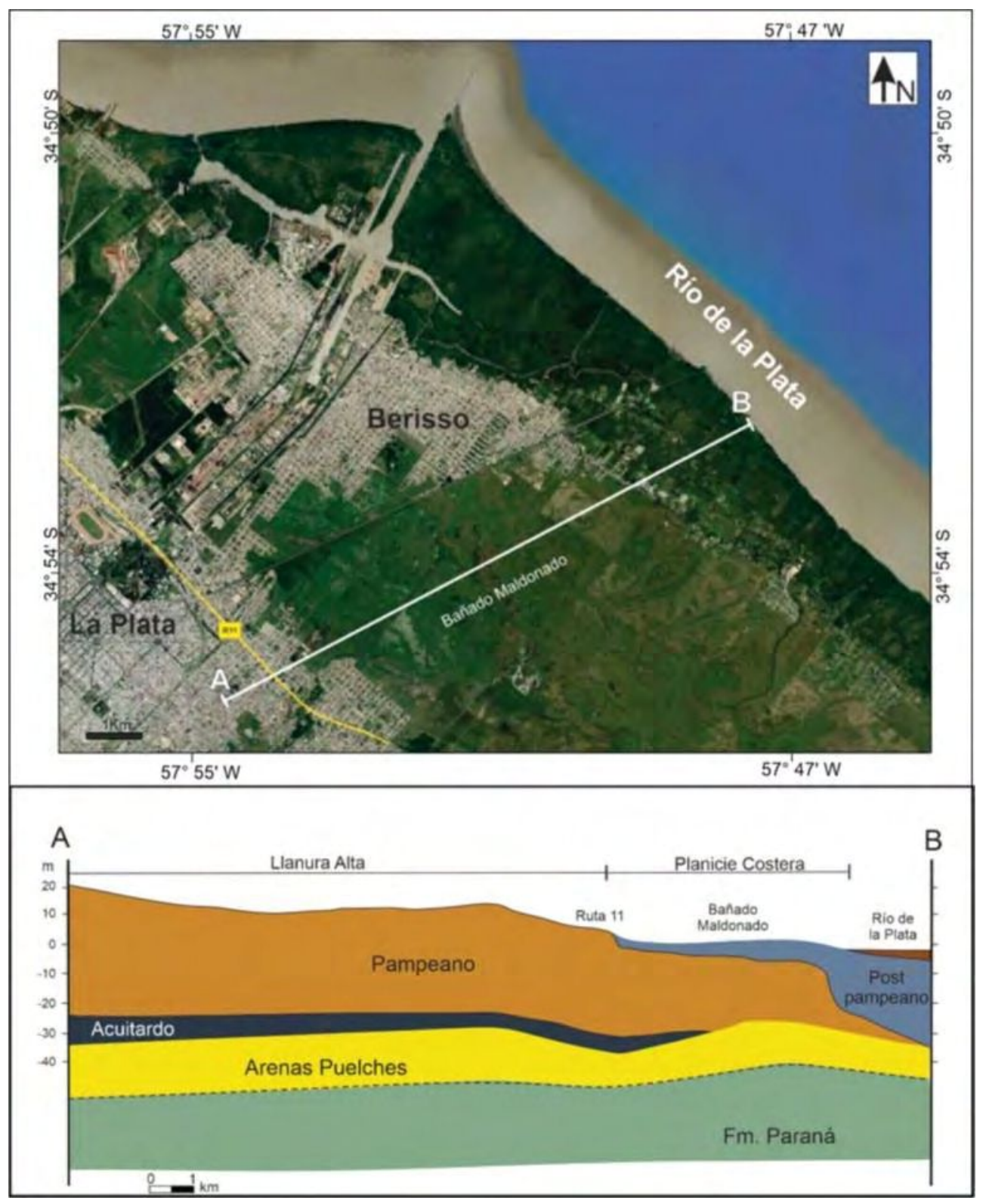

Figura 5.3 Perfil hidrogeológico. Tomado y modificado de Auge (2005).

En Llanura Alta el acuífero freático Pampeano se encuentra a una profundidad de entre 5 y $10 \mathrm{~m}$. Su espesor puede alcanzar los $50 \mathrm{~m}$, siendo la transmisividad media de alrededor de $200 \mathrm{~m}^{2} /$ día. Continua un paquete de arcillas cuyo espesor promedio es de $10 \mathrm{~m}$. Este nivel acuitardo se va acuñado hasta desaparecer en planicie costera. El acuífero Puelche que posee un carácter semiconfinado se encuentra a una profundidad media de $45 \mathrm{~m}$, variando siendo su espesor entre los 20 a $30 \mathrm{~m}$ (Auge, 1995) con una transmisividad media de $500 \mathrm{~m}^{2} /$ día.

En Planicie Costera afloran los sedimentos postpampeanos ocupando una franja paralela al Río de la Plata. Existen acuíferos productivos muy restringidos alojados en conchillas altamente permeables. Estas unidades se desarrollan como cordones cuyo 
ancho aproximado es de $3 \mathrm{~m}$ por $6 \mathrm{~m}$ de profundidad. Debido a la explotación de este material conchil los cordones han quedado sustituidos por canteras con agua freática aflorante. El escurrimiento subterráneo regional es de sudoeste a noreste, tendiendo a descargar en el Río de la Plata.

En cuanto al comportamiento hidrodinámico e hidroquímico, en la Llanura Alta los acuíferos Pampeano y Puelche presentan baja salinidad, siendo ambos utilizados para abastecimiento de agua en La Plata (Deluchi et al., 2010). La recarga de las Arenas Puelches es autóctona indirecta a través del acuífero Pampeano mediante filtración vertical descendente, siendo la recarga de este último de origen meteórico.

En la planicie costera (Berisso) el agua subterránea adquiere un carácter salino no apta para consumo humano (Ainchil y Kruse, 2002). Entre los acuíferos Pampeano y Puelche no existe nivel que los separe. La diferencia de carga hidráulica es a favor del acuífero Puelche, es decir que la filtración vertical es ascendente pasando a ser el acuífero Puelche el que recarga al Pampeano (Tabla 7).

Tabla 7. Sistema hidrogeológico que caracteriza al noreste de la Provincia de Buenos Aires. Tomado de Auge (1995).

\begin{tabular}{|c|c|c|c|c|c|c|c|c|}
\hline \multirow[b]{2}{*}{ Formación } & \multirow{2}{*}{$\begin{array}{c}\text { Post- } \\
\text { pampeano }\end{array}$} & \multicolumn{2}{|c|}{ Pampeano } & \multicolumn{2}{|c|}{ Arenas Puelches } & \multirow[b]{2}{*}{ Paraná } & \multirow[b]{2}{*}{ Olivos } & \multirow{2}{*}{$\begin{array}{c}\text { Basamento } \\
\text { Cristalino }\end{array}$} \\
\hline & & $\begin{array}{c}\text { Llanura } \\
\text { Alta }\end{array}$ & $\begin{array}{l}\text { Planicie } \\
\text { Costera }\end{array}$ & $\begin{array}{c}\text { Llanura } \\
\text { Alta }\end{array}$ & $\begin{array}{l}\text { Planicie } \\
\text { Costera }\end{array}$ & & & \\
\hline $\begin{array}{c}\text { Comportamiento } \\
\text { hidrolitológico }\end{array}$ & $\begin{array}{c}\text { Acuícludo- } \\
\text { acuitardo } \\
\text { dominante. } \\
\text { Acuífero en } \\
\text { los cordones } \\
\text { conchiles. }\end{array}$ & Acuífero & Acuífero & Acuífero & Acuífero & Acuícludo & Acuícludo & Acuífugo \\
\hline $\begin{array}{c}\text { Espesor } \\
\text { (m) }\end{array}$ & 0 a 30 & 25 a 45 & 0 a 30 & 15 a 30 & 15 a 25 & $\begin{array}{c}234 \\
\text { (Perf. Pza. } \\
\text { Armas) }\end{array}$ & $\begin{array}{c}189 \\
\text { (Perf. Pza. } \\
\text { Armas) }\end{array}$ & \\
\hline Caudal $\left(\mathrm{m}^{3} / \mathrm{h}\right)$ & $\begin{array}{c}0 \text { (arcilla) } \\
3 \text { (conchilla) }\end{array}$ & 10 a 30 & & 40 a 160 & 30 a 120 & 15 a 70 & & \\
\hline $\begin{array}{l}\text { Transmisividad } \\
\qquad\left(\mathrm{m}^{2} / \mathrm{d}\right)\end{array}$ & $\begin{array}{c}5 \cdot 10^{-3} \\
\text { (arcilla) } \\
10 \\
\text { (conchilla) }\end{array}$ & 10 a 315 & & $\begin{array}{l}150 a \\
1500\end{array}$ & & & & \\
\hline $\begin{array}{l}\text { Permeabilidad } \\
\qquad(\mathrm{m} / \mathrm{d})\end{array}$ & $\begin{array}{c}1.10^{-3} \\
\text { (arcilla) } \\
2 \text { (conchilla) }\end{array}$ & 1 a 10 & & 10 a 50 & & & & \\
\hline Salinidad (g/L) & $\begin{array}{c}15 \text { (arcilla) } \\
1 \text { (conchilla) }\end{array}$ & 0,3 a 1 & 4 a 15 & 0,5 a 1 & 8 a 20 & 3 a 7,5 & 6 a 40 & \\
\hline Litología & $\begin{array}{l}\text { Arcillas y } \\
\text { limos } \\
\text { arcillosos y } \\
\text { arenosos } \\
\text { dominantes. } \\
\text { Conchilla y } \\
\text { arena }\end{array}$ & $\begin{array}{l}\text { Limos } \\
\text { arenosos } \\
\text { loessoide } \\
\text { S }\end{array}$ & $\begin{array}{l}\text { Limos } \\
\text { arenosos } \\
\text { loessoide } \\
\text { s }\end{array}$ & $\begin{array}{l}\text { Arenas } \\
\text { medianas } \\
\text { a finas }\end{array}$ & $\begin{array}{l}\text { Arenas } \\
\text { medianas a } \\
\text { finas algo } \\
\text { arcillosas }\end{array}$ & $\begin{array}{l}\text { Arcillas en } \\
\text { la sección } \\
\text { sup arenas } \\
\text { arc. en la } \\
\text { inferior }\end{array}$ & $\begin{array}{l}\text { Arcillas } \\
\text { yesiferas en } \\
\text { la sección } \\
\text { sup. Y } \\
\text { conglomera } \\
\text { do arenoso } \\
\text { en la inferior }\end{array}$ & \\
\hline
\end{tabular}




\begin{tabular}{|c|l|l|l|l|l|l|l|l|}
\hline & $\begin{array}{l}\text { subordinado } \\
\text { s. }\end{array}$ & & & & & & & \\
\hline \multirow{2}{*}{ Origen } & $\begin{array}{l}\text { Marino, } \\
\text { fluvial y } \\
\text { lacustre }\end{array}$ & $\begin{array}{l}\text { Eólico y } \\
\text { fluvial }\end{array}$ & $\begin{array}{l}\text { Eólico y } \\
\text { fluvial }\end{array}$ & Fluvial & Fluvial & Marino & $\begin{array}{l}\text { Élico y } \\
\text { fluvial }\end{array}$ & $\begin{array}{l}\text { Metamórfic } \\
0\end{array}$ \\
\hline \multirow{2}{*}{ Edad } & $\begin{array}{l}\text { Pleistoceno } \\
\text { sup. } \\
\text { Holoceno }\end{array}$ & $\begin{array}{l}\text { Pleistoce } \\
\text { no medio } \\
\text { - sup. }\end{array}$ & $\begin{array}{l}\text { Pleistoce } \\
\text { no medio } \\
\text { - sup. }\end{array}$ & $\begin{array}{l}\text { Plio - } \\
\text { Pleistoce } \\
\text { no }\end{array}$ & $\begin{array}{l}\text { Plio - } \\
\text { Pleistoceno }\end{array}$ & $\begin{array}{l}\text { Mioceno } \\
\text { sup. }\end{array}$ & $\begin{array}{l}\text { Oligoceno - } \\
\text { Mioceno Inf. }\end{array}$ & $\begin{array}{l}\text { Precámbric } \\
\text { o }\end{array}$ \\
\hline
\end{tabular}




\section{CONDICIONES HIDROGEOLÓGICAS A ESCALA LOCAL}

\subsection{Costa marítima (Mar del Tuyú)}

\subsubsection{Caracterización del acuífero freático}

El acuífero freático que abastece de agua a la localidad de Mar del Tuyú está formado por las arenas finas a medianas del cordón costero. La unidad acuífera está compuesta por una secuencia de arenas finas a medianas con un contenido variable de fragmentos de valvas y detritos vegetales con un espesor entre 5 y $10 \mathrm{~m}$ que pertenecen a la Fm. Punta Médanos y la facies Mar de Ajó de la Fm. Pozo n¹7 (Tabla 8).

En la base del acuífero freático se desarrolla la unidad acuícluda con intercalaciones acuíferas y acuitardas. Al paquete arenoso descripto, le siguen 10 a $15 \mathrm{~m}$ de material limo arcilloso finamente arenoso con restos de bivalvos o arcillas de diferentes coloraciones que se corresponderían con la Fm. Pozo $n^{\circ} 8$.

Tabla 8 Sección representativa del sistema acuífero freático (Modificado de CFI, 1990b)

\begin{tabular}{|c|c|c|c|c|c|}
\hline Hidrogeología & Litología & Formación & Ambiente & & $\mathrm{ad}$ \\
\hline \multirow{3}{*}{$\begin{array}{l}\text { Acuífero } \\
\text { freático }\end{array}$} & $\begin{array}{l}\text { arenas finas a medianas } \\
\text { castaño amarillentas }\end{array}$ & $\begin{array}{c}\text { Punta } \\
\text { Médanos }\end{array}$ & $\begin{array}{l}\text { continental } \\
\text { (cordón } \\
\text { costero) }\end{array}$ & \multirow{4}{*}{$\begin{array}{l}\frac{0}{0} \\
\mathbb{0} \\
0 \\
\frac{0}{0} \\
1\end{array}$} & \multirow{2}{*}{$\frac{0}{\frac{0}{\sigma}}$} \\
\hline & $\begin{array}{c}\text { arenas conchilíferas } \\
\text { aumenta al E, desaparece } \\
\text { al } \mathrm{O}\end{array}$ & $\begin{array}{c}\text { Pozo } \mathrm{n}^{\circ} 17 \\
\text { Facies Mar de } \\
\text { Ajó }\end{array}$ & $\begin{array}{c}\text { marino } \\
\text { (barrera } \\
\text { litoral) }\end{array}$ & & \\
\hline & $\begin{array}{l}\text { arenas finas y arenas } \\
\text { arcillosas }\end{array}$ & \multirow{2}{*}{$\begin{array}{c}\text { Pozo n8 } \\
\text { Facies } \\
\text { Destacamento } \\
\text { Río Salado }\end{array}$} & $\begin{array}{c}\text { marino } \\
\text { (playa- } \\
\text { barrera } \\
\text { litoral) }\end{array}$ & & \multirow{2}{*}{ 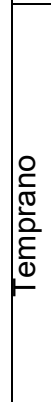 } \\
\hline $\begin{array}{l}\text { Acuitardo- } \\
\text { acuícludo }\end{array}$ & $\begin{array}{c}\text { arcillas y arcillas arenosas } \\
\text { verde grisáceas con } \\
\text { valvas enteras }\end{array}$ & & albufera & & \\
\hline
\end{tabular}

Como una primera aproximación de los parámetros hidráulicos podrían considerarse los calculados en San Clemente del Tuyú cuya transmisividad (T) es del orden de 100 $\mathrm{m}^{2} / \mathrm{d}$, un coeficiente de almacenamiento $(\mathrm{S})$ de 0,10 y una conductividad hidráulica $(K)$ aproximada de 20 m/d (Carretero, 2011; Carretero y Kruse, 2015a). 
En Mar del Tuyú se cuenta con la descripción litológica de dos perforaciones antecedentes (PR1 y PR7), las cuales pertenecen al estudio hidrogeológico realizado por el Consejo Federal de Inversiones (CFI, 1989a) en el Partido de La Costa. Con esta información se identificaron las unidades litológicas presentes en el área, se realizó el perfil hidrogeológico (Figura 6.1) lo que permitió definir espesores, continuidad areal y la geometría del acuífero freático.

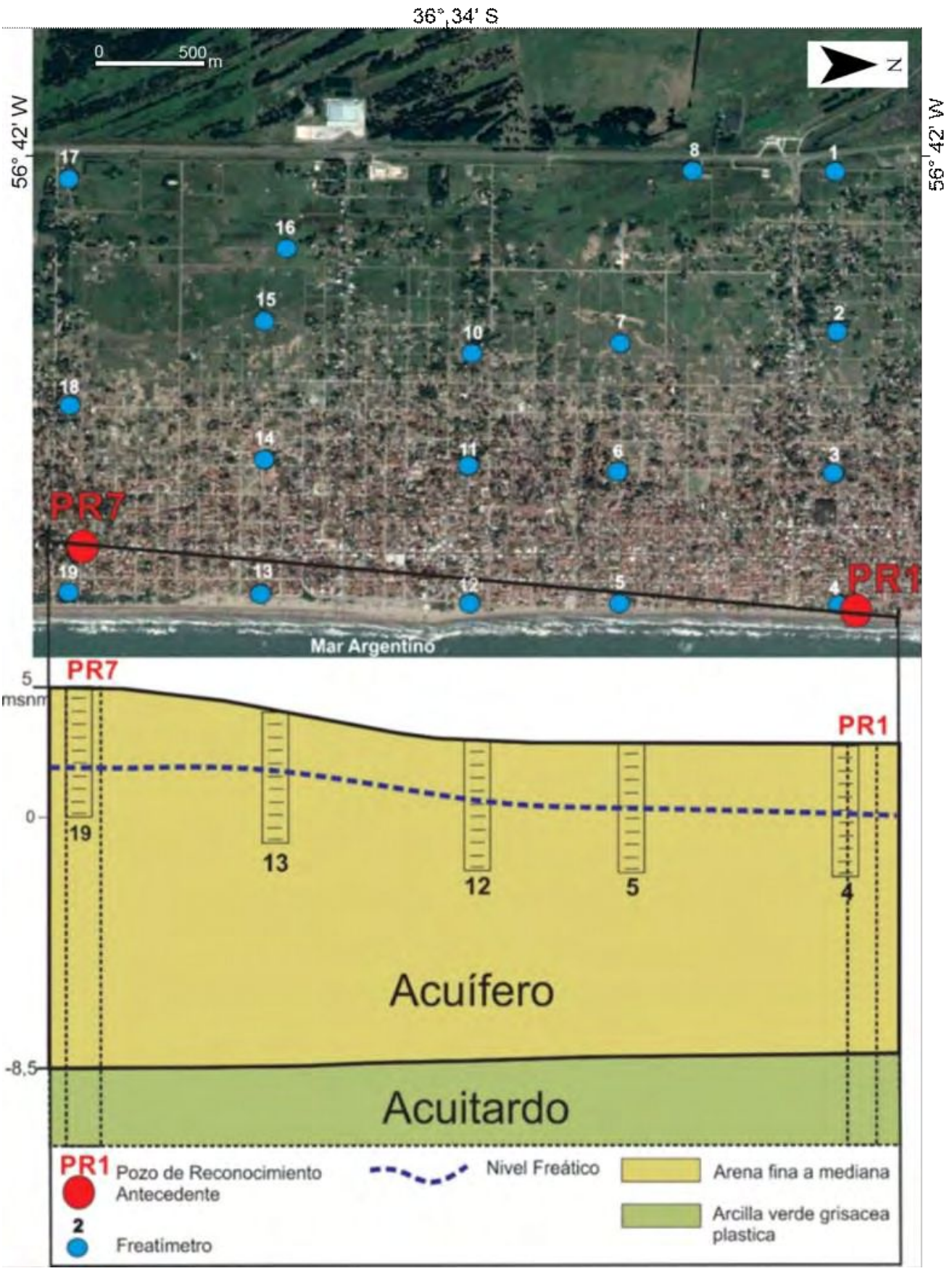

Figura 6.1 Perfil hidrogeológico de Mar del Tuyú. 


\subsubsection{Estimación de la conductividad hidráulica (K)}

Se realizaron 11 ensayos Slug Test por el método de Hvorslev (1951) para acuíferos libres (Ver Anexo 3).

Los resultados obtenidos se encuentran en la Tabla 9 en la cual se advierte que la conductividad hidráulica no sería homogénea en el área. Dividiendo al área en cuatro cuadrantes se puede distinguir los menores $\mathrm{K}(8 \mathrm{~m} / \mathrm{d})$ al SE, máximo $\mathrm{K}$ al SO $(41,44$, $59 \mathrm{~m} / \mathrm{d}$ ) y hacia el NE y NO entre 24 y $35 \mathrm{~m} / \mathrm{d}$ (Figura 6.2).

En el caso del pozo MT19, donde se ha obtenido el valor más bajo, es llamativo este resultado ya que se trata de una zona de duna casi natural. Pero la particularidad de este sector es que hay mucho tránsito vehicular y áreas de estacionamiento. Esto sugiere algún grado de compactación de las arenas lo cual muy probablemente lleve a reducir los valores de $\mathrm{K}$.

Existen valores de $\mathrm{K}$ publicados en estudios previos para otros sectores del acuífero costero. El CFI (1990b) menciona K entre 7 y $30 \mathrm{~m} / \mathrm{d}$ indicando un incremento de norte a sur. Sala et al (1976) a partir de ensayos granulométricos asigna un valor de $20 \mathrm{~m} / \mathrm{d}$ para el sector de San Clemente donde Carretero y Kruse (2015a) calcularon mediante ensayos de bombeo un rango entre 16 y $26 \mathrm{~m} / \mathrm{d}$ con un promedio de $20 \mathrm{~m} / \mathrm{d}$. De acuerdo a los antecedentes la metodología aplicada sería válida en el área de estudio ya que se han obtenido valores dentro de los rangos conocidos para el acuífero freático. Si bien en general se tiende a tomar un valor único de $\mathrm{K}$, queda demostrado que en Mar del Tuyú este parámetro del acuífero no es homogéneo.

Tabla 9 Valores de K calculados mediante los ensayos Slug Test.

\begin{tabular}{|c|c|c|c|c|c|c|c|c|c|c|c|}
\hline & MT1 & MT5 & MT6 & MT7 & MT11 & MT10 & MT14 & MT15 & MT16 & MT18 & MT19 \\
\hline $\begin{array}{c}\text { K } \\
\text { (m/d) }\end{array}$ & 31 & 24 & 24 & 23 & 35 & 31 & 41 & 41 & 59 & 44 & 8 \\
\hline
\end{tabular}




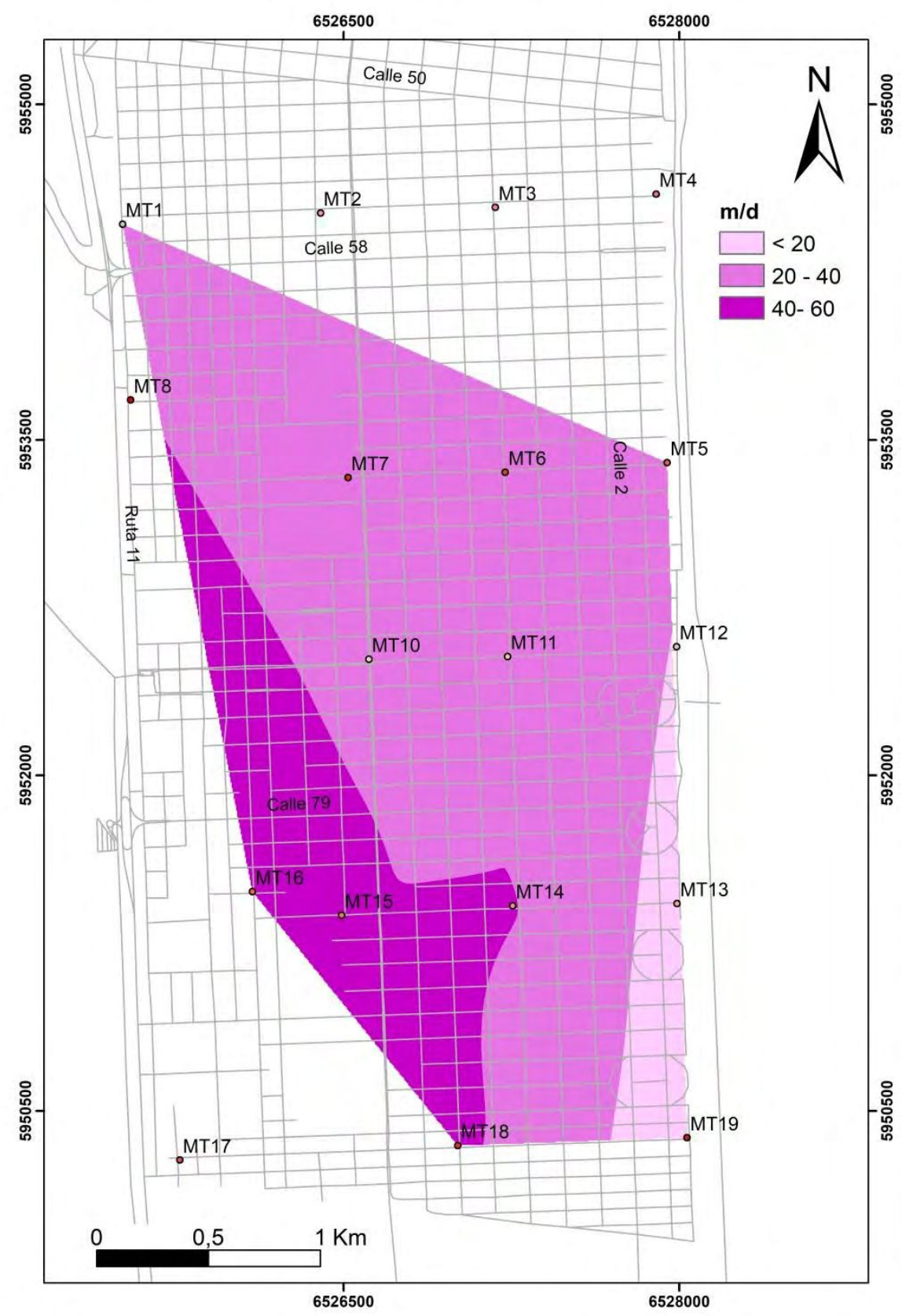

Figura 6.2 Distribución areal de la conductividad hidráulica.

\subsubsection{Estimación de la velocidad de infiltración}

La tasa o velocidad de infiltración ( $\mathrm{Vi}$ ) es la velocidad con la que el agua penetra en el suelo a través de su superficie. Normalmente se expresa en $\mathrm{mm} / \mathrm{h}$ y su valor mínimo coincide con la conductividad hidráulica del suelo saturado.

Se realizaron ensayos de infiltración según el método de doble anillo en 6 lugares cercanos a los pozos de monitoreo de agua subterránea. Se dispusieron en tres zonas diferentes con el objetivo de evaluar la velocidad de infiltración en los diferentes 
sectores: duna activa (MT5 y MT12), duna semiactiva urbanizada (MT6 y MT11), y el tercer grupo en el campo de dunas inactivo (MT7 y MT10). Asociado a estos ensayos se determinó el porcentaje de humedad del suelo mediante el uso de instrumental. Se construyeron calicatas hasta una profundidad de $80 \mathrm{~cm}$ donde se inserta el sensor de humedad cada $10 \mathrm{~cm}$.

Los ensayos se realizaron sobre suelo seco ya que no hubo lluvias en los días previos a los ensayos realizados entre el 14 y 15 de octubre de 2017. La última lluvia registrada por la estación automática de Santa Teresita fue el 9/10/17 con 10,71 mm. El análisis de datos de cada ensayo de infiltración se realizó utilizando el método de Kostiakov (1932) (Ver Anexo 4).

La mayor velocidad de infiltración se obtuvo en el ensayo realizado sobre la duna activa (MT12). Los resultados del ensayo de infiltración demuestran que en este sector la velocidad de infiltración es alta. Comienza con velocidades de $534 \mathrm{~mm} / \mathrm{h}$ hasta que tiende a hacerse constante al llegar a $450 \mathrm{~mm} / \mathrm{h}$. La humedad es muy baja, menor al 5\% (Figura 6.3). 


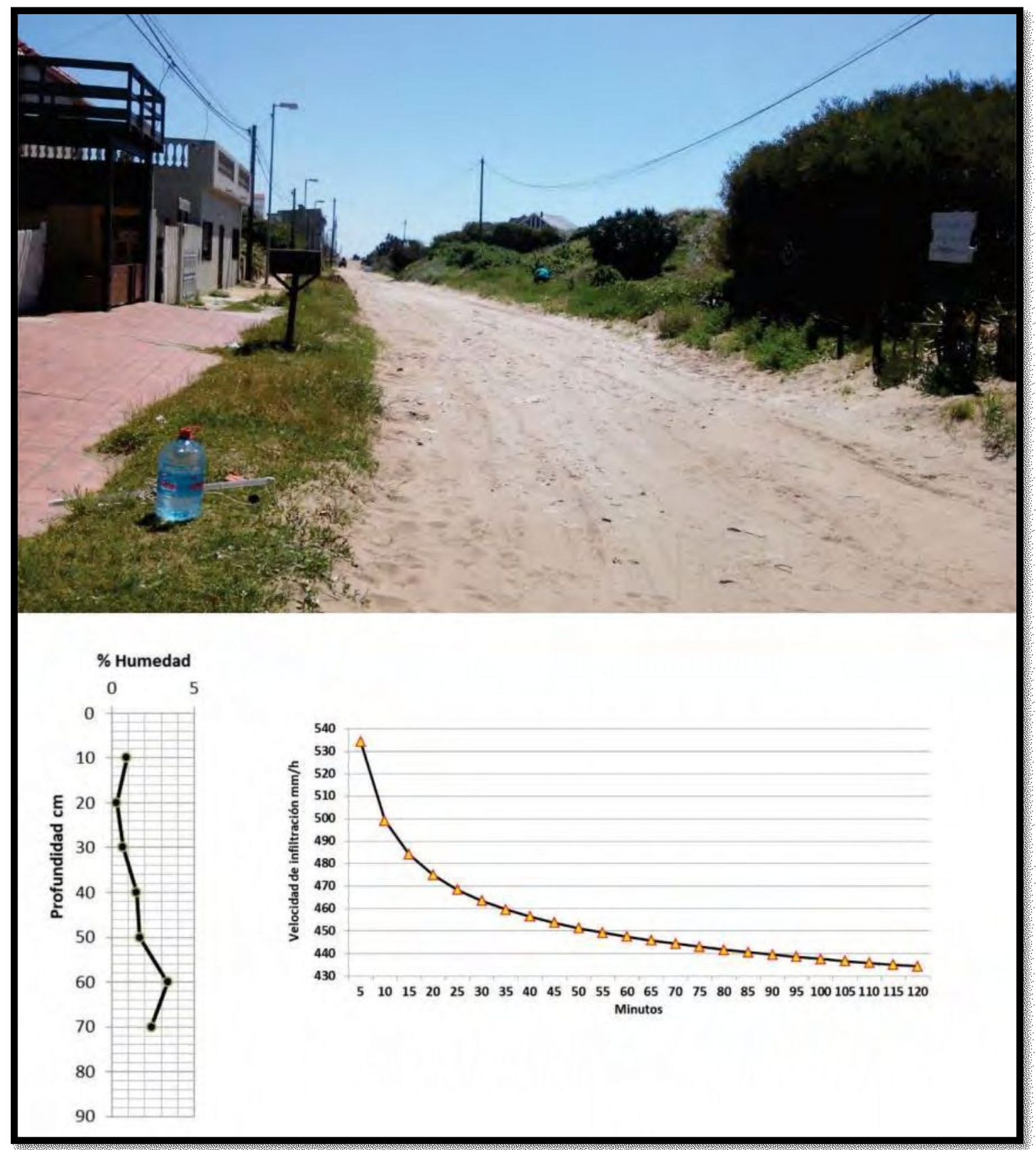

Figura 6.3 Ensayo para el pozo MT12. Sector duna activa.

El siguiente ensayo se realizó también en el ambiente de duna activa pero esta vez en una vereda de arena (MT5). A diferencia del ensayo en MT12 en este sector la duna activa no está muy desarrollada y la línea urbana llega hasta la playa, por lo cual constituye un ejemplo del comportamiento de la duna activa, pero antropizada.

La litología del perfil consiste en $8 \mathrm{~cm}$ de arena fina, un nivel de conchilla de $4 \mathrm{~cm}$ de espesor y luego continua arena fina castaña. El suelo se caracteriza por un $50 \%$ de cobertura vegetal, abundantes raíces y muy compacto. 
La velocidad de infiltración es casi constante durante todo el ensayo siendo de 199 $\mathrm{mm} / \mathrm{h}$. La humedad comienza en 0 los primeros $\mathrm{cm}$ luego aumenta hasta $7 \%$ y a los 40 $\mathrm{cm}$ de profundidad comienza a descender (Figura 6.4).

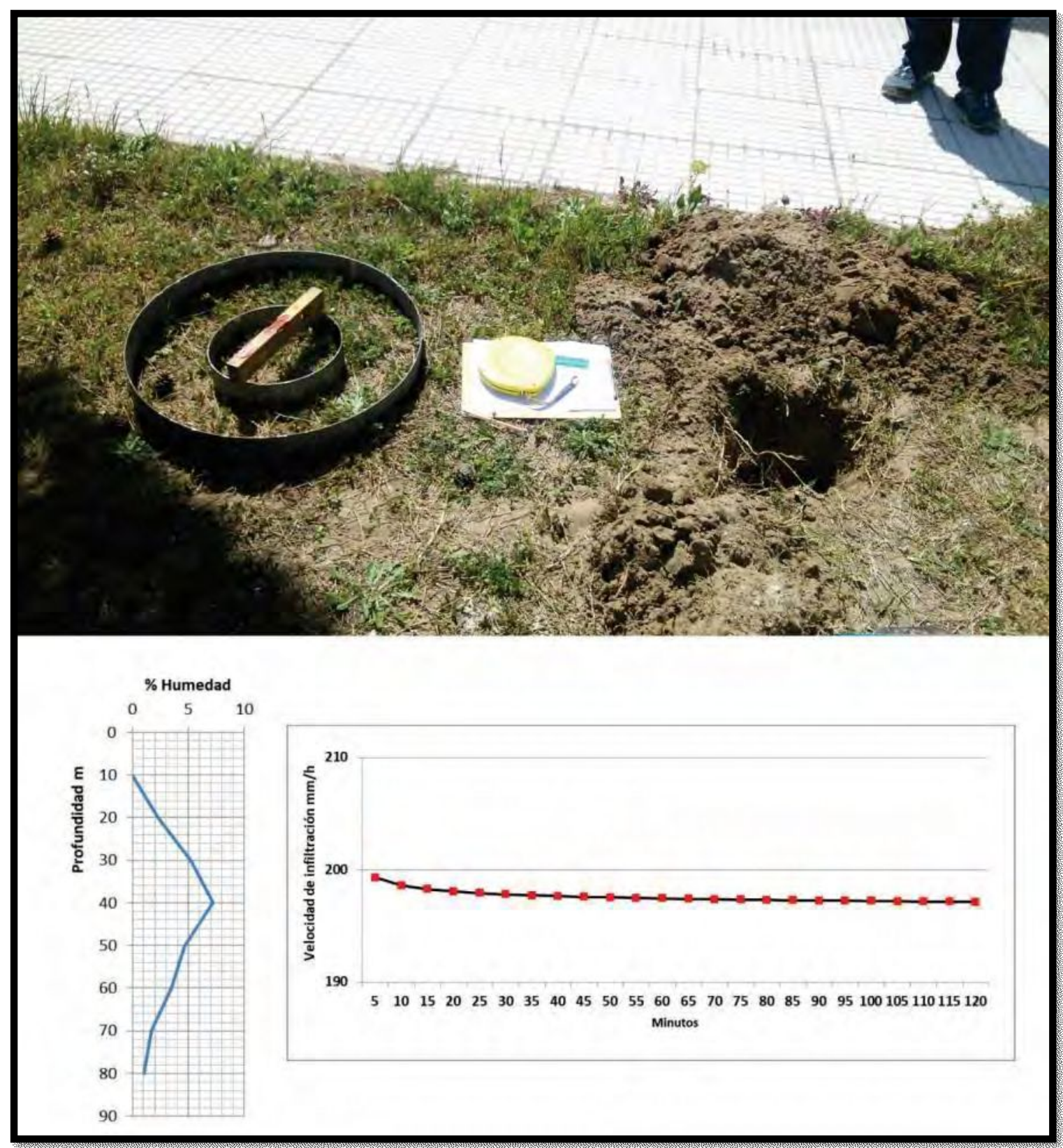

Figura 6.4 Ensayo para el pozo MT5. Sector duna activa antropizada.

La zona elegida para el ensayo de MT6 (duna semiactiva, urbanizada) se caracteriza por una cobertura vegetal de $100 \%$ y raíces abundantes. El perfil de suelo en los primeros $80 \mathrm{~cm}$ está constituido por arena fina de color rojiza, totalmente húmedo y sin horizontes. El suelo es muy compacto dificultando el hincado del sensor de humedad. Los resultados indican una velocidad de infiltración que comienza en $336 \mathrm{~mm} / \mathrm{h}$ y se hace constante a los $297 \mathrm{~mm} / \mathrm{h}$. En cuanto a la humedad se observan valores 
menores a $4 \%$ hasta los $40 \mathrm{~cm}$ de profundidad donde se ve un quiebre de la curva hacia valores más altos mayores al 10\% (Figura 6.5).

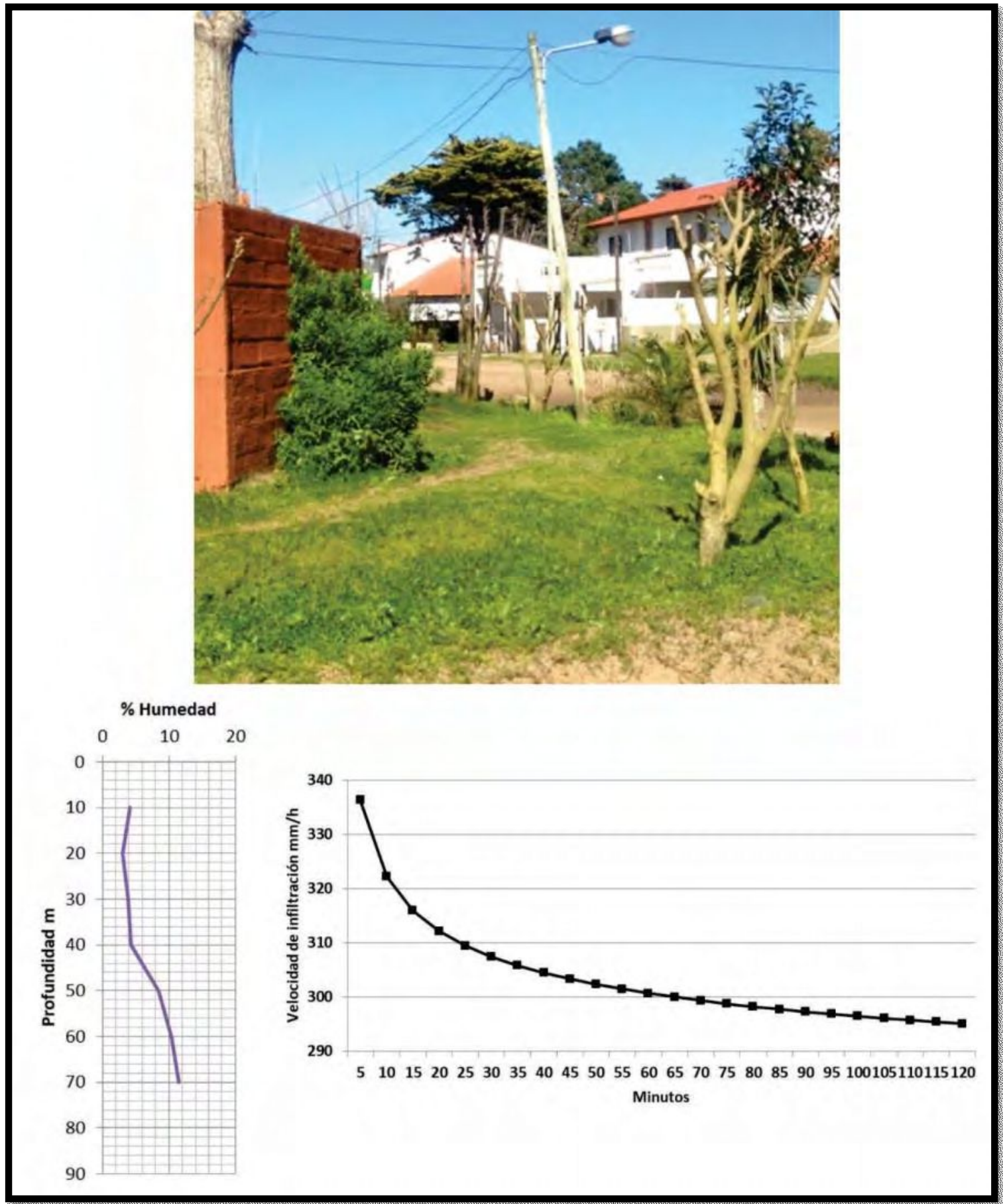

Figura 6.5 Ensayo para el pozo MT6. Sector duna semiactiva urbanizada.

El sector cercano a MT11 (duna semiactiva urbanizada) seleccionado para realizar los ensayos de infiltración y perfil de humedad es una vereda de relieve positivo, constituida por arena fina castaña con muy escasa conchilla. La cobertura vegetal es de un $40 \%$. 
La velocidad obtenida comienza con valores de $310 \mathrm{~mm} / \mathrm{h}$ hasta que tiende a hacerse constante al llegar a los $276 \mathrm{~mm} / \mathrm{h}$. La humedad comienza en cero en superficie y aumenta en los primeros $40 \mathrm{~cm}$ hasta $10 \%$ luego de esa profundidad se mantiene en valores cercanos a 11\% (Figura 6.6).

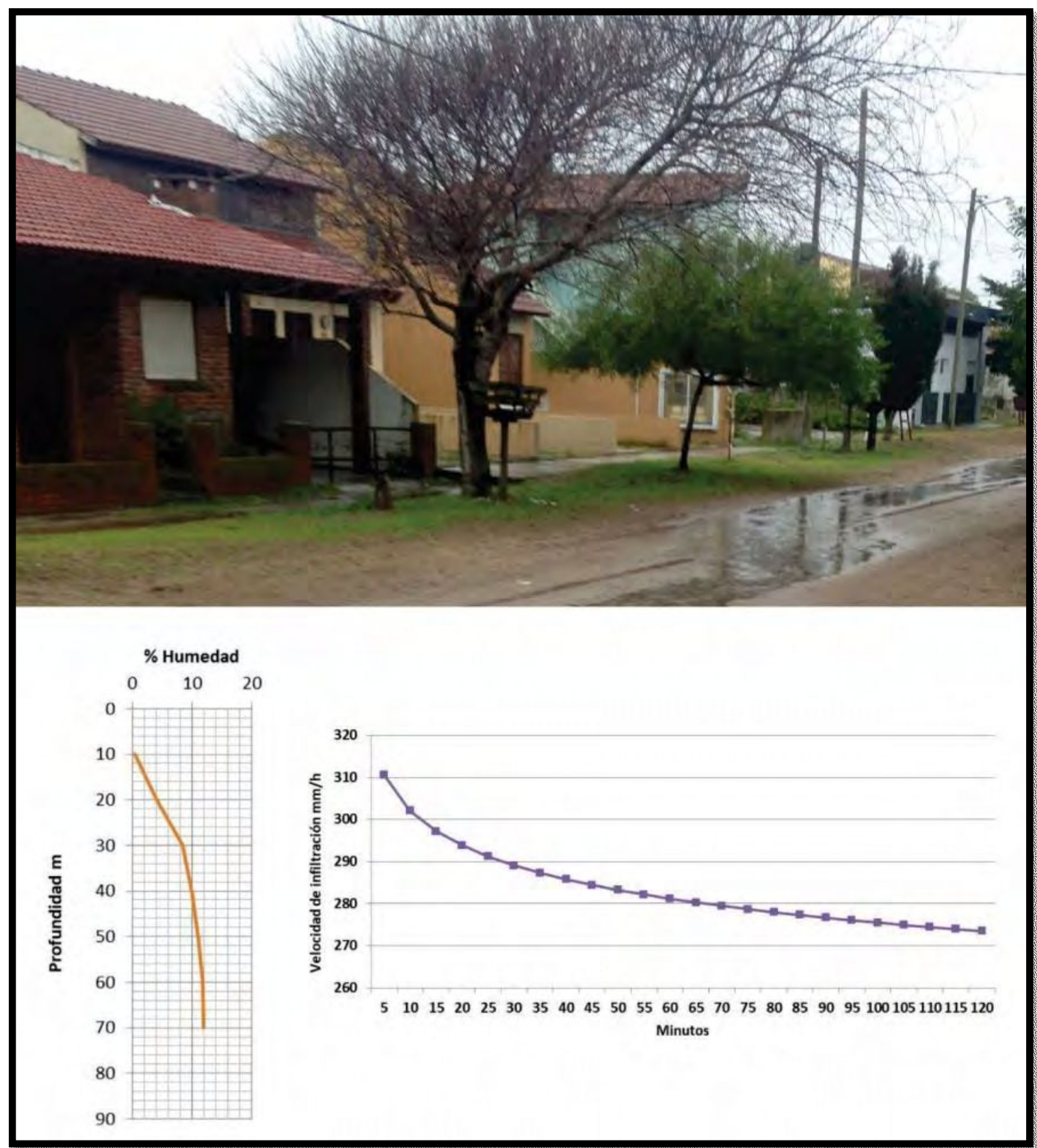

Figura 6.6 Ensayo para el pozo MT11. Sector duna semiactiva antropizada. El ensayo se realizó sobre la vereda vegetada.

En el último grupo de ensayos en el sector del campo de dunas inactivo en MT7 el suelo se caracteriza por estar $100 \%$ cubierto de vegetación y constituido por una arena media a fina, de color rojiza, con conchilla fragmentada fina. Los $80 \mathrm{~cm}$ perforados para hacer el perfil de humedad se encontraban húmedos. 
La velocidad de infiltración es baja, comienza en $180 \mathrm{~mm} / \mathrm{h}$ y se vuelve algo más constante en velocidades cercanas a los $79 \mathrm{~mm} / \mathrm{h}$. En cuanto a la humedad presenta valores altos desde superficie que van descendiendo desde 18 a $16 \%$ y luego a los 40 $\mathrm{cm}$ de profundidad aumenta hasta un $22 \%$ de humedad (Figura 6.7).

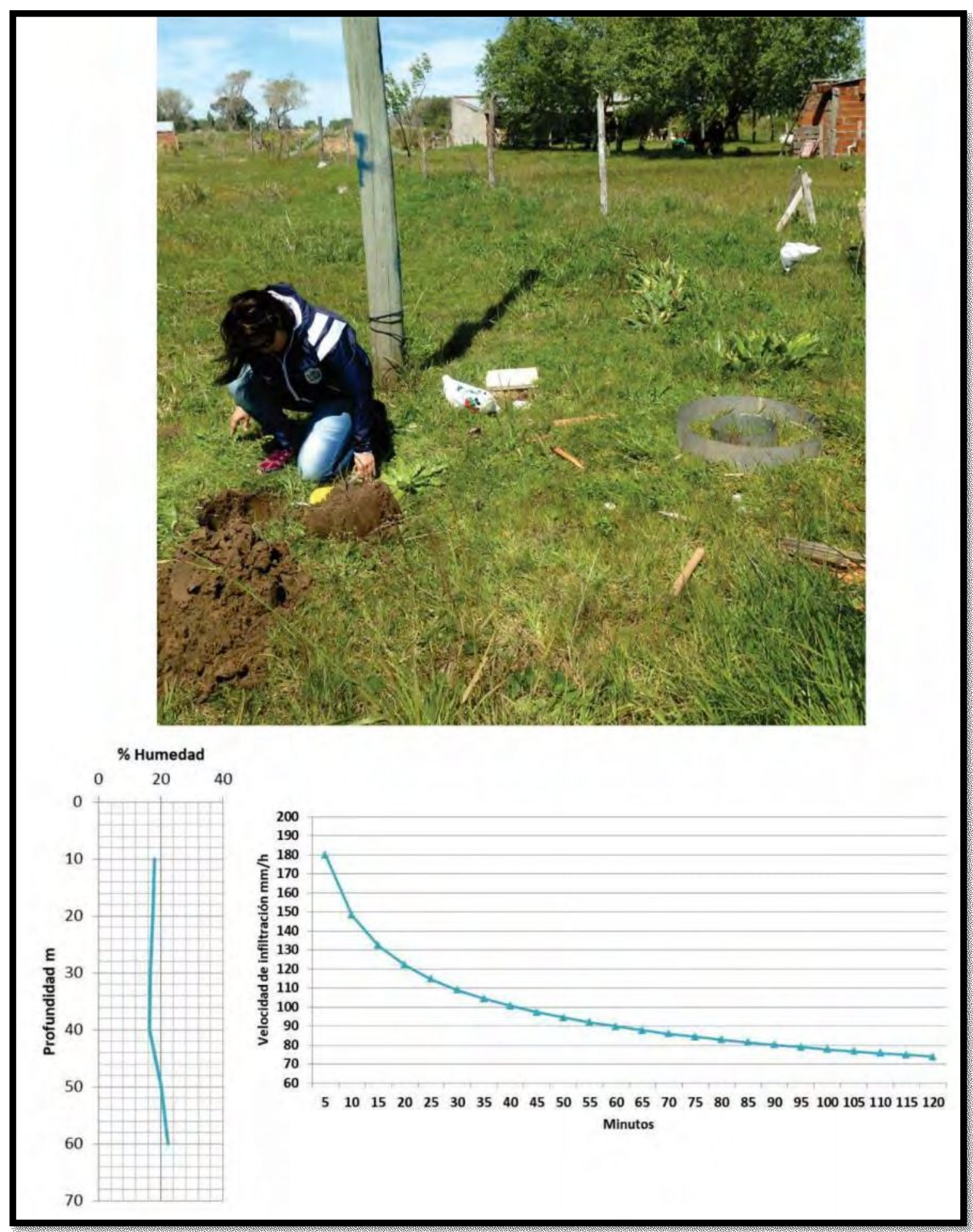

Figura 6.7 Ensayo para el pozo MT7. Sector campo de dunas inactivo. 
El perfil de suelo en MT10 se caracteriza por estar constituido de arena fina a media de color rojiza, la cobertura vegetal es del $100 \%$ y las raíces son abundantes en los primeros $40 \mathrm{~cm}$. El nivel freático se encuentra próximo a la superficie $(0,79 \mathrm{~m})$. Los resultados indican una velocidad de infiltración inicial de $290 \mathrm{~mm} / \mathrm{h}$ que se estabiliza a $250 \mathrm{~mm} / \mathrm{h}$. La humedad aumenta desde $4,7 \%$ a los $10 \mathrm{~cm}$ hasta $15 \%$ a los $70 \mathrm{~cm}$ de profundidad (Figura 6.8).

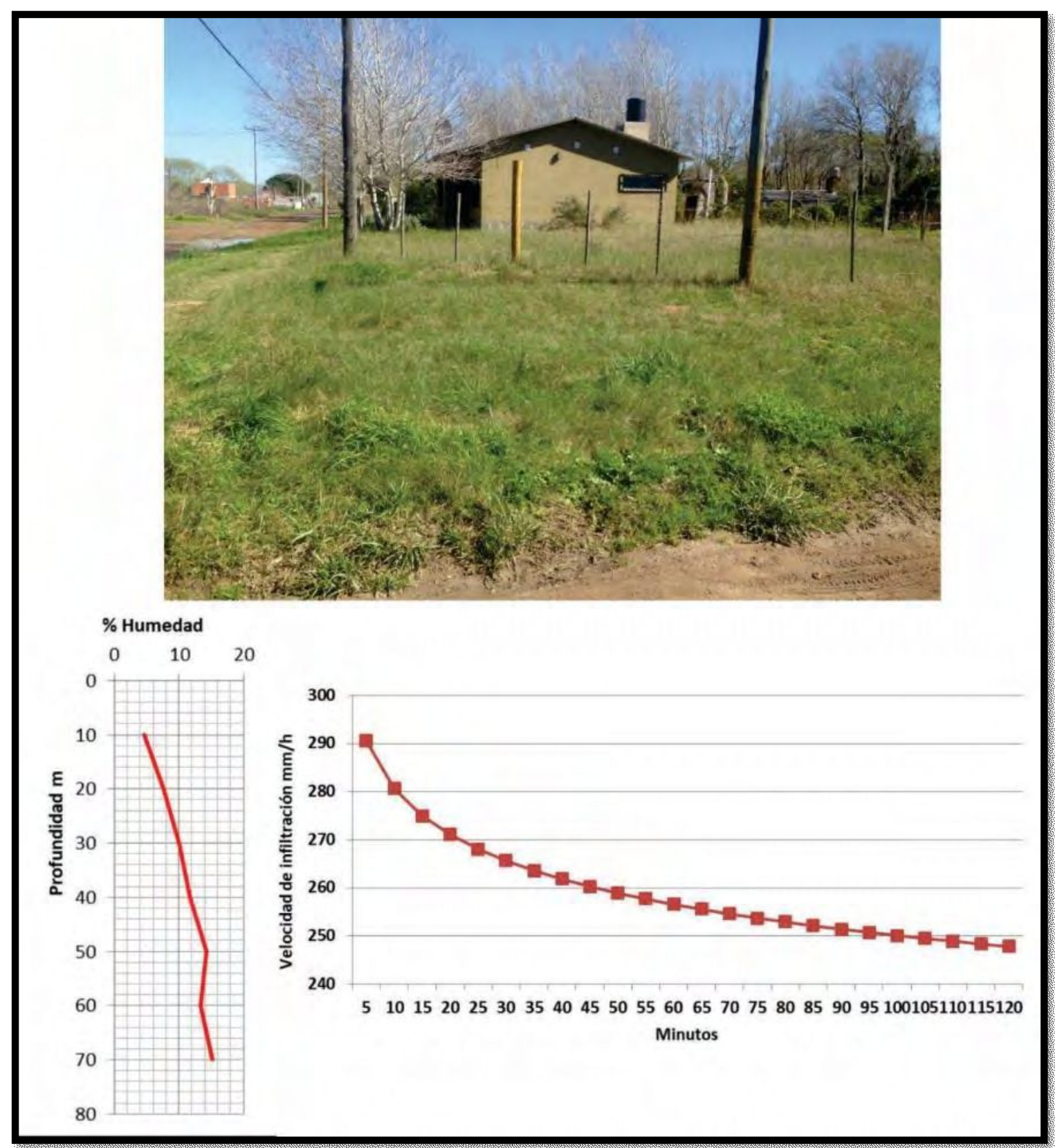

Figura 6.8 Ensayo para el pozo MT10. Sector campo de dunas inactivo.

Los perfiles de humedad en la ZNS se realizaron junto a cada ensayo de infiltración. En general se observa que hay un incremento del porcentaje de humedad con la profundidad (Figura 6.9). A su vez si se considera la localización respecto de los 
ambientes, la humedad aumenta en dirección este-oeste siendo los de menor porcentaje los ubicados en la duna activa, y los de mayor los del campo de dunas inactivas. La conservación de la humedad podría estar relacionada a una mayor cobertura vegetal y niveles freáticos más someros.

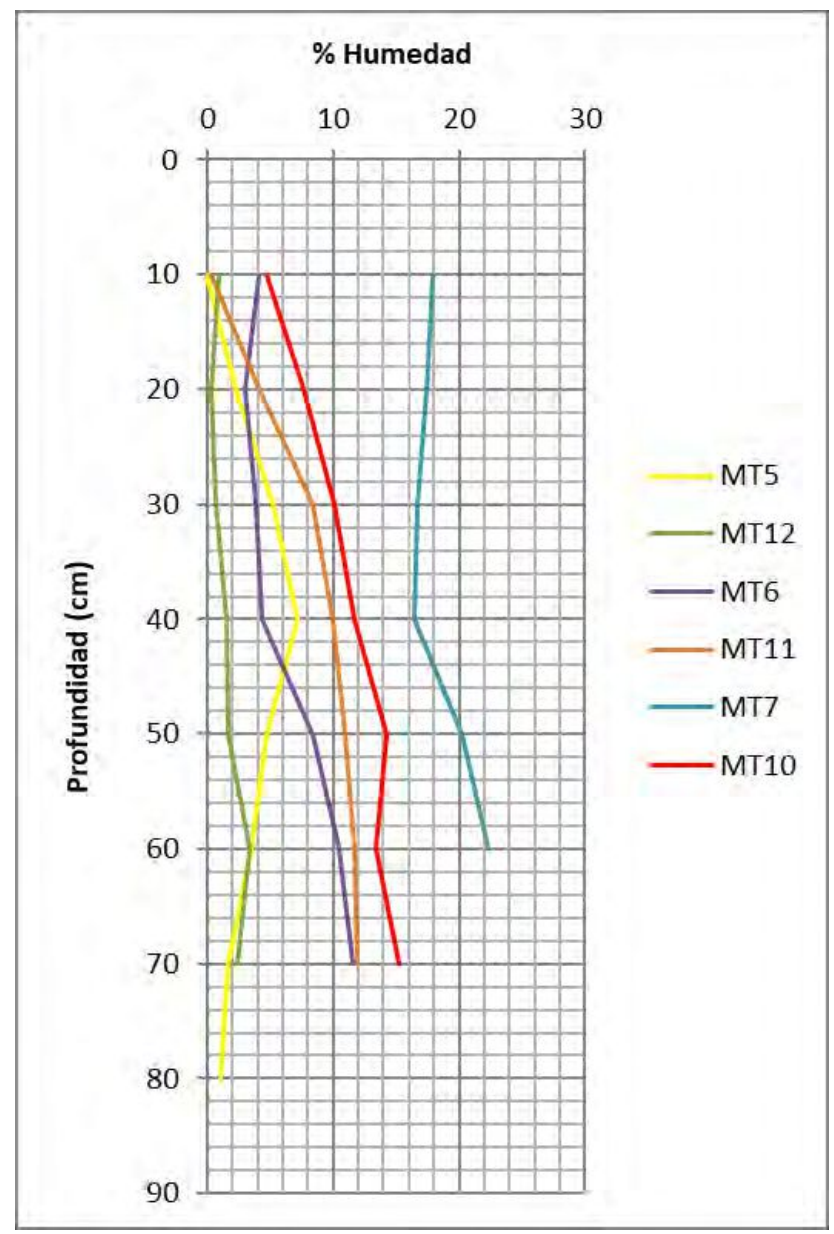

Figura 6.9 Perfiles de porcentaje de humedad en la ZNS.

Las velocidades de infiltración para la duna urbanizada presentan valores más homogéneos (Tabla 10) en el orden de los $280 \mathrm{~mm} / \mathrm{h}$. La mayor velocidad $(439 \mathrm{~mm} / \mathrm{h}$ ) se registra en el pozo representativo de las condiciones naturales de la duna activa mientras que ésta disminuye bajo condiciones de compactación del terreno (197 $\mathrm{mm} / \mathrm{h}$ ). La duna inactiva presenta valores muy disímiles $251 \mathrm{~mm} / \mathrm{h}$ (MT10) y $79 \mathrm{~mm} / \mathrm{h}$ (MT7). Estas diferencias podrían deberse a que MT10 se encuentra en una zona topográficamente más alta que MT7 y presenta raíces abundantes que podrían funcionar como canales preferenciales. 
Tabla 10 Velocidades de infiltración obtenidas.

\begin{tabular}{|c|c|c|c|c|c|c|}
\hline & \multicolumn{2}{|c|}{ Duna activa } & \multicolumn{2}{c|}{$\begin{array}{c}\text { Duna } \\
\text { urbanizada }\end{array}$} & \multicolumn{2}{c|}{ Duna inactiva } \\
\hline Pozo n $^{\circ}$ & MT5 & MT12 & MT6 & MT11 & MT7 & MT10 \\
\hline Velocidad de Infiltración $(\mathrm{mm} / \mathrm{h})$ & 197 & 439 & 297 & 276 & 79 & 251 \\
\hline
\end{tabular}

\subsubsection{Estimación de difusividad hidráulica en el acuífero freático}

En un freatímetro ubicado en Mar del Tuyú a $50 \mathrm{~m}$ del mar se colocó un sensor de presión a partir del cual se obtuvieron los niveles horarios en forma continua. La marea horaria se obtuvo de los registros del Servicio de Hidrografía Naval (SHN).

Las variaciones de nivel freático y marea se muestran en la Figura 6.10, donde está representado el registro completo de $3492 \mathrm{hs}$.

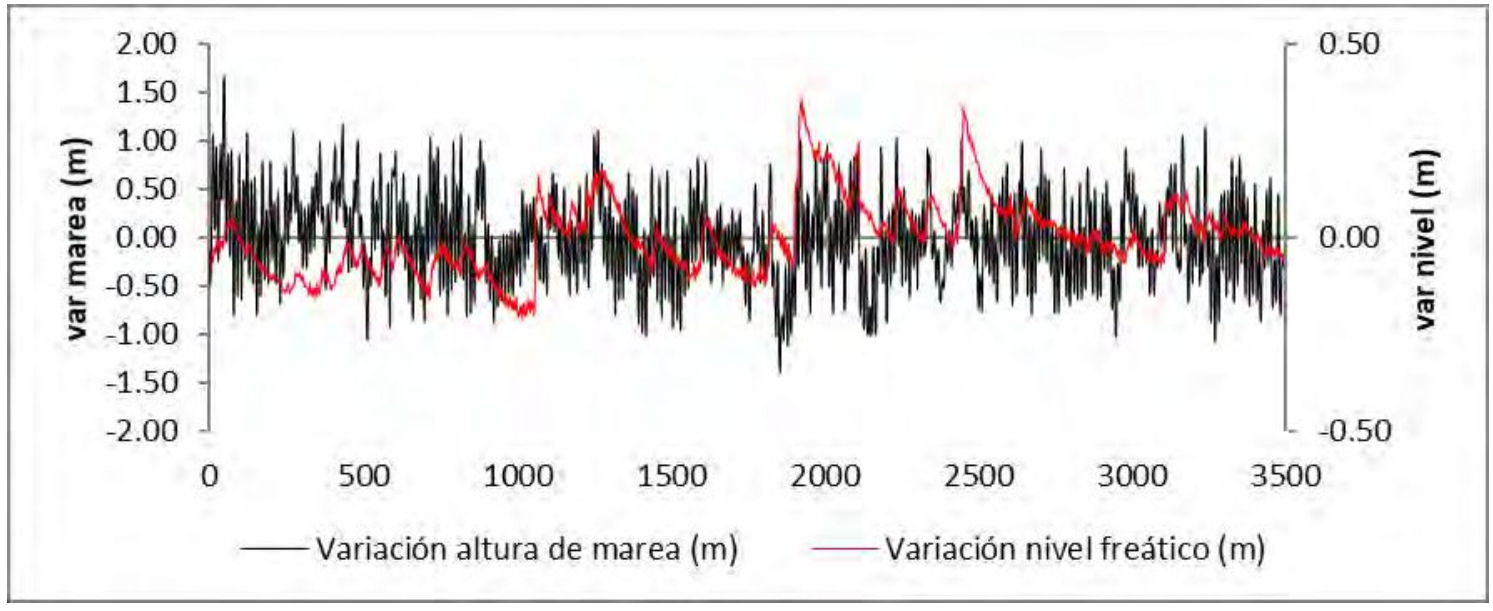

Figura 6.10 Serie de datos completa.

La búsqueda de tramos cortos se restringe a momentos en los cuáles sólo se registren variaciones de nivel por efecto de las mareas marinas. Se seleccionaron 9 tramos cortos de aproximadamente 24 hs. En la Figura 6.11 se muestra un ejemplo de uno de ellos. 


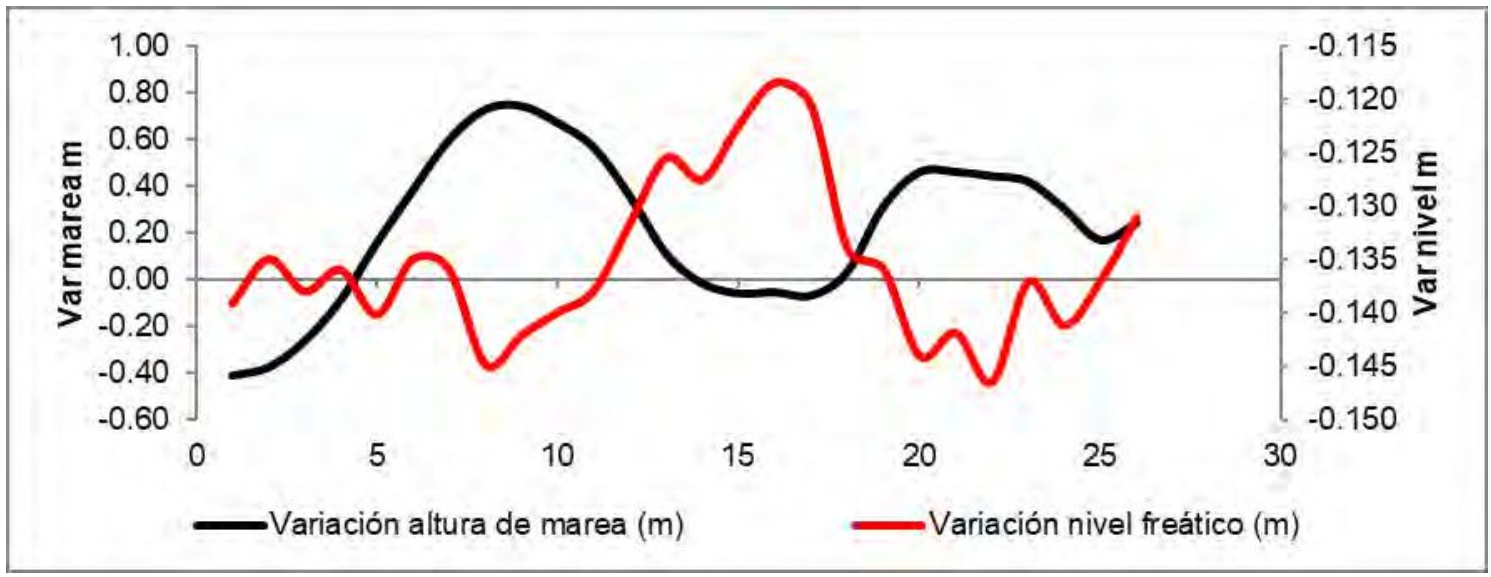

Figura 6.11 Datos sin procesar, ejemplo de un tramo corto.

A ambas señales se le aplicaron los procesos de mejoramiento y filtrado de señal, en la Figura 5.12 se muestra como disminuye el ruido de mayor frecuencia.

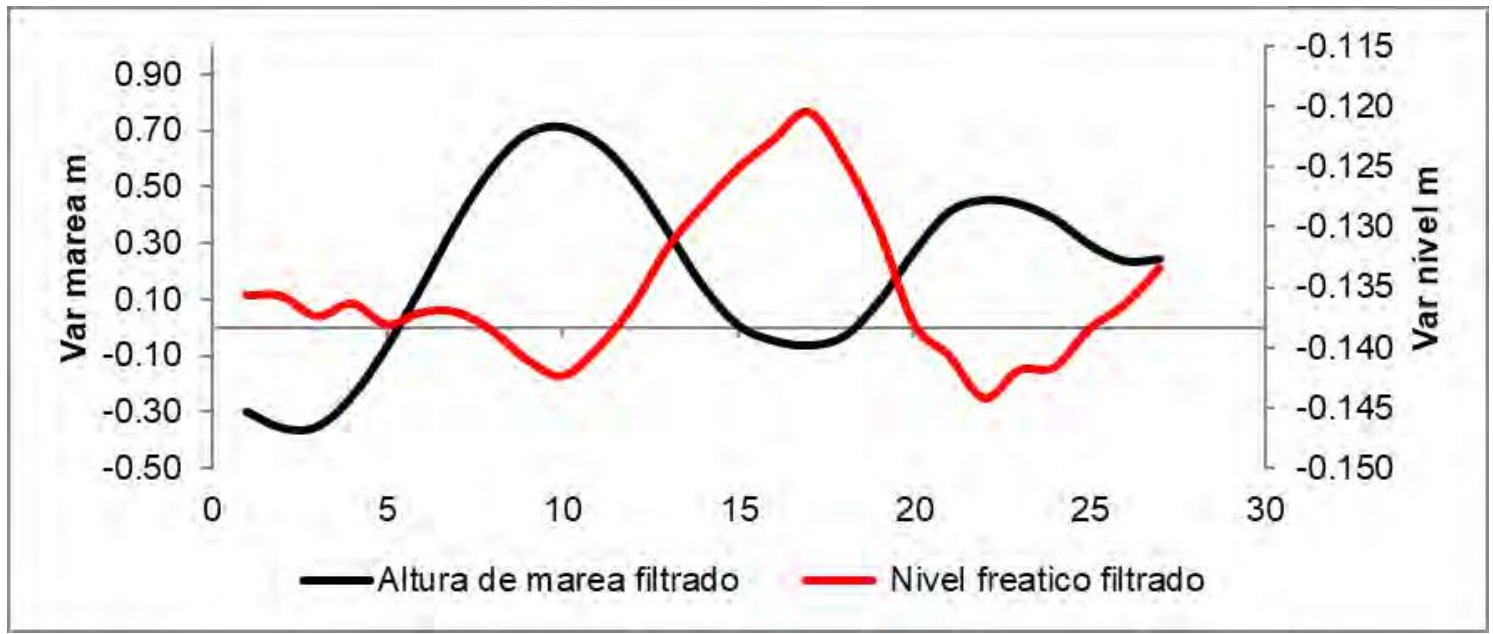

Figura 6.12 Señales mejoradas con la aplicación de una ventana deslizante de 2 hs.

Por último, se descuenta la recta de regresión lineal calculada para cada serie. Una vez realizados todos los pasos de filtrado se obtienen las curvas definitivas desde las cuales se extraen los datos necesarios para introducir en las fórmulas del cálculo de D (Figura 6.13 y 6.14 ). 


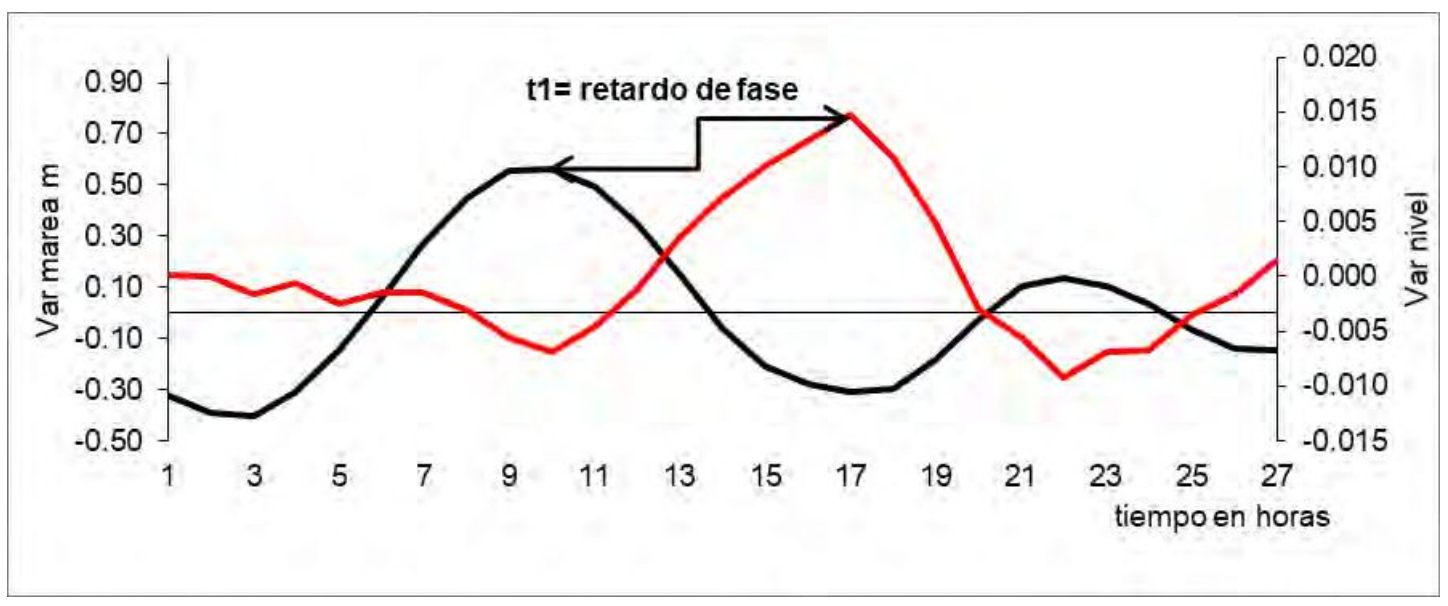

Figura 6.13 Estimación del retardo de fase $(\mathrm{t} 1$ =TL) por medición directa desde el grafico.

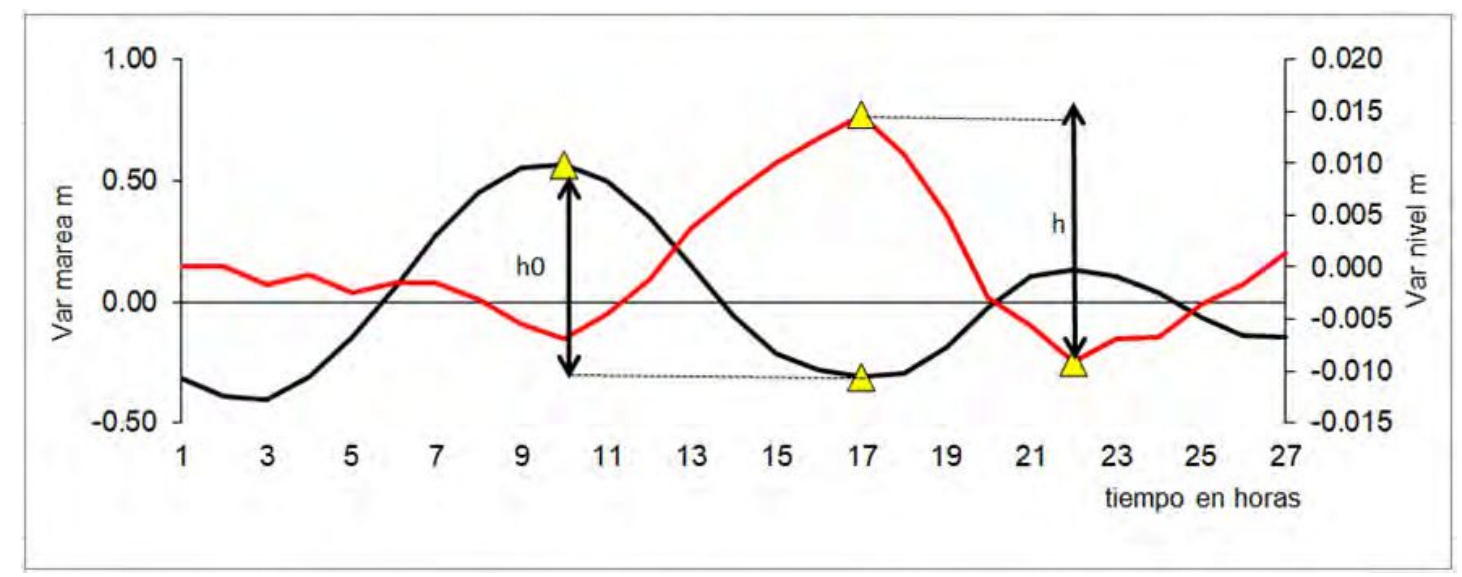

Figura 6.14 Estimación de TE a partir de $\mathrm{h}_{0}$ (pico marea - valle marea) y h (pico nivel - valle nivel).

Además del método gráfico, donde se obtiene TE y TL, se obtuvo TE a partir de las desviaciones estándar de las variaciones de la marea y de los niveles en el pozo. Los resultados de calcular $S / T=1 / D$ se observan en la Tabla 11 columna "cresta-valle" y "retardo" para el primer método y "desviación" para el segundo.

Tabla 11 Resultados de calcular S/T=1/D por los métodos gráficos y desviación estándar.

\begin{tabular}{|c|c|c|c|}
\hline & $\mathrm{S} / \mathrm{T}=1 / \mathrm{D}(\mathrm{TE})$ & $\mathrm{S} / \mathrm{T}=1 / \mathrm{D}(\mathrm{TE})$ & $\mathrm{S} / \mathrm{T}=1 / \mathrm{D}(\mathrm{TL})$ \\
\hline tramo & Desviación & Cresta - valle & Retardo \\
\hline & TE & TE & TL \\
\hline 1 & $1,05 \mathrm{E}-03$ & $9,37 \mathrm{E}-04$ & $2,79 \mathrm{E}-04$ \\
\hline 2 & $9,42 \mathrm{E}-04$ & $8,27 \mathrm{E}-04$ & $8,55 \mathrm{E}-04$ \\
\hline 3 & $8,29 \mathrm{E}-04$ & $9,02 \mathrm{E}-04$ & $5,28 \mathrm{E}-04$ \\
\hline 4 & $7,00 \mathrm{E}-04$ & $7,32 \mathrm{E}-04$ & $1,12 \mathrm{E}-03$ \\
\hline 5 & $9,98 \mathrm{E}-04$ & $8,63 \mathrm{E}-04$ & $9,82 \mathrm{E}-04$ \\
\hline 6 & $9,60 \mathrm{E}-04$ & $1,06 \mathrm{E}-03$ & $2,79 \mathrm{E}-04$ \\
\hline 7 & $8,70 \mathrm{E}-04$ & $8,33 \mathrm{E}-04$ & $1,12 \mathrm{E}-03$ \\
\hline
\end{tabular}




\begin{tabular}{|c|c|c|c|}
\hline 8 & $8,98 \mathrm{E}-04$ & $9,00 \mathrm{E}-04$ & $1,57 \mathrm{E}-04$ \\
\hline 9 & $8,98 \mathrm{E}-04$ & $8,48 \mathrm{E}-04$ & $8,55 \mathrm{E}-04$ \\
\hline Promedio & $9,05 \mathrm{E}-04$ & $8,78 \mathrm{E}-04$ & $6,86 \mathrm{E}-04$ \\
\hline $\begin{array}{c}\text { Desviación } \\
\text { estándar }\end{array}$ & $1,02 \mathrm{E}-04$ & $9,12 \mathrm{E}-05$ & $3,79 \mathrm{E}-04$ \\
\hline Máx. & $1,05 \mathrm{E}-03$ & $1,06 \mathrm{E}-03$ & $1,12 \mathrm{E}-03$ \\
\hline Min & $7,00 \mathrm{E}-04$ & $7,32 \mathrm{E}-04$ & $1,57 \mathrm{E}-04$ \\
\hline
\end{tabular}

Los datos recolectados entre junio y octubre de 2017 son adecuados para aplicar las técnicas de análisis armónico simple o de ajustes por cuadrados mínimos (Rotzoll et al., 2013), y análisis espectral por medio de la transformada rápida de Fourier (FFT) (Trefry and Bekele, 2004). Este análisis se ha desarrollado en Guaraglia et al. (2019) donde se estimaron valores de S/T de 0,0014 y 0,00158 respectivamente. Los resultados promedios para S/T fueron de 0,000905 utilizando la desviación estándar y 0.000878 con el método de cresta - valle. Los resultados obtenidos son concordantes con los estimados a partir de ensayos de bombeo (S/T entre 0,001 y 0,0005), por lo que la metodología propuesta es aplicable a la zona costera oriental de la provincia de Buenos Aires.

\subsection{Costa estuárica (Río de La Plata)}

\subsubsection{Características del acuífero freático}

La caracterización litológica generada a partir de las perforaciones en el subsuelo de la planicie costera de Berisso muestra la alternancia de arenas, limos, arcillas y conchillas. Estas litologías permiten suponer la existencia de un contraste en las propiedades físicas entre estos niveles resultando este último un aspecto fundamental para la aplicación de un método geofísico que posibilite realizar interpretaciones de detalle razonables dentro de la escala de trabajo empleada. Las perforaciones realizadas con barreno manual son muy poco profundas. La aplicación de métodos geofísicos permite determinar la profundidad y distribución de los sedimentos en el subsuelo.

El conocimiento de la variación lateral de estas unidades adquiere un papel destacable para la caracterización hidrológica del medio. Las técnicas geoeléctricas vinculadas a la geofísica, que plantean conocer cuál es la respuesta del subsuelo frente a la inducción de una corriente eléctrica, resultan una metodología adecuada para relacionar los datos puntuales de los perfiles litológicos con las variaciones espaciales de las unidades litológicas. 
Se midieron dos transectas de resistividad en 2D (Figura 6.15) usando el instrumental mencionado en el apartado de Metodología.

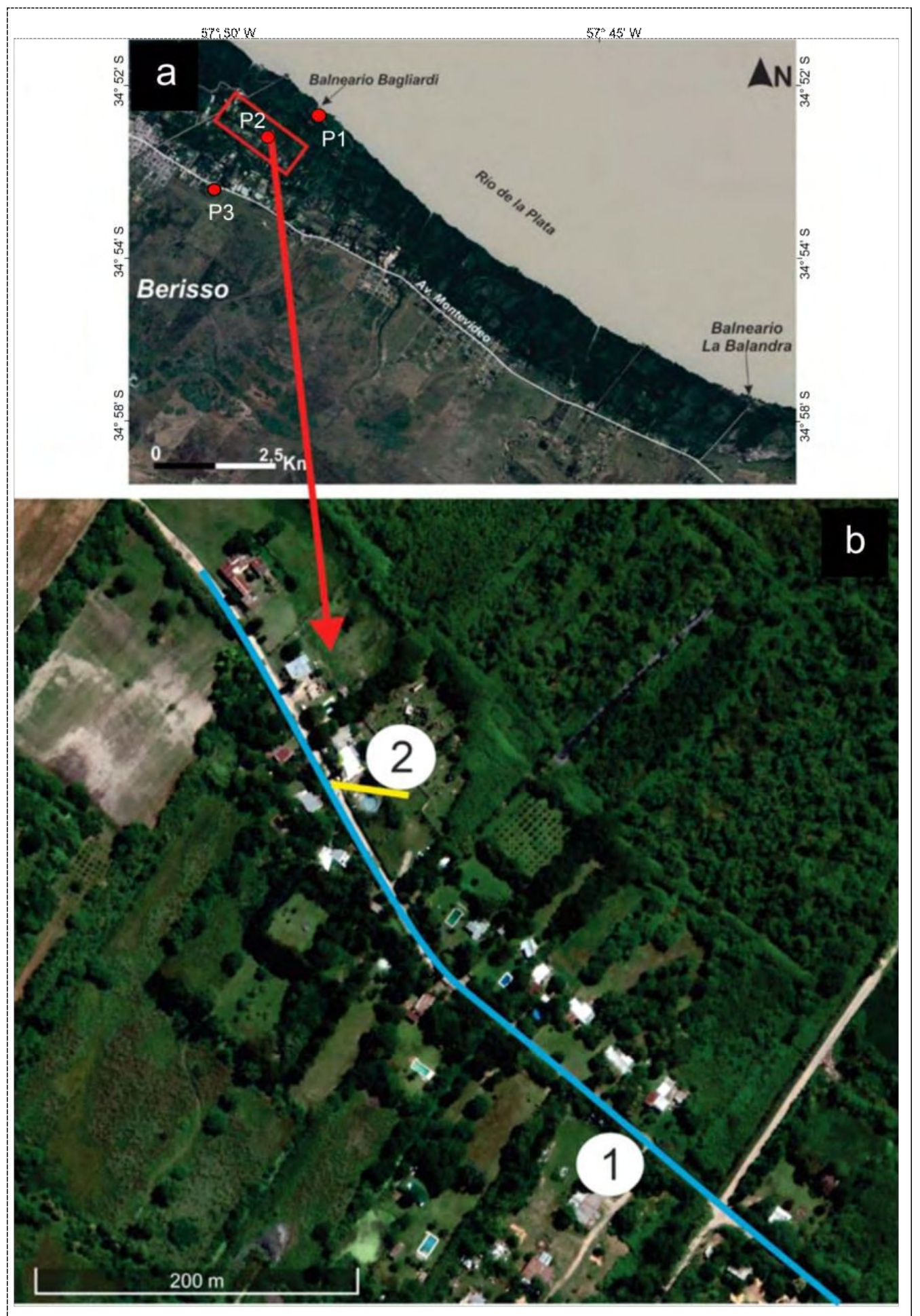

Figura 6.15. a) Ubicación de los freatímetros (P1, P2 y P3), b) transectas a lo largo de las cuales se llevaron a cabo las mediciones. El número 1 hace referencia a la transecta 1 mientras que el número 2 hace referencia a la transecta 2 . 
Tomografía 1

Corresponde a la transecta más amplia abarcando 410 metros en la horizontal y llegando a 16 metros de profundidad. Se observa a lo largo de todo el perfil una tendencia ondulatoria evidenciando una morfología cordoniforme tal como era de esperar según lo planteado en el marco geológico.

Predominan sobre la sección (Figura 6.16) valores relativamente bajos de resistividades (entre 1 y 10 ohm.m). El límite entre estas capas menos resistivas con otras más resistivas varía su profundidad desde puntos cercanos a los $7 \mathrm{~m}$ (progresivas 10-55 y 95-110) hasta zonas más superficiales, próximas a los $2 \mathrm{~m}$ por debajo del suelo (progresivas 165-180). Ya en la superficie (o próximo a ella), es común encontrar capas con valores resistivos que varían entre 20 y 50 ohm.m. El rango de resistividades que abarca todo el perfil se encuentra entre 1 y 1050 ohm.m.

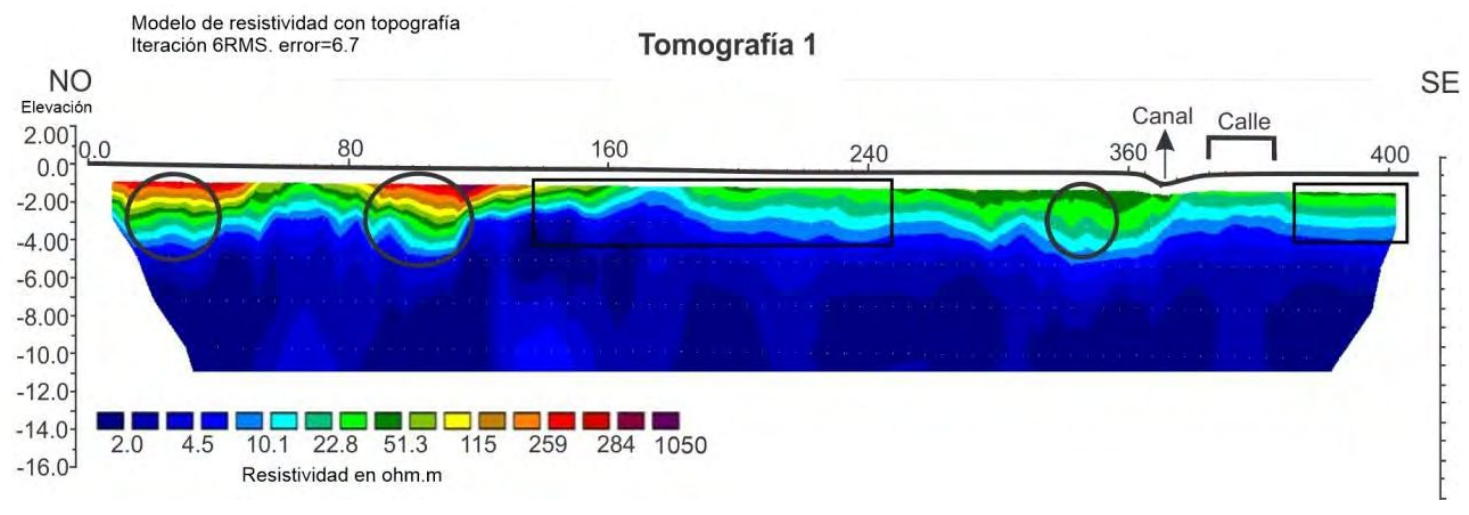

Figura 6.16 Interpretación de la tomografía 1. Los círculos indican lugares en donde potencialmente podría encontrarse agua dulce mientras que la forma rectangular indica presencia de agua salobre.

En su tramo izquierdo (Figura 6.16) es más notoria la presencia de conchilla saturada en agua dulce reflejada por las capas con valores más resistivos. Las progresivas 2050 y 90-105 son zonas en donde es esperable encontrar agua dulce debido a los grandes espesores de capas de resistividad entre 30 y 100 ohm.m (valores típicos para la conchilla saturada en agua dulce). Esta información inferida del gráfico se condice con lo constatado en el campo, ya que en estas ubicaciones se pueden observar perforaciones destinadas a la extracción de agua dulce para el uso doméstico. Esta misma tendencia se aprecia entre las progresivas 295-315 que, a pesar de no contar con niveles de gran resistividad en la superficie, se pudo corroborar por el propietario del lugar, que existía un nivel de saturación en agua dulce. Además, se efectuaron mediciones in situ de la conductividad del agua para el sector, arrojando valores cercanos a los $520 \mu \mathrm{S} / \mathrm{cm}$. 
El tramo central del perfil está caracterizado por la disminución en el espesor del cordón de conchilla derivando en una marcada reducción del nivel de agua dulce y pasando directamente a la capa salobre. Se observan niveles de baja resistividad (alta conductividad) muy cercanos a la superficie. Lo mismo se puede notar en la progresiva 370-400 en donde, además, los residentes de esta zona manifestaron que el agua que extraen del suelo no es apta para el consumo.

A lo largo de todo el perfil se observa que el límite entre los niveles de agua dulce y salobre se da en los valores de resistividad de 10 ohm.m aproximadamente (color celeste oscuro y claro en las figuras). Además, basándonos en las resistividades obtenidas y la profundidad de investigación alcanzada se puede afirmar que todo el perfil es una caracterización de los sedimentos Postpampeanos.

Por último, se midió la conductividad del agua del canal obteniendo $880 \mu \mathrm{S} / \mathrm{cm}$. Este valor refleja un aumento en la conductividad con respecto al sector ubicado a la izquierda $(520 \mu \mathrm{S} / \mathrm{cm})$ lo cual se corresponde con la disminución de los valores de resistividad observados en el modelo.

Tomografía 2

Corresponde a la transecta 2, la cual abarca $80 \mathrm{~m}$ en la horizontal. Su topografía es prácticamente regular, presentando una pendiente suave entre las progresivas $20 \mathrm{y}$ 50 .

Predominan las capas conductivas (azul y celeste) las que se encuentran más profundas del lado izquierdo del perfil volviéndose prácticamente superficiales en el borde derecho del mismo. Las capas siguen manteniendo un patrón ondulado presentándose un acuñamiento de la forma hacia el este. Esto se puede apreciar con claridad a la derecha del perfil, en donde los niveles más conductivos se tornan prácticamente superficiales. El rango de resistividades de la tomografía varía entre 1 y 800 ohm.m.

De la tomografía mostrada en la Figura 6.17, se puede observar cómo el cordón de conchilla va reduciendo su espesor en la dirección O-E hasta llegar a desaparecer por completo. 
Tomografía 2

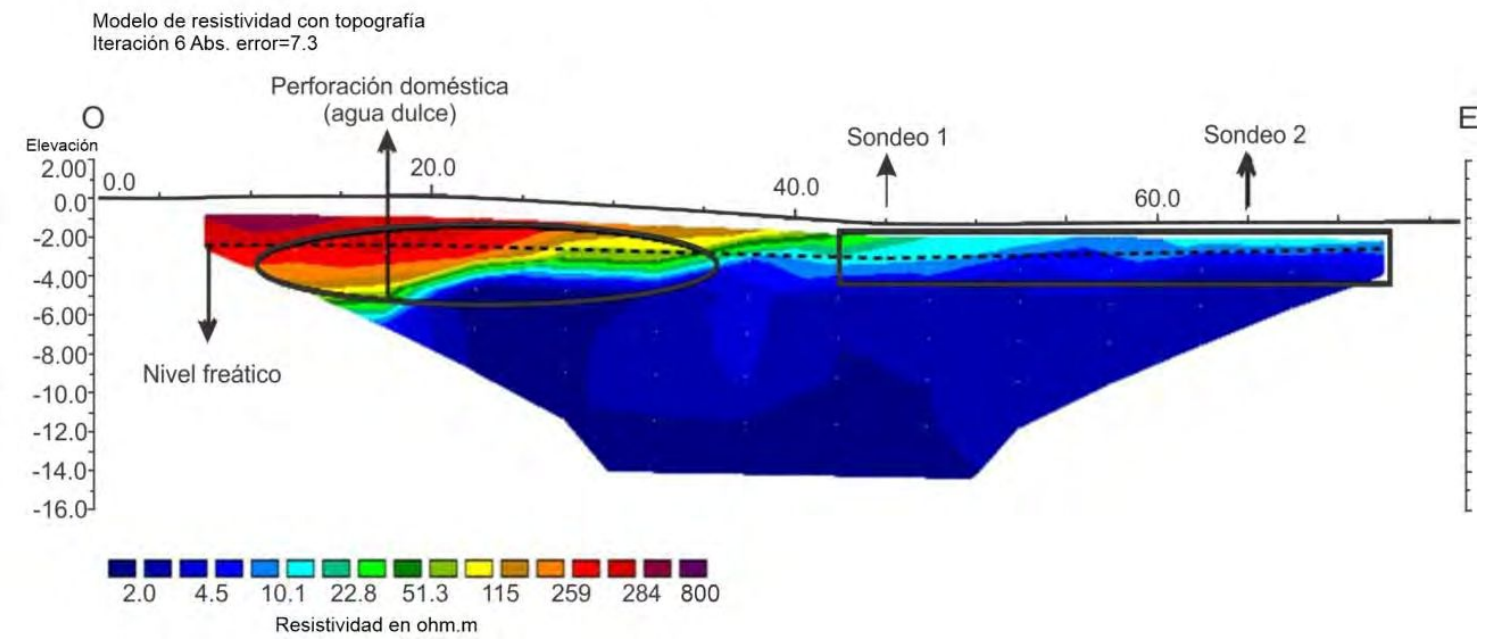

Figura 6.17 Interpretación de la tomografía 2.

Se puede apreciar del lado derecho de la imagen el estrecho grosor de niveles de resistividad de entre 30 y 200 ohm.m indicando una escasez (o total ausencia) de conchilla saturada con agua dulce. Esto último fue constatado entre las progresivas 45 y 65 mediante la realización de dos sondeos de barreno manual. En ellos se puede notar la ausencia de material conchil y la presencia de material de grano muy fino saturado con agua salada. Teniendo en cuenta estos datos se puede inferir que en todo el sector recuadrado en la Figura 6.17 se puede encontrar agua salobre muy próxima a la superficie. Al igual que en la tomografía anterior, el límite entre el nivel salobre y el dulce se da en la capa de los 10 ohm.m aproximadamente.

El terreno en donde se llevó a cabo la medición, más precisamente en la progresiva 18, contaba con una perforación de agua potable para el uso doméstico. Esto último se condice con lo mostrado en la Figura 6.17, en donde se puede observar (marcado con un círculo) que en tal sector se encuentran niveles resistivos acordes, entre $30 \mathrm{y}$ 200 ohm.m, para poder inferir la presencia de agua dulce no solo en el lugar en donde se ubica la perforación, sino que también en sectores aledaños (entre las progresivas 10 y 35). Además, en este sector se midió in situ la conductividad del agua a $2 \mathrm{~m}$ de profundidad, arrojando un valor de $500 \mu \mathrm{S} / \mathrm{cm}$.

\subsubsection{Estimación de la velocidad de infiltración}

La tasa o velocidad de infiltración es la velocidad con la que el agua penetra en el suelo a través de su superficie. Normalmente se expresa en $\mathrm{mm} / \mathrm{h}$ y su valor mínimo coincide con la conductividad hidráulica del suelo saturado. 
Se presentan los resultados de la obtención de valores de velocidad de infiltración (Vi) mediante el uso del infiltrómetro de doble anillo.

El ensayo $\mathrm{N}^{\circ} 1$ se realizó en la unidad llanura estuárica donde se encuentra instalado el freatímetro P1 (Figura 6.15 a), cuya zona no saturada (ZNS) presenta, desde la superficie hasta los $3 \mathrm{~m}$ de profundidad, litologías alternantes que van desde arena suelta en los primeros $\mathrm{cm}$ del perfil, pasando a arcilla y luego textura franco arenosa. La morfología consiste en una suave lomada paralela al río cuya superficie es inundada por mareas extraordinarias o sudestadas periódicamente (Tabla 11). El comportamiento de la curva de infiltración se observa en la Figura 6.18 otorgando a estos sedimentos un valor de velocidad de infiltración (Vi) de $27 \mathrm{~mm} / \mathrm{h}$.

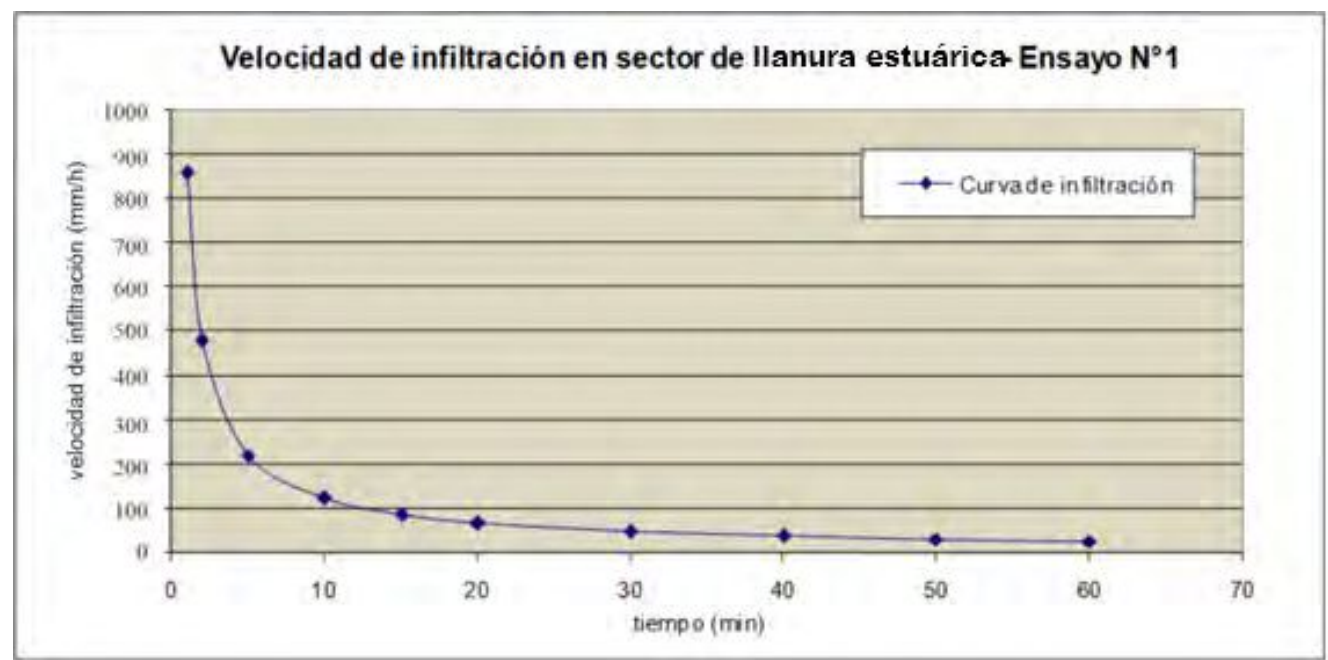

Figura 6.18 Ensayo $\mathrm{N}^{\circ} 1$, realizado en el sector de llanura estuárica.

El ensayo $\mathrm{N}^{\circ} 2$ se realizó en la geoforma cordón litoral (pozo P2) (Figura 6.15 a) cuya ZNS (0 a $2 \mathrm{~m}$ ) está integrada por fragmentos esqueletales de moluscos (conchillas) y arena que le confieren una porosidad y permeabilidad elevada (Tabla 11). Su posición elevada respecto al resto de las geoformas, hace que funcione como una zona de recarga del acuífero freático que en este sector presenta salinidades muy bajas a consecuencia del agua de lluvia que se infiltra casi instantáneamente. La Vi calculada para este ambiente fue de $155 \mathrm{~mm} / \mathrm{h}$ cuya curva de infiltración se muestra en la Figura 6.19 . 


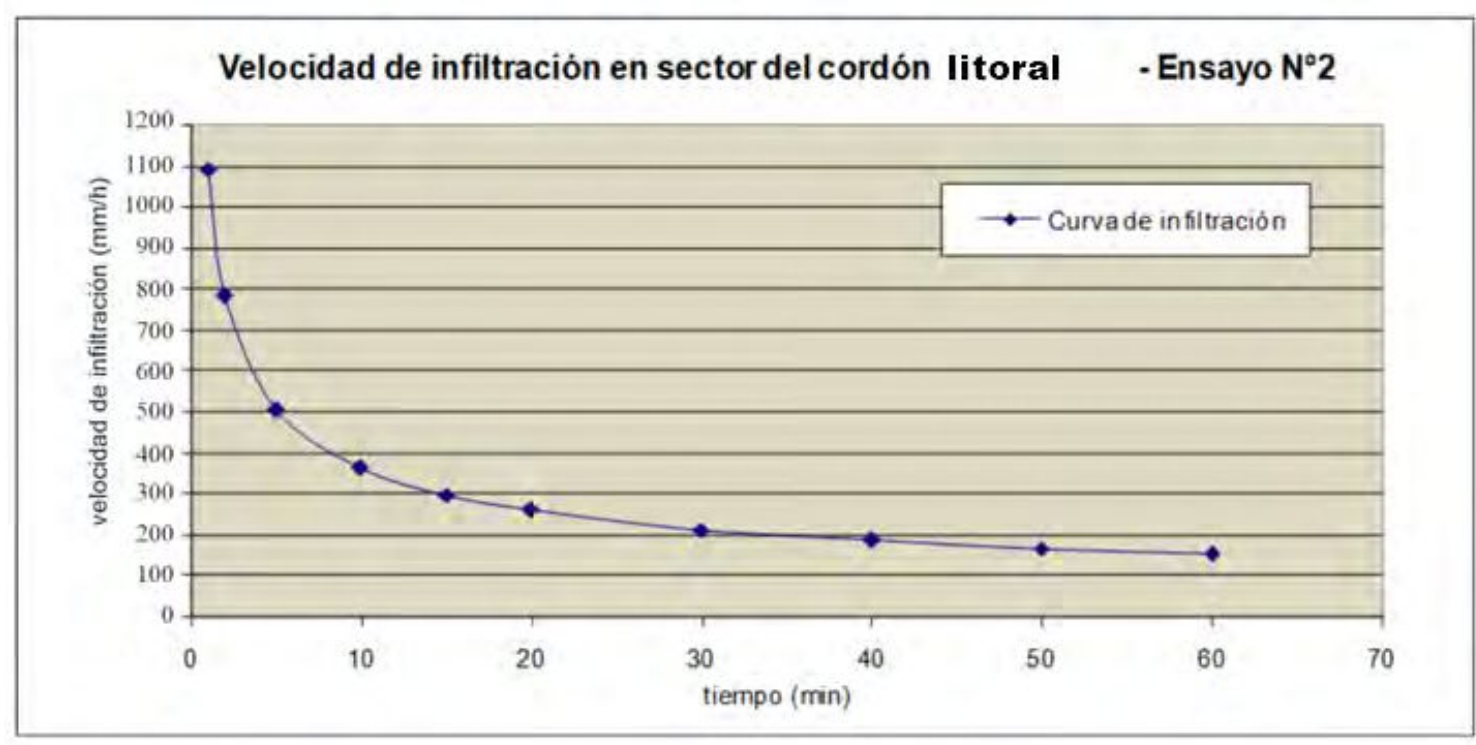

Figura 6.19 Ensayo $\mathrm{N}^{\circ} 2$, realizado en el sector de cordones litorales (conchilla).

Por último, el ensayo $\mathrm{N}^{\circ} 3$ se realizó en la geoforma planicie de marea relictual (pozo P3) (Figura 6.15a), donde los suelos en seco presentan estructura en bloque subangulares y grietas de desecación abundantes. La ZNS de esta geoforma es esencialmente arcillosa, presenta rasgos hidromórficos como son las concreciones de hierro producto de los ascensos y descensos del nivel freático (Tabla 12). Las características del suelo de la planicie costera como son la abundante vegetación, estructura en bloque subangular, y profundas grietas de desecación, influyen en la capacidad de infiltración. El caudal aportado al subsuelo en los primeros minutos de saturación es mayor tal como se puede observar en la Figura 6.20, donde las Vi iniciales son elevadas y disminuyen en el tiempo, debido a la infiltración directa a través de vías preferenciales (grietas de desecación de amplio tamaño). Estas grietas se van saturando y cerrando por lo que la Vi desciende con el tiempo hasta hacerse menor y representativa de litologías de texturas arcillosas. 


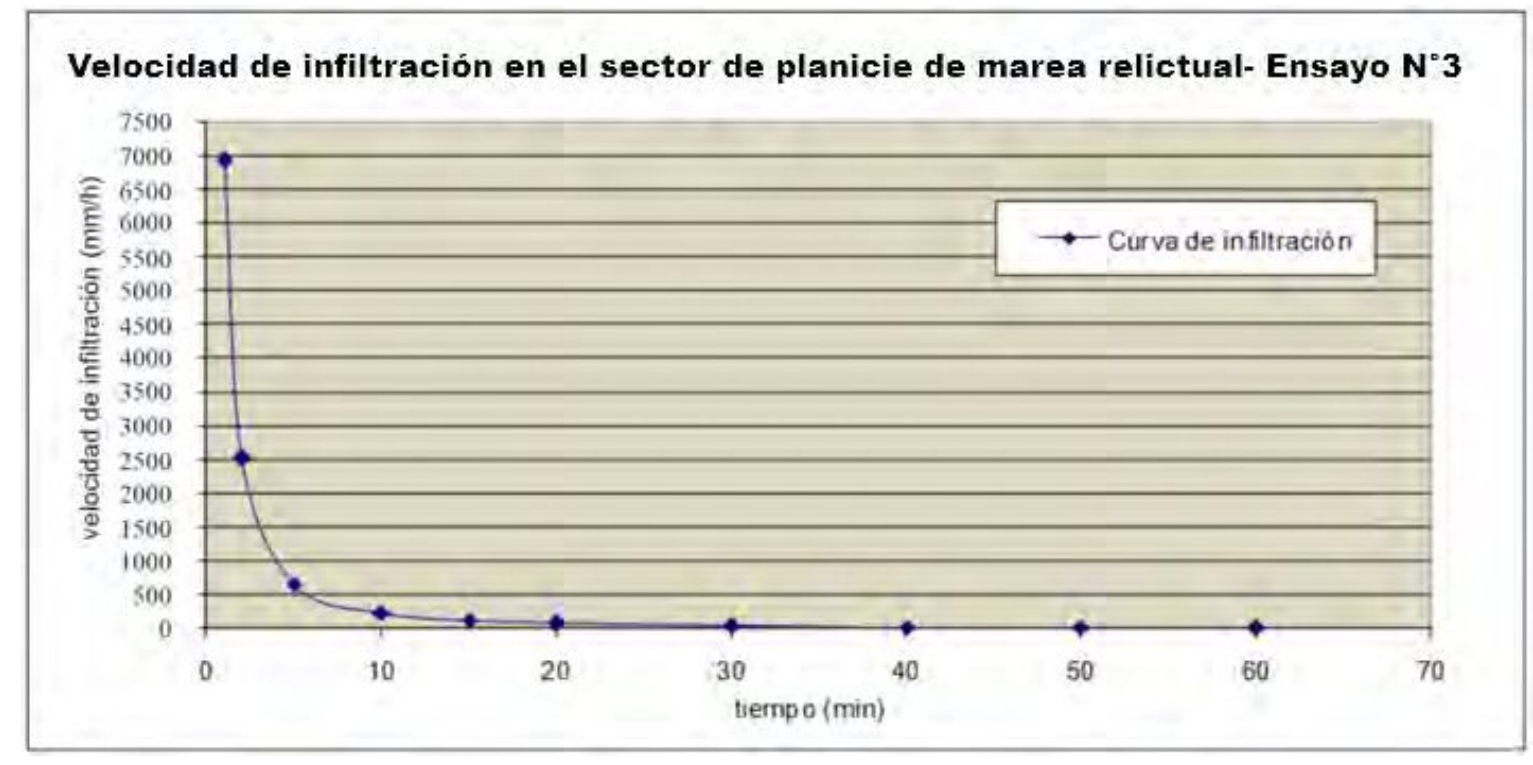

Figura 6.20 Ensayo $\mathrm{N}^{\circ} 3$, realizado en el sector de planicie de marea relictual. 
Tabla 12 Características generales de las unidades geomorfológicas y velocidades de infiltración.

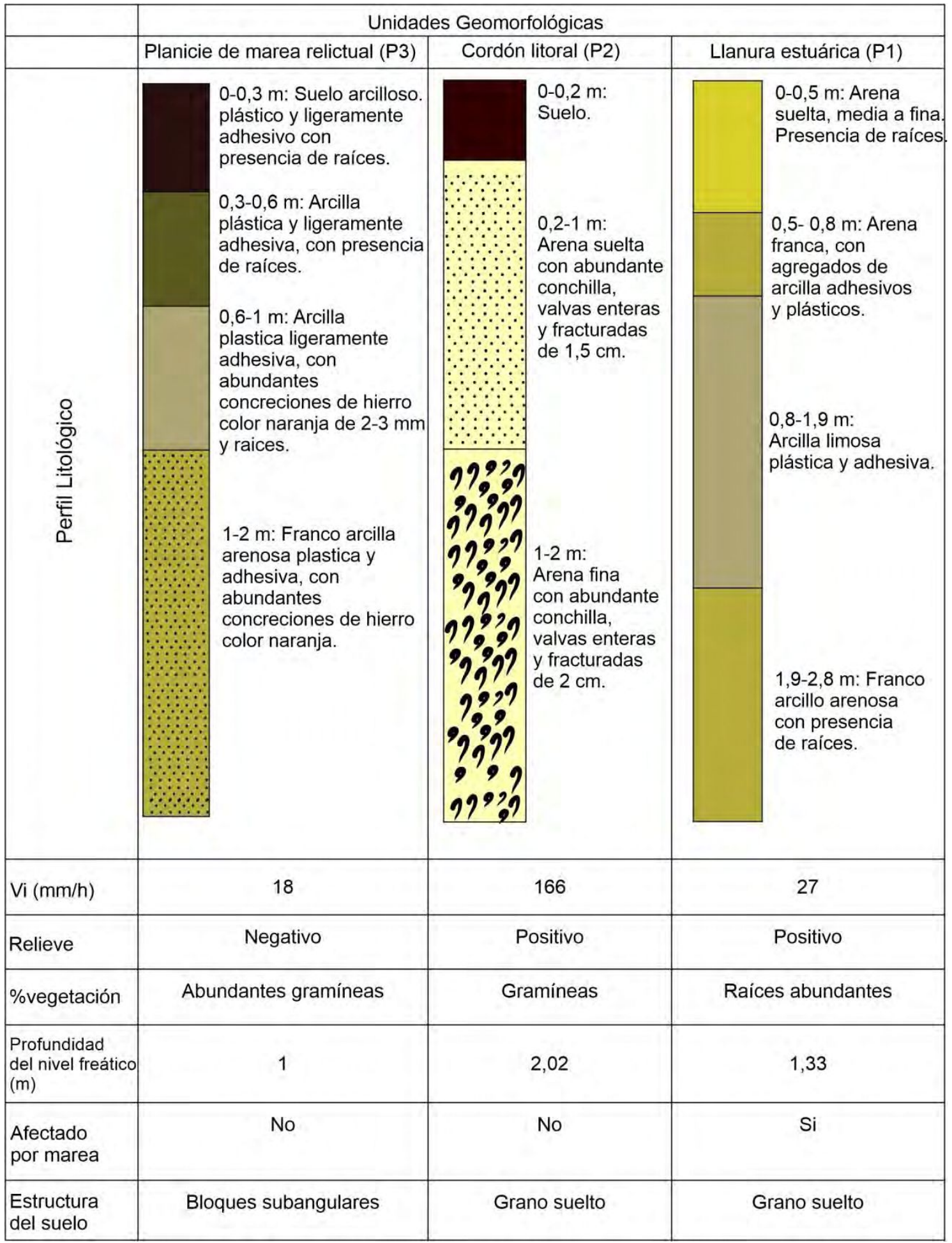


La interpretación de los ensayos de infiltración mediante el método de Kostiakov (1932) arrojó los siguientes valores promedios de velocidad de infiltración (Vi) en los tres ambientes estudiados: cordón litoral $155 \mathrm{~mm} / \mathrm{h}$, continuado por la llanura estuárica con $27 \mathrm{~mm} / \mathrm{h}$ y para la planicie de marea relictual $18 \mathrm{~mm} / \mathrm{h}$ que representa el valor más bajo.

Es importante señalar que el sector de los cordones de conchillas es donde se registraron los mayores valores de $\mathrm{Vi}$, producto de su alta porosidad adquirida por los sedimentos que la integran (valvas y arenas) y su topografía elevada. 


\section{BALANCES HÍDRICOS DURANTE LOS RELEVAMIENTOS}

\subsection{Costa marítima}

Para evaluar las condiciones del ciclo hidrológico durante el periodo coincidente con las mediciones de campo se calcularon balances hídricos a paso diario (Balshort) para el período 2016-2018 ver Anexo 8.

Las precipitaciones para 2016 suman 733 mm (Figura 7.1), 906 mm para 2017 (Figura 7.2) y $816 \mathrm{~mm}$ para 2018 (Figura 7.3). Respecto a la precipitación media anual del área $(1000 \mathrm{~mm})$ los tres años considerados se encuentran por debajo de este valor. La ETR está en el orden del $60 \%$ de las precipitaciones y los excesos del $40 \%$.

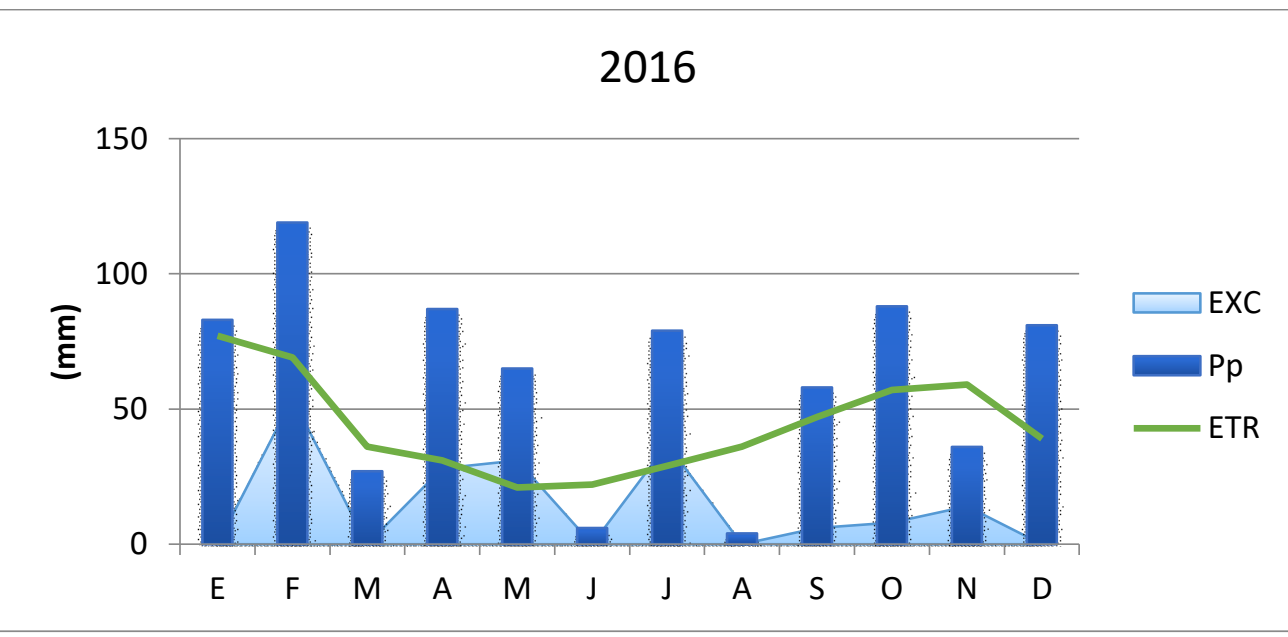

Figura 7.1 Excesos, precipitaciones y ETR para el año 2016.

Las Tablas 12, 14 y 16 representan la síntesis mensual de los resultados del balance a paso diario para los años 2016, 2017 y 2018 respectivamente. Estos valores corresponden a las sumas del mes calendario.

Para el año 2016 (Tabla 12) se registraron excesos en los meses de febrero, abril, mayo, julio, septiembre, octubre y noviembre. El mes más lluvioso fue febrero y en el que hubo mayores excesos.

Tabla 12 Síntesis mensual de los resultados del balance de paso de diario (Balshort) para el año 2016. Valores expresados en $\mathrm{mm}$.

\begin{tabular}{|c|c|c|c|c|c|c|c|c|c|c|c|c|c|}
\hline \multicolumn{10}{|c|}{2016} \\
\hline & Ene & Feb & Mar & Abr & May & Jun & Jul & Ago & Sep & Oct & Nov & Dic & Año \\
\hline $\begin{array}{c}\text { T } \\
\left({ }^{\circ} \mathbf{C}\right)\end{array}$ & 23 & 24 & 19 & 16 & 12 & 9 & 10 & 11 & 11 & 14 & 17 & 22 & 16 \\
\hline P & 83 & 119 & 27 & 87 & 65 & 6 & 79 & 4 & 58 & 88 & 36 & 81 & 733 \\
\hline ETP & 121 & 102 & 90 & 72 & 46 & 22 & 23 & 29 & 47 & 53 & 75 & 96 & 776 \\
\hline
\end{tabular}




\begin{tabular}{|c|c|c|c|c|c|c|c|c|c|c|c|c|c|} 
ETR & 78 & 70 & 37 & 39 & 24 & 24 & 23 & 30 & 35 & 42 & 51 & 43 & 496 \\
\hline Exc & 2 & 56 & 0 & 24 & 23 & 0 & 38 & 0 & 17 & 26 & 20 & 0 & 206 \\
\hline
\end{tabular}

Las Tablas 13, 15 y 17 corresponden a las sumas entre fechas de medición, se hace esta distinción debido a que el sistema es muy dinámico y de respuesta rápida y las fechas entre mediciones no coinciden con el mes calendario.

Tabla 13 Datos agrupados entre fechas de medición 2016. Valores expresados en mm.

\begin{tabular}{|c|c|c|c|}
\hline Fechas de censos & Precipitación & Excesos & $\begin{array}{c}\text { Cantidad de días } \\
\text { entre censos }\end{array}$ \\
\hline $31 / 1 / 2016$ & 129 & 0 & 41 \\
\hline $26 / 2 / 2016$ & 119 & 56 & 26 \\
\hline $30 / 3 / 2016$ & 27 & 0 & 33 \\
\hline $30 / 4 / 2016$ & 87 & 24 & 31 \\
\hline $28 / 5 / 2016$ & 1 & 0 & 29 \\
\hline $30 / 6 / 2016$ & 70 & 23 & 33 \\
\hline $29 / 7 / 2016$ & 79 & 38 & 29 \\
\hline $14 / 8 / 2016$ & 4 & 0 & 15 \\
\hline $29 / 9 / 2016$ & 58 & 17 & 47 \\
\hline $28 / 10 / 2016$ & 82 & 26 & 30 \\
\hline $8 / 11 / 2016$ & 31 & 20 & 12 \\
\hline $29 / 12 / 2016$ & 50 & 0 & 52 \\
\hline
\end{tabular}

Para 2017 los excesos se registran entre enero y octubre, siendo nulos en junio, noviembre y diciembre (Figura 7.2). El mes con mayores excesos fue agosto siendo también el mes de mayor precipitación.

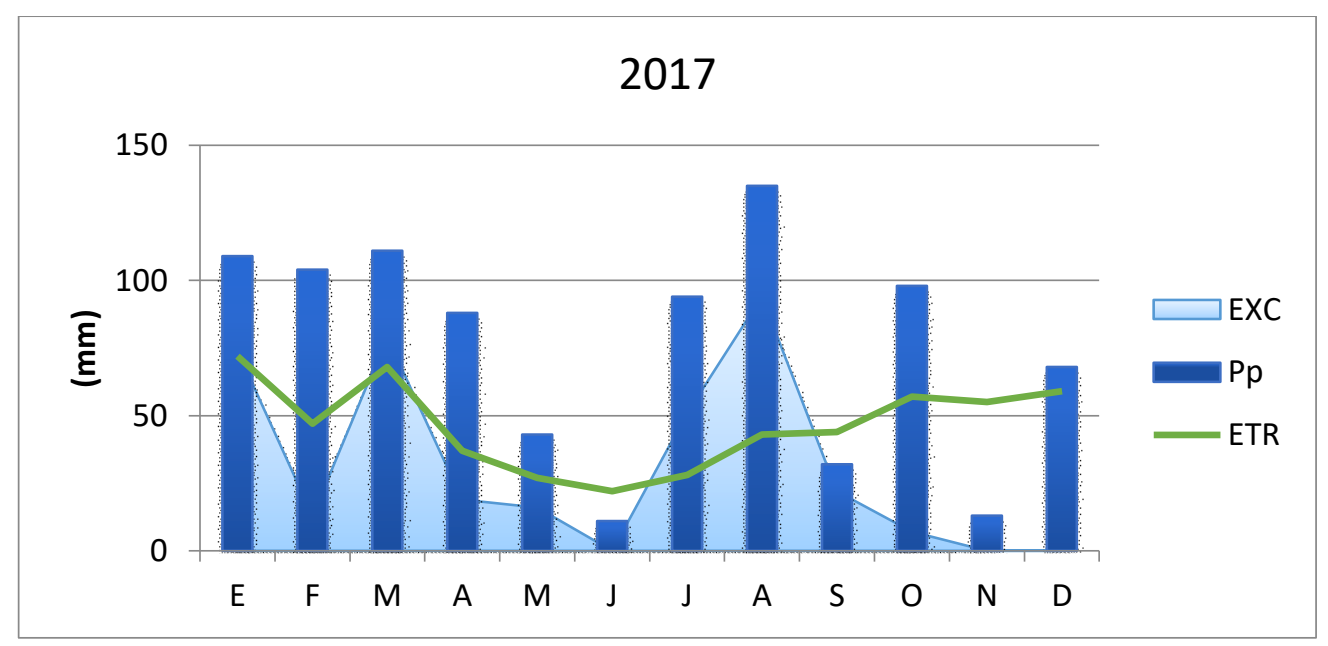

Figura 7.2 Excesos, precipitaciones y ETR para el año 2017. 
Tabla 14 Síntesis mensual de los resultados del balance de paso de diario (Balshort) para el año 2017. Valores expresados en $\mathrm{mm}$.

\begin{tabular}{|c|c|c|c|c|c|c|c|c|c|c|c|c|c|}
\hline \multicolumn{14}{|c|}{2017} \\
\hline & Ene & Feb & Mar & Abr & May & Jun & Jul & Ago & Sep & Oct & Nov & Dic & Año \\
\hline $\begin{array}{c}\mathrm{T} \\
\left({ }^{\circ} \mathrm{C}\right)\end{array}$ & 23 & 23 & 20 & 18 & 15 & 12 & 12 & 13 & 13 & 14 & 16 & 20 & 16.6 \\
\hline $\mathbf{P}$ & 109 & 104 & 111 & 88 & 43 & 11 & 94 & 135 & 32 & 98 & 13 & 68 & 906 \\
\hline ETP & 130 & 109 & 88 & 65 & 45 & 28 & 30 & 37 & 40 & 51 & 66 & 103 & 792 \\
\hline ETR & 70 & 47 & 68 & 46 & 40 & 22 & 23 & 31 & 34 & 44 & 49 & 59 & 534 \\
\hline Exc & 78 & 14 & 80 & 13 & 3 & 0 & 51 & 106 & 25 & 27 & 0 & 0 & 396 \\
\hline
\end{tabular}

En la Tabla 15 se presentan los datos de precipitación y excesos sumados entre fechas de medición, los censos en algunos casos abarcan más de un mes superando entre censo y censo los 30 días.

Tabla 15 Datos agrupados entre fechas de medición 2017. Valores expresados en mm.

\begin{tabular}{|c|c|c|c|}
\hline Fechas de censos & Precipitación & Excesos & $\begin{array}{c}\text { Cantidad de días } \\
\text { entre censos }\end{array}$ \\
\hline $26 / 1 / 17$ & 150 & 78 & 27 \\
\hline $15 / 2 / 17$ & 19 & 0 & 20 \\
\hline $9 / 4 / 17$ & 221 & 94 & 53 \\
\hline $24 / 5 / 17$ & 102 & 16 & 45 \\
\hline $17 / 7 / 17$ & 87 & 41 & 54 \\
\hline $31 / 8 / 17$ & 157 & 115 & 45 \\
\hline $17 / 10 / 17$ & 63 & 25 & 47 \\
\hline $30 / 12 / 17$ & 140 & 27 & 74 \\
\hline
\end{tabular}

En 2018 los excesos se registran en marzo, abril, mayo, septiembre y diciembre (Figura 7.3). El mes que presentó mayores precipitaciones y excesos fue septiembre.

Tabla 16 Síntesis mensual de los resultados del balance de paso de diario (Balshort) para el año 2018. Valores expresados en $\mathrm{mm}$.

\begin{tabular}{|c|c|c|c|c|c|c|c|c|c|c|c|c|c|}
\hline \multicolumn{10}{|c|}{2018} \\
\hline & Ene & Feb & Mar & Abr & May & Jun & Jul & Ago & Sep & Oct & Nov & Dic & Año \\
\hline $\begin{array}{c}\text { T } \\
\left({ }^{\circ} \text { C) }\right.\end{array}$ & 22 & 22 & 20 & 19 & 15 & 10 & 10 & 11 & 14 & 14 & 17 & 19 & 16 \\
\hline P & 14 & 75 & 108 & 89 & 106 & 10 & 33 & 38 & 199 & 19 & 10 & 115 & 816 \\
\hline
\end{tabular}




\begin{tabular}{|c|c|c|c|c|c|c|c|c|c|c|c|c|c|}
\hline ETP & 122 & 103 & 83 & 72 & 47 & 22 & 23 & 29 & 47 & 53 & 75 & 97 & 773 \\
\hline ETR & 33 & 62 & 54 & 47 & 38 & 26 & 24 & 31 & 36 & 39 & 32 & 40 & 461 \\
\hline Exc & 0 & 2 & 41 & 20 & 66 & 0 & 4 & 8 & 152 & 0 & 0 & 35 & 330 \\
\hline
\end{tabular}

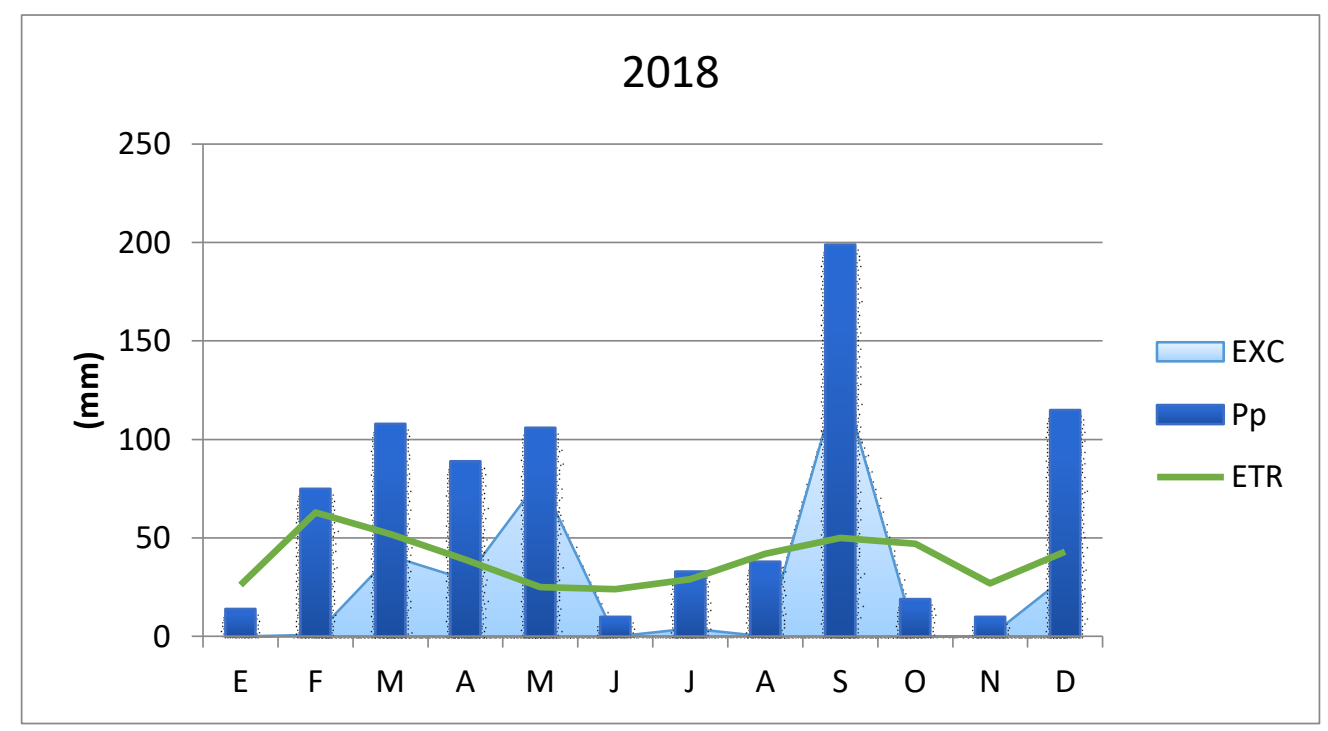

Figura 7.3 Excesos, precipitaciones y ETR para el año 2018.

Tabla 17 Datos agrupados entre fechas de medición 2018. Valores expresados en mm.

\begin{tabular}{|c|c|c|c|}
\hline Fechas de censos & Precipitación & Excesos & $\begin{array}{c}\text { Cantidad de días } \\
\text { entre censos }\end{array}$ \\
\hline $31 / 1 / 2018$ & 26 & 26 & 33 \\
\hline $20 / 4 / 2018$ & 64 & 68 & 78 \\
\hline $7 / 6 / 2018$ & 67 & 84 & 48 \\
\hline $12 / 10 / 2018$ & 164 & 137 & 127 \\
\hline
\end{tabular}

\subsection{Costa estuárica}

Se calcularon los balances hídricos de paso mensual para 2016 y 2017 para evaluar las condiciones del ciclo hidrológico durante el periodo coincidente con las mediciones de campo.

Las precipitaciones para el balance hídrico de 2016 suman 1143 mm (Tabla 19) y $1128 \mathrm{~mm}$ para 2017 (Tabla 20). No se ha observado una variabilidad importante entre los años donde se llevaron a cabo las mediciones de los niveles freáticos. En ambos periodos la ETR alcanza el $70 \%(\approx 790 \mathrm{~mm})$ de las precipitaciones y los excesos el $30 \%(\approx 340 \mathrm{~mm})$. 
Tabla 18 Balance hídrico de paso mensual para el año 2016. Valores expresados en mm.

\begin{tabular}{|l|l|l|l|l|l|l|l|l|l|l|l|l|c|}
\hline \multicolumn{10}{|c|}{ Berisso 2016 } \\
\hline & Ene & Feb & Mar & Abr & May & Jun & Jul & Ago & Sep & Oct & Nov & Dic & Año \\
\hline T ( ${ }^{\circ}$ C) & 23.6 & 22.4 & 20.3 & 16.3 & 13.2 & 10.1 & 9.6 & 11.1 & 13.1 & 16.1 & 19.2 & 22.0 & $\mathbf{1 6 . 4}$ \\
\hline P & 79 & 86 & 77 & 196 & 79 & 30 & 183 & 48 & 63 & 114 & 74 & 114 & $\mathbf{1 1 4 3}$ \\
\hline ETP & 158 & 134 & 94 & 63 & 29 & 19 & 28 & 22 & 37 & 42 & 86 & 139 & $\mathbf{8 5 1}$ \\
\hline ETR & 132 & 102 & 89 & 53 & 36 & 21 & 22 & 28 & 40 & 64 & 89 & 120 & $\mathbf{7 9 6}$ \\
\hline Def & 2 & 12 & 12 & 12 & 25 & 6 & 78 & 13 & 13 & 36 & 0 & 0 & $\mathbf{8}$ \\
\hline Exc & 0 & 0 & 0 & 13 & 50 & 11 & 155 & 26 & 26 & 72 & 0 & 0 & $\mathbf{3 5 3}$ \\
\hline
\end{tabular}

Tabla 19 Balance hídrico de paso mensual para el año 2017. Valores expresados en mm.

\begin{tabular}{|l|l|l|l|l|l|l|l|l|l|l|l|l|l|}
\hline \multicolumn{10}{|c|}{ Berisso 2017 } \\
\hline & Ene & Feb & Mar & Abr & May & Jun & Jul & Ago & Sep & Oct & Nov & Dic & Año \\
\hline T $\left({ }^{\circ} \mathbf{C}\right)$ & 25 & 25 & 22 & 18 & 15 & 13 & 13 & 14 & 15 & 16 & 18 & 24 & $\mathbf{1 8 . 3}$ \\
\hline P & 127 & 77 & 24 & 85 & 143 & 145 & 80 & 73 & 161 & 0 & 100 & 113 & $\mathbf{1 1 2 8}$ \\
\hline ETP & 146 & 124 & 100 & 60 & 40 & 28 & 29 & 37 & 45 & 57 & 74 & 138 & $\mathbf{8 7 8}$ \\
\hline ETR & 143 & 111 & 64 & 60 & 40 & 28 & 29 & 37 & 45 & 50 & 74 & 113 & $\mathbf{7 9 4}$ \\
\hline Def & 3 & 13 & 36 & 0 & 0 & 0 & 0 & 0 & 0 & 7 & 0 & 25 & $\mathbf{8 4}$ \\
\hline Exc & 0 & 0 & 0 & 0 & 14 & 117 & 51 & 36 & 116 & 0 & 0 & 0 & $\mathbf{3 3 4}$ \\
\hline
\end{tabular}

Los excesos de las precipitaciones se contabilizan entre abril y octubre en 2016 (Figura 7.4), y entre mayo y septiembre en 2017 (Figura 7.5). Para 2016, los excesos máximos fueron observados en julio (155 mm), mientras que para 2017 fue en junio $(117 \mathrm{~mm})$ seguido de septiembre casi con el mismo valor $(116 \mathrm{~mm})$. Si bien los excesos anuales son similares en los dos años, para 2017 se han concentrado en 5 meses a diferencia del 2016 donde se distribuyen a lo largo de 7 meses.

La temperatura media anual fue de $16,4{ }^{\circ} \mathrm{C}$ para 2016 y $18,3^{\circ} \mathrm{C}$ para 2017. 


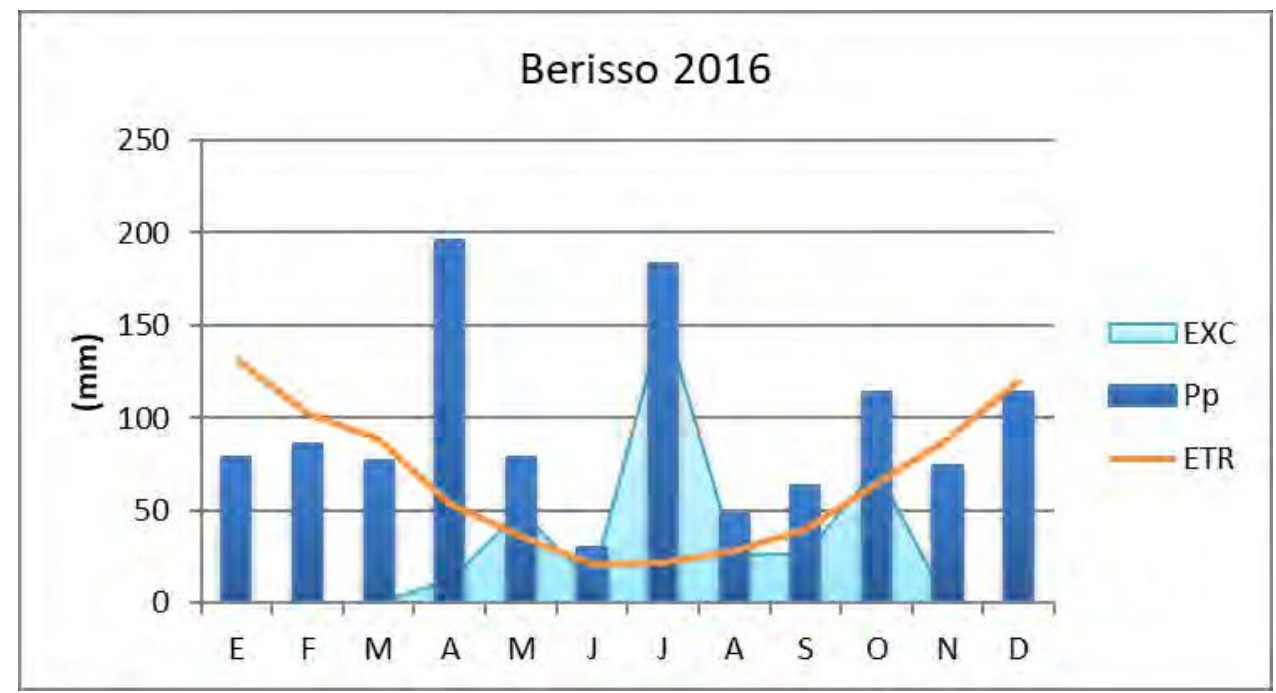

Figura 7.4 Excesos, precipitaciones y ETR para el año 2016.

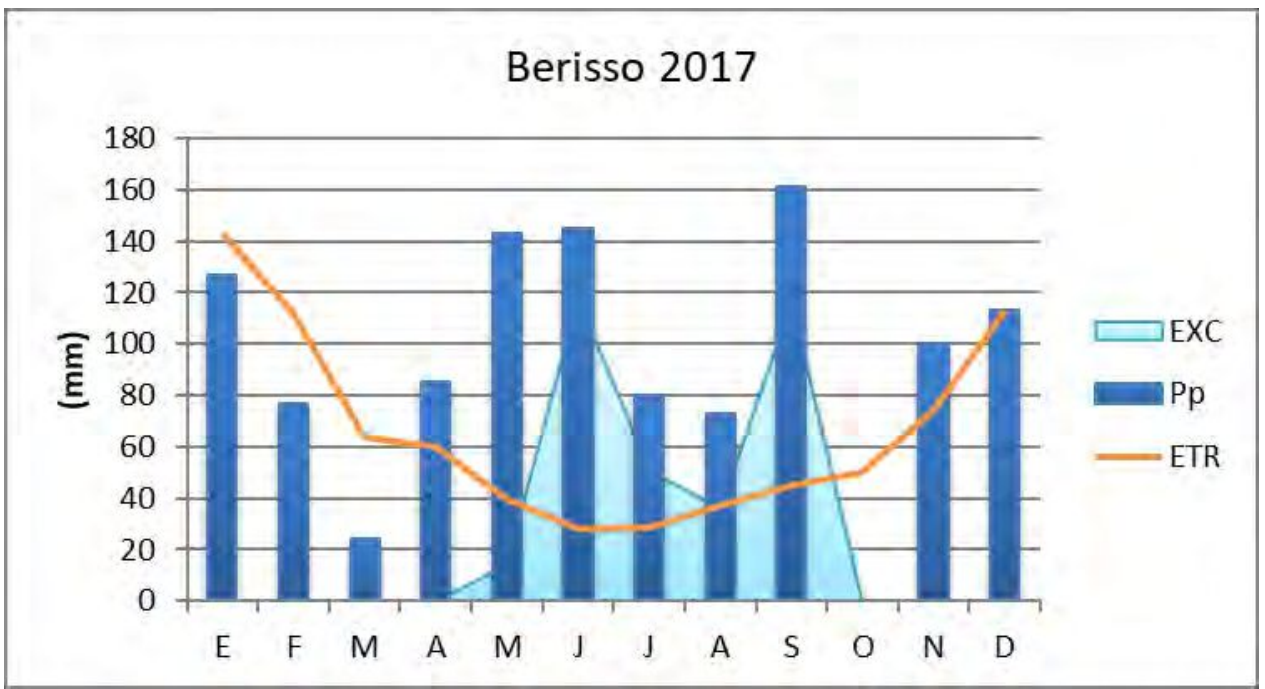

Figura 7.5 Excesos, precipitaciones y ETR para el año 2017. 


\section{RECARGA / DESCARGA DEL AGUA SUBTERRÁNEA}

En este capítulo se analizan las evidencias que permiten conocer con distintas aproximaciones los procesos de recarga y descarga del agua subterránea.

Se incluyen aspectos cualitativos que reflejan tales evidencias y las estimaciones que es posible alcanzar sujeta a las incertidumbres que generan los datos disponibles y la propia complejidad de estos fenómenos.

Se analiza como tema central para la definición de estos procesos a las evaluaciones realizadas en la costa marítima (Mar del Tuyú) y en forma complementaria aquellos encarados en la costa estuárica (Berisso).

\subsection{Condiciones hidrodinámicas en la costa marítima (Mar del Tuyú)}

\subsubsection{Generalidades}

Se evalúan las características del flujo subterráneo en condiciones medias y en condiciones extremas de la capa freática y su relación con los rasgos geomorfológicos A partir de los mapas de flujo subterráneo del período diciembre 2015 - enero 2018 (Anexo 5) se reconoce una condición media de la morfología freática de forma elongada en sentido norte-sur, donde las mayores alturas se encuentran en el sector central (área de recarga) y disminuyen hacia los sectores este y oeste (áreas de descarga). El flujo es divergente desde la zona de recarga con dos direcciones opuestas de descarga una hacia el continente y otra al mar (Figura 8.1). 


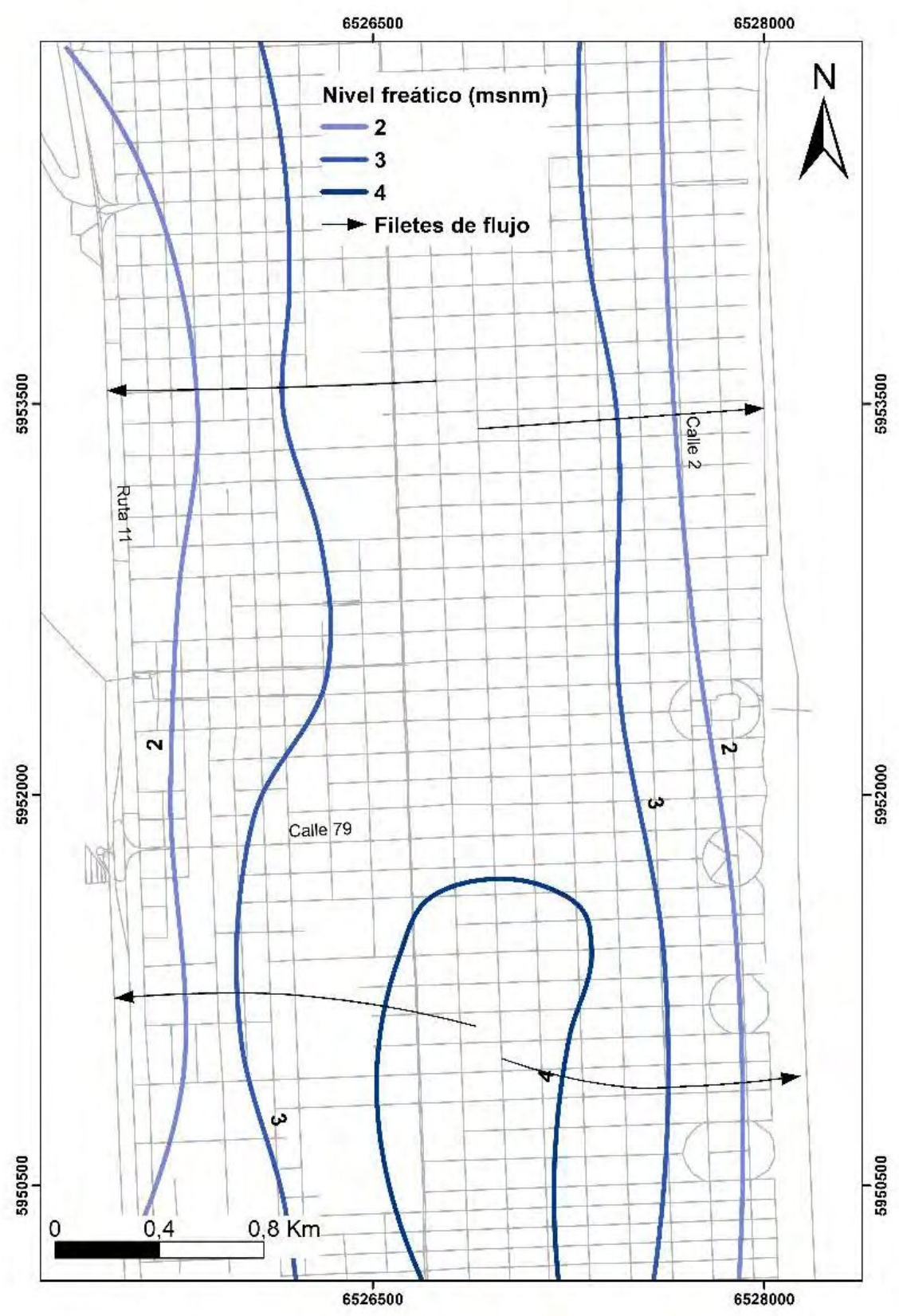

Figura 8.1 Mapa general de flujo subterráneo.

A su vez se presentan dos situaciones extremas, las correspondiente a niveles freáticos más profundos (marzo-2016, Figura 8.2) y más someros (julio-2016, Figura 8.3) dentro de un año hidrológico. 


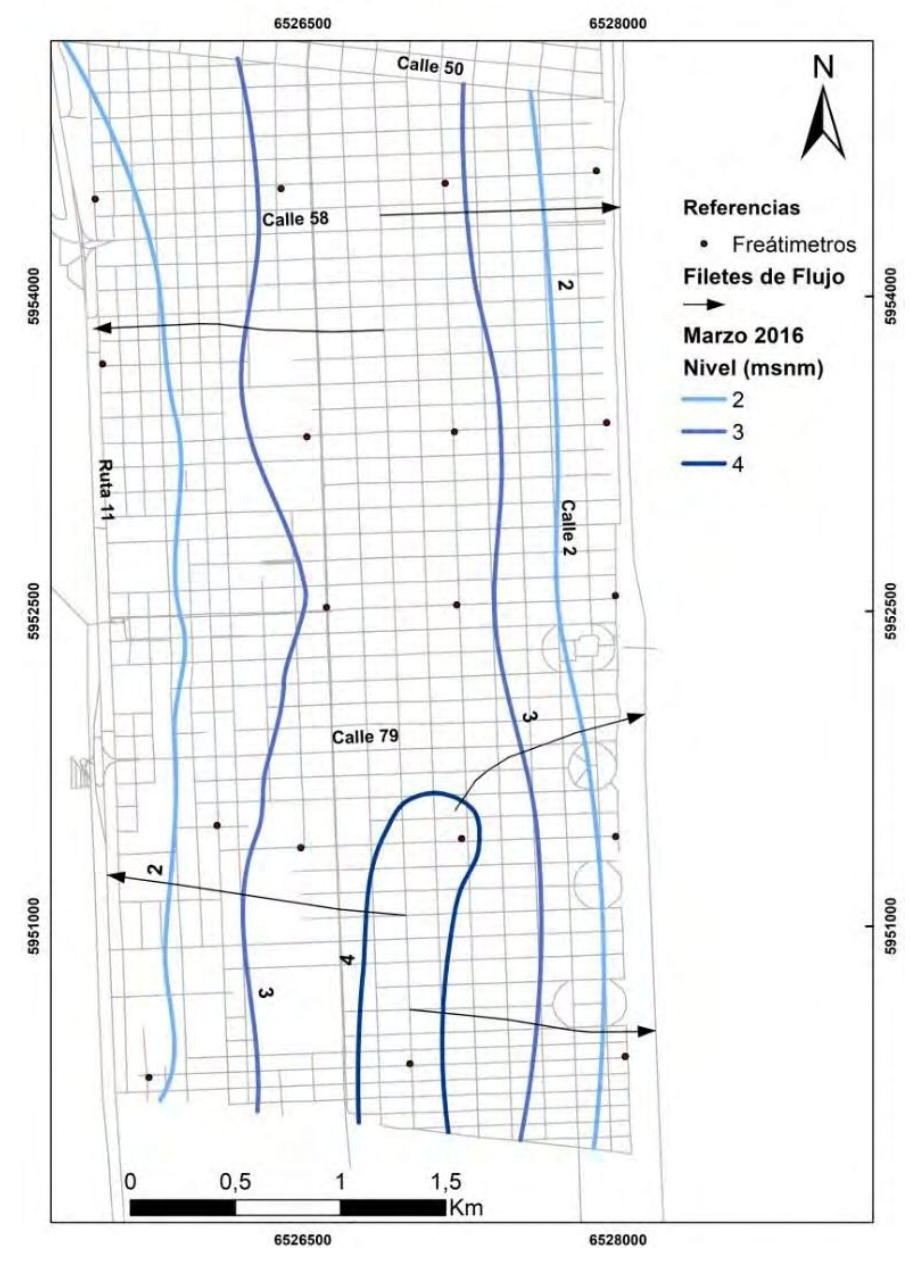

Figura 8.2 Mapa isofreáticos correspondientes al censo de marzo 2016.

Los niveles freáticos más profundos se observaron en marzo-2016 mientras que los más someros se relevaron en julio-2016. En la situación de mayor altura de la capa freática los niveles alcanzan un máximo de $5 \mathrm{~m} \mathrm{~s}$. $\mathrm{n}$. $\mathrm{m}$. y un mínimo de $1,5 \mathrm{~m} \mathrm{~s}$. $\mathrm{n}$. $\mathrm{m}$.. Para el caso contrario, oscilan entre 1,5 y $4 \mathrm{~m} \mathrm{~s}$. n. m. Los mapas de flujo subterráneo mensuales permitieron determinar una zona principal de recarga, desde donde divergen los filetes de flujo, ubicada en la parte central de la zona en coincidencia con las cotas más altas. 


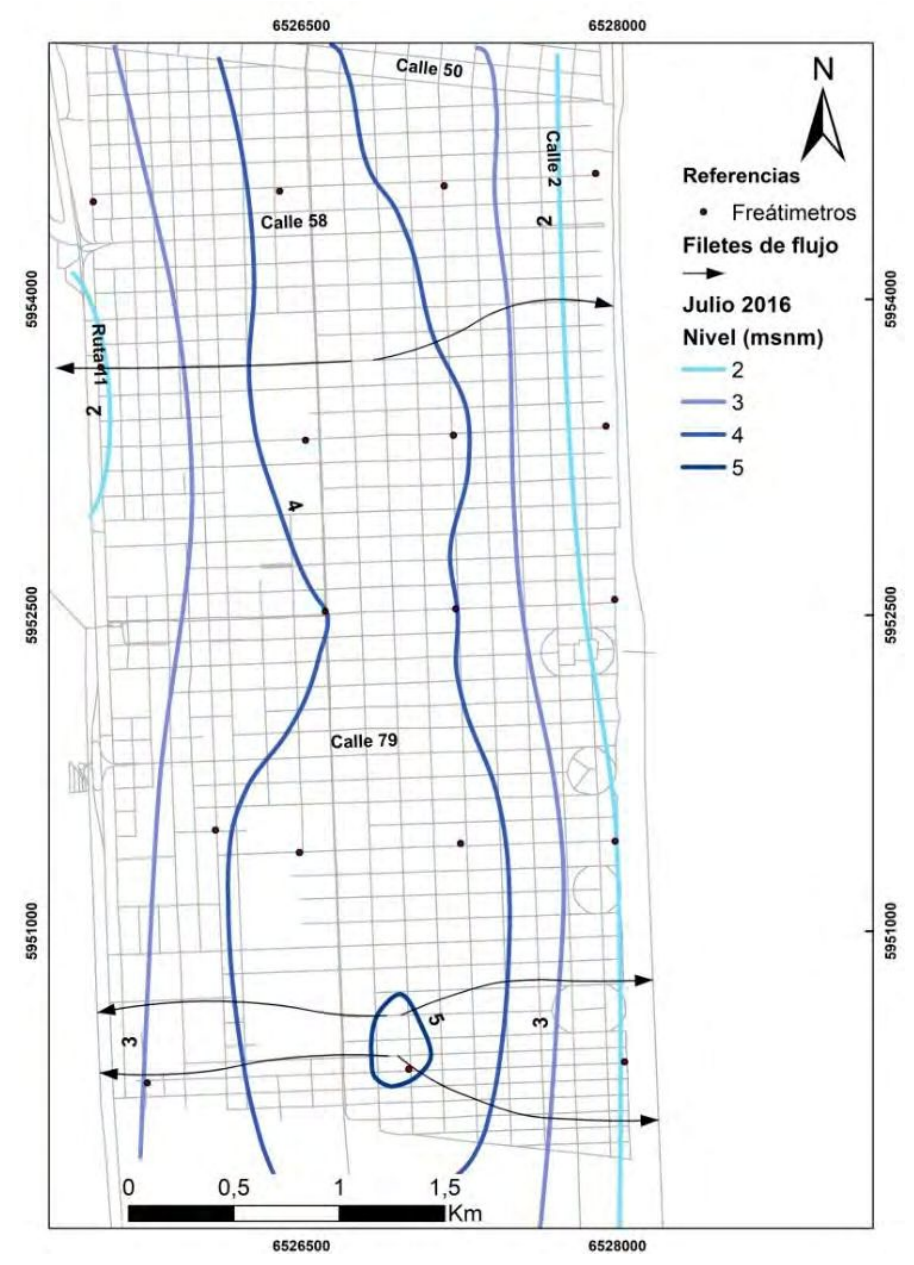

Figura 8.3 Mapa isofreáticos correspondientes al censo de julio de 2016.

El valor de gradiente hidráulico, durante la estación cálida en el flanco oriental es de 0,002 con una velocidad efectiva de $0,4 \mathrm{~m} / \mathrm{d}$. Para el flanco occidental el valor es de 0,0023 y la velocidad efectiva de $0,46 \mathrm{~m} / \mathrm{d}$.

Los gradientes estimados en invierno para el flanco oriental y occidental respectivamente son de 0,003 y 0,0022. A su vez, las velocidades efectivas alcanzan los $0,6 \mathrm{~m} / \mathrm{d}$ y $0,44 \mathrm{~m} / \mathrm{d}$.

En base a los valores de gradiente calculados, la transmisividad y la longitud del área de descarga obtenida mediante el SIG sobre los mapas de flujo, se estimaron los valores de descarga. La descarga hacia el mar, en marzo fue de $2000 \mathrm{~m}^{3} / \mathrm{d}$ y en julio de $3000 \mathrm{~m}^{3} / \mathrm{d}$ mientras que hacia la llanura deprimida estos valores son de $2300 \mathrm{y}$ $2200 \mathrm{~m}^{3} / \mathrm{d}$ respectivamente. De acuerdo a estos cálculos, la descarga hacia el oeste en general es relativamente uniforme, mientras que hacia el mar se produce un incremento del $50 \%$ entre los meses cálidos y los fríos.

En el sector norte se ha detectado una migración de las curvas isofreáticas desplazando la zona de recarga hacia el oeste. Este fenómeno se detecta durante los 
meses de junio a noviembre del año estudiado. Se observa un aumento de los gradientes y las velocidades efectivas en el flanco oriental del cordón costero entre marzo y julio. Esto podría deberse al aumento de los niveles freáticos en los meses de invierno y al desplazamiento de la zona de recarga hacia el oeste.

En el mapa de isovariación de los niveles entre las fechas analizadas (Figura 8.4) se observa que los mayores incrementos $(>0,8 \mathrm{~m}$ ) se produjeron desde el sector central de la duna y hacia la zona de descarga al oeste. En algunos sectores estos aumentos superan el metro. Incrementos entre 0,3 y $0,6 \mathrm{~m}$ se dieron desde el sector central hacia la zona de descarga al mar.

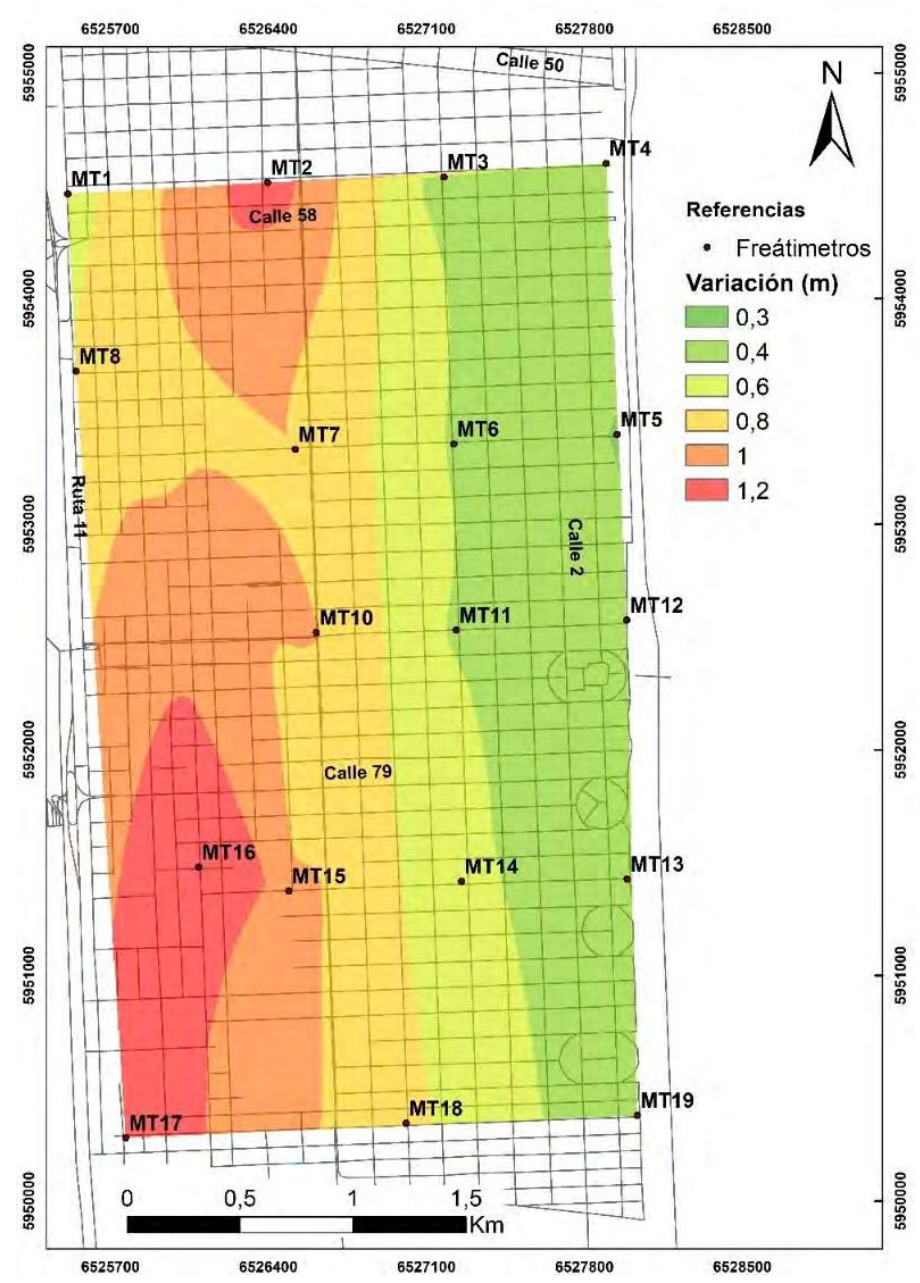

Figura 8.4 Mapa de isovariación de los niveles freáticos para las dos situaciones extremas descriptas de marzo-julio 2016.

En el análisis de detalle de variación de niveles freáticos, en el área de estudio se consideraron las subunidades geomorfológicas de cordones litorales, campo de dunas inactivo, campo de dunas semiactivo, y dunas costeras (activas).

Dada la dinámica del sistema se considera la suma de los excesos entre fechas de mediciones las cuales no coinciden exactamente con el mes calendario. Si bien el 
periodo de estudio fue mayor, se ha elegido el año 2016 para un análisis detallado del comportamiento del agua subterránea ya que presenta mediciones de paso mensual lo cual permite observar las variaciones en el sistema.

Se estimaron los promedios de los niveles mínimos, máximos y medios para cada unidad (Tabla 21). En términos generales puede resumirse que la capa freática se encuentra más elevada en el campo de dunas inactivo y es en donde existe una mayor oscilación de los niveles (hasta 1,2 m). Los valores para el campo de dunas semiactivo son similares pero las variaciones son del orden del $50 \%$ respecto de la duna inactiva. La zona de transición hacia los cordones litorales presenta valores de niveles medios de $2 \mathrm{~m} \mathrm{~s}$. $\mathrm{n}$. m. y variaciones que alcanzan los 0,9 m. Los niveles más bajos, así como las menores variaciones, se encuentran en la duna costera activa.

Tabla 20 Valores promedios de los niveles mínimos, máximos y medios para cada ambiente.

\begin{tabular}{|l|c|c|c|c|}
\hline Ambiente & $\begin{array}{c}\text { Min. } \\
\text { (m s. } \mathbf{n . ~ m . )}\end{array}$ & $\begin{array}{c}\text { Max. } \\
\text { (m s. n. m.) }\end{array}$ & $\begin{array}{c}\text { Media } \\
\text { (m s. n. m.) }\end{array}$ & $\begin{array}{c}\text { Variación } \\
\text { (m) }\end{array}$ \\
\hline Transicional a cordones litorales & 1,9 & 2,8 & 2,0 & 0,9 \\
\hline Campo dunas inactivo & 3,3 & 4,5 & 3,8 & 1,2 \\
\hline $\begin{array}{l}\text { Campo de dunas semiactivo } \\
\text { (urbanizado) }\end{array}$ & 3,8 & 4,4 & 3,7 & 0,6 \\
\hline Duna costera activa & 1,2 & 1,7 & 1,2 & 0,4 \\
\hline
\end{tabular}

El detalle del comportamiento en cada ambiente se presenta a continuación:

\section{- Zona oeste transicional a cordones litorales}

Los pozos que representan esta zona son MT1, MT8 en el sector norte con una cota promedio de 2,5 y MT16 y MT17 al sur con cotas de 3,8 m s. n. m. La capa freática sigue la morfología superficial por lo cual los niveles del sector norte son más bajos que los del sur.

En general, en esta unidad, los niveles freáticos se encuentran entre 1 y $4 \mathrm{~m} \mathrm{~s} . \mathrm{n} . \mathrm{m}$. La mayor altura se produjo en julio-2016 con los mayores descensos en marzo y diciembre. Puede observarse que a pesar de que los excesos en febrero-2016 fueron los mayores registrados $(56 \mathrm{~mm}$ ) no se registraron ascensos de los niveles, los cuales mantuvieron su altura para comenzar a descender en marzo a consecuencia de excesos nulos en ese mes (Figura 8.5). El descenso en los niveles en los meses de verano puede atribuirse a un mayor consumo, debido al incremento de la población por el turismo y también al aumento de la EVT. 


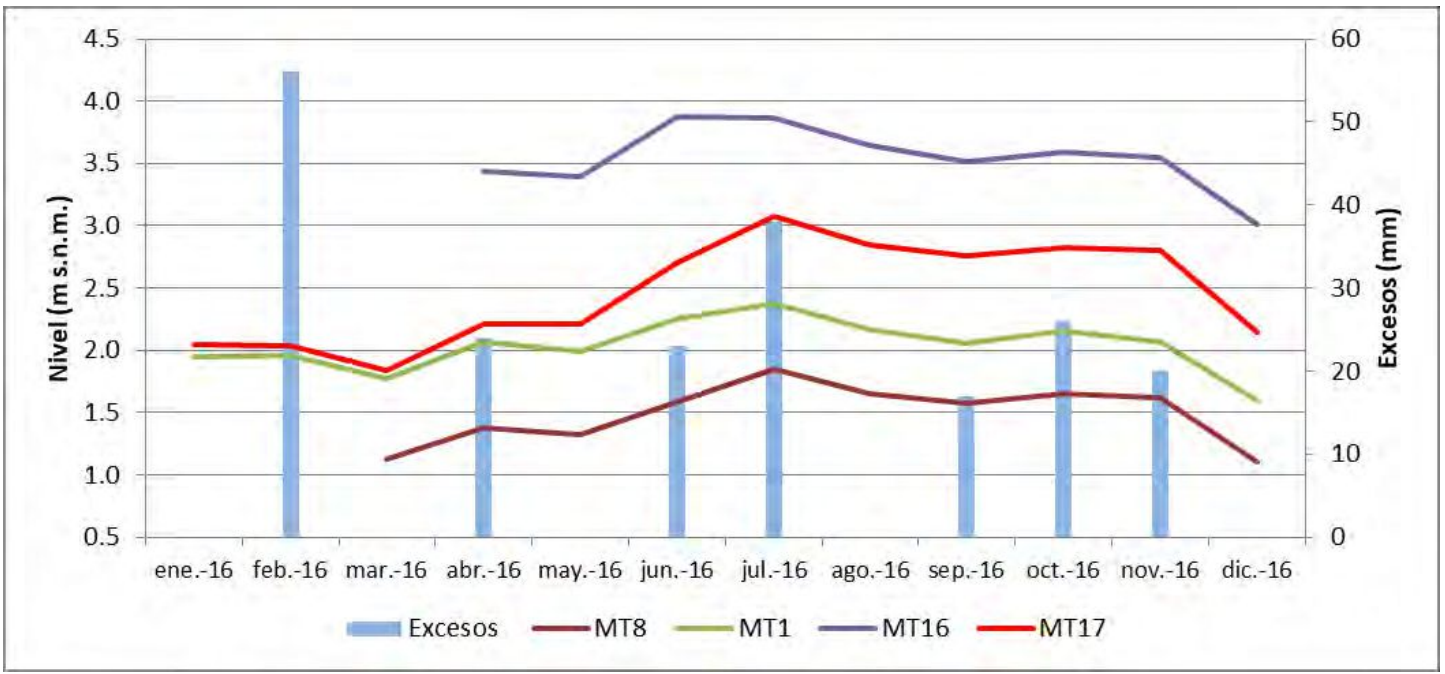

Figura 8.5 Fluctuaciones de los niveles freáticos en función de los excesos para 2016 en el ambiente transicional a cordones litorales.

\section{- Campo de dunas inactivo}

Los pozos que representan esta zona son MT2, MT7, MT10 y MT15. La cota promedio para los pozos del sector es de 4,8 m s. n. m.

Los niveles fluctúan entre los 3 y los $4,8 \mathrm{~m} \mathrm{~s}$. $\mathrm{n}$. m. con las mayores alturas de la capa freática en julio-2016 y las menores en marzo-2016.

Los elevados excesos de febrero producen un leve incremento en algunos pozos. Los descensos están relacionados a periodos con excesos iguales a cero. En abril el pozo MT7 muestra un descenso marcado del nivel freático que no coincide con el comportamiento del resto de los pozos los cuales responden a los excesos de $24 \mathrm{~mm}$ (Figura 8.6).

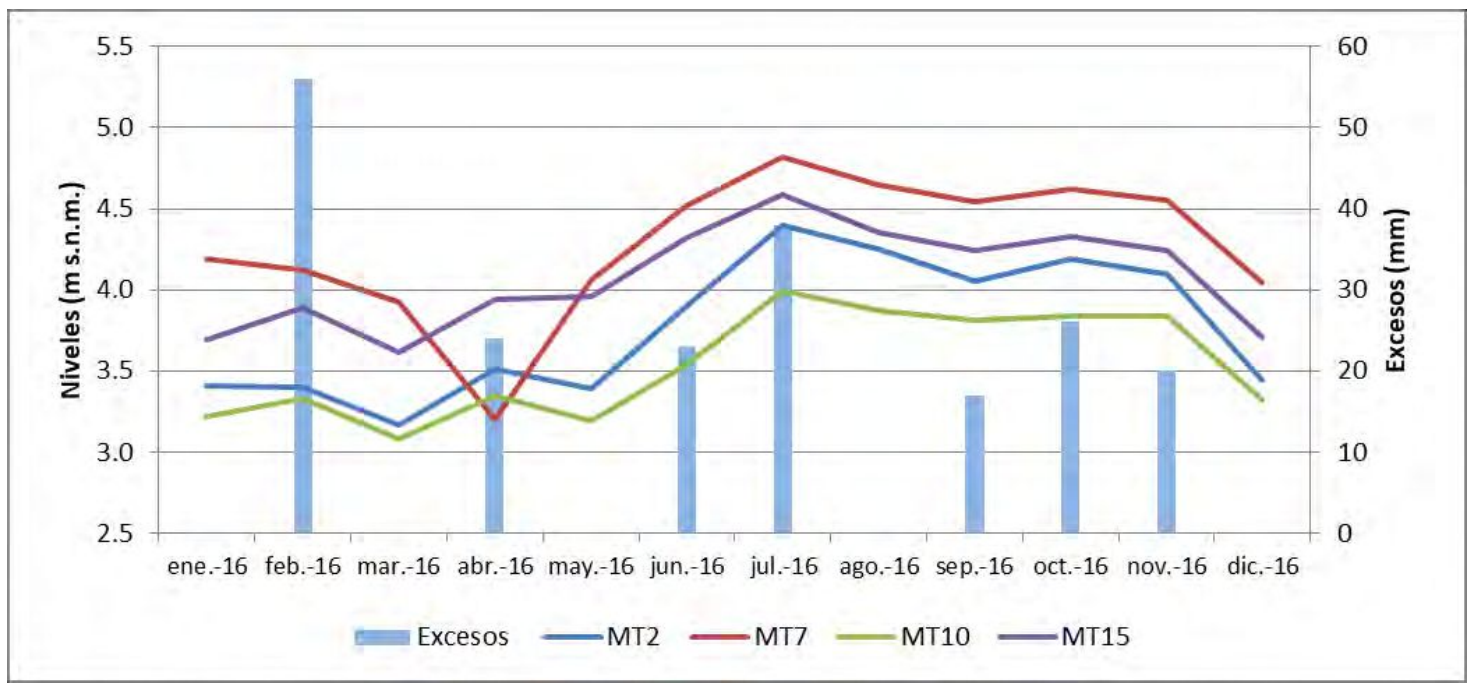

Figura 8.6 Fluctuaciones de los niveles freáticos en función de los excesos para 2016 en el ambiente campo de dunas inactivo. 


\section{- Campo de dunas semiactivo o duna urbanizada}

Los pozos que representan este ambiente son MT3, MT6, MT11, MT14. La cota promedio es de $6 \mathrm{~m} \mathrm{~s}$. n. m., siendo el sitio con la topografía más elevada del área de estudio.

El nivel mínimo se registró en el mes de marzo con 3,34 m s. n. m. y el máximo se da en noviembre con 4,87 m s.m.n. (Figura 8.7).

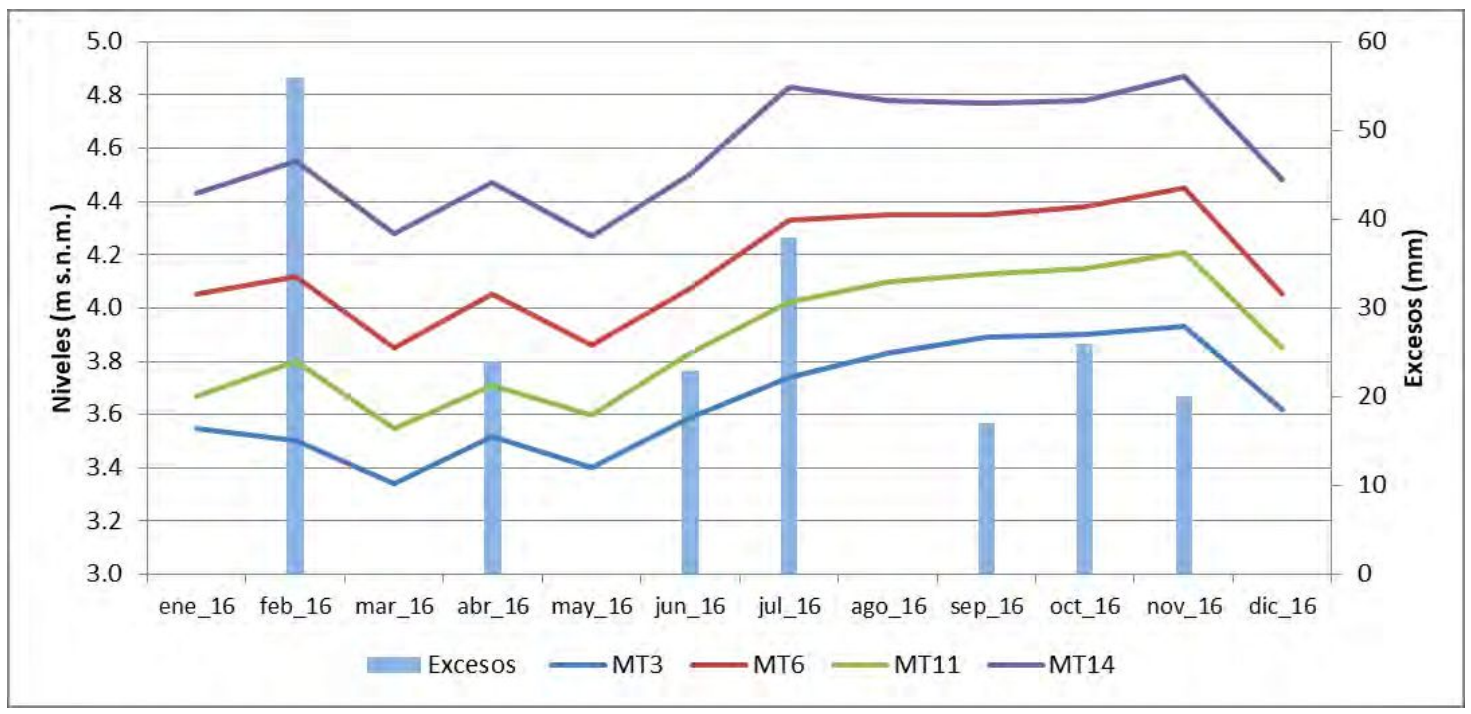

Figura 8.7 Fluctuaciones de los niveles freáticos en función de los excesos para 2016 en el ambiente campo de dunas semiactivo o duna urbanizada.

Se observa que el comportamiento de los niveles en los cuatro pozos es similar. La altura de la capa freática se incrementa de acuerdo a los excesos de las precipitaciones resultando en recarga al acuífero. En los meses sin excesos se producen descenso de los niveles, salvo en agosto, donde a pesar de excesos nulos los niveles se mantienen, probablemente debido a la recarga producida en julio y la baja ETR en estos meses de invierno.

\section{- Duna costera activa}

Los pozos que representan esta geoforma son MT4, MT5, MT12, MT13 y MT19 (Figura 8.8) La altura topográfica en el sector norte es de $3,3 \mathrm{~m} \mathrm{~s}$. n. m. y al sur aumenta a $4 \mathrm{~m} \mathrm{s.}$. m. 


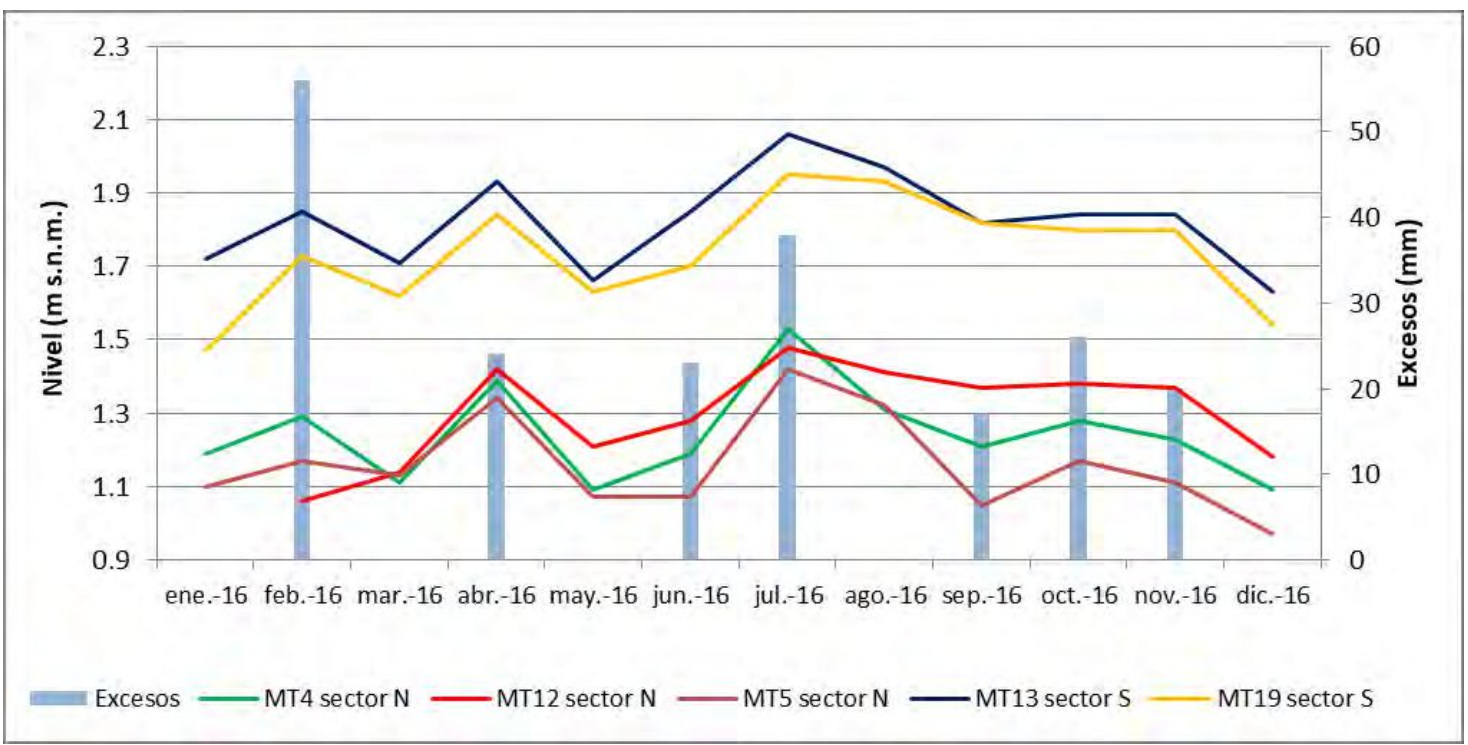

Figura 8.8 Fluctuaciones de los niveles freáticos en función de los excesos para 2016 en el ambiente duna costera activa.

En esta unidad el comportamiento diferencial de los niveles respecto a la zona norte y sur de la localidad es notorio. Se observa como los pozos MT13 y MT19 del sector sur se separan del resto, esto se debe a la diferencia de altura topográfica de $1 \mathrm{~m}$ entre ambos sectores. De todas maneras, en general, el comportamiento es similar en ambos sectores de la duna.

Los niveles freáticos mínimos al norte de la duna son de $1,47 \mathrm{~m} \mathrm{~s}$. $\mathrm{n}$. $\mathrm{m}$. en enero y 1,10 m s. n. m. al sur de dicha geoforma. Los niveles máximos se registraron en julio 2016; 1,53 m s. n. m. al norte y 2,06 al sur.

Se puede observar como las fluctuaciones del agua subterránea responden al efecto de las lluvias cuyos excesos se transforman en recarga.

\subsection{2 Índice de variación nivel freático / precipitaciones}

En la costa marítima de Mar del Tuyú se intentó establecer un índice de relación entre las variaciones de los niveles freáticos medios entre mediciones y las precipitaciones caídas en ese periodo. Se consideraron las mediciones con un paso de tiempo mensual. Además, se dividieron los muestreos según semestre cálido y frío para evaluar la posibilidad de cambios estacionales.

Las variaciones promedio de los niveles, las precipitaciones entre las mediciones y los días transcurridos entre cada uno pueden visualizarse en la Tabla 21. 
Tabla 21 Variaciones de los niveles freáticos y precipitaciones (dic16-ene18).

\begin{tabular}{|c|c|c|c|c|c|}
\hline & Periodo & $\begin{array}{l}\text { Variación } \\
\text { del N.F. } \\
\text { (m) }\end{array}$ & $\begin{array}{c}P \\
(\mathrm{~mm})\end{array}$ & $\begin{array}{c}\text { Días entre } \\
\text { censos }\end{array}$ & $\begin{array}{l}\text { Índice } \\
\text { (P/días) }\end{array}$ \\
\hline \multirow{8}{*}{$\begin{array}{c}\text { Meses de } \\
\text { semestre } \\
\text { frío }\end{array}$} & mar16-abr16 & 0,20 & 87 & 31 & 2,8 \\
\hline & abr16-may16 & $-0,09$ & 1 & 29 & 0,03 \\
\hline & may16-jun16 & 0,27 & 70 & 31 & 2,1 \\
\hline & jun16-jul16 & 0,28 & 79 & 29 & 2,7 \\
\hline & jul16-ago16 & $-0,11$ & 4 & 14 & 0,3 \\
\hline & ago16-sep16 & $-0,08$ & 58 & 47 & 1,2 \\
\hline & abr17-may17 & 0,29 & 102 & 45 & 2,3 \\
\hline & jul17-ago17 & 0,09 & 157 & 45 & 3,5 \\
\hline \multirow{7}{*}{$\begin{array}{c}\text { Meses de } \\
\text { semestre } \\
\text { cálido }\end{array}$} & dic15-ene16 & $-0,06$ & 148 & 28 & 5,3 \\
\hline & ene16-feb16 & 0,07 & 120 & 28 & 4,3 \\
\hline & feb16-mar16 & $-0,18$ & 27 & 31 & 0,9 \\
\hline & sep16-oct16 & 0,05 & 82 & 30 & 2,7 \\
\hline & nov16-dic16 & $-0,40$ & 50 & 52 & 1,0 \\
\hline & dic16-ene17 & 0,001 & 150 & 25 & 5,6 \\
\hline & dic17-ene18 & $-0,2$ & 26 & 33 & 0,8 \\
\hline
\end{tabular}

Se trató de aplicar un índice que reflejara la relación entre las variables (Figura 8.9). Para ello se divide las precipitaciones por la cantidad de días ocurridos entre las mediciones. En términos generales, valores de índice menores a 1,5 significan una profundización de los niveles. Para el semestre frío índices superiores a 2,1 implican aumento de los niveles y para el cálido, esta situación estaría representada por un valor de 2,7 a excepción de un punto que no sigue la regla, con un índice de 5,3 y descenso de los niveles. En este caso particular, se trata del periodo diciembre2015/enero-2016 donde a pesar de las elevadas precipitaciones la recarga no ha sido suficiente como para observar una reacción en la capa freática. Además las diferencias en las variaciones podrían estar respondiendo a un factor antrópico, ya que en los meses de verano en esta localidad balnearia la demanda de agua se incrementa debido al turismo. 


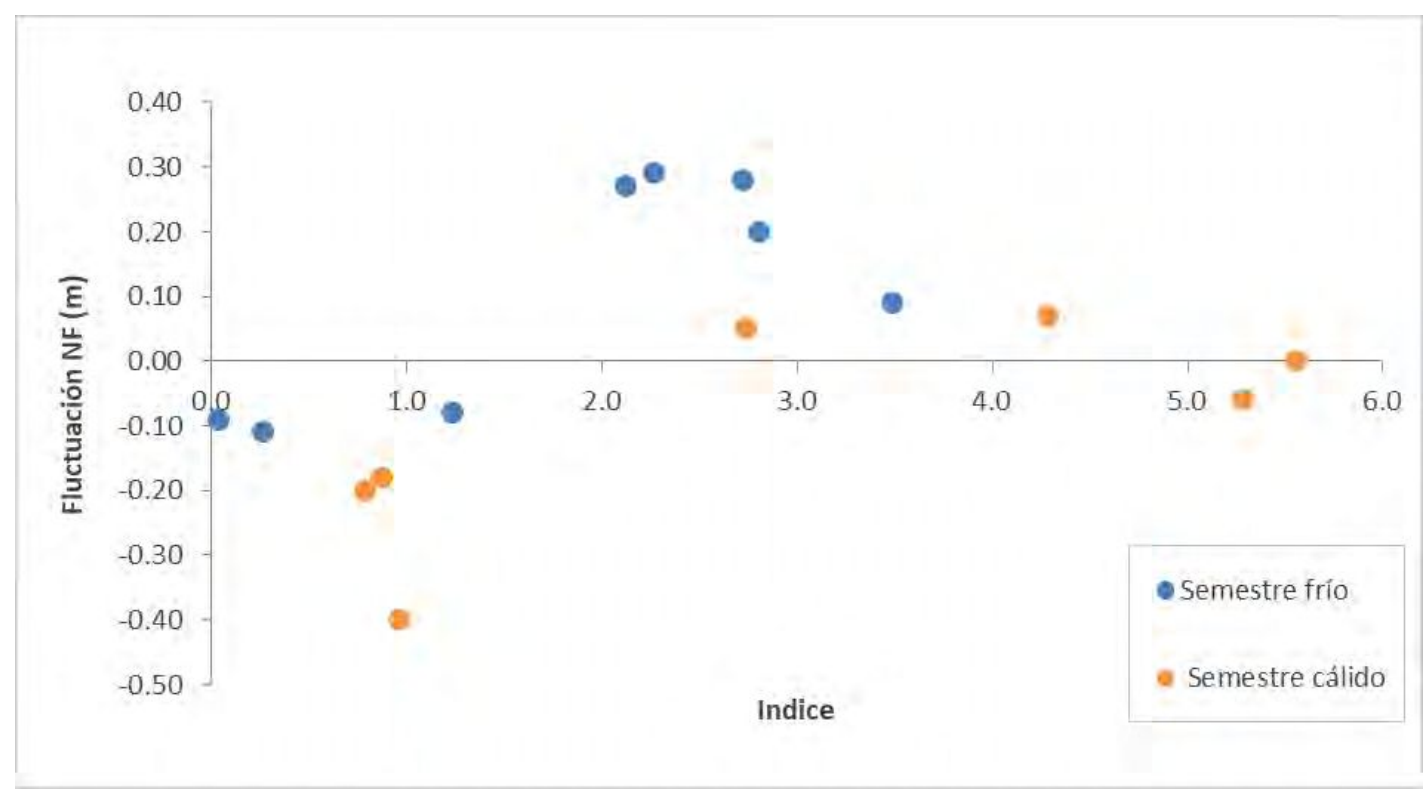

Figura 8.9 Relación variaciones de nivel freático e índice.

En términos generales si las precipitaciones acumuladas entre las fechas de relevamientos son inferiores a $70 \mathrm{~mm}$ (Figura 8.10), no se registra una elevación en los niveles freáticos. Es decir, que no se manifiesta una respuesta detectable entre un relevamiento y el siguiente si el total de las precipitaciones están por debajo de dicho valor.

Se observa un comportamiento diferencial según la época del año. Para el semestre frío se registran ascensos del orden de los 0,30 m con precipitaciones de $70 \mathrm{~mm}$. Esta situación es diferente para el semestre cálido, donde con $82 \mathrm{~mm}$ de lluvias caídas entre mediciones sólo se registran $0,05 \mathrm{~m}$ de ascenso medio de la capa freática. El caso se repite para precipitaciones cercanas a los $150 \mathrm{~mm}$ donde para el periodo cálido se producen descensos de los niveles y en el frío los mayores ascensos. Es llamativo el hecho de que tanto con lluvias de 70 y $150 \mathrm{~mm}$ en el semestre frío los niveles se incrementen en promedio el mismo valor, no más de $0,30 \mathrm{~m}$. 


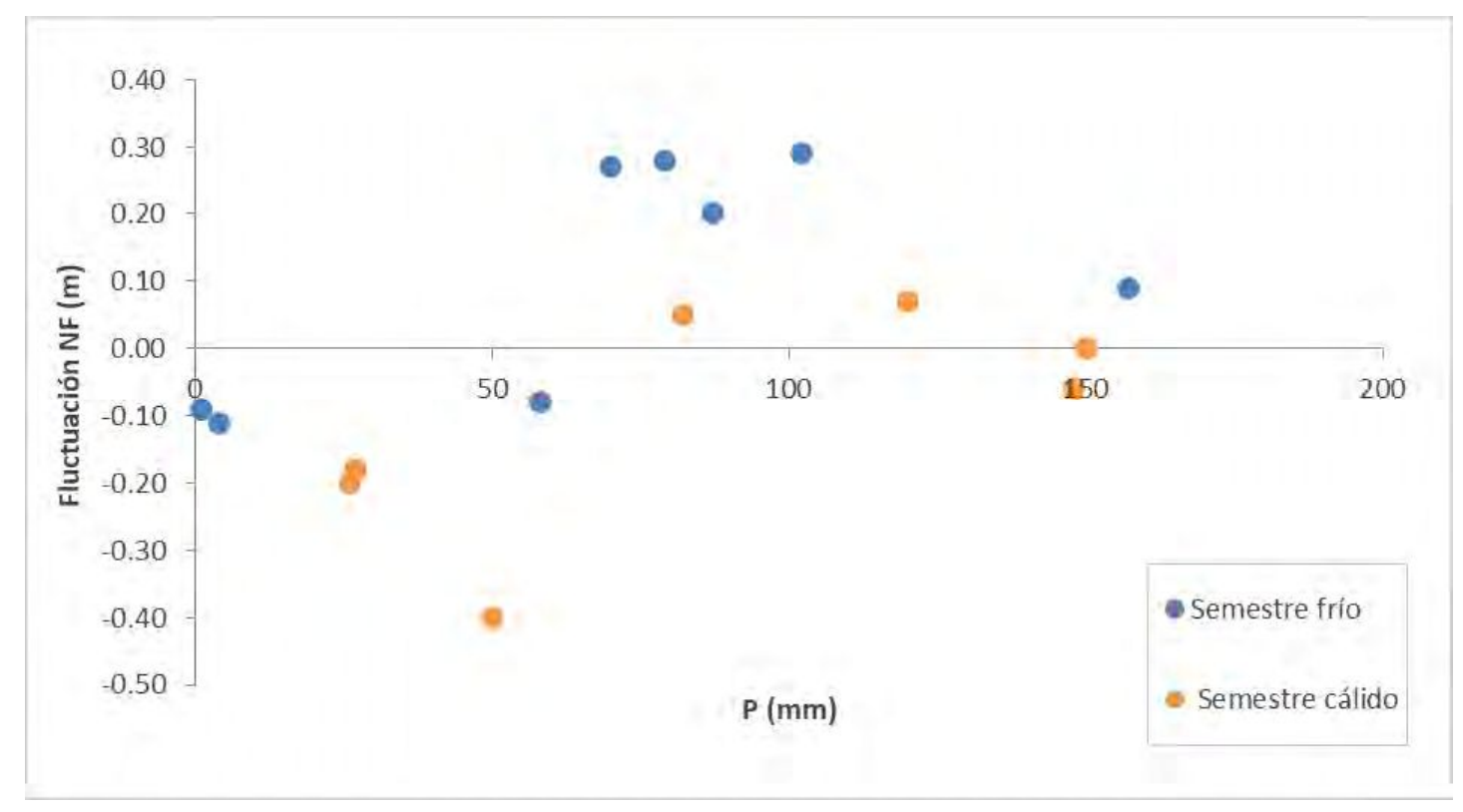

Figura 8.10 Relación variaciones de nivel freático y precipitaciones.

Este índice fue desarrollado por Carretero (2011), luego perfeccionado en Carretero y Kruse (2012) y aplicado en el acuífero costero en la localidad de San Clemente del Tuyú. Cabe destacar que se observan algunas diferencias entre ambos sectores. Para San Clemente valores menores a 2 significaron una profundización de los niveles, mientras que los mayores a 5 mostraron un ascenso superior a 0,35 m. En Mar del Tuyú los índices que reflejan descensos son menores a 1,5.

En cuanto a la relación de los niveles con las precipitaciones, en San Clemente, lluvias superiores a $60 \mathrm{~mm}$ se manifiestan en variaciones positivas (ascenso de los niveles) mientras que las menores producen variaciones negativas (descenso) en el periodo entre mediciones. Para Mar del Tuyú este valor es de $70 \mathrm{~mm}$. Otra diferencia es que no se han registrado ascensos medios de nivel mayores a 0,30 m mientras que en San Clemente hay registros de hasta $0,60 \mathrm{~m}$ con precipitaciones dentro del mismo orden de magnitud.

\subsection{Condiciones hidrodinámicas en la costa estuárica (Berisso)}

\subsubsection{Generalidades}

Los mapas de flujo subterráneo del período 2016 - 2017 (Anexo 6) muestran como generalidad que las curvas equipotenciales son paralelas a la costa, e indican un movimiento del agua en dirección SO - NE, desde la planicie de marea relictual, pasando por la llanura estuárica y descargando hacia el Río de la Plata. En un análisis algo más detallado se puede observar que en el sector donde la presencia del 
cordón litoral de conchillas es manifiesta, se detectan curvas cerradas, que representan un alto en la capa freática debido al agua dulce contenida en estos cordones.

Como representativos para visualizar dichas características se han seleccionado dos situaciones extremas. Una es la correspondiente a la posición de la capa freática más elevada (julio-2016) y otra la más profunda (febrero-2017) (Figura 8.11 y 8.12).

Para julio-2016, en el sector norte, las curvas oscilan entre los $2 \mathrm{~m} \mathrm{~s}$. n. m. y 0,5 m s. n. m., observándose un alto en la curva cerrada de $1 \mathrm{~m} \mathrm{~s} . \mathrm{n}$. m. que modifica localmente la dirección del flujo. Hacia el sur las alturas registradas van desde 2,50 a $0,5 \mathrm{~m} \mathrm{~s}$. n. m. desde el continente hacia la costa. El gradiente hidráulico medio calculado es de 0,0009, lo cual representa una velocidad efectiva de 0,010 m/d. La descarga al Río de la Plata es de $2160 \mathrm{~m}^{3} / \mathrm{d}$.

En febrero-2017 la curva de $2 \mathrm{~m} \mathrm{~s}$. n. m. se transforma en $1 \mathrm{~m} \mathrm{~s}$. n. m. indicando un descenso de la capa freática hacia el sector de la planicie de marea relictual. El pequeño domo que formaba la curva de $1 \mathrm{~m} \mathrm{~s}$. n. m. en julio-2016 se ve desdibujado ya que, en febrero-2017, ese sector se ve representado por una curva abierta de 0,5 m s. n. m. que continúa hacia la costa del río. El descenso de los niveles también se ve evidenciado por la aparición de curvas de $0 \mathrm{~m} \mathrm{~s}$. n. m. lo cual cambia el sentido de flujo desde el alto del cordón conchil hacia un sector de la llanura estuárica. Para esta instancia el gradiente hidráulico se calcula en 0,0006 y la velocidad efectiva en 0, 09 $\mathrm{m} / \mathrm{d}$ con una descarga al Río de la Plata de $1440 \mathrm{~m}^{3} / \mathrm{d}$. 


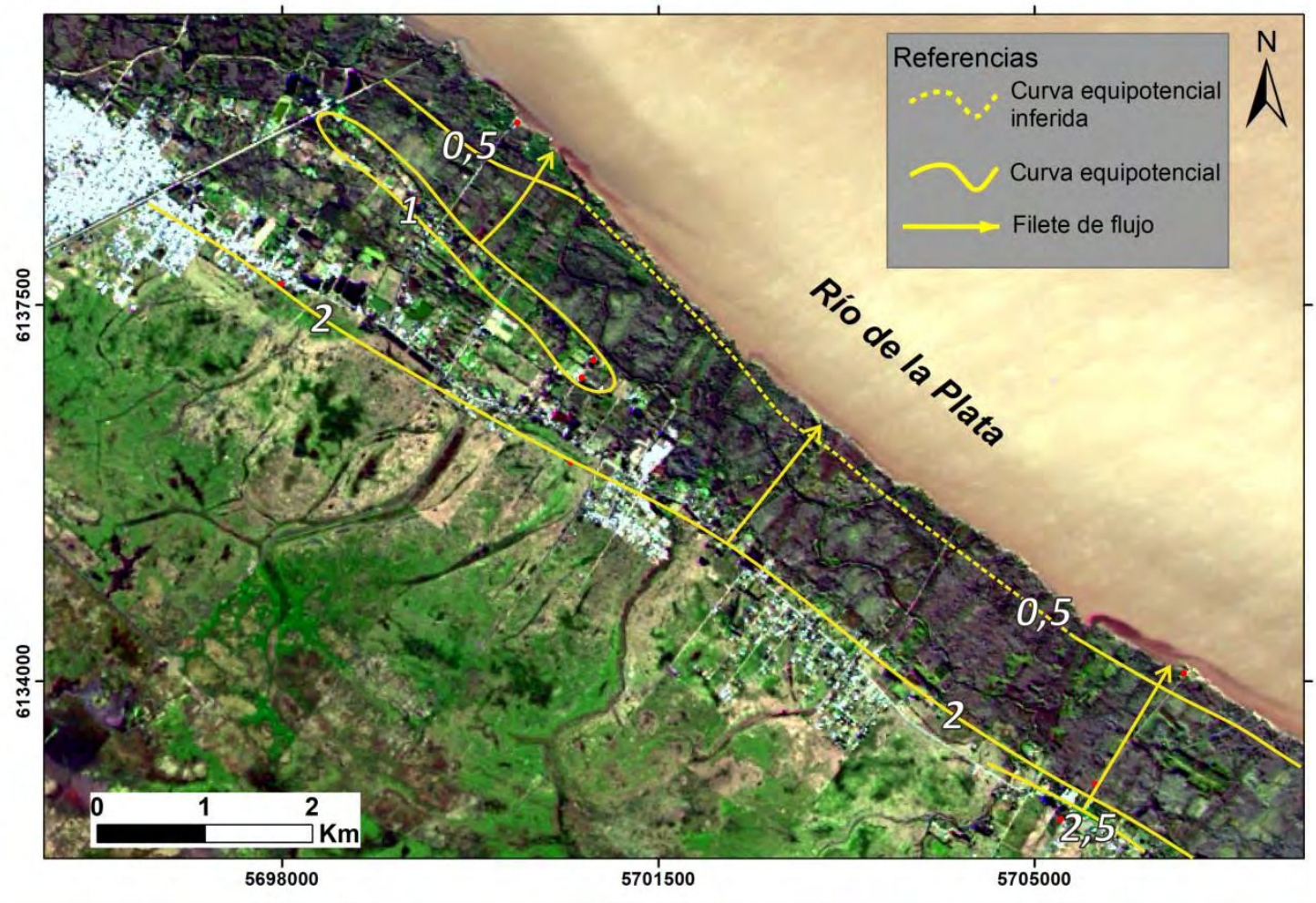

Figura 8.11 Mapa de flujo para julio 2016.

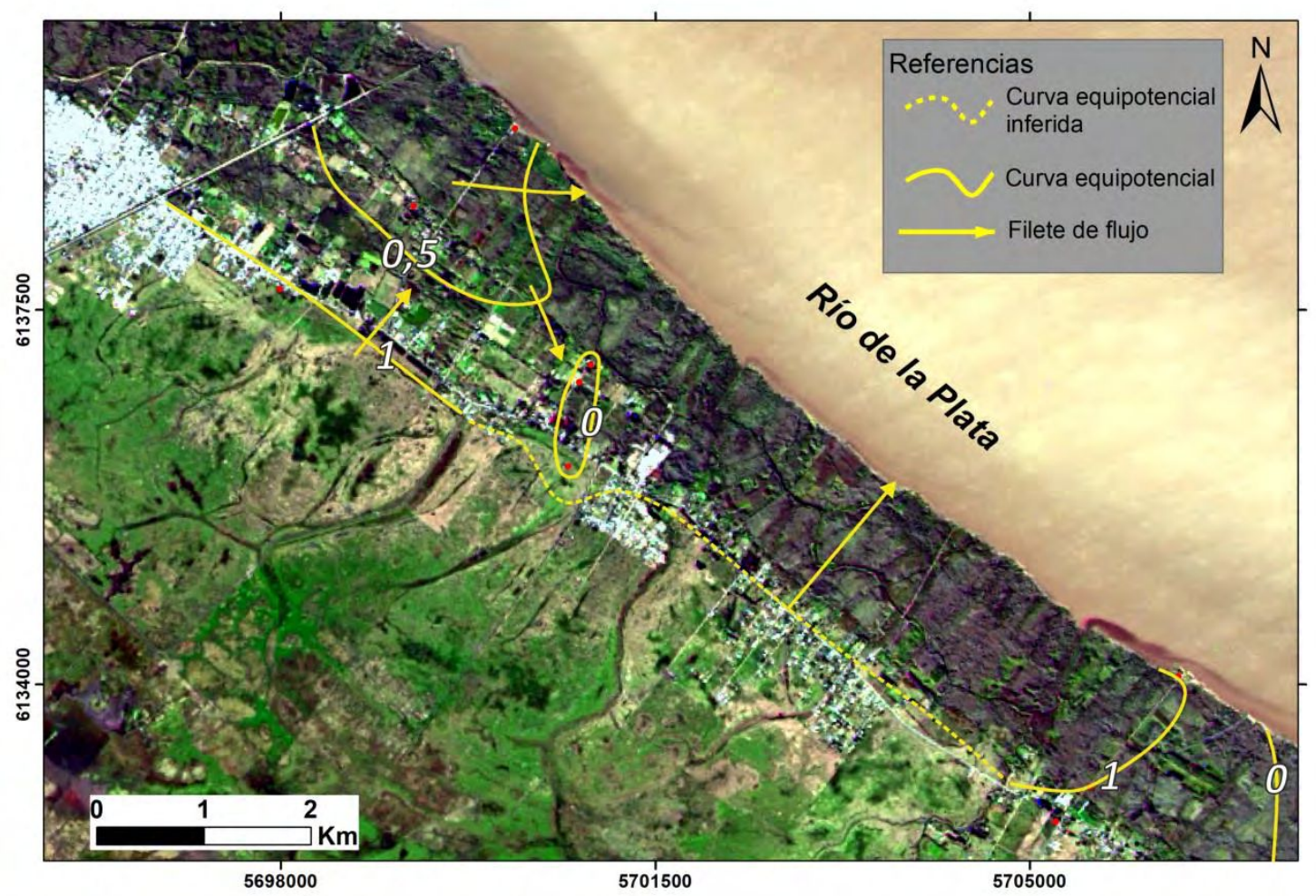

Figura 8.12 Mapa de flujo para febrero 2017.

En el análisis de detalle de variación de niveles freáticos, en el área de estudio se consideraron las unidades geomorfológicas de planicie de marea relictual (P3, P6 y 
P9), llanura estuárica (P1, P4, P5, P7, P8, P10 y P11) y cordón litoral (P2) (Figura 8.13).

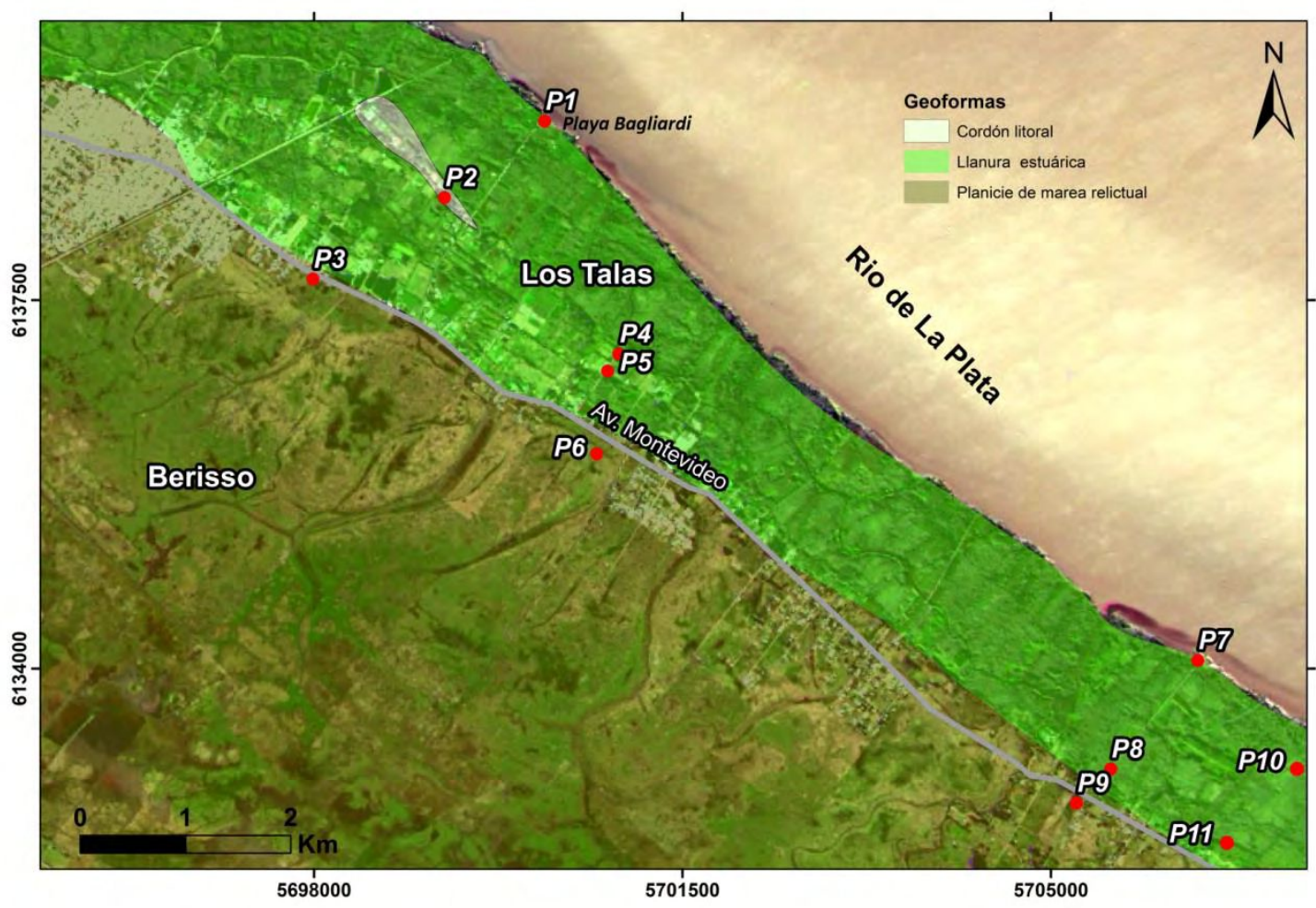

Figura 8.13 Red de monitoreo en los ambientes geomorfológicos de la costa de Berisso.

Se evaluó el comportamiento de los niveles freáticos a lo largo del tiempo y su relación con los excesos mensuales de los balances hídricos considerando, además, la ubicación de acuerdo a los ambientes.

Los niveles freáticos para el cordón litoral oscilan entre 0,83 y 1,32 m s. n. m. con un valor medio de 1,09 m s. $\mathrm{n}$. m. En la planicie de marea relictual los niveles máximos promedian los 2,34 m s. n. m. y los mínimos $1,33 \mathrm{~m} \mathrm{~s}$. n. m. Para la llanura estuárica la capa freática oscila entre los 0,54 y $1,16 \mathrm{~m} \mathrm{~s}$. n. m. con una media de 0,87 m s. n. m. (Tabla 22). 
Tabla 22 Valores máximos, mínimos y media para los freatímetros según el ambiente geomorfológico.

\begin{tabular}{|c|c|c|c|c|c|c|c|c|c|c|c|c|c|}
\hline \multicolumn{14}{|c|}{ Niveles freáticos (m s. n. m.) } \\
\hline & $\begin{array}{c}\text { Cordón } \\
\text { litoral }\end{array}$ & \multicolumn{4}{|c|}{$\begin{array}{c}\text { Planicie de marea } \\
\text { relictual }\end{array}$} & \multicolumn{8}{|c|}{ Llanura estuárica } \\
\hline Pozo & P2 & $\mathbf{P 3}$ & P6 & P9 & Media & P1 & P4 & P5 & P7 & $\begin{array}{l}\mathbf{P 8} \\
\end{array}$ & P10 & P11 & Media \\
\hline Máximo & 1,32 & 2,10 & 2,34 & 2,58 & 2,34 & 1,23 & 1,14 & 1,42 & 1,37 & 1,17 & 0,64 & 1,14 & 1,16 \\
\hline Mínimo & 0,83 & 1,20 & 1,54 & 1,26 & 1,33 & $-0,02$ & 0,78 & 0,75 & 0,78 & 0,90 & 0,21 & 0,38 & 0,54 \\
\hline Media & 1,09 & 1,72 & 1,95 & 1,96 & 1,88 & 0,75 & 1,00 & 1,00 & 1,10 & 1,04 & 0,51 & 0,69 & 0,87 \\
\hline
\end{tabular}

Se ha seleccionado un pozo por ambiente para evaluar las fluctuaciones de los niveles en donde los excesos se han transformado en recarga al acuífero. En el cordón litoral se observa claramente la relación entre los excesos y los niveles (Figura 8.14). En periodos con valores de excesos nulos los niveles descienden. Entre julio y octubre2016 los excesos son de 155 y $72 \mathrm{~mm}$ y los niveles descienden, durante este periodo se producen excesos de $20 \mathrm{~mm}$ en agosto y septiembre pero no son suficientes para producir recarga al acuífero en este ambiente. Desde mayo a septiembre-2017 la suma de excesos igual a $334 \mathrm{~mm}$ se traduce en un ascenso de los niveles de $0.50 \mathrm{~m}$.

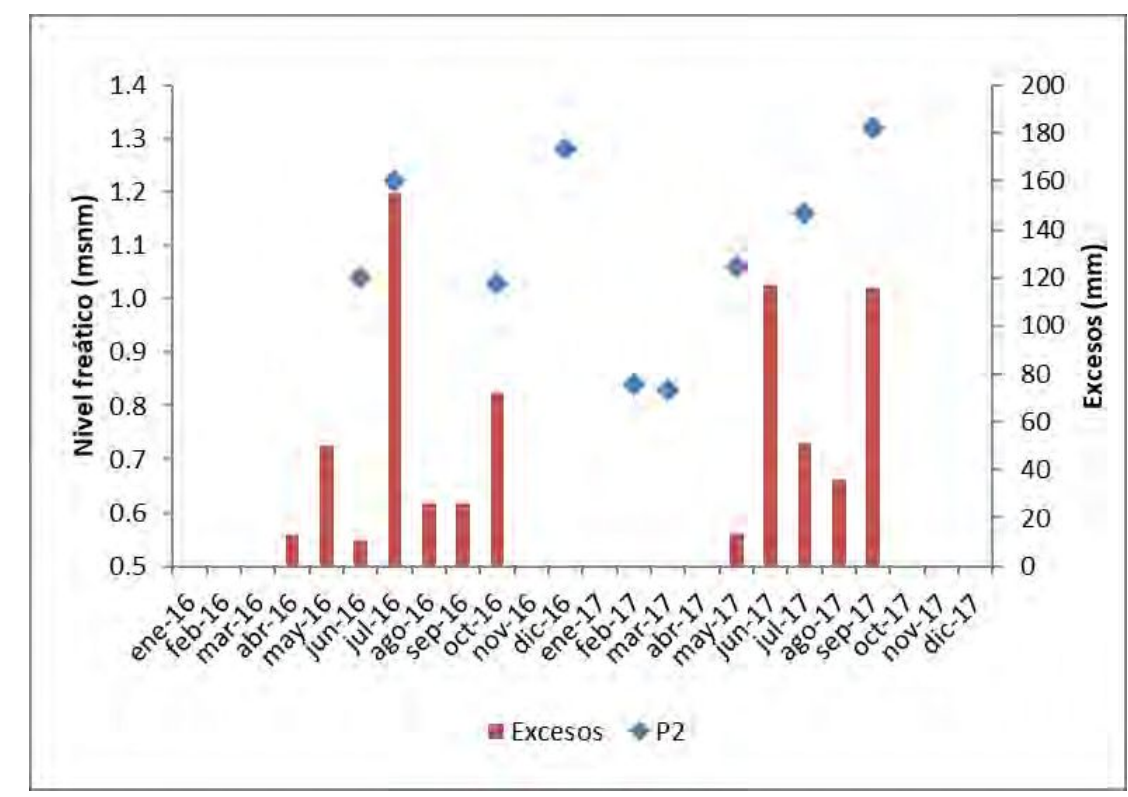

Figura 8.14 Variaciones del nivel freático para el Pozo 2 del cordón litoral. 
En la planicie de marea relictual (Figura 8.15) también se observa un descenso marcado de los niveles ante la falta de excesos del balance y con excesos de menor magnitud. La altura de la capa freática cae de 1,84 m s. n. m. a 1,20 m s. n. m. entre diciembre-2016 y febrero-2017 y se recupera en junio donde los excesos son de gran magnitud. A diferencia del cordón litoral entre julio y septiembre-2017 se produce un descenso de los niveles, podría deberse a la diferencia en la litología en este ambiente al ser más arcilloso la respuesta no es tan rápida como en la conchilla.

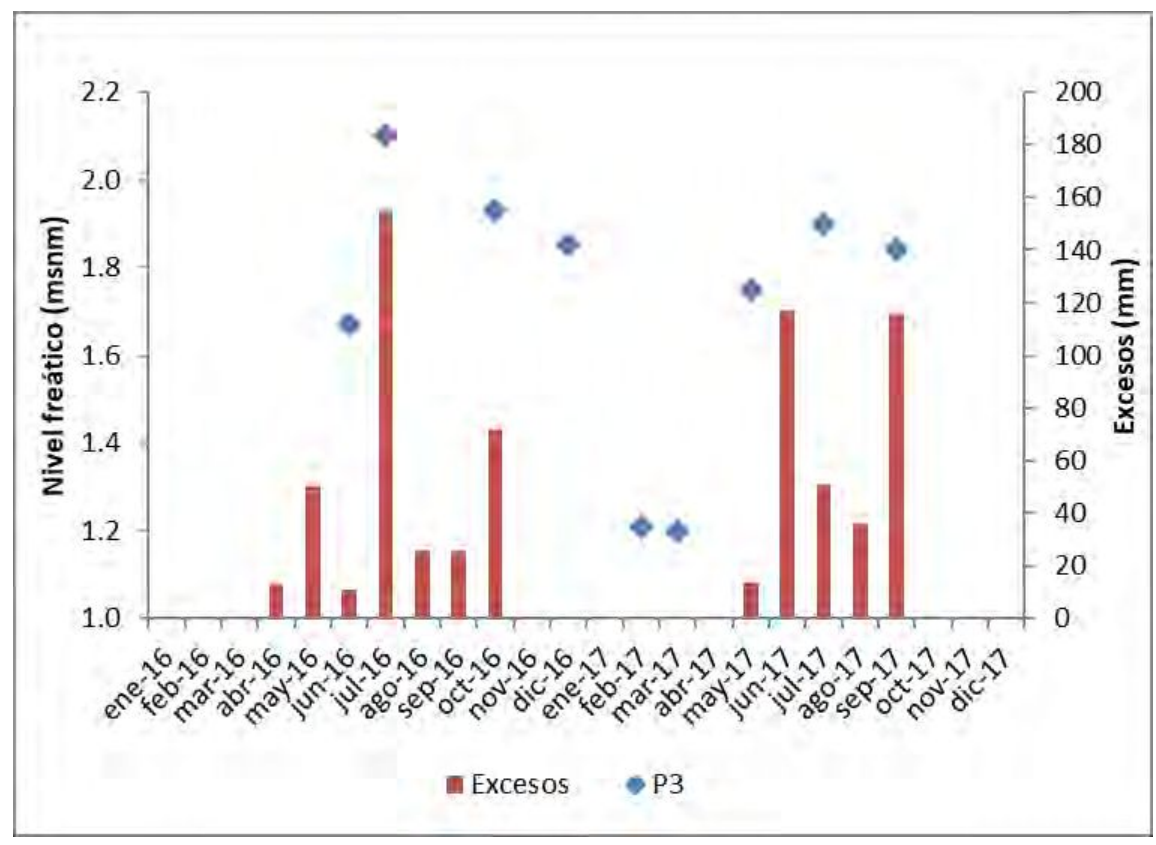

Figura 8.15 Variaciones del nivel freático para los pozos de la planicie de marea relictual.

Analizando la Figura 8.16 correspondiente a la llanura estuárica la relación entre las fluctuaciones de los niveles y los excesos no es tan clara como en los otros ambientes. A pesar de obtenerse excesos de $155 \mathrm{~mm}$ en julio-2016 los niveles permanecen sin variaciones entre junio y julio-2016. Los meses con excesos nulos no parecen afectar los niveles ya que se observan descensos y ascensos de los mismos durante esos periodos. Desde octubre-2016 a septiembre-2017 los niveles fluctúan entre un mínimo de 0,79 y un máximo de $1,23 \mathrm{~m}$ s. $\mathrm{n}$. $\mathrm{m}$. sin una respuesta clara en función de los excesos. La localización de este pozo y el comportamiento observado hacen pensar que existiría una influencia de las mareas del Río de la Plata que enmascara la relación niveles-recarga.

La variación máxima entre los niveles registrados en el período analizado es de 0,49, 1,01 y 0,62 m para el cordón litoral, la planicie de marea relictual y la llanura estuárica respectivamente. 


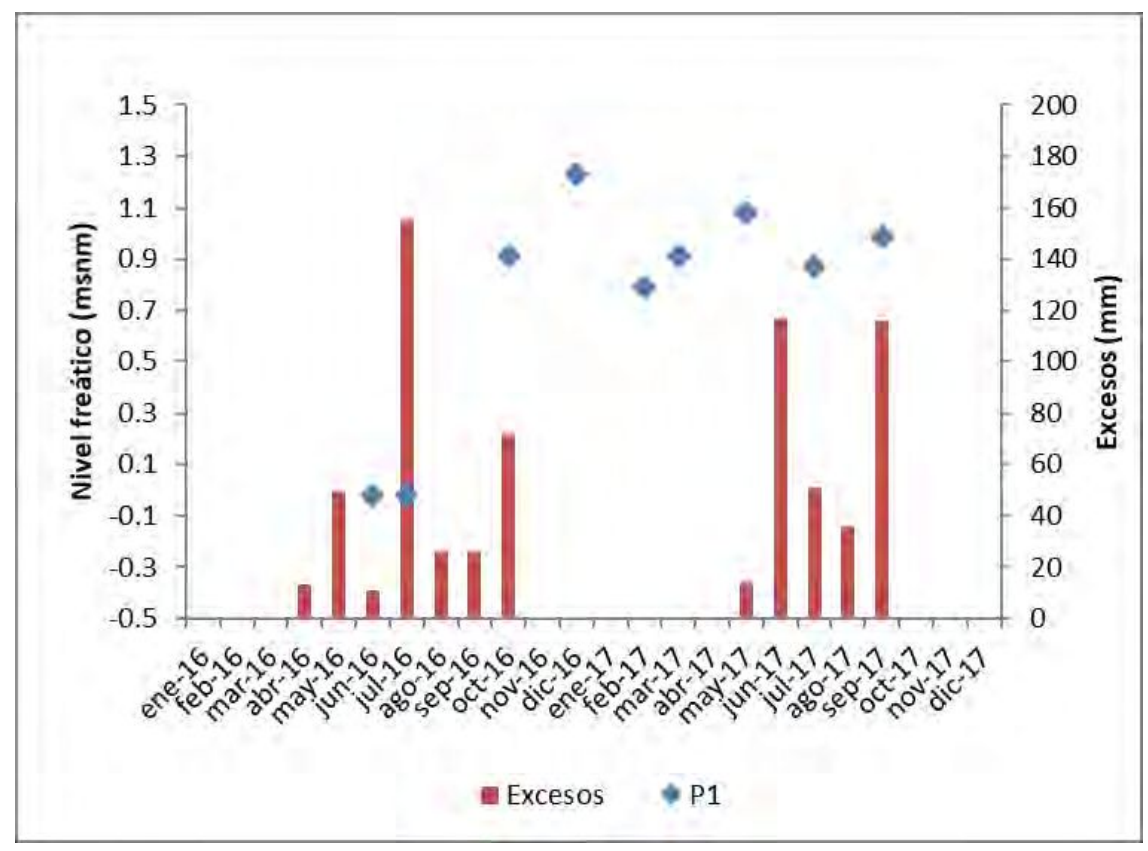

Figura 8.16 Variaciones del nivel freático para los pozos de la llanura estuárica.

\subsubsection{Efecto de las mareas del Río de la Plata sobre el agua subterránea en la costa estuárica}

El ambiente de llanura estuárica en particular adquiere relevancia ya que alberga un humedal estuarino. Éstos son reconocidos como importantes rasgos del paisaje en el contexto del manejo costero y estrategias de protección costera (Shepard et al., 2011). Además de su alto valor ecológico son considerados como un elemento crucial del enfoque denominado "building with nature" (construyendo con la naturaleza) el cual busca estrategias alternativas de protección y adaptación frente a las inundaciones en zonas costeras sin utilizar las estructuras de defensa clásicas. Los humedales estuarinos son reconocidos por ser eficientes en disipar olas de tormenta y disminuir el riesgo de inundaciones en ciudades costeras del sector interior de grandes estuarios (Temmerman et al., 2013). Su desarrollo morfológico depende de la disponibilidad de sedimentos en suspensión, de las olas, del régimen hidrológico local y, a largo plazo, del incremento del nivel del mar debido al cambio climático (Callaghan et al., 2010; Schuerch et al., 2016).

Los humedales han sido estudiados más recientemente por su importancia ecológica y biodiversidad donde el agua subterránea tiene un rol fundamental. En forma particular el humedal en estudio se emplaza en un sector costero, expuesto a inundaciones periódicas, tanto por mareas como por tormentas. Posee un especial interés agroecológico dado que se desarrolla una agricultura sostenible que aprovecha los nutrientes aportados por los sedimentos que acarrea el río por efecto de las mareas y 
que se acumulan en canales artificiales (Abbona et al., 2007). Las inundaciones periódicas están relacionadas con la intensidad y persistencia del viento del sector este-sudeste sobre el estuario (sudestada). El estuario del Río de la Plata posee un régimen micromareal de pocas decenas de centímetros de amplitud con desigualdades diurnas y grandes diferencias entre pleamares o bajamares consecutivas (Kruse et al., 2014).

Existen canteras de conchillas abandonadas, que hoy se encuentran ocupadas por afloramiento del agua subterránea. También se distinguen sectores con sistemas hortícolas, plantaciones de caña y especies forestales. En el ámbito adyacente al Río de la Plata se ubican parcelas dedicadas a cultivos de vid (Vitis labrusca L.) para la producción local del "vino de la costa" donde se destacan canales artificiales de distinta jerarquía que funcionan como canales de mareas y posibilitan la salida más rápida del agua luego de las pleamares.

El sistema costero de Berisso muestra una alta sensibilidad a las modificaciones climáticas y antrópicas que debe ser estudiado en detalle para prevenir su deterioro ambiental y posibilitar la planificación territorial.

En esta sección se analiza el comportamiento del agua freática en el humedal con relación a las variaciones de altura del Río de la Plata en una transecta perpendicular a la costa.

Se analizó el comportamiento del agua freática en relación a las variaciones de altura del río para lo cual se instalaron sensores de nivel con frecuencia de medición horaria durante el período diciembre-2015 a marzo-2016. En el pozo ubicado más próximo al río (P1), se instaló, a su vez, un sensor con registro de temperatura y conductividad eléctrica (CE) del agua subterránea.

Para completar este análisis se incluyeron datos de las variaciones del nivel del río provistas por el Servicio de Hidrografía Naval y de las precipitaciones de la estación meteorológica La Plata - Observatorio (UNLP).

Se presentan los resultados de tres perforaciones ubicadas en distintas geoformas de la planicie costera (Figura 8.13). El pozo P1 está a escasos metros de la línea de costa en la llanura estuárica; el pozo P2 se localiza a aproximadamente $1200 \mathrm{~m}$ de la costa en un cordón litoral y la perforación P3 dista $3800 \mathrm{~m}$ y se encuentra dentro de la llanura de marea relictual. En todos los casos se midieron variaciones del nivel freático que fueron contrastadas con el registro de mareas del Río de la Plata. Para el período analizado, el río tuvo oscilaciones entre un nivel mínimo de $-0,09 \mathrm{~m}$ y un máximo de 
2,78 m. Desde comienzo del registro, mediados de diciembre-2015, hasta los primeros días de enero-2016, se presentan las fluctuaciones de menor amplitud de mareas, mientras que en el mes de enero se registra la mayor frecuencia de picos de máximas mareas.

\section{Llanura estuárica}

El pozo P1 se ubica sobre la playa Bagliardi siendo la cota del sitio 1,78 $\mathrm{m} \mathrm{s}$. n. m. En la Figura 8.17, se puede observar que los niveles freáticos se ajustan a los ascensos y descensos del nivel del Río de la Plata. Se pueden reconocer e identificar tres situaciones del comportamiento del nivel freático con respecto a las mareas.

Un primer período (18/12/2015-4/01/2016), con mareas relativamente uniformes en cuanto a su amplitud, con oscilaciones variables entre 0,14 y 1,93 m s. n. m., donde el nivel freático responde con suaves fluctuaciones que varían entre $0,38 \mathrm{~m} \mathrm{~s} . \mathrm{n}$. m. y 0,74 m s. n. m.

Un segundo período que se extiende a lo largo de todo el mes de enero, donde se registra una alta frecuencia de picos de pleamar con valores que superan o están próximos a los $2,5 \mathrm{~m} \mathrm{~s}$. n. $\mathrm{m}$. Se reconocen a la vez, las máximas diferencias de mareas, siendo el valor más elevado de 1,13 m. En esta situación, el nivel freático responde con ascensos rápidos y descensos graduales que, como se puede observar en el gráfico, quedan indicados por una marcada asimetría. La diferencia máxima del nivel freático es de $1,06 \mathrm{~m}$.

En el tercer período que abarca los meses de febrero y marzo se observa una situación de mareas con amplitudes intermedias con respecto a los anteriores, habiendo dos ascensos del nivel freático que responden a eventos de lluvias de los días 13 y 17 de febrero. En marzo se observa un ascenso del nivel freático que responde a una sucesión de mareas altas (superior a los $2,5 \mathrm{~m} \mathrm{~s} . \mathrm{n} . \mathrm{m}$.).

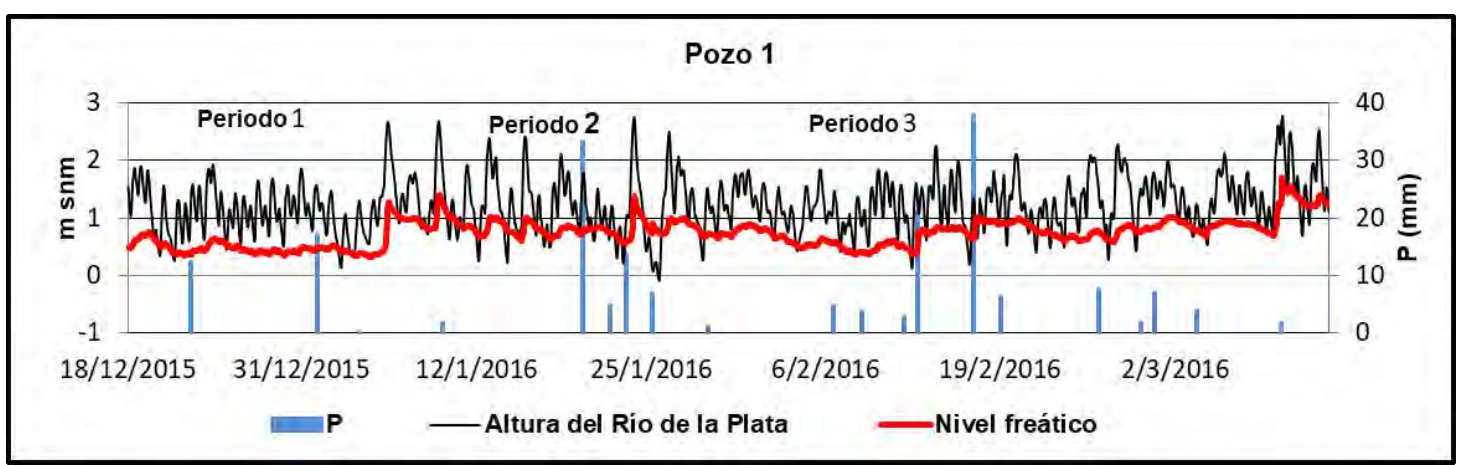

Figura 8.17 Nivel freático vs. mareas y precipitaciones. 
En la Figura 8.18, la temperatura del agua subterránea presenta cambios vinculados a las mareas cuando estas superan los $2,50 \mathrm{~m} \mathrm{~s}$. n. m.. Asimismo, quedan registrados dos aumentos de temperatura (máximos del registro) que están relacionados con los 2 eventos de lluvias arriba indicados. A comienzo del verano, la temperatura registrada es de $16^{\circ} \mathrm{C}$ y se incrementa $2^{\circ} \mathrm{C}$ hasta principios de enero. En este mes, en forma concordante con un pico de marea, la temperatura se incrementa el mismo valor, $2^{\circ} \mathrm{C}$, para alcanzar los $20^{\circ} \mathrm{C}$. La temperatura permanece próxima a este valor durante el verano, con picos de ascenso en respuesta a las mareas altas. Si bien hay un pico de marea alta a fines del registro, la temperatura del agua subterránea no se modifica, ya que hay una tendencia al descenso debido al cambio estacional. Estos cambios se producen por las mezclas de aguas superficial y subterránea debido al flujo mareal.

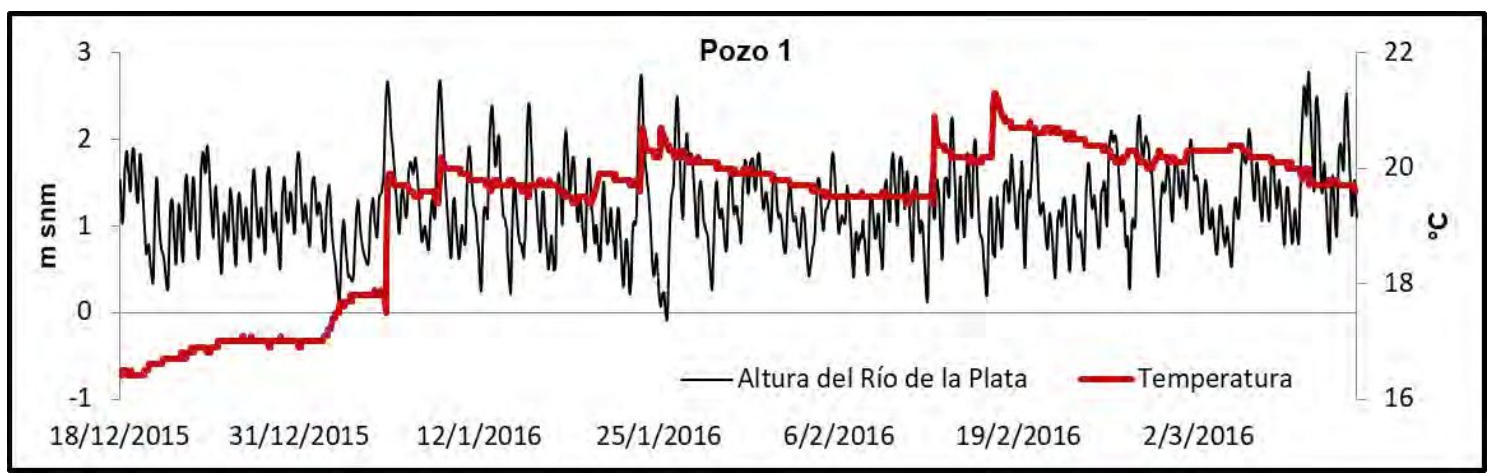

Figura 8.18 Variación de temperatura del agua subterránea vs. mareas.

Con respecto a la CE (Figura 8.19), el agua subterránea tiene un valor medio de 1700 $\mu \mathrm{S} / \mathrm{cm}$. Se observa que la misma disminuye frente a las mareas altas superiores a 2,50 m, llegando a valores de $1000 \mu \mathrm{S} / \mathrm{cm}$. Para este período la CE media del Río de la Plata, en este sector fue de $600 \mu \mathrm{S} / \mathrm{cm}$. En general, cuando los niveles freáticos están más altos, ante picos importantes de marea alta, la CE responde disminuyendo sus valores. Por ejemplo, el 23 de enero, con un nivel freático de 1,36 m s. n. m. y una altura del río de $2,73 \mathrm{~m} \mathrm{~s}$. n. m., la CE disminuyó a $1045 \mu \mathrm{S} / \mathrm{cm}$. Existen dos valores de CE mínimos de 770 y $820 \mu \mathrm{S} / \mathrm{cm}$ vinculados a lluvias ocurridos los días 13 y 17 de febrero, con 21 y $38 \mathrm{~mm}$. 


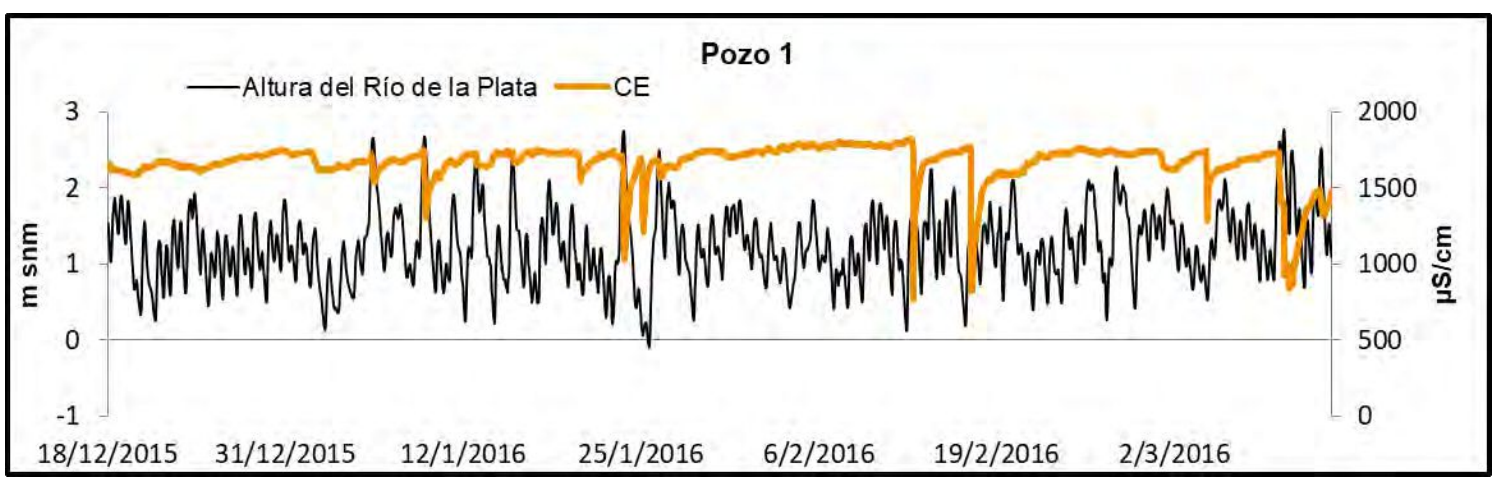

Figura 8.19 Variación de la conductividad eléctrica del agua subterránea vs. mareas.

\section{Cordón litoral}

El pozo P2 se encuentra en un cordón litoral cuya composición está integrada fundamentalmente por conchillas, la cota donde se ubica la perforación es de 2,97 m s. n. m.. Durante el período analizado, el nivel freático presenta una diferencia máxima de 0,33 m correspondiente a los niveles mínimos y máximos de 0,63 m y 0,96 m (Figura 8.20). Si bien estas fluctuaciones son bajas, se puede observar que responden a las mareas. Se destaca que la influencia mareal es menos marcada con respecto al pozo 1, dado que la distancia a la costa atenúa su efecto. Las fluctuaciones del nivel freático frente a las precipitaciones quedan enmascaradas por las oscilaciones de las mareas.

La temperatura del agua subterránea (Figura 8.21) presenta cambios graduales vinculados a la estacionalidad incrementándose de $18,6{ }^{\circ} \mathrm{C}$ hasta llegar a $21^{\circ} \mathrm{C}$.

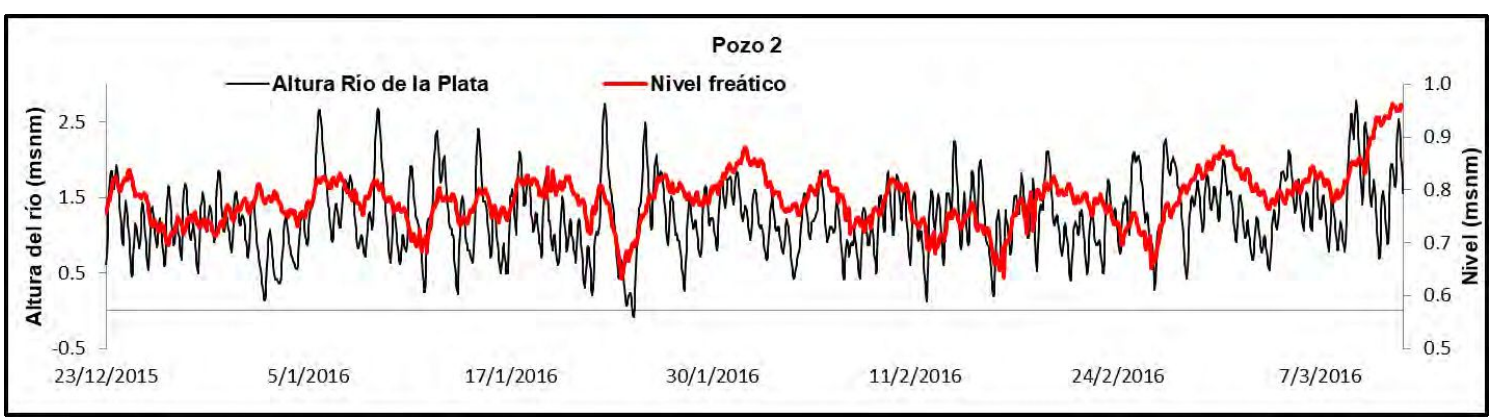

Figura 8.20 Variación de niveles freáticos vs. mareas. 


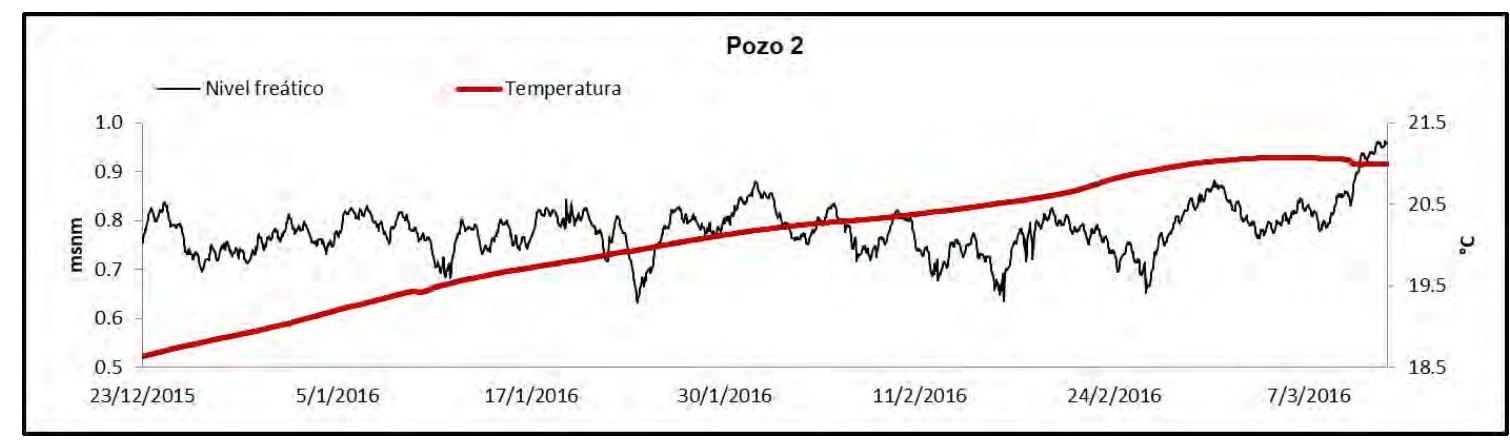

Figura 8.21 Variacion de la temperatura en el cordon litoral.

\section{Planicie de marea relictual}

El pozo P3 se encuentra en la llanura de marea relictual, con una cota de 2,47 m s. $\mathrm{n}$. m. En la Figura 8.22 se puede observar que el nivel freático tiene un descenso de $0,77 \mathrm{~m}$ desde el comienzo del registro hasta el 24 de enero. Luego el nivel permanece relativamente estable hasta el 26 de febrero, a partir del cual comienza a elevarse. Así los niveles freáticos descienden fundamentalmente en respuesta a la evaporación y en forma secundaria a las oscilaciones de las mareas. A comienzos del verano el nivel freático tiene las mayores alturas con un máximo de 1,22 m s. n. m., en enero se observa un descenso, registrándose una altura mínima de 0,36 m s. n. m.. Durante febrero se mantienen prácticamente constantes, con un valor medio de 0,5 m s. n. m. y hacia el final del registro se evidencia un leve ascenso llegando a 0,71 m s. n. m..

La temperatura del agua subterránea en este sector presenta también un incremento gradual que va desde los 18,3 a $20,7{ }^{\circ} \mathrm{C}$ producto de la estacionalidad. El 17 de febrero se destaca un ascenso brusco en la temperatura del agua subterránea de 20 a $24^{\circ} \mathrm{C}$ (Figura 8.23), que podría deberse a que durante el día se produce una precipitación y la temperatura del ambiente fue de $37,8^{\circ} \mathrm{C}$.

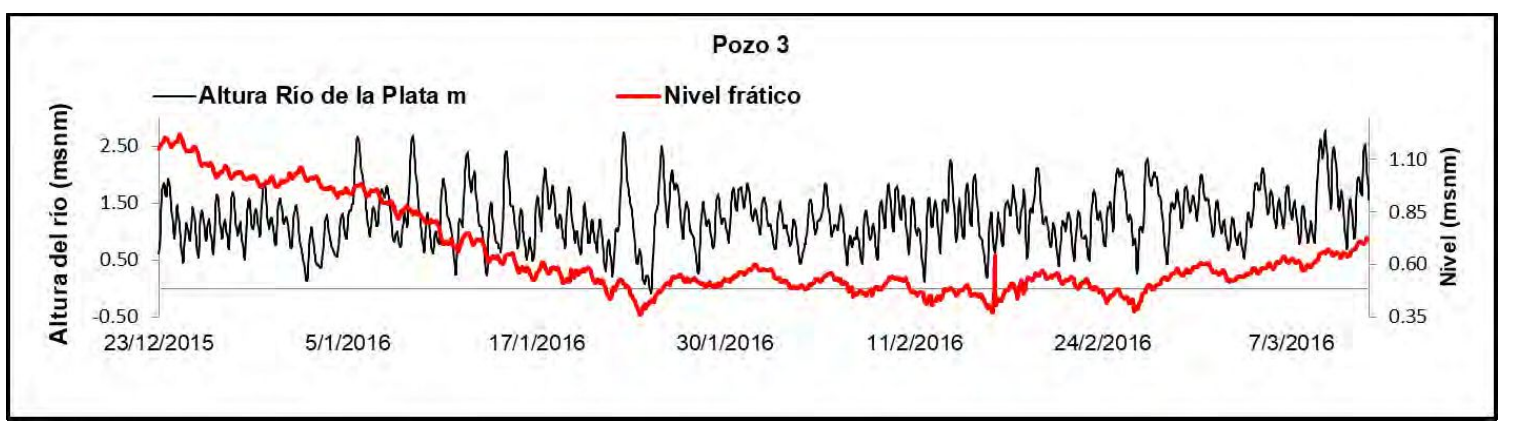

Figura 8.22 Pozo 3.Variacion de niveles freaticos vs. mareas. 


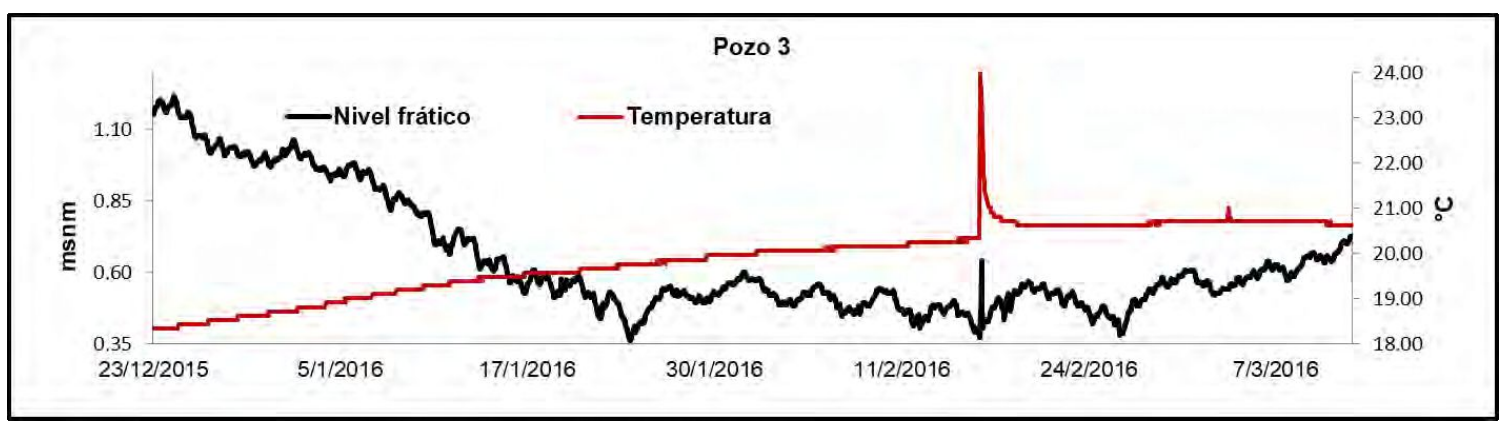

Figura 8.23 Variacion de la temperatura en la llanura de marea relictual.

Se ha reconocido la influencia de la intensidad de los ciclos de marea en las respuestas de los niveles, salinidad y temperatura del agua subterránea que alimenta el humedal estuarino.

El humedal costero desarrollado en el ambiente de la llanura estuárica presenta un nivel freático con dos tipos de respuestas frente a la acción de las mareas dependiendo si superan o no la cota del terreno. Por un lado, se observa una respuesta simétrica en el ascenso y descenso de los niveles cuando las mareas no superan la cota del pozo, dado por el cambio del nivel de descarga en el río. Esta variación rápida genera cambios de baja incidencia en la temperatura y CE. Cuando el río supera la cota del terreno, los niveles freáticos responden con picos asimétricos, debido a un rápido ingreso del agua del río al sistema subterráneo dado principalmente por infiltración. El descenso es gradual por flujo lateral, donde las condiciones de mezcla permanecen por lapsos de días a lo largo de los cuales los niveles van disminuyendo. La temperatura y la CE muestran cambios que evidencian este comportamiento como así también por el ingreso de agua por precipitaciones. Este patrón de inundación por mareas establece una dinámica superficial y subterránea que crea condiciones de mezclas de aguas, que determinarían, junto al aporte de sedimentos del agua superficial, un balance positivo de nutrientes. Este ambiente presenta la mayor sostenibilidad ecológica para el cultivo de vid.

En el cordón litoral, el nivel freático está a mayor profundidad comparado con los otros ambientes y es donde se registran sus menores variaciones. El efecto de las mareas queda registrado en forma atenuada. Debido a la distancia a la costa el ascenso de los niveles se produce en forma más lenta.

En la llanura de marea relictual, distante casi $4 \mathrm{~km}$ de la costa, los niveles se encuentran, en promedio, a menos de $2 \mathrm{~m}$ de profundidad. Sus fluctuaciones están controladas esencialmente por la precipitación - evaporación y en forma subordinada por el efecto muy amortiguado de las mareas. 
El conocimiento del comportamiento hidrogeológico del humedal con respecto a las características, frecuencia y duración de las mareas constituye un estudio esencial para el funcionamiento de estos ecosistemas estuarinos y para su conservación.

\subsection{Condiciones hidroquímicas en la costa marítima (Mar del Tuyú)}

\subsubsection{Características generales}

Se separaron las muestras de acuerdo con su localización con el objeto de identificar las características de las zonas de recarga principal y descarga. En la Tabla 23 se exponen los valores medios, máximos y mínimos calculados para cada sector.

Tabla 23 Valores medios, máximos y mínimos para los sectores recarga y descarga.

\begin{tabular}{|c|c|c|c|c|c|c|c|c|c|}
\hline \multirow{2}{*}{ Sep-16 } & \multicolumn{3}{|c|}{ Descarga oeste } & \multicolumn{3}{|c|}{ Recarga central } & \multicolumn{3}{|c|}{ Descarga este } \\
\hline & Media & Máx. & Min. & Media & Máx. & Min. & Media & Máx. & Min. \\
\hline $\mathrm{pH}$ & 7,43 & 7,60 & 7,32 & 7,39 & 7,64 & 6,95 & 7,27 & 7,53 & 7,08 \\
\hline $\begin{array}{c}\text { TSD } \\
(\mathrm{mg} / \mathrm{L})\end{array}$ & 661 & 876 & 427 & 305 & 563 & 189 & 356 & 421 & 314 \\
\hline $\begin{array}{c}\text { CE } \\
(\mu \mathrm{S} / \mathrm{cm})\end{array}$ & 1322 & 1751 & 853 & 613 & 1125 & 368 & 711 & 842 & 627 \\
\hline $\mathrm{Ca}(\mathrm{mg} / \mathrm{L})$ & 53 & 66 & 35 & 44 & 66 & 23 & 40 & 58 & 21 \\
\hline $\mathrm{Mg}(\mathrm{mg} / \mathrm{L})$ & 29 & 50 & 15 & 9 & 17 & 2 & 12 & 25 & 6 \\
\hline $\mathrm{Na}(\mathrm{mg} / \mathrm{L})$ & 209 & 285 & 128 & 96 & 197 & 40 & 111 & 137 & 77 \\
\hline $\mathrm{K}(\mathrm{mg} / \mathrm{L})$ & 25 & 41 & 4 & 8 & 15 & 3 & 12 & 18 & 6 \\
\hline $\mathrm{Cl}(\mathrm{mg} / \mathrm{L})$ & 226 & 376 & 78 & 27 & 82 & 11 & 59 & 103 & 34 \\
\hline $\begin{array}{c}\mathrm{SO}_{4} \\
(\mathrm{mg} / \mathrm{L})\end{array}$ & 6 & 12 & 3 & 4 & 6 & 2 & 23 & 33 & 5 \\
\hline $\begin{array}{l}\mathrm{HCO}_{3} \\
(\mathrm{mg} / \mathrm{L})\end{array}$ & 413 & 450 & 370 & 318 & 515 & 205 & 282 & 300 & 245 \\
\hline $\mathrm{Fe}(\mathrm{mg} / \mathrm{L})$ & $<0,01$ & $<0,01$ & $<0,01$ & $<0,01$ & $<0,01$ & $<0,01$ & 0,33 & 1,6 & $<0,01$ \\
\hline $\mathrm{Mn}(\mathrm{mg} / \mathrm{L})$ & 0,1 & 0,2 & $<0,05$ & $<0,05$ & $<0,05$ & $<0,05$ & $<0,05$ & $<0,05$ & $<0,05$ \\
\hline $\begin{array}{c}\mathrm{NO}_{3} \\
(\mathrm{mg} / \mathrm{L})\end{array}$ & 6 & 9 & 3 & 6 & 19 & 2 & 24 & 42 & 15 \\
\hline
\end{tabular}




\begin{tabular}{|c|c|c|c|c|c|c|c|c|c|}
\hline $\begin{array}{c}\mathrm{NO}_{2} \\
(\mathrm{mg} / \mathrm{L})\end{array}$ & $<0,01$ & $<0,01$ & $<0,01$ & $<0,01$ & $<0,01$ & $<0,01$ & $<0,01$ & $<0,01$ & $<0,01$ \\
\hline $\begin{array}{c}\text { Dureza } \\
(\mathrm{mg} / \mathrm{L})\end{array}$ & 254 & 372 & 152 & 151 & 250 & 76 & 146 & 234 & 75 \\
\hline $\begin{array}{c}\text { Alcalinidad } \\
(\mathrm{mg} / \mathrm{L})\end{array}$ & 339 & 369 & 303 & 231 & 246 & 201 & 260 & 422 & 168 \\
\hline
\end{tabular}

La zona de descarga al oeste se caracteriza por los valores medios de CE más altos $(1322 \mu \mathrm{S} / \mathrm{cm})$ así como de dureza y alcalinidad. Los tenores de Fe se encuentran en 0,01 $\mathrm{mg} / \mathrm{L}$ y los de $\mathrm{Mn}$ alcanzan un máximo de 0,2 $\mathrm{mg} / \mathrm{L}$, valor que excede el límite del Código Alimentario Argentino (CAA) (A.N.M.A.T., 2007).

El sector de recarga principal, en el centro de la duna, presenta los valores medios más bajos en CE $(613 \mu \mathrm{S} / \mathrm{cm})$ al igual que de TSD (305 mg/L). La dureza y alcalinidad son bajas, así como la concentración de cloruros. El Fe y Mn se encuentran por debajo del límite de detección del laboratorio. Los nitratos no sobrepasan los $19 \mathrm{mg} / \mathrm{L}$. Según el CAA y en base a los parámetros analizados estas aguas serían aptas para consumo humano.

La zona de descarga hacia el mar (este) al igual que la zona de recarga, presenta valores bajos de CE, pero algo superiores a la anterior $(711 \mu \mathrm{S} / \mathrm{cm})$. La dureza media es menor pero la alcalinidad es algo mayor. Presenta concentraciones de Fe que alcanzan los 1,6 mg/L, pero Mn por debajo del límite de detección. Un pozo presenta nitratos de $42 \mathrm{mg} / \mathrm{L}$, si bien no se encuentra por fuera de la norma, el margen es muy pequeño. Se trata de un foco puntual muy probablemente debido a pérdida de un pozo séptico cercano al freatímetro.

Se clasificaron las aguas de acuerdo al diagrama de Piper. La mayoría de las muestras son aguas bicarbonatadas sódicas, un grupo son aguas bicarbonatadas cálcicas y solo una se clasifica como clorurada sódica (Figura 8.24).

Teniendo en cuenta los estudios previos del cordón costero (CFI 1990b, Carretero 2011), existen diferencias entre la clasificación de Piper obtenida para San Clemente del Tuyú donde el agua subterránea es bicarbonatada cálcica en su totalidad, salvo las que pasan a la llanura deprimida que son cloruradas sódicas y donde la diferenciación entre los dos ambientes es bien marcada. En Mar del Tuyú el pasaje es más transicional y las aguas hacia el sector de la llanura deprimida no presentan tan elevada salinidad como en San Clemente. En cuanto a los tenores de Fe y Mn, los 
análisis químicos para Mar del Tuyú dieron valores mucho menores que aquellos obtenidos para la otra localidad.

\section{Mar del Tuyú (sep-2016)}

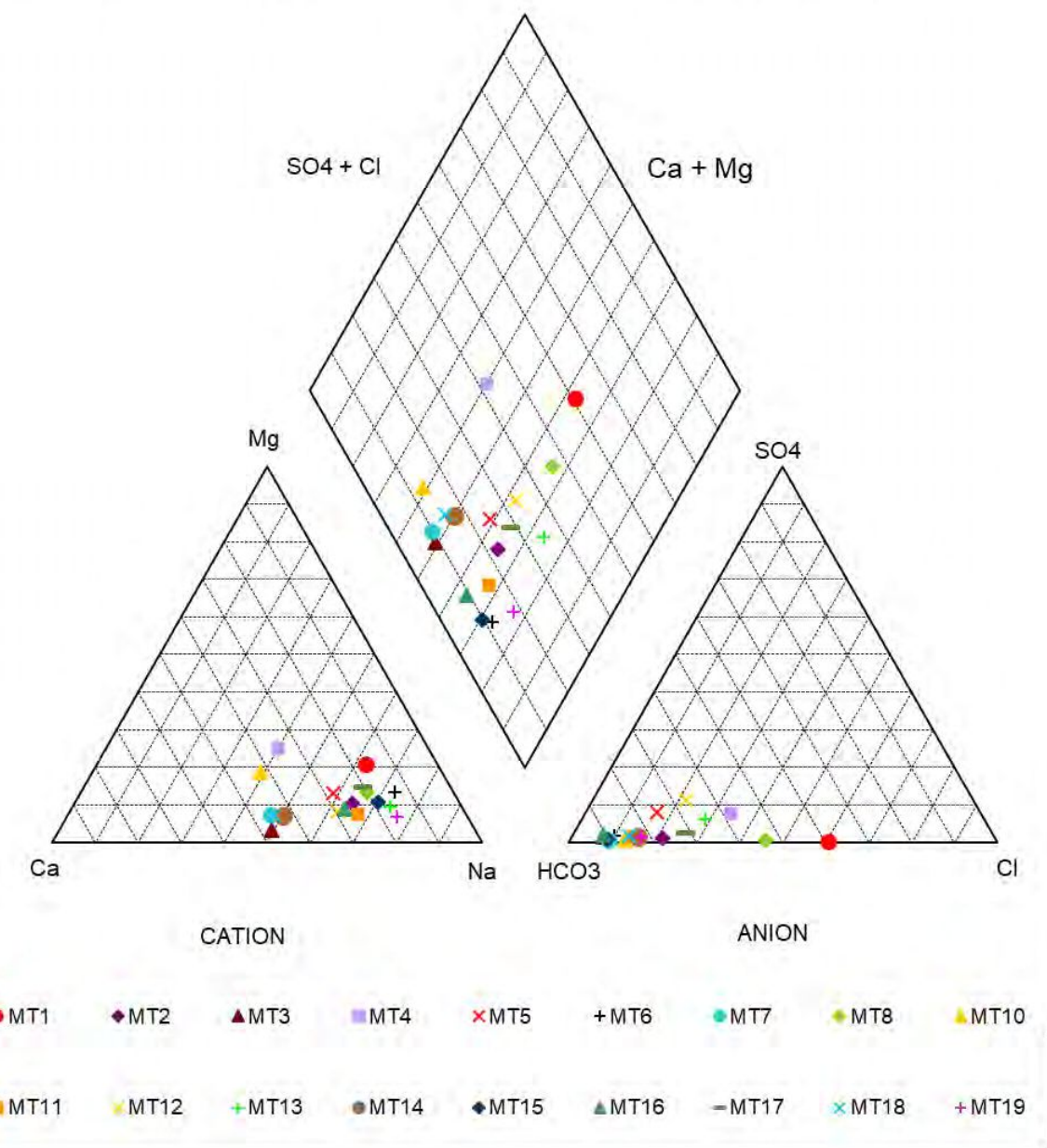

Figura 8.24 Diagrama de Piper para la totalidad de las muestras.

Si se separan las muestras de acuerdo a los ambientes de recarga y descarga, puede observarse que el sector de recarga central (Figura 8.25) tiene muestras de tipo bicarbonatada sódica y algunas de ellas con tendencia a bicarbonatada cálcica. 


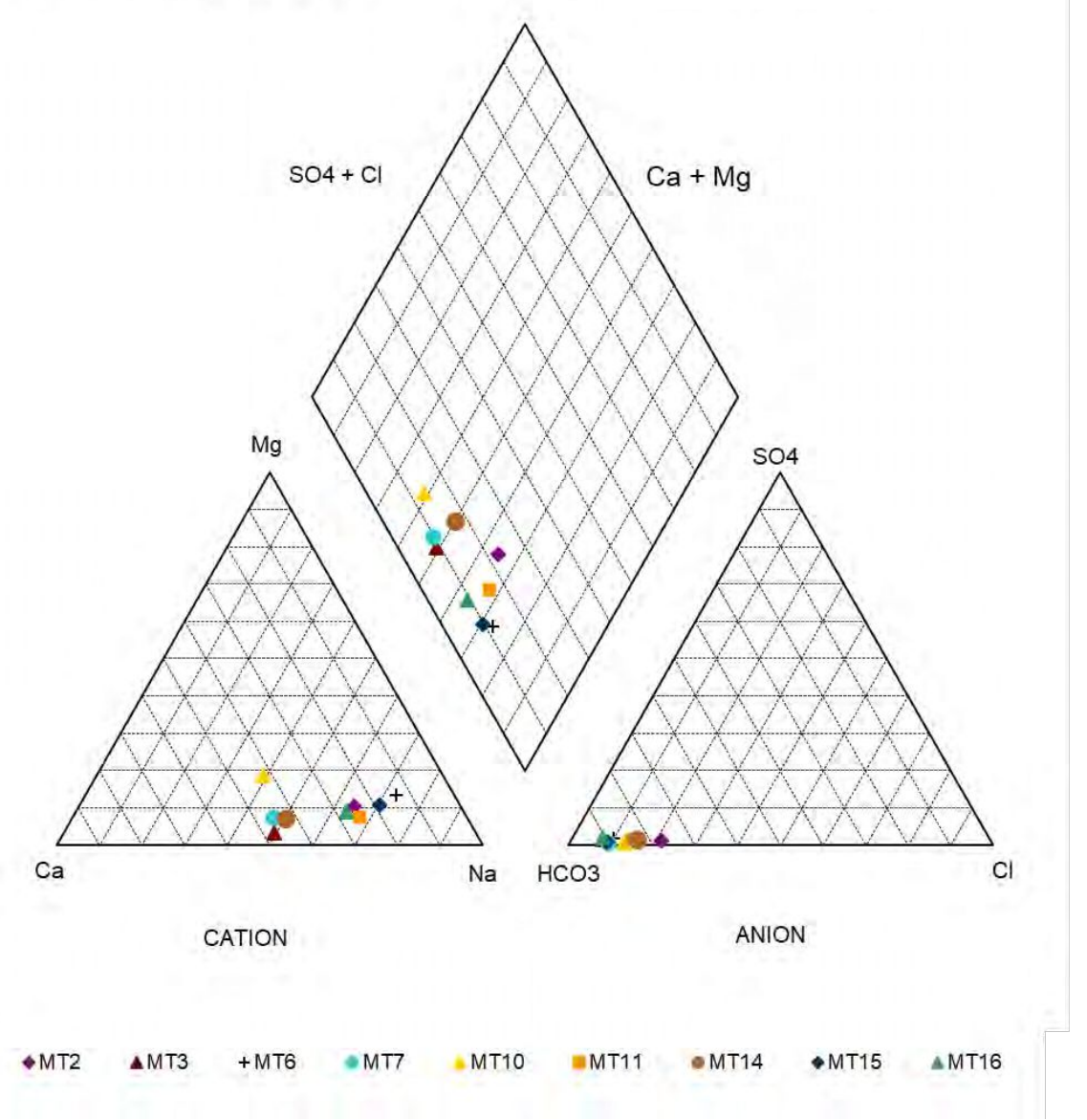

Figura 8.25 Diagrama de Piper para el sector de recarga principal.

Para la descarga al este todas las muestras, menos una que es bicarbonatada cálcica, son de tipo bicarbonatada sódica (Figura 8.26). 


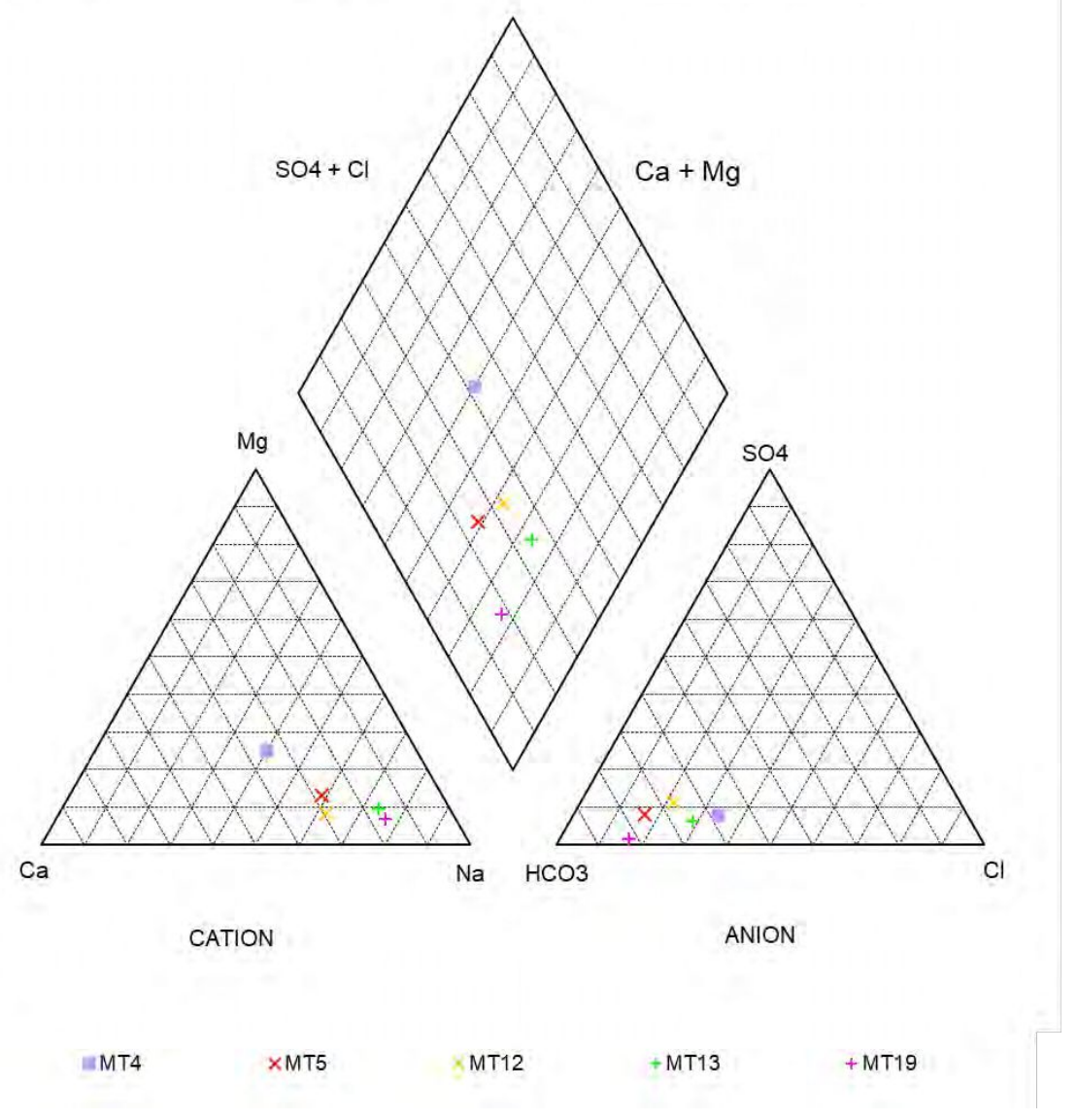

Figura 8.26 Diagrama de Piper para el sector de descarga al mar.

Finalmente, para la descarga al oeste se observa una muestra clorurada sódica, y dos bicarbonatadas sódicas, pero una de ellas con una marcada tendencia hacia el campo de las cloruradas sódicas (Figura 8.27). 


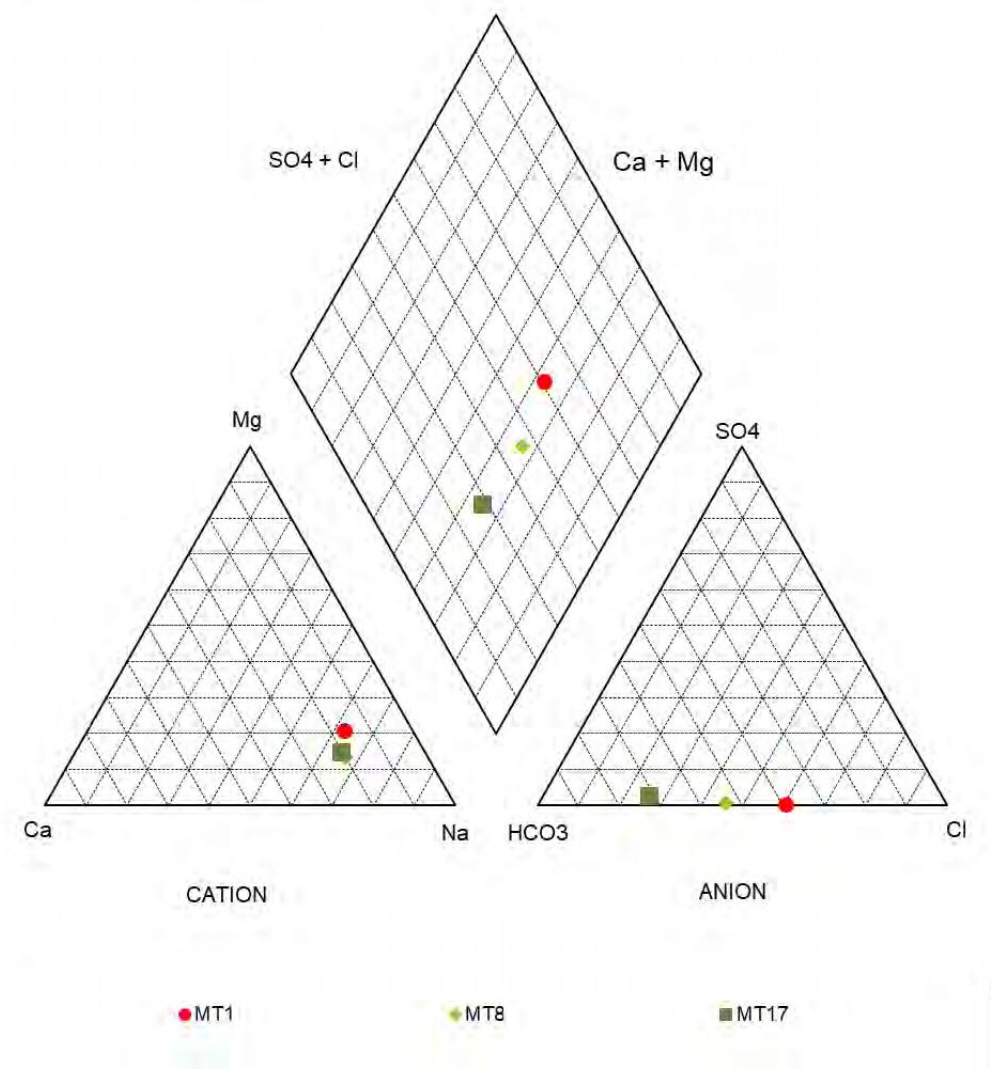

Figura 8.27 Diagrama de Piper para el sector de descarga al oeste.

También se han graficado las muestras en diagramas de Schöeller-Berkaloff. Si se comparan la zona de descarga al mar (Figura 8.28) con la de recarga (Figura 8.29), ambas presentan en general el predominio del anión bicarbonato y el catión sodio. Cabe resaltar que las concentraciones de sulfatos en la zona central son mucho más bajas que en la descarga.

En cuanto a la descarga hacia el oeste (Figura 8.30) los sulfatos son igual de bajos que en la zona de recarga, predominando el catión sodio y anión cloruro seguido del bicarbonato. 


\section{Descarga al este (2016)}

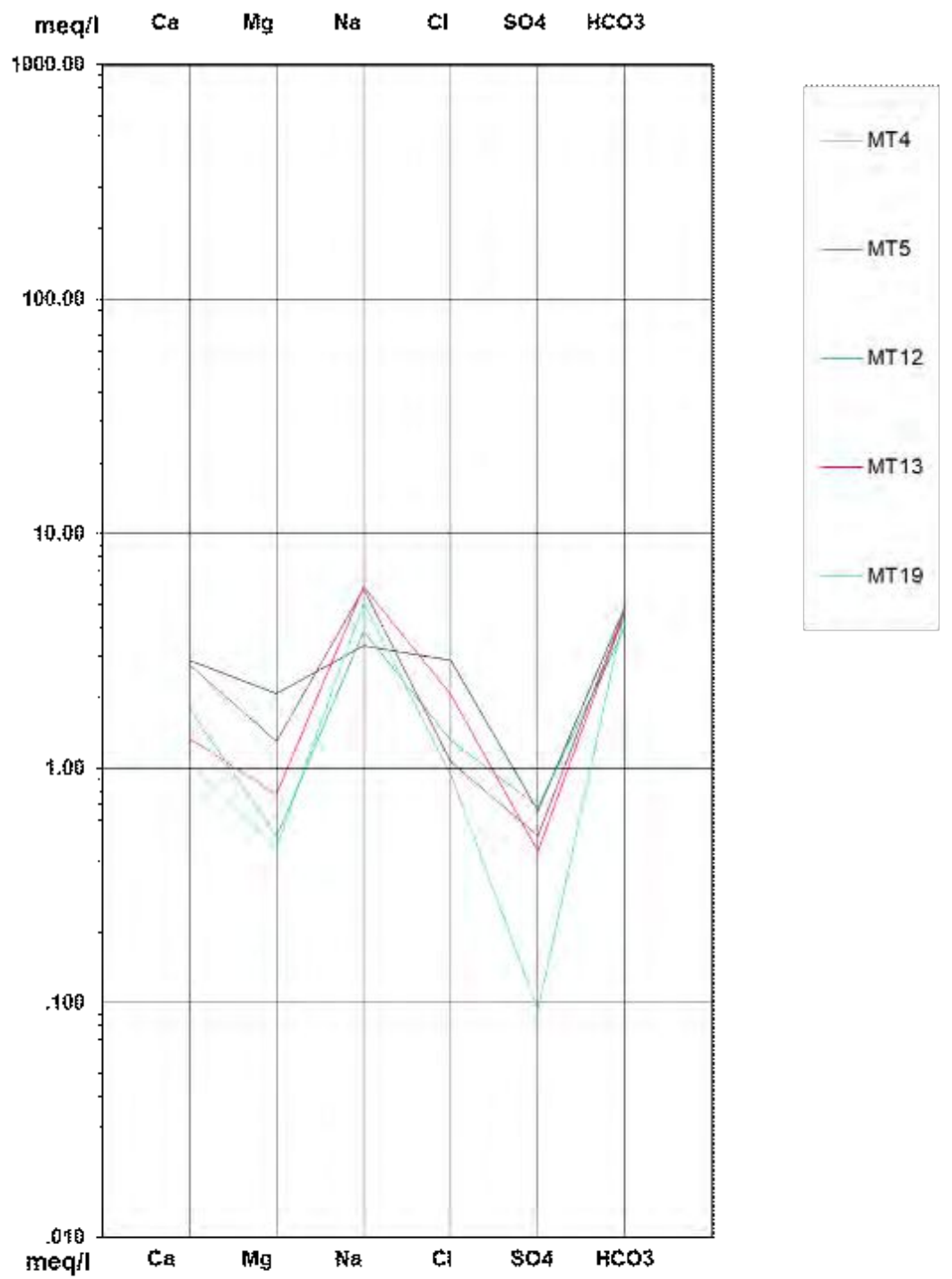

Figura 8.28 Diagrama de Schöeller-Berkaloff para la descarga al mar. 


\section{Recarga central (2016)}

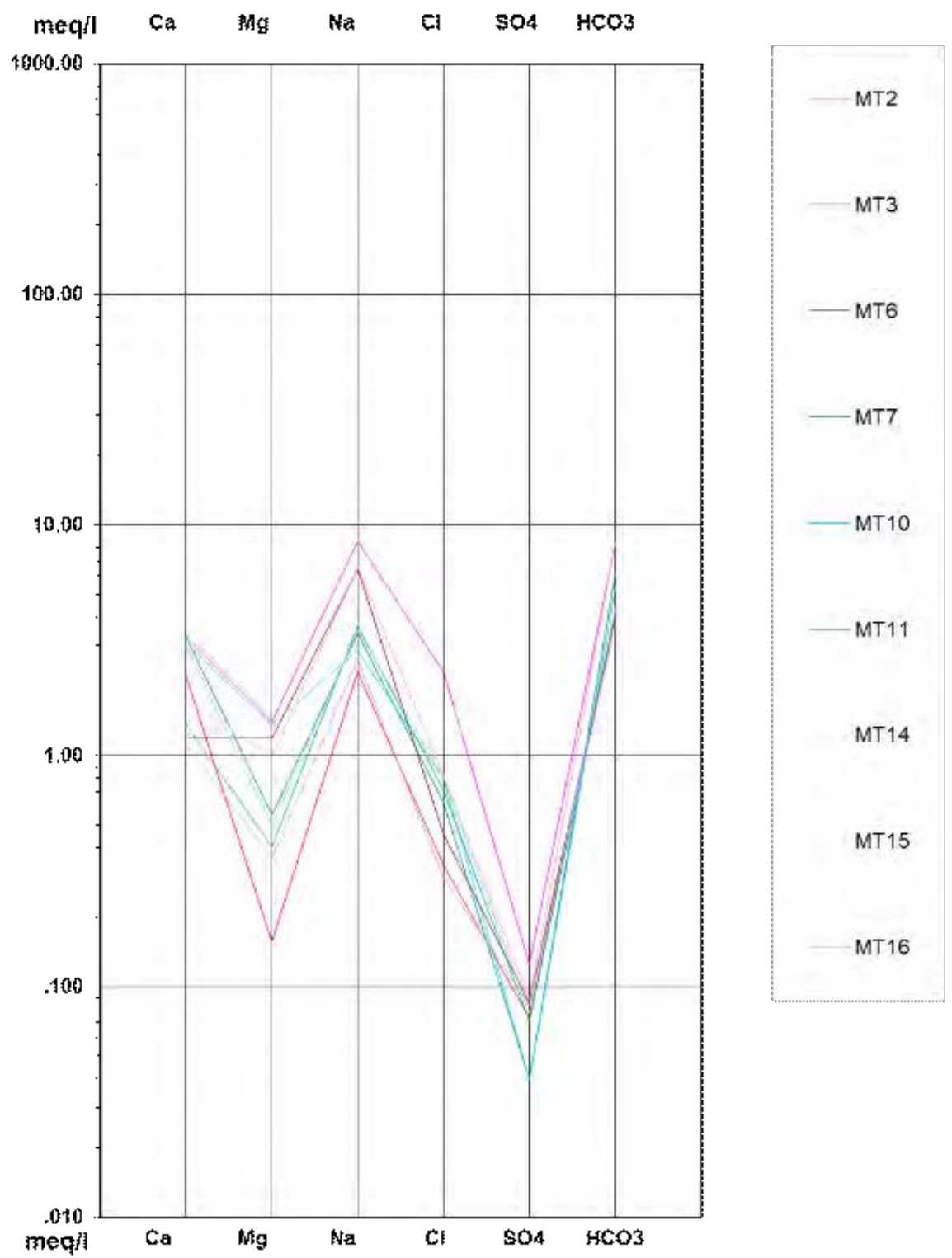

Figura 8.29 Diagrama de Schöeller-Berkaloff para la zona de recarga principal. 
Descarga oeste (2016)

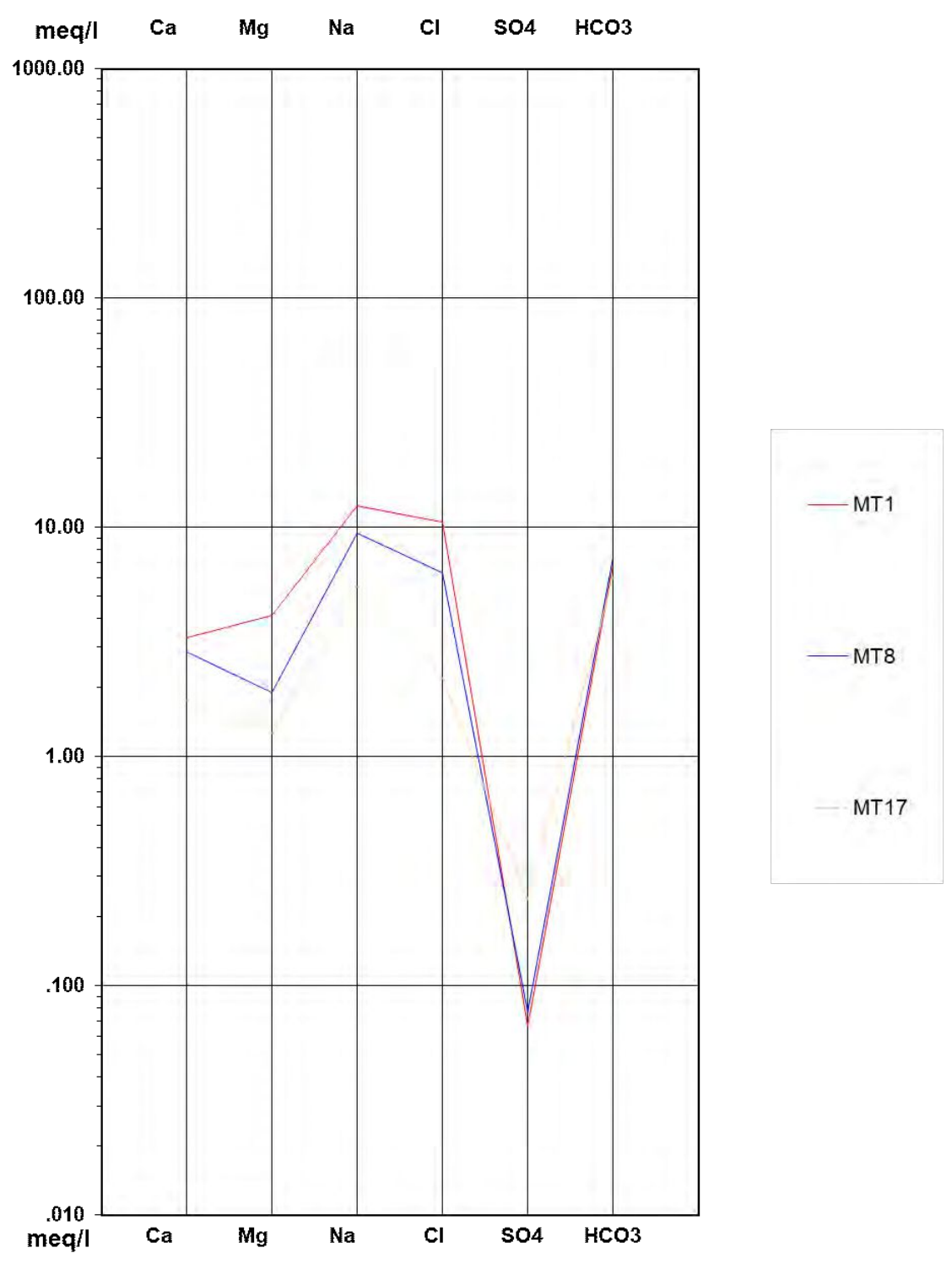

Figura 8.30 Diagrama de Schöeller-Berkaloff para la descarga al oeste.

\subsubsection{Variaciones areales}

Se han seleccionado algunos elementos para describir la distribución areal. Aquí se representan: CE, cloruro, sodio, bicarbonato y dureza.

Como puede observarse en el mapa que representa la CE (Figura 8.31), los mayores valores se localizan hacia el oeste, zona transicional a la llanura deprimida, con una diferenciación entre el sector norte y sur. Luego hacia la zona de descarga al este también se produce un incremento. 
La distribución de los cloruros refleja el sentido de flujo subterráneo, incrementando su concentración hacia el este y el oeste (Figura 8.32).

En cuanto al sodio (Figura 8.33) se observan las menores concentraciones en la parte central de la duna y aumenta hacia el oeste con los mayores valores, y hacia el este con concentraciones algo más bajas. Los mayores valores de bicarbonatos se detectan en el sector oeste, y el resto de la duna se caracteriza por concentraciones menores a $300 \mathrm{mg} / \mathrm{L}$ (Figura 8.34).

Los mayores tenores de dureza (250-350 mg/L) se detectan en el sector norte hacia la llanura deprimida (Figura 8.35). Luego no se advierte una distribución espacial relacionada al flujo o a los ambientes geomorfológicos. 


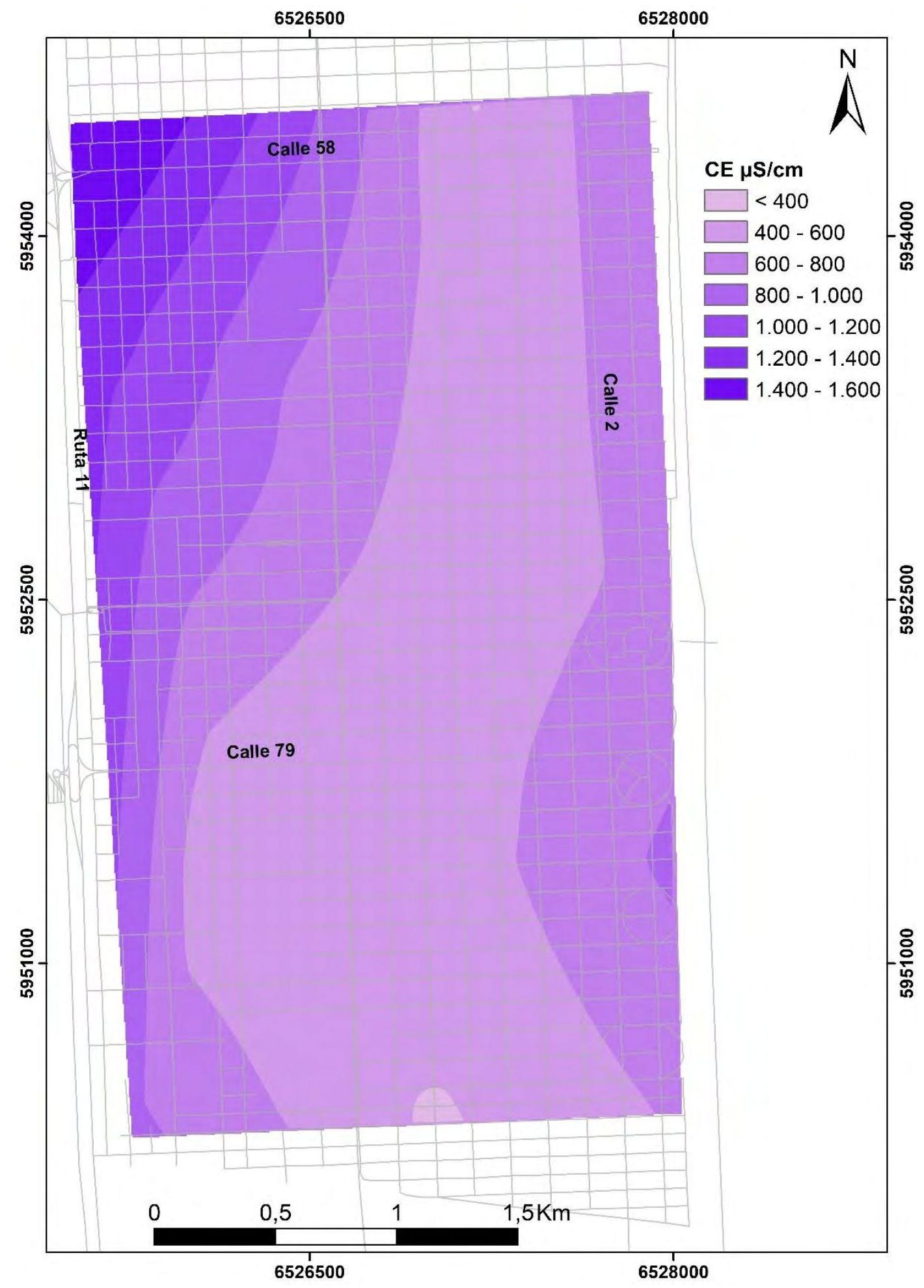

Figura 8.31 Mapa de distribución de CE (2016). 


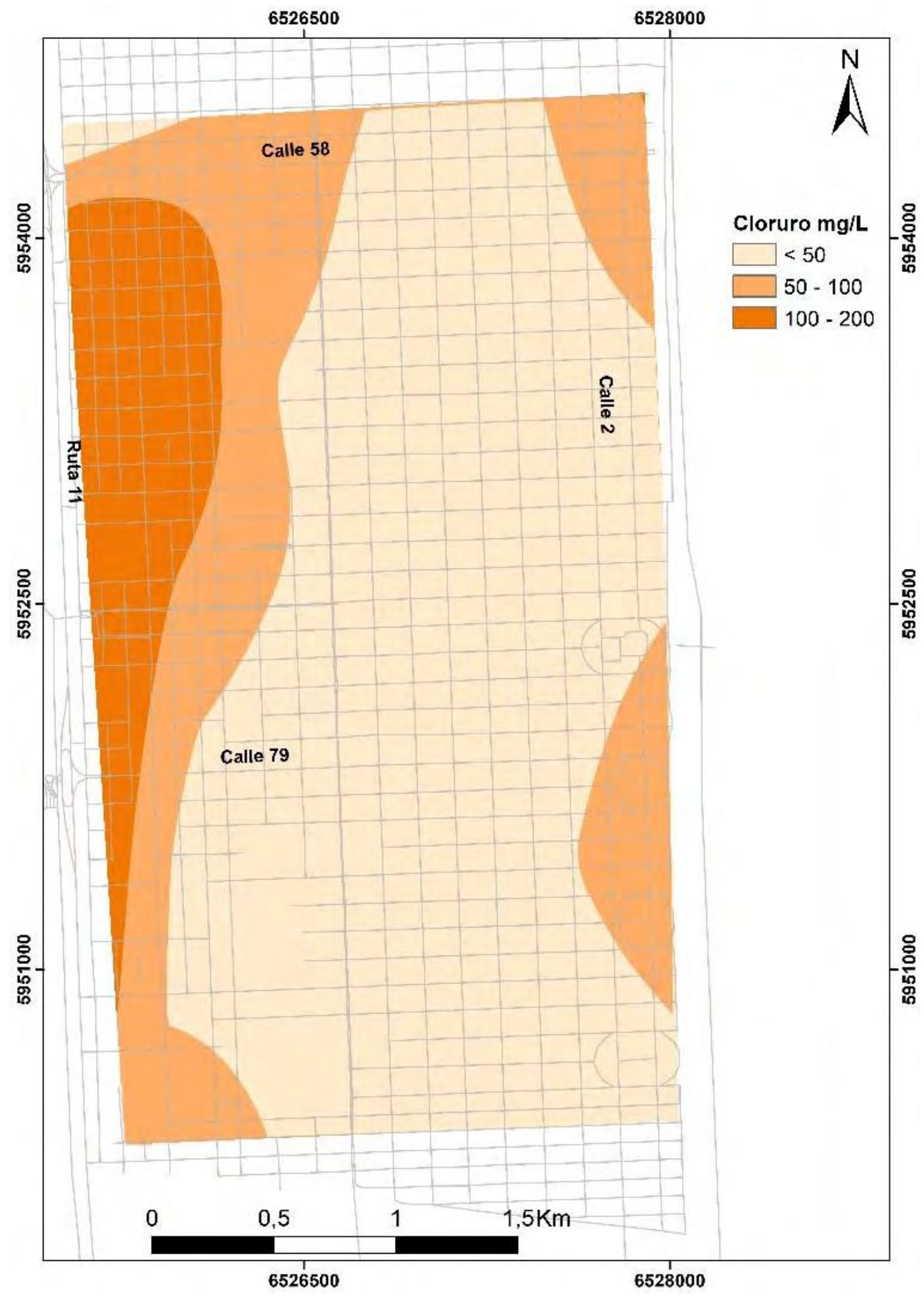

Figura 8.32 Mapa de distribución de cloruros (2016). 


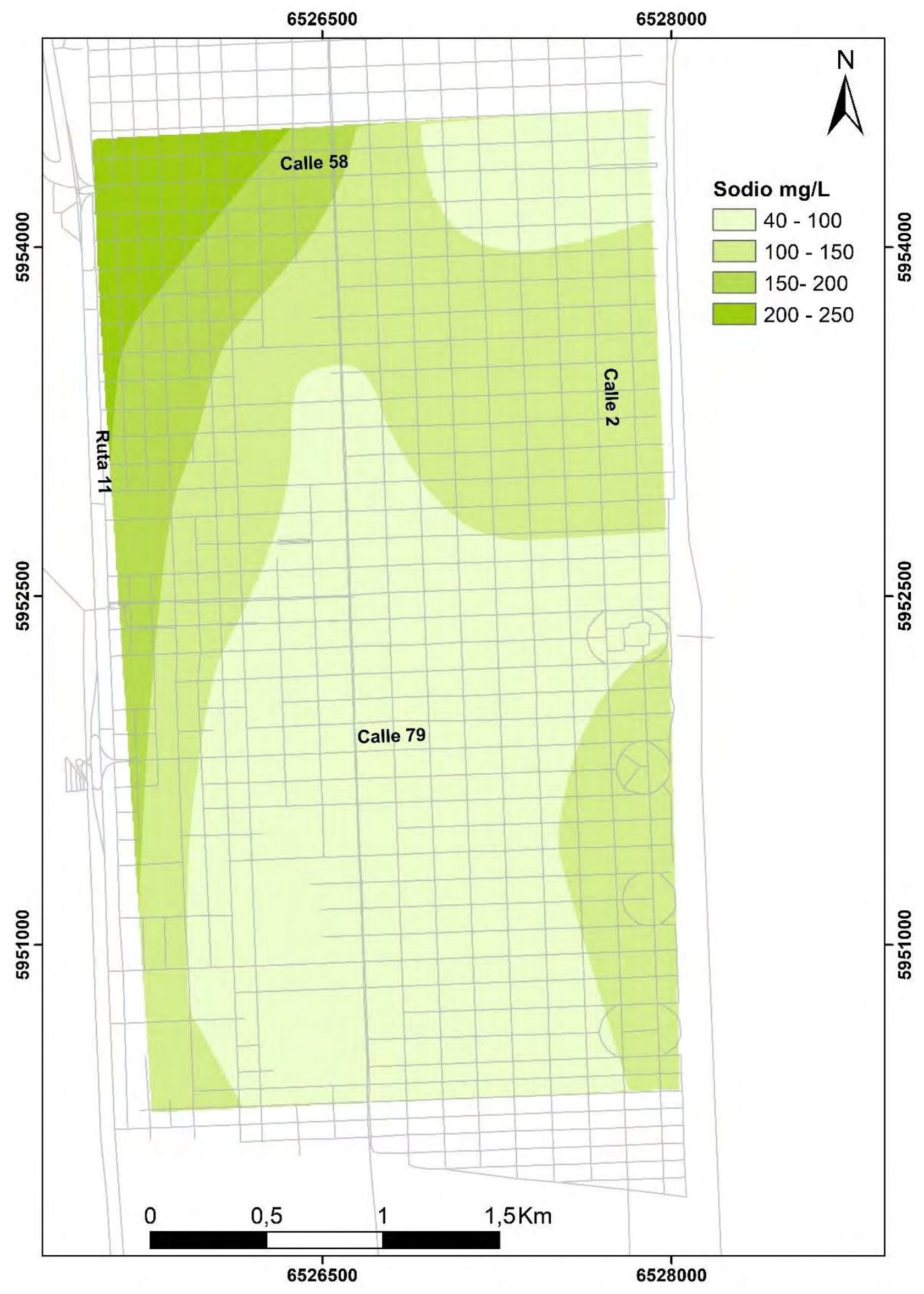

Figura 8.33 Mapa de distribución de sodio (2016). 


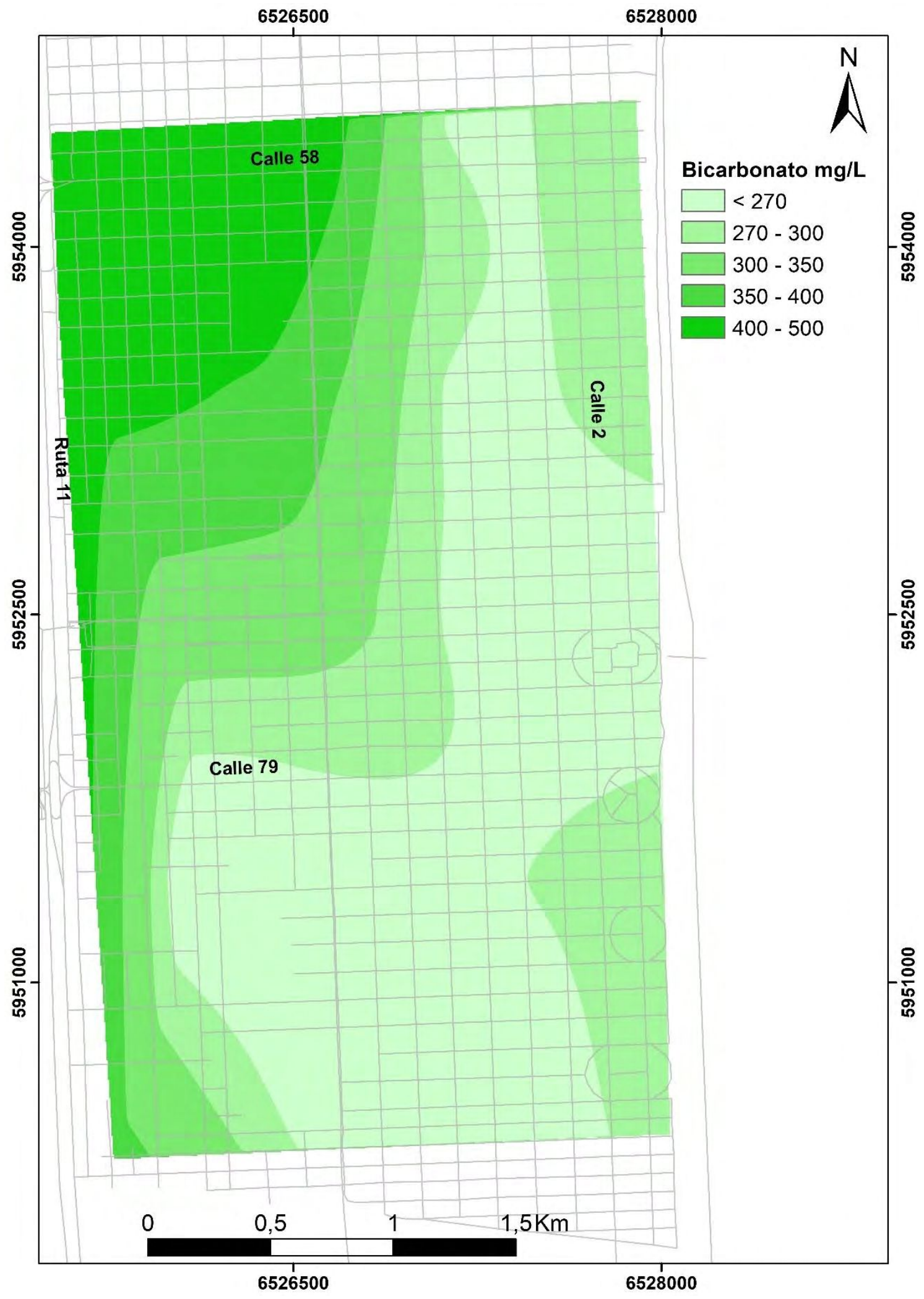

Figura 8.34 Mapa de distribución de bicarbonatos (2016). 


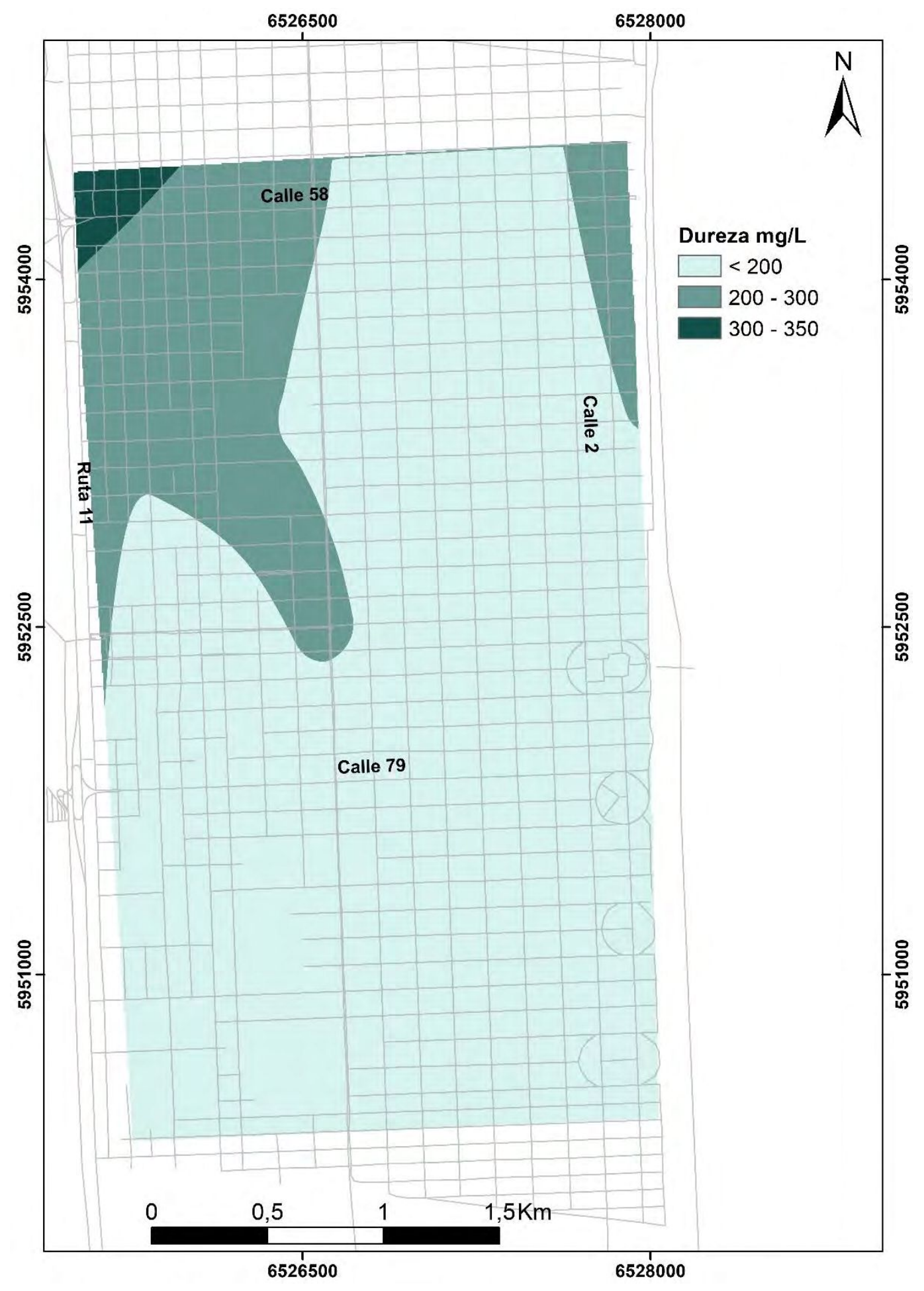

Figura 8.35 Mapa de distribución de dureza (2016). 


\subsubsection{Variaciones temporales}

Se comparan los resultados de la química de las aguas subterráneas obtenidas en Septiembre de 2016 con las muestras de CFI (1990,b) tomadas en Agosto de 1987.

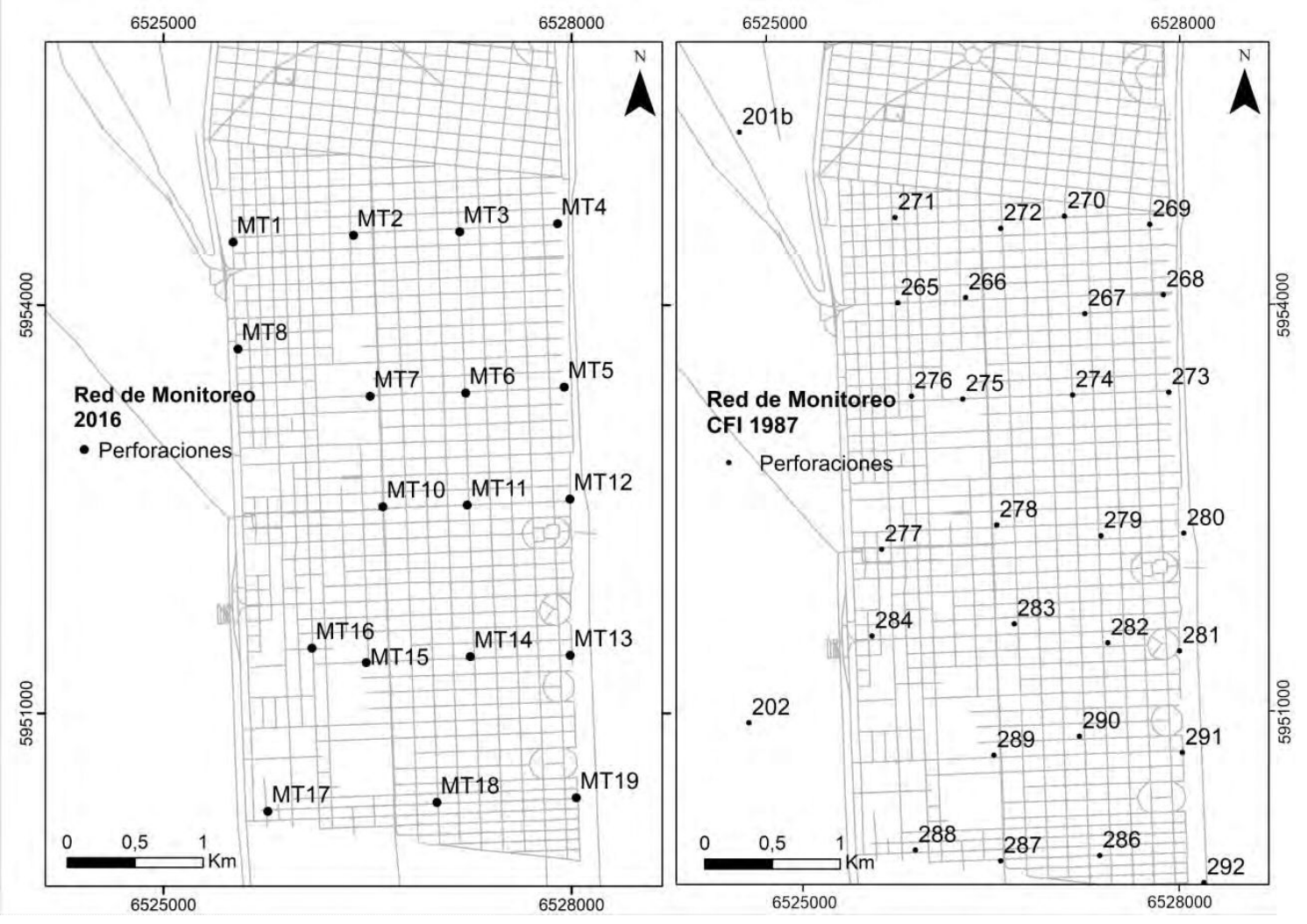

Figura 8.36 Ubicación de la red de monitoreo del acuifero freático para el año 2016 y 1987.

La red de monitoreo del acuífero freático para el año 1987 estaba constituida por 29 perforaciones de 6 metros de profundidad (CFI, 1990, b) con una distribución similar a la de red utilizada en 2016 Figura 8.36. Por lo tanto, se considera que los muestreos son comparables tanto sea por la distribución como por la profundidad de la toma de las muestras. Las fechas de muestreo son similares en el año hidrológico ya que fueron tomadas en agosto 1987 y septiembre 2017.

El diagrama de Piper (Figura 8.37) muestra que para 1987 la mayoría de las muestras son de tipo bicarbonatadas cálcicas y un pequeño grupo, cloruradas sódicas. El primero corresponde a pozos del cordón costero y el segundo a la zona transicional a la llanura deprimida o directamente a pozos localizados hacia el oeste (201b y 202), donde este ambiente se encuentra ya bien definido.

De acuerdo a estos datos se observó un cambio en la clasificación de las aguas de un muestreo al otro en el tiempo. Siendo en 1987 la mayoría bicarbonatadas cálcicas y en 
2016 se clasifican en su mayoría como bicarbonatadas sódicas dentro del cordón costero.

\section{Mar del Tuyú (CFI, 1987)}

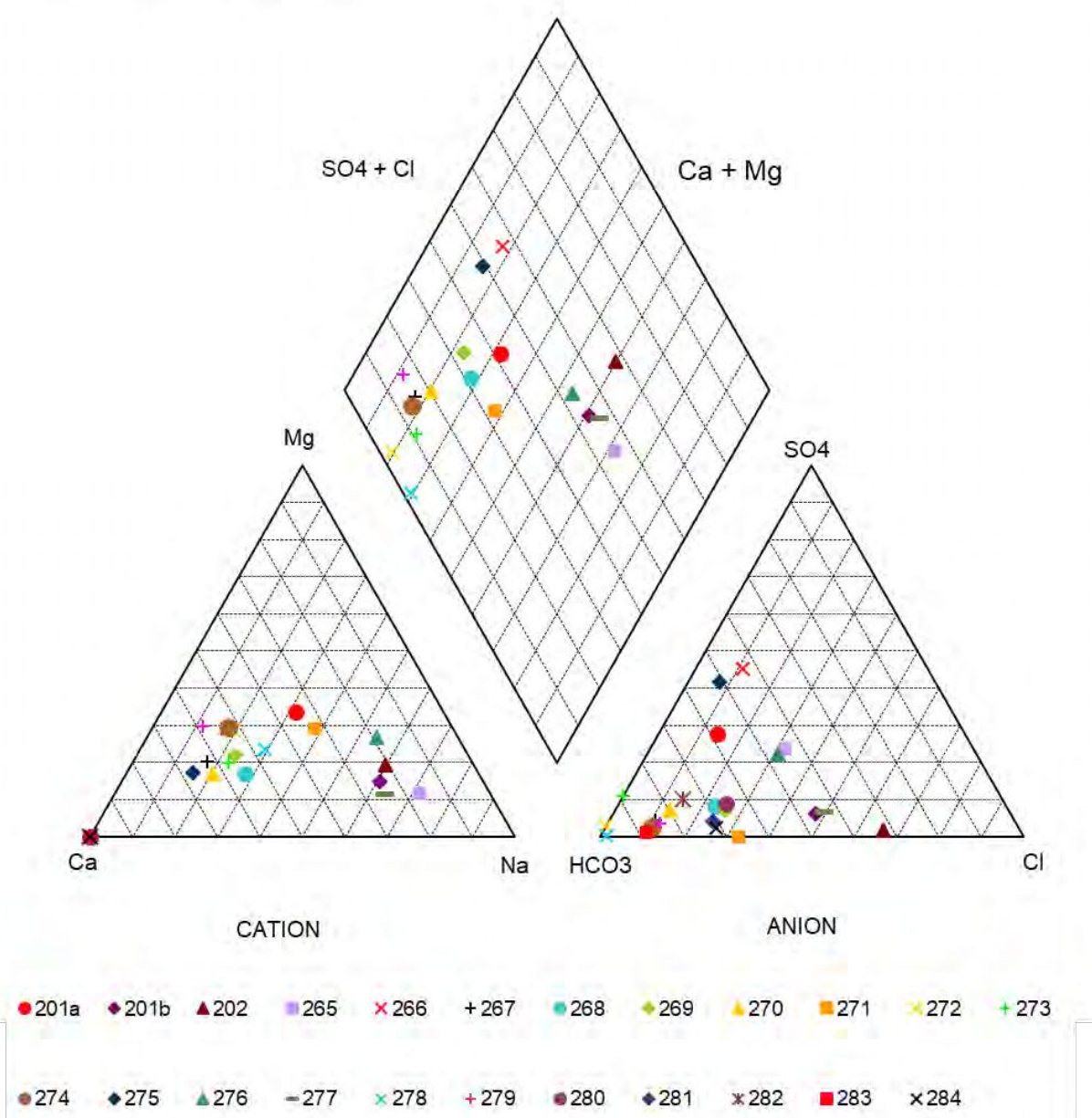

Figura 8.37 Diagrama de Piper para 1987.

Analizando la distribución areal de los elementos mediante mapas de isocontenidos puede observarse en el mapa que representa la CE (Figura 8.38), los mayores valores se localizan hacia el oeste en la llanura deprimida. En este sector existen valores elevados de CE los cuales llegan hasta $3500 \mu \mathrm{S} / \mathrm{cm}$. Luego hacia la zona de descarga al este también produce un incremento, pero con valores que no sobrepasan los 1250 $\mu \mathrm{S} / \mathrm{cm}$. Las menores concentraciones se observan en el sector central de la duna.

La distribución de los cloruros refleja el sentido de flujo subterráneo y la influencia de la llanura deprimida. Se incrementan hacia el este y el oeste (Figura 8.39) al igual que el sodio (Figura 8.40). Los mayores valores de bicarbonatos se detectan en el sector oeste, y el resto de la duna se caracteriza por concentraciones entre 250 y $500 \mathrm{mg} / \mathrm{L}$ (Figura 8.41) resultando en valores mayores que en el muestreo de 2016. 


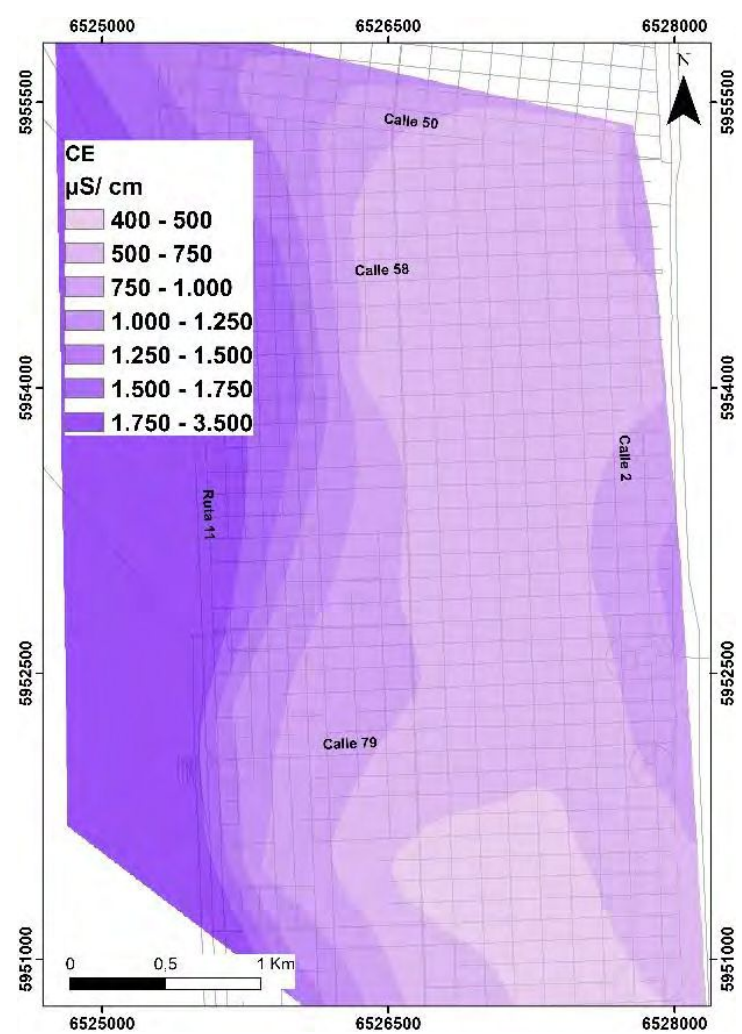

Figura 8.38 Mapa de distribución de CE (1987).

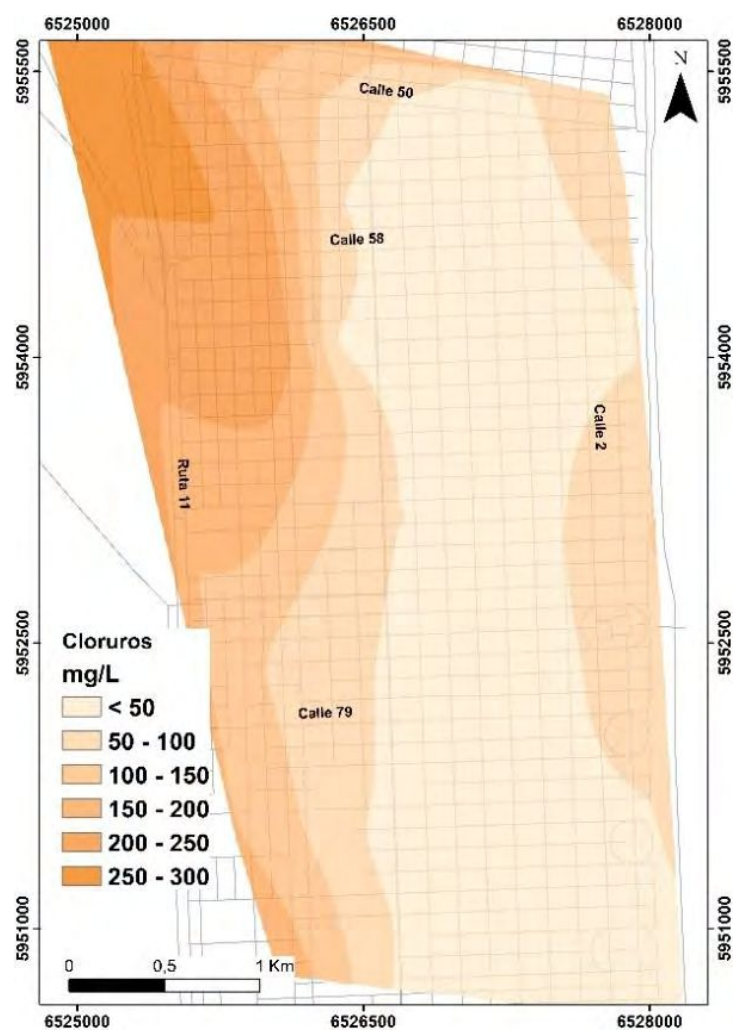

Figura 8.39 Mapa de distribución de cloruros (1987). 


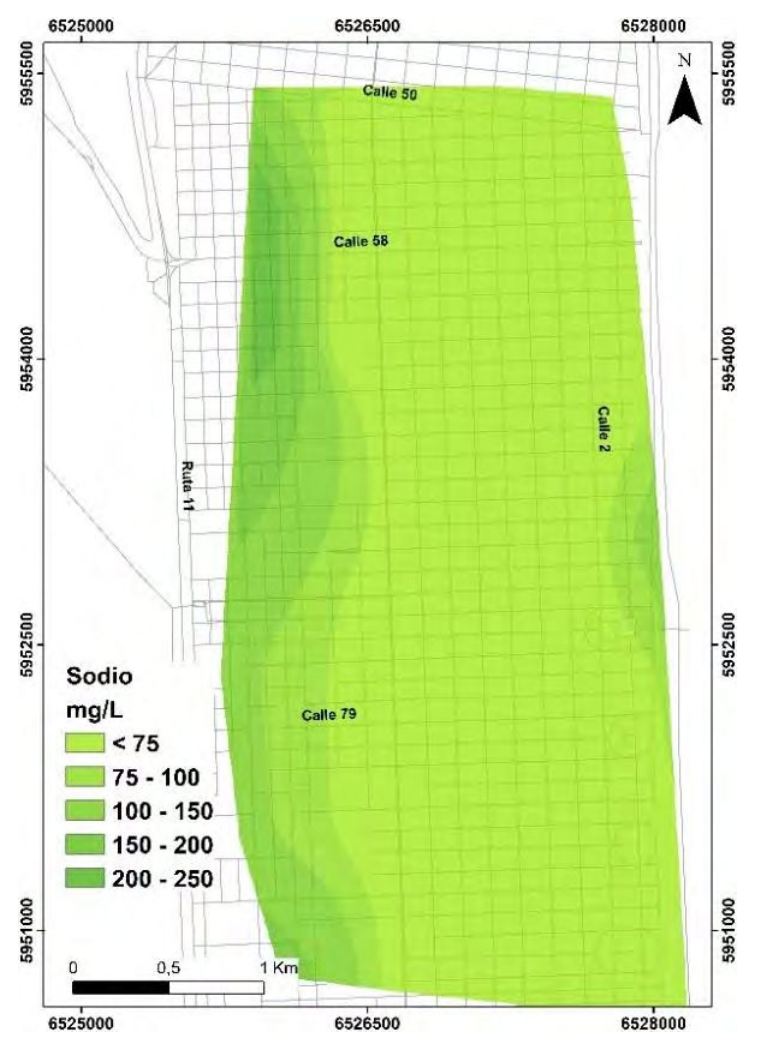

Figura 8.40 Mapa de distribución de sodio (1987).

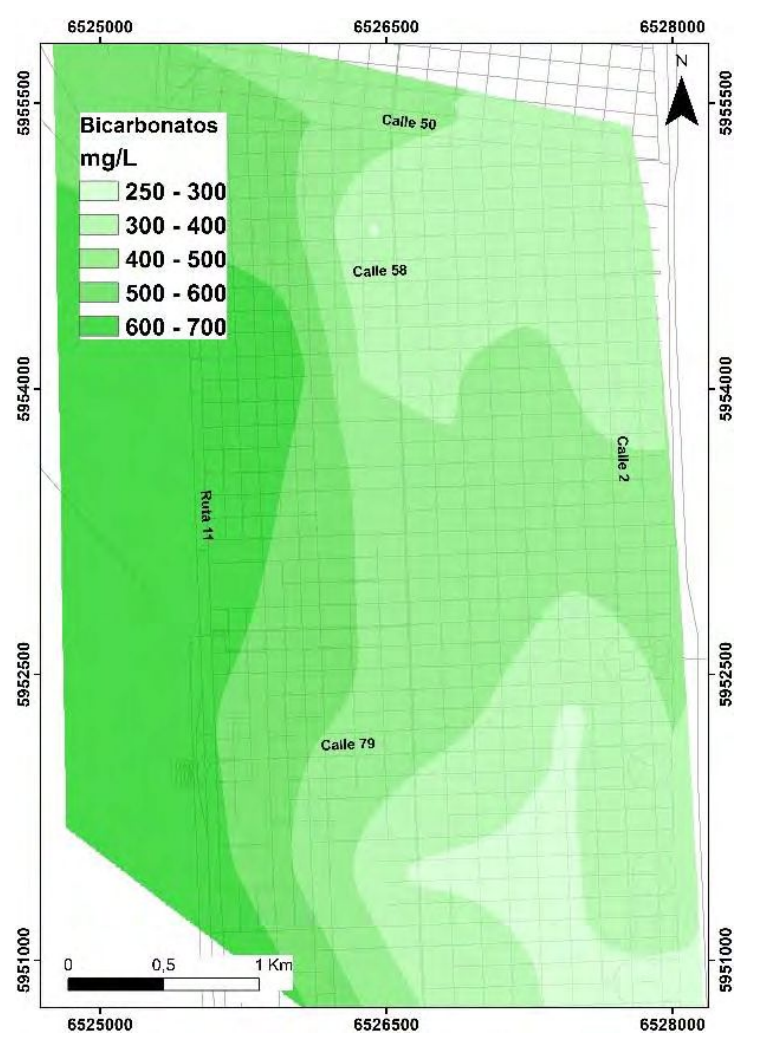

Figura 8.41 Mapa de distribución de bicarbonatos (1987). 


\subsection{Condiciones hidroquímicas en la costa estuárica (Berisso)}

\subsubsection{Características generales}

En el ámbito de costa estuárica del Río de la Plata correspondiente a la localidad de Berisso, la conductividad eléctrica (CE) del agua subterránea del acuífero freático presenta diferencias significativas según la geomorfología a la que pertenece.

De acuerdo a los resultados de los análisis químicos efectuados (Tabla 24), en la planicie de marea relictual la CE media es $1771 \mu \mathrm{S} / \mathrm{cm}$, el agua subterránea alojada en cordones litorales presenta valores medios de $573 \mu \mathrm{S} / \mathrm{cm}$, mientras que en zona de llanura estuárica es de $1403 \mu \mathrm{S} / \mathrm{cm}$. En sectores de la llanura estuárica (Pozo P1) próximos al río ocurre un fenómeno que depende de las mareas. Durante pleamares donde se supera la cota del terreno, se produce inundación y la infiltración de agua desde la superficie provoca una disminución en la CE.

Se realizó un seguimiento de la CE a lo largo del tiempo en coincidencia con las mediciones de niveles en el área. El cordón litoral presenta los valores de CE más bajos con un promedio de $530 \mu \mathrm{S} / \mathrm{cm}$ (Tabla 24). La planicie de marea relictual se caracteriza por concentraciones medias que varían entre 700 y $3700 \mu \mathrm{S} / \mathrm{cm}$, existiendo una gran variabilidad en este ambiente en particular. Para la llanura estuárica la CE presenta una media de $1300 \mu \mathrm{S} / \mathrm{cm}$ con extremos que oscilan entre los 800 y 2000 $\mu \mathrm{S} / \mathrm{cm}$.

Tabla 24 Valores máximos, mínimos y promedios de conductividad eléctrica del agua subterránea según ambientes.

\begin{tabular}{|c|c|c|c|c|c|c|c|c|c|c|c|c|c|}
\hline \multicolumn{10}{|c|}{ Conductividad eléctrica $(\mu \mathrm{S} / \mathrm{cm})$} \\
\hline & $\begin{array}{c}\text { Cordón } \\
\text { litoral }\end{array}$ & \multicolumn{1}{|c|}{ Planicie de marea relictual } & \multicolumn{1}{|c|}{ Llanura estuárica } \\
\hline Pozo & P2 & P3 & P6 & P9 & Media & P1 & P4 & P5 & P7 & P8 & P10 & P11 & Media \\
\hline Máx. & 682 & 2430 & 4710 & 4000 & 3713 & 1091 & 3590 & 1739 & 1460 & 2400 & 2700 & 1218 & 2028 \\
\hline Min. & 335 & 1090 & 574 & 670 & 778 & 777 & 300 & 1074 & 985 & 428 & 1219 & 990 & 825 \\
\hline Media & 530 & 1607 & 3311 & 1556 & 2158 & 970 & 2028 & 1388 & 1148 & 1006 & 1763 & 1102 & 1344 \\
\hline
\end{tabular}

Tanto en la planicie de marea relictual como en la llanura estuárica las muestras caen en el campo de las aguas de tipo cloruradas y/o sulfatadas sódicas salvo el pozo P1 que tiene influencia del Río de la Plata como se ha mencionado y es del tipo bicarbonatada cálcica (Figura 8.42). 
La planicie de marea relictual presenta valores de cloruros medios de $420 \mathrm{mg} / \mathrm{L}$. Las concentraciones de sulfatos varían entre mínimos de 82 y máximos de $597 \mathrm{mg} / \mathrm{L}$ (Tabla 25). Los valores medios de alcalinidad y dureza total son de 300 y $317 \mathrm{mg} / \mathrm{L}$ respectivamente. Respecto al hierro, 2 de 3 pozos presentan valores elevados de este elemento y al igual que el manganeso.

En llanura estuárica los contenidos de cloruros medios son de $479 \mathrm{mg} / \mathrm{l}$ y los sulfatos varían entre 14 y $688 \mathrm{mg} / \mathrm{L}$ (Tabla 26). La alcalinidad media es de $392 \mathrm{mg} / \mathrm{L}$ y la dureza de $257 \mathrm{mg} / \mathrm{L}$. El pozo P4 presenta una dureza que excede el límite para bebida de 400 mg/L del Código Alimentario Argentino (CAA) (A.N.M.A.T., 2007). El pozo P1 presenta tenores muy elevados de hierro $(8 \mathrm{mg} / \mathrm{L})$ y de manganeso $(1,2 \mathrm{mg} / \mathrm{L})$ también por fuera de los límites de admisibilidad.

Los ambientes de planicie de marea relictual y llanura estuárica presentan contenidos de cloruros y sulfatos que superan el límite propuesto por el CAA, siendo los límites para el cloruro, en agua de bebida un máximo, de $350 \mathrm{mg} / \mathrm{L}$ y sulfatos de $400 \mathrm{mg} / \mathrm{L}$.

El agua de los cordones litorales (P2) de acuerdo a la clasificación de Piper es bicarbonatada cálcica (Figura 8.42) y es apta para consumo humano ya que presenta valores bajos de cloruros $(3,2 \mathrm{mg} / \mathrm{L})$ y sulfatos $(15,2 \mathrm{mg} / \mathrm{L})$ y los nitratos se encuentran por debajo del límite de detección (Tabla 26). El único parámetro por fuera de la normativa sería el manganeso con $1,2 \mathrm{mg} / \mathrm{L}$.

En el área no se registran concentraciones de nitratos elevadas, los cuales se encuentran en concentraciones menores a $17 \mathrm{mg} / \mathrm{L}$. Los nitritos están por debajo del límite de detección en todas las muestras.

Tabla 25 Resultados del análisis de laboratorio para el cordón litoral y planicie de marea relictual. Se calcularon los valores máximos, mínimos y medios.

\begin{tabular}{|c|c|c|c|c|c|c|c|}
\hline & $\begin{array}{c}\text { Cordón } \\
\text { litoral }\end{array}$ & \multicolumn{5}{|c|}{ Planicie de marea relictual } \\
\hline & $\mathbf{P 2}$ & $\mathbf{P 3}$ & $\mathbf{P 6}$ & $\mathbf{P 9}$ & Máx. & Min. & Media \\
\hline $\mathrm{pH}$ & 7,2 & 7,2 & 7,1 & 8,4 & $\mathbf{8 , 4}$ & $\mathbf{7 , 1}$ & $\mathbf{7 , 6}$ \\
\hline $\begin{array}{c}\mathrm{CE} \\
(\mu \mathrm{S} / \mathrm{cm})\end{array}$ & 573 & 1730 & 2900 & 684 & $\mathbf{2 9 0 0}$ & $\mathbf{6 8 4}$ & $\mathbf{1 7 7 1}$ \\
\hline $\begin{array}{c}\mathrm{STD} \\
(\mathrm{mg} / \mathrm{L})\end{array}$ & 2060 & 1088 & 839 & 720 & $\mathbf{2 0 6 0}$ & $\mathbf{7 2 0}$ & $\mathbf{8 8 2}$ \\
\hline \begin{tabular}{c}
$\mathrm{Ca}(\mathrm{mg} / \mathrm{L})$ \\
\hline
\end{tabular} & 84,1 & 85,3 & 42,6 & 40,4 & $\mathbf{8 5}$ & $\mathbf{4 0}$ & $\mathbf{5 6}$ \\
\hline
\end{tabular}




\begin{tabular}{|c|c|c|c|c|c|c|c|}
\hline $\mathrm{Mg}(\mathrm{mg} / \mathrm{L})$ & 36,4 & 37,7 & 49,1 & 28,4 & 49 & 28 & 38 \\
\hline $\mathrm{Na}(\mathrm{mg} / \mathrm{L})$ & 43 & 170 & 665 & 268 & 665 & 170 & 368 \\
\hline $\mathrm{K}(\mathrm{mg} / \mathrm{L})$ & 32,2 & 32,4 & 32,5 & 19,6 & 33 & 20 & 28 \\
\hline $\mathrm{Fe}(\mathrm{mg} / \mathrm{L})$ & $<0,01$ & 0,70 & 0,30 & $<0,01$ & 0,7 & 0,3 & 0,5 \\
\hline $\mathrm{Mn}(\mathrm{mg} / \mathrm{L})$ & 1,2 & 0,2 & 0,1 & 0,2 & 1,2 & 0,1 & 0,2 \\
\hline $\mathrm{Cl}(\mathrm{mg} / \mathrm{L})$ & 3 & 21 & 1000 & 242 & 1000 & 21 & 421 \\
\hline $\begin{array}{c}\mathrm{SO}_{4} \\
(\mathrm{mg} / \mathrm{L})\end{array}$ & 15 & 597 & 286 & 82 & 597 & 82 & 322 \\
\hline $\begin{array}{l}\mathrm{HCO}_{3} \\
(\mathrm{mg} / \mathrm{L})\end{array}$ & 300 & 300 & 400 & 460 & 460 & 300 & 387 \\
\hline $\begin{array}{c}\mathrm{NO}_{3} \\
(\mathrm{mg} / \mathrm{L})\end{array}$ & $<0,01$ & 10 & 17 & 12 & 17 & 10 & 13 \\
\hline $\begin{array}{c}\mathrm{NO}_{2} \\
(\mathrm{mg} / \mathrm{L})\end{array}$ & $<0,01$ & $<0,01$ & $<0,01$ & $<0,01$ & $<0,01$ & $<0,01$ & $<0,01$ \\
\hline $\begin{array}{c}\text { Alcalinidad } \\
\text { (mg/L) }\end{array}$ & 362 & 370 & 311 & 219 & 370 & 219 & 300 \\
\hline $\begin{array}{c}\text { Dureza } \\
(\mathrm{mg} / \mathrm{L})\end{array}$ & 246 & 246 & 328 & 377 & 377 & 246 & 317 \\
\hline
\end{tabular}

Tabla 26 Resultados del análisis de laboratorio para los pozos ubicados en la llanura estuárica. Se calcularon los valores máximos, mínimos y medios.

\begin{tabular}{|c|c|c|c|c|c|c|c|c|c|}
\hline & \multicolumn{7}{|c|}{ Llanura estuárica } \\
\hline & $\mathbf{P 1}$ & $\mathbf{P 4}$ & $\mathbf{P 5}$ & $\mathbf{P 8}$ & $\mathbf{P 1 0}$ & $\mathbf{P 1 1}$ & Máx, & Min, & Media \\
\hline $\mathrm{pH}$ & 6,7 & 7,2 & 7,0 & 6,5 & 6,7 & 6,7 & $\mathbf{7 , 2}$ & $\mathbf{6 , 5}$ & $\mathbf{6 , 8}$ \\
\hline $\begin{array}{c}\mathrm{CE} \\
(\mu \mathrm{S} / \mathrm{cm})\end{array}$ & 877 & 3354 & 1551 & 428 & 1219 & 990 & $\mathbf{3 3 5 4}$ & $\mathbf{4 2 8}$ & $\mathbf{1 4 0 3}$ \\
\hline $\begin{array}{c}\mathrm{STD} \\
(\mathrm{mg} / \mathrm{L})\end{array}$ & 1209 & 2160 & 1640 & 2540 & 1650 & 1331 & $\mathbf{2 5 4 0}$ & $\mathbf{1 2 0 9}$ & $\mathbf{1 7 5 5}$ \\
\hline \begin{tabular}{c}
$\mathrm{Ca}(\mathrm{mg} / \mathrm{L})$ \\
\hline $\mathrm{Mg}(\mathrm{mg} / \mathrm{L})$
\end{tabular} & 24 & 97 & 89 & 87 & 72 & 78 & $\mathbf{9 7}$ & $\mathbf{7 2}$ & $\mathbf{8 4}$ \\
\hline $\mathrm{Na}(\mathrm{mg} / \mathrm{L})$ & 41 & 378 & 189 & 588 & 144 & 151 & $\mathbf{5 8 8}$ & $\mathbf{4 1}$ & $\mathbf{2 4 9}$ \\
\hline $\mathrm{K}(\mathrm{mg} / \mathrm{L})$ & 14 & 35 & 5 & 10 & 13 & 9 & $\mathbf{3 5}$ & $\mathbf{5}$ & $\mathbf{1 4}$ \\
\hline
\end{tabular}




\begin{tabular}{|c|c|c|c|c|c|c|c|c|c|}
\hline $\mathrm{Fe}(\mathrm{mg} / \mathrm{L})$ & 8,00 & $<0,01$ & $<0,01$ & $<0,01$ & $<0,01$ & $<0,01$ & $\mathbf{8 , 0}$ & $<\mathbf{0 , 0 1}$ & $\mathbf{8 , 0}$ \\
\hline $\mathrm{Mn}(\mathrm{mg} / \mathrm{L})$ & 1,2 & 0,2 & 0,1 & $<0,05$ & $<0,05$ & $<0,05$ & $\mathbf{1 , 2}$ & $\mathbf{0 , 1}$ & $\mathbf{0 , 5}$ \\
\hline $\mathrm{Cl}(\mathrm{mg} / \mathrm{L})$ & 12 & 852 & 171 & 756 & 784 & 302 & $\mathbf{8 5 2}$ & $\mathbf{1 2}$ & $\mathbf{4 7 9}$ \\
\hline $\begin{array}{c}\mathrm{SO}_{4} \\
(\mathrm{mg} / \mathrm{L})\end{array}$ & 59 & 75 & 124 & 688 & 33 & 15 & $\mathbf{6 8 8}$ & $\mathbf{1 5}$ & $\mathbf{1 6 5}$ \\
\hline $\begin{array}{c}\mathrm{HCO} \\
(\mathrm{mg} / \mathrm{L})\end{array}$ & 350 & 605 & 355 & 100 & 130 & 340 & $\mathbf{6 0 5}$ & $\mathbf{1 0 0}$ & $\mathbf{3 1 3}$ \\
\hline $\begin{array}{c}\mathrm{NO} \\
(\mathrm{mg} / \mathrm{L})\end{array}$ & $<0,01$ & 17 & 11 & 8 & 10 & 9 & $\mathbf{1 7}$ & $\mathbf{8}$ & $\mathbf{1 1}$ \\
\hline $\begin{array}{c}\mathrm{NO} \\
(\mathrm{mg} / \mathrm{L})\end{array}$ & $<0,01$ & $<0,01$ & $<0,01$ & $<0,01$ & $<0,01$ & $<0,01$ & $<\mathbf{0 , 0 1}$ & $<\mathbf{0 , 0 1}$ & $<\mathbf{0 , 0 1}$ \\
\hline $\begin{array}{c}\mathrm{Alcalinidad} \\
(\mathrm{mg} / \mathrm{L})\end{array}$ & 308 & 461 & 341 & 438 & 407 & 278 & $\mathbf{4 6 1}$ & $\mathbf{3 0 8}$ & $\mathbf{3 9 2}$ \\
\hline $\begin{array}{c}\text { Dureza } \\
(\mathrm{mg} / \mathrm{L})\end{array}$ & 287 & 496 & 291 & 82 & 107 & 279 & $\mathbf{4 9 6}$ & $\mathbf{8 2}$ & $\mathbf{2 5 7}$ \\
\hline
\end{tabular}

\section{Berisso (Octubre-2016)}

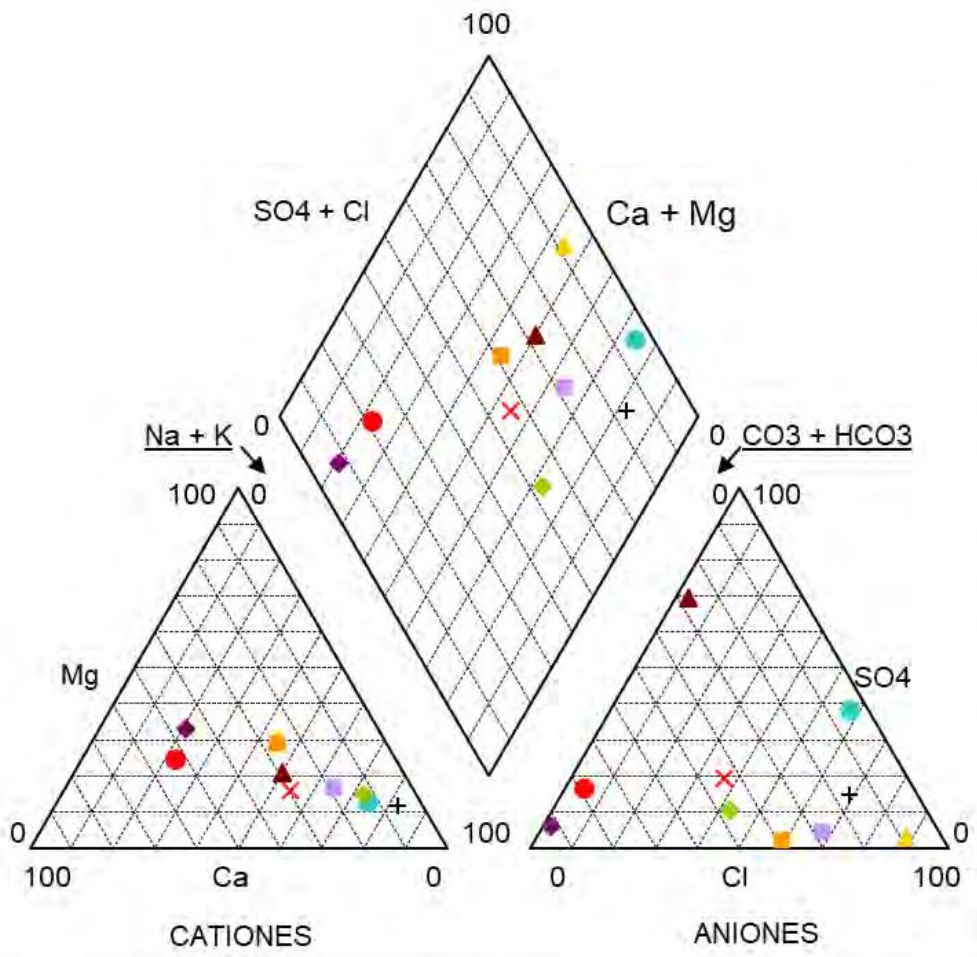

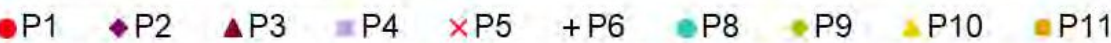

Figura 8.42 Diagrama de Piper para el muestreo de octubre de 2016. 
En el análisis de los diagramas de Schoeller-Berkaloff separados para los tres ambientes se observa que para la planicie de marea relictual el pozo P3 presenta mayores contenidos de sulfatos respecto de los cloruros (Figura 8.43) y en todos los pozos domina el catión sodio.

\section{Planicie de marea relictual (Octubre-2016)}

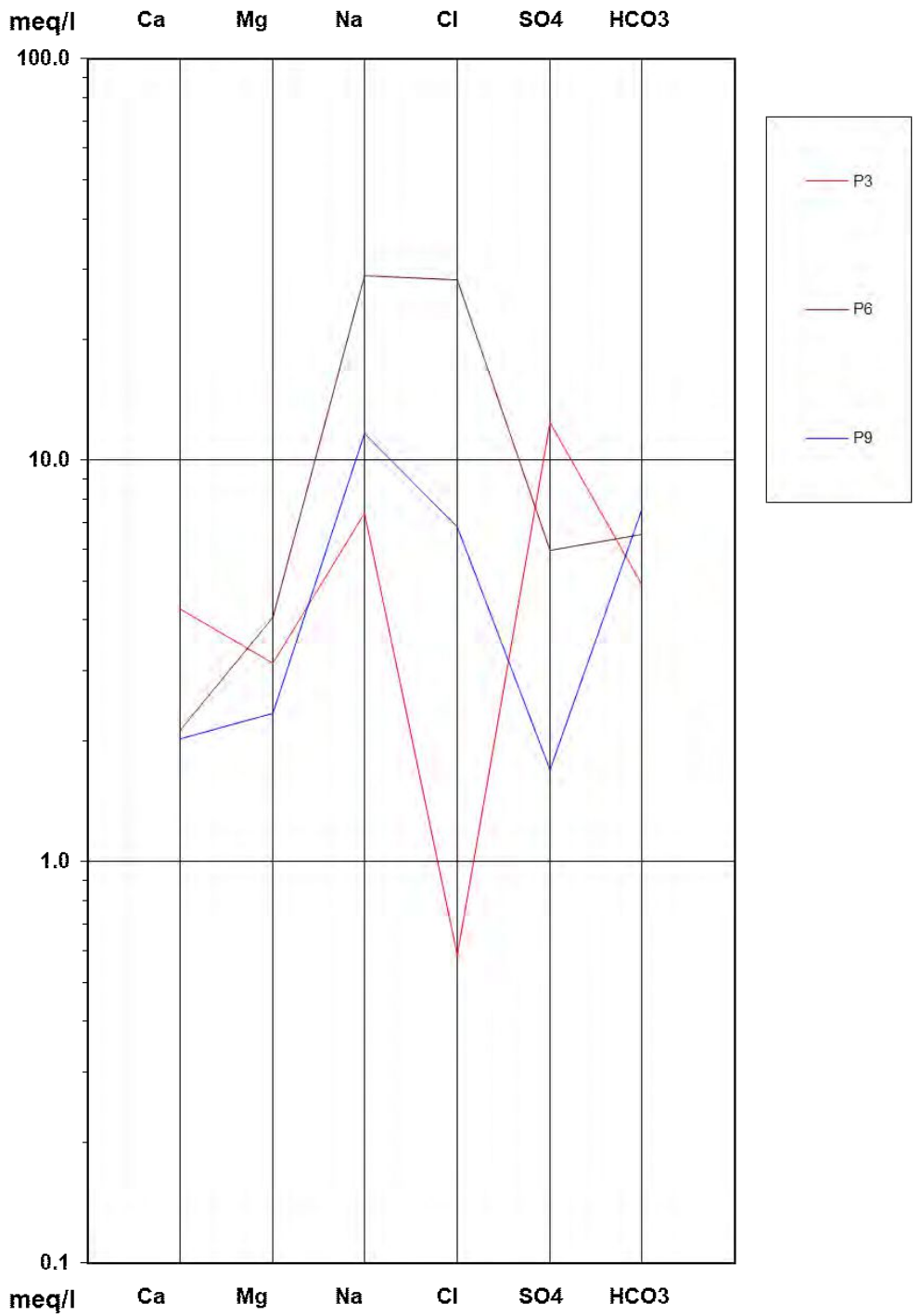

Figura 8.43 Diagrama de Schoeller-Berkaloff para la planicie de marea relictual.

En la llanura estuárica (Figura 8.44) se destaca que en el pozo P1 el anión dominante es el bicarbonato y el catión, el calcio mientras que en el resto de las muestras domina el cloruro y el sodio. El pozo P8 presenta también una elevada concentración de sulfatos. 


\section{Llanura estuárica (Octubre-2016)}

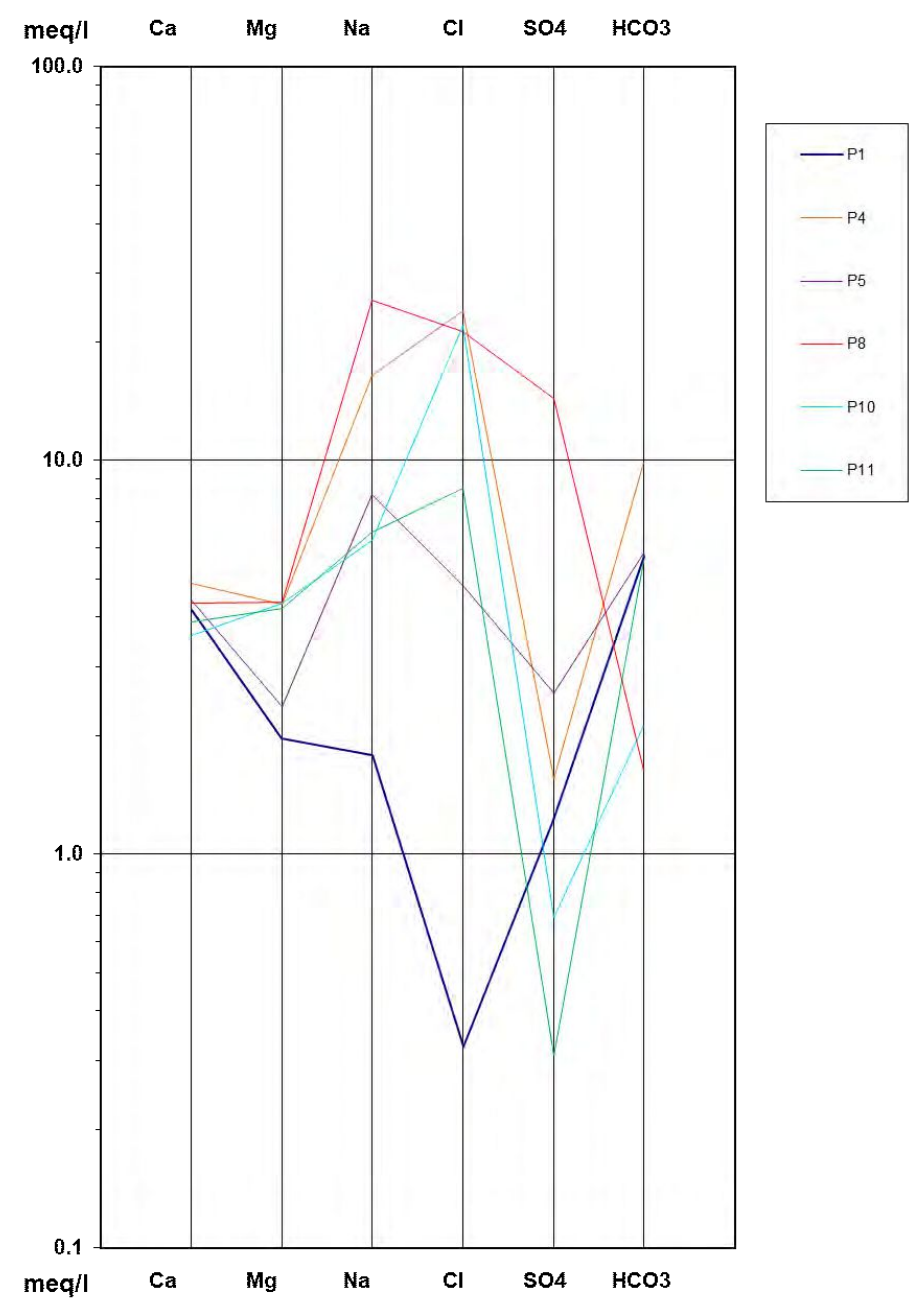

Figura 8.44 Diagrama de Schoeller-Berkaloff para la llanura estuárica.

Para la muestra del cordón litoral se advierte dominio del calcio y el bicarbonato (Figura 8.45). 
Cordón litoral (Octubre-2016)

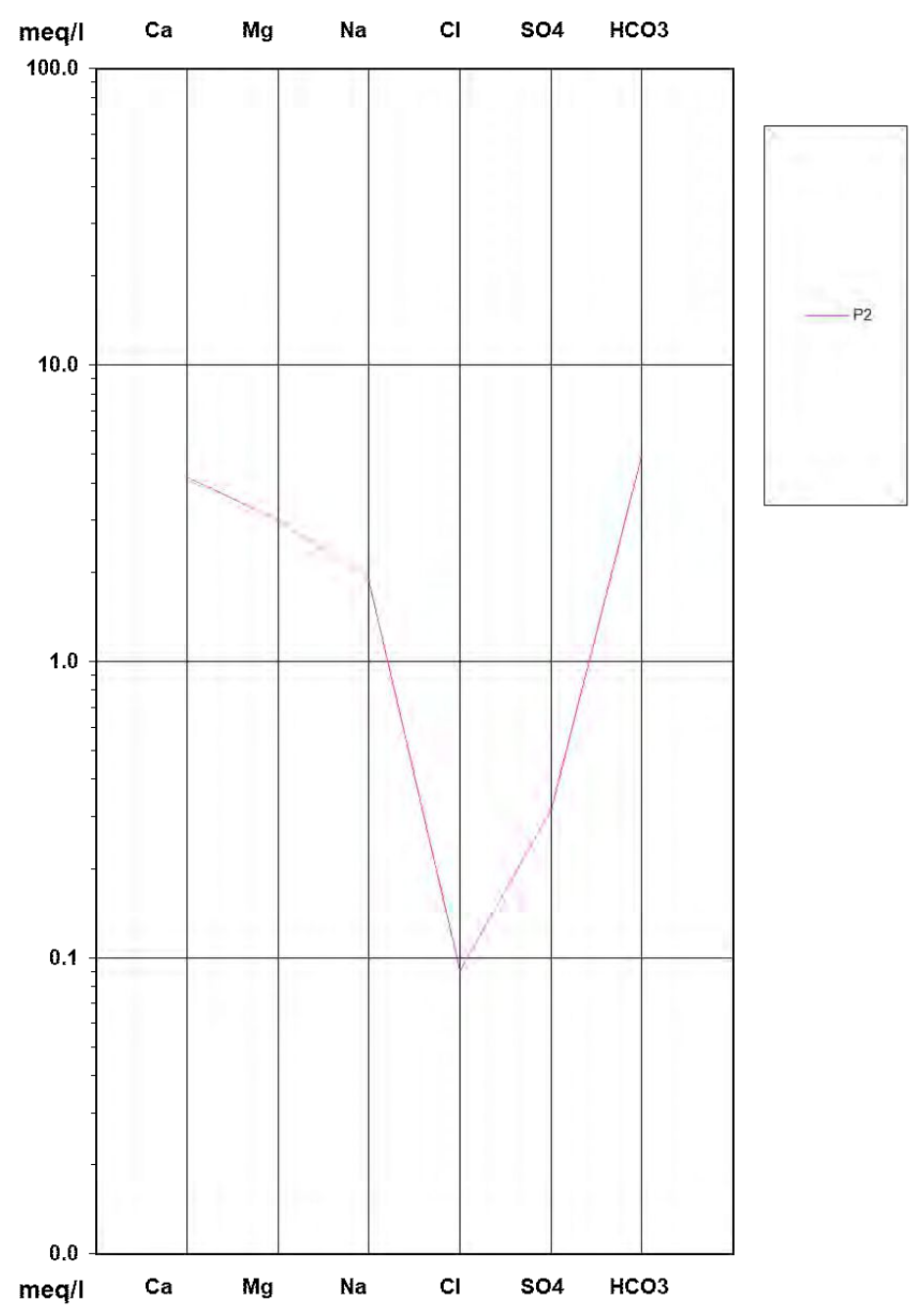

Figura 8.45 Diagrama de Schoeller-Berkaloff para el cordón litoral.

\subsubsection{Variaciones areales}

Se han seleccionado algunos elementos para describir la distribución areal mediante mapas de isotenores.

Respecto a la CE se puede observar que la mayor parte del área presenta valores superiores a los $1000 \mu \mathrm{S} / \mathrm{cm}$ (Figura 8.46) llegando a valores de $2500 \mu \mathrm{S} / \mathrm{cm}$. Las menores concentraciones se detectan en la franja costera más cercana al Río de la Plata, hacia el sureste y en el desarrollo del cordón litoral. 
El cordón litoral presenta los valores más bajos de sulfatos (Figura 8.47) pero el resto de los ambientes se caracteriza por concentraciones superiores a $100 \mathrm{mg} / \mathrm{L}$ llegando hasta $700 \mathrm{mg} / \mathrm{L}$ en algunos sectores de la llanura estuárica.

Las menores concentraciones de dureza (Figura 8.48) se visualizan, en general, en los pozos de la planicie de marea relictual y en un sector cercano al río, en la zona del pozo $\mathrm{P} 1$, con influencia del mismo.

Los bicarbonatos parecen incrementarse en sentido SE-NO, con mayores valores (450-600 mg/L) en un sector de la llanura estuárica (Figura 8.49).

Los cloruros se comportan en el sentido opuesto a los bicarbonatos, aumentando su concentración en sentido NO-SE (Figura 8.50). Los mayores valores entre 750 y 1000 $\mathrm{mg} / \mathrm{L}$ se observan en algunos sectores de la llanura estuárica y en la planicie de marea relictual.

El hierro se incrementa en sentido NO-SE con valores entre 1,5 y $8 \mathrm{mg} / \mathrm{L}$ en los sectores más cercanos al río (Figura 8.51).

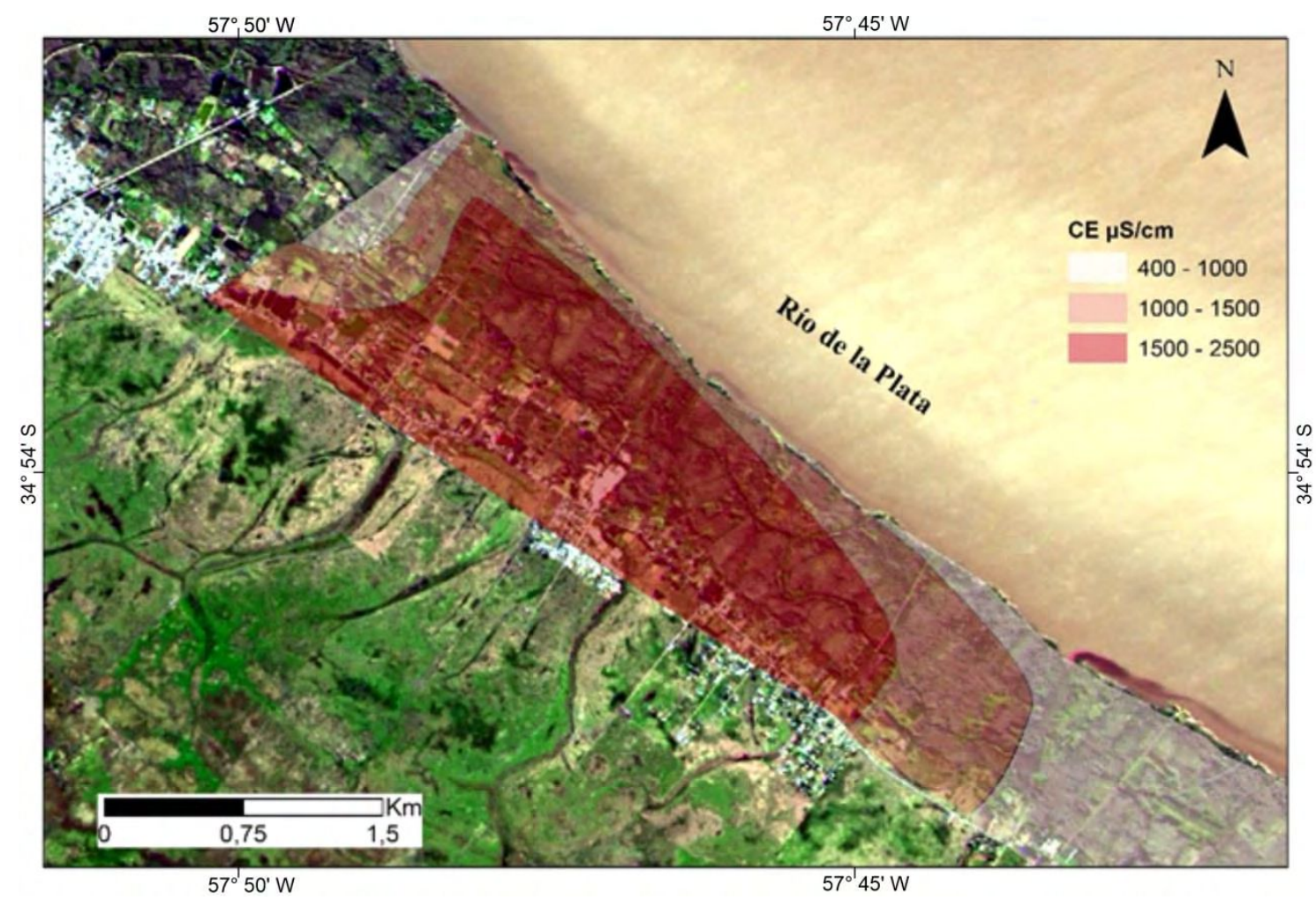

Figura 8.46 Mapa de distribución de CE (2016). 


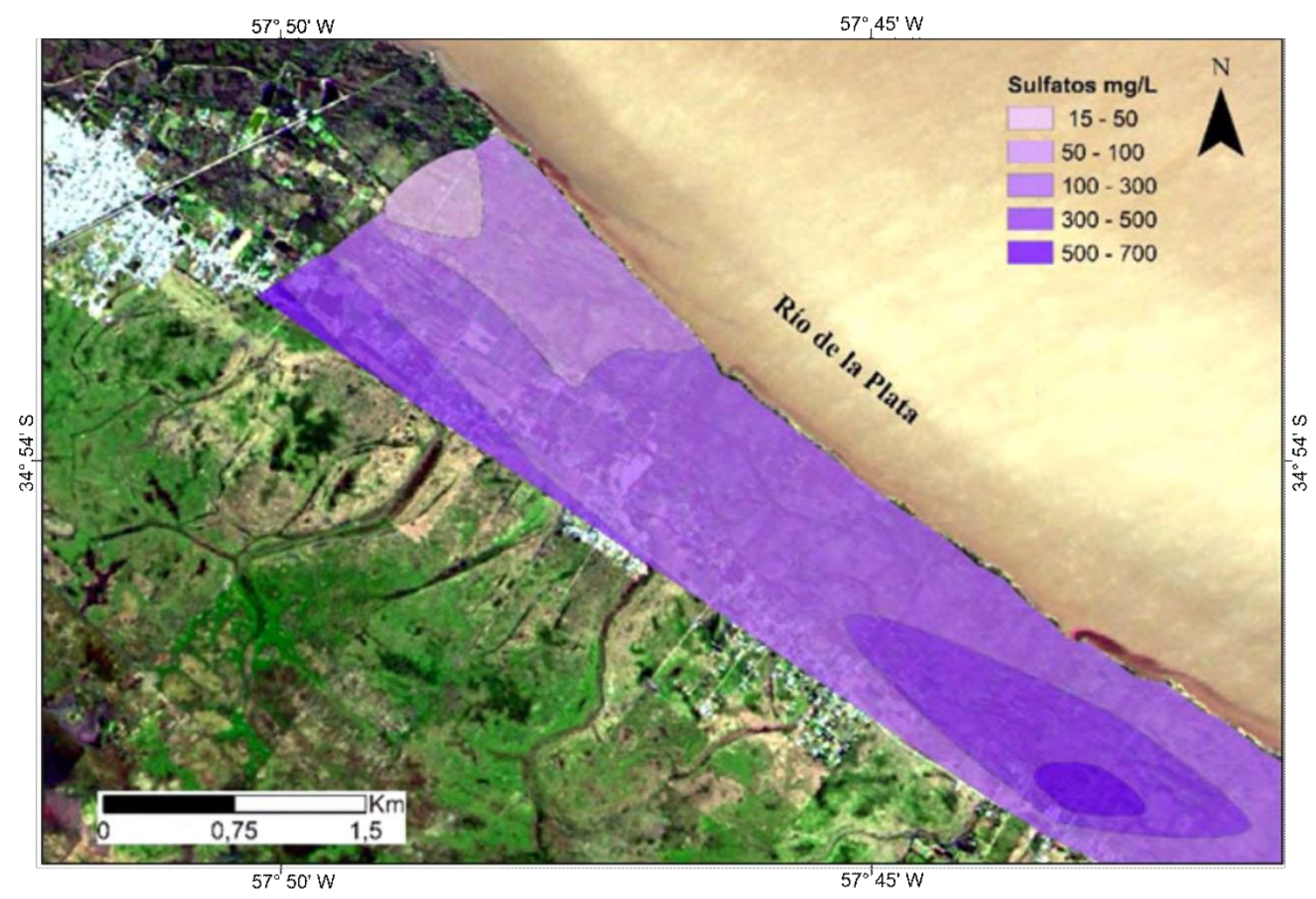

Figura 8.47 Mapa de distribución de sulfatos (2016).

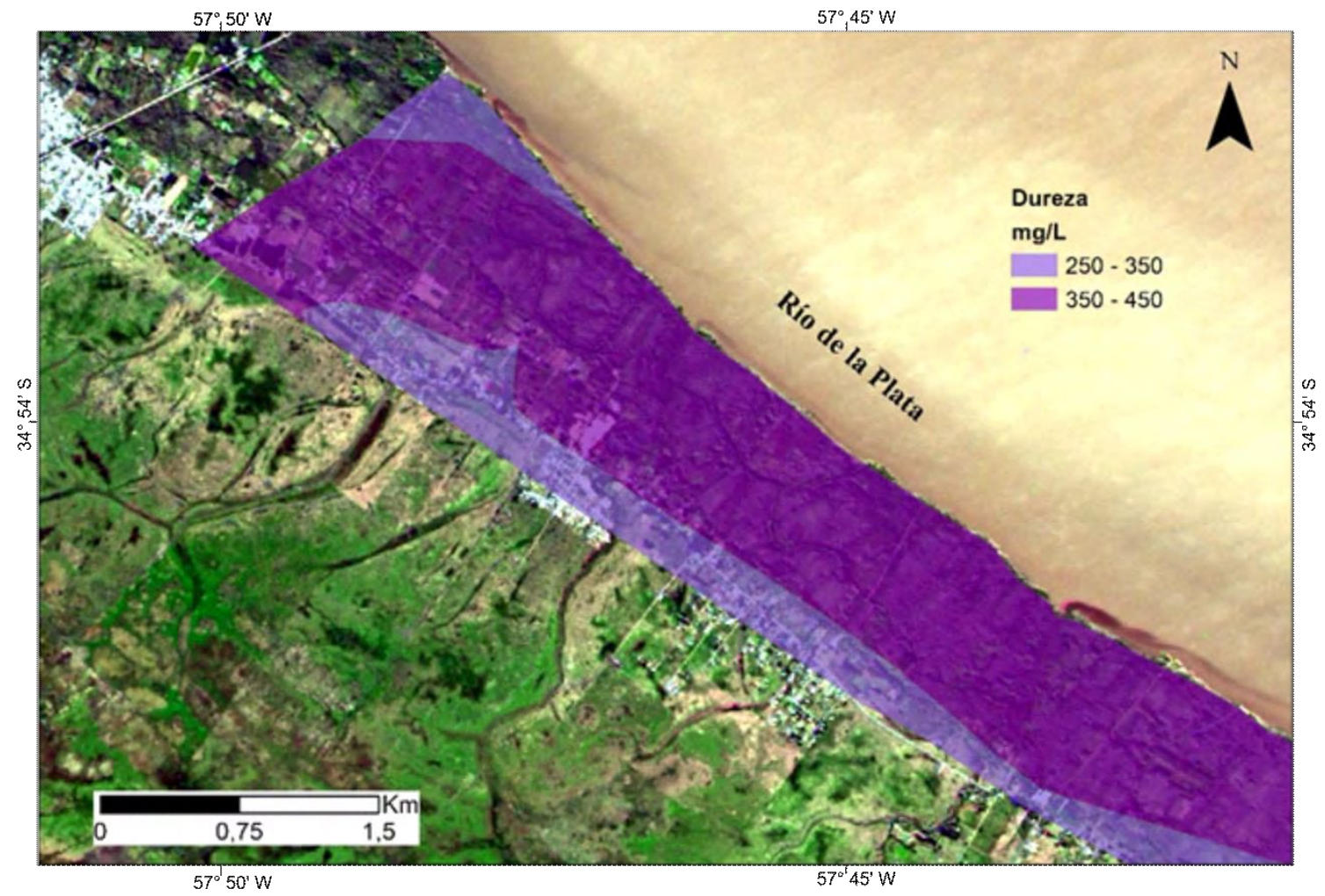

Figura 8.48 Mapa de distribución de dureza (2016). 


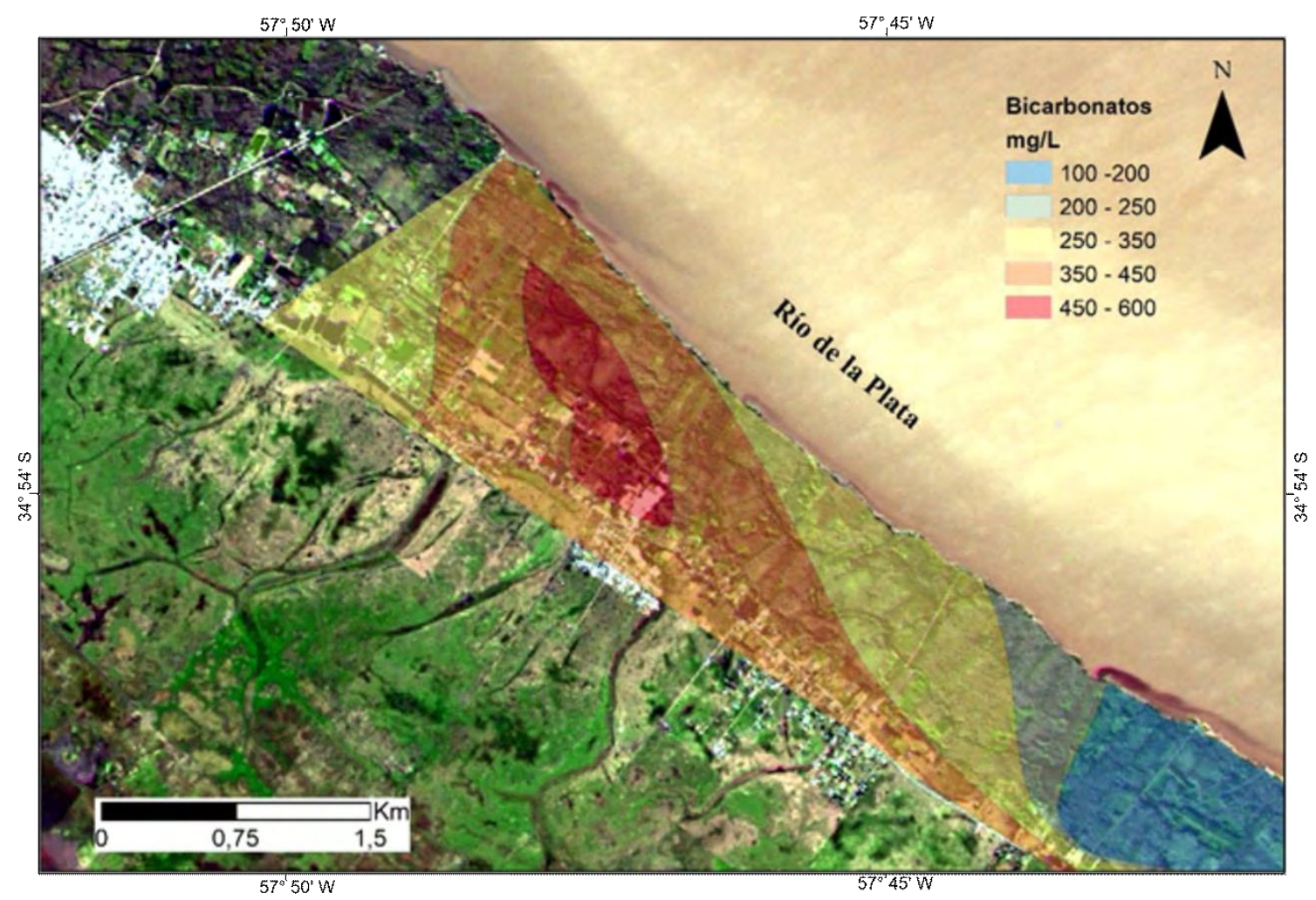

Figura 8.49 Mapa de distribución de bicarbonatos (2016).

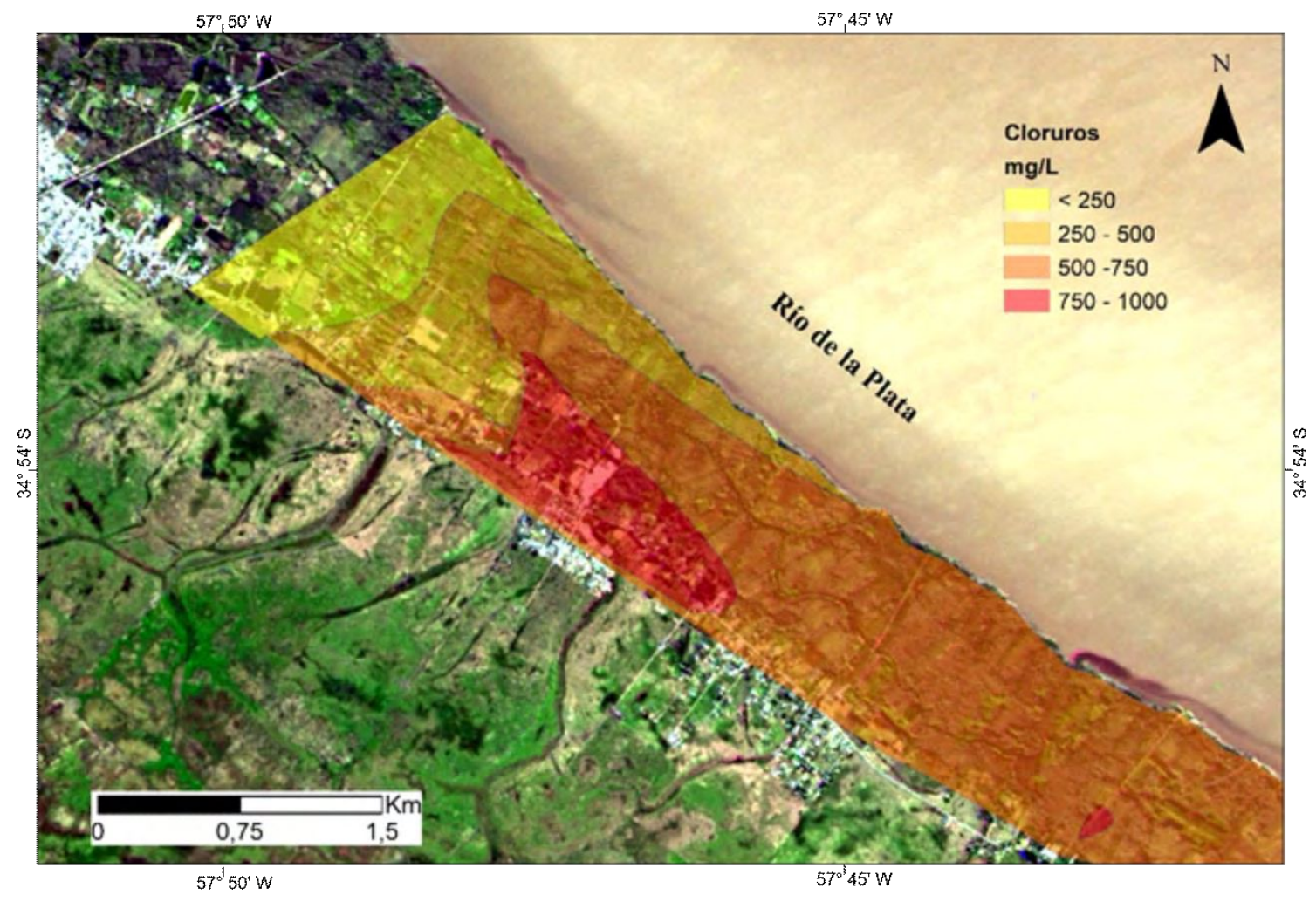

Figura 8.50 Mapa de distribución de cloruros (2016). 


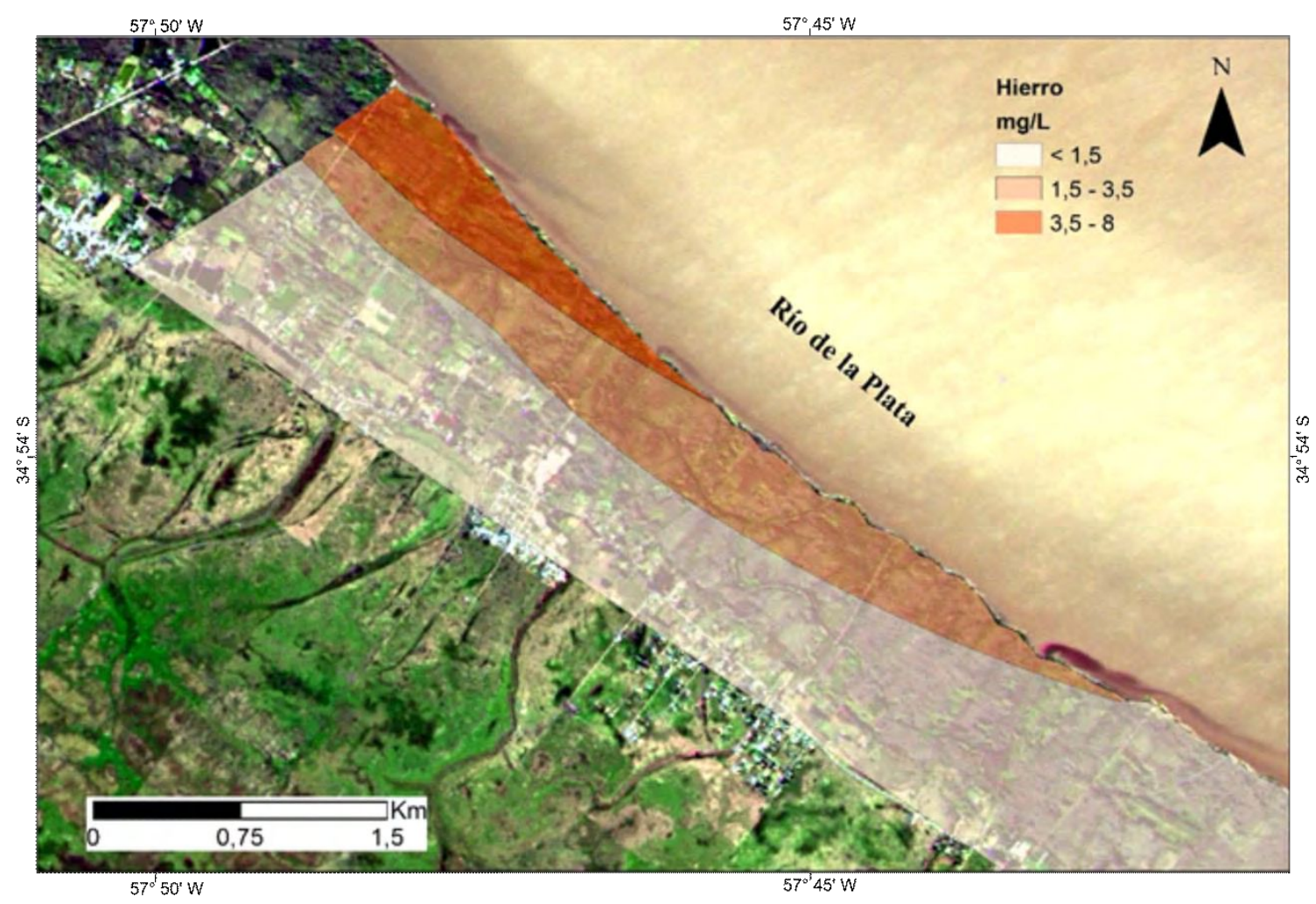

Figura 8.51 Mapa de distribución de hierro (2016).

\subsection{Caracterización de isótopos estables (Deuterio y Oxígeno-18) del agua subterránea.}

\subsubsection{Costa marítima}

Los resultados de ${ }^{18} \mathrm{O},{ }^{2} \mathrm{H}$ y exceso de deuterio (d) se presentan en la Tabla 27 para el muestreo de septiembre de 2016. La composición isotópica de las aguas subterráneas se encuentra en un rango de $-6,3 \%$ a $-3,8 \%$ en $\delta^{18} \mathrm{O},-41 \%$ a $-19 \%$ en $\delta^{2} \mathrm{H}$ y d (\%o) entre 9 y 11.

Tabla 27 Análisis isotópicos, cloruros $(\mathrm{Cl})$ y conductividad eléctrica del agua (CE) para los sectores de recarga y descarga.

\begin{tabular}{|c|c|c|c|c|c|c|}
\hline & Pozo & $\mathrm{CE}(\mu \mathrm{S} / \mathrm{cm})$ & $\mathrm{Cl}$ (meq/L) & $\delta^{18} \mathrm{O}(\%)$ & $\delta^{2} \mathrm{H}(\%)$ & d (\%o) \\
\hline \multirow{3}{*}{$\begin{array}{c}\text { Descarga } \\
\text { (oeste) }\end{array}$} & MT1 & 1751 & 10.6 & $-5,1$ & -32 & 9 \\
\hline & MT8 & 1362 & 6,3 & $-4,8$ & -28 & 11 \\
\hline & MT17 & 853 & 2,2 & $-3,9$ & -22 & 9 \\
\hline \multirow{8}{*}{$\begin{array}{l}\text { Recarga } \\
\text { (centro) }\end{array}$} & MT2 & 1125 & 2,3 & $-4,8$ & -28 & 10 \\
\hline & MT3 & 387 & 0,3 & $-6,0$ & -38 & 10 \\
\hline & MT6 & 502 & 0,5 & $-3,9$ & -20 & 11 \\
\hline & MT7 & 711 & 0,6 & $-4,7$ & -27 & 10 \\
\hline & MT10 & 598 & 0,8 & $-4,5$ & -24 & 11 \\
\hline & MT11 & 511 & 0,7 & $-3,8$ & -19 & 11 \\
\hline & MT14 & 566 & 0,8 & $-4,1$ & -24 & 9 \\
\hline & MT15 & 923 & 0,8 & $-4,2$ & -25 & 9 \\
\hline
\end{tabular}




\begin{tabular}{|c|c|c|c|c|c|c|} 
& MT16 & 439 & 0,3 & $-4,8$ & -28 & 10 \\
\cline { 2 - 7 } & MT18 & 368 & 0,5 & $-5,9$ & -32 & 15 \\
\hline \multirow{4}{*}{$\begin{array}{c}\text { Descarga } \\
\text { (este) }\end{array}$} & MT4 & 768 & 2,9 & $-4,0$ & -22 & 9 \\
\cline { 2 - 7 } & MT5 & 672 & 1,1 & $-6,3$ & -41 & 9 \\
\cline { 2 - 7 } & MT12 & 647 & 1,3 & $-4,4$ & -25 & 10 \\
\cline { 2 - 7 } & MT13 & 842 & 2,1 & $-4,1$ & -24 & 9 \\
\cline { 2 - 7 } & MT19 & 627 & 0,9 & $-5,6$ & -33 & 11 \\
\hline
\end{tabular}

Teniendo en cuenta la localización de los pozos según la zona principal de recarga (sector central de la duna) y de descarga (este y oeste) se puede generalizar que los pozos localizados al este tienen en su mayoría valores de $\delta^{18} \mathrm{O}$ entre $-6,3 \%$ y $-4,0 \%$ y de $-41 \%$ a $-22 \%$ para el $\delta^{2} \mathrm{H}$. El área en el centro de la duna presenta valores de $6,0 \%$ a $-3,8 \%$ en $\delta^{18} \mathrm{O}$ y de $-41 \%$ a $-22 \%$ en $\delta^{2} \mathrm{H}$. Para el agua subterránea del sector oeste, el $\delta^{18} \mathrm{O}$ varía entre $-5,1 \%$ y $-3,9 \%$ mientras que el $\delta^{2} \mathrm{H}$ lo hace entre $-32 \%$ y $22 \%$.

Los análisis isotópicos se representaron en un diagrama convencional $\delta^{2} \mathrm{H} v s \delta^{18} \mathrm{O}$ junto a la línea meteórica local definida por Dapeña (2008) a partir de las estaciones Ciudad Universitaria (Ciudad de Buenos Aires), período 1979-2003 y Estación Azul (Ciudad de Azul, provincia de Buenos Aires), período 1998-2003, i.e.: $\delta^{2} \mathrm{H} \%$ o $=8$ $\delta^{18} \mathrm{O} \%+12 / 14$ (Figura 8.52) y como referencia el valor de agua de mar medido en Mar de Ajó y el valor promedio del agua del océano (SMOW). Dado que no existen registros isotópicos del agua de lluvia de Mar del Tuyú se han utilizado las líneas mencionadas ya que se ha demostrado que son válidas para la región (Carretero et al., 2013b). Las muestras de agua subterránea del área de estudio están comprendidas por estas líneas, indicando su origen meteórico. La composición isotópica del agua subterránea obtenida responde a la composición isotópica promedio del agua de lluvia lo que confirma lo establecido por Gat y Tzur (1967) para climas templados y analizado por Panarello et al. (1995), Carretero (2011) y Carretero et al. (2013b) para este sector de la costa bonaerense. 


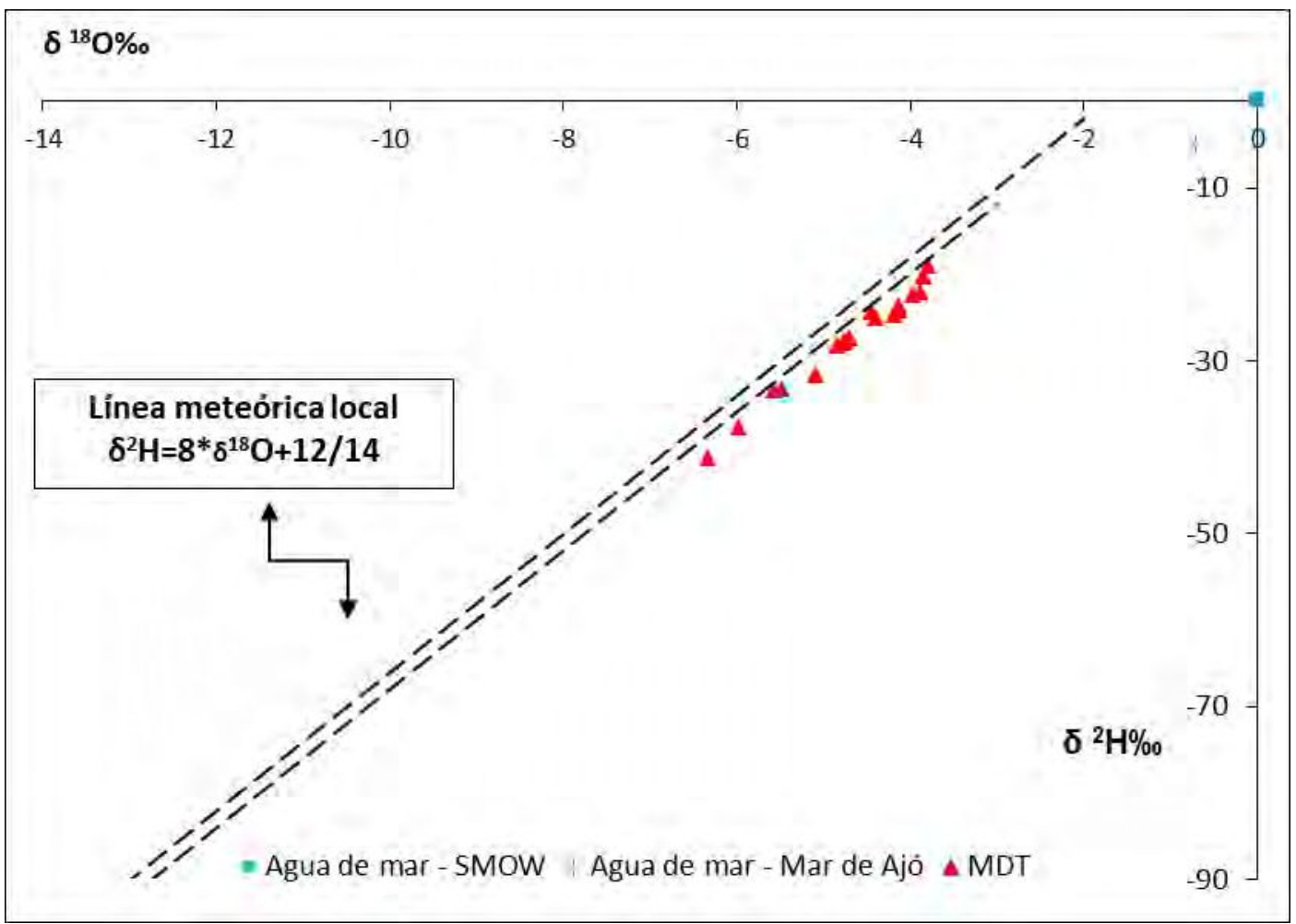

Figura 8.52 Gráfico $\delta^{2} \mathrm{H}$ vs $\delta^{18} \mathrm{O}$ (septiembre-2016).

En el gráfico cloruros vs $\delta^{2} \mathrm{H} \%$ (Figura 8.53) se observa que los pozos MT1 y MT8 presentan concentraciones de cloruros algo más elevadas que el resto. Ambas muestras se encuentran en el ambiente transicional hacia la llanura deprimida que se caracteriza por elevado contenido salino. Por otro lado, los valores de $\delta^{18} \mathrm{O}$ y $\delta^{2} \mathrm{H} \%$ así como el exceso de deuterio son consistentes con la precipitación y, además, la CE se encuentra por debajo de los $2000 \mu \mathrm{S} / \mathrm{cm}$ en este sector con lo cual, si bien se detecta un desmejoramiento de la calidad química del agua, no parece indicar una mezcla con el agua salobre de la llanura deprimida, cosa que sí ocurre más al norte del Partido de La Costa, en la localidad de San Clemente del Tuyú (Carretero, 2011).

El agua subterránea al este de la duna, donde se localiza la interfase agua dulce agua salada marina, no presenta signos de mezcla, indicando en ese caso que no hay manifestación de un proceso de intrusión salina, lo cual puede ser detectado a partir de esta metodología y de hecho ha sido identificado en Santa Teresita, localidad inmediatamente al norte de Mar del Tuyú (Carretero et al., 2013a; Perdomo et al., 2013c). 


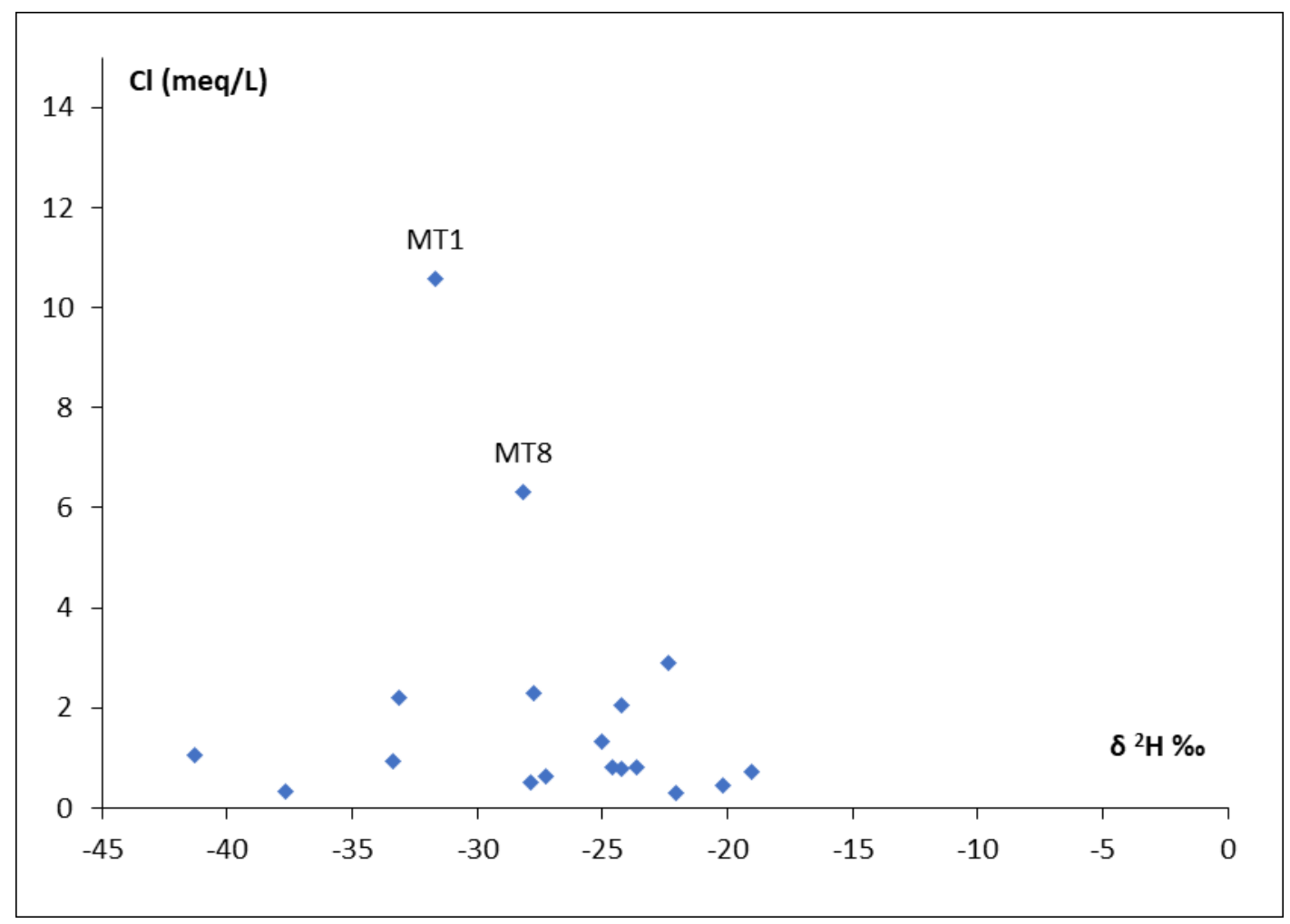

Figura 8.53 Gráfico $\delta^{2} \mathrm{H} \%$ vs cloruros.

\subsubsection{Costa estuárica}

Los resultados de ${ }^{18} \mathrm{O},{ }^{2} \mathrm{H}$ y exceso de deuterio (d) se presentan en la Tabla 28 y las Figuras 8.54, 8.55 y 8.56 para el muestreo de octubre de 2016. La composición isotópica de las aguas subterráneas se encuentra en un rango de $-5,5 \%$ a $-3,0 \%$ en $\delta^{18} \mathrm{O},-30 \%$ a $-10 \%$ en $\delta^{2} \mathrm{H}$ y d (\%o) entre 14 y $8 \%$.

Tabla 28 Datos isotópicos y químicos separados según ambientes.

\begin{tabular}{|c|c|c|c|c|c|c|c|}
\hline Ambiente & Pozo & $\begin{array}{c}\text { CE } \\
(\mu \mathbf{S} / \mathbf{c m})\end{array}$ & $\mathbf{C l}(\mathbf{m g} / \mathbf{L})$ & $\begin{array}{c}\text { SO4 } \\
(\mathbf{m g} / \mathbf{L})\end{array}$ & $\begin{array}{c}\mathbf{\delta}^{18} \mathbf{O} \\
(\%)\end{array}$ & $\begin{array}{c}\boldsymbol{\delta}^{2} \mathbf{H} \\
(\%)\end{array}$ & $\mathbf{d}(\%)$ \\
\hline \multirow{3}{*}{$\begin{array}{c}\text { Llanura } \\
\text { Estuárica }\end{array}$} & $\mathrm{P} 1$ & 877 & 11,5 & 58,6 & $-4,4$ & -24 & 11 \\
\cline { 2 - 8 } & $\mathrm{P} 4$ & 3354 & 852,3 & 74,6 & $-4,4$ & -24 & 11 \\
\cline { 2 - 8 } & $\mathrm{P} 5$ & 1551 & 171,3 & 123,6 & $-5,0$ & -25 & 14 \\
\cline { 2 - 8 } & $\mathrm{P} 8$ & 428 & 756,3 & 688,2 & $-3,5$ & -19 & 9 \\
\cline { 2 - 8 } & $\mathrm{P} 10$ & 1219 & 783,5 & 33,1 & $-3,3$ & -19 & 8 \\
\cline { 2 - 8 } & $\mathrm{P} 11$ & 990 & 301,7 & 14,8 & $-4,2$ & -23 & 11 \\
\hline \multirow{2}{*}{$\begin{array}{c}\text { Cordón Litoral } \\
\text { Planicie de }\end{array}$} & $\mathrm{P} 2$ & 573 & 3,2 & 15,2 & $-3,0$ & -10 & 14 \\
\cline { 2 - 8 } marea & $\mathrm{P} 3$ & 1730 & 20,8 & 596,8 & $-4,4$ & -23 & 12 \\
\cline { 2 - 8 } & $\mathrm{P} 6$ & 2900 & 1000,2 & 286,2 & $-5,0$ & -27 & 13 \\
\cline { 2 - 8 } & $\mathrm{P} 9$ & 684 & 241,7 & 81,5 & $-5,5$ & -30 & 14 \\
\hline
\end{tabular}


Los análisis isotópicos se representaron en un diagrama convencional $\delta^{2} \mathrm{H} v s . \delta^{18} \mathrm{O}$ junto a la línea meteórica local definida por Dapeña (2008) a partir de la estación Ciudad Universitaria (Ciudad de Buenos Aires) para el período 1979-2003. i.e. $\delta^{2} \mathrm{H} \%$ $8 \delta^{18} \mathrm{O} \%{ }^{+12 / 14}$ (Figura 8.54). La composición isotópica de la precipitación de esta estación tiene un promedio ponderado de ${ }^{18} \mathrm{O}=-5,3 \%$ o, ${ }^{2} \mathrm{H}=-30 \%$ y una amplia variabilidad a lo largo de los años con valores extremos de $-1,9 \%$ y $-0,9 \%$ para ${ }^{18} \mathrm{O}$ y 85\% y $9 \%$ para ${ }^{2} \mathrm{H}$ (Dapeña, 2008).

Debido a que esta zona sufre la influencia de las mareas también se considera la composición isotópica del agua del estuario del Río de la Plata. A partir de 10 años de registro (1997-2007), Panarello y Dapeña (2009) muestran la variabilidad de su composición en función de parámetros meteorológicos como la zona de interconvergencia tropical (ITCZ) y el fenómeno El Niño - Oscilación del Sur (ENSO), con valores entre $-6,6 \%$ y $2,7 \%$. para ${ }^{18} \mathrm{O},-45 \%$ y $-15 \%$ o para ${ }^{2} \mathrm{H}$ y excesos de deuterio entre $1 \%$ y $18 \%$. EI INGEIS continua con el monitoreo del estuario e informa que el promedio de la composición isotópica para el período 1997-2016 es -4,4\% para ${ }^{18} \mathrm{O}$ y $-14 \%$ para ${ }^{2} \mathrm{H}$ con valores extremos de ${ }^{18} \mathrm{O}$ entre $-6,6 \%$ y $2,7 \%$ y ${ }^{2} \mathrm{H}$ entre $-45 \%$ $-14 \%$ con excesos de deuterio 7\%o (Dapeña, comunicación personal) y que particularmente en los meses de abril y mayo 2016 la composición isotópica era de ${ }^{18} \mathrm{O}$ $=-4,1 \%$, ${ }^{2} \mathrm{H}=-24 \%$ y $\mathrm{d}=8 \%$ o (INGEIS, 2019). Santucci et al. (2017) y Cellone et al. (2019) midieron composiciones similares en 2015 y 2016 respectivamente en aguas del Río de La Plata. 


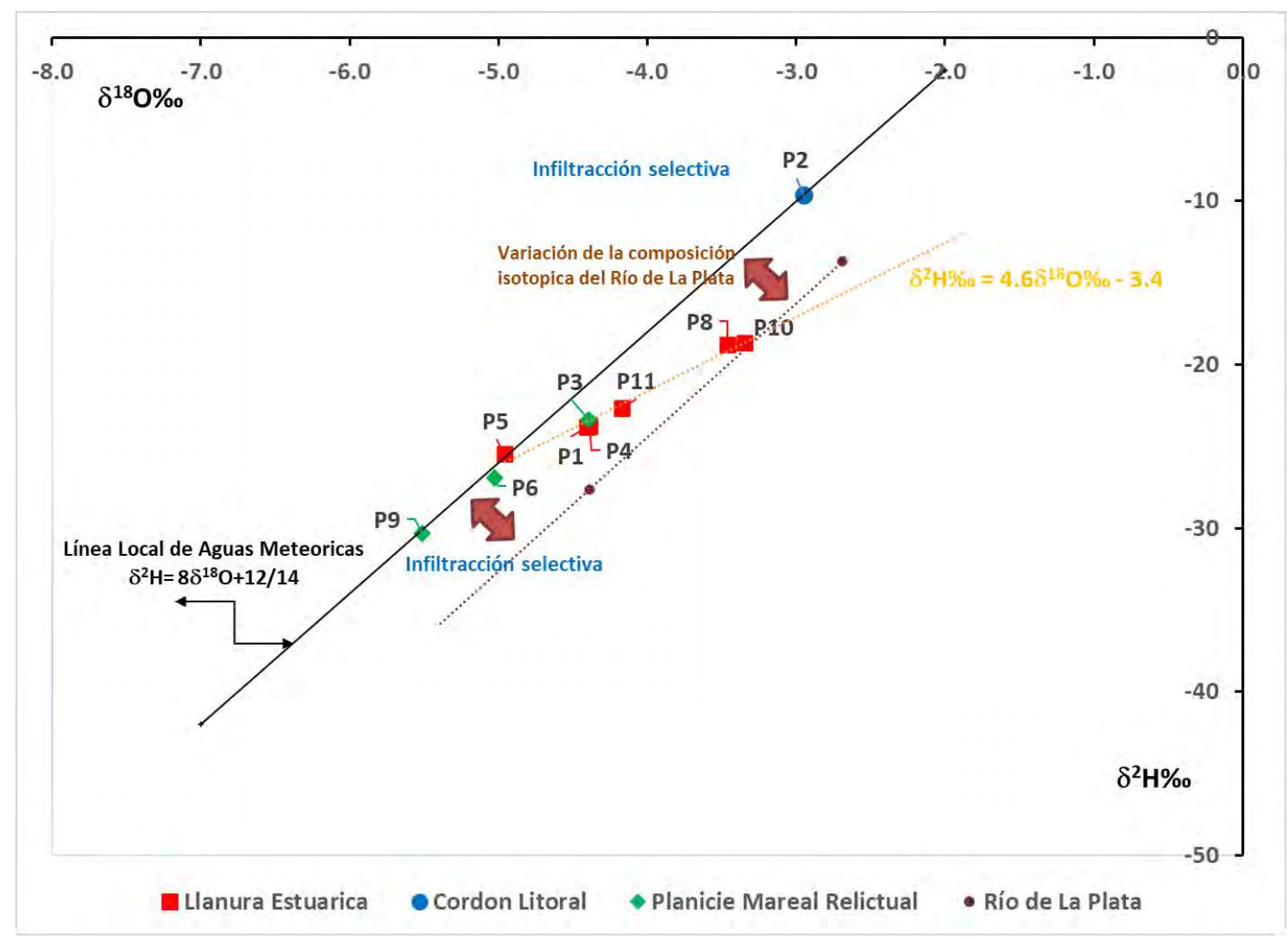

Figura $8.54 \delta^{2} \mathrm{H}(\%)$ vs. $\delta^{18} \mathrm{O}(\%)$. Donde en rojo punteado se indica el proceso de evaporación y en amarillo la ecuación de la recta de evaporación y la línea punteada negra la variación isotópica del Río de La Plata.

La composición isotópica del agua subterránea en climas templados refleja con buena aproximación la composición isotópica del promedio de la precipitación de una localidad (Gat y Tzur, 1967). Sin embargo, pueden ocurrir procesos que la modifiquen durante los mecanismos de recarga, tal como la evaporación previa a la infiltración o variaciones estacionales de la precipitación evidenciadas por una infiltración selectiva. Fontes (1980) estableció que las lluvias individuales muestran una composición isotópica con una amplia dispersión, pero que converge en el promedio anual dentro de las fluctuaciones climáticas normales de un año a otro. El agua subterránea promedia bastante bien ese contenido, indicando que no hay fraccionamiento significativo durante el proceso de recarga. Una distribución homogénea de los isótopos en el agua indica su origen en tanto que las variaciones describen su historia. La comparación entre los valores $\delta^{18} \mathrm{O}$ de las aguas subterráneas y la precipitación a escala regional muestra la conexión que existe entre ambas, aunque como se indicó precedentemente bajo ciertas circunstancias la composición isotópica del agua subterránea puede diferir de la precipitación media anual (Gat, 1983). La atenuación de las variaciones durante la recarga y el grado de homogeneidad de las aguas en un acuífero están relacionados con el mecanismo de recarga y con los patrones de flujo y 
mezcla en el acuífero (Gat, 1974). En el caso de acuíferos poco profundos es frecuente encontrar en los primeros metros una composición isotópica más heterogénea que refleja la variabilidad de la precipitación. Por otro lado, en la planicie baja de la provincia de Buenos Aires influenciada por las aguas del Río de La Plata y sometida (sujeta) a las sudestadas. Pera lbarguren et al. (2003; 2007) confirman a través de la concentración de tritio que el ingreso de las aguas del estuario debido a la marea recarga el sistema.

Las muestras de agua subterránea del área de estudio son consistentes con los valores de precipitación y similares a los informados por Panarello et al. (1995) y Dapeña y Panarello (2004) pero además se observan diversos procesos modificadores (Figura 8.54). La composición isotópica y el bajo contenido de cloruros del pozo P2 (cordón litoral) indican infiltración selectiva que no ha alterado la composición de la lluvia original. La composición isotópica de los pozos ubicados en la planicie de marea relictual (P3, P6 y P9) tienen composición isotópica variable y P6 y P9 responden a infiltración selectiva de la precipitación. En el caso de P9, responde a una precipitación más empobrecida y valores de cloruros bajos. En cambio, P3 posee exceso de deuterio < $10 \%$ pero muy bajo contenido de cloruros sugiriendo influencia de las aguas del Río de La Plata por acción de la marea. Por otra parte, el P6 tiene mayor salinidad, pero no muestra evidencias de evaporación y el contenido de cloruros probablemente se deba a la disolución de sales por tránsito relacionado con los patrones de flujo y su ubicación en la zona de descarga del sistema (Figura 8.54 y 8.55).

En los pozos P1, P4, P5, P8, P10 y P11 ubicados en la llanura estuárica y sometidos a la influencia de las mareas se registran tres escenarios. EI P5 no muestra influencia de las aguas del estuario y bajos contenidos de cloruros. La composición isotópica del resto de los pozos revela una mezcla con aguas del estuario, pero además $P 4, P 8, P$ 10 y P11 tiene contenidos de cloruros consistentes con evaporación y las muestras se alinean en una recta ${ }^{2} \mathrm{H} \%$ o $=4.6{ }^{18} \mathrm{O} \%$-3,4. Este proceso puede ser comprobado en el grafico $\mathrm{Cl}(\mathrm{mg} / \mathrm{L})$ vs. ${ }^{18} \mathrm{O} \%$. (Figura 8.54 y 8.55 ). 


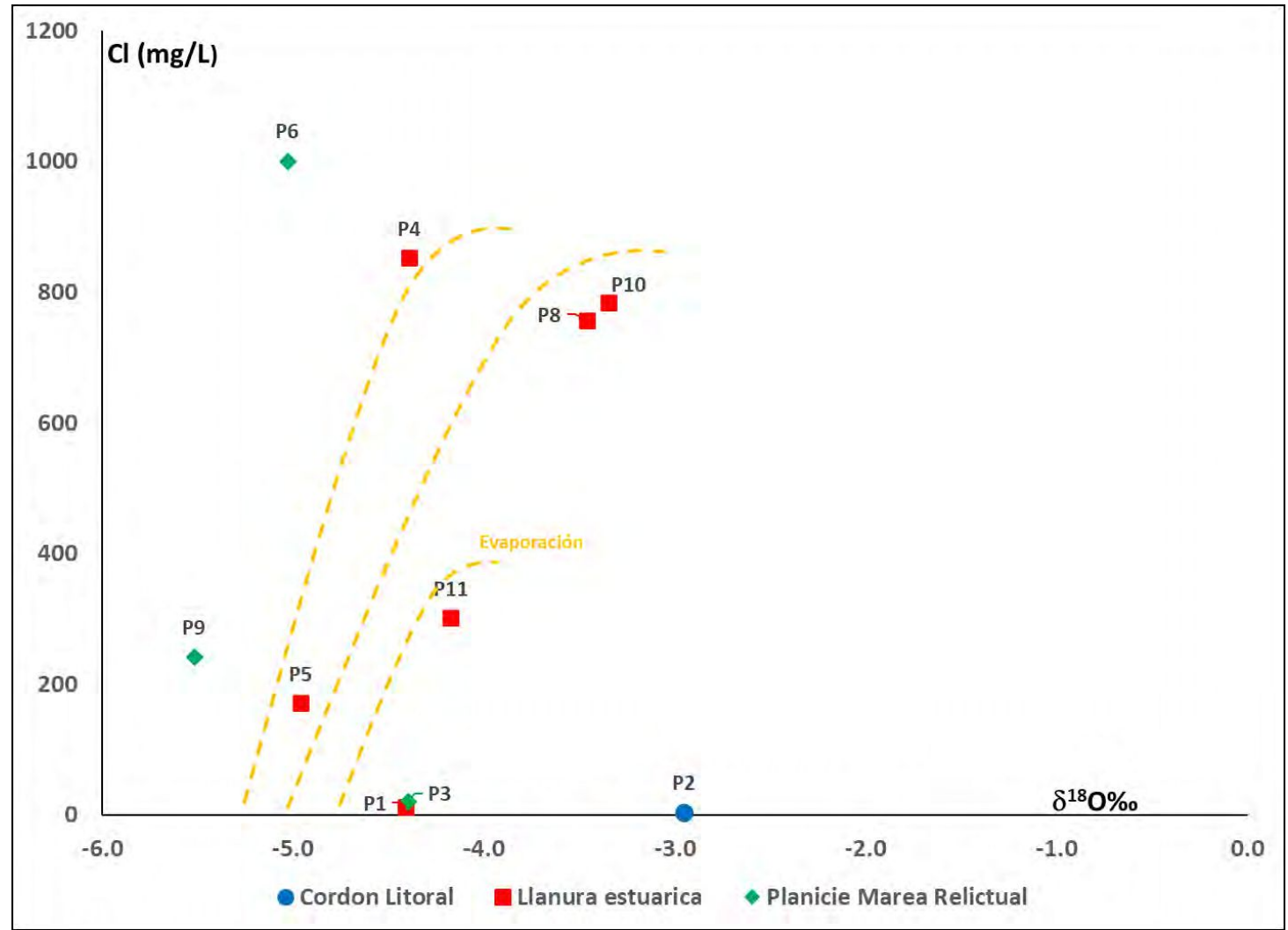

Figura $8.55 \mathrm{Cl}^{-}(\mathrm{mg} / \mathrm{L})$ vs. $\delta^{18} \mathrm{O}(\%)$.

Por otro lado, los elevados contenidos de cloruros y sulfatos en algunos de los pozos sugieren la participación de otros procesos. En el caso del sulfato, los pozos P3 y P8 (Tabla 29, Figura 8.56) muestran un contenido muy elevado, los pozos P6 y P5 tienen valores intermedios mientras que en el resto de los pozos las concentraciones son muy bajas. No se observa relación entre el contenido de sulfato y la composición isotópica del agua (Fig. 8.56). En un estudio llevado a cabo en la planicie baja por Logan y Nicholson (1997) y Logan et al. (1999) encontraron aguas con relaciones molares $\mathrm{SO}^{2}{ }^{2} / \mathrm{Cl}^{-}$cercanas a 2 y contenidos de sulfato mayores que $20 \mathrm{~g} / \mathrm{L}$. El estudio de los isótopos estables del azufre realizado en ese trabajo sugiere que el sulfato proviene de procesos de reoxidación de sulfuros (pirita) en la zona pantanosa de la planicie baja que recargan el agua subterránea en esa zona. 


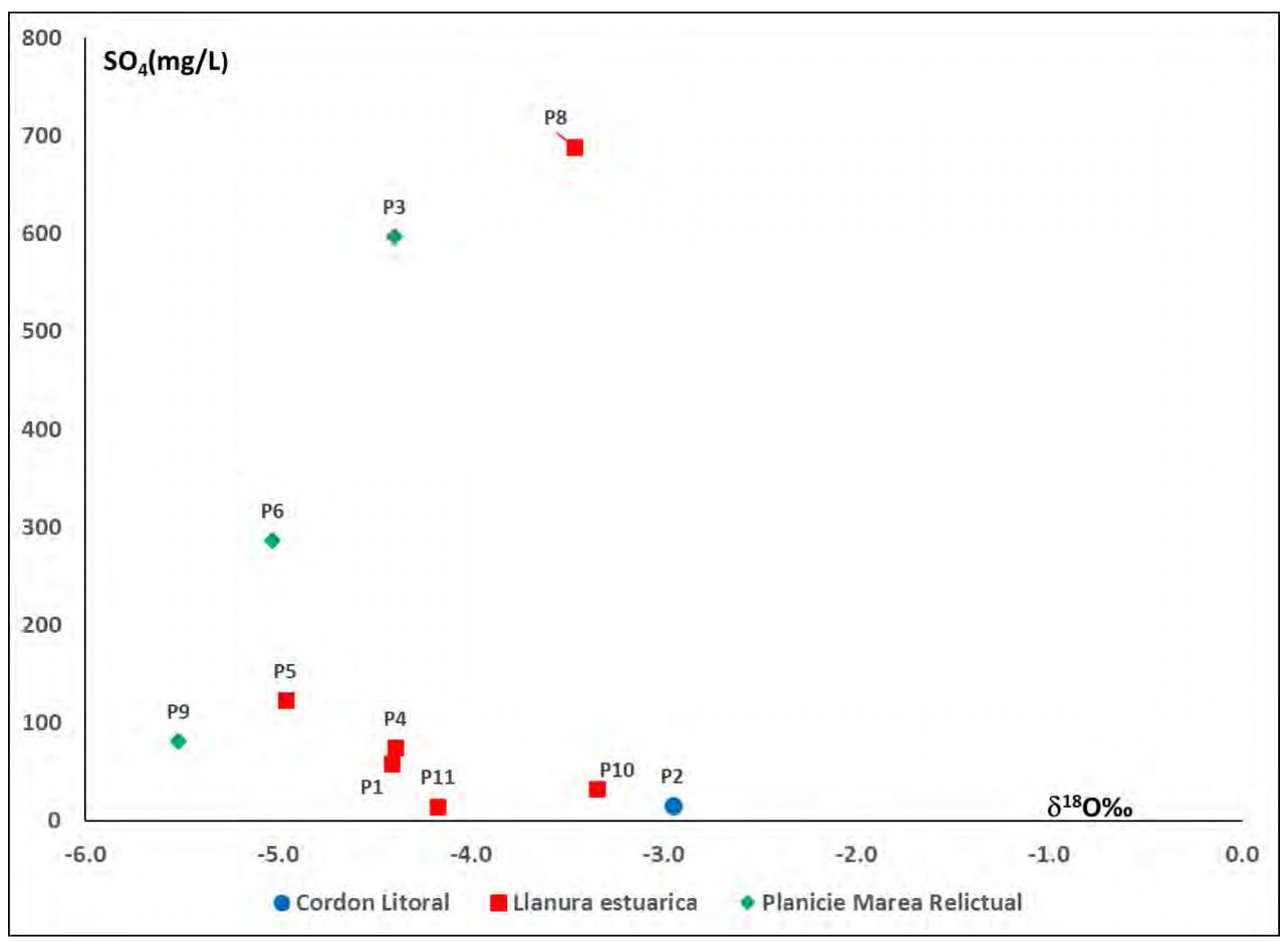

Figura $8.56 \mathrm{SO}_{4}{ }^{=}(\mathrm{mg} / \mathrm{L})$ vs. $\delta^{18} \mathrm{O}(\%)$.

\subsection{Relación recarga / conductividad eléctrica del agua subterránea}

\subsubsection{Costa marítima}

Este análisis se enfoca en determinar el grado de variabilidad espacio-temporal de la conductividad eléctrica (CE) y su vinculación con la hidrodinámica local (Tabla 29). Se han seleccionado tres pozos representativos para la zona de recarga principal en el centro de la duna, y las dos zonas de descarga. Se analizaron registros mensuales de niveles freáticos y CE in situ, medidos entre febrero-2016 y abril-2018 asociados con los excesos del balance.

Como se ha descripto, el sentido del flujo subterráneo es divergente en dos direcciones desde una zona de recarga central, con descarga hacia el oeste (Ruta 11) y al este (Mar Argentino). Esto se refleja en la CE promedio, que es menor en la zona de recarga $(330 \mu \mathrm{S} / \mathrm{cm})$ aumentando hacia zonas de descarga al este $(535 \mu \mathrm{S} / \mathrm{cm})$ y al oeste $(2320 \mu \mathrm{S} / \mathrm{cm})$ (Tabla 29$)$. 
Tabla 29 Valores medios, máximos y mínimos de CE para los pozos representativos de los sectores de recarga principal y descarga.

\begin{tabular}{|c|c|c|c|}
\hline $\begin{array}{c}\mathrm{CE} \\
(\mu \mathrm{S} / \mathrm{cm})\end{array}$ & $\begin{array}{c}\text { MT1 } \\
\text { Descarga } \\
\text { (oeste) }\end{array}$ & $\begin{array}{c}\text { MT18 } \\
\text { Recarga } \\
\text { (centro) }\end{array}$ & $\begin{array}{c}\text { MT19 } \\
\text { Descarga } \\
\text { (este) }\end{array}$ \\
\hline Media & 2320 & 330 & 535 \\
\hline Máx. & 3120 & 407 & 795 \\
\hline Min. & 1055 & 253 & 422 \\
\hline
\end{tabular}

Se esperaría que aumentos en la recarga condujeran a menores concentraciones de los elementos químicos del agua subterránea debido a procesos de dilución, sin embargo se detalla a continuación los resultados obtenidos.

En la zona de recarga principal la CE en el periodo estudiado ha variado entre 253 y $407 \mu \mathrm{S} / \mathrm{cm}$. De julio-2016 a octubre-2016 se observa un incremento en la CE con un descenso en los excesos registrados. En este periodo la CE aumenta de 317 a 376 $\mu \mathrm{S} / \mathrm{cm}$ y los excesos disminuyen de 38 a $26 \mathrm{~mm}$. En ese periodo pareciera haber una relación inversa entre la recarga y la CE (a menor recarga mayor conductividad), pero en el resto del estudio incluso hay incrementos de CE con recargas producto de grandes excesos como por ejemplo entre julio y agosto de 2017 (Figura 8.57). 


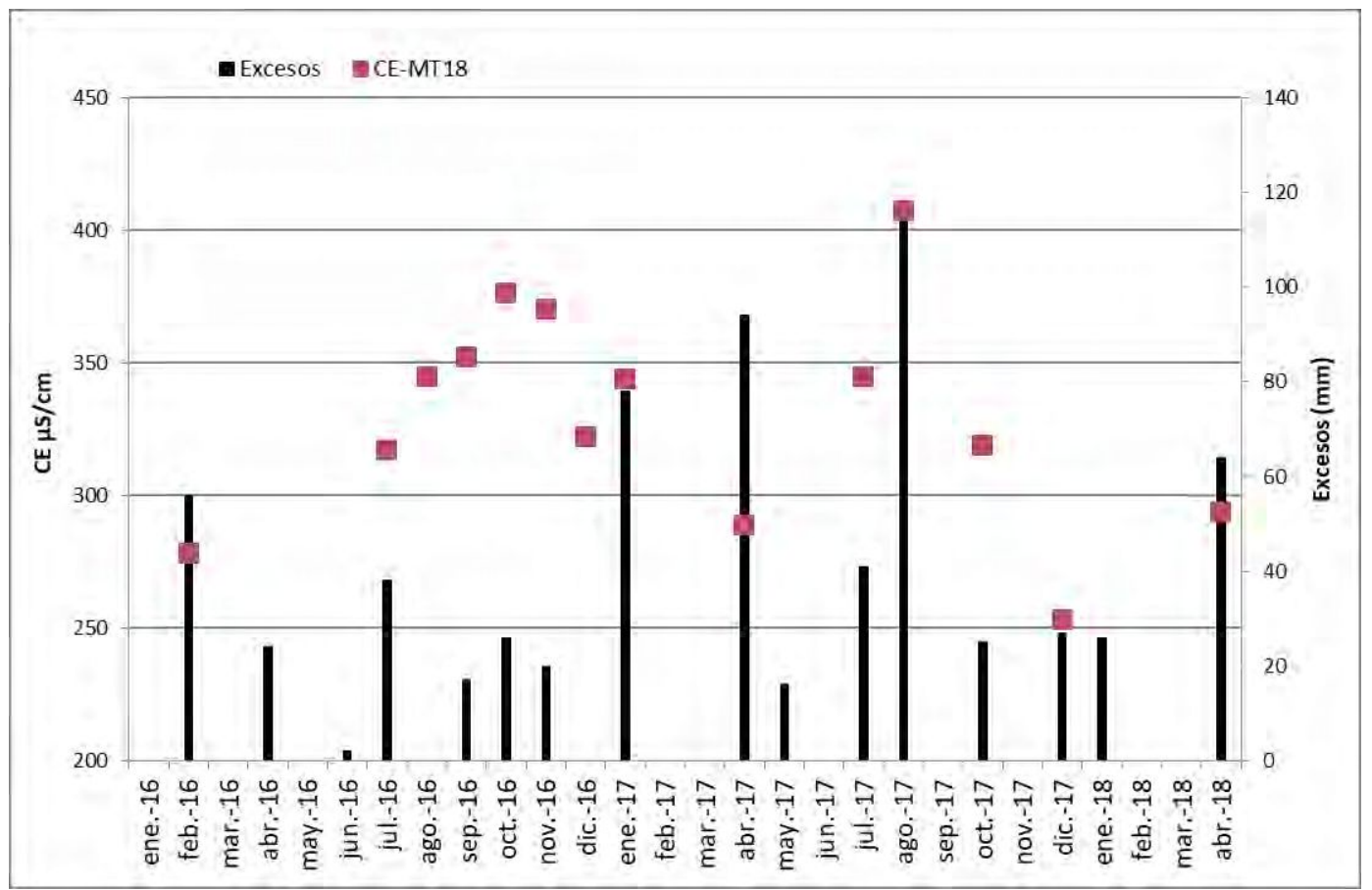

Figura 8.57 Relación excesos vs CE para la zona de recarga principal.

Para la zona de descarga hacia el oeste la CE ha oscilado entre 1055 y $3120 \mu \mathrm{S} / \mathrm{cm}$, lo cual es una variabilidad mucho más marcada que en la zona de recarga. En este caso no pareciera observarse una variabilidad estacional. Hay una ligera tendencia entre agosto y noviembre de 2016 donde la CE disminuye de 1814 y $1496 \mu S / c m$ y los excesos aumentan de 0 a $20 \mathrm{~mm}$. Con poca recarga, la CE tiende a disminuir en su concentración. Sin embargo, en el resto del periodo este fenómeno no se detecta (Figura 8.58).

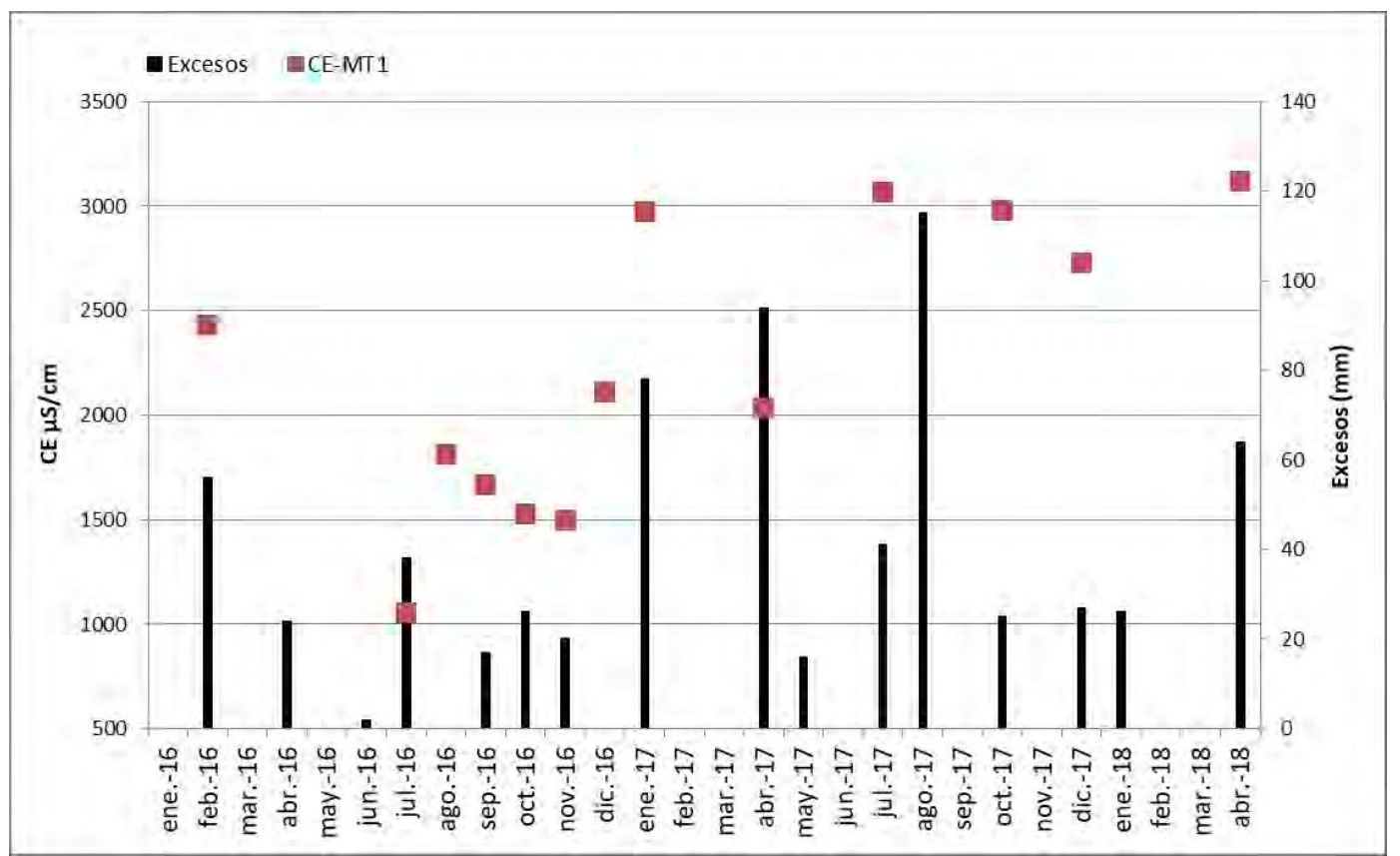


Figura 8.58 Relación excesos vs CE para la zona de descarga al oeste.

Finalmente, en el sector de descarga al este, la CE oscila entre 422 y $795 \mu \mathrm{S} / \mathrm{cm}$. Entre julio y noviembre de 2016 la relación inversa entre recarga y CE es claramente observable donde la CE aumenta de 443 a $628 \mu \mathrm{S} / \mathrm{cm}$ y los excesos disminuyen de 38 a $20 \mathrm{~mm}$. Con excesos menores a $60 \mathrm{~mm}$ la CE sigue incrementándose a lo largo de ese lapso de tiempo. Entre enero y abril de 2017 desciende de 800 a $450 \mu \mathrm{S} / \mathrm{cm}$ para luego mantenerse dentro de ese orden de magnitud hasta agosto-2017 donde se producen los mayores excesos (Figura 8.59).

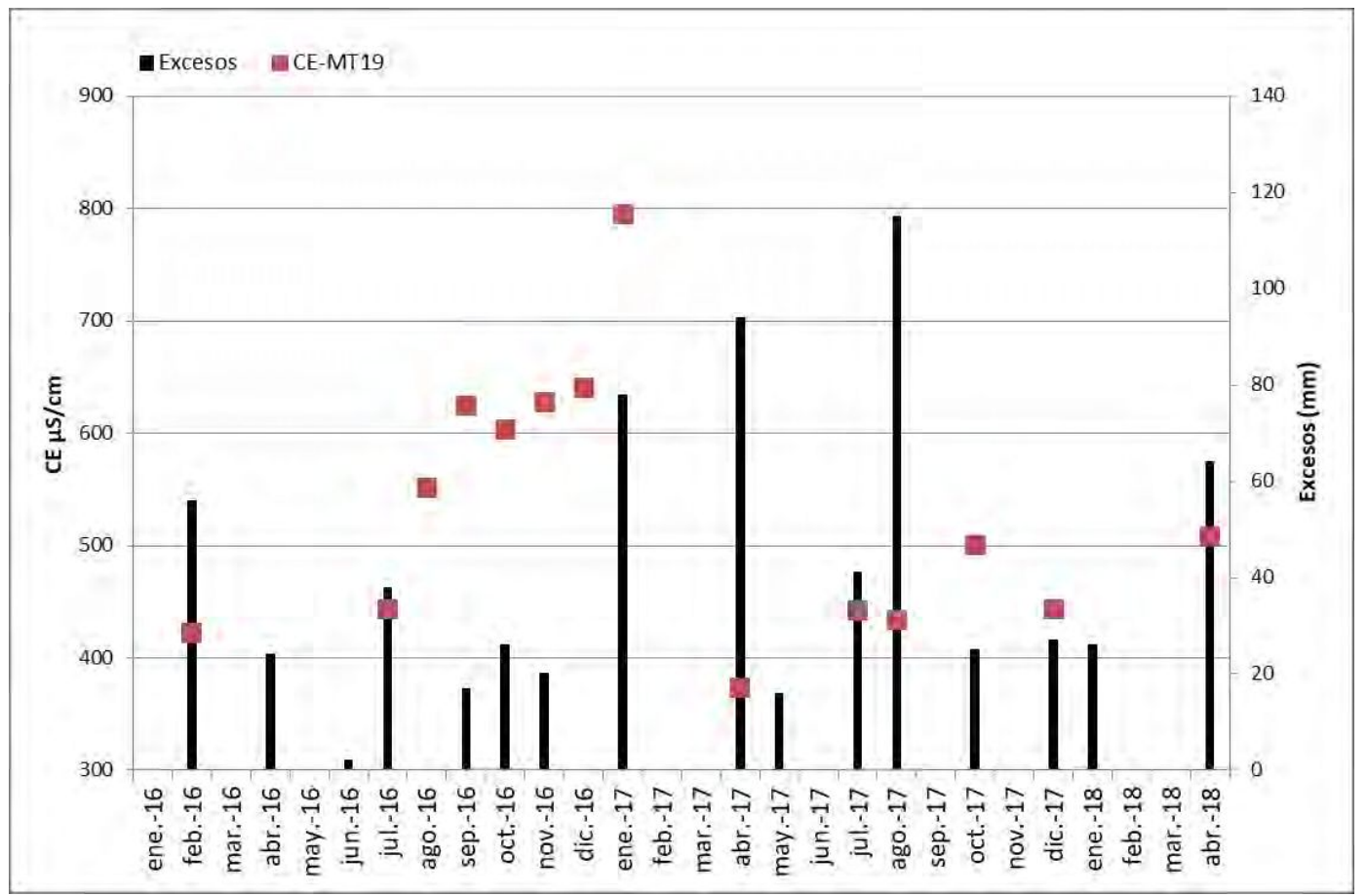

Figura 8.59 Relación excesos vs CE para la zona de descarga al este.

\subsubsection{Costa estuárica}

A partir de las mediciones de campo de la CE que se tomaron en conjunto con la profundidad de la capa freática se elaboraron gráficos para estudiar la relación entre las oscilaciones de los niveles (relacionados al ciclo hidrológico) y las variaciones en CE. Se consideró la localización de acuerdo a los ambientes para lo cual se presenta un ejemplo de cada caso.

En la Figura 8.60, en llanura estuárica, se observa que entre junio y julio de 2016 los niveles permanecieron casi sin variaciones lo cual también se refleja en la CE. De julio a octubre los niveles ascienden y se registra un descenso en la concentración de la CE. Entre octubre y diciembre si bien los niveles siguen ascendiendo la CE varía muy poco. Entre diciembre-2016 y febrero-2017 los niveles vuelven a caer con el 
consecuente incremento de CE. Entre febrero y marzo se observa el mismo comportamiento, así como entre las mediciones de agosto y septiembre de 2017.

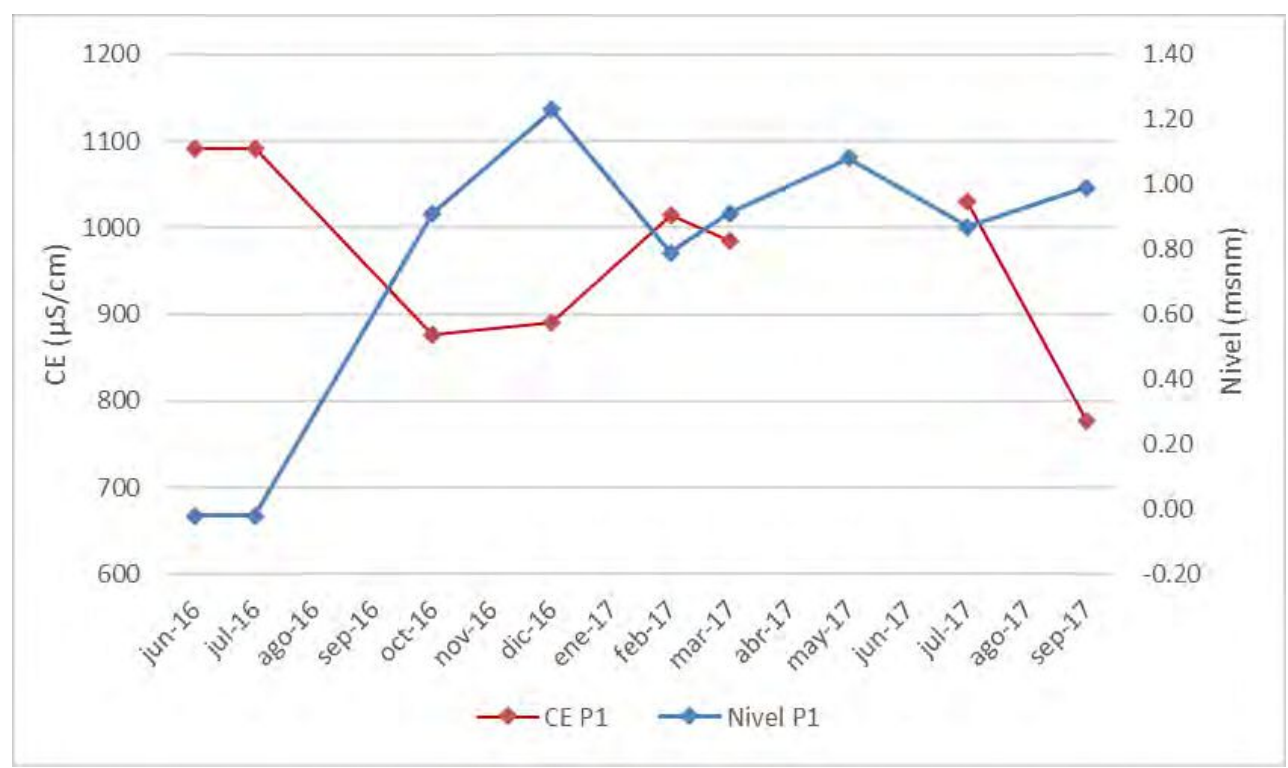

Figura 8.60 Comportamiento de la CE en función de los niveles freáticos. Pozo P1, ambiente llanura estuárica.

En la planicie de cordón litoral, de junio a julio-2016 se incrementan los niveles y descienden entre julio y octubre para registrarse un aumento en enero-2017. En esos mismos periodos la relación con la CE es inversa. Aumento de niveles implicaron decrecimientos de la CE y viceversa. Este comportamiento no se observa entre enero y febrero-2017 ya que descienden los niveles al igual que la CE (Figura 8.61). No hay datos de CE hasta septiembre-2017 por lo cual no se puede establecer la relación en esos meses donde se observa un constante incremento de la altura de la capa freática. 


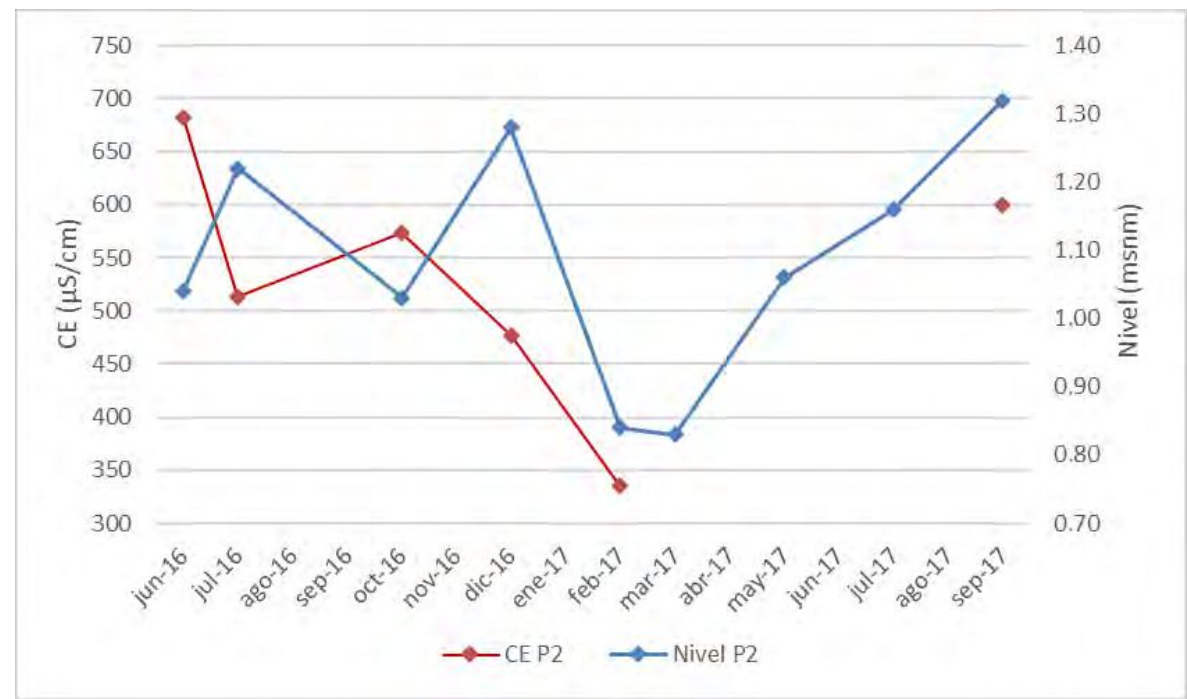

Figura 8.61 Comportamiento de la CE en función de los niveles freáticos. Pozo P2, ambiente cordón litoral.

Los niveles freáticos en la planicie de marea relictual (Figura 8.62) se incrementan de junio a julio-2016 pero descienden hasta enero-2017 con un constante incremento de la CE. Desde enero a febrero-2017 tanto los niveles como la CE descienden. Entre febrero y marzo los niveles se mantienen en el mismo valor, pero se registra un aumento de la CE. Al igual que para el caso anterior no hay datos de CE hasta septiembre-2017.

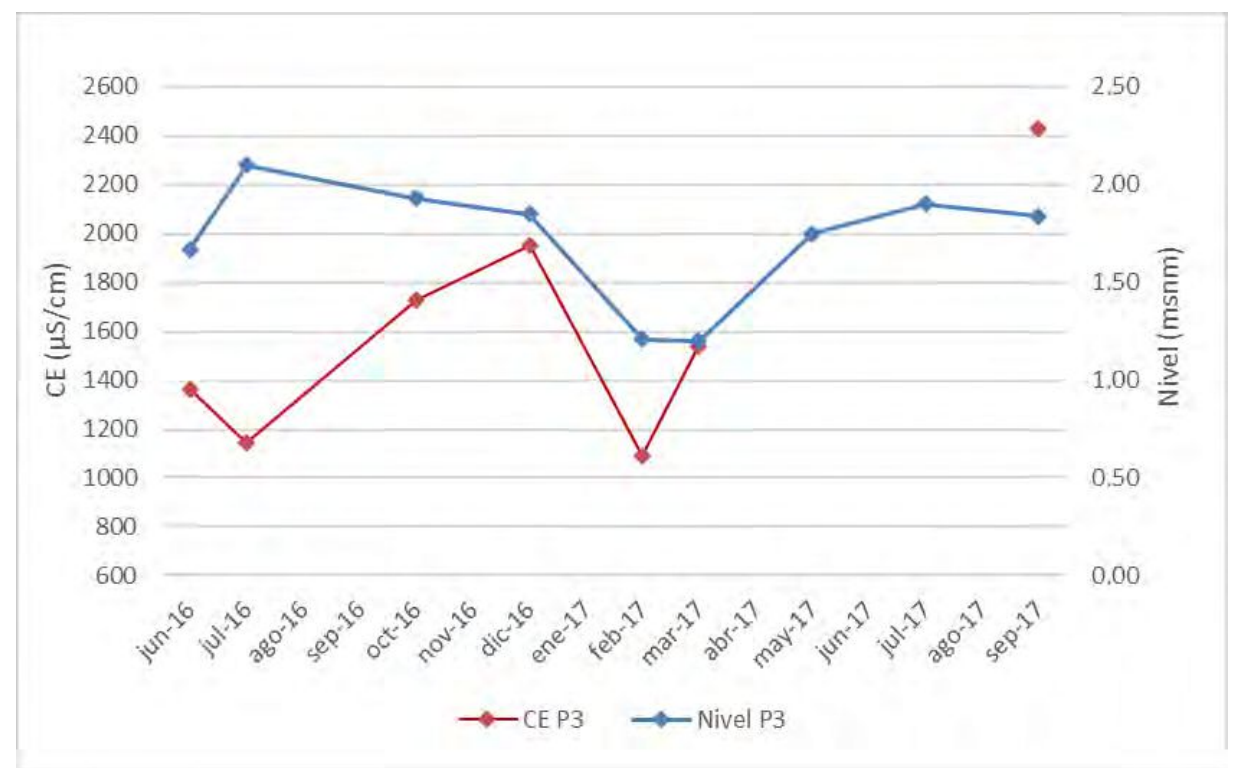

Figura 8.62 Comportamiento de la CE en función de los niveles freáticos. Pozo P3, ambiente planicie de marea relictual. 


\subsection{Estimación de la recarga}

\subsubsection{Estimación de la recarga por método de fluctuaciones de niveles freáticos y balance hídrico}

Para estimar los valores de recarga en la costa marítima, se construyeron mapas isofreáticos a partir de los cuales se obtuvieron mapas de isovariación. En ellos se digitalizó el área entre las curvas para determinar el volumen de agua para ese momento, tomando como referencia el $0 \mathrm{~m} \mathrm{~s}$. n. m. y los parámetros hidráulicos. Se comparan los resultados de los excesos del balance hídrico con el agua disponible calculada a partir de los mapas.

En la Tabla 30 se presentan los excesos del balance hídrico que fueron sumados entre las fechas de las mediciones y el valor de recarga obtenido según los mapas de isovariación para el año 2016. A su vez se detallan observaciones puntuales de los mapas. Si bien los valores obtenidos por ambos métodos no son coincidentes numéricamente, si existe una correlación entre los meses con excesos y la respuesta de los niveles freáticos ante la recarga. Esto se refleja en los periodos ene-feb, marabr, may-jun, jun-jul, sep-oct (Figuras 8.63 a,c,e,f,i).

En general, en los periodos donde los excesos son nulos el cálculo de la recarga también lo es. Existen situaciones puntuales como el caso de feb-mar (Figura 8.63 b) donde el mapa refleja un ascenso de $0,07 \mathrm{~m}$ en un pozo de la costanera lo cual podría estar relacionado a influencia de la marea o algún proceso particular relacionado únicamente a ese pozo.

En jul-ago (Figura $8.63 \mathrm{~g}$ ), ago-sep (Figura $8.63 \mathrm{~h}$ ) y oct-nov (Figura $8.63 \mathrm{j}$ ) los mapas muestran descenso de los niveles en toda el área a excepción de dos pozos localizados en el sector central de la duna. En el caso de ago-sep esos ascensos de nivel restringidos podrían reflejar la recarga producto de $17 \mathrm{~mm}$ de excesos, al igual que en oct-nov con $20 \mathrm{~mm}$.

En jul-ago, donde los excesos fueron nulos, el ascenso en ese sector probablemente se deba a que la capa freática sigue respondiendo a la gran recarga que se produjo entre mayo y julio. Es de destacar, entonces, que el sector central de la duna es el área donde se produce la mayor recarga al acuífero y donde el acuífero reacciona más rápidamente.

Para el periodo 2016 la recarga a partir de los excesos según el balance hídrico representa el $34 \%$ de las precipitaciones mientras que la estimación en base a los mapas indica un $24 \%$. 
Tabla 30. Precipitaciones, excesos y recarga para 2016. Valores considerados entre fechas de censos.

\begin{tabular}{|c|c|c|c|c|}
\hline & $\underset{(\mathrm{mm})}{\mathbf{P}}$ & $\begin{array}{c}\text { Excesos } \\
(\mathrm{mm})\end{array}$ & $\begin{array}{l}\text { Recarga en } \\
\text { altura de } \\
\text { lámina }(\mathrm{mm})\end{array}$ & Observaciones Mapa \\
\hline ene-feb & 119 & 56 & 27,5 & $\begin{array}{c}\text { ascensos máximos } \\
0,20 \mathrm{~m} \text {, promedio }\end{array}$ \\
\hline feb-mar & 27 & 0 & 4 & $\begin{array}{c}\text { todos descensos, ascenso } 1 \text { pozo en la } \\
\text { costa }(0,07 \mathrm{~m})\end{array}$ \\
\hline mar-abr & 87 & 24 & 27,5 & $\begin{array}{c}\text { ascensos máximos } 0,20 \mathrm{~m} \text {, en un pozo } \\
\text { descenso }\end{array}$ \\
\hline abr-may & 1 & 0 & 0 & $\begin{array}{c}\text { todos descensos excepto en MT7 } \\
\text { (excepción } 0,80 \mathrm{~m})\end{array}$ \\
\hline may-jun & 70 & 23 & 37 & ascensos máximos $0,5 \mathrm{~m}$ \\
\hline jun-jul & 79 & 38 & 25 & ascensos máximos $0,5 \mathrm{~m}$ \\
\hline jul-ago & 4 & 0 & 2,5 & $\begin{array}{c}\text { todos descensos. Ascenso en } 2 \text { pozos zona } \\
\text { central }\end{array}$ \\
\hline ago-sep & 58 & 17 & 2,5 & $\begin{array}{c}\text { todos descensos. Ascenso en } 2 \text { pozos zona } \\
\text { central }\end{array}$ \\
\hline sep-oct & 82 & 26 & 10 & ascenso máximo $0,07 \mathrm{~m}$ \\
\hline oct-nov & 31 & 20 & 10 & $\begin{array}{c}\text { en general descenso. Ascenso máximo } \\
0,10 \mathrm{~m} \text { en el sector central }\end{array}$ \\
\hline nov-dic & 50 & 0 & 0 & todos descensos \\
\hline Total & 608 & 204 & 146 & \\
\hline
\end{tabular}




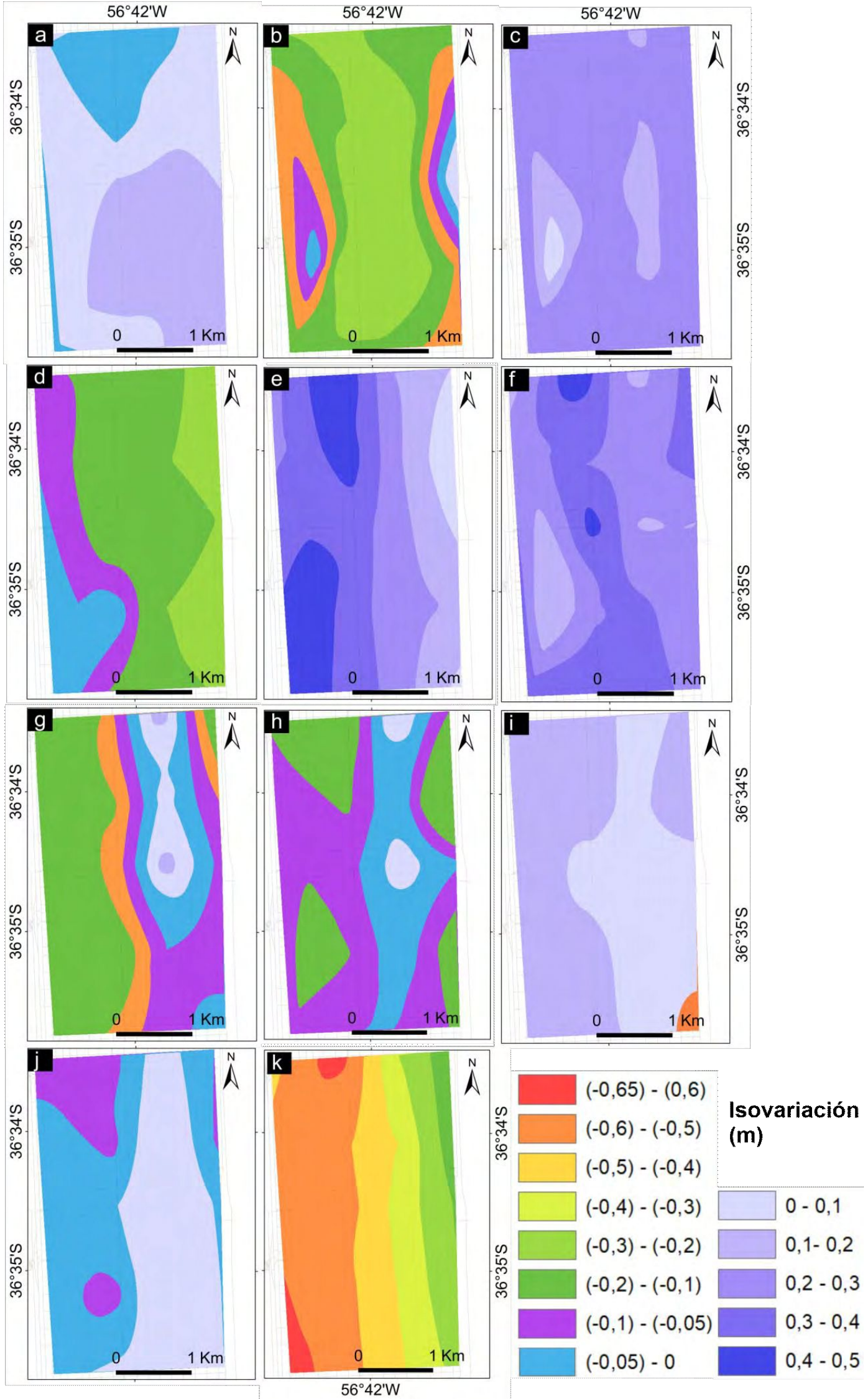

Figura 8.63 Mapas de isovariación desde enero a diciembre de 2016. a) enero-febrero, b) febrero-marzo, c) marzo-abril, d) abril- mayo, e) mayo-junio, f) junio- julio, g) julio-agosto, h) agosto-septiembre, i) septiembre- octubre, j) octubre-noviembre, k) noviembre-diciembre. 


\subsubsection{Estimación de la recarga por el método de balance de cloruros}

Se calculó la recarga considerando los valores medios de concentraciones de cloruros en el agua subterránea muestreadas en septiembre de 2016 y las precipitaciones recolectadas entre abril-2015 y octubre-2016. El valor para el agua subterránea se estimó en $69 \mathrm{mg} / \mathrm{L}$ y el de las precipitaciones en $7 \mathrm{mg} / \mathrm{L}$.

Con el método de balance del ion cloruro la recarga calculada fue del orden de los 105 $\mathrm{mm}$ lo cual corresponde al $10 \%$ de las precipitaciones.

Este valor de $10 \%$ es mucho menor al obtenido por los otros métodos, esta diferencia puede deberse a que se están comparando métodos con diferente representatividad temporal. Es probable que la estimación del balance de cloruros se aproxime más al promedio multianual de los otros métodos.

\subsubsection{Comparación entre métodos.}

Existen diversas técnicas para cuantificar la recarga, pero elegir las apropiadas puede resultar complejo. Entre las consideraciones a tener en cuenta, hay que citar las escalas espacial y temporal y el rango y la fiabilidad de las estimaciones por medio de técnicas diferentes. También hay otros factores que pueden limitar la aplicación de técnicas particulares. La fiabilidad de las estimaciones basadas en técnicas diferentes es variable. La incertidumbre asociada a cada método corrobora la necesidad de aplicar varias técnicas distintas para aumentar la fiabilidad de las estimaciones de la recarga.

La forma más común de estimar la recarga es por el método de balance hídrico el cual es un enfoque indirecto o "residual", donde todas las variables de la ecuación del balance, excepto la recarga ( $R$ ), se miden o estiman. La ventaja de este método es su flexibilidad ya que con algunas asunciones en su ecuación puede ser aplicado en un amplio espectro de tiempo y escalas. La principal limitación del enfoque residual es que la precisión de la estimación de recarga depende de la precisión con la que se miden los demás componentes de la ecuación de balance hídrico. En este trabajo el balance hídrico ha sido adaptado a las condiciones particulares del área, que se caracteriza por un clima húmedo ( $\mathrm{P}=1000 \mathrm{~mm} / \mathrm{año})$. La geología y geomorfología se expresan en un médano arenoso, donde se aloja un acuífero freático con los niveles de agua subterránea someros. Estas características controlan la recarga, siendo que la única entrada de agua se produce a través de los excesos de las precipitaciones, la salida de agua es por evapotranspiración, se considera que la capacidad de campo de las arenas es de $50 \mathrm{~mm}$ y el escurrimiento superficial es nulo debido a la alta 
permeabilidad de los sedimentos. Con el balance hídrico aplicado para el periodo 2016-2018 se obtuvo una recarga a partir de los excesos que representa el $34 \%$ de las precipitaciones. Si bien el método simplifica y generaliza variables del área, es una aproximación y permite obtener los excesos que se asumen como la recarga del acuífero.

El método de las fluctuaciones de los niveles freáticos se basa en la premisa de que el incremento de los niveles en un acuífero freático se produce por agua de recarga. Se recomienda la aplicación de esta metodología en cortos periodos de tiempo y en regiones con acuíferos someros donde se observen fluctuaciones notorias. Sin embargo, también es aplicable para determinar la magnitud de cambios en la recarga a largo plazo causadas por diversos factores como, por ejemplo, cambios en el uso del suelo o un cambio climático. Las dificultades del método se basan en determinar la representatividad de los valores del coeficiente de almacenamiento, en asegurarse que las fluctuaciones no se deban a cambios atmosféricos, la presencia de aire entrampado $u$ otros fenómenos como el bombeo. En el caso de estudio se ha elegido un valor de coeficiente de almacenamiento que se considera apropiado para las arenas de acuífero y se han tomado todos los recaudos para una correcta medición de los niveles en el campo. La interpolación para construcción de los mapas de isovariación de niveles a partir de estos datos fue cuidadosa, aunque podría haber algún factor mínimo de error. De todas maneras, se considera que es el método que más representa al comportamiento del acuífero costero. Los resultados muestran que el porcentaje de recarga obtenido a partir de mapas de isovariación fue del $24 \%$. Con este método se verifica que en los meses donde los excesos son nulos los niveles descienden y cuando hay excesos los niveles aumentan. En general cuando hay excesos la zona de recarga central es la que presenta mayores variaciones de nivel. La distribución homogénea de la red de monitoreo permite obtener buenas interpolaciones de los datos de nivel, siendo los mapas representativos del área y obteniendo buenos resultados.

El método del balance de cloruros se encuentra dentro de los métodos denominados de trazadores. Según su ecuación se define que la recarga presenta una relación inversa respecto a las concentraciones de $\mathrm{Cl}$ en el acuífero. De acuerdo a esta relación, el método sería más confiable en sitios donde la tasa de recarga es baja, ya que la concentración de $\mathrm{Cl}$ cambia notablemente con pequeños cambios en el flujo de recarga. Con el método de balance del ion cloruro la recarga calculada fue del orden de los $105 \mathrm{~mm}$ lo cual corresponde al 10\% de las precipitaciones. La incertidumbre de 
este método radica en que solo se considera un solo muestreo de agua subterránea, lo que implica que no se está considerando la variabilidad entre los diferentes meses para los que se hace el balance. Por otro lado, y de acuerdo a lo expuesto previamente y considerando las tasas de infiltración obtenidas para los sedimentos arenosos, probablemente no sea un método apropiado para aplicarse en el ambiente de dunas costeras.

De acuerdo a los tres métodos aplicados, los valores de recarga calculados fueron de 34, 24 y 10\% para el balance hídrico, fluctuaciones de niveles y balance de cloruro respectivamente. Entre los dos primeros métodos se observó una variabilidad del 10\% entre los resultados obtenidos, lo cual parece ser aceptable dadas las posibles incertidumbres asociadas a los métodos. En cambio, la diferencia con el balance de cloruros es más notoria, obteniéndose un valor sustancialmente menor.

\subsection{Variaciones estacionales de la recarga}

Se considera recarga al aumento temporal o permanente del agua subterránea, debiéndose considerar el intervalo de tiempo en el que el agua pasa desde la superficie al subsuelo. La infiltración es rápida al principio y luego se estabiliza, lo cual depende de la permeabilidad del perfil de suelo. Las propiedades físicas del suelo como textura, estructura, regulan la recarga como así también la profundidad del nivel freático, la vegetación, la evapotranspiración y humedad del suelo (Balek, 1988).

En el ambiente de dunas la recarga se manifiesta a través de variaciones rápidas de nivel luego de una precipitación. Estas variaciones fueron registradas simultáneamente en diferentes freatímetros. Para ello se colocaron registradores de nivel continuo con una frecuencia de medición de 15 minutos. Los datos de nivel fueron relacionados con registros de lluvia, también tomados cada 15 minutos por una estación meteorológica ubicada en las cercanías del área de estudio. Con este nivel de detalle fue posible estudiar el comportamiento areal y temporal de la recarga a través de las diferencias en las velocidades de infiltración que se observan en cada perforación, frente a dos eventos de lluvia particulares.

Los datos disponibles para realizar este análisis corresponden a dos periodos de tiempo en los cuales se midieron diferentes freatímetros, siendo solo coincidente en ambos periodos el pozo MT18. Entre los meses de mayo a octubre de 2017 (estación fría) se realizó el registro simultáneo de niveles en 4 perforaciones ubicados al norte y sur de la duna (MT1, MT4 sector norte, MT17 y MT18 sector sur). Mientras que en los 
meses de diciembre de 2017 a enero de 2018 (estación cálida) se midieron 5 perforaciones ubicadas en sentido norte-sur a lo largo de la zona central de la duna (MT2, MT7, MT10, MT15, MT18). A partir del registro de precipitaciones se identificaron lluvias de igual distribución y magnitud en dos fechas. Una corresponde al 8 de agosto de 2017 (invierno) con una precipitación de $22 \mathrm{~mm}$ y la otra, al 14 de enero de 2018 (verano) con $26 \mathrm{~mm}$.

Cada evento de precipitación es un evento de recarga cuando el agua de lluvia infiltrada se incorpora inmediatamente al almacenamiento subterráneo. La recarga puntual puede estimarse a partir del método de las fluctuaciones del nivel freático (Healy y Cook, 2002) calculándose como:

$R=S_{y}(\Delta \mathrm{h} / \Delta \mathrm{t})$

donde Sy es porosidad efectiva, $\mathrm{h}$ altura del nivel freático y t el tiempo. Se considera un valor de porosidad efectiva $\left(S_{y}\right)$ en las arenas del acuífero freático de 0,10 (CFI, 1990b; Carretero, 2011).

\subsubsection{Recarga: Condiciones climáticas / Niveles freáticos}

En el período mayo a octubre de 2017 (estación fría), se registró una precipitación total de $413 \mathrm{~mm}$, los excesos del balance hídrico fueron de $212 \mathrm{~mm}$, con una ETR de 194 $\mathrm{mm}$.

En el período noviembre 2017 a marzo 2018 (estación cálida) la precipitación acumulada fue de $278 \mathrm{~mm}$, los excesos de $43 \mathrm{~mm}$ y la ETR de $257 \mathrm{~mm}$. Ver Anexo 8.

La Figura 8.64 es un ejemplo de la tendencia general de los niveles freáticos del área de estudio. En todas las perforaciones se registraron niveles freáticos más someros durante el invierno y más profundos durante el verano.

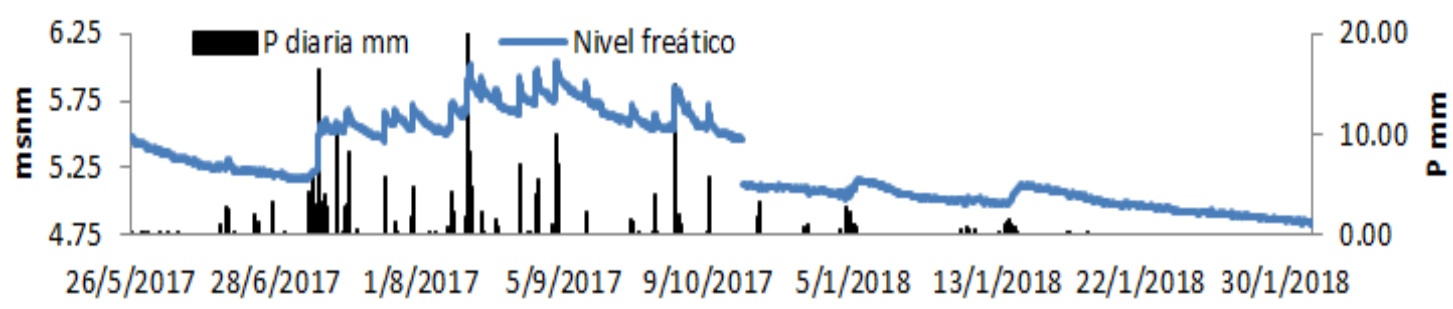

Figura 8.64 Tendencia general de los niveles freáticos y precipitaciones. Mediciones de registro continuo.

En los mapas de flujo subterráneo (Figura 8.65, A y B) se reconoce un área de recarga central desde donde divergen los filetes de flujos hacia dos zonas de descarga 
opuestas (oeste-este). En agosto (A) la altura hidráulica máxima en la zona de recarga es de $5,5 \mathrm{~m} \mathrm{~s}$. n. m., disminuyendo hacia ambos lados hasta $0 \mathrm{~m} \mathrm{~s}$. n. m. al este y 2,5 m s. n. m. al oeste. Para enero se observan alturas más bajas de 4,5 m s. n. m. en las áreas de recarga y disminuyendo a $0 \mathrm{~m} \mathrm{~s} . \mathrm{n}$. m. al este y $2 \mathrm{~m} \mathrm{~s} . \mathrm{n}$. $\mathrm{m}$. al oeste.

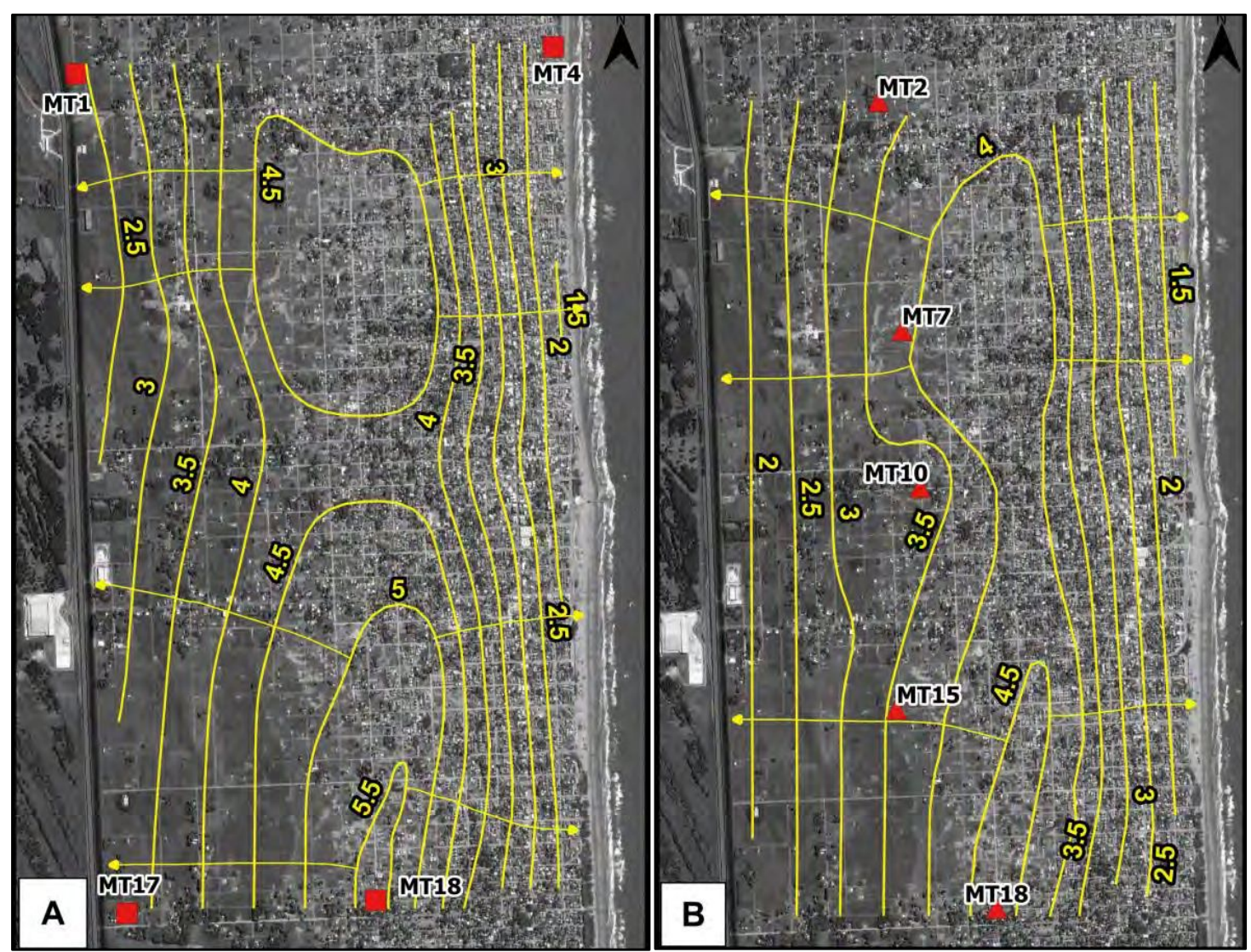

Figura 8.65 (A) mapa de equipotencial mes de agosto de 2017 y (B) mapa equipotencial de enero de 2018.

\section{Evento de precipitaciones, estación fría}

En el evento de precipitación de agosto de 2017 se observaron los ascensos del nivel freático en diferentes sectores del área de estudio (Figura 8.66). En los gráficos se muestra la lluvia acumulada cada 6 horas y la variación de nivel en cada perforación. 

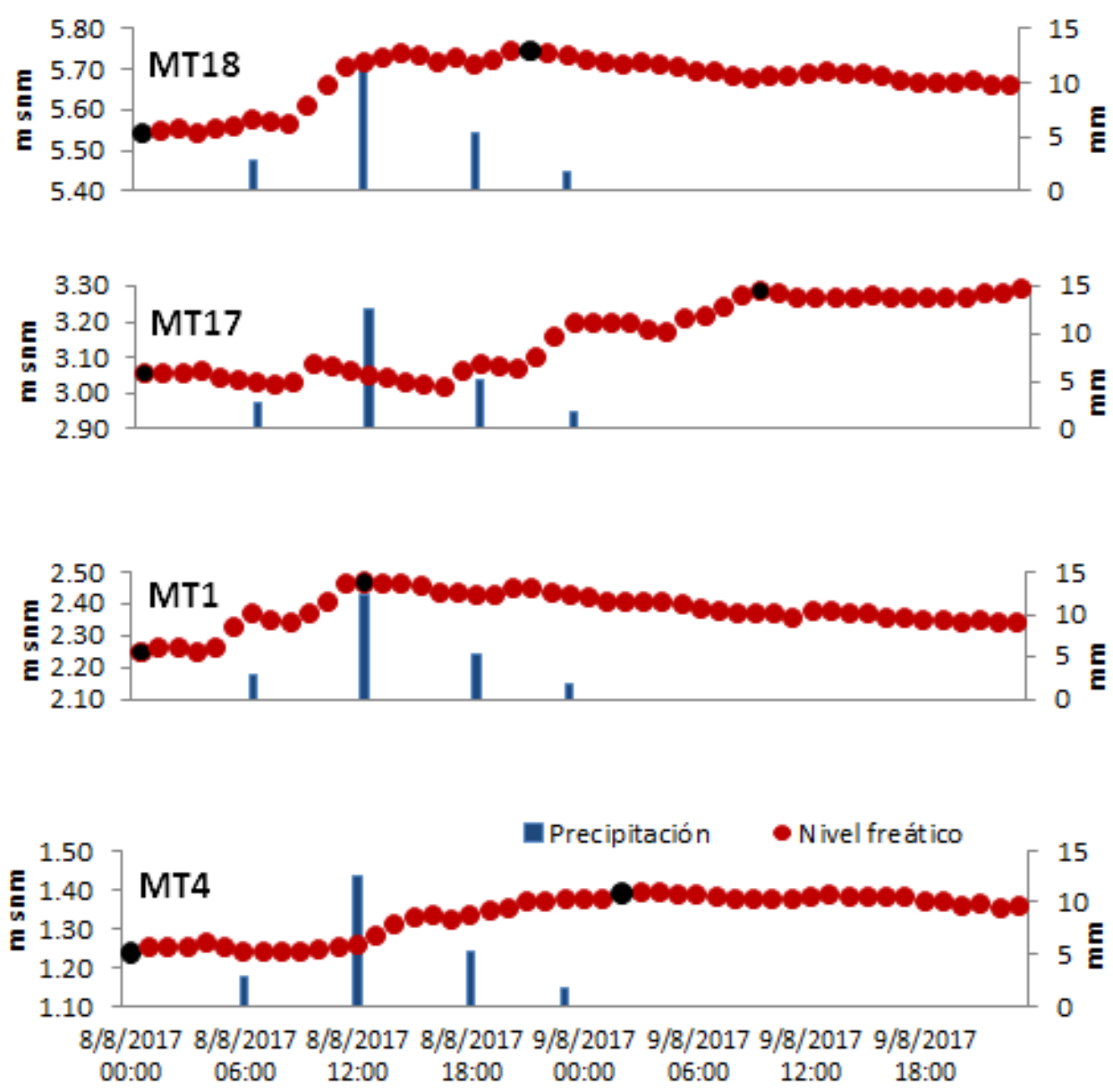

Figura 8.66 Variaciones del nivel freático y eventos de precipitaciones para el período frío. Los círculos negros indican el máximo y mínimo registrado.

Las perforaciones que se ubican en la zona de descarga al oeste (MT1 y MT17) se encuentran en una zona de transición hacia la llanura deprimida donde la topografía es baja y los sedimentos se vuelven más arcillosos. En el pozo MT1 se encuentra al norte, con una cota de $2,5 \mathrm{~m} \mathrm{~s}$. $\mathrm{n}$. $\mathrm{m}$. la litología es arenosa con matriz arcillosa, el perfil presenta abundantes raíces y materia orgánica. Los niveles freáticos están muy próximos a la superficie y durante el evento de recarga se supera el nivel del terreno quedando la zona encharcada durante un tiempo. Las condiciones del suelo cambian al sur, en la ubicación de MT17, se han encontrado niveles de arcilla intercaladas con arenas, lo que podría explicar el retraso y escalonamiento que se observa en la respuesta de los niveles freáticos (Figura 8.66).

El cordón costero en su sector central (MT18) y al este (MT4) presenta una composición arenosa homogénea. Si se consideran los diferentes ambientes geohidrológicos, la zona de recarga principal (MT18) presenta una tasa de recarga 
superior a las zonas de descarga al oeste (MT17) y al este (MT4). El detalle de las tasas de recarga calculadas para cada pozo puede observarse en la Tabla 31.

Tabla 31 Tasa de recarga para los dos eventos de precipitaciones.

\begin{tabular}{|c|c|c|}
\hline \multirow{4}{*}{$\begin{array}{c}\text { Periodo } \\
\text { frío }\end{array}$} & Pozo & $\begin{array}{c}\text { Tasa de recarga } \\
\mathbf{( m / d}\end{array}$ \\
\cline { 2 - 3 } & MT1 & 0,048 \\
\cline { 2 - 3 } & MT17 & 0,014 \\
\cline { 2 - 3 } & MT18 & 0,014 \\
\hline \multirow{4}{*}{$\begin{array}{c}\text { Periodo } \\
\text { cálido }\end{array}$} & MT2 & 0,023 \\
\cline { 2 - 3 } & MT17 & 0,009 \\
\cline { 2 - 3 } & MT10 & 0,005 \\
\cline { 2 - 3 } & MT15 & 0,013 \\
\cline { 2 - 3 } & MT18 & 0,012 \\
\hline
\end{tabular}

\section{Evento de precipitaciones, estación cálida}

Las manifestaciones de recarga luego del evento de precipitación se observan en la Figura 8.67. En este caso los 5 registradores fueron colocados en la parte central del cordón en sentido norte-sur abarcando toda el área de recarga principal.

La variación de niveles es similar entre los pozos MT2 y MT7 al norte y entre MT15 y MT18, y al sur (Figura 8.67). El pozo MT10 se encuentra en la misma línea que los anteriores pero no responde de igual forma. Pareciera que la recarga en ese punto es menor, pudiendo tal vez diferir en la litología. 

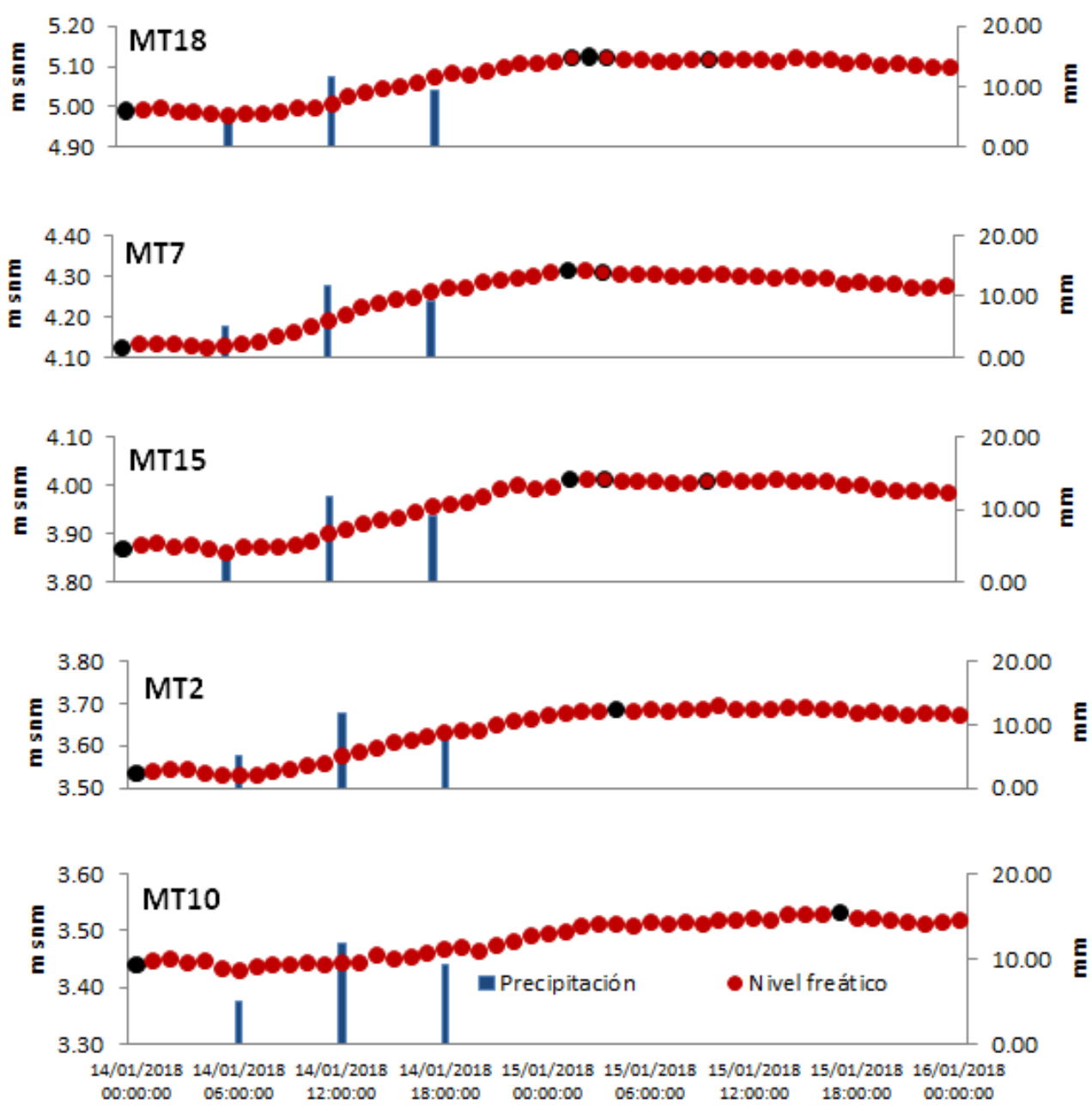

Figura 8.67. Variaciones del nivel freático y eventos de precipitaciones para el periodo cálido.

El registro simultaneo del nivel freático permitió evaluar la recarga al acuífero en diferentes sectores del área de estudio. Frente a un mismo evento de precipitación se obtuvieron tasas de recarga diferentes. A nivel local diferencias en las condiciones del suelo, sedimentos, niveles de baja permeabilidad en la zona no saturada y encharcamientos provocan cambios en la recarga.

Hacia el oeste, en la zona de transición hacia la llanura deprimida la presencia de niveles arcillosos retrasaría la velocidad del flujo subterráneo, así como en los sectores inundables, afectando la recarga.

En el pozo MT18, evaluado en ambos eventos, en invierno se han registrado tasas de recarga de 0,023 $\mathrm{m} / \mathrm{d}$ mientras que, en verano, frente a lluvias de igual magnitud, el valor disminuyó en un 50\% (0,012 m/d). Los valores de evapotranspiración real diaria asociados a cada evento fueron de 0,6 y 2,1 $\mathrm{mm}$ en invierno y verano respectivamente. En la Figura 8.68 se observa una respuesta más inmediata en 
invierno que en verano donde el nivel reacciona de manera más lenta y la curva es más tendida. Esa diferencia puede estar relacionada a que en el invierno el suelo se encuentra más próximo a la saturación que en verano.
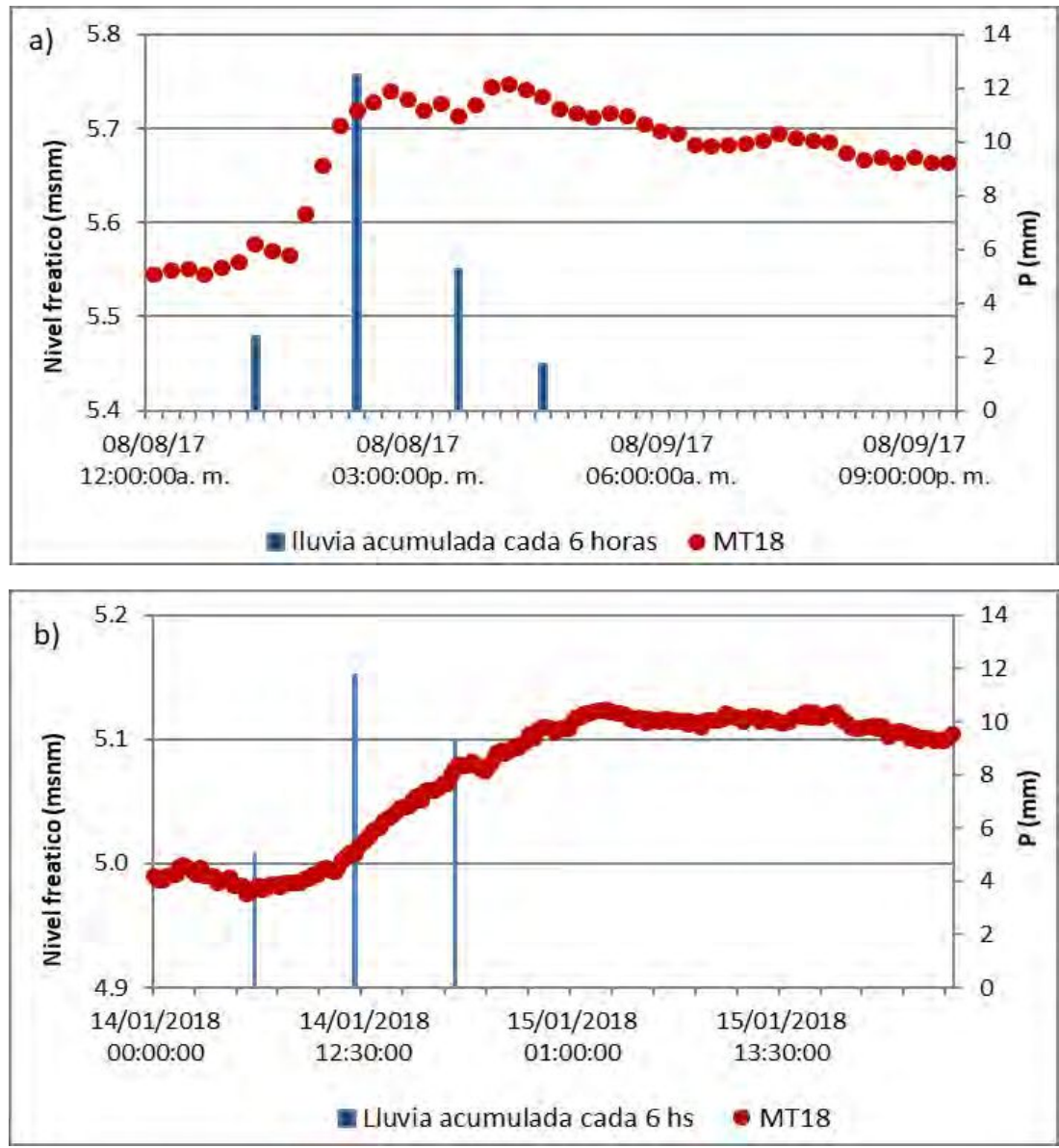

Figura 8.68 Comportamiento del nivel freático del pozo MT18 para el evento de precipitaciones en invierno (a) y verano (b).

En cuanto a la generalidad de los pozos, los resultados indican menores tasas de recarga durante el verano las que se corresponderían con menores excesos de agua asociados a una mayor evapotranspiración consecuencia de las temperaturas más altas que caracterizan a la época estival. Para el periodo frío, en términos generales, la tasa de recarga en las zonas de descarga es de 0,014 m/d mientras que en la de recarga principal es de $0,023 \mathrm{~m} / \mathrm{d}$.

Durante el periodo cálido, para la zona principal de recarga y frente a un evento de lluvia de similares características que en el periodo frio, las tasas de recarga calculadas en este sector varían entre 0,009 y $0,016 \mathrm{~m} / \mathrm{d}$ con respuestas bastante homogéneas. 
Si la precipitación y medio físico fueran homogéneos e isótropos las tasas de recarga deberían ser equivalentes en toda el área y considerando solo el flujo vertical. Sin embargo, se ha observado que existen heterogeneidades en la respuesta de los niveles frente a un mismo evento de lluvia. Si el medio fuera isótropo, a mayor espesor de ZNS, mayor debería sería el tiempo de recorrido hasta llegar al nivel freático. Esto no ocurre, evidenciando que existirían cambios en las conductividades hidráulicas o vías de infiltración preferenciales en los sectores analizados. En las zonas de descarga la componente de flujo lateral podría contribuir a desviar el comportamiento.

\subsection{Cambios en el uso del suelo y modificaciones en las reservas}

\subsubsection{Respuesta de los niveles freáticos en un sector de duna urbanizada y natural}

Se analiza la existencia de cambios en la infiltración de las arenas del cordón costero como consecuencia de las actividades antrópicas.

Se seleccionaron cuatro pozos de monitoreo (freatímetros), ubicados en la unidad geomorfológica campo de dunas semiactivas que a su vez hidrodinámicamente corresponde a la zona principal de recarga. Los pozos MT6 y MT11 se ubican en el sector urbanizado y los dos restantes MT7 y MT10 se ubican más al oeste donde prevalecen las características naturales.

En febrero de 2017 se registraron precipitaciones bajas (2 y 13,5 mm) los días 13 y 14 y mayores (18,5 y $21 \mathrm{~mm}$ ) para los días 17 y 18 según la suma de los valores diarios de la estación (Tabla 32).

Tabla 32 Precipitaciones entre el 13 y 18 de febrero-2017.

\begin{tabular}{|c|c|c|c|c|}
\hline & \multicolumn{4}{|c|}{ Pluviómetro mm } \\
\hline Pozo & $13 / 2 / 2017$ & $14 / 2 / 2017$ & $17 / 2 / 2017$ & $18 / 2 / 2017$ \\
\hline MT6 & 5 & 2 & 15 & 24 \\
\hline MT7 & 6 & 8 & 20 & 20 \\
\hline MT10 & 5 & 2,5 & 18 & 22 \\
\hline MT11 & 5 & 2 & 17 & 24 \\
\hline Promedio & $\mathbf{5}$ & $\mathbf{4}$ & $\mathbf{1 8}$ & $\mathbf{2 3}$ \\
\hline Estación & $\mathbf{2}$ & $\mathbf{1 3 , 5}$ & $\mathbf{1 8 , 5}$ & $\mathbf{2 1}$ \\
\hline
\end{tabular}


Las precipitaciones contabilizadas en los pluviómetros se encuentran dentro del orden de las registradas por la estación meteorológica excepto para el 14/2/17 donde la estación registró un valor 3 veces superior. En esa misma fecha se observa una mayor variabilidad entre los datos de los diferentes pluviómetros cuya media es de 2 $\mathrm{mm}$, destacándose el ubicado al lado del pozo MT7 con $8 \mathrm{~mm}$. En general la variabilidad entre dispositivos oscila entre el 17 y $25 \%$ lo cual podría deberse a una heterogeneidad en las precipitaciones del área.

Para poder analizar la reacción de los niveles en conjunto con la caída de lluvia se graficaron los datos de la estación meteorológica (Figura 8.69).

En el pozo MT7 se registró un ascenso de nivel de $0,05 \mathrm{~m}$ el 13/2 seguido de otro igual el día $14 / 2$ producto de precipitaciones acumuladas de 5 y $13 \mathrm{~mm}$ respectivamente. Entre el $15 / 2$ y el 16/2 los niveles descienden levemente para incrementarse el 17/2 en 0,18 m luego de 18,5 mm de precipitaciones. El 18/2 luego de $21 \mathrm{~mm}$ de lluvias caídas se produce otro aumento de 0,19 m. En cambio, en el pozo MT10 sólo se registran ascensos de 0,05 y $0,08 \mathrm{~m}$ el $17 / 2$ y $18 / 2$ respectivamente.

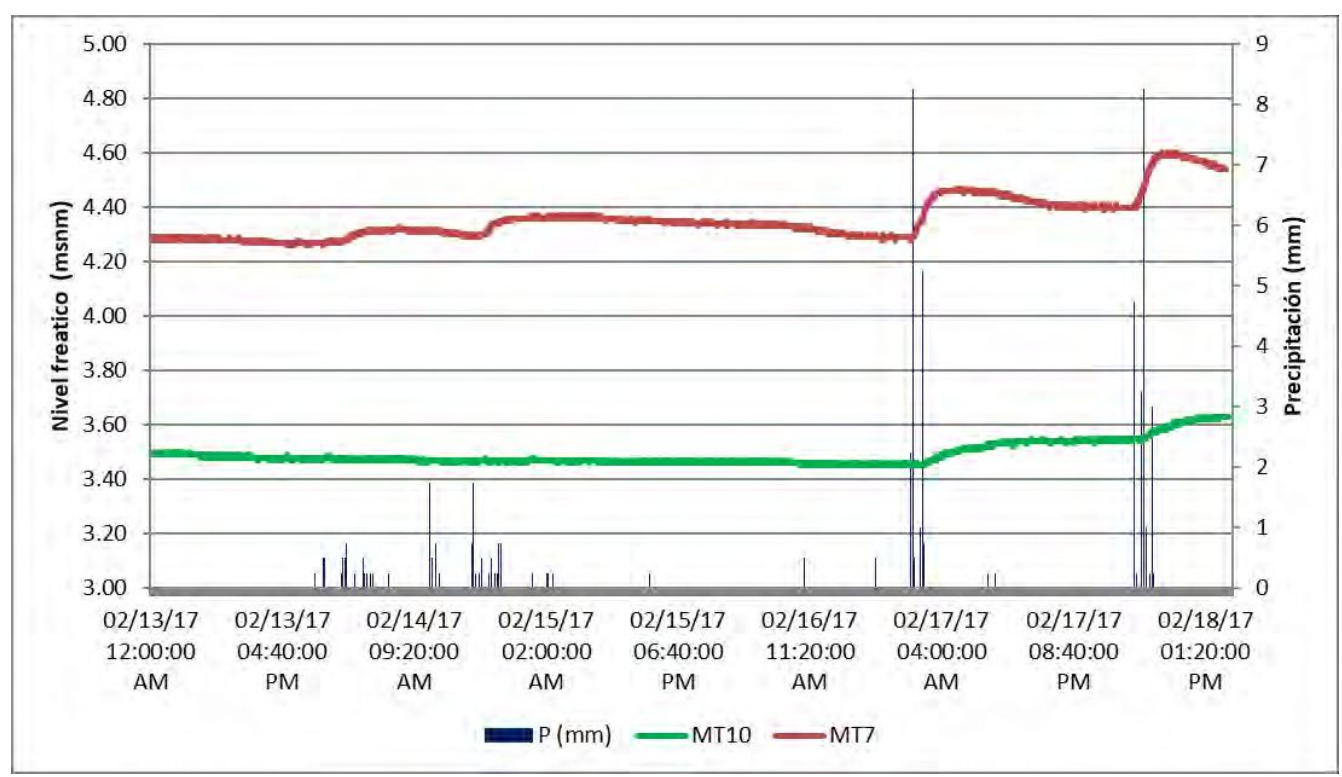

Figura 8.69 Comportamiento de los niveles para los freatímetros localizados en el sector natural.

Los pozos ubicados en el sector urbano siguen un comportamiento similar entre sí, permaneciendo casi imperturbados luego de cada lluvia (Figura 8.70). Se observa un incremento de 0,04 m en el pozo MT6 luego de $21 \mathrm{~mm}$ de lluvias del 18/2. 


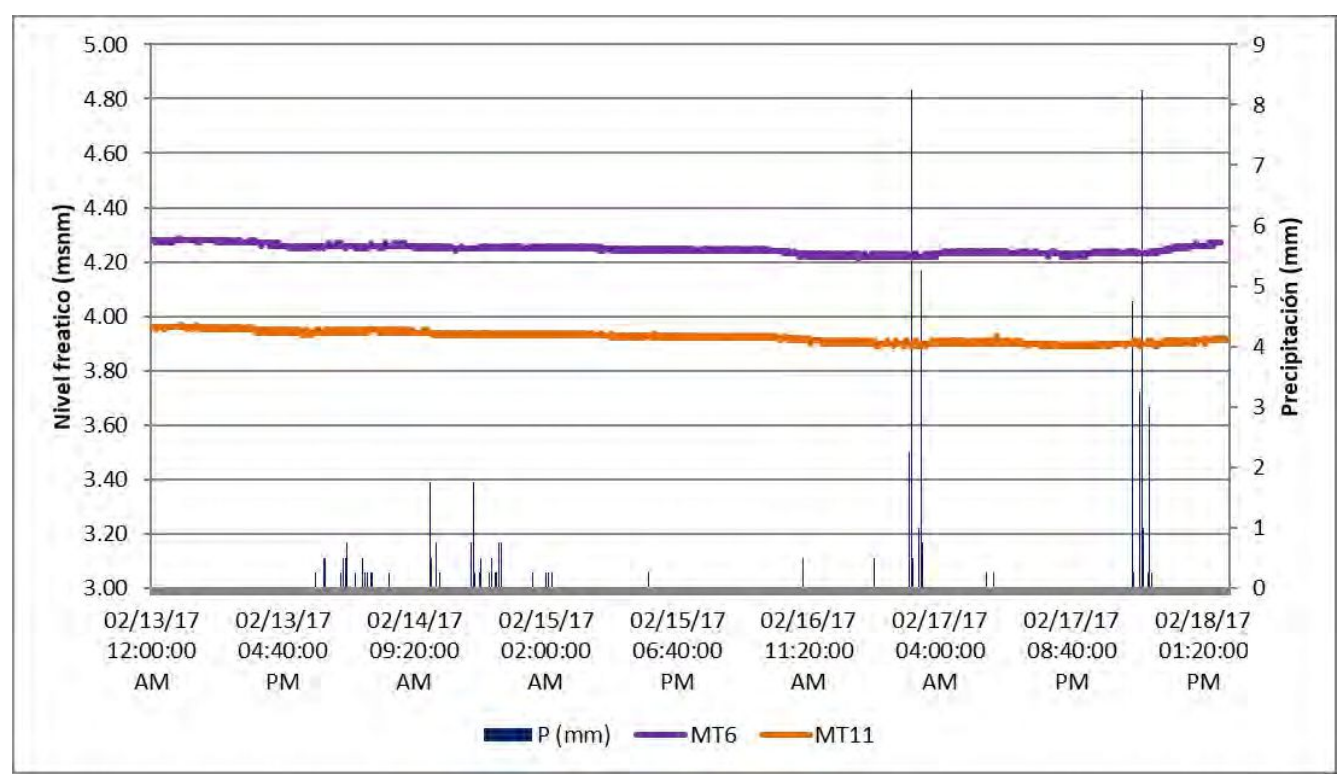

Figura 8.70 Comportamiento de los niveles para los freatímetros localizados en el sector urbanizado.

La experiencia realizada permitió identificar cambios en el patrón de infiltración del cordón costero debido a modificaciones en el uso del suelo. Existe una diferencia en la infiltración entre ambos sectores. Los cambios de uso del suelo como la instalación urbana, el asfaltado de calles, la mayor compactación de la arena por el tránsito, contribuyen a una fuerte disminución de la infiltración y en consecuencia de la recarga al acuífero.

En el capítulo 6.1.3 se estimaron las velocidades de infiltración siendo de $439 \mathrm{~mm} / \mathrm{h}$ en la duna activa, $276 \mathrm{~mm} / \mathrm{h}$ en la duna urbanizada y de $251 \mathrm{~mm} / \mathrm{h}$ en el sector natural, duna inactiva.

A partir de las velocidades de infiltración obtenidas en los ensayos de campo se calculó el porcentaje de recarga de cada ambiente. Considerando que en la duna activa se da el $100 \%$ de recarga a la mayor velocidad de infiltración, en la duna inactiva se reduce al $57 \%$ y en el ambiente de duna urbanizada se obtuvo un valor de $63 \%$, Tabla 33. 
Tabla 33 Porcentajes de recarga a partir de las velocidades de infiltración de cada ambiente de duna.

\begin{tabular}{|c|c|c|c|}
\hline & Duna Activa & Duna urbanizada & Duna Inactiva \\
\cline { 2 - 4 } & MT12 & MT11 & MT10 \\
\hline Vi (mm/h) & 439 & 276 & 251 \\
\hline \% Recarga & 100 & 63 & 57 \\
\hline
\end{tabular}

Resulta llamativo que el valor obtenido para la zona urbana sea mayor que la duna inactiva. Esto podría deberse, tal vez, a que los sectores ensayados (veredas), si bien se encontraban dentro del uso de suelo urbano, presentaran características más cercanas a la duna natural, con menos compactación, permitiendo una mayor infiltración.

\subsubsection{Análisis periodo (1955 - 2017) mediante el uso de imágenes.}

El cordón costero constituye el medio hidrogeológico apto para el desarrollo del acuífero freático que abastece de agua dulce a la población. La recarga de este acuífero es a partir de la infiltración directa de las precipitaciones, por lo tanto, los cambios producidos en la superficie impactan directamente en la recarga del agua subterránea.

Se analizaron los cambios de uso de suelo en el cordón costero de Mar del Tuyú y se evaluó su afectación a la recarga del acuífero freático entre los años 1955 y 2017.

Se realizaron dos clasificaciones supervisadas a partir de la utilización de un SIG, la primera a partir de una fotografía aérea (1955) y la segunda de una imagen Landsat (2017).

En el primer caso debido a la baja densidad de población se tomaron dos clases de uso del suelo: arena y vegetación. En la imagen de 2017 se tomaron tres clases: vegetación (Figura 8.71 a), arena (Figura 8.71 b) y urbano (Figura $8.71 \mathrm{c}$ ).

La clase vegetación incluye todos los tipos de árboles, pastizal, vegetación de bajos inundados e interdunas vegetadas. La clase arena incluye a las dunas activas, dunas semiactivas y mantos de arena con escasa vegetación. La clase urbano abarca todo tipo de edificaciones urbanas.

Se calculó el balance hídrico para el periodo 1989-2006. A cada clase se le asignó un porcentaje de infiltración de los excesos de agua obtenidos del balance. Se considera que en la clase arena, como consecuencia de las características geomorfológicas de 
la duna activa, como la alta permeabilidad de los sedimentos y la falta de una red de drenaje donde escorrentía superficial tiende a cero, la infiltración se produce en un $100 \%$ de su superficie. Para la zona ocupada por vegetación se estima que la infiltración disminuye, alcanzando el $70 \%$ de la superficie, teniendo en cuenta que la vegetación puede compactar un poco la arena y provocar una ligera escorrentía superficial.

Según diversos autores y en diferentes ciudades para las áreas urbanizadas se han asignado valores de infiltración que van desde 6 hasta $36 \%$ de las precipitaciones (Auge, 2005; Kruse et al., 2013; Vazquez Suñé y Sánchez-Vila, 1997; Wiles y Sharp, 2008). En cuanto a la clase de uso de suelo urbano, se le ha asignado un $15 \%$ como consecuencia de la impermeabilización, ya que en este caso prevalecería la escorrentía superficial de los volúmenes de lluvia por las calles asfaltadas. Esta escorrentía junto con la proveniente de los techos de las casas pasaría directamente a la red pluvial y posterior descarga al mar. Ese $15 \%$ asignado al uso de suelo correspondería a los sitios de parques, jardines y sectores donde la infiltración sería posible dentro de una urbanización. Se han considerado estos valores por haber sido aplicados en otro sector del cordón costero con características similares (Carretero et al. 2014). 


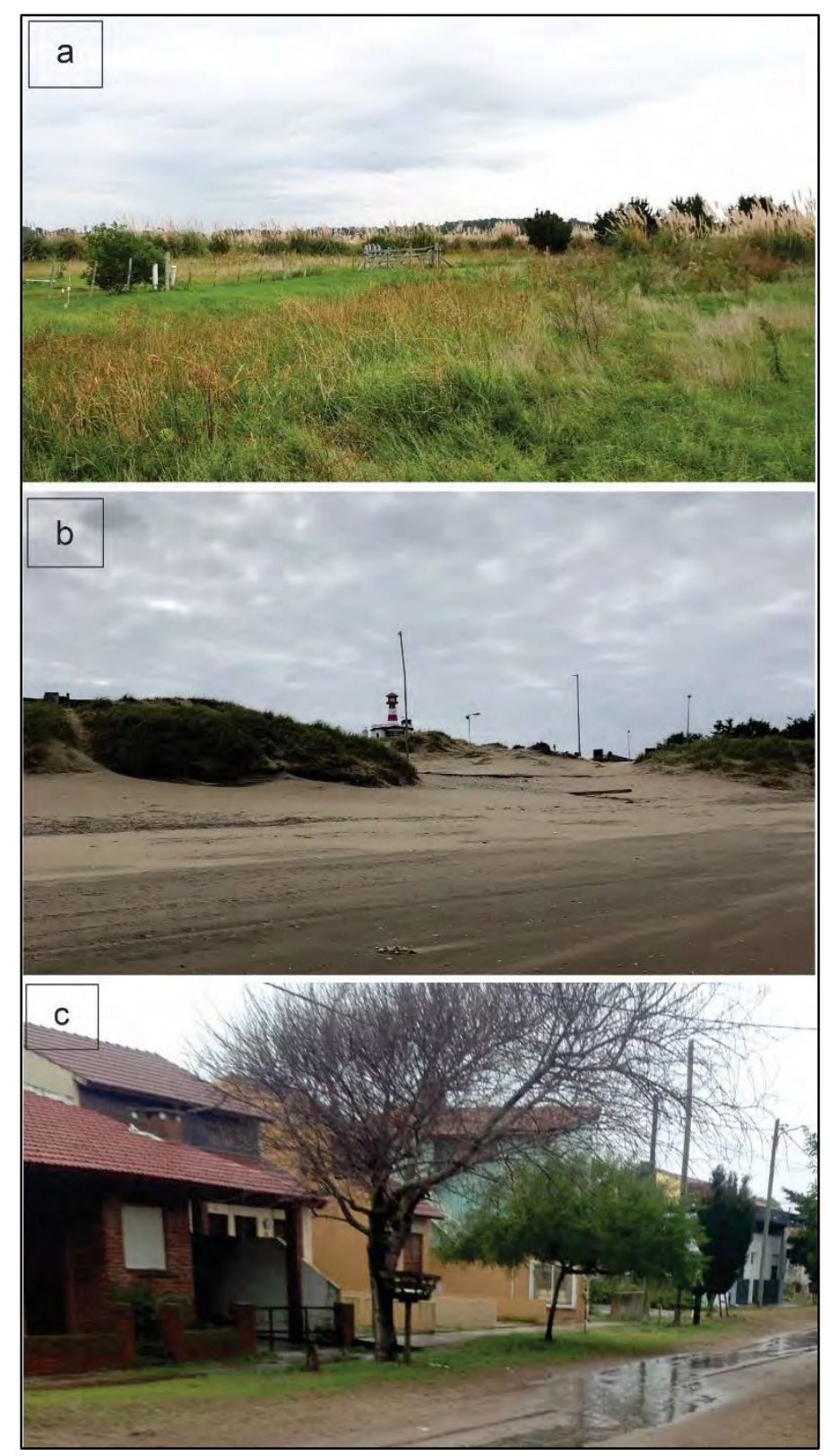

Figura 8.71 Tres tipos de uso de suelo: vegetación (a), arena (b) y urbano (c).

En la fotografía aérea de 1955 (Figura 8.72 a, Tabla 34) se observan, de oeste a este, las unidades geomorfológicas definidas por Marcomini y Lopez (2010). Se distinguen cordones litorales de rumbo NO hacia el oeste, luego un campo de dunas inactivo formado por mantos de arena vegetados debido a las mayores condiciones de humedad.

Hacia el este continúan las dunas semiactivas donde se distinguen crestas de dunas con espacios interdunales totalmente vegetados. Por último, las dunas activas, que se desarrollan en contacto con la playa y donde se observan interrupciones por el trazado 
de calles y vegetación implantada, resultando en los primeros indicios de la modificación del paisaje natural.

La clasificación supervisada correspondiente a 1955 (Figura 8.72 b) dio como resultados que el $46 \%\left(6 \mathrm{~km}^{2}\right)$ del área total estaba ocupado por arena y el restante $54 \%\left(7 \mathrm{~km}^{2}\right)$ se componía de suelo arenoso con vegetación.

La clasificación para el 2017 (Figura 8.72 d, Tabla 34) muestra que el área ocupada por arena es del $13 \%\left(1,7 \mathrm{~km}^{2}\right)$. No es posible identificar en la imagen (Figura $8.72 \mathrm{c}$ ) las geoformas previamente descriptas para la duna ya que en su mayoría fueron arrasadas por el sector urbano.

La vegetación ocupa un área similar con el $58 \%\left(7,5 \mathrm{~km}^{2}\right)$ y el sector urbano representa el $29 \%$ desarrollándose en una franja de $3,7 \mathrm{~km}^{2}$ paralela y cercana al mar. Esta distribución de la población está controlada no solo por el atractivo del mar sino porque allí el agua subterránea presenta mejor calidad para consumo. Hacia el oeste la calidad química del agua desmejora, aumentando la salinidad y la presencia de elevadas concentraciones de hierro y manganeso que es común en otros sectores del Partido de La Costa (CFI 1990b, Carretero, 2011 Carretero y Kruse 2015b).

Se calculó el volumen de agua infiltrado para los años 1955 y 2017 a partir de las áreas obtenidas de cada clase y el porcentaje de infiltración teóricos (100\% clase arena, $70 \%$ vegetación y $15 \%$ para la clase urbano) y considerando excesos promedio de $333 \mathrm{~mm} / a n ̃ o$. Los resultados indican una reserva total de $3,6 \mathrm{hm}^{3}$ para 1955 y de $2,5 \mathrm{hm}^{3}$ para la situación actual.

La clase arena es la que presenta mayores cambios de uso de suelo y consecuentemente, en donde se produjo la mayor reducción en la recarga, resultando una reducción en las reservas pasando de $2 \mathrm{hm}^{3}$ a $0,6 \mathrm{hm}^{3}$. La reserva en el sector ocupado por vegetación no ha sufrido cambios significativos y representa un volumen de $1,7 \mathrm{hm}^{3}$ para ambos años, mientras que el sector urbano, inexistente en 1955, aportaría sólo $0,2 \mathrm{hm}^{3}$.

Tabla 34 Clases de uso del suelo, área afectada y recarga para ambos años estudiados.

\begin{tabular}{|c|c|c|c|c|}
\hline & \multicolumn{2}{|c|}{1955} & \multicolumn{2}{c|}{2017} \\
\hline Clase & Área $\left(\mathrm{m}_{2}\right)$ & Reserva $\left(\mathrm{hm}_{3}\right)$ & Área $\left(\mathrm{m}_{2}\right)$ & Reserva $\left(\mathrm{hm}_{3}\right)$ \\
\hline Arena & 6000000 & $\mathbf{2 , 0}$ & 1700000 & $\mathbf{0 , 6}$ \\
\hline Vegetación & 7000000 & $\mathbf{1 , 6}$ & 7500000 & $\mathbf{1 , 7}$ \\
\hline Urbano & 0 & $\mathbf{0 , 0}$ & 3800000 & $\mathbf{0 , 2}$ \\
\hline Total & 13000000 & $\mathbf{3 , 6}$ & 13000000 & $\mathbf{2 , 5}$ \\
\hline
\end{tabular}


El acuífero freático se ve afectado por el crecimiento urbano ya que disminuyen las superficies de infiltración. La impermeabilización de la duna conduce a una menor recarga luego de las precipitaciones y un aumento del escurrimiento superficial.

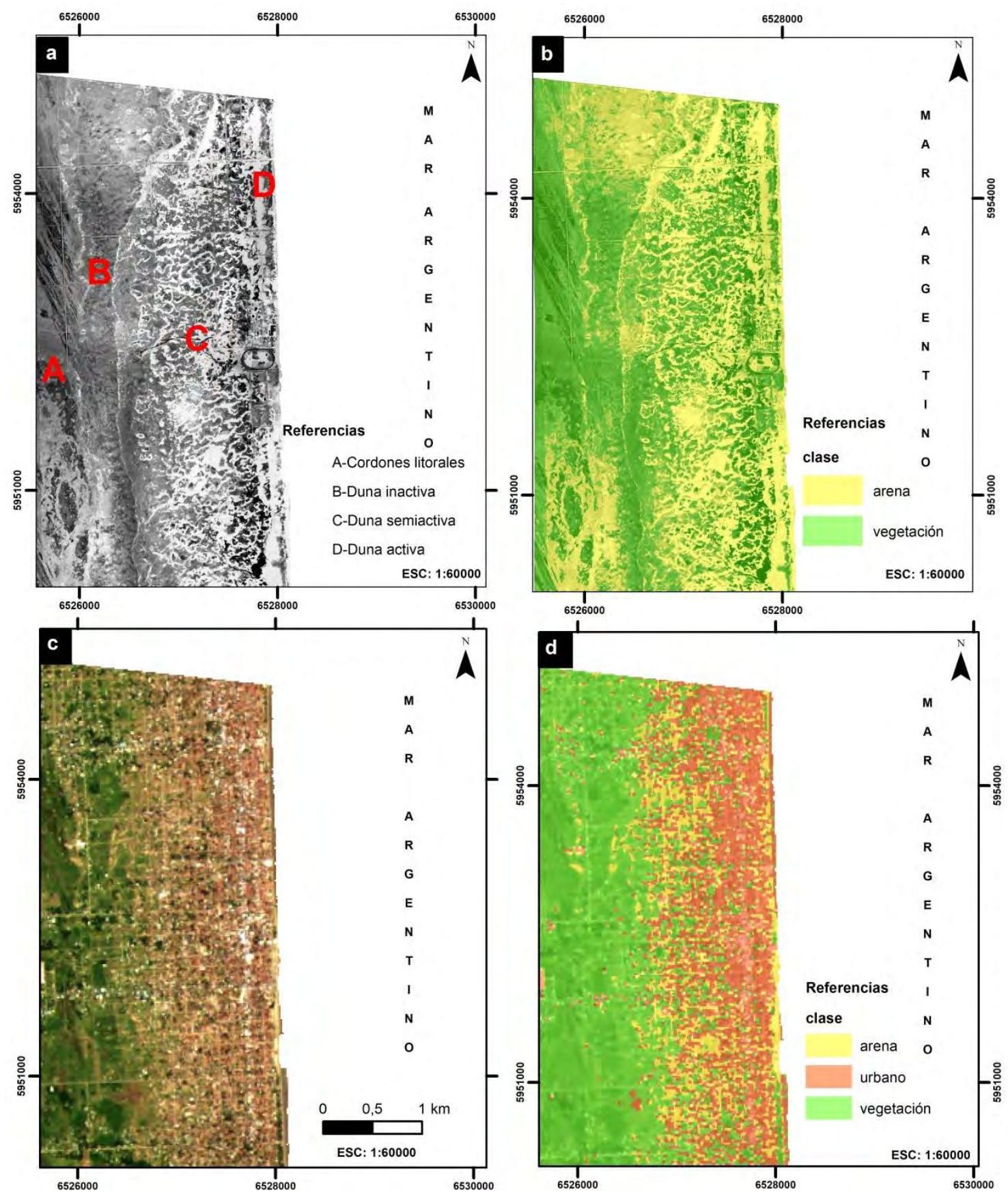

Figura 8.72 a) fotografía aérea de 1955 con sus rasgos geomorfológicos asociados; b) clasificación supervisada para 1955; c) imagen Landsat 2017; d) clasificación supervisada para 2017.

Tomando las mismas condiciones y realizando los mismos cálculos. pero reemplazando los porcentajes de recarga obtenidos en el capítulo 8.9.1 se estimó una 
reserva total de $3,3 \mathrm{hm}^{3}$ para el año 1955 y $2,8 \mathrm{hm}^{3}$ para el 2017 Tabla 35 . Si se comparan estos resultados con los obtenidos previamente utilizando porcentajes de infiltración teóricos, los totales no parecen variar demasiado.

Tabla 35 Clases de uso del suelo, área total y reserva reguladora calculada utilizando porcentajes de infiltración propios.

\begin{tabular}{|c|c|c|c|c|}
\hline & \multicolumn{2}{|c|}{1955} & \multicolumn{2}{c|}{2017} \\
\hline Clase & Área $\left(\mathrm{m}_{2}\right)$ & Reserva $\left(\mathrm{hm}^{3}\right)$ & Área $\left(\mathrm{m}_{2}\right)$ & Reserva $\left(\mathrm{hm}^{3}\right)$ \\
\hline Arena & 6000000 & $\mathbf{2 , 0}$ & 1700000 & $\mathbf{0 , 6}$ \\
\hline Vegetación & 7000000 & $\mathbf{1 , 5}$ & 7500000 & $\mathbf{1 , 4}$ \\
\hline Urbano & 0 & $\mathbf{0}$ & 3800000 & $\mathbf{0 , 8}$ \\
\hline Total & 13000000 & $\mathbf{3 , 3}$ & 13000000 & $\mathbf{2 , 8}$ \\
\hline
\end{tabular}

La clase urbano es la que presenta mayores diferencias ya que el porcentaje de infiltración teórico considerado para esta zona es del $15 \%$ y el valor estimado por ensayos de infiltración es de $63 \%$. Siendo la reserva estimada de 0,2 $\mathrm{hm}^{3}$ y 0,8 $\mathrm{hm}^{3}$ respectivamente. Esta variabilidad podría deberse a la heterogeneidad particular del área urbanizada tomada para este estudio. En la zona urbana se considera que el área ocupada por calles asfaltadas y casas tiene una infiltración igual a cero ya que el agua pasa directamente a la red pluvial y/o descarga al mar. Sin embargo existe infiltración en áreas urbanas donde las calles y veredas son de arena. Además, se podría considerar que parte de lo que llueve sobre los techos cae y se infiltra en los costados de las casas. De todas maneras, el porcentaje obtenido en el ensayo parece ser demasiado elevado considerando las condiciones descriptas para el sector urbano. Obsérvese que incluso el valor de infiltración es mayor que el obtenido para la duna inactiva. Es muy probable que este resultado sea producto de la evaluación de un sector de la duna con características no tan antropizadas, pero localizado dentro de la clase de uso de suelo urbano.

\subsection{Análisis mediante mapas de flujo (1987-2016)}

A partir de la información antecedente y la elaboración de balances hídricos para el período anual previo a los relevamientos de aguas subterráneas de agosto 1987 (datos de CFI, 1990a) Tabla 36 y octubre de 2016 Tabla 37. 
Tabla 36 Balance hidrológico 1987

\begin{tabular}{|c|r|r|r|r|r|r|r|r|r|r|r|r|r|}
\hline \multicolumn{10}{|c|}{1987} \\
\hline & Ene & Feb & Mar & Abr & May & Jun & Jul & Ago & Sep & Oct & Nov & Dic & Año \\
\hline P & 82 & 116 & 140 & 70 & 18 & 0 & 100 & 38 & 121 & 83 & 131 & 23 & 921 \\
\hline ETP & 68 & 62 & 71 & 64 & 46 & 33 & 36 & 50 & 60 & 66 & 65 & 68 & 690 \\
\hline ETR & 54 & 50 & 59 & 51 & 25 & 6 & 27 & 40 & 44 & 57 & 56 & 42 & 511 \\
\hline Exc & 11 & 61 & 86 & $\mathbf{3 7}$ & $\mathbf{0}$ & $\mathbf{0}$ & $\mathbf{4 3}$ & $\mathbf{6}$ & 99 & 6 & 76 & 0 & 424 \\
\hline
\end{tabular}

Tabla 37 Balance hidrológico 2016

\begin{tabular}{|c|c|c|c|c|c|c|c|c|c|c|c|c|c|}
\hline \multicolumn{10}{|c|}{2016} \\
\hline & Ene & Feb & Mar & Abr & May & Jun & Jul & Ago & Sep & Oct & Nov & Dic & Año \\
\hline P & 83 & 119 & 27 & 87 & 65 & 6 & 79 & 4 & 58 & 88 & 36 & 81 & 733 \\
\hline ETP & 121 & 102 & 90 & 72 & 46 & 22 & 23 & 29 & 47 & 53 & 75 & 96 & 776 \\
\hline ETR & 78 & 70 & 37 & 39 & 24 & 24 & 23 & 30 & 35 & 42 & 51 & 43 & 496 \\
\hline Exc & 2 & 56 & 0 & 24 & 23 & $\mathbf{0}$ & $\mathbf{3 8}$ & $\mathbf{0}$ & $\mathbf{1 7}$ & $\mathbf{2 6}$ & 20 & 0 & 206 \\
\hline
\end{tabular}

La precipitación durante el año previo a cada uno de los relevamientos se encuentra en el entorno de los valores medios (entre 921 y $733 \mathrm{~mm}$ ). Se consideró la suma de los excesos de agua del balance hídrico tales que al momento de las mediciones para ambas situaciones fue de $86 \mathrm{~mm}$ (abril-agosto 1987) y $81 \mathrm{~mm}$ (junio-octubre 2016). De esta manera, se deduce que los relevamientos de 1987 y 2016 responden a condiciones en que los balances hídricos son representativos de las condiciones climáticas medias y los excesos no presentan diferencias significativas. A partir de ello se puede reconocer que el ingreso de agua al sistema subterráneo no muestra variaciones importantes para las situaciones representadas. Es decir que al momento de la medición de niveles la recarga en ambos periodos es de la misma magnitud.

De acuerdo a las condiciones establecidas, se reconoce que en la duna se produce la infiltración de prácticamente la totalidad de los excesos, los cuales alimentarán a la capa freática transformándose en recarga.

En base a los mapas de flujo (Figura 8.73), a los parámetros hidráulicos del acuífero (coeficiente de permeabilidad $20 \mathrm{~m} / \mathrm{d}$ y porosidad efectiva 0,10 ) y considerando como plano de referencia el $0 \mathrm{~m} \mathrm{~s}$. n. m., se estimó el volumen de agua dulce disponible para cada fecha. A partir de los volúmenes y las áreas de cada una de las zonas fue posible estimar el agua disponible por unidad de área y así reconocer comparativamente el significado de esa agua almacenada y sus variaciones temporales. 
En 1987 los niveles freáticos se encontraban entre 2 y $5 \mathrm{~m} \mathrm{~s}$. $\mathrm{n}$. m. El sector central de la duna estaba delimitado por la curva de $4,5 \mathrm{~m} \mathrm{~s}$. n. m. Hacia el este los niveles descienden a 2 m s. n. m. y hacia el este a 3 m s. n. m. La situación para 2016 muestra que la curva de $4,5 \mathrm{~m} \mathrm{~s}$. $\mathrm{n}$. $\mathrm{m}$. se reduce considerablemente. Al sur se evidencian curvas de mayor altura de la capa freática (promedio de 4,5 m s. n. m.). Los niveles hacia el este llegan a 1,5 m s. n. m. y hacia el oeste a $2 \mathrm{~m} \mathrm{s.} \mathrm{n.} \mathrm{m..}$
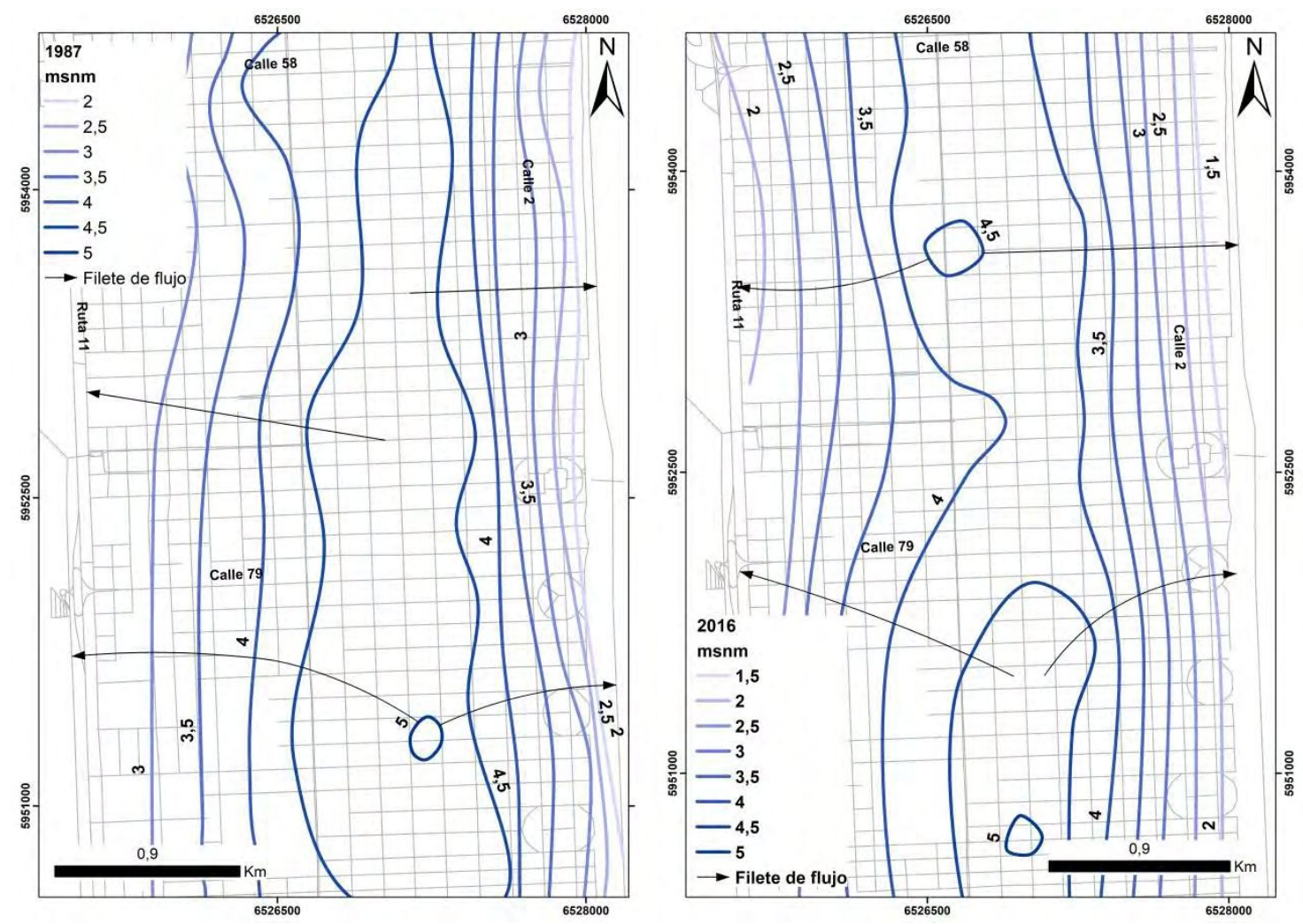

Figura 8.73 Mapas isofreáticos para 1987 y 2016.

Se ha calculado el volumen de agua almacenada para cada situación. En 1987 era de $4,7 \mathrm{hm}^{3}$ y para 2016 de $3,9 \mathrm{hm}^{3}$ con lo cual la reducción en la reserva se estimaría en $0,8 \mathrm{hm}^{3}$. Si se analiza en detalle el mapa de isovariación entre ambos periodos (Figura 8.74) se evidencia que las modificaciones en la reserva no son simplemente numéricas, sino que se asocian con el cambio en el uso del suelo y la localización de la urbanización en crecimiento.

De esta manera se puede observar que existen dos sectores asociados a la zona de descarga al oeste donde los niveles aumentaron entre 0 y 0,5 m. En contraposición, desde la parte central de la duna y hacia el este se visualizan descensos de 0,5 m en algunos sectores y de hasta $1 \mathrm{~m}$ en los más cercanos a la línea de costa. Como puede observarse en la imagen satelital de fondo, las áreas asociadas a los mayores descensos de niveles son aquellas donde hay un mayor grado de urbanización. Cabe 
recordar que la localidad no posee servicios de agua de red, por lo tanto, el uso del recurso sería más intensivo en los sectores donde se refleja la mayor disminución de la recarga.

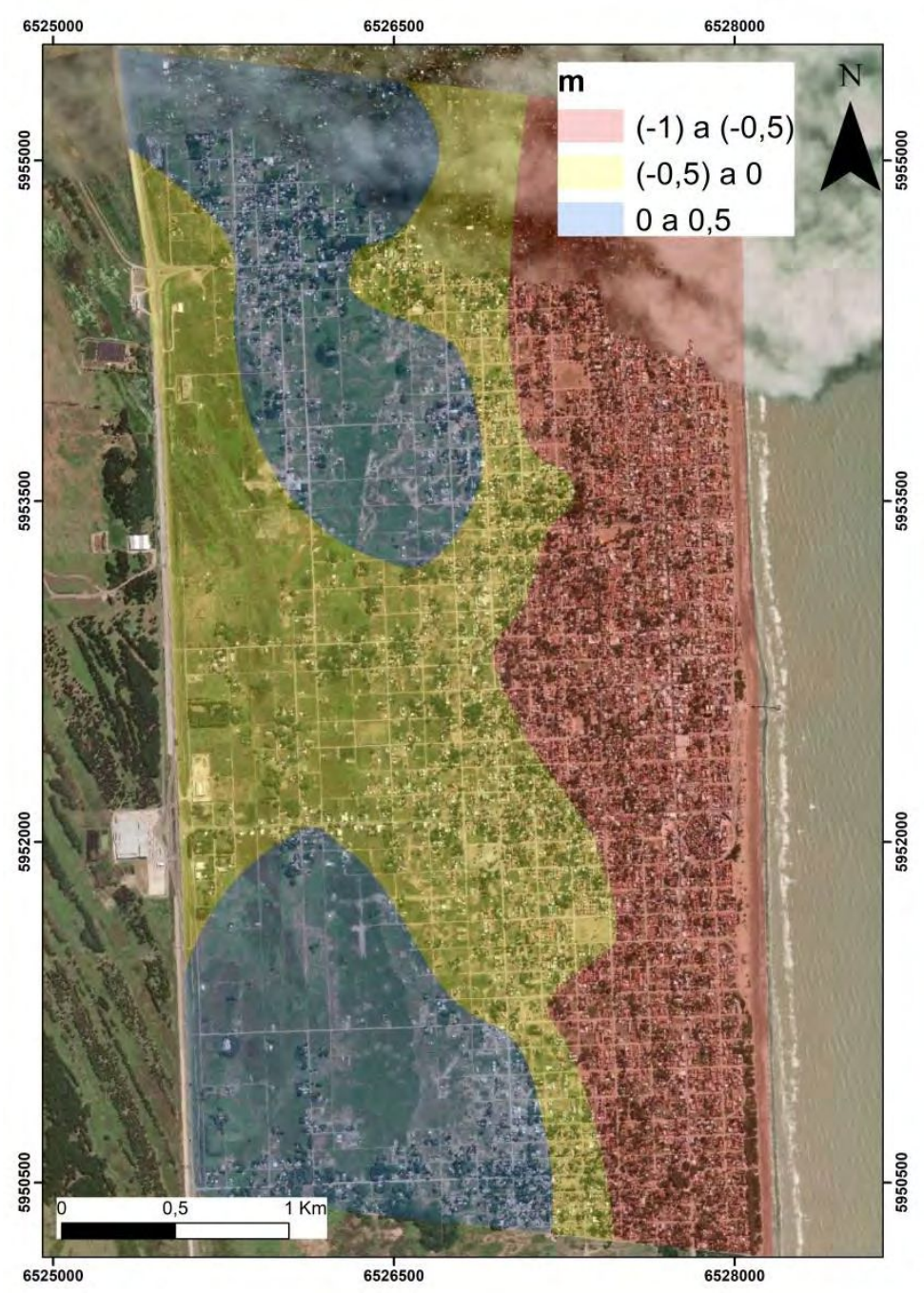

Figura 8.74 Mapa de isovariación de los niveles freáticos entre 1987 y 2016.

\subsection{Evolución de la reserva vs el consumo}

El uso del agua en Mar del Tuyú se destina únicamente para consumo humano ya que no hay industrias, agricultura y ganadería que se desarrollen en la región.

Se estimó la cantidad de agua por año utilizada por la población asumiendo un consumo medio de 200 L/d (Planas et al., 2000). Siendo la cantidad de habitantes de 2800 habitantes (Mar del Tuyú y Costa del Este) en 1991 y de 8070 habitantes (Mar del Tuyú y Costa del Este) en 2010 (INDEC 1991, 2010). Se considera que, en la temporada veraniega, debido al turismo la demanda de agua puede hasta quintuplicarse. 
En 1991 el consumo anual fue estimado en $0,2 \mathrm{hm}^{3}$ y en 2010 en 0,6 hm $\mathrm{hm}^{3}$, valor que se ha triplicado mientras la recarga tiende a reducirse por cambios en el uso de la tierra. Por otra parte, si se considera la demanda en los meses de verano la situación es mucho más delicada (Figura 8.75) donde estos valores se transforman en 1 y 3 $\mathrm{hm}^{3}$. Es de destacar que además de un mayor consumo, en estos meses la recarga es menor debido a mayores valores de evapotranspiración. El sistema luego se recupera en la estación fría donde, si bien las precipitaciones suelen ser menores, la recarga es mayor debido a la escasa evapotranspiración.

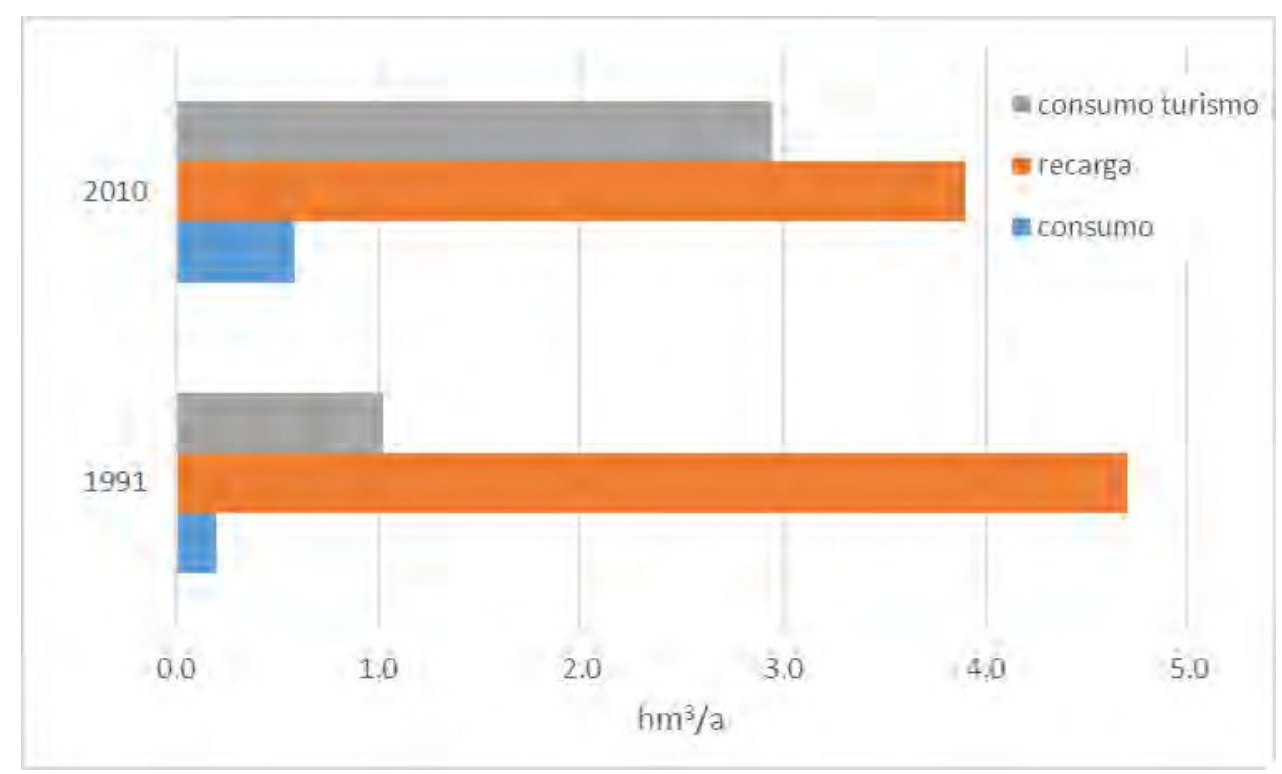

Figura 8.75 Recarga vs consumo para la población estable y un estimado de turismo (1991 y 2010).

\subsection{Comparación entre metodologías y otros sitios del cordón costero}

A partir del método imágenes satelitales se observa una disminución general de las reservas del $31 \%$ en 60 años. La recarga en el sector de duna ha sido reducida en un $71 \%$ debido al reemplazo por urbanización. Mediante el uso de mapas de flujo e isovariación la reducción en la recarga sería del $17 \%$ en 30 años.

Estos valores se encuentran dentro del orden de los calculados para otros sectores del Partido de La Costa utilizando la misma metodología con imágenes. En Carretero y Kruse (2012) se expone la existencia de una reducción en la recarga del $47 \%$ en el sector más urbanizado de San Clemente del Tuyú en casi 50 años (1958-2006). Luego en Carretero et al. (2014) en un análisis entre 1973 y 2010 considerando el partido según sus aglomerados urbanos principales, la reducción de la recarga se calculó en 
el orden del $18 \%$ para los sectores de San Clemente y Las Toninas-Mar del Tuyú, mientras que para San Bernardo-Mar de Ajó fue del 25\%.

Mediante la variación de los niveles freáticos y el uso de los mapas de flujo entre 1987 y 2006 se estimó para San Clemente una reducción en la recarga de 21\% (Carretero, 2011) y del 30\% para Las Toninas-Santa Teresita entre 1987 y 2012 (Carretero et al., 2013c). En Mar del Tuyú este valor fue estimado en $17 \%$.

\subsection{Detección de la descarga del agua subterránea al mar}

La descarga de agua dulce subterránea en el mar (SGD submarine groundwater discharge) es un proceso hidrológico complejo que ocurre en la interfaz continenteocéano y juega un papel importante en la dinámica costera. En la costa oriental de la provincia de Buenos Aires se planteó como objetivo detectar la descarga de agua dulce desde el acuífero arenoso hacia el Océano Atlántico.

La SGD en el frente costero de Mar del Tuyú en marzo de 2016 ha sido confirmada mediante tres enfoques complementarios: hidrodinámica, un trazador $\left({ }^{222} R n\right)$ y métodos geoeléctricos.

El mapa isofreático muestra curvas entre 1,5 y $4 \mathrm{~m} \mathrm{~s}$. $\mathrm{n}$. m. (Figura 8.77 ), resultando las mayores alturas de la capa freática en la zona central de la duna. El gradiente hidráulico calculado al este fue de 0,002. El valor de caudal de descarga obtenido a partir del mapa de flujo es de $2000 \mathrm{~m}^{3} / \mathrm{d}$, o de $0,38 \mathrm{~m}^{3} / \mathrm{d} / \mathrm{m}$ si se considera la unidad $\mathrm{m}^{3} / \mathrm{d}$ por metro de costa.

Usando el promedio de la actividad del ${ }^{222} \mathrm{Rn}$ en la transecta $(7,3 \mathrm{dpm} / \mathrm{L})$ y el promedio de los pozos (130 dpm/L) como valor extremo, se ha intentado calcular el flujo de descarga. Los valores indican que la SDG en el Partido de La Costa es de $1,1 \mathrm{~m}^{3} / \mathrm{s}$ o $3,5( \pm 2,5) \mathrm{m} 3 / \mathrm{m} / \mathrm{d}$. Esto resulta en un orden de magnitud mayor que el calculado por medio de la Ley de Darcy. Esta diferencia podría atribuirse a la incertidumbre en el tiempo de residencia, en los valores extremos de radón en los pozos, la recirculación de agua de mar y complicaciones debidas a la alta turbidez del agua en el extremo norte del Partido de La Costa.

El modelo de resistividad obtenido a partir de la tomografía de resistividad eléctrica (Figura 8.76) presenta una primera capa de resistividad constante de 0,25 Ohm $\mathrm{m}$, que corresponde al agua de mar, con una parte superior plana y la base constituida por la batimetría del fondo. Por debajo del fondo marino se observan valores entre 0,25 y $10 \mathrm{Ohm} \cdot \mathrm{m}$, para los cuales, asumiendo una uniformidad litológica de los sedimentos marinos, los valores más bajos corresponderían a la presencia de agua 
salada, mientras que las zonas de mayor resistividad pueden interpretarse como zonas de mezcla entre el agua salada subterránea y agua dulce producto de la descarga.

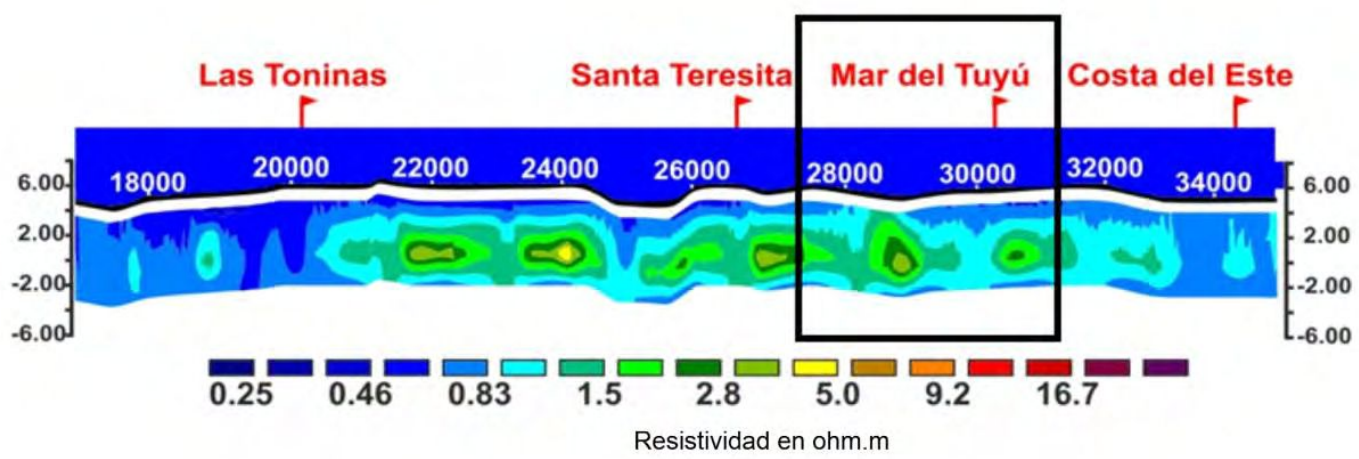

Figura 8.76 Modelo de resistividad.

En la Figura 8.76 puede observarse la correlación entre las líneas de flujo subterráneo y los sectores con resistividades entre 0,25 y $10 \mathrm{Ohm} \cdot \mathrm{m}$ que se asume zona de descarga de agua dulce al mar.

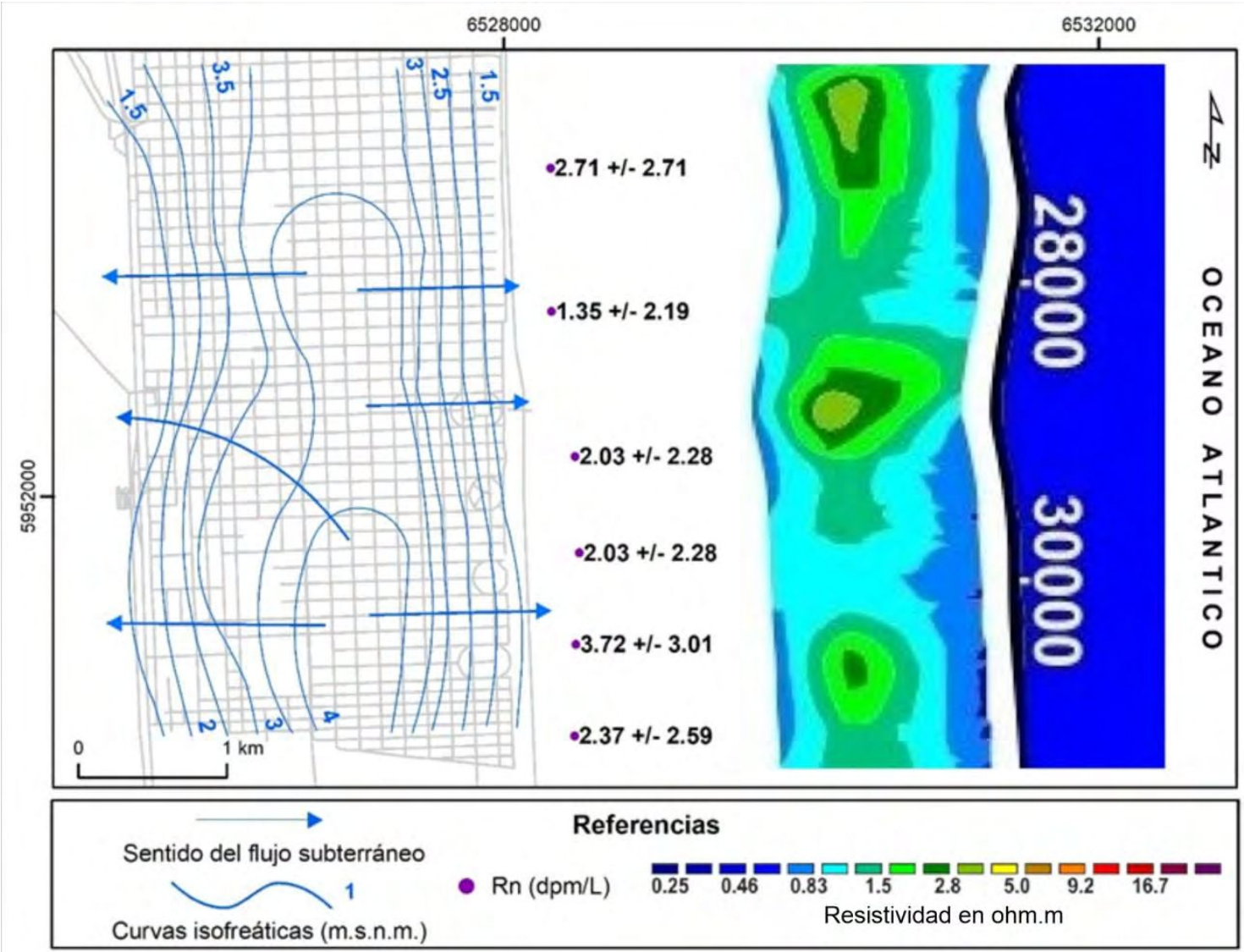

Figura 8.77 Mapa que indica la correlación entre las líneas de flujo del agua subterránea, la actividad del ${ }^{222} \mathrm{Rn}$ y las zonas preferentes de SGD detectadas a partir de la ERT. 
La hidrodinámica y el uso de ${ }^{222} \mathrm{Rn}$ permitieron realizar una cuantificación, mientras que el método geofísico resulta más cualitativo y muestra la distribución areal de la SGD a lo largo de la línea de costa. 


\section{CONCLUSIONES}

Las características geológicas y geomorfológicas de los ámbitos costeros de la región nororiental de la provincia de Buenos Aires están asociadas a los sucesivos ciclos transgresivo-regresivos acaecidos durante el Cuaternario. Se reconoció su significado en la hidrogeología de la costa del litoral marítimo y complementariamente en la costa estuárica (Río de la Plata).

En la costa marítima (Mar del Tuyú) se identifica como geoforma positiva al cordón costero que limita hacia el continente con la llanura deprimida. Específicamente vinculado al cordón costero se reconocen formas menores que inciden en el comportamiento hidrológico: cordones litorales, campo de dunas inactivo, dunas semiactivas y dunas activas desarrolladas en contacto con la playa.

En la costa estuárica (zona de Berisso) se desarrolla una llanura costera en la cual se diferencian como formas menores la planicie de marea relictual, los cordones litorales (conchiles) y la llanura estuárica. La geoforma positiva la constituyen los cordones conchiles, con la particularidad que en esta zona prácticamente han desaparecido por la actividad del hombre (minería de calcáreos).

El acuífero freático de la costa marítima (Mar del Tuyú) está alojado en los sedimentos arenosos correspondientes al cordón costero. La unidad acuífera está compuesta por una secuencia de arenas finas a medianas con un contenido variable de fragmentos de valvas y un espesor que varía entre 5 y $10 \mathrm{~m}$. La conductividad hidráulica de los sedimentos muestra una marcada heterogeneidad espacial, con valores que oscilan entre $8 \mathrm{~m} / \mathrm{d}$ y $59 \mathrm{~m} / \mathrm{d}$. La velocidad de infiltración presenta los valores más altos en la duna activa en condiciones naturales, los cuales disminuyen cuando existe una compactación y urbanización del terreno.

Los mapas de flujo subterráneo indican que las mayores alturas del nivel freático coinciden con el sector central del cordón costero (mayores alturas topográficas), a partir del cual el sentido de flujo es divergente con dos direcciones opuestas, una hacia el continente y otra al mar.

La morfología freática indica que la mayor profundidad de los niveles se produce en verano, mientras que es menor en el invierno. En gradiente hidráulico es relativamente uniforme para ambas situaciones hacia el oeste, mientras que hacia el este (mar) se incrementa en un $50 \%$ en los meses de invierno.

La capa freática se encuentra más elevada y presenta las mayores oscilaciones $(1,2$ $\mathrm{m}$ ) en el campo de dunas activas, mientras que, en las dunas semiactivas, si bien la 
variación es coincidente en el tiempo, en términos cuantitativos representan un $50 \%$ de las activas.

En la zona más elevada del cordón costero se reconocen aguas de baja salinidad, bicarbonatadas sódicas y algunos casos muestran aguas bicarbonatadas cálcicas. Hacia el este de la parte central del cordón costero (mar) el agua presenta un carácter bicarbonatado sódico. En cambio, hacia el oeste (transición a la llanura deprimida) las aguas tienen mayor contenido salino siendo cloruradas sódicas y bicarbonatadas sódicas. En el primer caso el agua presenta valores aceptables para uso humano, en cambio en llanura deprimida no resultan aceptables, con especial influencia en el contenido de Fe y Mn.

Los isótopos ambientales $\left({ }^{18} \mathrm{O},{ }^{2} \mathrm{H}\right.$ y exceso de deuterio (d)) evidencian que el agua de las precipitaciones se infiltra rápidamente alcanzando el nivel freático sin modificaciones en su composición.

Las evidencias hidrodinámicas, hidroquímicas e isotópicas reflejan que el cordón costero representa una zona de predominio de la recarga a partir de la infiltración de los excesos de agua de las precipitaciones. Esta recarga da lugar a la conformación de una lente de agua dulce, los cuales limitan tanto al este como al oeste con agua de mayor salinidad. La descarga se manifiesta en dos direcciones opuestas, una hacia el mar al este y la otra hacia la llanura deprimida al oeste.

La estimación de la recarga a partir de las fluctuaciones de los niveles freáticos y balance hídrico, que alcanzan a valores del orden del $40 \%$ de la precipitación. Si bien los valores obtenidos por ambos métodos no son coincidentes numéricamente, existe una relación entre los meses con excesos de agua y la respuesta de los niveles freáticos ante la recarga. El valor obtenido a partir del balance de cloruros es mucho menor debido a los pocos datos disponibles para la estimación de la recarga.

La recarga es menor durante el verano en que si bien se registran mayores precipitaciones se producen menores excesos de agua debido a una mayor evapotranspiración consecuencia de las temperaturas más altas que caracterizan a la época estival. La descarga de agua subterránea dulce en el mar (SGD), según las condiciones hidrodinámicas se estimó en $0,38 \mathrm{~m}^{3} / \mathrm{d} / \mathrm{m}$ y mediante el uso de ${ }^{222} \mathrm{Rn} 3,5$ $( \pm 2,5) \mathrm{m}^{3} / \mathrm{d} / \mathrm{m}$. Se reconoció el desarrollo de la distribución areal de la SGD a lo largo de la línea de costa a partir de procedimientos geoeléctricos.

Las modificaciones en el uso del suelo producen cambios en la velocidad de infiltración de las arenas del cordón costero, lo cual se evidencia en las variaciones de 
los niveles freáticos detectadas en los pozos que se ubican en posiciones donde las dunas activas mantienen sus condiciones naturales y aquellos situados en sectores en los cuales los procesos antrópicos dan lugar a una reducción en los volúmenes infiltrados. El avance de la urbanización redujo la recarga, estimándose que dicha reducción alcanzó un $17 \%$ en los últimos 30 años.

En la costa estuárica (Berisso) también se reconoce la morfología freática positiva asociada al cordón litoral conchil. Su expresión es menos acentuada que en la costa marítima. Unos pocos centímetros diferencian las alturas freáticas en el cordón con respecto a las otras geoformas (planicie de marea relictual y llanura estuárica). Incluso la forma freática positiva es restringida arealmente y no es continua, dada la eliminación que ha sufrido el cordón debido a la extracción del material calcáreo.

En el cordón conchil de este ámbito costero la velocidad de infiltración es significativamente más alta, dada por la porosidad de los sedimentos que lo conforman (valvas y arenas) que en la llanura estuárica y la planicie de marea relictual vecinas. Sin embargo, estos valores de velocidad de infiltración son inferiores a las dunas activas en condiciones naturales de la costa marítima.

El agua alojada en los cordones conchiles litorales es bicarbonatada cálcica y el contenido isotópico muestra que la infiltración de la precipitación es el origen del agua subterránea. En la planicie de marea relictual son cloruradas y/o sulfatadas sódicas y en la llanura estuárica es bicarbonatada cálcica. De acuerdo con los datos de los isótopos, en los pozos de la llanura estuárica se reconocen tres situaciones con relación a la alimentación de agua freática, una con la infiltración de los excesos de las precipitaciones, otra que indicaría una mezcla con las aguas del Río de la Plata y la tercera donde además de la mezcla se reconocen procesos de evaporación.

El cordón litoral de conchillas constituye un ámbito de predominio de la recarga a partir de la infiltración de las precipitaciones, formándose lentes de agua dulce. Estas lentes se encuentran limitadas al oeste y por debajo por aguas de mayor salinidad. Hacia el este, el límite lo constituye el agua dulce del Río de la Plata, hacia donde se produce la descarga local y regional. El espesor y distribución de los sedimentos en el subsuelo y la delimitación de la geometría y el contenido de agua dulce de las lentes, fueron reconocidos a partir de la aplicación de métodos geoeléctricos.

En el cordón conchil de la zona costera próxima a Berisso se define una relación directa entre las fluctuaciones de los niveles freáticos y los excesos del balance hídrico. En la llanura estuárica no existe tal relación reconociéndose la influencia de 
las mareas del Río de la Plata. La temperatura y la CE del agua presentan cambios que evidencian este tipo de influencia.

Este patrón de ascensos de los niveles del Río de la Plata, como consecuencia de las mareas establece una dinámica superficial y subterránea que crea condiciones de mezclas de aguas, que determinarían, junto al aporte de sedimentos del agua superficial, un balance positivo de nutrientes. En cambio, en el cordón costero marítimo, dada la morfología de las dunas activas, el efecto de las mareas queda restringido a una corta distancia de la costa.

Las diferentes actividades socioeconómicas que se desarrollan en los ámbitos costeros descriptos determinan que existan distintos usos y demandas de agua subterránea. En la costa marítima los requerimientos de agua dulce para consumo humano se incrementan significativamente durante los meses de verano debido al turismo, dando lugar a una explotación intensa del agua subterránea. Por el contrario, en la costa estuárica se realizan distintos cultivos (entre ellos la vid) y la explotación de conchilla por lo que existen canteras abandonadas y en actividad. En ambos casos el agua dulce almacenada en los cordones litorales (arenosos y conchiles) corresponde a los acuíferos someros costeros.

Las reservas de agua almacenada dependen de la recarga natural a partir de la infiltración, siendo la fuente de abastecimiento a la población y cuya explotación se efectúa mediante pozos. La gestión de las lentes de agua dulce requiere de pautas precisas, ajustadas a las condiciones hidrodinámicas e hidroquímicas reconocidas y a las variaciones de las reservas para evitar problemas de agotamiento y/o deterioro de la calidad química. 


\section{BIBLIOGRAFÍA}

Abbona, E., Sarandón, S. y Marasas, M. (2007). Los viñateros de Berisso y el manejo ecológico de los nutrientes. LEISA, revista de agroecología. Vol. 22-n²4:13 -15.

Acharya, T., Kumbhakar, S., Prasad, R., Mondal, S., y Biswas, A. (2019). Delineation of potential groundwater recharge zones in the coastal area of north-eastern India using geoinformatics. Sustainable Water Resources Management, 5(2), 533-540.

Ainchil J. y Kruse, E. (2002). Características hidrogeológicas de la Planicie Costera en el Noreste de La Plata, Buenos Aires, Argentina. Groundwater and Human Development. Mar del Plata (Argentina). XXXII IAH Congress. Proceedings: 606-612.

Albino Martínez, C. (2017). Análisis y procesamiento de tomografía de resistividad eléctrica sobre el fondo marino. Tesis de Grado en Geofísica. Facultad de Ciencias Astronómicas y Geofísicas. Universidad Nacional de La Plata, 64 p.

Alcalá, F.J., y Custodio, E. (2014). Spatial average aquifer recharge through atmospheric chloride mass balance and its uncertainty in continental Spain. Hydrological Processes, 28(2), 218-236.

Andersen, M.S., Baron, L., Gudbjerg, J., Gregersen, J., Chapellier, D., Jakobsen, R., y Postma, D. (2007). Discharge of nitrate-containing groundwater into a coastal marine environment. Journal of Hydrology, 336(1-2), 98-114.

A.N.M.A.T. (2007). Administración Nacional de Medicamentos, Alimentos y Tecnología médica. Ministerio de Salud de la Nación Argentina. Código Alimentario Argentino. Capitulo XII. Bebidas hídricas, agua y agua gasificada. Disponible en: http://www.anmat.gov.ar/CODIGOA/Capitulo_XII_Agua_2007-05.pdf.

Auge, M.P. (1995). Manejo del agua subterránea en La Plata-Argentina. 3 T: 1149. Inéd. La Plata.

Auge, M.P. (2005). Hidrogeología de La Plata, Provincia de Buenos Aires. In Relatorio del XVI Congreso Geológico Argentino (pp. 293-311). La Plata: Quick Press. 
Balek, J. (1988). Groundwater recharge concepts. En Estimation of natural groundwater recharge (pp. 3-9). Springer, Dordrecht.

Bellot, J., Bonet A., Peña J y Sánchez J. (2007). Human Impacts on Land Cover and Water Balances in a Coastal Mediterranean County. Environmental Management 39:412-422.

Burnett, W.C. y Dulaiova, H., (2003). Estimating the dynamics of groundwater input into the coastal zone via continuous radon-222 measurements. Journal of Environmental Radioactivity 69(1-2): 21-35.

Burnett, W.C., Aggarwal, P.K., Aureli, A., Bokuniewicz, H., Cable, J.E., Charette, M.A., y Moore, W.S. (2006). Quantifying submarine groundwater discharge in the coastal zone via multiple methods. Science of the total Environment, 367(2-3), 498-543.

Callaghan, D.P., Bouma, T.J., Klaassen, P., Van der Wal, D., Stive, M.J.F. y Herman, P.M.J., (2010). Hydrodynamic forcing on salt-marsh development: Distinguishing the relative importance of waves and tidal flows. Estuar. Coast. Shelf Sci., 89(1), 73-88.

Carretero S. (2011). Comportamiento hidrológico de las dunas costeras en el sector nororiental de la provincia de Buenos Aires. Tesis doctoral. Facultad de Ciencias Naturales y Museo. UNLP. La Plata.

Carretero, S. y Kruse E. (2012). "Relationship between Precipitation and Water-Table Fluctuation in a Coastal Dune Aquifer: Northeastern Coast of the Buenos Aires Province, Argentina”. Hydrogeology Journal, vol. 20, n. ${ }^{\circ} 8$, pp. 1613-1621. doi: 10.1007/s10040-012-0890-y.

Carretero, S., y Kruse, E. (2014). Impacto de la urbanización en la infiltración en un área costera, Argentina. Tecnología y ciencias del agua, 5(6), 5-24.

Carretero S. y Kruse E. (2015a). Estudio hidrogeológico de detalle Planta COS, San Clemente del Tuyú. Informe Técnico. Destinatario COS. 112p. 
Carretero S. y Kruse E. (2015b). Iron and manganese content in groundwater on the northeastern coast of the Buenos Aires province, Argentina. Environmental Earth Science 73 (5):1983-1995. DOI 10.1007/s12665-014-3546-5.

Carretero, S.C., Dapeña, C., y Kruse, E.E. (2013a). Hydrogeochemical and isotopic characterisation of groundwater in a sand-dune phreatic aquifer on the northeastern coast of the province of Buenos Aires, Argentina. Isotopes in environmental and health studies, 49(3), 399-419.

Carretero S., Braga F., Kruse E. y Tosi L. (2013b). Análisis temporal de las modificaciones en los médanos del Partido de La Costa y su relación con los recursos hídricos. En: N. González, E. Kruse, M.M. Trovatto y P. Laurencena (Editores) Temas actuales en hidrología subterránea 2013. ISBN 978-9871985-03-6. La Plata, EDULP, pp 36-43.

Carretero, S., Rapaglia, J., Bokuniewicz, H., y Kruse, E. (2013c). Impact of sea-level rise on saltwater intrusion length into the coastal aquifer, Partido de La Costa, Argentina. Continental Shelf Research, 61, 62-70.

Carretero, S., Braga F., Kruse E., Tosi L. (2014). Temporal analysis of the changes in the sand-dune barrier in the Buenos Aires Province, Argentina, and their relationship with the water resources. Applied Geography (54): 169-181.

Carretero, S., Perdomo S., Kruse E. y Ainchil J. (2016). Respuesta eléctrica de la zonación química en un nivel acuífero en la costa arenosa oriental de la Provincia de Buenos Aires. En: García R. y Mariño E. (Editores) Calidad del agua subterránea. Editorial Científica Universitaria - Secretaría de Ciencia y Tecnología - Universidad Nacional de Catamarca, San Fernando del Valle de Catamarca, Catamarca, pp 93-100.

Carretero, S., Rodrigues Capítulo L. y Kruse E. (2021). Evolution of groundwater recharge as a result of forest development on the east coast of the province of Buenos Aires, Argentina. Hydrogeology Journal.

Carrica, J. (1993). Balshort: Un programa de balance hidrológico diario del suelo aplicado a la región sudoccidental pampeana. XII Congreso Geológico Argentino y II Congreso de Exploración de Hidrocarburos. Actas, 6, 243-248. 
Cellone, F., Carol, E. y Tosi, L., (2019). Groundwater geochemistry in coastal wetlands: A case study in the Parque Costero del Sur biosphere reserve, Argentina. Catena 182: 104-143.

CFI. (1989a). Evaluación del Recurso Hídrico Subterráneo de la Región Costera Atlántica de la Provincia de Buenos Aires Regiones I y II Punta Rasa-Punta Médanos. Provincia de Buenos Aires Informe Final. Tomo II. Geología y Geomorfología. 192 p.

CFI. (1989b). Evaluación del recurso hídrico subterráneo de la región costera atlántica; región I: Punta Rasa. Punta Médanos, provincia de Buenos Aires; Prospección geoeléctrica en la costa Atlántica de la provincia de Buenos Aires entre Punta Rasa y Punta Médanos.33 p.

CFI. (1990a). Evaluación del Recurso Hídrico Subterráneo de la Región Costera Atlántica de la Provincia de Buenos Aires Región I Punta Rasa-Punta Médanos. Informe Final Tomo IV Caracterización climática y Balance Hidrológico. 177 p.

CFI. (1990b). Evaluación del Recurso Hídrico Subterráneo de la Región Costera Atlántica de la Provincia de Buenos Aires Región 1 Punta Rasa-Punta Médanos. Informe Final. Tomo I. Hidrología Subterránea. 177 p.

Chowdhury, A., Jha, M. K., y Chowdary, V. M. (2010). Delineation of groundwater recharge zones and identification of artificial recharge sites in West Medinipur district, West Bengal, using RS, GIS and MCDM techniques. Environmental Earth Sciences, 59(6), 1209.

COPUAP (1982). Complejo Portuario de Ultramar en Aguas Profundas.

Custodio, E. (1998). Recarga de los acuíferos: Aspectos generales sobre el proceso, la evaluación y la incertidumbre. Boletín Geológico y Minero de España. Vol. 109-4: 329-346.

Custodio, E. (2010). Estimation of aquifer recharge by means of atmospheric chloride deposition balance. Contributions to Science, 6(1): 81-97. 
Dapeña, C. y Panarello, H., (2004). Composición isotópica de la lluvia de Buenos Aires. Su importancia para el estudio de los sistemas hidrológicos pampeanos. Revista Latino-Americana de Hidrogeologia 4, 17-25.

Dapeña, C., (2008). Isótopos Ambientales Livianos: su aplicación en hidrología e hidrogeología. Universidad de Buenos Aires.Tesis Doctorado 4282. 442p.

De Vries, J.J. y Simmers, I., (2002) Groundwater recharge: an overview of processes andchallenges. Hydrogeol. J., Vol. 10, 1, 5-17.

DeGroot-Hedlin, C. y Constable, S. (1990). Occam's inversion to generate smooth, two-dimensional models for magnetotelluric data. Geophysics, 55, 1613-1624.

Deluchi, M., Kruse, E., Laurencena, P. C., Rojo, A., \& Rodrigues Capítulo, L. (2010). Características de la explotación de aguas subterráneas en un sector del noreste de la provincia de Buenos Aires, Argentina. Aguas Subterráneas y Desarrollo Sustentable de los Pueblos Latinoamericanos (Caracas, Venezuela), 10.

Dias Pons N., Pejon J. y Zuquette L. (2007). Use of geoprocessing in the study of land degradation in urban environments: the case of the city of Sao Carlos, state of Sao Paulo, Brazil. Environmental Geology 53:727-739.

Difrieri, H. (1982). Cuencas fluviales. En: Historia Marítima Argentina, Destefani, L. (Ed), Cuántica Editora S.A., 135-177.

Dirección Provincial de Obras Sanitarias (DOSBA) (1980). Estudio de prefactibilidad hidrológica de provisión de agua potable al Municipio Urbano de la Costa. Informe de avance. Inédito.

Edmunds, W., Fellman, E., Goni, I., y Prudhomme, C. (2002). Spatial and temporal distribution of groundwater recharge in northern Nigeria. Hydrogeology Journal, 10(1), 205-215.

Eriksson, E., y Khunakasem, V. (1969). Chloride concentration in groundwater, recharge rate and rate of deposition of chloride in the Israel Coastal Plain. Journal of Hydrology, 7(2), 178-197. 
Erskine, A.D. (1991). The effect of tidal fluctuation on a coastal aquifer in the UK. Groundwater, 29(4), 556-562.

Falasca S, Forte Lay J.A. (2006) Actualización de la evapotranspiración de referencia por el método de Penman-Monteith en la República Argentina [Reference evapotranspiration actualization in Argentina using the Penman-Monteith method]. Congreso de AADA. La Plata: Asociación Argentina de Agrometeorología.

http://agro.unc.edu.ar/ clima/AADA/Congresos/MDQ/55.htm. Cited 22 October 2019.

Ferris, J. G. (1951). Cyclic fluctuations of water level as a basis for determining aquifer transmissibility . International Association of Scientific Hydrology, Publ. 33, 148155.

Fidalgo, F., Colado, U.R., y De Francesco, F.O. (1973). Sobre ingresiones marinas cuaternarias en los partidos de Castelli, Chascomús y Magdalena (Provincia de Buenos Aires). In V Congreso Geológico Argentino, Vol. 4, pp. 225-240.

Fidalgo, F., De Francesco, F.O. y Pascual, R. (1975). Geología superficial de la llanura bonaerense (Argentina). Geología de la Provincia de Buenos Aires. $6^{\circ}$ Congreso Geológico Argentino, Relatorio, 103-138, Bahía Blanca.

Fontes, J.Ch. (1980). Environmental Isotopes in Groundwater Hydrology. En Fritz, P. y Fontes, J.Ch. (eds.), 1980. Handbook of Environ ᄀmental Isotope Geochemistry. The Terrestrial Environment, A. Chapter 3. 75-140.

Forte Lay, J.A., y Spescha, L.B. (2001). Métodos para la estimación de la climatología del agua edáfica en las provincias pampeanas de la Argentina (Methodology to estimate the climatology of soil moisture in the pampeana region, Argentina). Rev Argent Agrometeorol, 1(1), 67-74.

Fucks, E., D’Amico, G., Pisano, F. y Nuccetelli, G. (2017). Evolución geomorfológica de la región del Gran La Plata y su relación con eventos catastróficos. Revista Asociación Geológica Argentina 74 (2): 141-154. 
Fucks, E., Schnack, E., Pisano M., Briones, L., Nuccetelli, G. y Charó, M. (2014). Procesos de formación y colmatación de la Ensenada de Barragan, partido de Ensenada, provincia de Buenos Aires. $19^{\circ}$ Congreso Geológico Argentino, Resúmenes: S12-20, Córdoba.

Fucks, E., Schnack, E.J. y Aguirre, M. (2010). Nuevo ordenamiento estratigráfico de las secuencias marinas del sector continental de la Bahía Samborombón, provincia de Buenos Aires. Revista de la Asociación Geológica Argentina 67: 27-39.

García-Aróstegui, J.L., Baudron, P., Taddei, D., Fernández-Molina, P., Leduc, C., Gomariz-Castillo, F., y Blondet, I. (2017). Caracterización de la recarga en un episodio excepcional e implicaciones sobre un lagoon costero asociado (campo de Cartagena-mar menor, de España).

Gat, J.R. (1974). Local variability of the isotope composition of groundwater. International Atomic Energy Agency (IAEA). Proceedings Symposium Vienna IAEA SM, 182, Vol II: 51-60.

Gat, J.R. (1983). Precipitation, groundwater and surface waters. En: Proceedings Palaeoclimates and paleowaters: A collection of environmental isotope studies. International Atomic Energy Agency, Vienna: 3-12.

Gat, J.R. y Tzur, Y. (1967). Modification of the isotopic composition of rainwater by processes which occur before groundwater recharge. Isotopes in Hydrology. International Atomic Energy Agency (IAEA). Proceedings Symposium Symposium Vienna IAEA SM, 83: 49-60.

González Bonorino, F. (1965). Mineralogía de las fracciones arcilla y limo del pampeano en el área de la Ciudad de Buenos Aires y su significado estratigráfico y sedimentológico. Revista de la Asociación Geológica Argentina 20: $67-148$.

Groeber, P. (1945). Las aguas surgentes y semisurgentes del norte de la provincia de Buenos Aires. Revista La Ingeniería, Año XLIX, №6, pp. 371-387, Buenos Aires. 
Guaraglia D., Gómez L., Carretero S., Kruse E. (2019). Cálculo de difusividad hidráulica en el acuífero freático de Mar del Tuyu. Comparacion de metodologias.. Libro. Artículo Completo. Congreso. $7^{\circ}$ Congreso de Ciencias Ambientales COPIME 2019. Consejo Profesional de Ingenieria y Electricista.

Guilderson, T.P., Burkle, L., Hemming, S. y Peltier, W.R., (2000). Late Pleistocene sea level variations derived from the Argentine Shelf. Geochemistry, Geophysics, Geosystems., Vol. 1, Paper number 2000GC000098. Published December 15, 2000.

Hargreaves, G.H., y Samani, Z.A. (1985). Reference crop evapotranspiration from temperature. Applied engineering in agriculture, 1(2), 96-99.

Healy, RW, y Cook, PG. (2002). Using groundwater levels to estimate recharge. Hydrogeology Journal, 10(1), 91-109.

Houlahan, J. y Findlay, C. (2004). Estimating the 'critical' distance at which adjacent land-use degrades wetland water and sediment quality. Landscape Ecology 19: $677-690$.

Hvorslev, M.J. (1951). Time lag and soil permeability in ground-water observations (No. 36). Waterways Experiment Station, Corps of Engineers, US Army.

INDEC (Instituto Nacional de Estadística y Censos de la República Argentina) (1991, 2010). Censo Nacional de Población, Hogares y Viviendas. Buenos Aires. Disponible en http://www.indec.gov.ar.

INGEIS, (2019). Base de datos. Proyecto: Composición isotópica de las aguas del Estuario del Rio de La Plata. Inédito.

Israfilov, R.G. (2006). Anthropogenic changes to hydrogeological conditions in urban areas. New Perspectives from Azerbaijan. En: J.H. Tellam et al.. (eds.), Urban Groundwater Management and Sustainability, Springer: 11-28.

Jacob, C.E., (1950). Flow of groundwater. In: Rouse H de Engineering. Wiley, New York. 
Kim Y., Lee K., Koh D., Lee D., Lee S., Park W., Koh G., y Woo N. (2003). Hydrogeochemical and isotopic evidence of groundwater salinization in a coastal aquifer: a case study in Jeju volcanic island, Korea. Journal of Hidrogeology 270: 282-294.

Kim, Y. (2004). Analysis of hydrochemical processes controlling the urban groundwater system in Seoul area, Korea. Geosciences Journal 8 (3): 313-318.

Kostiakov, A.M., (1932). On the dynamics of the coefficient of water-percolation in soils and on the necessities for studying it from a dynamic point of view for purpose of amelioration (en ruso). In International Society of Sotl Science, 6th Commission Transactions, Gronigen Holland V. A. PP, 17-21.

Krothe, J.N., Garcia-Fresca B., y Sharp, Jr. J. M. (2002). Effects of Urbanization on Groundwater Systems. En: Bocanegra, E.; Martínez, D.; Massone, H. (Eds.) Groundwater and Human Development: 354-364.

Kruse E., Carol E., Mancuso M., Laurencena P., Deluchi M., y Rojo, A. (2013). Recharge assessment in an urban area: a case study of La Plata, Argentina. Hydrogeology Journal, 21: 1091-1100.

Kruse, E., Sarandón, R. y Gaspari, F. (2014). Impacto del cambio climático en el Gran La Plata. Editorial Universidad Nacional de La Plata, 105 p., La Plata.

Lerner, D.N., Issar, A. y Simmers, I., (1990). A guide to understanding and estimating naturalrecharge, Int. contribution to hydrogeology, I.A.H. Publ., Vol. 8, Verlag Heinz Heisse, pp 345.

Logan, W.S., y Nicholson, R.V. (1997). Origin of dissolved groundwater sulphate in coastal plain sediments of the Rio de la Plata, Eastern Argentina. Aquatic Geochemistry, 3(4), 305-328.

Logan, W.S., Auge, M.P., y Panarello, H.O. (1999). Bicarbonate, sulfate, and chloride water in a shallow, clastic-dominated coastal flow system, Argentina. Ground water, 37(2), 287. 
Loke, M.H., Wilkinson, P.B., Chambers, J.E., Uhlemann, S.S., y Sorensen, J.P.R. (2015). Optimized arrays for 2-D resistivity survey lines with a large number of electrodes. Journal of Applied Geophysics, 112, 136-146.

Marcomini, S.C. (2002). Morfodinámica, sedimentología, geomorfología ambiental y sus alteraciones antropogénicas en costas de dunas del noreste de la provincia de Buenos Aires (Doctoral dissertation, Universidad de Buenos Aires. Facultad de Ciencias Exactas y Naturales).

Marcomini, S.C., y López, R.A., (2010), "Erosión y manejo costero en Las Toninas, Partido de La Costa, Provincia de Buenos Aires ", Revista Asociación Geológica Argentina, Vol, 66, № 4, pp, 490-498.

Nolan, B.T., Heal y R.W., Taber, P.E., Perkins, K., Hitt, K.J., y Wolock, D.M. (2007). Factors influencing ground-water recharge in the eastern United States. Journal of Hydrology, 332(1-2), 187-205.

Panarello, H.O., Dapeña, C. y Auge, M.P., (1995). Mecanismos de salinización del agua subterránea de la zona de La Plata, Buenos Aires, Argentina: su interpretación por medio de los isótopos ambientales. En: Isotope Hydrology Investigations in Latin America Investigations on Hydrology and Hydrogeology in Latin America on water resources and groundwater pollution. IAEA TECDOC-Series 835: 13-27.

Panarello, H.O., y Dapeña, C. (2009). Large scale meteorological phenomena, ENSO and ITCZ, define the Paraná River isotope composition. Journal of hydrology, 365(1-2), 105-112.

Park, S.S., Kim, S.O., Yun, S.T., Chae, G.T., Yu, S.Y., Kim, S., y Kim, Y. (2005). Effects of land use on the spatial distribution of trace metals and volatile organic compounds in urban groundwater, Seoul, Korea. Environmental Geology, 48(8), 1116-1131.

Pera Ibarguren, S., Zuppi, G. M., Panarello, H., y Ainchil, J. (2003). Isotope hydrology of the multi layer aquifer in NE Buenos Aires province, Argentina (No. IAEA-CN$-104)$. 
Pera Ibarguren, S., Del Soldato, S.C., Hernandez, M., Kruse, E., Panarello, H., y Zuppi, G.M. (2007). Surface wáter-groundwater interactions of the Rio de la Plata coastal plain, Argentina. Advances in Isotope Hydrology and its Role in Sustainable Water Resources Management (IHS-2007), 21, 283.

Perdomo, S.; Carretero, S.; Kruse, E. y Ainchil, J. (2013a). Identificación de la intrusión salina en Santa Teresita (Buenos Aires), mediante la aplicación de métodos eléctricos. In: N. González, E. Kruse, M.M. Trovatto y P. Laurencena (Editores) Temas actuales en hidrología subterránea 2013. EDULP, pp 44-49. La Plata.

Perdomo S., Rodrigues Capítulo L., Kruse E. y Ainchil J., (2013b). Aplicación de tomografías eléctricas en la configuración del acuífero costero en un sector oriental de la Provincia de Buenos Aires. In: N. González, E. Kruse, M.M. Trovatto y P. Laurencena (Editores) Temas actuales en hidrología subterránea 2013. EDULP, pp 57 - 62. La Plata.

Perdomo, S. (2015). Estimación de parámetros hidráulicos subterráneos a partir de estudios de resistividad eléctrica en 2D. Tesis Doctoral. Facultad de Ciencias Astronómicas y Geofísicas.

Planas A.C., Gaviño Novillo M., Mendiburo N., Calcagno A., y Urbano Jáuregui L. 2000. Informe sobre la gestión del agua en la República Argentina. Buenos Aires, JVP Consultores, pp. 146.

Prieto, A.R., Mourelle, D., Peltier, W. R., Drummond, R., Vilanova, I. y Ricci, L. (2016). Relative sea-level changes during the Holocene in the Río de la Plata, Argentina and Uruguay: A review. Quaternary International. http://dx.doi.org/10.1016/j.quaint.2016.02.044.

PROSAP (Programa de Servicios Agrícolas Provinciales) (2009). Instructivo (R014) Medición de la infiltración en el suelo mediante infiltrómetros doble anillo. http://www.prosap.gov.ar/Docs/INSTRUCTIVO\%20_R014_\%20infiltrometro\%20 doble\%20anillo.pdf.

Rapaglia, J., Grant, C., Bokuniewicz, H., Pick, T. y Scholten, J. (2015). A GIS typology to locate sites of submarine groundwater discharge. Journal of Environmental Radioactivity, 145(0): 10-18. 
Riggi, J.C., Fidalgo, F., Martínez, O.R. y Porro, N.E. (1986). Geología de los "sedimentos pampeanos" en el partido de La Plata. Revista de la Asociación Geológica Argentina 41: 316-333.

Rodrigues Capítulo, L., Carretero, S.C., y Kruse, E.E. (2018). Impact of afforestation on coastal aquifer recharge. Case study: eastern coast of the Province of Buenos Aires, Argentina. Environmental earth sciences, 77(3), 74.

Rotzoll, K., y El-Kadi, A.I. (2008). Estimating hydraulic properties of coastal aquifers using wave setup. Journal of Hydrology, 353(1-2), 201-213.

Rotzoll, K., Gingerich, S.B., Jenson, J.W., y El-Kadi, A.I. (2013). Estimating hydraulic properties from tidal attenuation in the Northern Guam Lens Aquifer, territory of Guam, USA. Hydrogeology Journal, 21(3), 643-654.

Sala, J.M., Gonzalez, N. y Hernandez, M. (1976). Factibilidad de la provision de agua potable a la localidad de San Clemente del Tuyú- El Tala. Convenio FCNYMULP- Coop. O.S. de San Clemente del Tuyú. La Plata. Inédito.

Samper, F.J. (1997). Evaluación de la recarga por lluvia mediante balances de agua: utilización, calibración e incertidumbres. Boletín Geológico y Minero de España. Vol. 109-4: 347-370.

Santa Cruz, J.N., y Busso, A.S. (2001). Elementos hidrodinámicos para la explotación sostenible de acuíferos en cordones de dunas en la provincia de Buenos Aires, Argentina. Boletín geológico y minero, 112(4), 97-105.

Santucci, L., Carol, E., Borzi, G., y García, M.G. (2017). Hydrogeochemical and isotopic signature of surface and groundwater in a highly industrialized sector of the Rio de la Plata coastal plain (Argentina). Marine Pollution Bulletin, 120(1-2), 387-395.

Sasaki, Y. (1992). Resolution of resistivity tomography inferred from numerical simulation. Geophysical Prospecting, 40, 453-464. 
Scanlon, B.R., Healy, R.W., y Cook, P.G. (2002). Choosing appropriate techniques for quantifying groundwater recharge. Hydrogeology journal, 10(1), 18-39.

Schneider J.C. y Kruse S.E. (2005). Assessing selected natural and anthropogenic impacts on freshwater lens morphology on small barrier Islands: Dog Island and St. George Island, Florida, USA. Hydrogeology Journal 14: 131-145.

Schoeller, H. (1962). Les eaux souterraines. Ed. Masson. Paris.

Schuerch M., Scholten J., Carretero S., García-Rodríguez F., Kumbier K., Baechtiger M. y Liebetrau V. (2016). The effect of long-term and decadal climate and hydrology variations on estuarine marsh dynamics: an identifying case study from the Río de la Plata. Geomorphology 269: 122-132.

Sharma, M.L. (1989) Groundwater Recharge. AA Balkema, Rotter-dam.

Shepard, C.C., Crain, C.M. y Beck, M.W. (2011). The Protective Role of Coastal Marshes: A Systematic Review and Meta-analysis. PLoS ONE, 6(11), e27374.

Shirahata, K., Ishida, S., Yoshimoto, S., y Tsuchihara, T. (2014). New simple method for estimating hydraulic properties of a freshwater-lens aquifer by analysis of tidal groundwater fluctuations. Tech. Rep. Natl. Inst. Rural. Eng. Japan.

Shirahata, K., Yoshimoto, S., Tsuchihara, T., y Ishida, S. (2016). Digital filters to eliminate or separate tidal components in groundwater observation time-series data. Japan Agricultural Research Quarterly: JARQ, 50(3), 241-252.

Simmers, I. (1988) Estimation of natural groundwater recharge. NATO ASI Series C. Vol 222. Reidel, Dordrecht, 510 pp.

Simmers, I. (1997). Groundwater recharge principles, problems and developments. Recharge of phreatic aquifers in (Semi-) arid areas, 1-18.

Simmers, I. (1998). Groundwater recharge: an overview of estimation 'problems' and recent developments. Geological Society, London, Special Publications, 130(1), 107-115. 
Sophocleus, M., y Perry, C.A. (1985) Experimental studies in natural groundwaterrecharge dynamics: The analysis of observed recharge events. Journal of Hydrology, 81 (3-4), 297-332.

Stieglitz, T. (2005). Submarine groundwater discharge into the near-shore zone of the Great Barrier Reef, Australia. Marine Pollution Bulletin, 51(1-4): 51.

Stieglitz, T.C., Cook, P.G. y Burnett, W.C., (2010). Inferring coastal processes from regional-scale mapping of 222Radon and salinity: examples from the Great Barrier Reef, Australia. Journal of Environmental Radioactivity, 101(7): 544-552.

Temmerman, S., Meire, P., Bouma, T., Herman, P., Ysebaert, T. y De Vriend, H., (2013). Ecosystem-based coastal defence in the face of global change. Nature, 504(7478), 79-83.

Thornthwaite, C.W. Y Mather, J.R. (1955). Instruction and tables for computing the potential evapotranspiration and the water balance. Climate Crewel Inst. of Technology. 10(3).

Trefry, M.G., y Bekele, E. (2004). Structural characterization of an island aquifer via tidal methods. Water Resources Research, 40(1).

U.S. Geological Survey. (2006). Techniques of Water-Resources Investigations Book 9. Handbooks for Water-Resources Investigations. National Field Manual for the Collection of Water-Quality Data. Chapter A4. Collection of water samples. 231 p.

Varela, L., Laurencena, P., Kruse, E., Deluchi, M., y Rojo A. (2002) Reconocimiento de la relación aguas superficiales - aguas subterráneas en la cuenca del arroyo del Gato. Buenos Aires. Groundwater and Human Development. Bocanegra, E., Martínez, D, Massone, H. (Eds) 2002. ISBN 987- 544-063-9. Pág: 1334-1341. Mar del Plata.

Vazquez Suñé, E. y Sanchez Vila X. (1997). Cálculo de balance y recarga en la ciudad de Barcelona. En La evaluación de la recarga a los acuíferos en la planificación hidrológica (pp. 399-406). Instituto Tecnológico Geominero de España. 
Vazquez-Suñe, E. y Serrano-Juan, A. (2012) Easy Quim v5.0. Grupo de Hidrología Subterránea. Disponible en https://h2ogeo.upc.edu/

Violante R.A., Parker G. y Cavallotto J.L. (2001). Evolución de las llanuras costeras del este bonaerense entre bahía Samborombón y la laguna Mar Chiquita durante el Holoceno. Revista de la Asociación Geológica Argentina, 56 (1): 51-66.

Wang X. (2001). Integrating water-quality management and land-use planning in a watershed context. Journal of Environmental Management 61: 25-36.

Wiles T. y Sharp J. (2008). The secondary permeability of impervious cover. Environmental \& engineering geoscience, 14(4), 251-265.

Xun, Z., Chao, S., Ting, L., Ruige, C., Huan, Z., Jingbo, Z., y Qin, C. (2014). Estimation of aquifer parameters using tide-induced groundwater level measurements in a coastal confined aquifer. Environmental earth sciences, 73(5), 2197-2204.

Zuquette L., Pejon O. y Dos Santos Collares J. (2004). Land degradation assessment based on environmental geoindicators in the Fortaleza metropolitan region, state of Ceará, Brazil. Environmental Geology 45: 408-425. 


\section{ÍNDICE}

Anexo 1. Protocolos analíticos.

Anexo 2. Planillas de censo de Costa marítima (Mar del Tuyú) y Costa estuárica (Berisso).

Anexo 3. Ensayos Slug Test, método de Hvorslev.

Anexo 4. Ensayos de infiltración.

Anexo 5. Mapas de flujo de Costa marítima (Mar del Tuyú) 2016-2018.

Anexo 6. Mapas de flujo de Costa estuárica (Berisso) 2016-2017.

Anexo 7. Protocolos análisis isotópicos.

Anexo 8. Balances hidrológicos de paso diario 2016-2018. 
Anexo 2

Planillas de censo

Costa marítima

(Mar del Tuyú) 


\begin{tabular}{|c|c|c|c|c|c|c|}
\hline Pozo & Latitud S & Longitud O & $x$ & $Y$ & Dirección & $\begin{array}{c}\text { Cota } \\
(\mathrm{msnm})\end{array}$ \\
\hline MT1 & 363328.90 & 564254.10 & 6525512 & 5954464 & 16 e/ 56 y $57 n^{\circ} 5665$ & 2.48 \\
\hline MT2 & 363327.20 & 564218.50 & 6526397 & 5954514 & 10 e/56 y 57 n5610 & 4.60 \\
\hline MT3 & 363326.30 & 564147.10 & 6527178 & 5954539 & 5 e/ 56 y 57 n $^{\circ} 5624$ & 6.15 \\
\hline MT4 & 363324.30 & 564118.20 & 6527897 & 5954599 & 56 y costanera & 3.39 \\
\hline MT5 & 363403.24 & 564116.08 & 6527946 & 5953398 & 66 y costanera & 3.28 \\
\hline MT6 & 373404.70 & 564145.20 & 6527222 & 5953355 & 66 y 5 & 5.95 \\
\hline MT7 & 363405.58 & 564213.43 & 6526520 & 5953331 & 66 e/ 9 y 10 & 5.05 \\
\hline MT8 & 363354.38 & 564252.57 & 6525548 & 5953678 & 63 y 16 & 2.50 \\
\hline MT10 & 363431.89 & 564209.58 & 6526613 & 5952519 & 73 y 9 & 4.79 \\
\hline MT11 & 363431.43 & 564144.64 & 6527233 & 5952531 & 73 y $5 n^{\circ} 504$ & 6.03 \\
\hline MT12 & 363429.94 & 564114.29 & 6527988 & 5952575 & 73 y costanera $n^{\circ} 7299$ & 3.18 \\
\hline MT13 & 363507.18 & 564114.04 & 6527990 & 5951427 & 83 y costanera $n^{\circ} 8310$ & 4.52 \\
\hline MT14 & 363507.57 & 564143.58 & 6527256 & 5951417 & 83 y 5 & 6.48 \\
\hline MT15 & 363509.05 & 564214.36 & 6526491 & 5951374 & 83 y 10 & 4.80 \\
\hline MT16 & 363505.65 & 564230.41 & 6526092 & 5951480 & 13 e/81 y 82 & 4.17 \\
\hline MT17 & 363544.61 & 564243.30 & 6525768 & 5950280 & 93 y 16 & 3.52 \\
\hline MT18 & 363542.38 & 564153.33 & 6527010 & 5950345 & 93 y $7 n^{\circ} 9293$ & 6.04 \\
\hline MT19 & 363541.14 & 564112.10 & 6528035 & 5950380 & 93 y costanera & 3.85 \\
\hline
\end{tabular}




\begin{tabular}{|l|c|c|c|c|c|c|c|c|c|}
\cline { 2 - 10 } \multicolumn{1}{c|}{} & \multicolumn{2}{|c|}{$31 / 1 / 2016$} & \multicolumn{3}{c|}{$26 / 2 / 2016$} & \multicolumn{2}{c|}{$30 / 3 / 2016$} & \multicolumn{2}{c|}{$30 / 4 / 2016$} \\
\hline Pozo & Prof. (m) & $\begin{array}{c}\text { Nivel } \\
(\mathrm{msnm})\end{array}$ & Prof. (m) & $\begin{array}{c}\text { Nivel } \\
(\mathrm{msnm})\end{array}$ & $\begin{array}{c}\text { CE } \\
(\mu \mathrm{S} / \mathrm{cm})\end{array}$ & Prof. $(\mathrm{m})$ & $\begin{array}{c}\text { Nivel } \\
(\mathrm{msnm})\end{array}$ & Prof. (m) & $\begin{array}{c}\text { Nivel } \\
(\mathrm{msnm})\end{array}$ \\
\hline MT1 & 0.53 & 1.95 & 0.52 & 1.96 & 2430 & 0.71 & 1.77 & 0.41 & 2.07 \\
\hline MT2 & 1.19 & 3.41 & 1.20 & 3.40 & 689 & 1.43 & 3.17 & 1.09 & 3.51 \\
\hline MT3 & 2.60 & 3.55 & 2.65 & 3.50 & 404 & 2.81 & 3.34 & 2.63 & 3.52 \\
\hline MT4 & 2.20 & 1.19 & 2.10 & 1.29 & 1526 & 2.28 & 1.11 & 2.00 & 1.39 \\
\hline MT5 & 2.18 & 1.10 & 2.11 & 1.17 & 514 & 2.15 & 1.13 & 1.94 & 1.34 \\
\hline MT6 & 1.90 & 4.05 & 1.83 & 4.12 & 490 & 2.10 & 3.85 & 1.90 & 4.05 \\
\hline MT7 & 0.86 & 4.19 & 0.93 & 4.12 & 571 & 1.13 & 3.92 & 1.85 & 3.20 \\
\hline MT8 & 1.27 & 1.23 & & & & 1.38 & 1.12 & 1.12 & 1.38 \\
\hline MT10 & 1.57 & 3.22 & 1.46 & 3.33 & 525 & 1.71 & 3.08 & 1.44 & 3.35 \\
\hline MT11 & 2.36 & 3.67 & 2.23 & 3.80 & 455 & 2.48 & 3.55 & 2.32 & 3.71 \\
\hline MT12 & & & 2.12 & 1.06 & 612 & 2.04 & 1.14 & 1.76 & 1.42 \\
\hline MT13 & 2.80 & 1.72 & 2.67 & 1.85 & 1108 & 2.81 & 1.71 & 2.59 & 1.93 \\
\hline MT14 & 2.05 & 4.43 & 1.93 & 4.55 & 522 & 2.20 & 4.28 & 2.01 & 4.47 \\
\hline MT15 & 1.11 & 3.69 & 0.91 & 3.89 & & 1.19 & 3.61 & 0.86 & 3.94 \\
\hline MT16 & & & & & 793 & & & 0.73 & 3.44 \\
\hline MT17 & 1.47 & 2.05 & 1.49 & 2.03 & 909 & 1.68 & 1.84 & 1.31 & 2.21 \\
\hline MT18 & 1.38 & 4.66 & 1.32 & 4.72 & 278 & 1.51 & 4.53 & 1.28 & 4.76 \\
\hline MT19 & 2.38 & 1.47 & 2.12 & 1.73 & 422 & 2.23 & 1.62 & 2.01 & 1.84 \\
\hline
\end{tabular}




\begin{tabular}{|c|c|c|c|c|c|c|c|c|c|c|}
\hline & \multicolumn{2}{|c|}{$28 / 5 / 2016$} & \multicolumn{2}{|c|}{$30 / 6 / 2016$} & \multicolumn{3}{|c|}{$29 / 7 / 2016$} & \multicolumn{3}{|c|}{$14 / 8 / 2016$} \\
\hline Pozo & Prof. (m) & $\begin{array}{c}\text { Nivel } \\
(\mathrm{msnm})\end{array}$ & Prof. (m) & $\begin{array}{c}\text { Nivel } \\
(\mathrm{msnm})\end{array}$ & Prof. (m) & $\begin{array}{c}\text { Nivel } \\
(\mathrm{msnm})\end{array}$ & $\begin{array}{c}\mathrm{CE} \\
(\mu \mathrm{S} / \mathrm{cm})\end{array}$ & Prof. (m) & $\begin{array}{c}\text { Nivel } \\
(\mathrm{msnm})\end{array}$ & $\begin{array}{c}\mathrm{CE} \\
(\mu \mathrm{S} / \mathrm{cm})\end{array}$ \\
\hline MT1 & 0.49 & 1.99 & 0.23 & 2.25 & 0.11 & 2.37 & 1055 & 0.31 & 2.17 & 1814 \\
\hline MT2 & 1.21 & 3.39 & 0.70 & 3.90 & 0.20 & 4.40 & 797 & 0.35 & 4.25 & 930 \\
\hline MT3 & 2.75 & 3.40 & 2.56 & 3.59 & 2.41 & 3.74 & 385 & 2.32 & 3.83 & 414 \\
\hline MT4 & 2.30 & 1.09 & 2.20 & 1.19 & 1.86 & 1.53 & 1286 & 2.08 & 1.31 & 1330 \\
\hline MT5 & 2.21 & 1.07 & 2.21 & 1.07 & 1.86 & 1.42 & 878 & 1.96 & 1.32 & 815 \\
\hline MT6 & 2.09 & 3.86 & 1.88 & 4.07 & 1.62 & 4.33 & 450 & 1.60 & 4.35 & 460 \\
\hline MT7 & 0.99 & 4.06 & 0.53 & 4.52 & 0.23 & 4.82 & 650 & 0.40 & 4.65 & 647 \\
\hline MT8 & 1.18 & 1.32 & 0.91 & 1.59 & 0.65 & 1.85 & 800 & 0.85 & 1.65 & 969 \\
\hline MT10 & 1.60 & 3.19 & 1.25 & 3.54 & 0.80 & 3.99 & 657 & 0.92 & 3.87 & 481 \\
\hline MT11 & 2.43 & 3.60 & 2.20 & 3.83 & 2.01 & 4.02 & 441 & 1.93 & 4.10 & 445 \\
\hline MT12 & 1.97 & 1.21 & 1.90 & 1.28 & 1.70 & 1.48 & 578 & 1.77 & 1.41 & 603 \\
\hline MT13 & 2.86 & 1.66 & 2.67 & 1.85 & 2.46 & 2.06 & 950 & 2.55 & 1.97 & 933 \\
\hline MT14 & 2.21 & 4.27 & 1.98 & 4.50 & 1.65 & 4.83 & 554 & 1.70 & 4.78 & 633 \\
\hline MT15 & 0.84 & 3.96 & 0.48 & 4.32 & 0.21 & 4.59 & 825 & 0.45 & 4.35 & 816 \\
\hline MT16 & 0.78 & 3.39 & 0.29 & 3.88 & 0.30 & 3.87 & 473 & 0.52 & 3.65 & 418 \\
\hline MT17 & 1.31 & 2.21 & 0.82 & 2.70 & 0.44 & 3.08 & 740 & 0.67 & 2.85 & 672 \\
\hline MT18 & 1.45 & 4.59 & 1.16 & 4.88 & 0.76 & 5.28 & 317 & 0.85 & 5.19 & 345 \\
\hline MT19 & 2.22 & 1.63 & 2.15 & 1.70 & 1.90 & 1.95 & 443 & 1.92 & 1.93 & 551 \\
\hline
\end{tabular}




\begin{tabular}{|c|c|c|c|c|c|c|c|c|c|c|c|c|}
\hline & \multicolumn{3}{|c|}{ 29/9/2016 } & \multicolumn{3}{|c|}{$28 / 10 / 2016$} & \multicolumn{3}{|c|}{$8 / 11 / 2016$} & \multicolumn{3}{|c|}{$29 / 12 / 2016$} \\
\hline Pozo & $\begin{array}{c}\text { Prof. } \\
\text { (m) }\end{array}$ & $\begin{array}{c}\text { Nivel } \\
\text { (msn } \\
\mathrm{m})\end{array}$ & $\begin{array}{c}\mathrm{CE} \\
(\mu \mathrm{S} / \mathrm{c} \\
\mathrm{m})\end{array}$ & $\begin{array}{c}\text { Prof. } \\
\text { (m) }\end{array}$ & $\begin{array}{c}\text { Nivel } \\
\text { (msn } \\
\mathrm{m})\end{array}$ & $\begin{array}{c}\mathrm{CE} \\
(\mu \mathrm{S} / \mathrm{c} \\
\mathrm{m})\end{array}$ & $\begin{array}{c}\text { Prof. } \\
\text { (m) }\end{array}$ & $\begin{array}{c}\text { Nivel } \\
\text { (msn } \\
\mathrm{m})\end{array}$ & $\begin{array}{c}\mathrm{CE} \\
(\mu \mathrm{S} / \mathrm{c} \\
\mathrm{m}) \\
\end{array}$ & $\begin{array}{c}\text { Prof. } \\
\text { (m) }\end{array}$ & $\begin{array}{c}\text { Nivel } \\
(\mathrm{msn} \\
\mathrm{m})\end{array}$ & $\begin{array}{c}\mathrm{CE} \\
(\mu \mathrm{S} / \mathrm{c} \\
\mathrm{m})\end{array}$ \\
\hline MT1 & 0.42 & 2.06 & 1669 & 0.32 & 2.16 & 1525 & 0.41 & 2.07 & 1496 & 0.87 & 1.61 & 2110 \\
\hline MT2 & 0.55 & 4.05 & 961 & 0.41 & 4.19 & 930 & 0.50 & 4.10 & 790 & 1.16 & 3.44 & 722 \\
\hline MT3 & 2.26 & 3.89 & 348 & 2.25 & 3.90 & 378 & 2.22 & 3.93 & 369 & 2.53 & 3.62 & 374 \\
\hline MT4 & 2.18 & 1.21 & 1029 & 2.11 & 1.28 & 930 & 2.16 & 1.23 & 907 & 2.30 & 1.09 & 2111 \\
\hline MT5 & 2.23 & 1.05 & 588 & 2.11 & 1.17 & 575 & 2.17 & 1.11 & 597 & 2.31 & 0.97 & 505 \\
\hline MT6 & 1.60 & 4.35 & 450 & 1.57 & 4.38 & 465 & 1.50 & 4.45 & 460 & 1.90 & 4.05 & 440 \\
\hline MT7 & 0.51 & 4.54 & 618 & 0.43 & 4.62 & 638 & 0.50 & 4.55 & 613 & 1.01 & 4.04 & 577 \\
\hline MT8 & 0.92 & 1.58 & 1111 & 0.85 & 1.65 & 765 & 0.88 & 1.62 & 850 & 1.40 & 1.10 & 752 \\
\hline MT10 & 0.98 & 3.81 & 513 & 0.95 & 3.84 & 401 & 0.95 & 3.84 & 368 & 1.47 & 3.32 & 392 \\
\hline MT11 & 1.90 & 4.13 & 448 & 1.88 & 4.15 & 459 & 1.82 & 4.21 & 480 & 2.18 & 3.85 & 449 \\
\hline MT12 & 1.81 & 1.37 & 484 & 1.80 & 1.38 & 686 & 1.81 & 1.37 & 610 & 2.00 & 1.18 & 504 \\
\hline MT13 & 2.70 & 1.82 & 780 & 2.68 & 1.84 & 632 & 2.68 & 1.84 & 661 & 2.89 & 1.63 & 477 \\
\hline MT14 & 1.71 & 4.77 & 533 & 1.70 & 4.78 & 443 & 1.61 & 4.87 & 436 & 2.00 & 4.48 & 285 \\
\hline MT15 & 0.56 & 4.24 & 821 & 0.47 & 4.33 & 838 & 0.56 & 4.24 & 700 & 1.09 & 3.71 & 696 \\
\hline MT16 & 0.65 & 3.52 & 372 & 0.58 & 3.59 & 366 & 0.62 & 3.55 & 372 & 1.16 & 3.01 & 315 \\
\hline MT17 & 0.76 & 2.76 & 780 & 0.70 & 2.82 & 705 & 0.72 & 2.80 & 640 & 1.37 & 2.15 & 715 \\
\hline MT18 & 0.89 & 5.15 & 352 & 0.84 & 5.20 & 376 & 0.81 & 5.23 & 370 & 1.27 & 4.77 & 322 \\
\hline MT19 & 2.03 & 1.82 & 624 & 2.05 & 1.80 & 603 & 2.05 & 1.80 & 628 & 2.31 & 1.54 & 640 \\
\hline
\end{tabular}




\begin{tabular}{|l|c|c|c|c|c|c|c|c|c|c|}
\hline & \multicolumn{3}{|c|}{$26 / 1 / 2017$} & \multicolumn{2}{|c|}{$15 / 2 / 2017$} & \multicolumn{3}{c|}{$9 / 4 / 2017$} & \multicolumn{2}{|c|}{$24 / 5 / 2017$} \\
\hline Pozo & $\begin{array}{c}\text { Prof. } \\
(\mathrm{m})\end{array}$ & $\begin{array}{c}\text { Nivel } \\
(\mathrm{msn} \\
\mathrm{m})\end{array}$ & $\begin{array}{c}\text { CE } \\
\left(\begin{array}{c}\mathrm{SS} / \mathrm{c} \\
\mathrm{m})\end{array}\right.\end{array}$ & $\begin{array}{c}\text { Prof. } \\
(\mathrm{m})\end{array}$ & $\begin{array}{c}\text { Nivel } \\
(\mathrm{msn} \\
\mathrm{m})\end{array}$ & $\begin{array}{c}\text { Prof. } \\
(\mathrm{m})\end{array}$ & $\begin{array}{c}\text { Nivel } \\
(\mathrm{msn} \\
\mathrm{m})\end{array}$ & $\begin{array}{c}\text { CE } \\
\left(\begin{array}{c}\mathrm{SS} / \mathrm{c} \\
\mathrm{m})\end{array}\right.\end{array}$ & $\begin{array}{c}\text { Prof. } \\
(\mathrm{m})\end{array}$ & $\begin{array}{c}\text { Nivel } \\
(\mathrm{msn} \\
\mathrm{m})\end{array}$ \\
\hline MT1 & 0.70 & 1.78 & 2970 & 0.35 & 2.13 & 0.26 & 2.22 & 2615 & 0.23 & 2.25 \\
\hline MT2 & 1.19 & 3.41 & 679 & 0.91 & 3.69 & 0.73 & 3.87 & 583 & 0.22 & 4.38 \\
\hline MT3 & 2.57 & 3.58 & 519 & 2.15 & 4.00 & 2.51 & 3.64 & 514 & 2.20 & 3.95 \\
\hline MT4 & 2.22 & 1.17 & 1799 & 2.15 & 1.24 & 2.10 & 1.29 & 1427 & 2.10 & 1.29 \\
\hline MT5 & 2.23 & 1.05 & & 2.22 & 1.06 & 2.25 & 1.03 & 502 & 2.06 & 1.22 \\
\hline MT6 & 1.91 & 4.04 & & 1.65 & 4.30 & 1.74 & 4.21 & 419 & 1.40 & 4.55 \\
\hline MT7 & 1.01 & 4.04 & 671 & 0.61 & 4.44 & 0.46 & 4.59 & 534 & 0.32 & 4.73 \\
\hline MT8 & 1.18 & 1.32 & 790 & 1.12 & 1.38 & 0.67 & 1.83 & 781 & 0.70 & 1.80 \\
\hline MT10 & 1.53 & 3.26 & 510 & 1.18 & 3.61 & 1.14 & 3.65 & 416 & 0.72 & 4.07 \\
\hline MT11 & 2.26 & 3.77 & 490 & 2.06 & 3.97 & 2.40 & 3.63 & 413 & 1.80 & 4.23 \\
\hline MT12 & 2.02 & 1.16 & 700 & 2.04 & 1.14 & 2.00 & 1.18 & 632 & 1.85 & 1.33 \\
\hline MT13 & 2.86 & 1.66 & 1150 & 2.97 & 1.55 & & & & & \\
\hline MT14 & 2.04 & 4.44 & 328 & 1.96 & 4.52 & 1.85 & 4.63 & 413 & 1.43 & 5.05 \\
\hline MT15 & 1.17 & 3.63 & 879 & 1.37 & 3.43 & 0.81 & 3.99 & 706 & 0.30 & 4.50 \\
\hline MT16 & 1.31 & 2.86 & 321 & 2.34 & 1.83 & 0.80 & 3.37 & 385 & 0.46 & 3.71 \\
\hline MT17 & 1.48 & 2.04 & 746 & 1.42 & 2.10 & 1.00 & 2.52 & 805 & 0.56 & 2.96 \\
\hline MT18 & 1.33 & 4.71 & 344 & 1.35 & 4.69 & 1.01 & 5.03 & 294 & 0.60 & 5.44 \\
\hline MT19 & 2.23 & 1.62 & 795 & 2.29 & 1.56 & 2.09 & 1.76 & 452 & 1.92 & 1.93 \\
\hline
\end{tabular}




\begin{tabular}{|c|c|c|c|c|c|c|c|c|c|c|c|c|}
\hline & \multicolumn{3}{|c|}{$17 / 7 / 2017$} & \multicolumn{3}{|c|}{$31 / 8 / 2017$} & \multicolumn{3}{|c|}{$17 / 10 / 2017$} & \multicolumn{2}{|c|}{$30 / 12 / 2017$} & \multirow[b]{2}{*}{$\begin{array}{c}\mathrm{CE} \\
(\mu \mathrm{S} / \mathrm{cm})\end{array}$} \\
\hline Pozo & $\begin{array}{c}\text { Prof. } \\
\text { (m) }\end{array}$ & $\begin{array}{c}\text { Nivel } \\
(\mathrm{msnm})\end{array}$ & $\begin{array}{c}\mathrm{CE} \\
(\mu \mathrm{S} / \mathrm{cm})\end{array}$ & $\begin{array}{l}\text { Prof. } \\
\text { (m) }\end{array}$ & $\begin{array}{c}\text { Nivel } \\
(\mathrm{msnm})\end{array}$ & $\begin{array}{c}\mathrm{CE} \\
(\mu \mathrm{S} / \mathrm{cm})\end{array}$ & $\begin{array}{c}\text { Prof. } \\
\text { (m) }\end{array}$ & $\begin{array}{c}\text { Nivel } \\
(\mathrm{msnm})\end{array}$ & $\begin{array}{c}\mathrm{CE} \\
(\mu \mathrm{S} / \mathrm{cm})\end{array}$ & $\begin{array}{c}\text { Prof. } \\
\text { (m) }\end{array}$ & $\begin{array}{c}\text { Nivel } \\
(\mathrm{msnm})\end{array}$ & \\
\hline MT1 & 0.15 & 2.33 & 3065 & 0.10 & 2.38 & 2978 & 0.31 & 2.17 & 2730 & 0.72 & 1.76 & 2960 \\
\hline MT2 & 0.10 & 4.50 & 1324 & 0.17 & 4.43 & 1335 & 0.52 & 4.08 & 1016 & 1.00 & 3.60 & 975 \\
\hline MT3 & 2.10 & 4.05 & 567 & 1.90 & 4.25 & 508 & 1.79 & 4.36 & 427 & 1.95 & 4.20 & 444 \\
\hline MT4 & 1.85 & 1.54 & 1432 & 1.95 & 1.44 & 1272 & 2.15 & 1.24 & 853 & 2.11 & 1.28 & 1402 \\
\hline MT5 & 1.87 & 1.41 & 700 & 1.91 & 1.37 & 579 & 2.02 & 1.26 & 523 & 1.96 & 1.32 & 735 \\
\hline MT6 & 1.30 & 4.65 & 518 & 0.94 & 5.01 & 528 & 1.14 & 4.81 & 531 & 1.41 & 4.54 & 415 \\
\hline MT7 & 0.15 & 4.90 & 802 & 0.20 & 4.85 & 849 & 0.50 & 4.55 & 643 & 0.85 & 4.20 & 600 \\
\hline MT8 & 0.75 & 1.75 & & 0.47 & 2.03 & 785 & 0.67 & 1.83 & 975 & 0.91 & 1.59 & 959 \\
\hline MT10 & 0.52 & 4.27 & 576 & 0.50 & 4.29 & 475 & 0.83 & 3.96 & 512 & 1.23 & 3.56 & 549 \\
\hline MT11 & 1.73 & 4.30 & & 1.74 & 4.29 & & & & 541 & 0.66 & 5.37 & 430 \\
\hline MT12 & 1.76 & 1.42 & 544 & 1.72 & 1.46 & 856 & 1.70 & 1.48 & 650 & 1.65 & 1.53 & 524 \\
\hline \multicolumn{13}{|l|}{ MT13 } \\
\hline MT14 & 1.39 & 5.09 & 593 & 1.03 & 5.45 & 648 & 1.27 & 5.21 & 457 & 1.50 & 4.98 & 325 \\
\hline MT15 & 0.25 & 4.55 & 586 & 0.15 & 4.65 & 1039 & 0.56 & 4.24 & 716 & 0.90 & 3.90 & 745 \\
\hline MT16 & 0.25 & 3.92 & 607 & 0.38 & 3.79 & 593 & 0.57 & 3.60 & 406 & 1.05 & 3.12 & 358 \\
\hline MT17 & 0.30 & 3.22 & & 0.26 & 3.26 & 554 & 0.79 & 2.73 & 801 & 1.16 & 2.36 & 893 \\
\hline MT18 & 0.80 & 5.24 & 345 & 0.35 & 5.69 & 407 & 0.65 & 5.39 & 319 & 0.93 & 5.11 & 253 \\
\hline MT19 & 1.90 & 1.95 & 441 & 1.80 & 2.05 & 434 & 1.95 & 1.90 & 501 & 2.02 & 1.83 & 443 \\
\hline
\end{tabular}




\begin{tabular}{|c|c|c|c|c|c|c|c|c|c|c|c|c|}
\hline & \multicolumn{2}{|c|}{$31 / 1 / 2018$} & \multicolumn{2}{|c|}{$5 / 2 / 2018$} & \multicolumn{3}{|c|}{$20 / 4 / 2018$} & \multicolumn{3}{|c|}{$7 / 6 / 2018$} & \multicolumn{2}{|c|}{ 12/10/2018 } \\
\hline Pozo & $\begin{array}{l}\text { Prof. } \\
\text { (m) }\end{array}$ & $\begin{array}{c}\text { Nivel } \\
(\mathrm{msnm})\end{array}$ & $\begin{array}{l}\text { Prof. } \\
\text { (m) }\end{array}$ & $\begin{array}{c}\text { Nivel } \\
(\mathrm{msnm})\end{array}$ & $\begin{array}{c}\text { Prof. } \\
\text { (m) }\end{array}$ & $\begin{array}{c}\text { Nivel } \\
(\mathrm{msnm})\end{array}$ & $\begin{array}{c}\mathrm{CE} \\
(\mu \mathrm{S} / \mathrm{cm})\end{array}$ & $\begin{array}{l}\text { Prof. } \\
(\mathrm{m})\end{array}$ & $\begin{array}{c}\text { Nivel } \\
(\mathrm{msnm})\end{array}$ & $\begin{array}{c}\mathrm{CE} \\
(\mu \mathrm{S} / \mathrm{cm})\end{array}$ & $\begin{array}{c}\text { Prof. } \\
\text { (m) }\end{array}$ & $\begin{array}{c}\text { Nivel } \\
(\mathrm{msnm})\end{array}$ \\
\hline MT1 & 0.95 & 1.53 & & & 0.20 & 2.28 & 3120 & 0.25 & 2.23 & 2100 & 0.17 & 2.31 \\
\hline MT2 & 1.25 & 3.35 & & & 1.00 & 3.60 & 976 & 0.21 & 4.39 & 898 & 0.29 & 4.31 \\
\hline MT3 & 2.20 & 3.95 & & & 2.48 & 3.67 & 648 & 1.71 & 4.44 & 526 & 1.39 & 4.76 \\
\hline MT4 & 2.14 & 1.25 & & & 1.96 & 1.43 & 1985 & 1.88 & 1.51 & 1526 & 1.91 & 1.48 \\
\hline MT5 & 2.01 & 1.27 & 2.00 & 1.28 & 2.05 & 1.23 & 712 & 1.82 & 1.46 & 654 & 1.78 & 1.50 \\
\hline MT6 & 1.68 & 4.27 & 1.69 & 4.26 & 1.89 & 4.06 & 504 & 1.10 & 4.85 & 479 & 0.88 & 5.07 \\
\hline MT7 & 1.07 & 3.98 & 1.08 & 3.97 & 0.82 & 4.23 & 664 & 0.20 & 4.85 & 645 & 0.24 & 4.81 \\
\hline MT8 & & & & & 0.48 & 2.02 & 817 & 0.32 & 2.18 & 723 & 0.39 & 2.11 \\
\hline MT10 & 1.53 & 3.26 & 1.54 & 3.25 & 1.40 & 3.39 & 625 & 0.60 & 4.19 & 547 & 0.56 & 4.23 \\
\hline MT11 & 1.98 & 4.05 & 2.00 & 4.03 & & & & & & & & \\
\hline MT12 & & & & & 1.80 & 1.38 & 571 & 1.40 & 1.78 & 260 & 1.29 & 1.89 \\
\hline MT13 & & & & & & & & & & & & \\
\hline MT14 & 1.80 & 4.68 & 1.82 & 4.66 & 1.89 & 4.59 & 908 & 1.16 & 5.32 & 410 & & \\
\hline MT15 & 1.18 & 3.62 & 1.19 & 3.61 & 0.95 & 3.85 & 981 & 0.18 & 4.62 & 853 & 0.40 & 4.40 \\
\hline MT16 & 1.41 & 2.76 & 1.42 & 2.75 & 1.13 & 3.04 & 553 & 0.30 & 3.87 & 381 & 0.41 & 3.76 \\
\hline MT17 & 1.47 & 2.05 & & & 1.45 & 2.07 & 951 & 0.44 & 3.08 & 477 & 0.46 & 3.06 \\
\hline MT18 & 1.24 & 4.80 & 1.22 & 4.82 & 1.19 & 4.85 & 294 & 0.47 & 5.57 & 309 & 0.44 & 5.60 \\
\hline MT19 & 2.13 & 1.72 & & & 2.05 & 1.80 & 508 & 1.60 & 2.25 & 550 & 1.59 & 2.26 \\
\hline
\end{tabular}




\section{Planillas de censo Costa estuárica (Berisso)}




\begin{tabular}{|r|c|c|c|c|c|c|}
\hline Pozo & Latitud S & Longitud O & X & Y & Dirección & $\begin{array}{c}\text { Cota } \\
\text { (msnm) }\end{array}$ \\
\hline 1 & 345225.30 & 574838.07 & 6139197 & 5700192 & Camping bagliardi & 1.78 \\
\hline 2 & 345249.49 & 574914.89 & 6138472 & 5699240 & Flia. Marziani & 2.97 \\
\hline 3 & 345315.46 & 57503.37 & 6137698 & 5697991 & Flia. Aulosqui Rosales & 2.47 \\
\hline 4 & 345336.40 & 57488.40 & 6136989 & 5700897 & Calle de la escuela al fondo & 1.78 \\
\hline 5 & 345341.8 & 574812.5 & 6136825 & 5700790 & Antes de llegar al P4 & 1.79 \\
\hline 6 & 34547.40 & 574815.90 & 6136038 & 5700686 & Campo molinos & 2.8 \\
\hline 7 & 34556.9 & 574429.5 & 6134076 & 5706394 & Camping municipal & 1.49 \\
\hline 8 & 345540.9 & 57451.1 & 6133046 & 5705568 & Calle que va al camping & 1.69 \\
\hline 9 & 345551.68 & 574513.62 & 6132720 & 5705243 & Calle 721 chanchos & 2.89 \\
\hline 10 & 345549.3 & 57433.00 & 6132719 & 5708560 & Camping la Balandra & 1.88 \\
\hline 11 & 34566.1 & 574326.2 & 6132214 & 5707960 & $\begin{array}{c}\text { Calle que va al Camping La } \\
\text { Balandra }\end{array}$ & 1.65 \\
\hline
\end{tabular}




\begin{tabular}{|c|c|c|c|c|c|c|c|c|c|}
\hline & \multicolumn{3}{|c|}{ Septiembre 2015} & \multicolumn{3}{|c|}{ Diciembre 2015} & \multicolumn{3}{|c|}{ Marzo 2016 diver } \\
\hline Pozo & $\begin{array}{l}\text { Prof. } \\
\text { (m) }\end{array}$ & $\begin{array}{c}\text { Nivel } \\
\text { (msnm) }\end{array}$ & $\begin{array}{c}\text { CE } \\
(\mu \mathrm{S} / \mathrm{cm})\end{array}$ & $\begin{array}{l}\text { Prof. } \\
\text { (m) }\end{array}$ & $\begin{array}{c}\text { Nivel } \\
\text { (msnm) }\end{array}$ & $\begin{array}{c}C E \\
(\mu S / c m)\end{array}$ & $\begin{array}{l}\text { Prof. } \\
(\mathrm{m})\end{array}$ & $\begin{array}{c}\text { Nivel } \\
\text { (msnm) }\end{array}$ & $\begin{array}{c}C E \\
(\mu S / c m)\end{array}$ \\
\hline 1 & 1.35 & 0.43 & 1800 & 1.46 & 0.32 & 1391 & & & \\
\hline 2 & 1.87 & 1.10 & 682 & 2.11 & 0.86 & 469 & & & \\
\hline 3 & 3.1 & -0.63 & 1362 & 1.02 & 1.45 & 1806 & & & \\
\hline 4 & & & & & & & & & \\
\hline 5 & & & & & & & & & \\
\hline 6 & & & & & & & & & \\
\hline 7 & & & & & & & & & \\
\hline 8 & & & & & & & & & \\
\hline 9 & & & & & & & & & \\
\hline 10 & & & & & & & & & \\
\hline 11 & & & & & & & & & \\
\hline
\end{tabular}

\begin{tabular}{|c|c|c|c|c|c|c|c|c|c|}
\hline & \multicolumn{3}{|c|}{ Junio 2016 } & \multicolumn{3}{c|}{ Julio 2016 } & \multicolumn{3}{c|}{ Octubre 2016 } \\
\hline Pozo & $\begin{array}{c}\text { Prof. } \\
(\mathrm{m})\end{array}$ & $\begin{array}{c}\text { Nivel } \\
(\mathrm{msnm})\end{array}$ & $\begin{array}{c}\text { CE } \\
(\mu \mathrm{S} / \mathrm{cm})\end{array}$ & $\begin{array}{c}\text { Prof. } \\
(\mathrm{m})\end{array}$ & $\begin{array}{c}\text { Nivel } \\
(\mathrm{msnm})\end{array}$ & $\begin{array}{c}\text { CE } \\
(\mu \mathrm{S} / \mathrm{cm})\end{array}$ & $\begin{array}{c}\text { Prof. } \\
(\mathrm{m})\end{array}$ & $\begin{array}{c}\text { Nivel } \\
(\mathrm{msnm})\end{array}$ & $\begin{array}{c}\text { CE } \\
(\mu \mathrm{S} / \mathrm{cm})\end{array}$ \\
\hline 1 & 1.80 & -0.02 & 1091 & 1.80 & -0.02 & 1091 & 0.87 & 0.91 & 877 \\
\hline 2 & 1.93 & 1.04 & 682 & 1.75 & 1.22 & 513 & 1.94 & 1.03 & 573 \\
\hline 3 & 0.80 & 1.67 & 1362 & 0.37 & 2.10 & 1145 & 0.54 & 1.93 & 1730 \\
\hline 4 & 1.00 & 0.78 & 300 & 0.65 & 1.13 & 2570 & 0.91 & 0.87 & 3354 \\
\hline 5 & 1.04 & 0.75 & 1148 & 0.58 & 1.21 & 1739 & 1.02 & 0.77 & 1551 \\
\hline 6 & 0.90 & 1.9 & 4710 & 0.70 & 2.10 & 3670 & 0.80 & 2.00 & 2900 \\
\hline 7 & 0.71 & 0.78 & 1144 & & & & 0.28 & 1.21 & 985 \\
\hline 8 & 0.71 & 0.98 & 700 & & & & 0.60 & 1.09 & 428 \\
\hline 9 & 1.25 & 1.64 & 4000 & 0.31 & 2.58 & 670 & 0.89 & 2.00 & 684 \\
\hline 11 & 0.86 & 0.79 & 1218 & 1.20 & 0.45 & 1143 & 1.27 & 0.38 & 990 \\
\hline
\end{tabular}




\begin{tabular}{|c|c|c|c|c|c|c|c|c|c|}
\hline & \multicolumn{3}{|c|}{ Diciembre 2016} & \multicolumn{3}{|c|}{ Febrero 2017} & \multicolumn{3}{|c|}{ Marzo 2017} \\
\hline Pozo & $\begin{array}{l}\text { Prof. } \\
\text { (m) }\end{array}$ & $\begin{array}{c}\text { Nivel } \\
\text { (msnm) }\end{array}$ & $\begin{array}{c}\text { CE } \\
(\mu \mathrm{S} / \mathrm{cm})\end{array}$ & $\begin{array}{c}\text { Prof. } \\
\text { (m) }\end{array}$ & $\begin{array}{c}\text { Nivel } \\
\text { (msnm) }\end{array}$ & $\begin{array}{c}\text { CE } \\
(\mu S / \mathrm{cm})\end{array}$ & $\begin{array}{c}\text { Prof. } \\
\text { (m) }\end{array}$ & $\begin{array}{c}\text { Nivel } \\
\text { (msnm) }\end{array}$ & $\begin{array}{c}C E \\
(\mu S / \mathrm{cm})\end{array}$ \\
\hline 1 & 0.55 & 1.23 & 890 & 0.99 & 0.79 & 1015 & 0.87 & 0.91 & 985 \\
\hline 2 & 1.69 & 1.28 & 477 & 2.13 & 0.84 & 335 & 2.14 & 0.83 & \\
\hline 3 & 0.62 & 1.85 & 1950 & 1.26 & 1.21 & 1090 & 1.27 & 1.20 & 1541 \\
\hline 4 & 0.79 & 0.99 & 325 & seco & & & seco & & \\
\hline 5 & 0.92 & 0.87 & 1430 & seco & & & seco & & \\
\hline 6 & 0.90 & 1.90 & 4700 & seco & & & seco & & \\
\hline 7 & & & & 0.46 & 1.03 & 1460 & & & \\
\hline 8 & 0.79 & 0.90 & 2400 & 0.59 & 1.10 & & & & \\
\hline 9 & 0.79 & 2.10 & 870 & 1.63 & 1.26 & & & & \\
\hline 10 & & & & 1.67 & 0.21 & 1688 & & & \\
\hline 11 & 0.51 & 1.14 & 1057 & & & & & & \\
\hline
\end{tabular}




\begin{tabular}{|c|c|c|c|c|c|c|c|c|}
\hline \multirow[b]{2}{*}{ Pozo } & \multicolumn{2}{|c|}{ Mayo 2017} & \multicolumn{3}{|c|}{ Julio 2017} & \multicolumn{3}{|c|}{ Septiembre 2017} \\
\hline & Prof. (m) & $\begin{array}{c}\text { Nivel } \\
\text { (msnm) }\end{array}$ & Prof. (m) & $\begin{array}{c}\text { Nivel } \\
\text { (msnm) }\end{array}$ & $\begin{array}{c}\mathrm{CE} \\
(\mu \mathrm{S} / \mathrm{cm})\end{array}$ & Prof. (m) & $\begin{array}{c}\text { Nivel } \\
\text { (msnm) }\end{array}$ & $\begin{array}{c}\text { CE } \\
(\mu S / \mathrm{cm})\end{array}$ \\
\hline 1 & 0.70 & 1.08 & 0.91 & 0.87 & 1030 & 0.79 & 0.99 & 777 \\
\hline 2 & 1.91 & 1.06 & 1.81 & 1.16 & & 1.65 & 1.32 & 600 \\
\hline 3 & 0.72 & 1.75 & 0.57 & 1.90 & & 0.63 & 1.84 & 2430 \\
\hline 4 & 0.71 & 1.07 & 0.76 & 1.02 & & 0.64 & 1.14 & 3590 \\
\hline 5 & 0.37 & 1.42 & 0.97 & 0.82 & & 0.63 & 1.16 & 1074 \\
\hline 6 & & 1.90 & 1.26 & 1.54 & & 0.46 & 2.34 & 574 \\
\hline 7 & 0.12 & 1.37 & & & & 0.39 & 1.10 & 1004 \\
\hline 8 & & 1.00 & 0.52 & 1.17 & 495 & & & \\
\hline 9 & 1.06 & 1.83 & 0.61 & 2.28 & & & & \\
\hline 10 & 1.24 & 0.64 & 1.27 & 0.61 & 1470 & 1.31 & 0.57 & 1700 \\
\hline 11 & & & & & & & & \\
\hline
\end{tabular}


Anexo 3

Ensayos Slug Test,
método de Hvorslev 


\begin{tabular}{|l|c|}
\hline Pozo & $M T 1$ \\
\hline Ubicación & 16 e/ 56 y $57 n^{\circ} 5665$ \\
\hline$t_{37}$ & 35 \\
\hline$K(\mathrm{~m} / \mathrm{d})$ & 31 \\
\hline
\end{tabular}

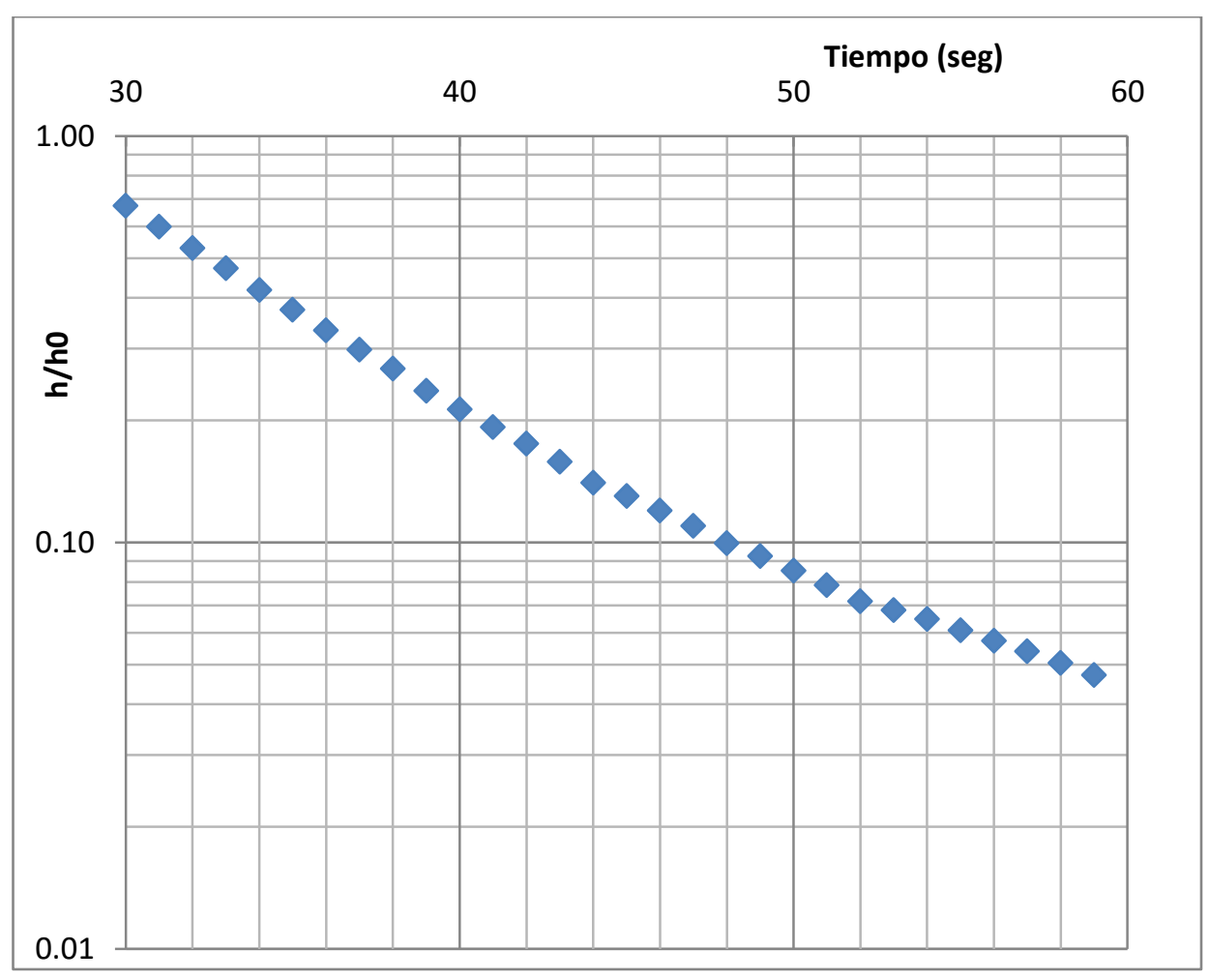




\begin{tabular}{|l|c|}
\hline Pozo & MT5 \\
\hline Ubicación & 66 y costanera \\
\hline$t_{37}$ & 50 \\
\hline$K(\mathrm{~m} / \mathrm{d})$ & 24 \\
\hline
\end{tabular}

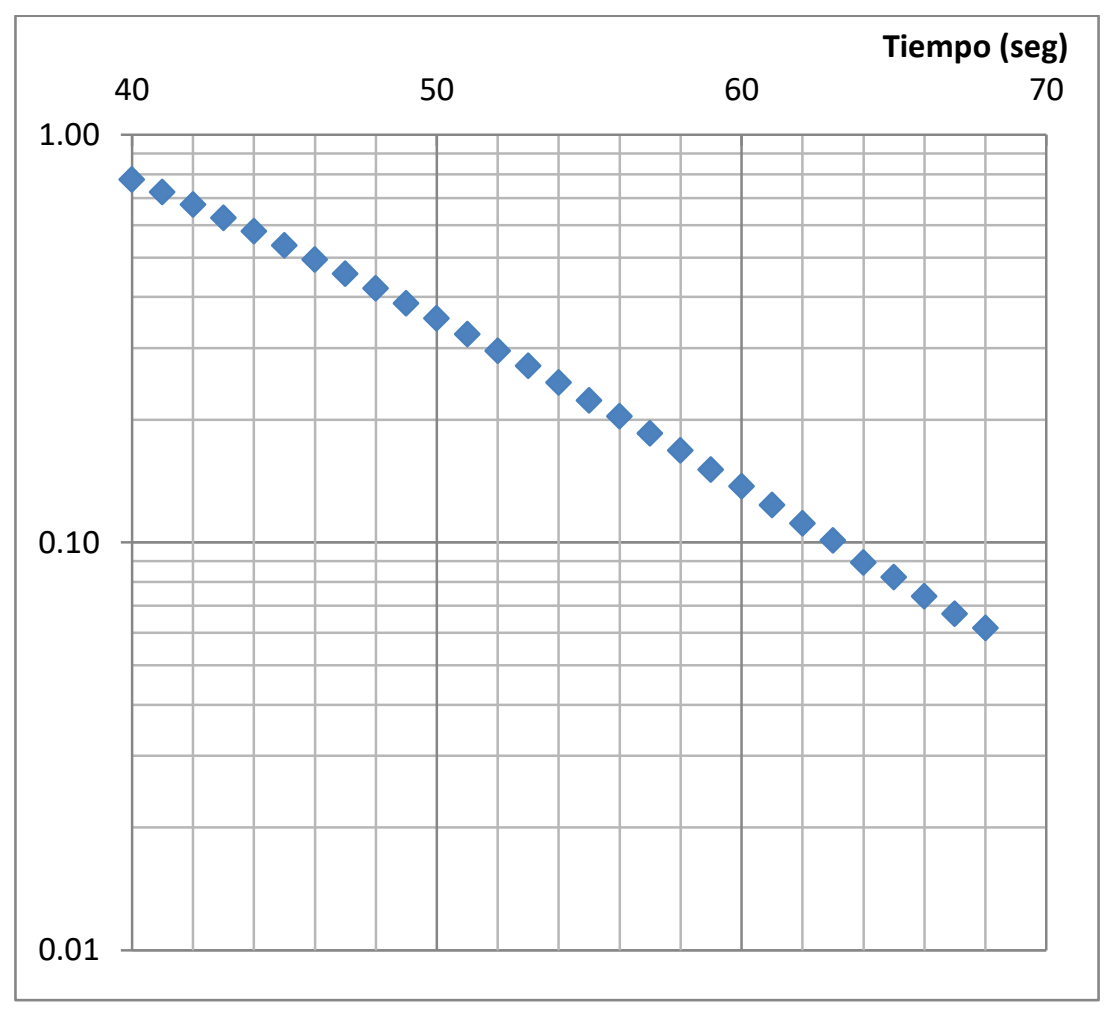




\begin{tabular}{|l|c|}
\hline Pozo & MT6 \\
\hline Ubicación & 66 y 5 \\
\hline$t_{37}$ & 51 \\
\hline$K(\mathrm{~m} / \mathrm{d})$ & 23 \\
\hline
\end{tabular}

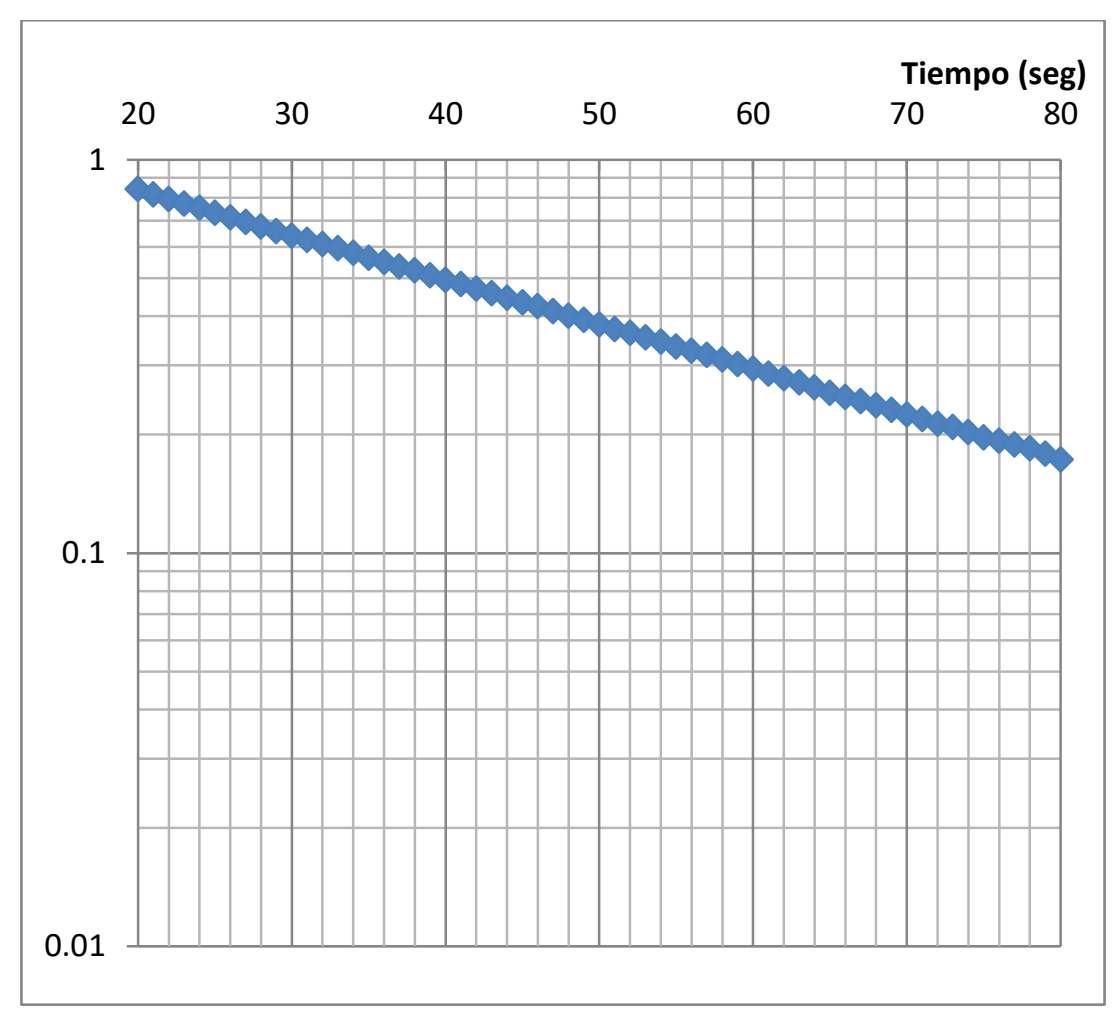




\begin{tabular}{|l|c|}
\hline Pozo & MT7 \\
\hline Ubicación & 66 e/ 9 y 10 \\
\hline$t_{37}$ & 52 \\
\hline$K(\mathrm{~m} / \mathrm{d})$ & 23 \\
\hline
\end{tabular}

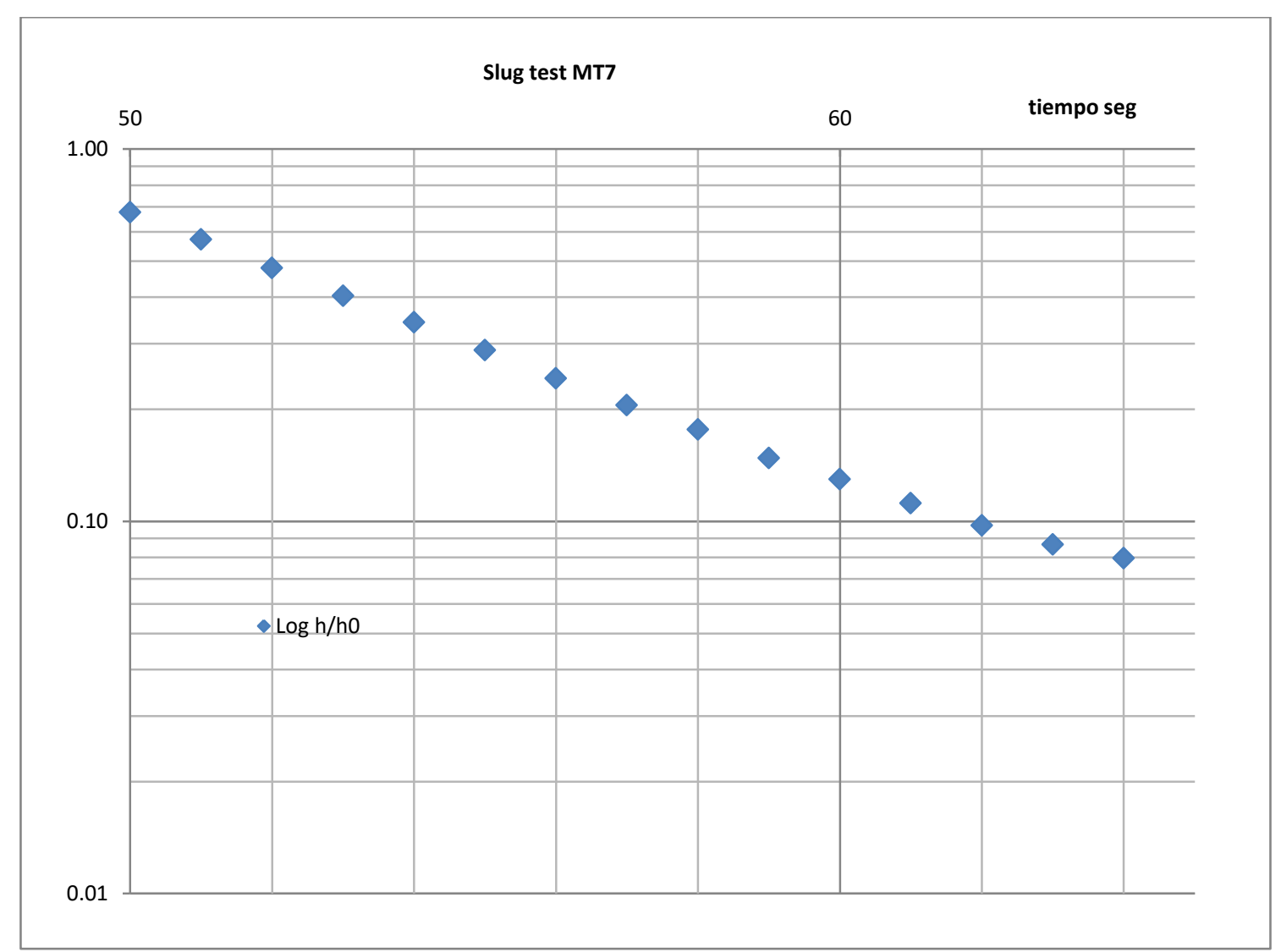




\begin{tabular}{|l|c|}
\hline Pozo & MT11 \\
\hline Ubicación & $73 y 5 n^{\circ} 504$ \\
\hline$t_{37}$ & 33 \\
\hline$K(\mathrm{~m} / \mathrm{d})$ & 35 \\
\hline
\end{tabular}

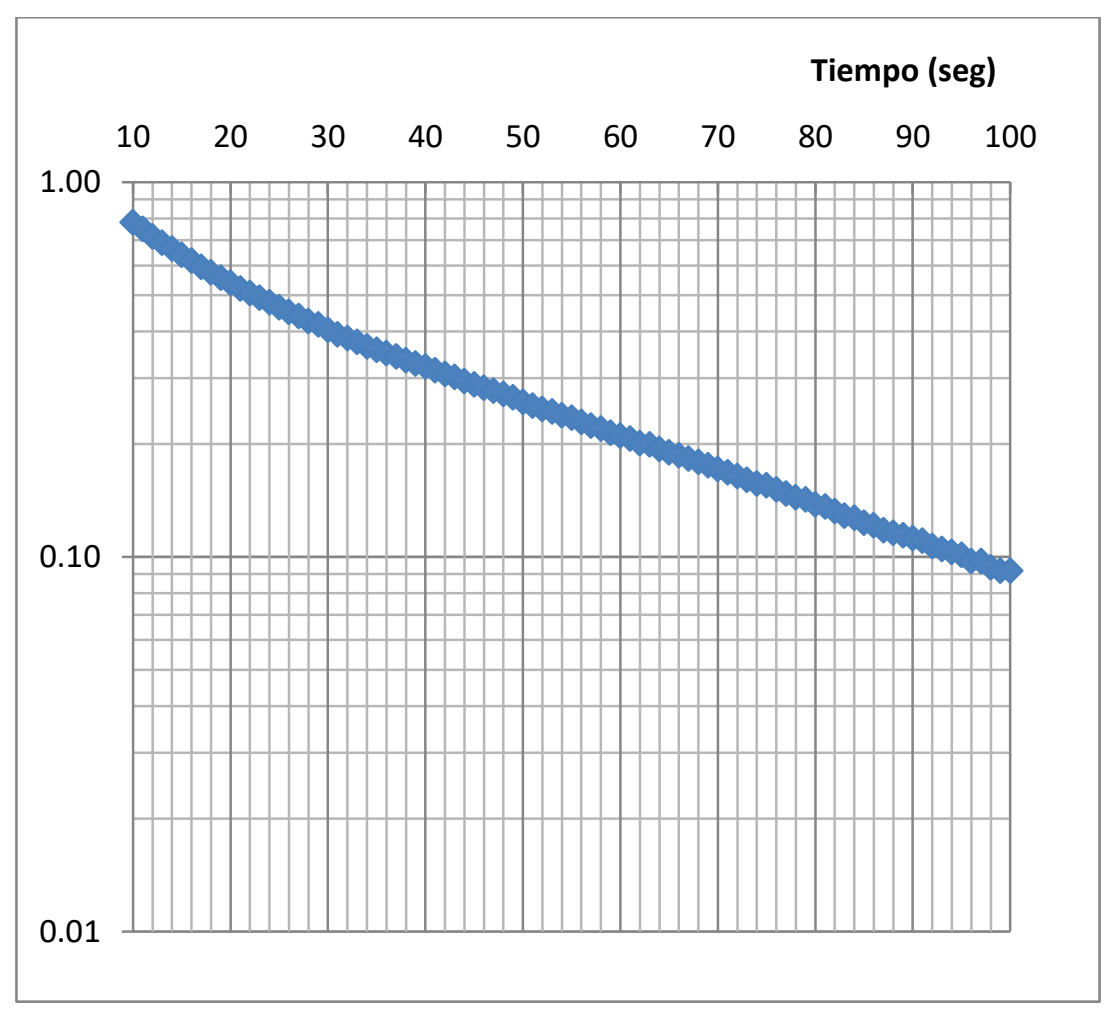




\begin{tabular}{|l|c|}
\hline Pozo & MT10 \\
\hline Ubicación & 73 y 9 \\
\hline$t_{37}$ & 31 \\
\hline$K(\mathrm{~m} / \mathrm{d})$ & 31 \\
\hline
\end{tabular}

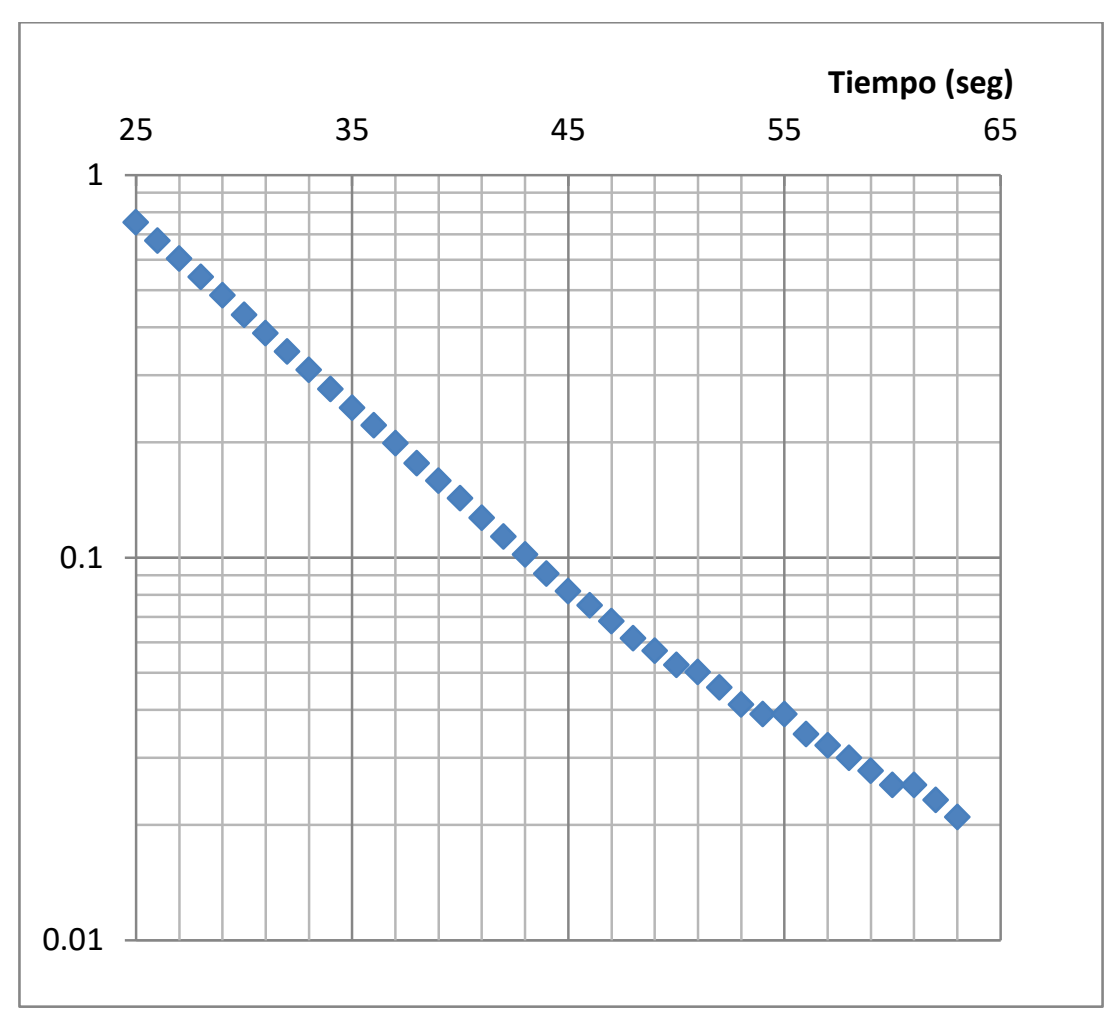




\begin{tabular}{|l|c|}
\hline Pozo & MT14 \\
\hline Ubicación & 83 y 5 \\
\hline$t_{37}$ & 23 \\
\hline$K(\mathrm{~m} / \mathrm{d})$ & 41 \\
\hline
\end{tabular}

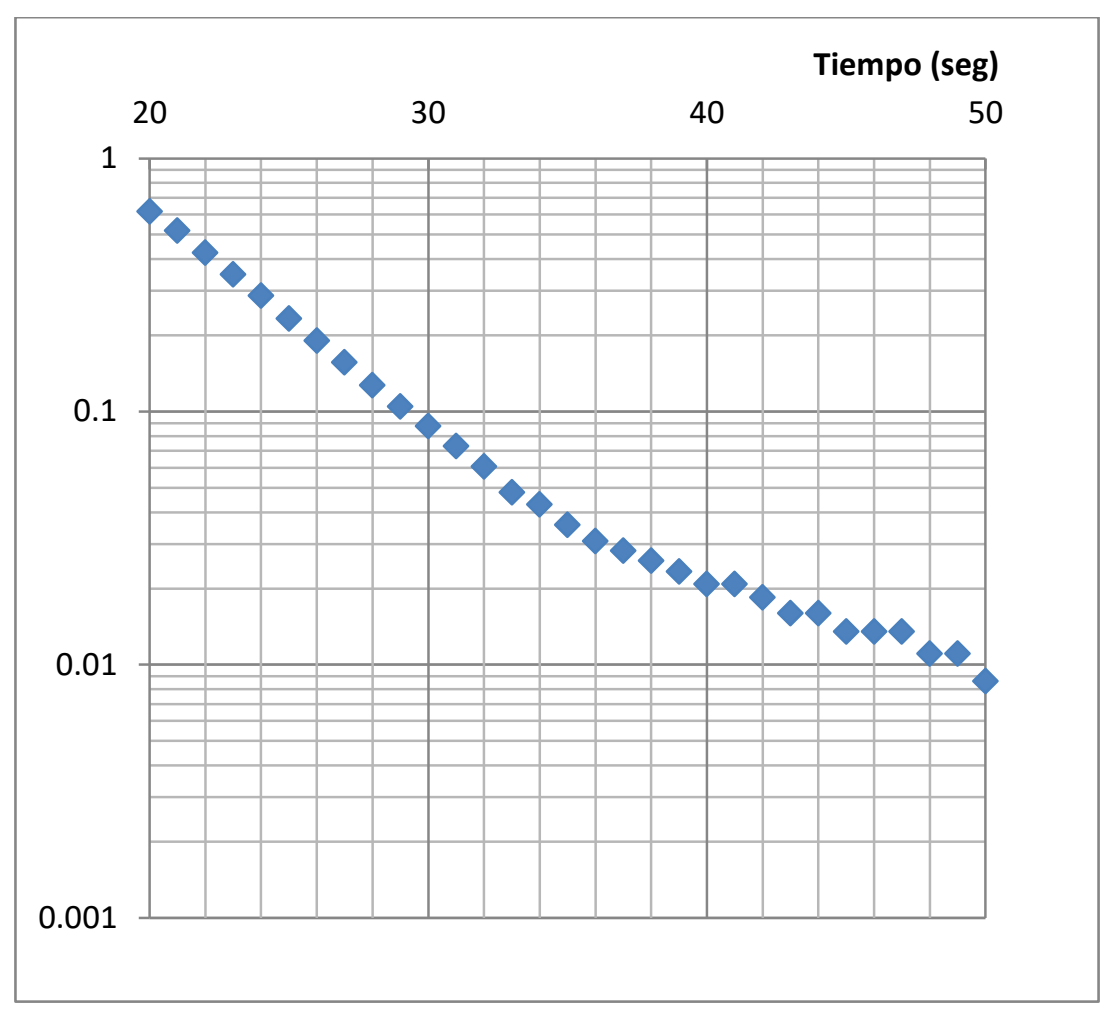




\begin{tabular}{|l|c|}
\hline Pozo & MT15 \\
\hline Ubicación & 83 y 10 \\
\hline$t_{37}$ & 23 \\
\hline$K(\mathrm{~m} / \mathrm{d})$ & 41 \\
\hline
\end{tabular}

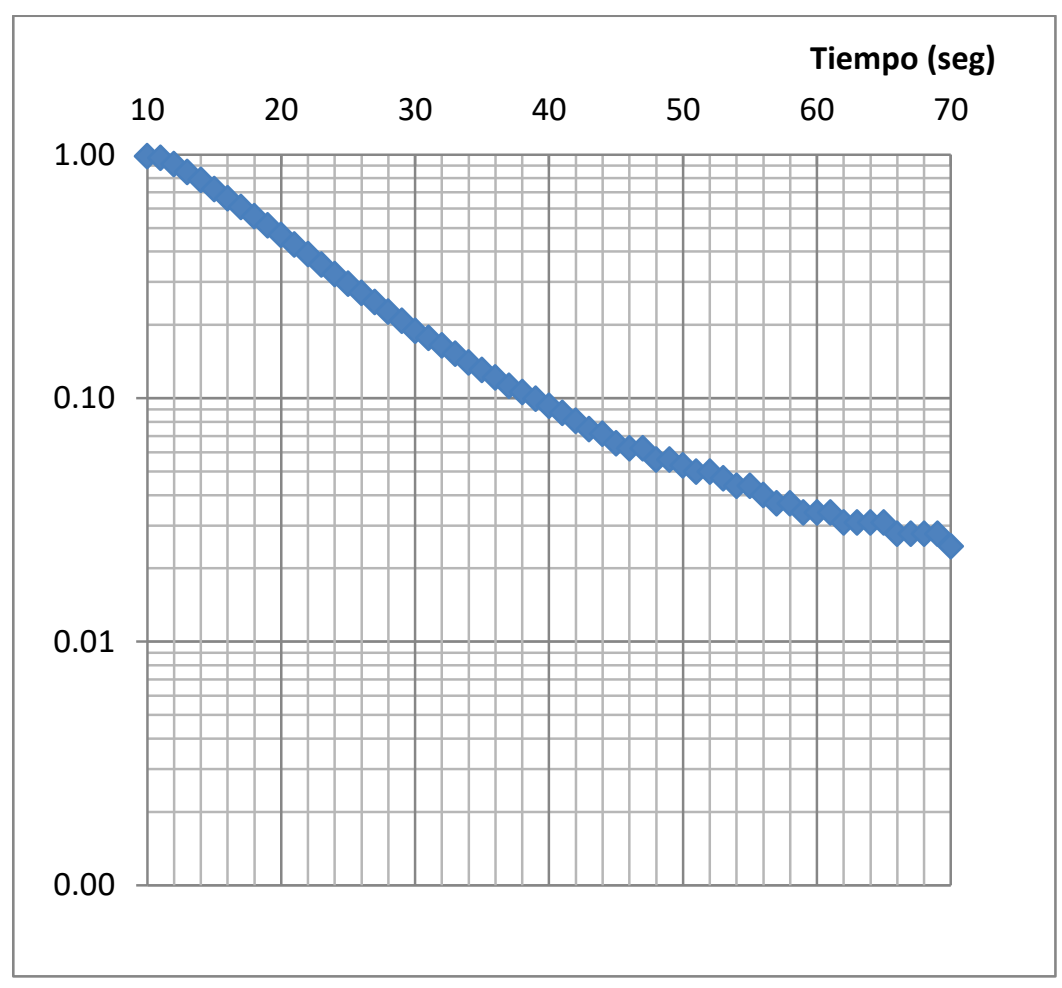




\begin{tabular}{|l|c|}
\hline Pozo & MT16 \\
\hline Ubicación & 13 e/81 y 82 \\
\hline$t_{37}$ & 30 \\
\hline$K(\mathrm{~m} / \mathrm{d})$ & 63 \\
\hline
\end{tabular}

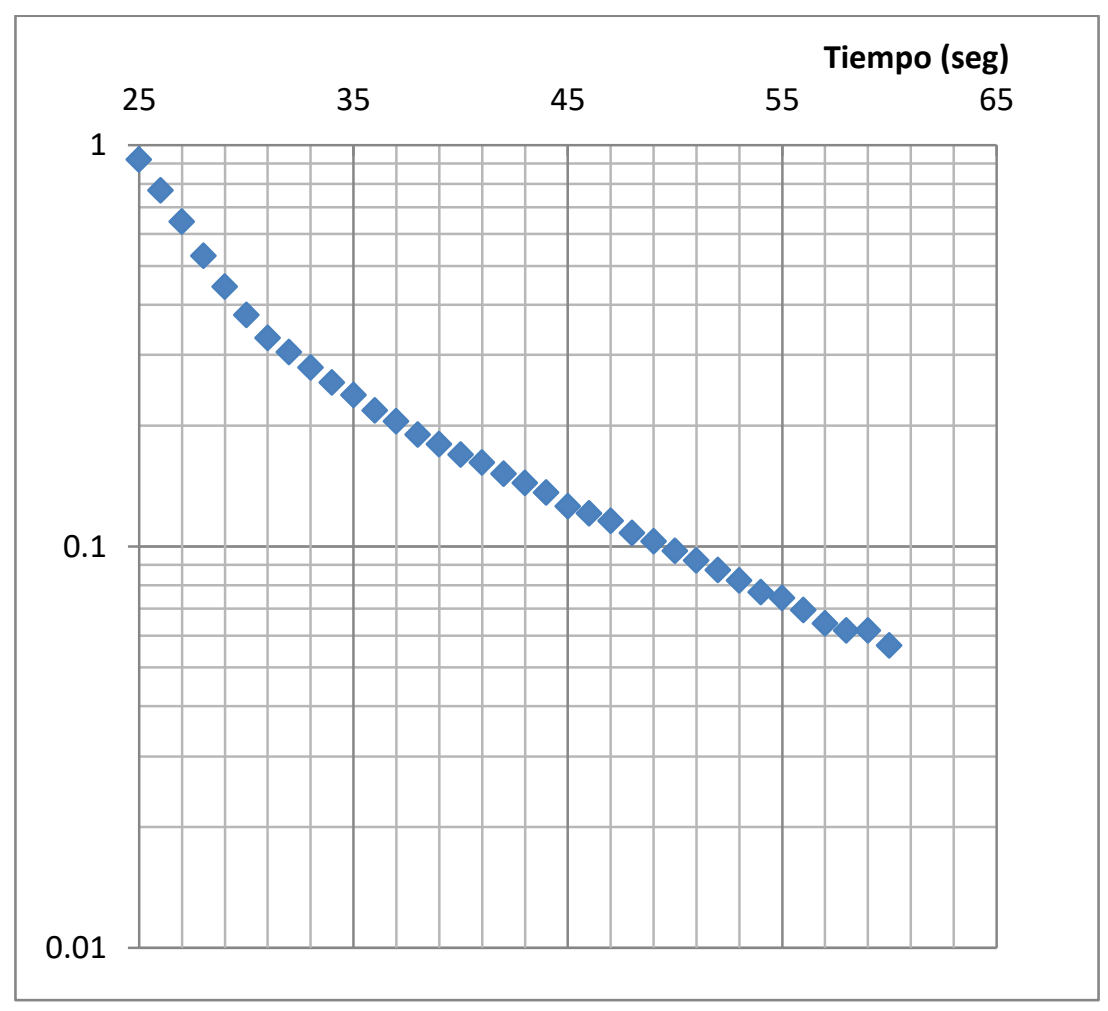




\begin{tabular}{|l|c|}
\hline Pozo & MT18 \\
\hline Ubicación & $93 y 7 n^{\circ} 9293$ \\
\hline$t_{37}$ & 25 \\
\hline$K(\mathrm{~m} / \mathrm{d})$ & 44 \\
\hline
\end{tabular}

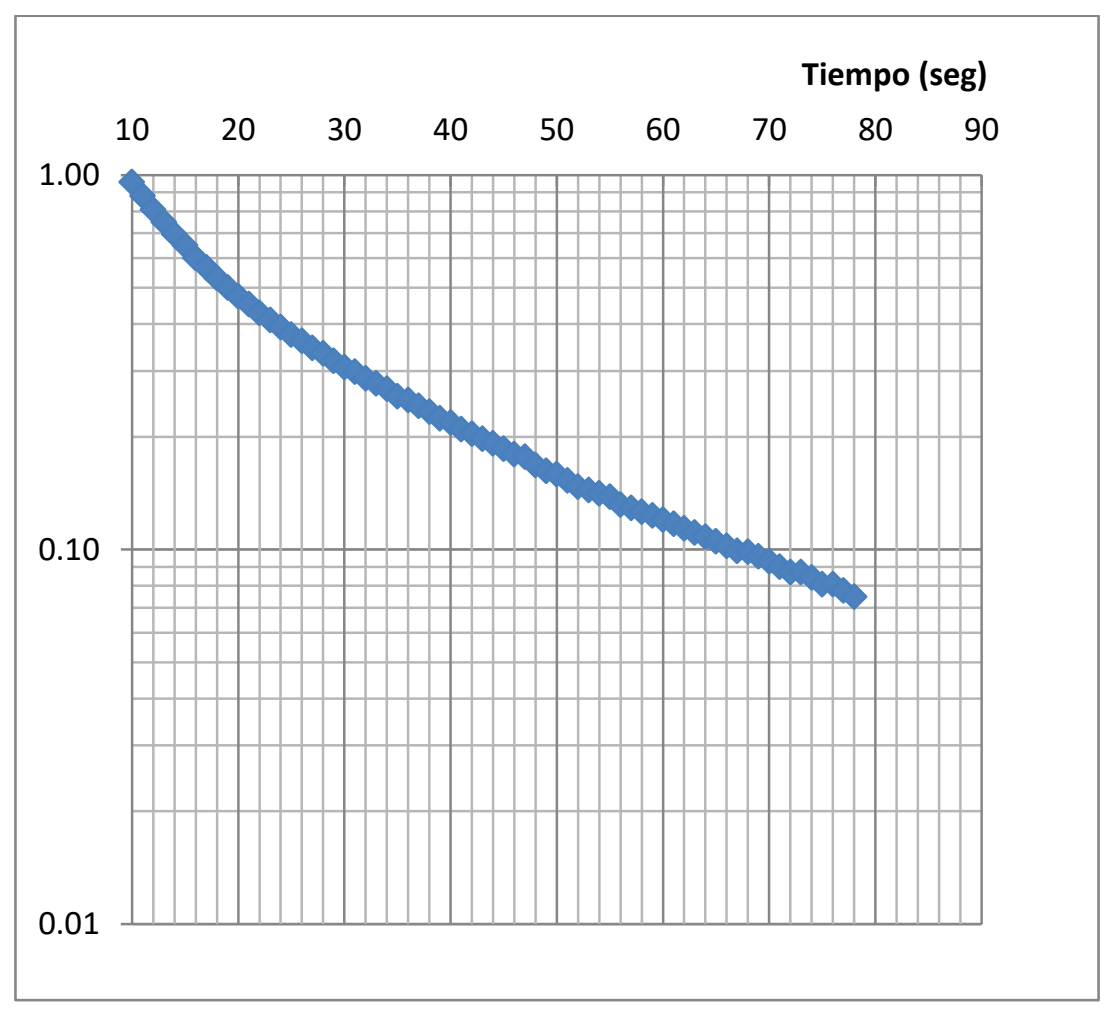




\begin{tabular}{|l|c|}
\hline Pozo & MT19 \\
\hline Ubicación & 93 y costanera \\
\hline$t_{37}$ & 171 \\
\hline$K(\mathrm{~m} / \mathrm{d})$ & 8 \\
\hline
\end{tabular}

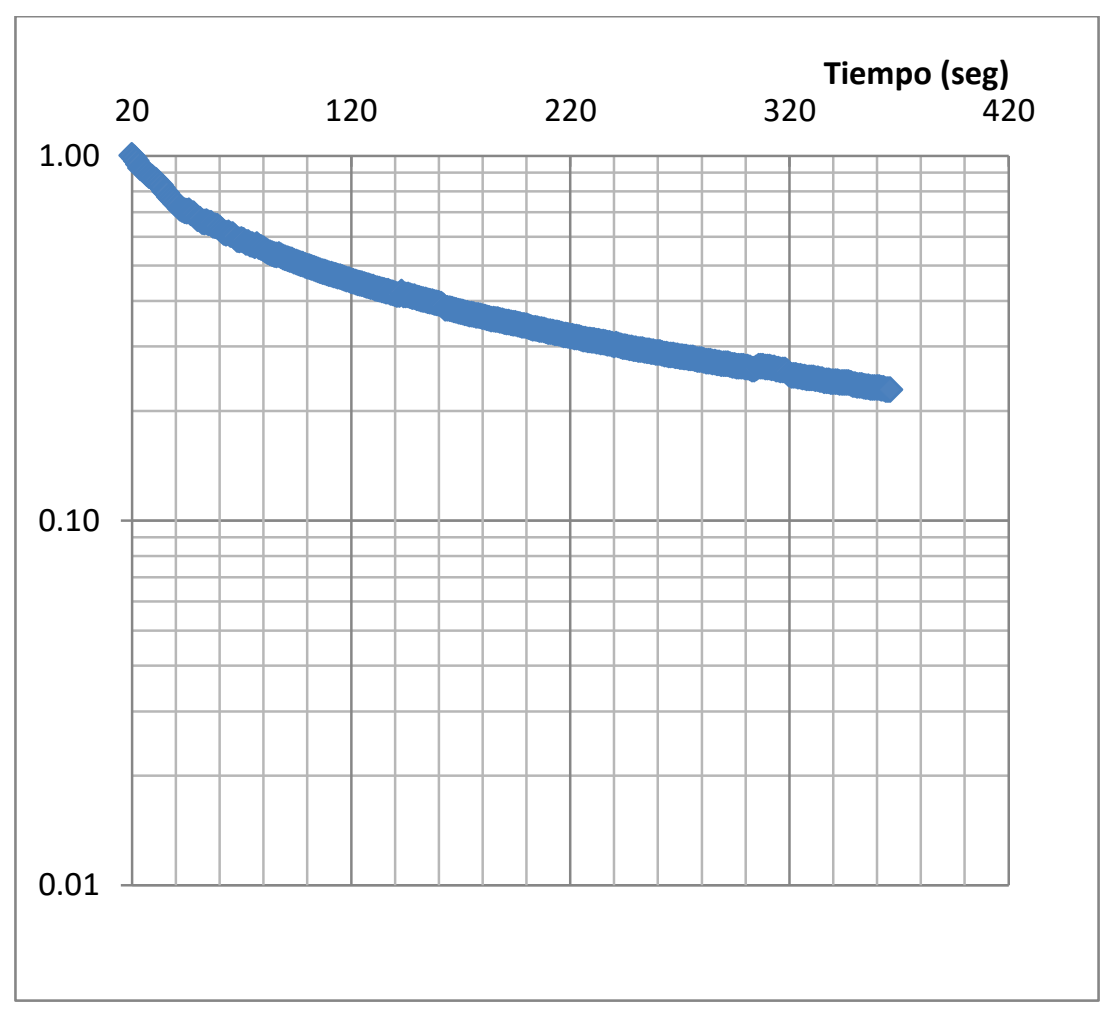


Anexo 4

\section{Ensayos de infiltración}


Ensayo realizado en las cercanías del freatímetro MT12.

El sitio ensayado corresponde a la zona de duna activa.
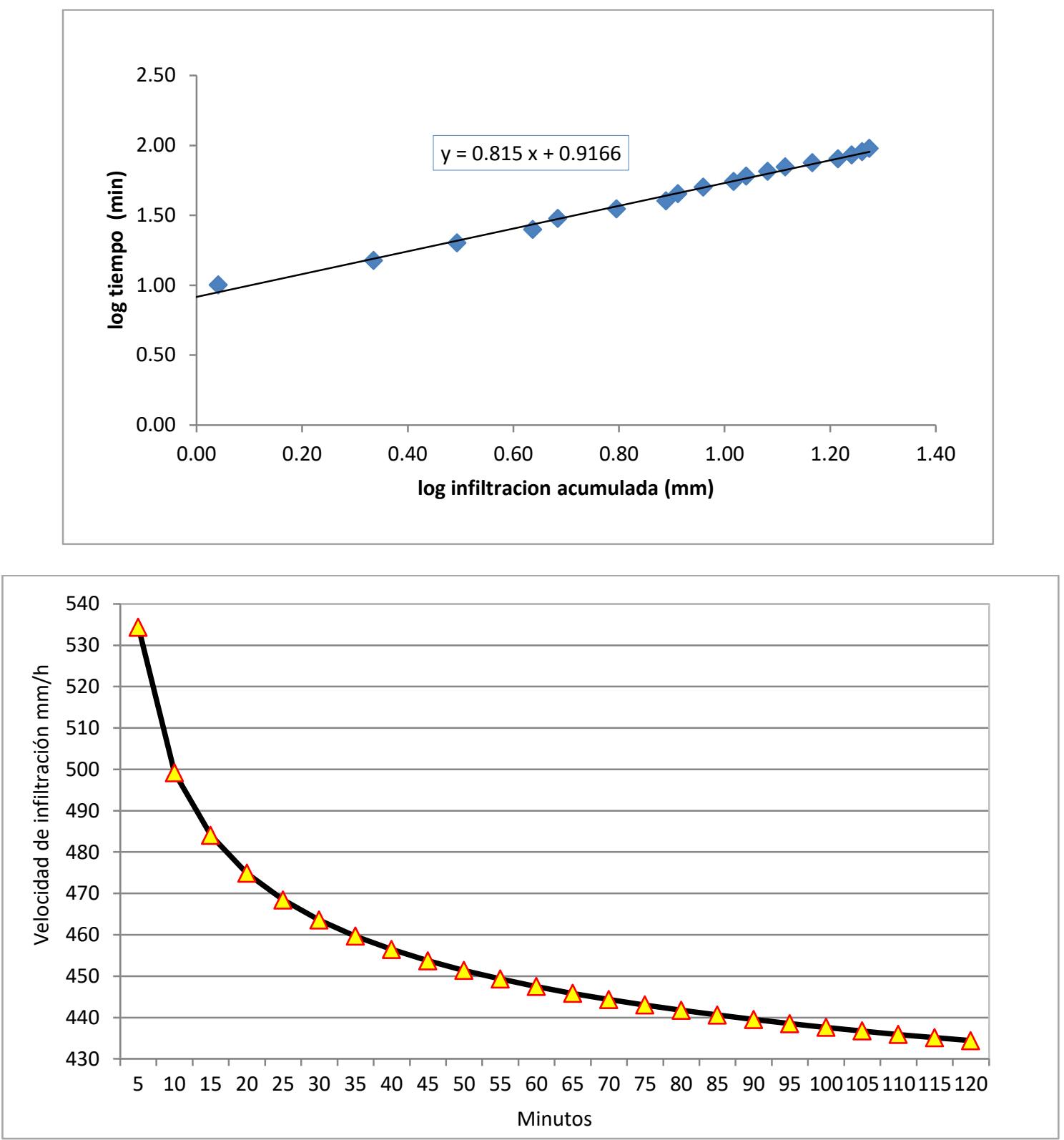
Ensayo realizado en las cercanías del freatímetro MT5.

El sitio ensayado corresponde a la zona de duna activa antropizada.
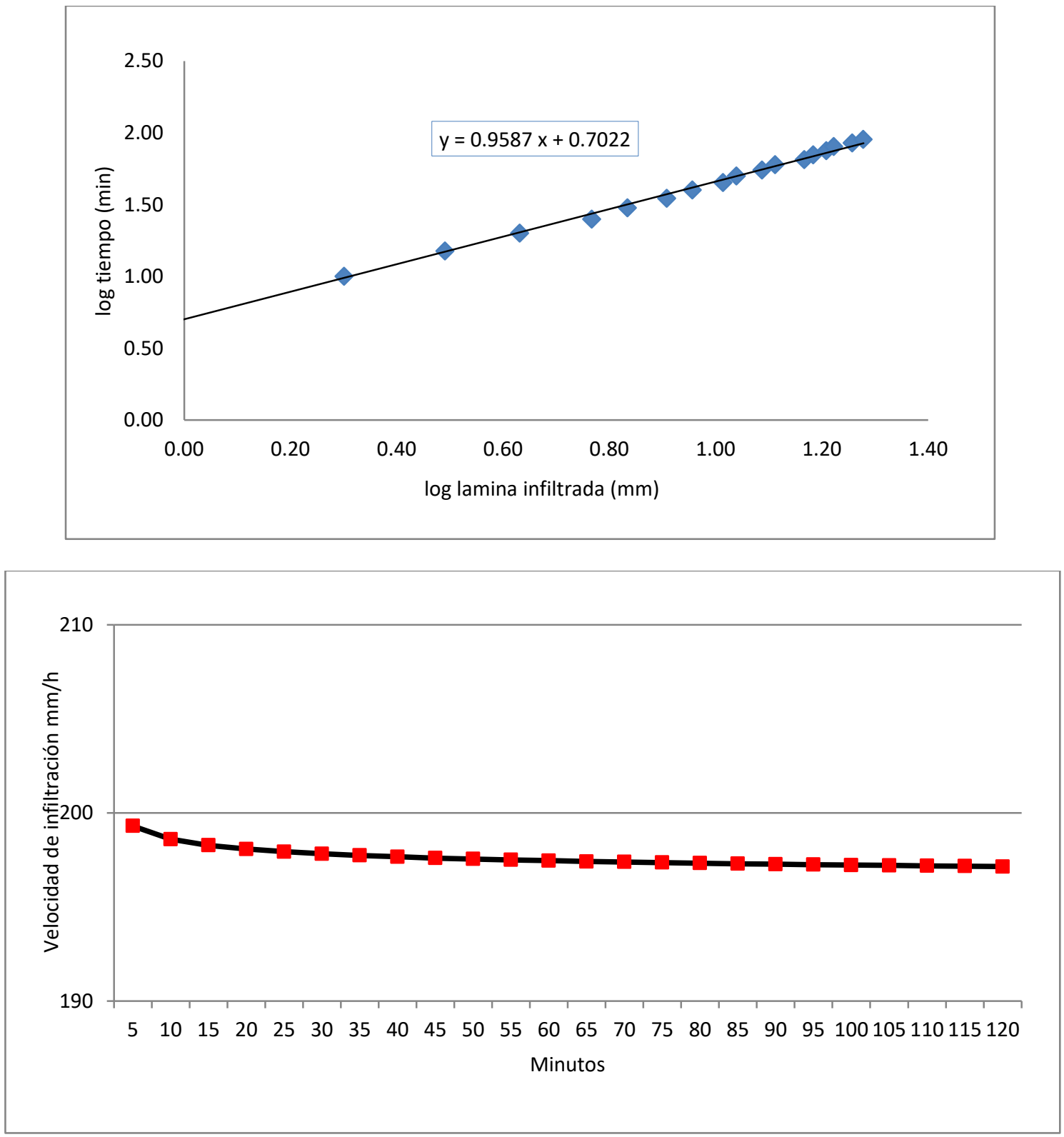
Ensayo realizado en las cercanías del freatímetro MT6.

El sitio ensayado corresponde a la zona de duna semiactiva urbanizada.
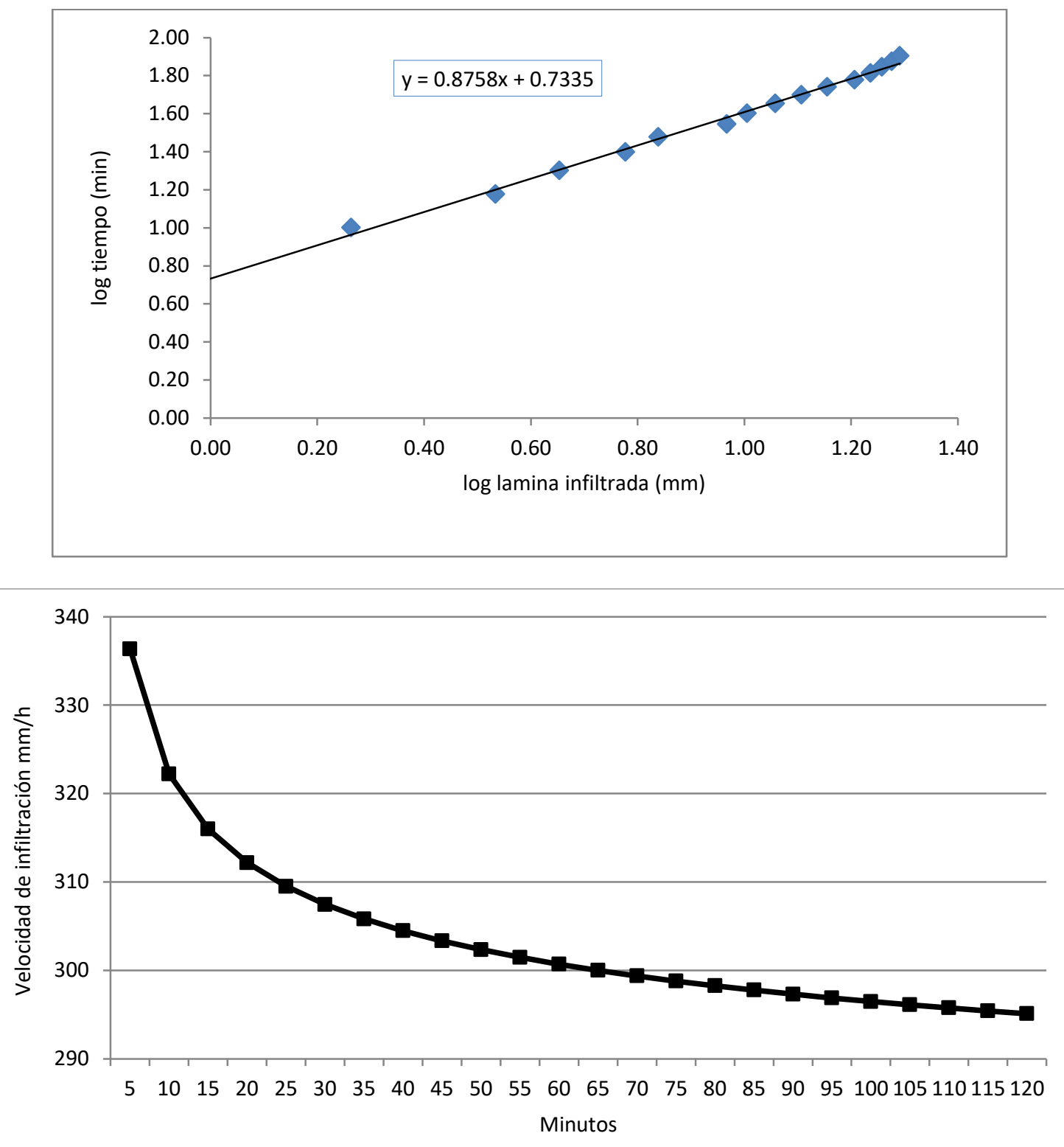
Ensayo realizado en las cercanías del freatímetro MT11.

El sitio ensayado corresponde a la zona de duna semiactiva urbanizada.
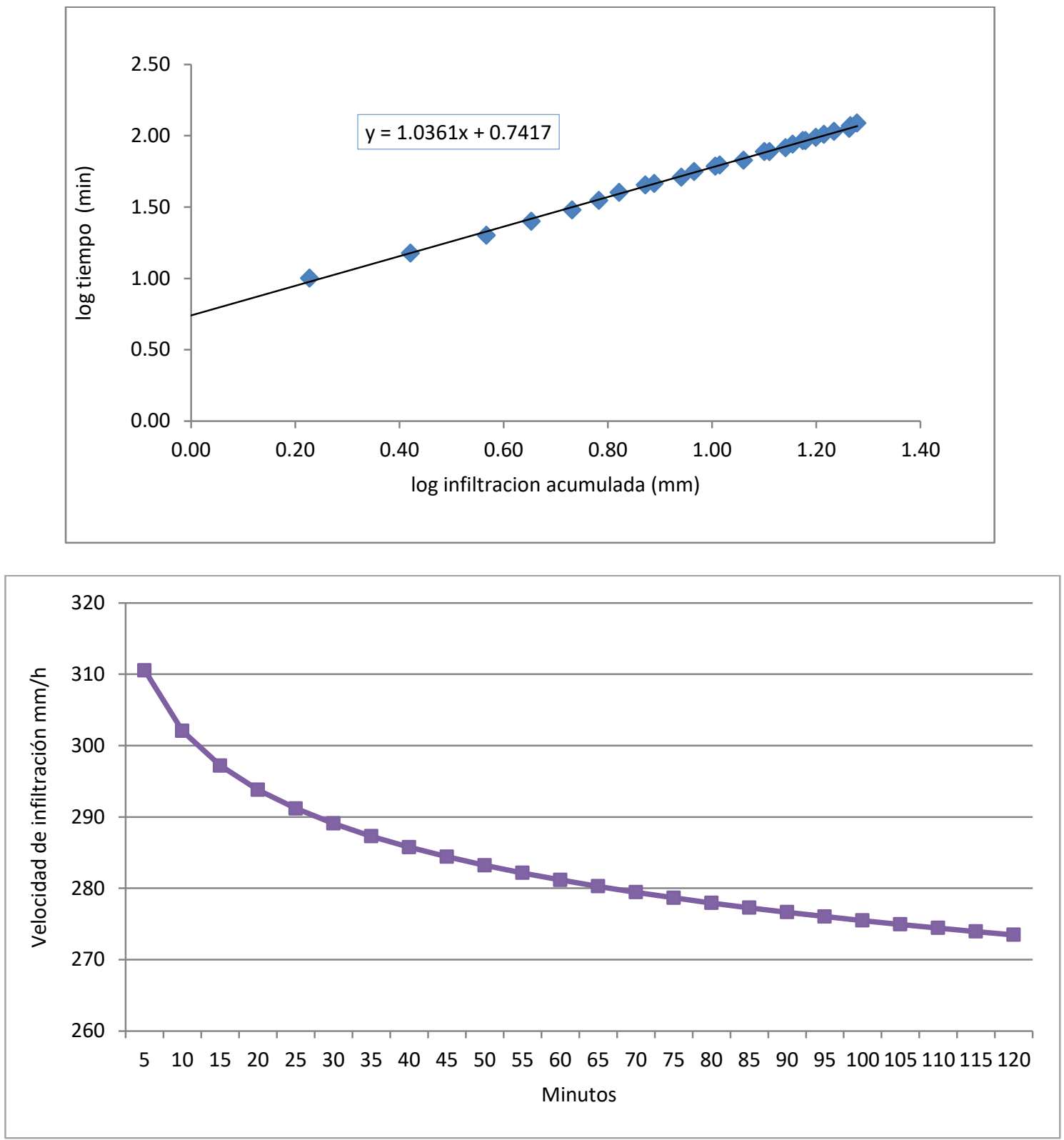
Ensayo realizado en las cercanías del freatímetro MT7.

El sitio ensayado corresponde al sector de campo de dunas inactivo.
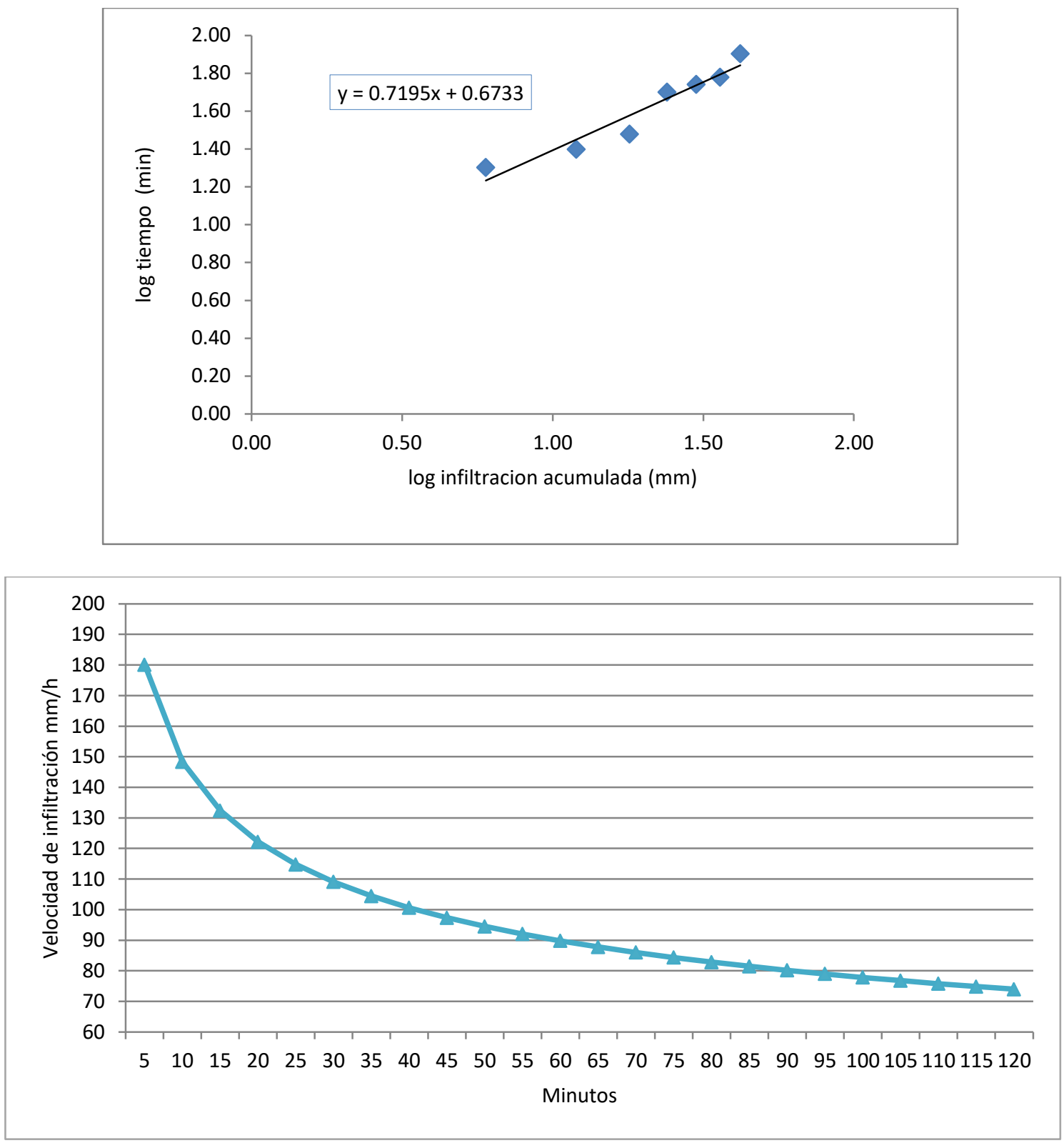
Ensayo realizado en las cercanías del freatímetro MT10.

El sitio ensayado corresponde al sector de campo de dunas inactivo.
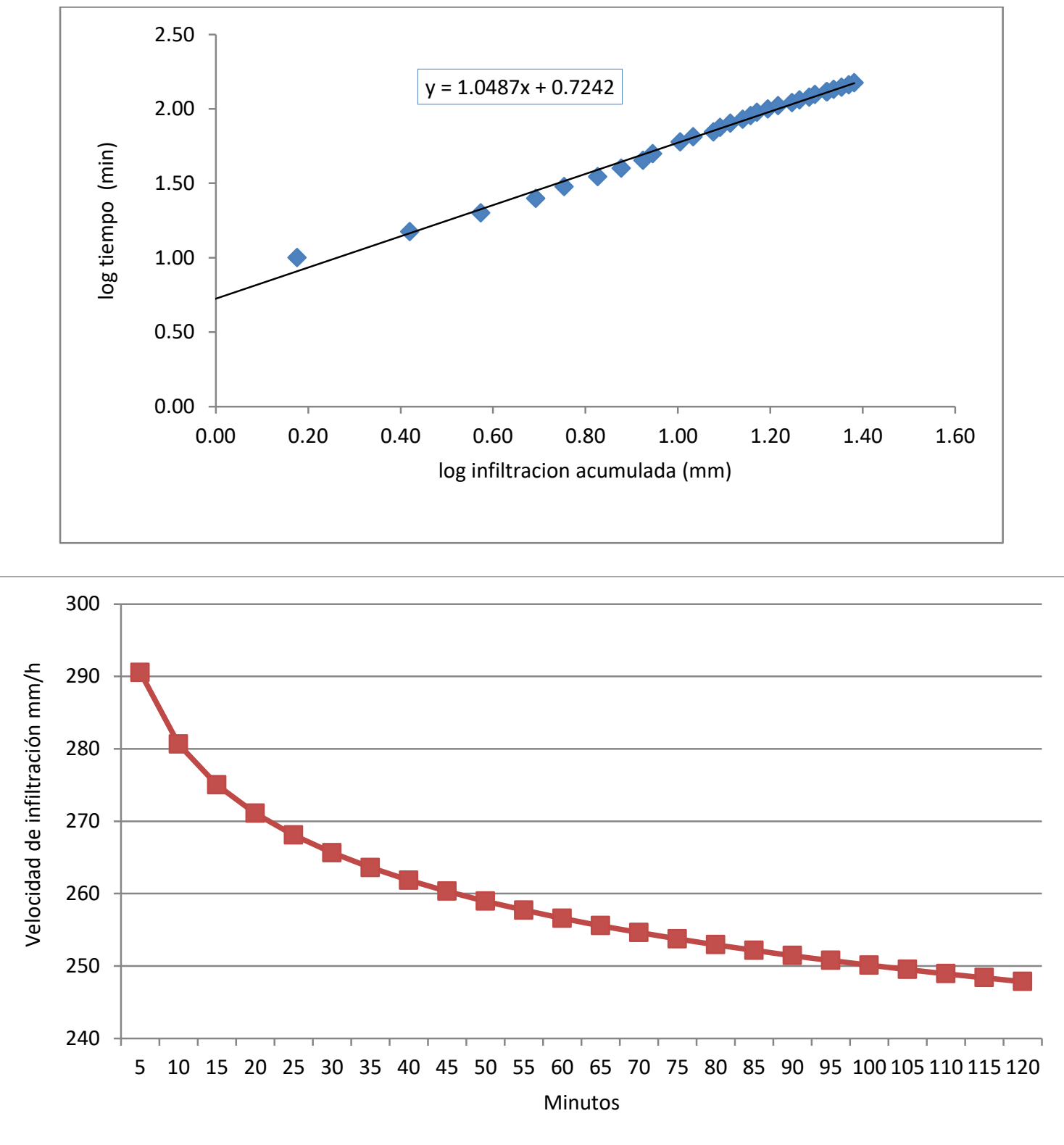


\section{Anexo 5}

Mapas de flujo de

Costa marítima

(Mar del Tuyú)

2016-2018 


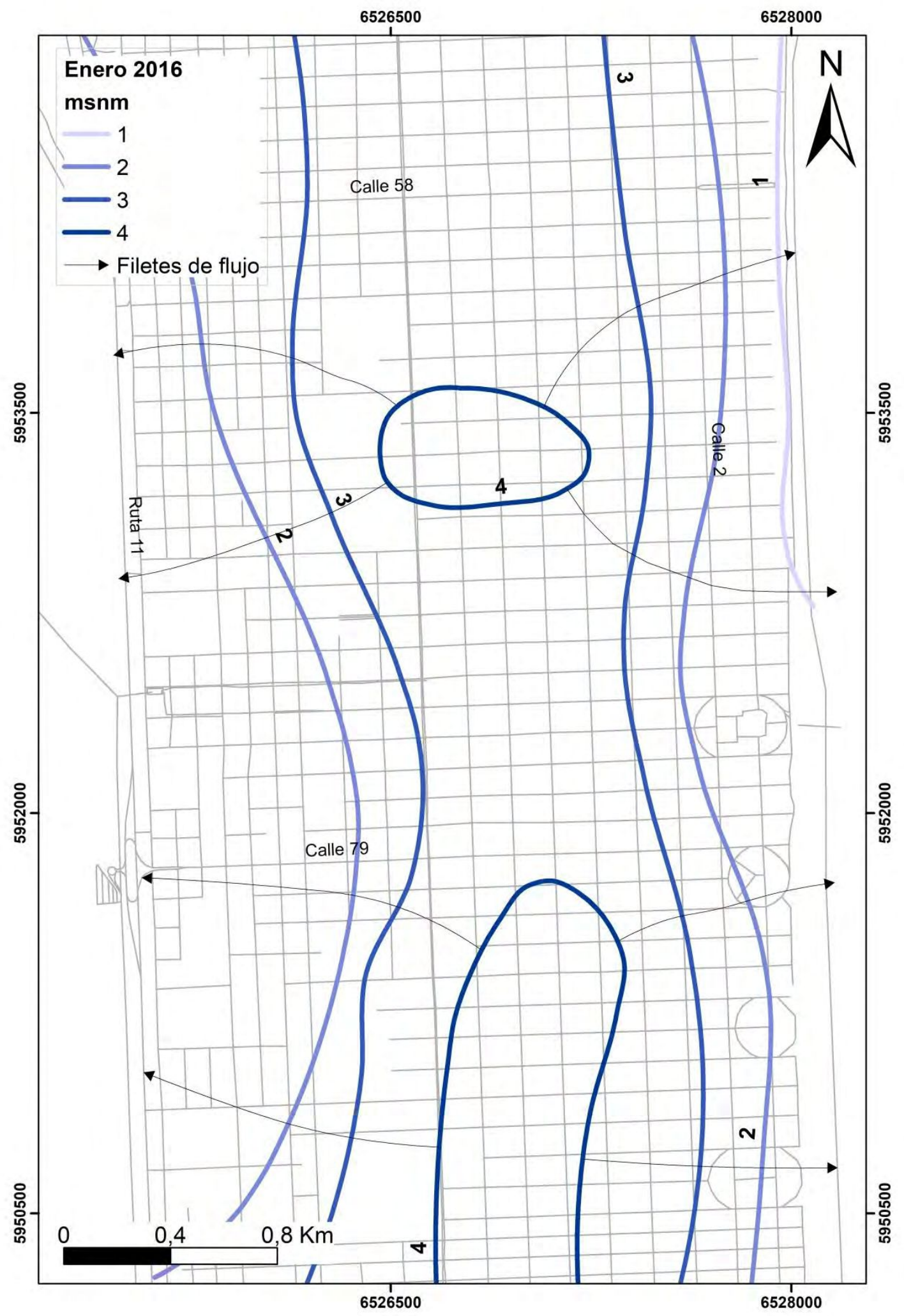

Figura 1. Mapa isofreático para enero de 2016. 


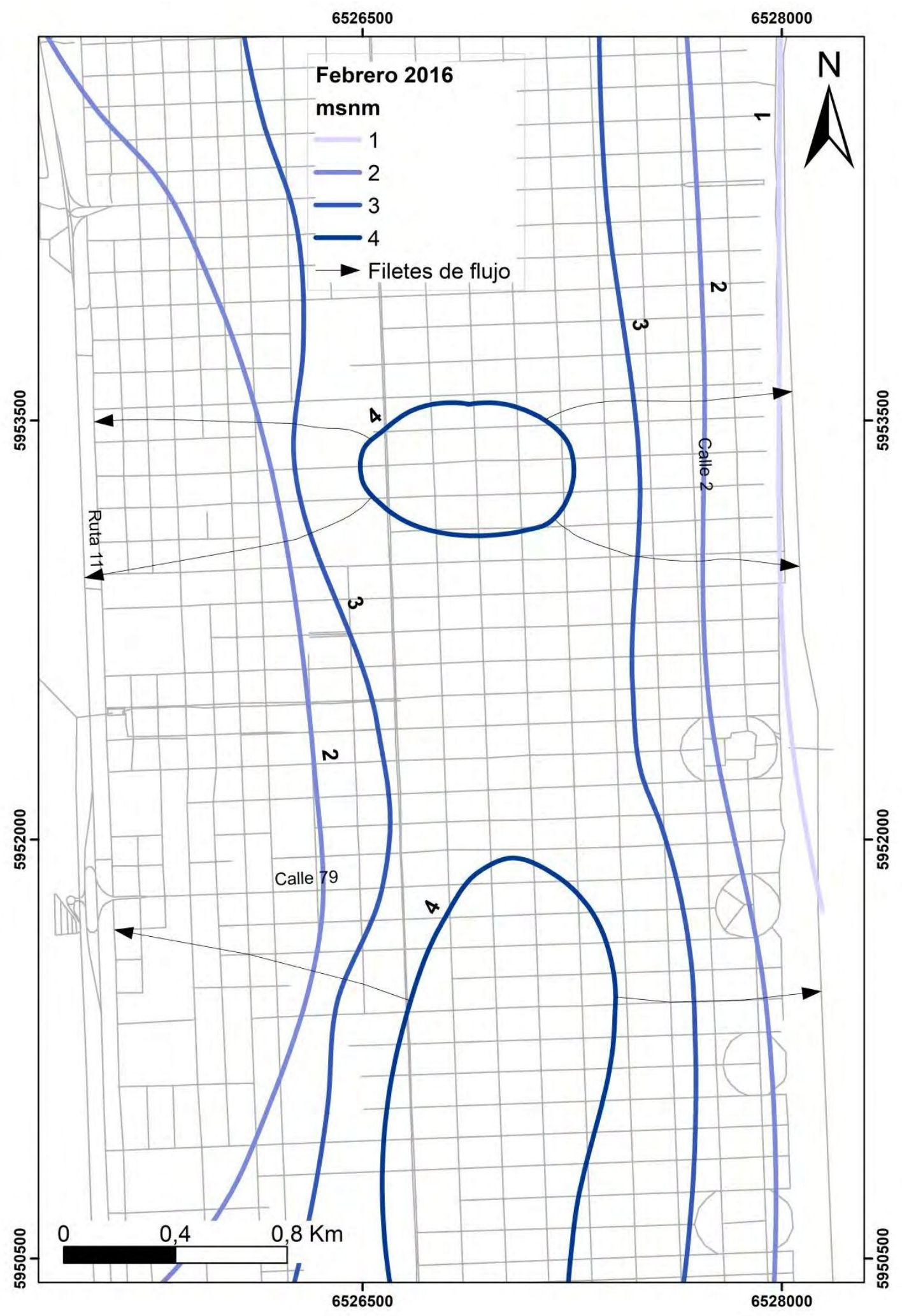

Figura 2. Mapa isofreático para febrero de 2016. 


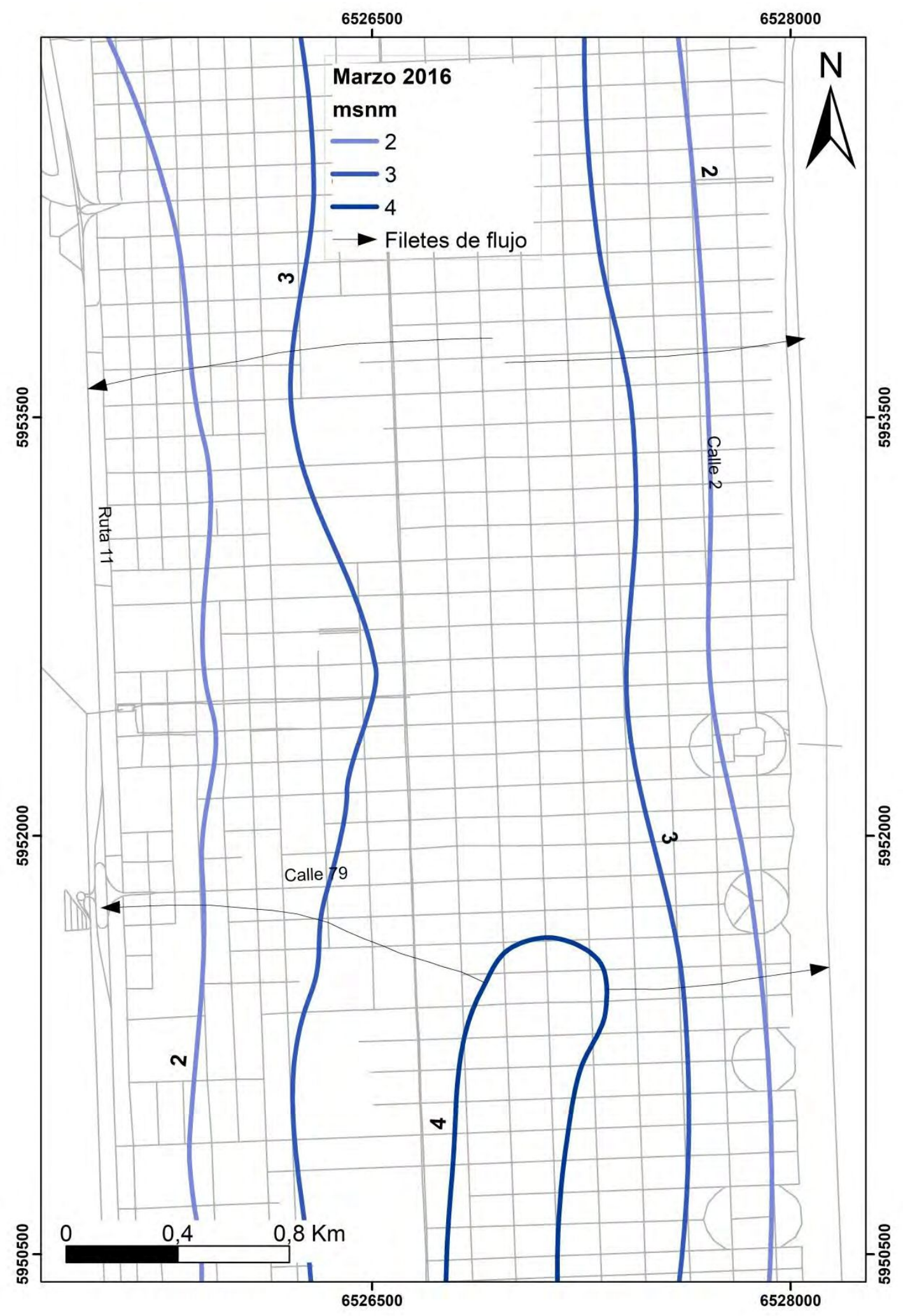

Figura 3. Mapa isofreático para marzo de 2016. 


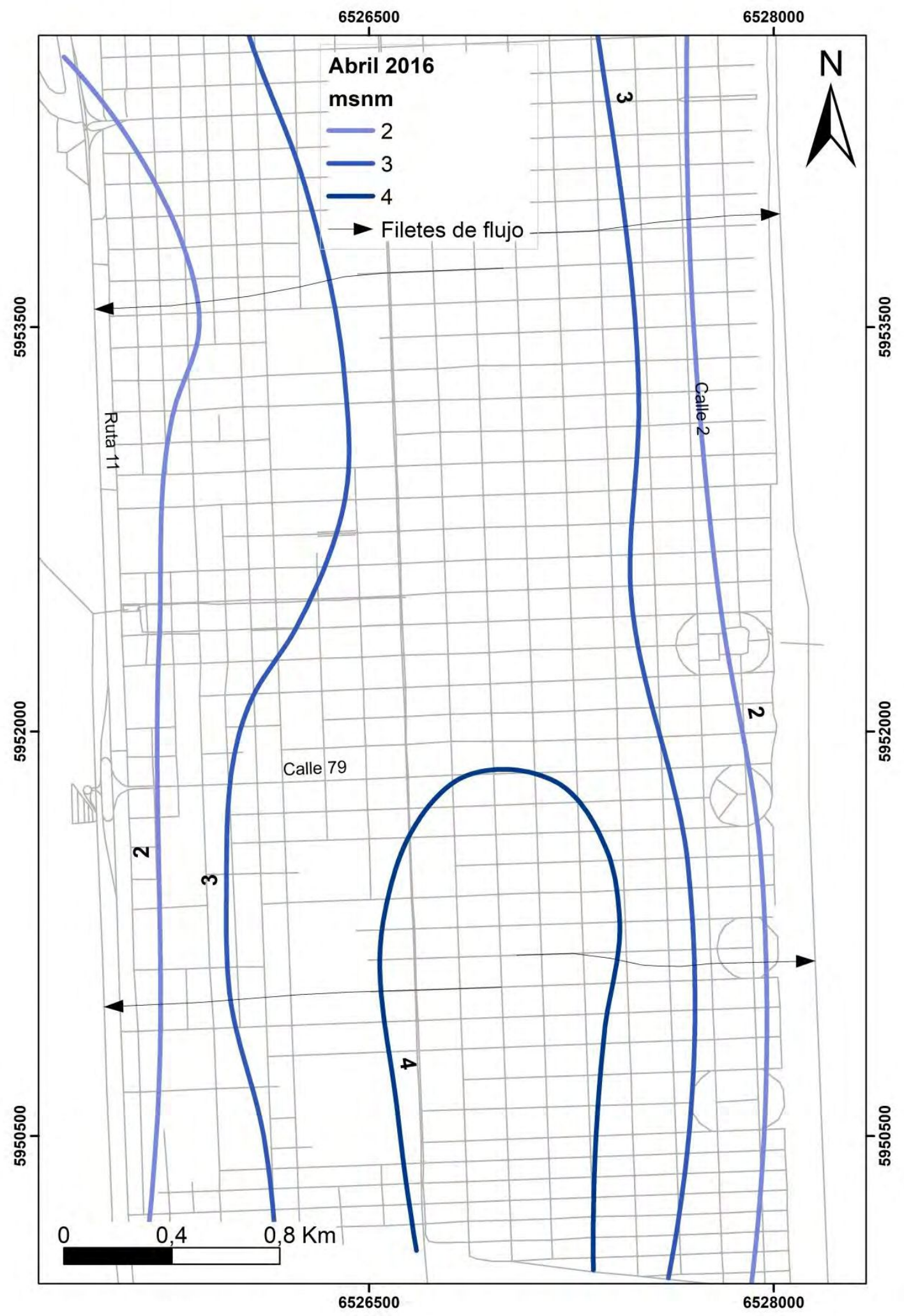

Figura 4. Mapa isofreático para abril de 2016. 


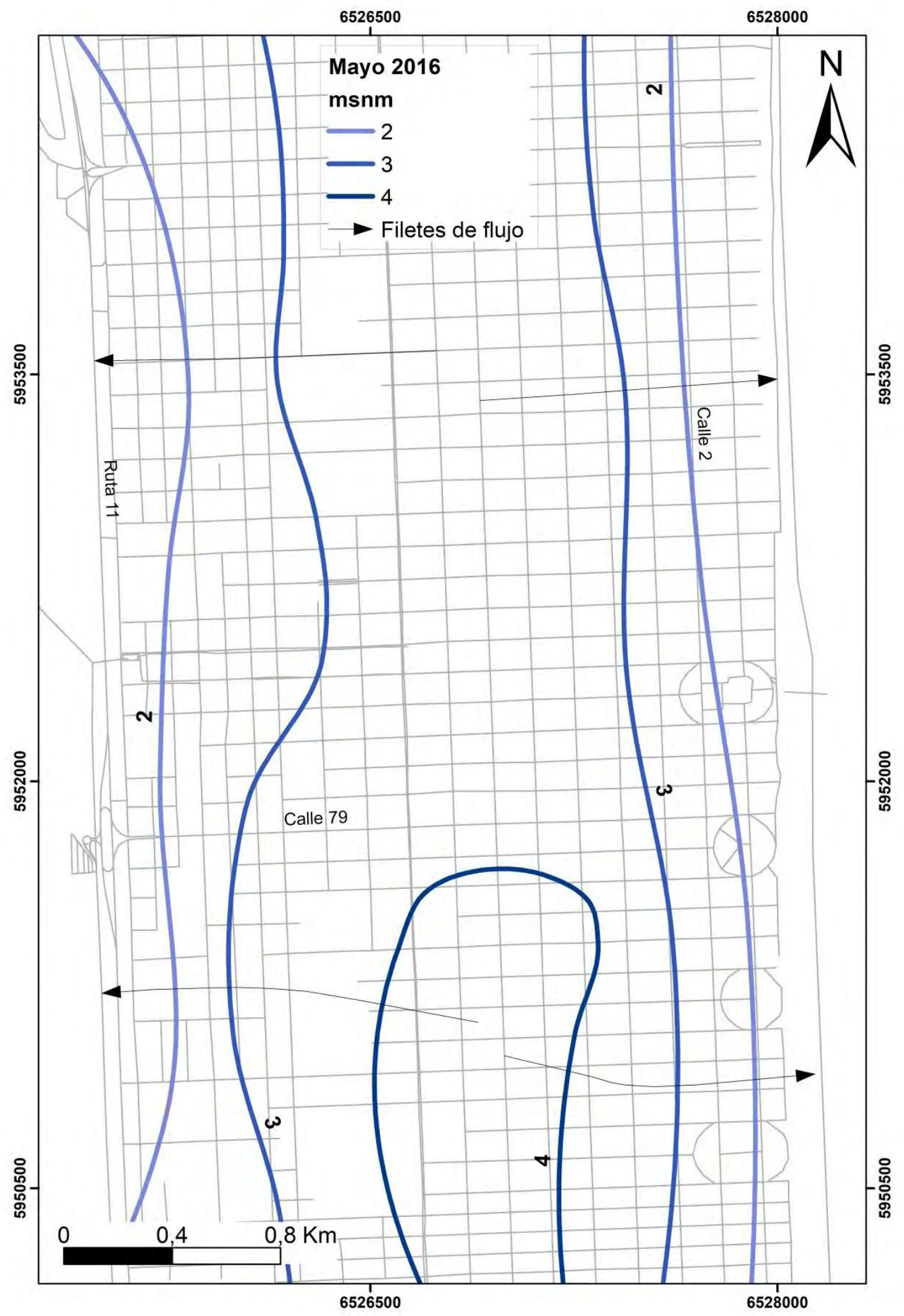

Figura 5. Mapa isofreático para mayo de 2016. 


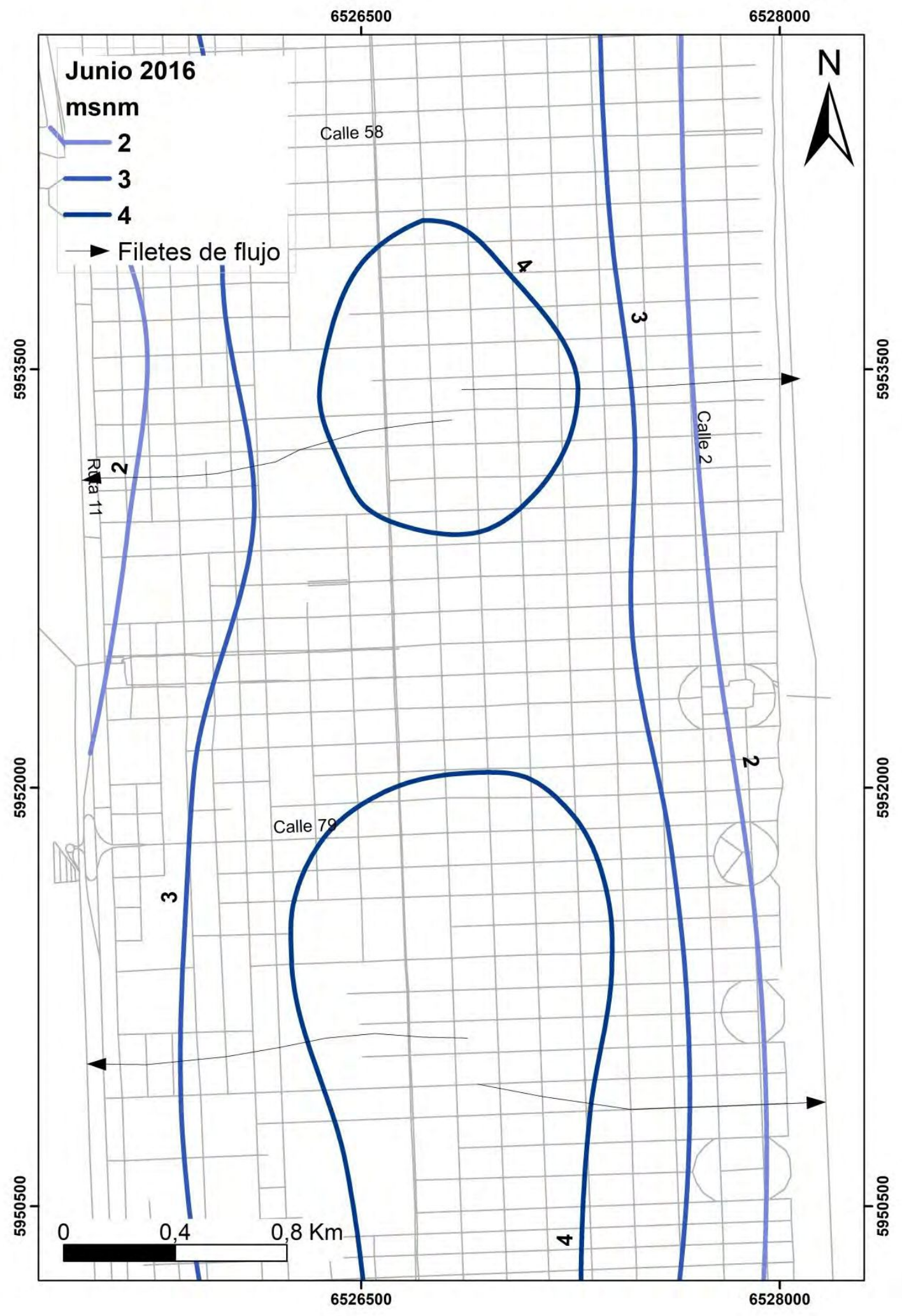

Figura 6. Mapa isofreático para junio de 2016. 


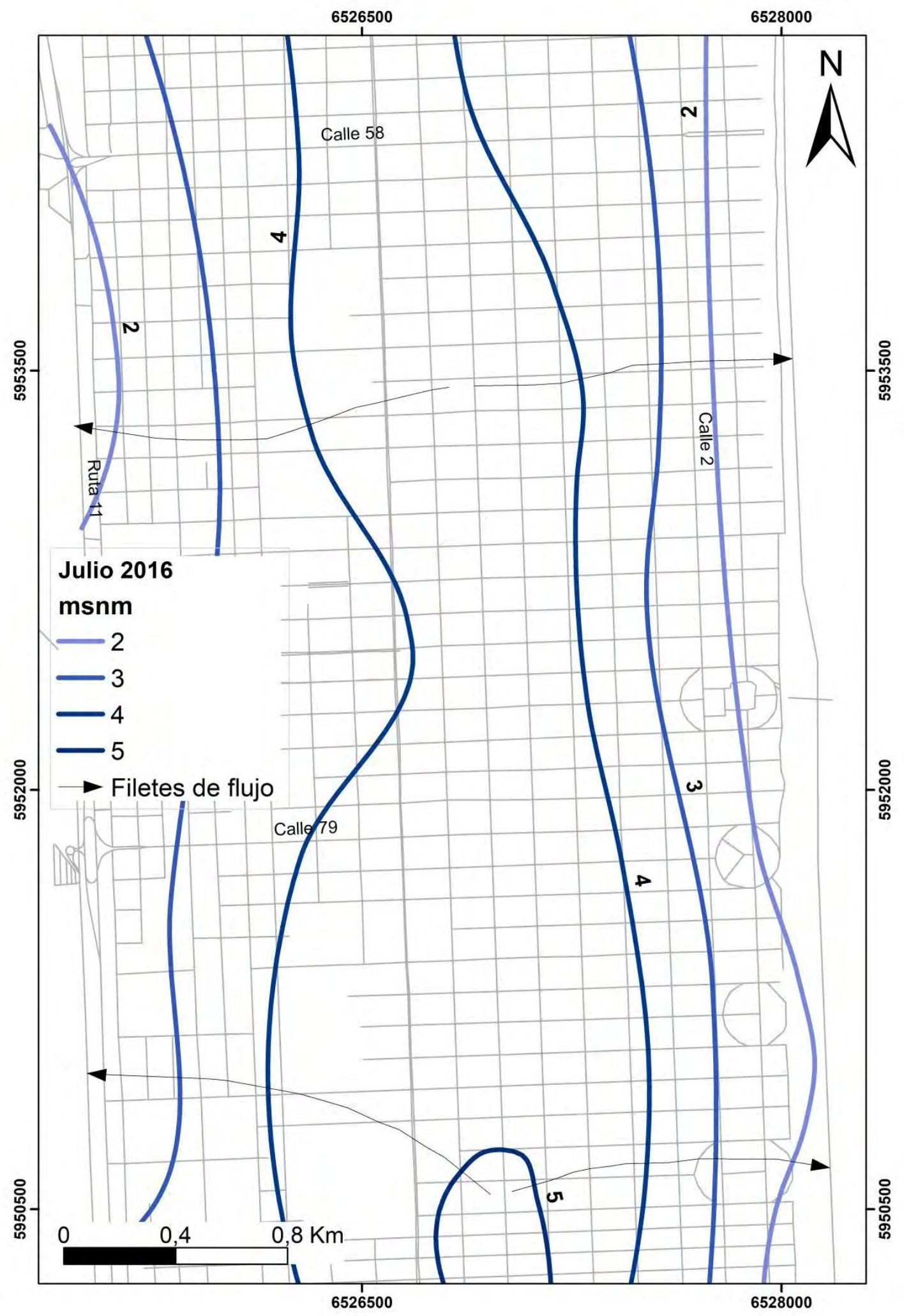

Figura 7. Mapa isofreático para julio de 2016. 


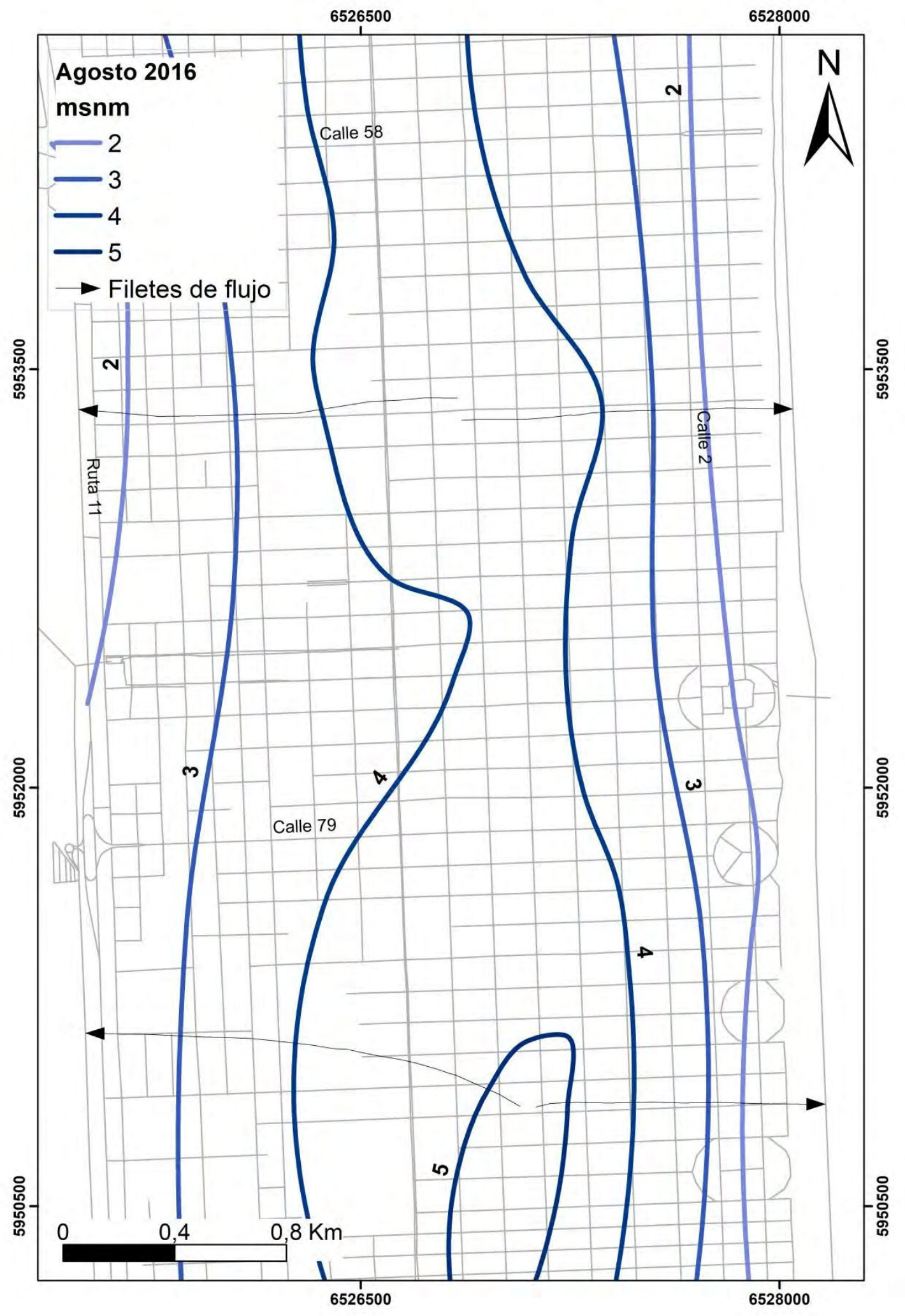

Figura 8. Mapa isofreático para agosto de 2016. 


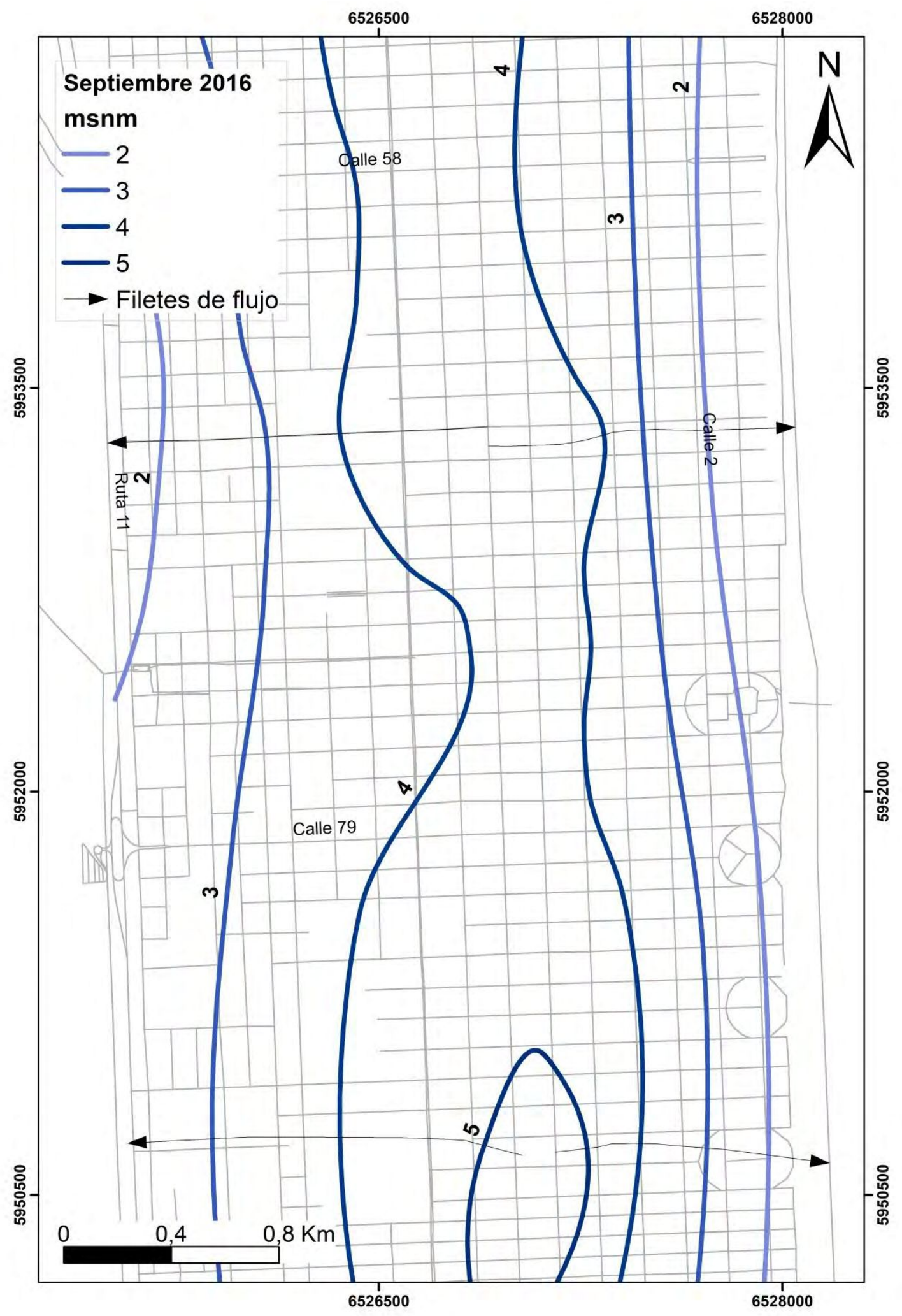

Figura 9. Mapa isofreático para septiembre de 2016. 


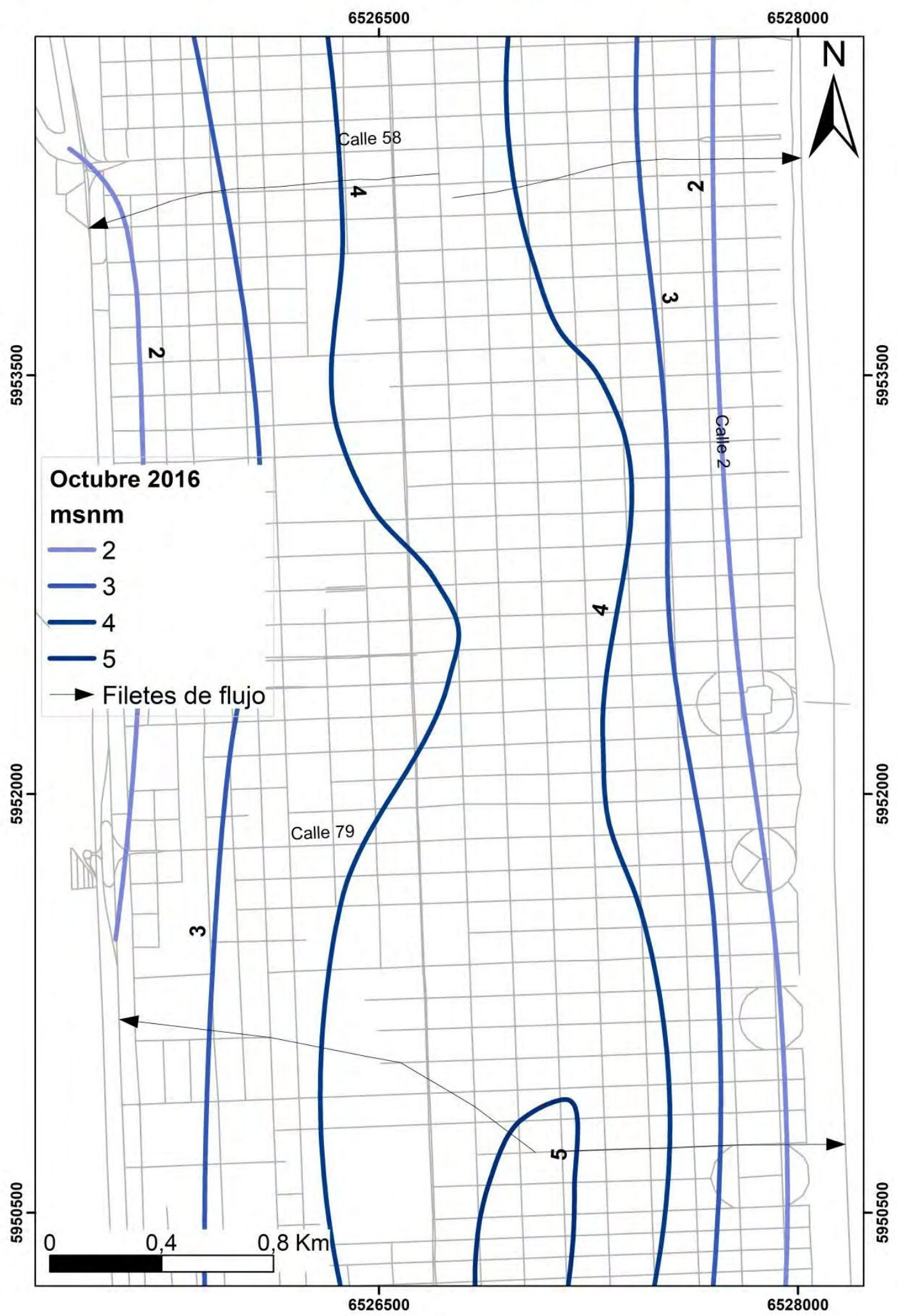

Figura 10. Mapa isofreático para octubre de 2016. 


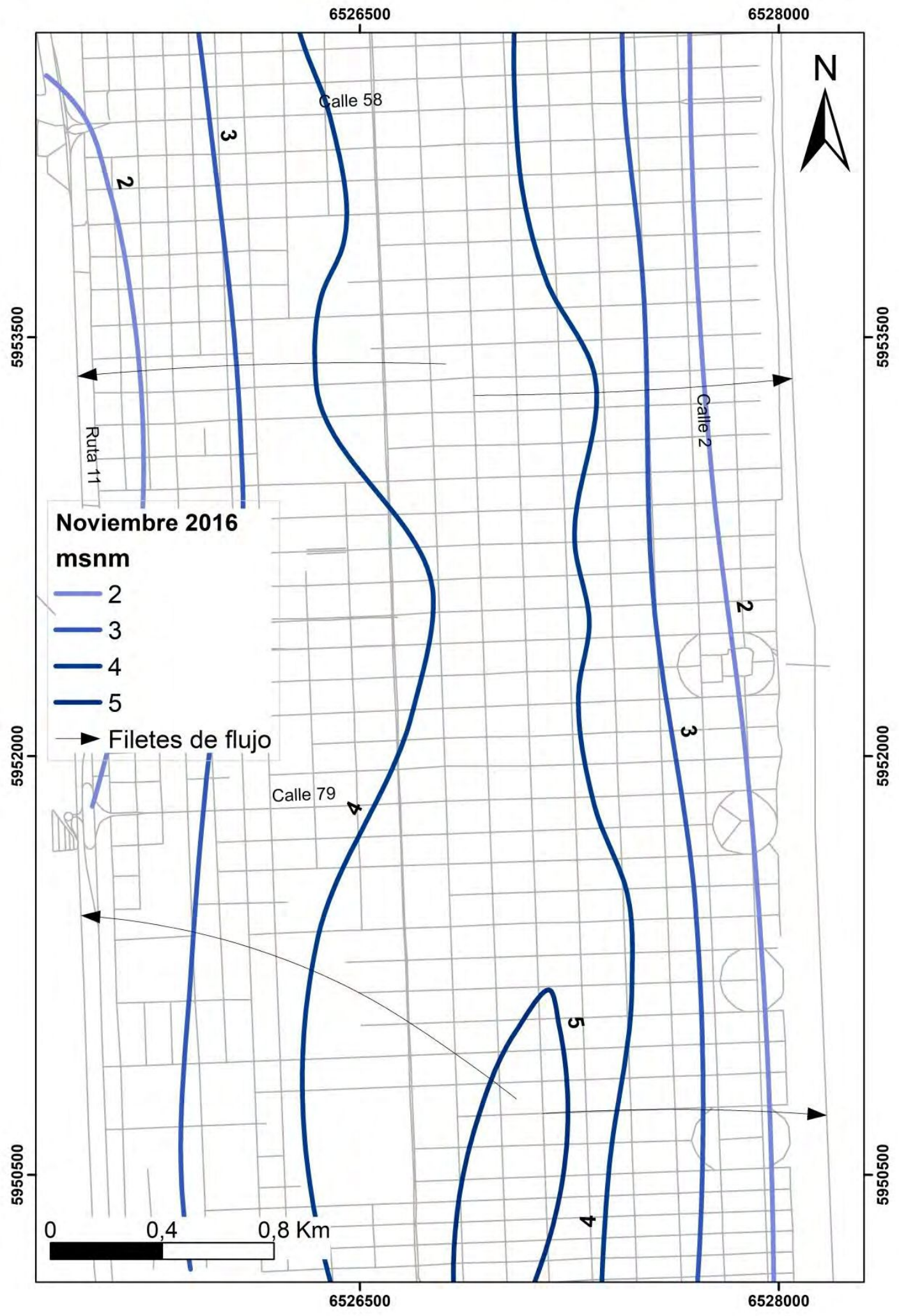

Figura 11. Mapa isofreático para noviembre de 2016. 


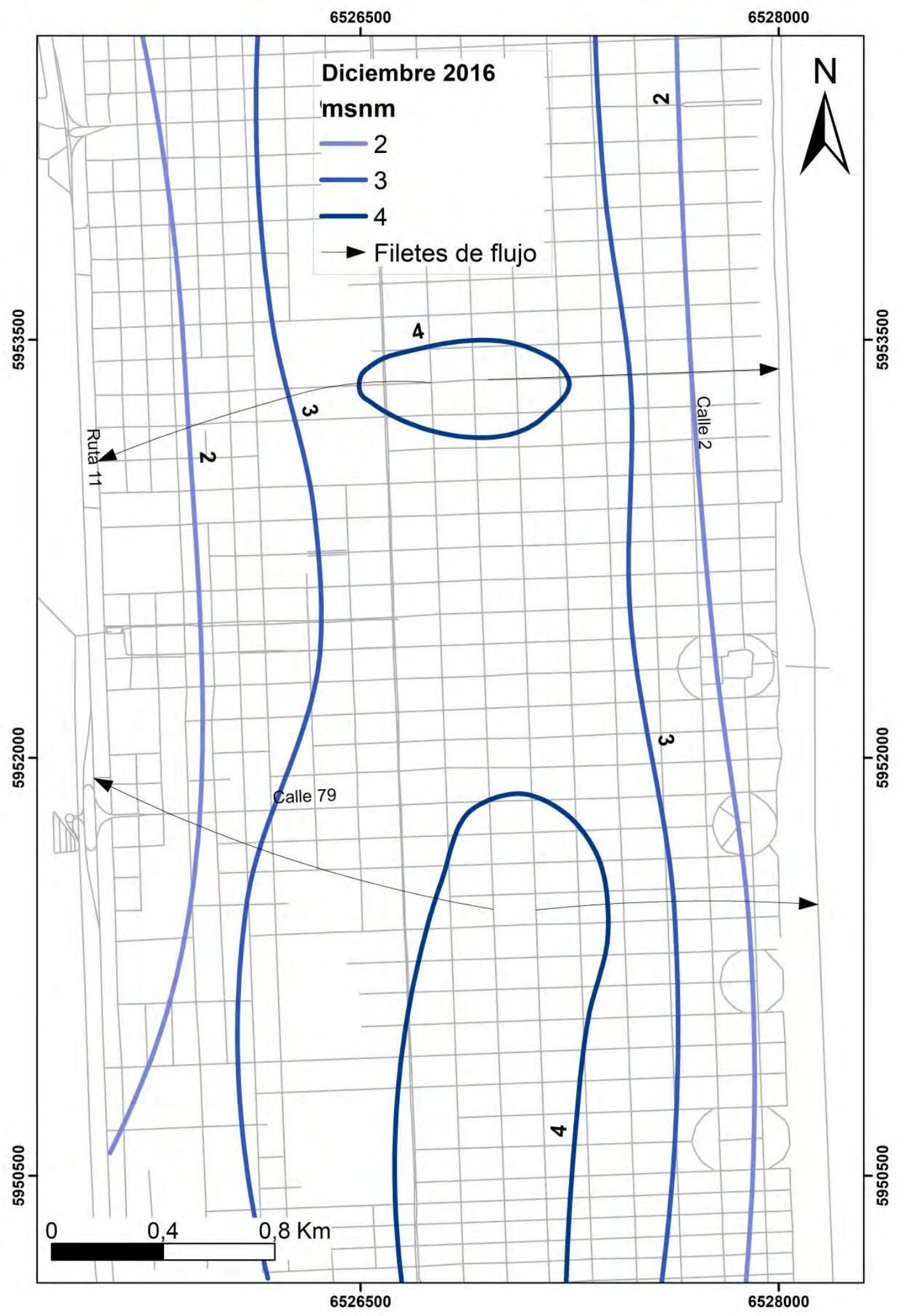

Figura 12. Mapa isofreático para diciembre de 2016. 


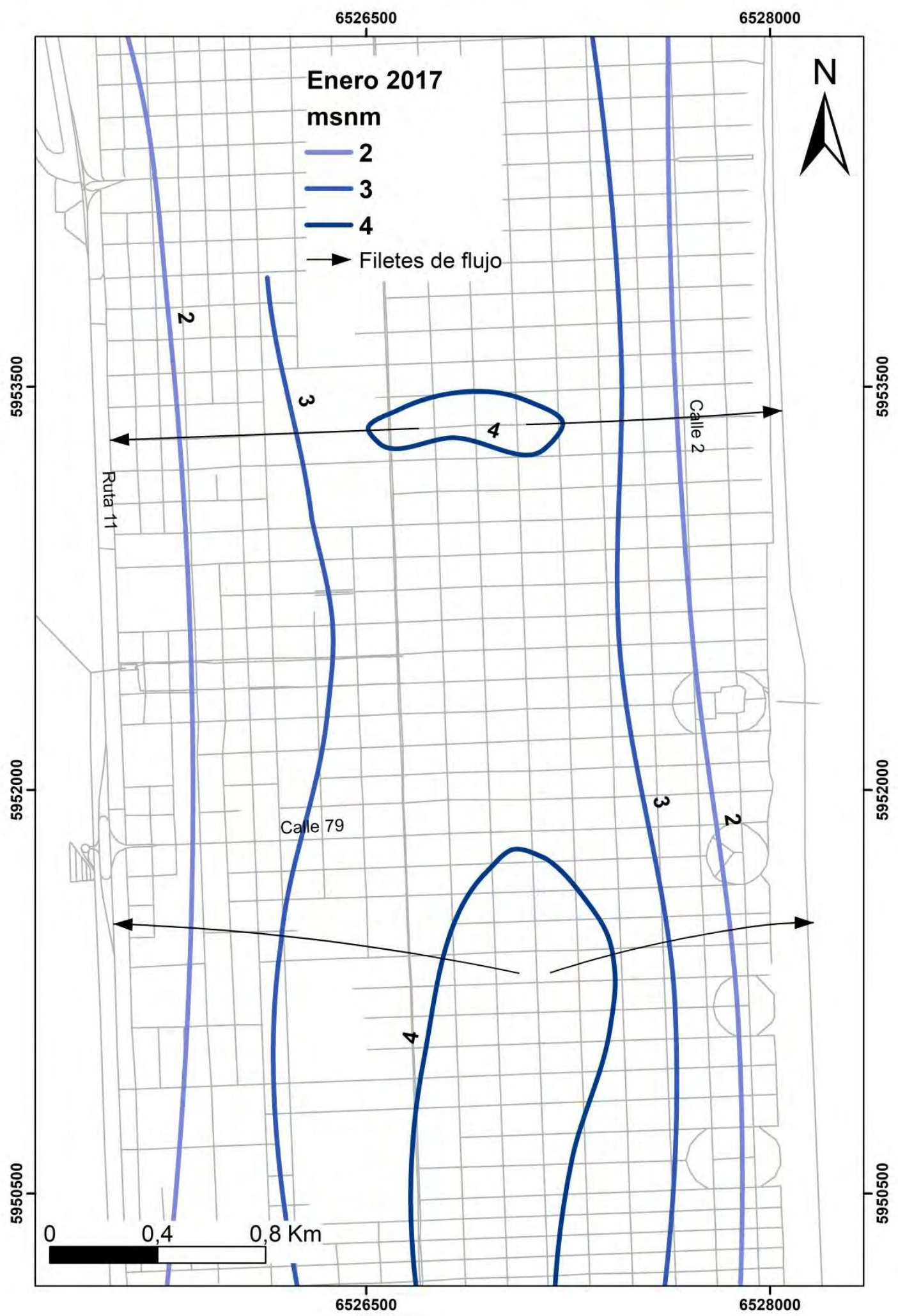

Figura 13. Mapa isofreático para enero de 2017. 


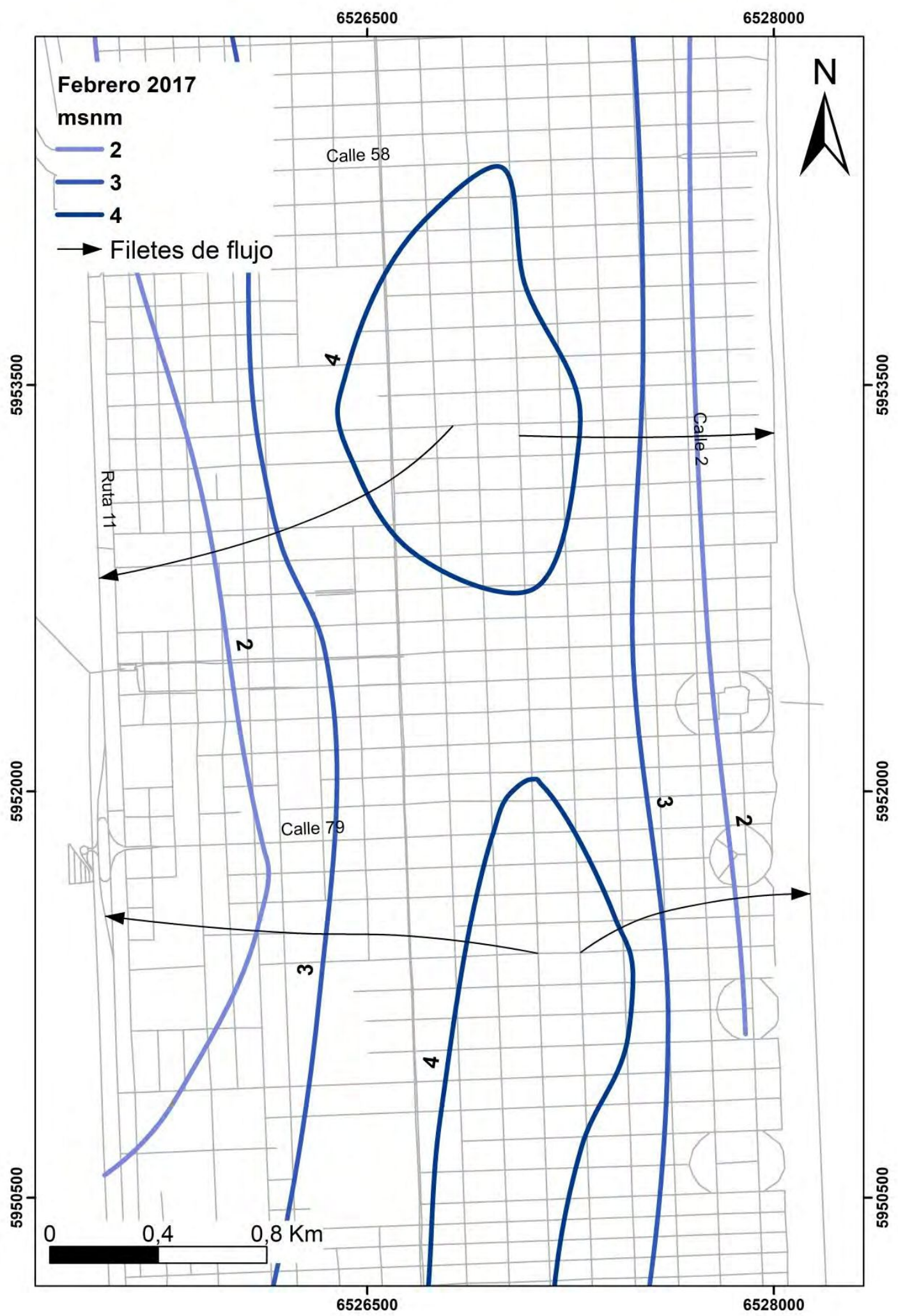

Figura 14. Mapa isofreático para febrero de 2017. 


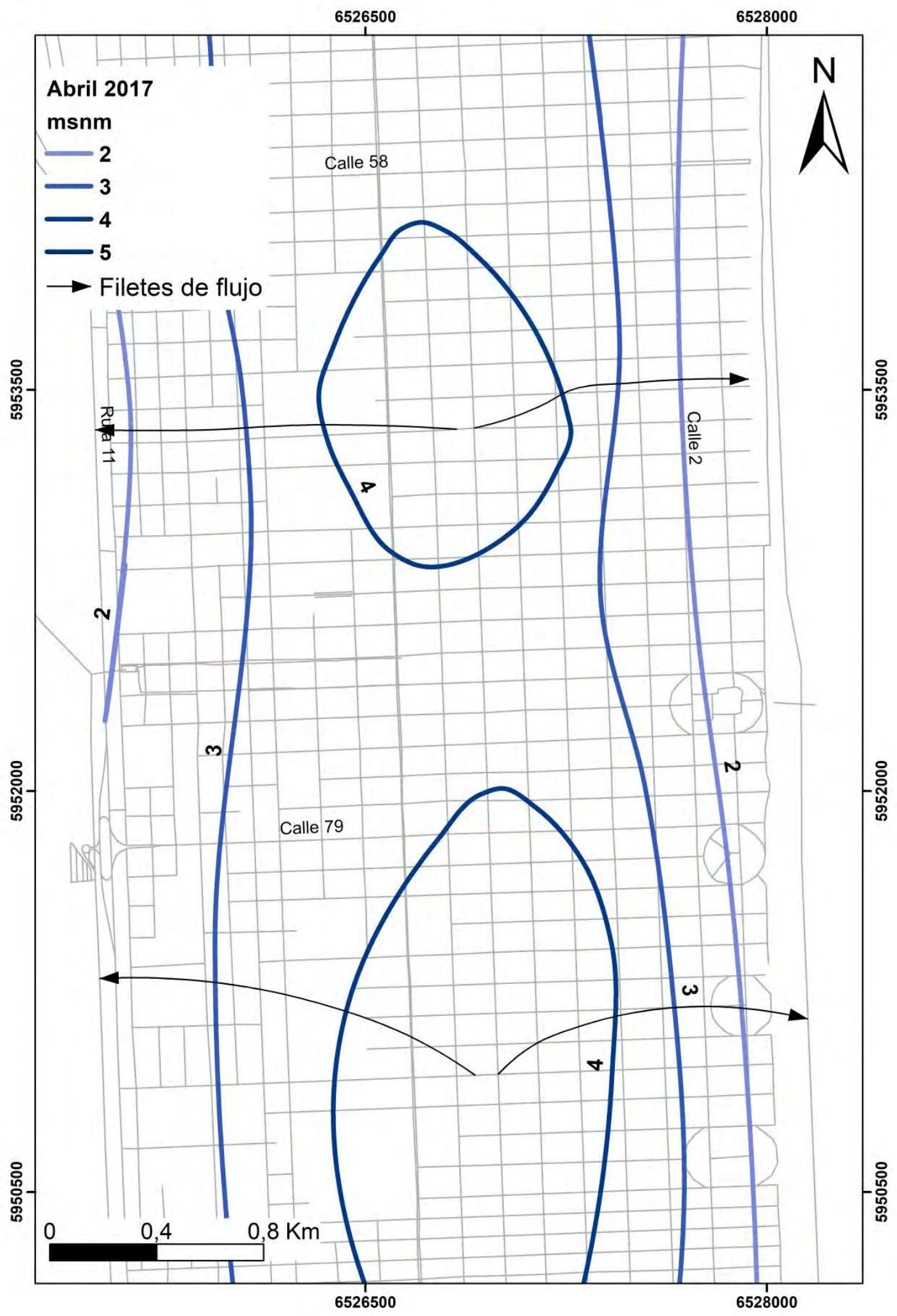

Figura 14. Mapa isofreático para abril de 2017. 


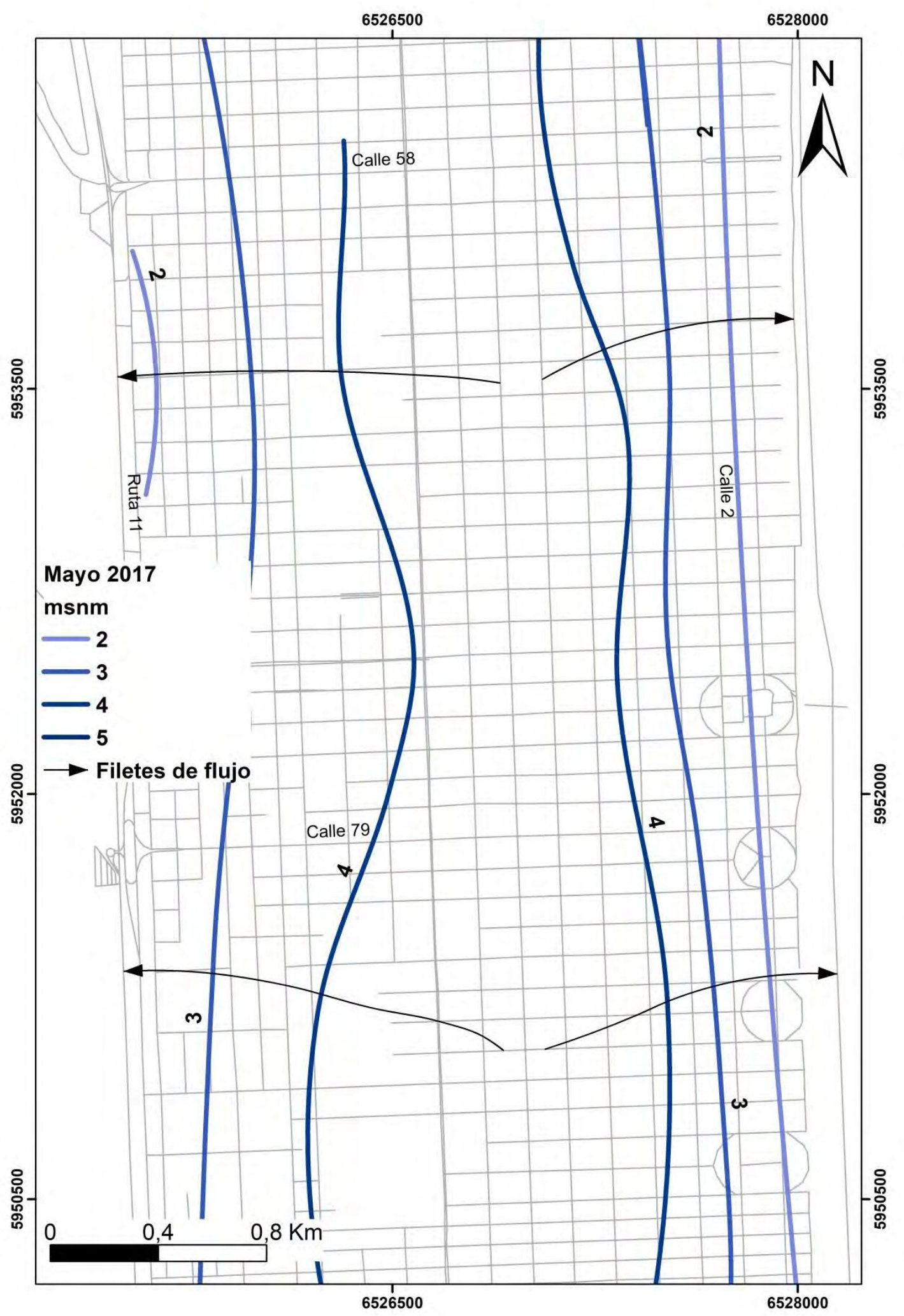

Figura 15. Mapa isofreático para mayo de 2017. 


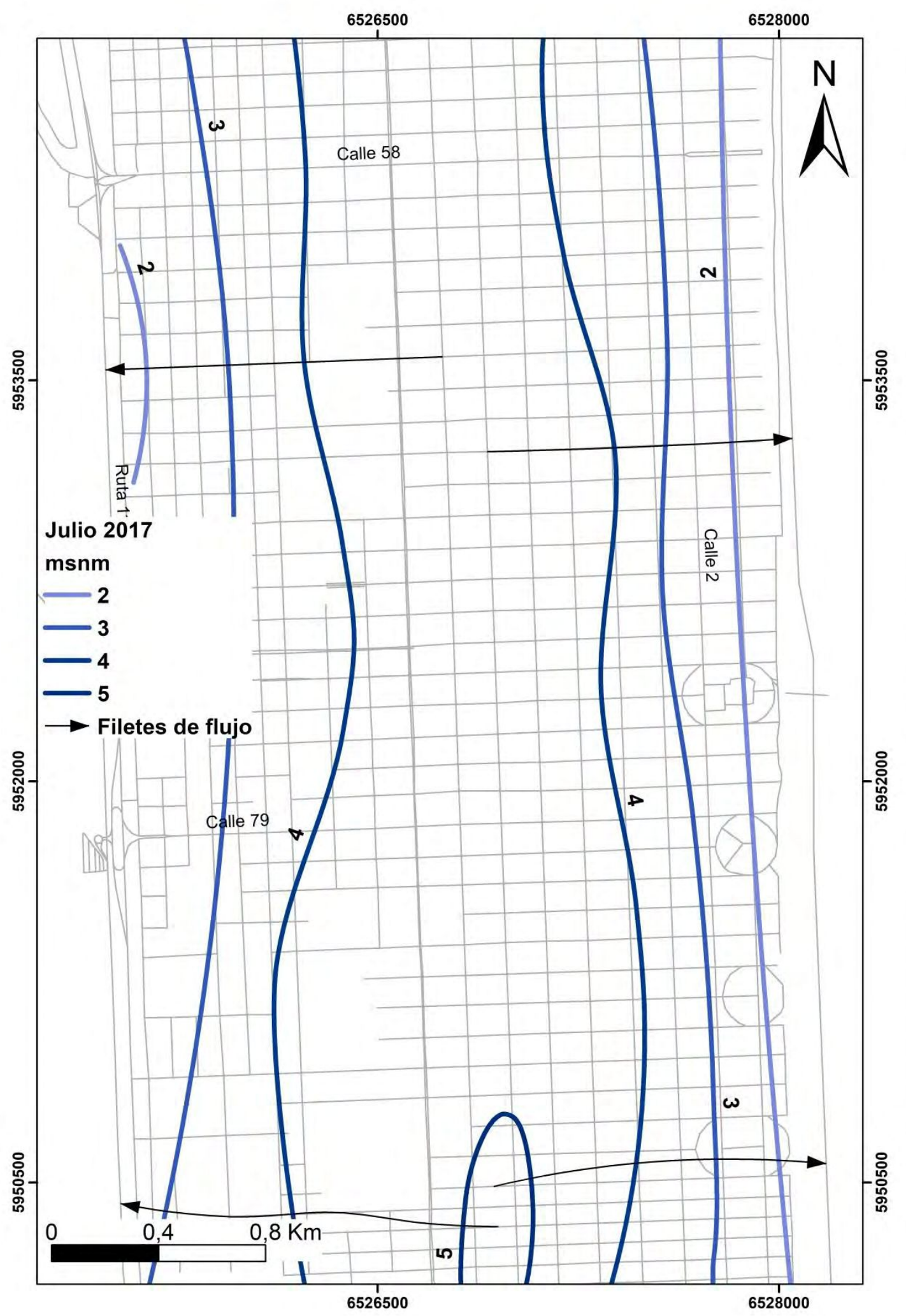

Figura 16. Mapa isofreático para julio de 2017. 


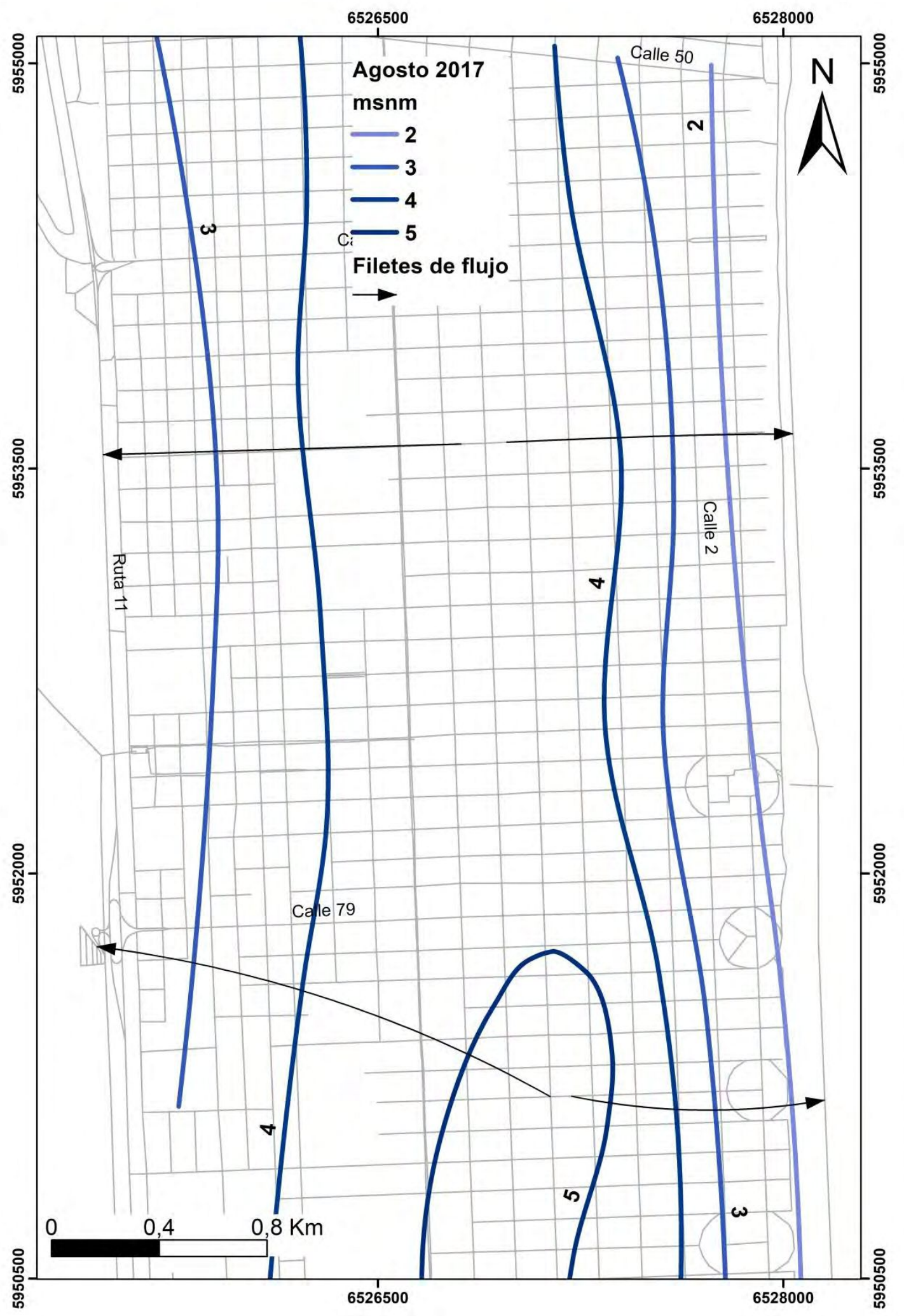

Figura 17. Mapa isofreático para agosto de 2017. 


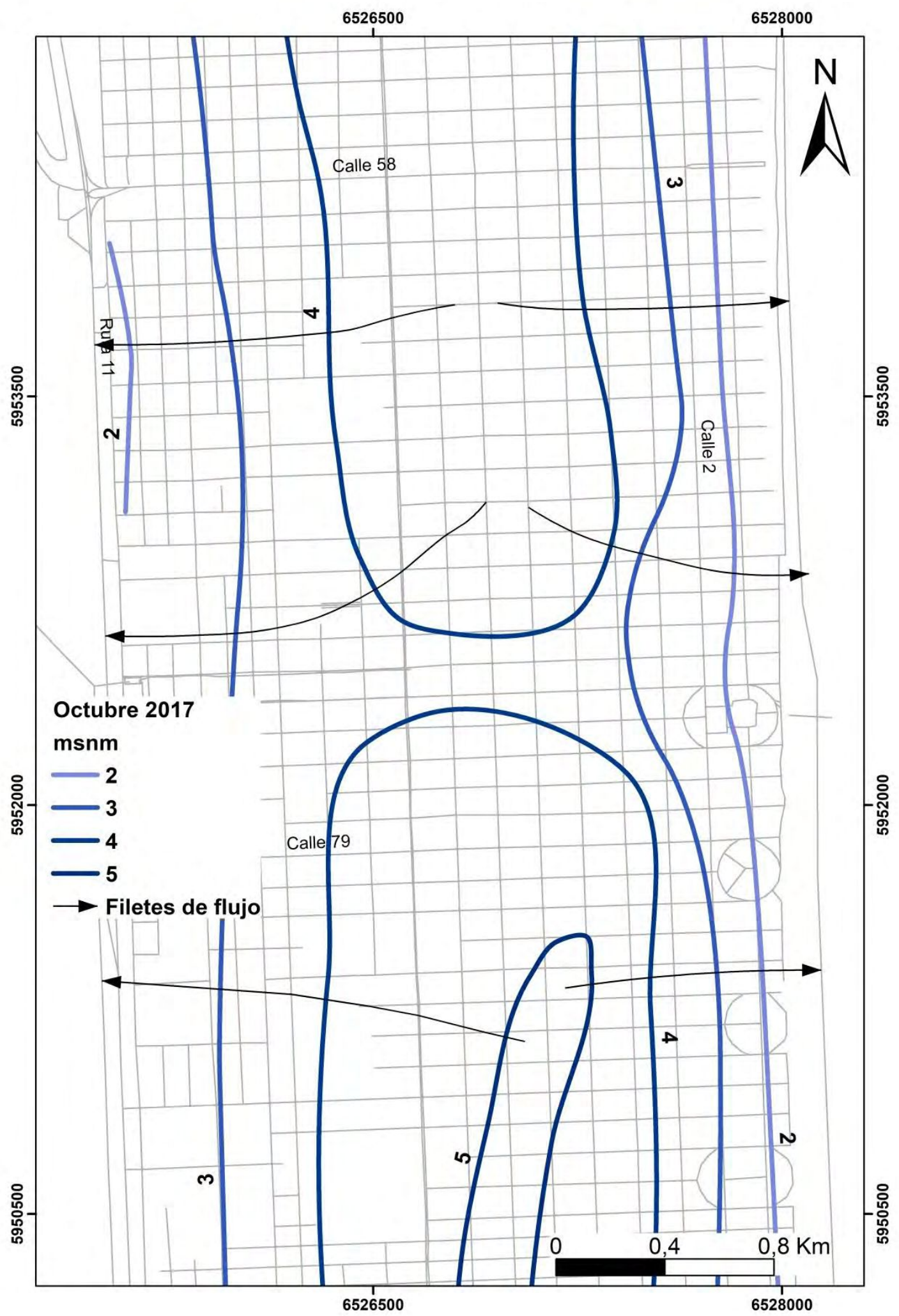

Figura 18. Mapa isofreático para octubre de 2017. 


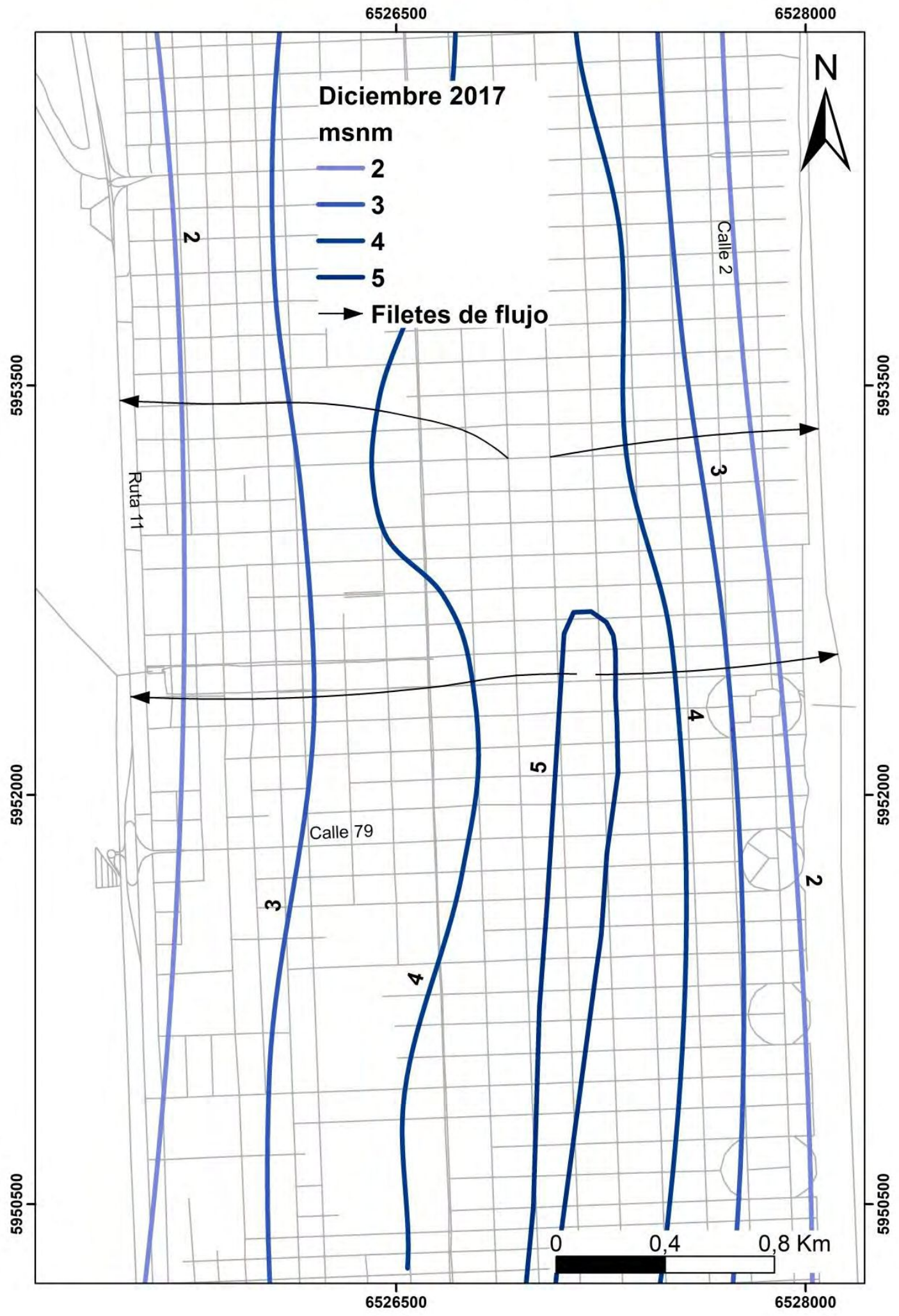

Figura 19. Mapa isofreático para diciembre de 2017. 


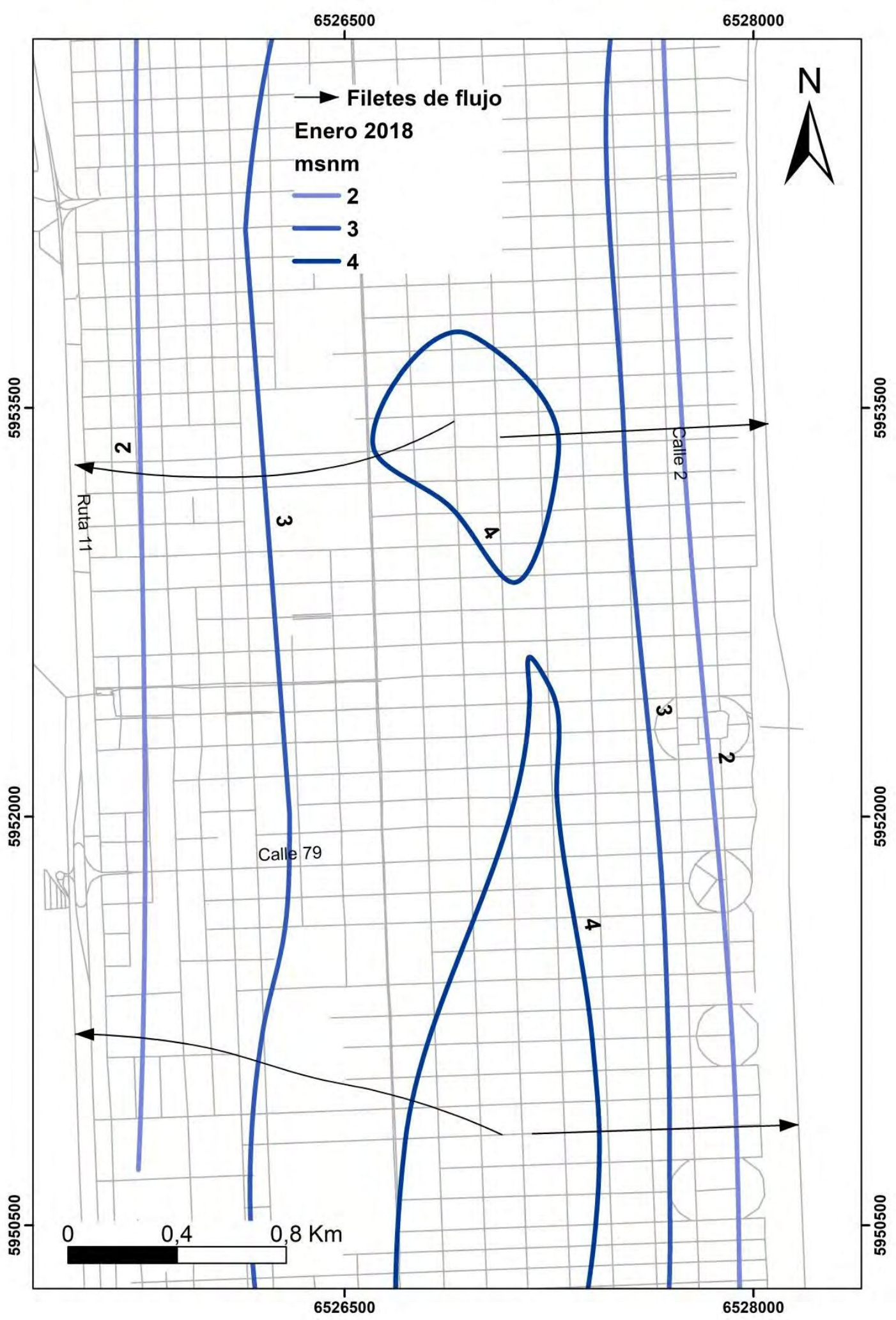

Figura 20. Mapa isofreático para enero de 2018. 


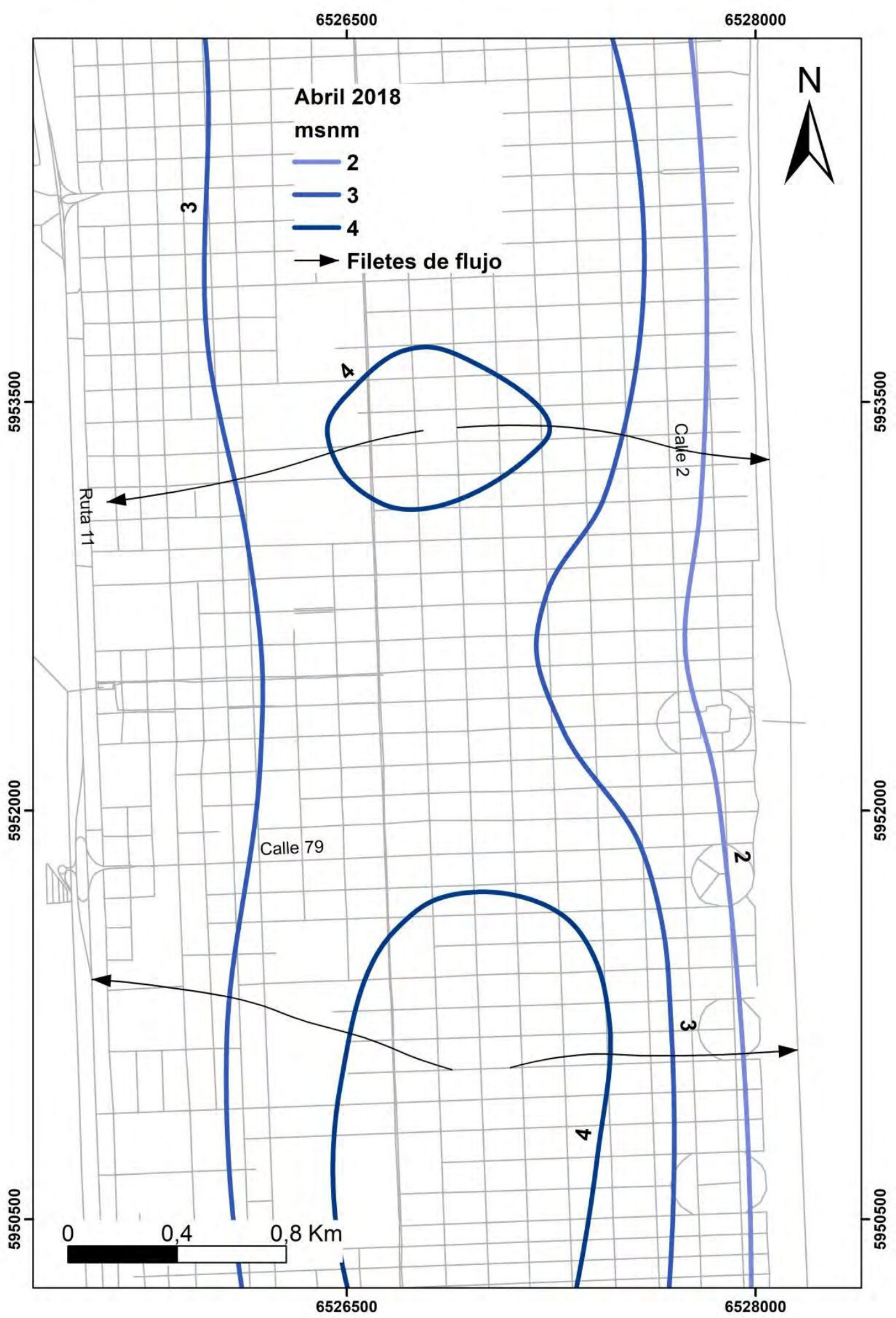

Figura 21. Mapa isofreático para abril de 2018. 


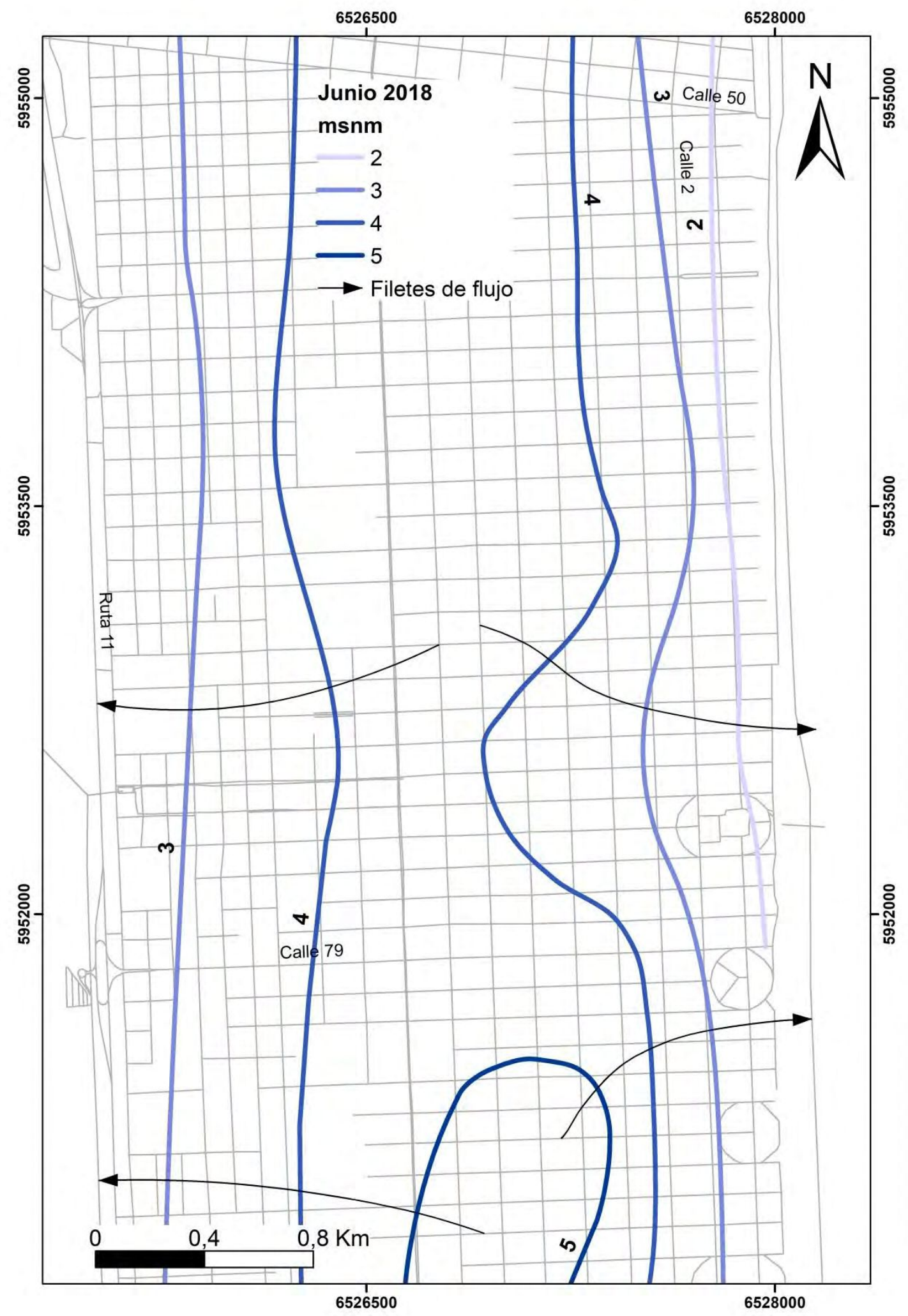

Figura 22. Mapa isofreático para junio de 2018. 


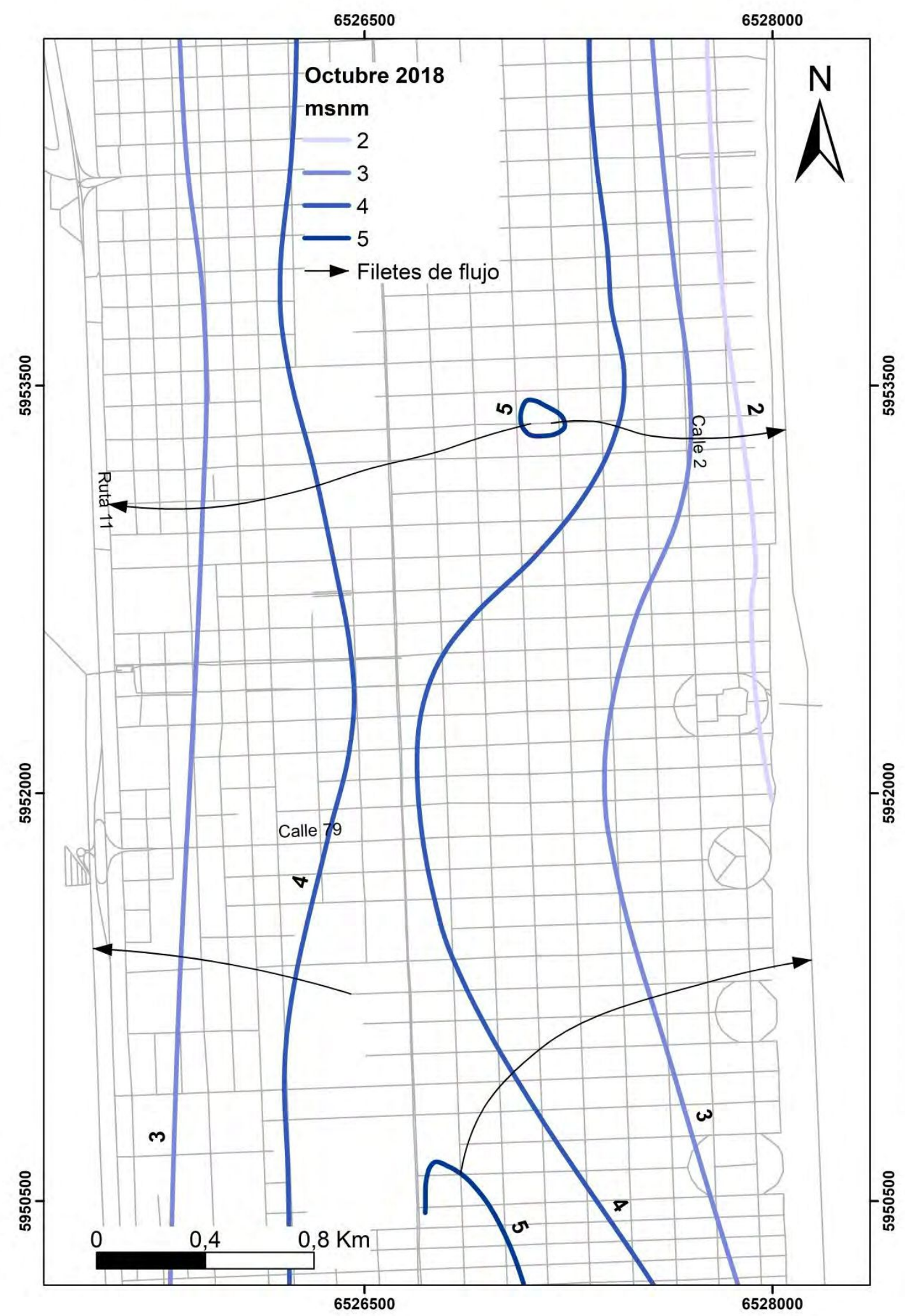

Figura 23. Mapa isofreático para octubre de 2018. 


\section{Anexo 6}

Mapas de flujo

Costa estuárica
(Berisso)
2016-2017 


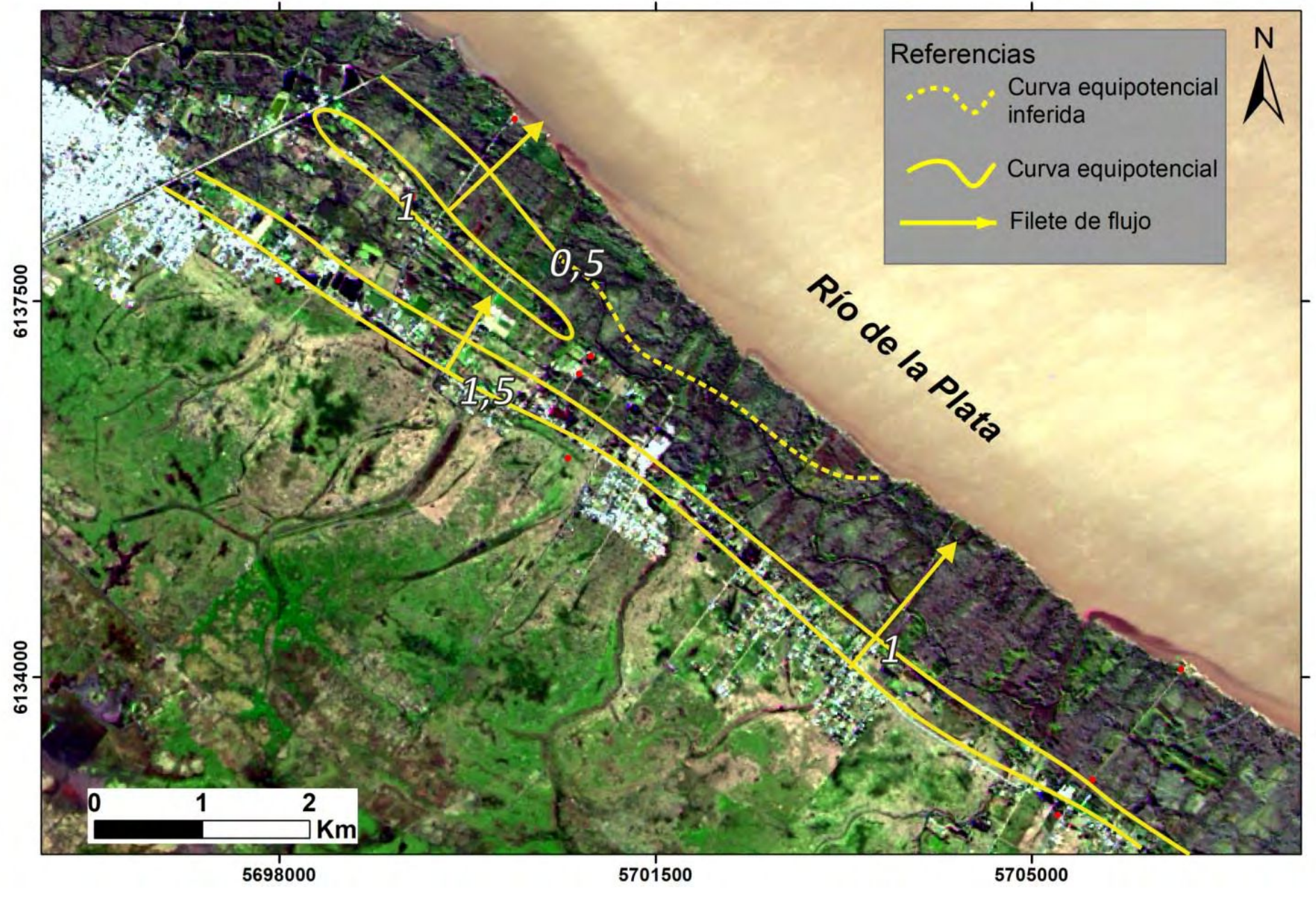

Figura 1. Mapa isofreático para junio de 2016. 


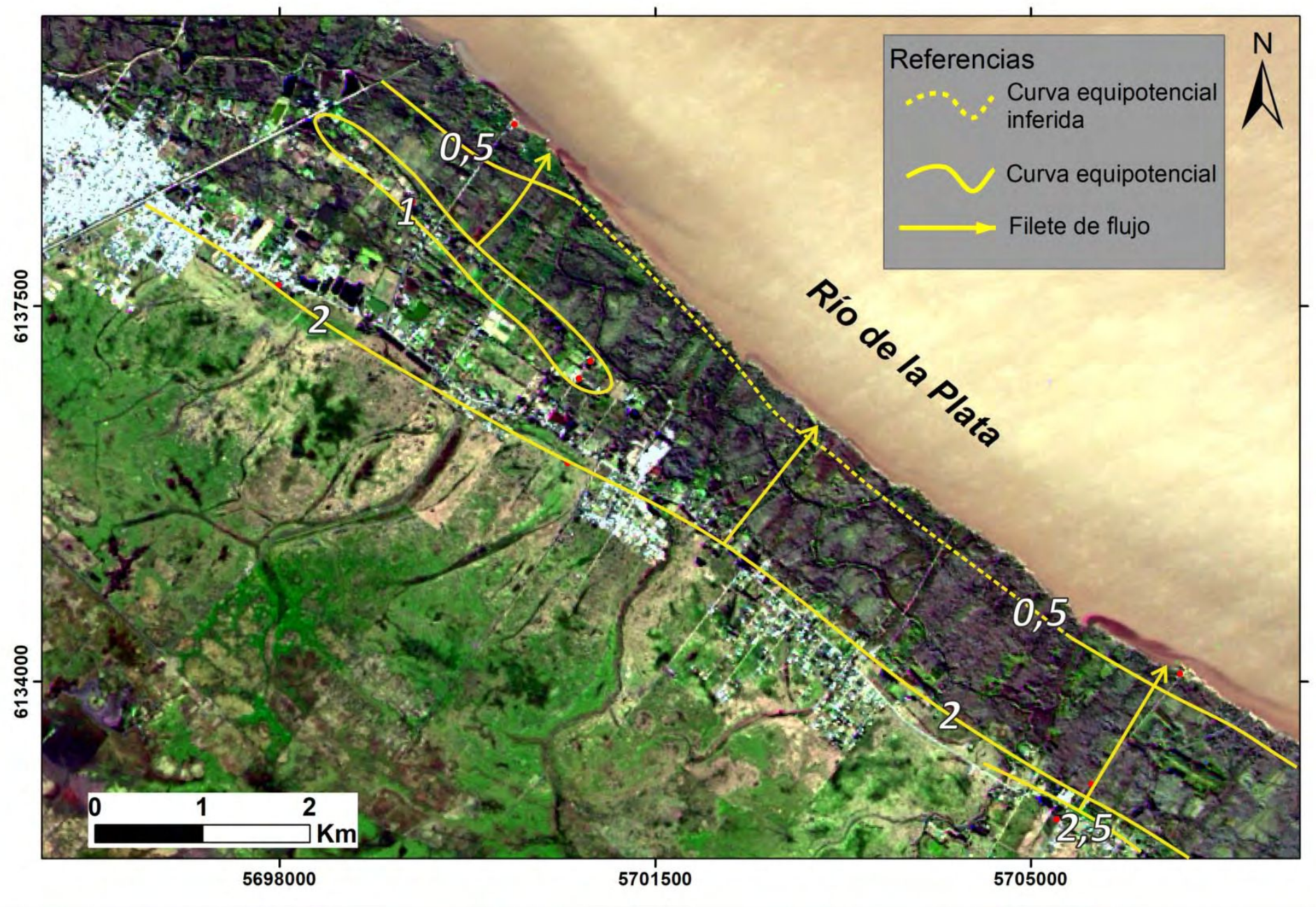

Figura 2. Mapa isofreático para julio de 2016. 


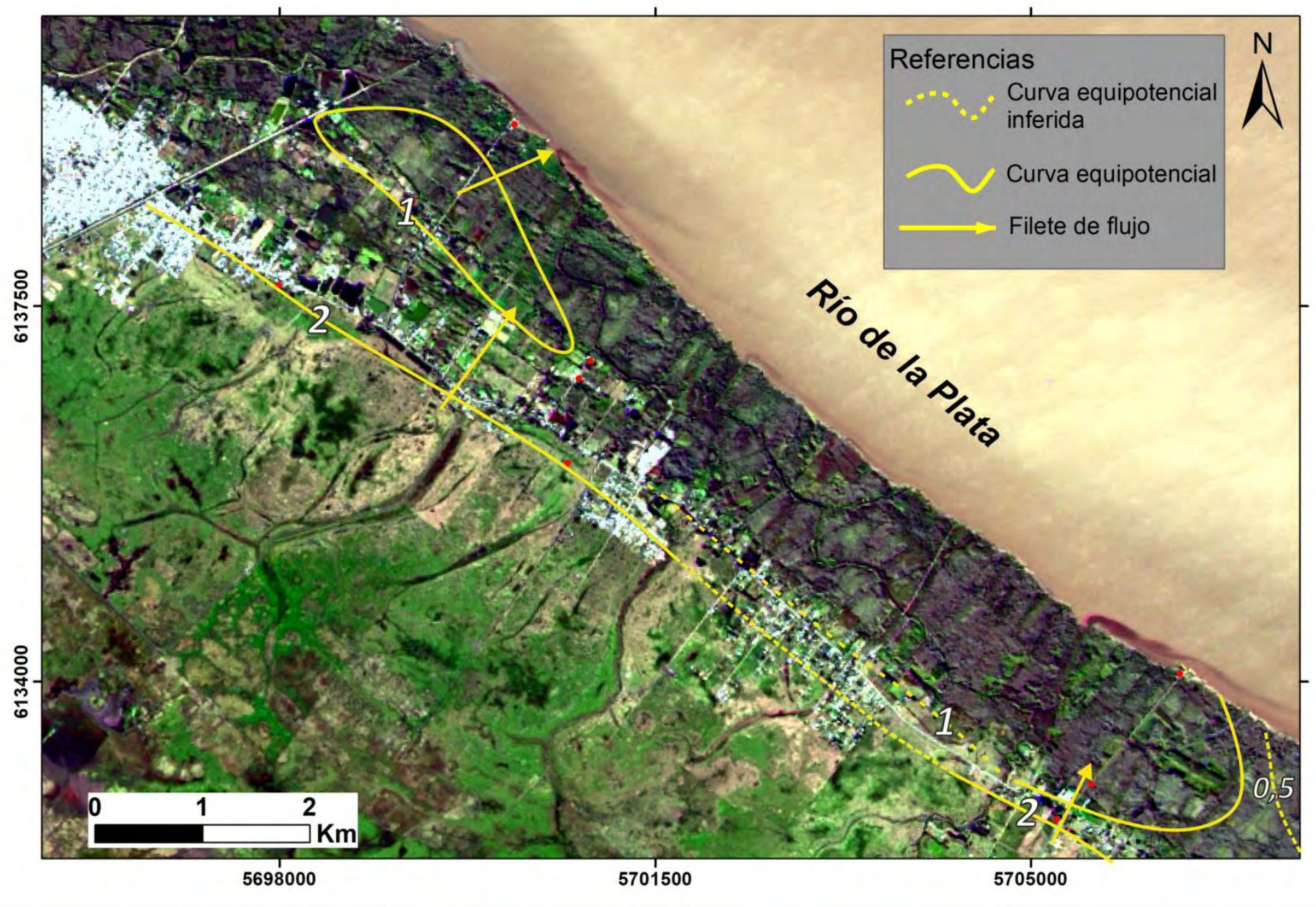

Figura 3. Mapa isofreático para octubre de 2016. 


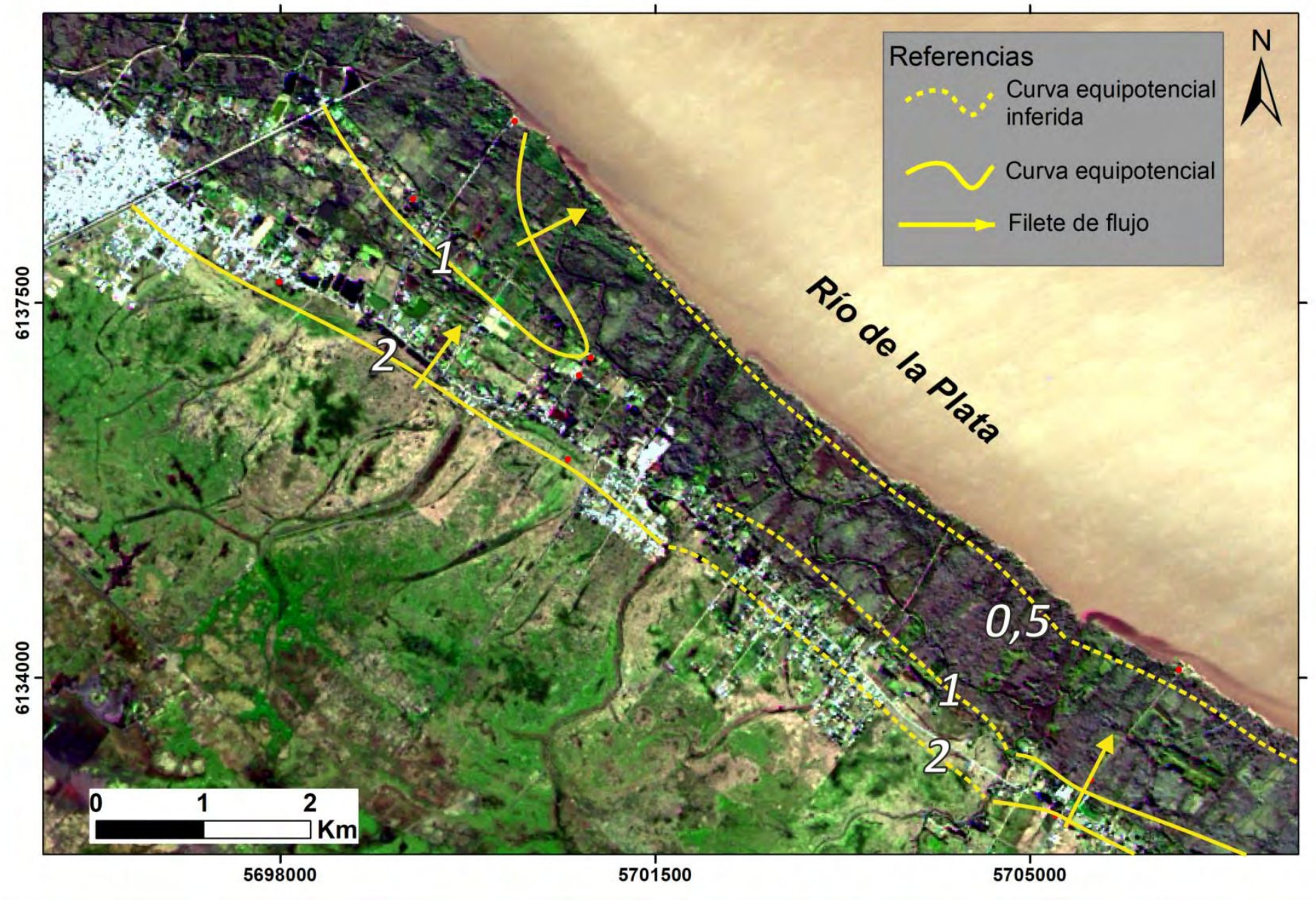

Figura 4. Mapa isofreático para diciembre de 2016. 


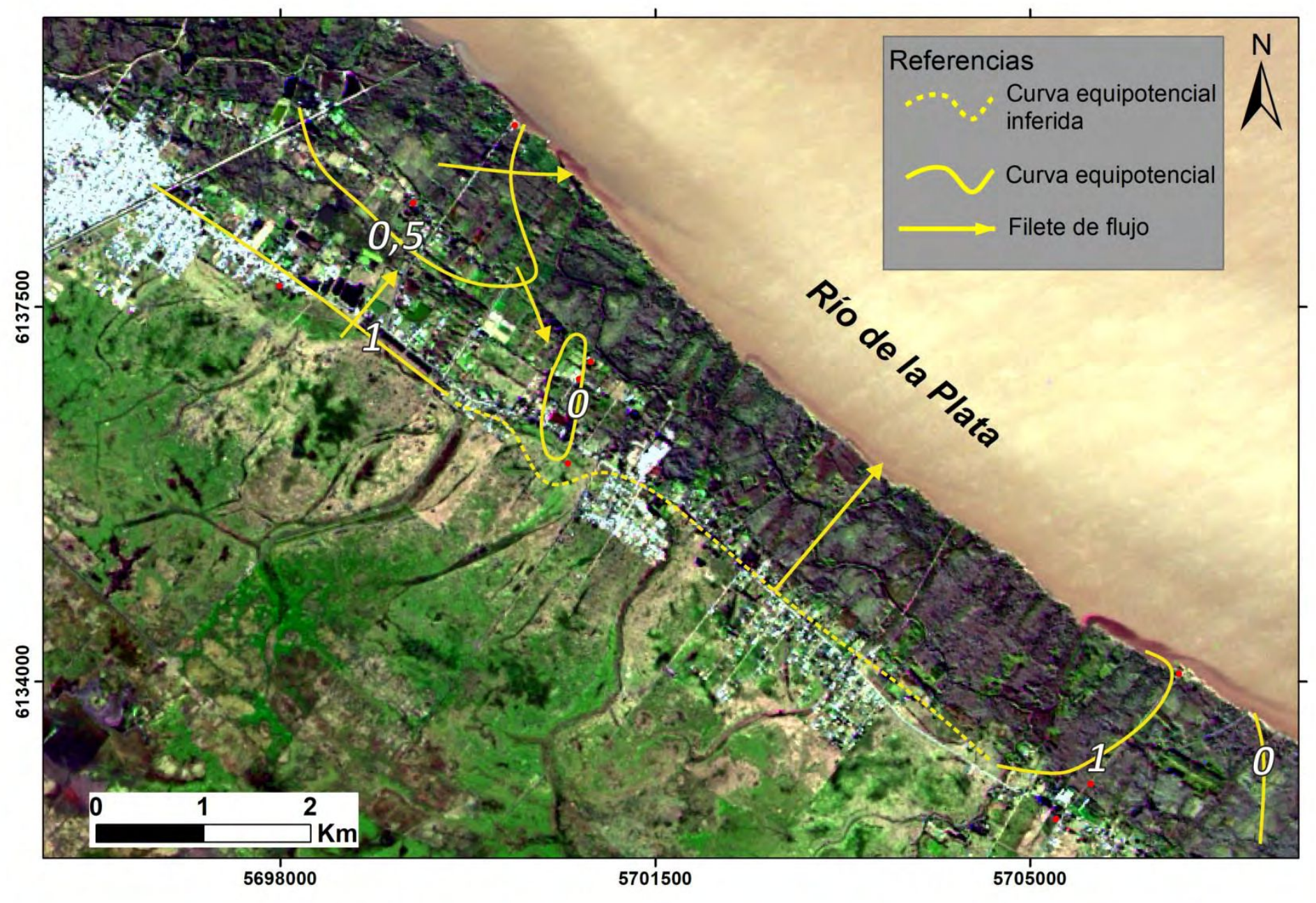

Figura 5. Mapa isofreático para febrero de 2017. 


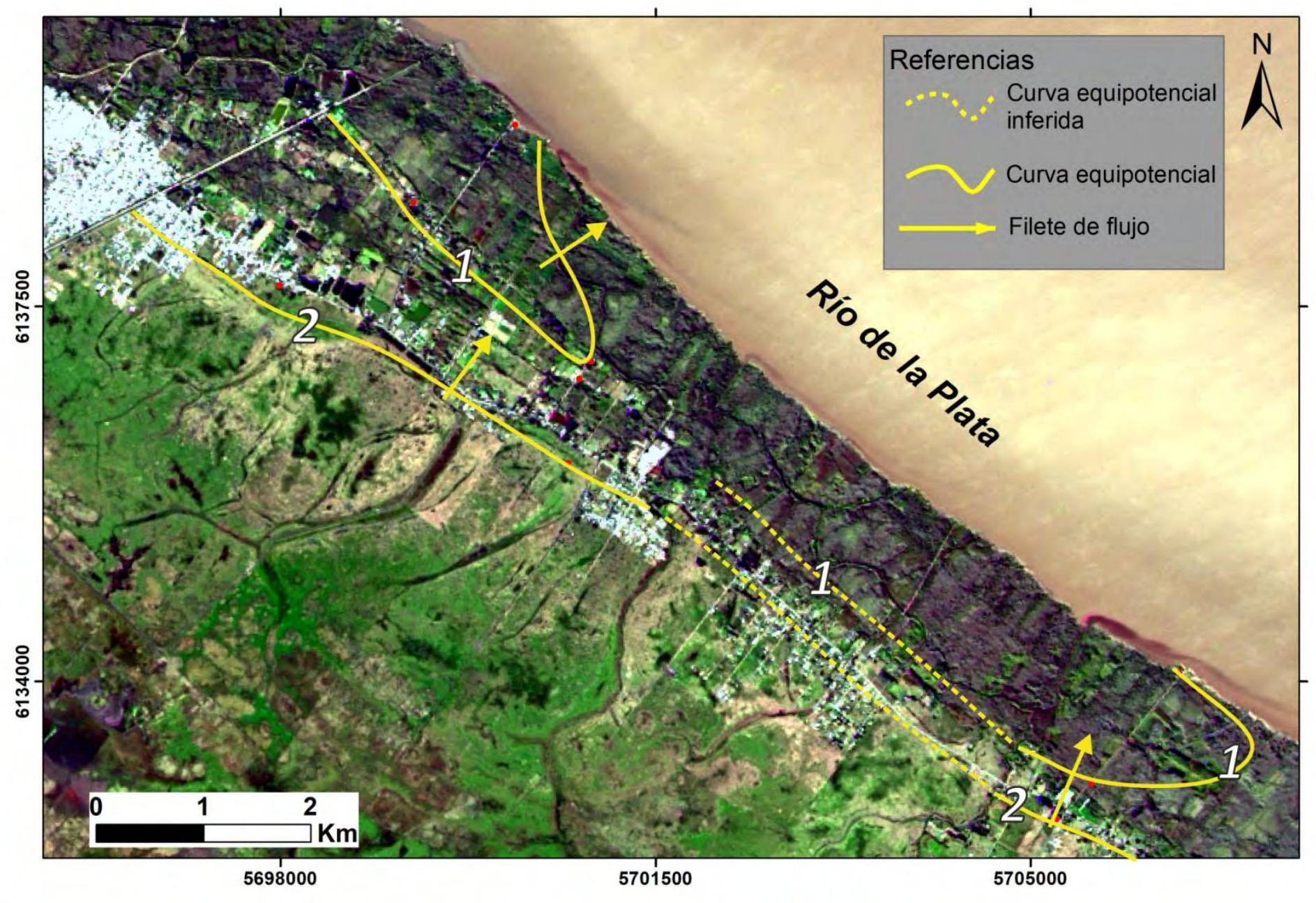

Figura 6. Mapa isofreático para mayo de 2017. 


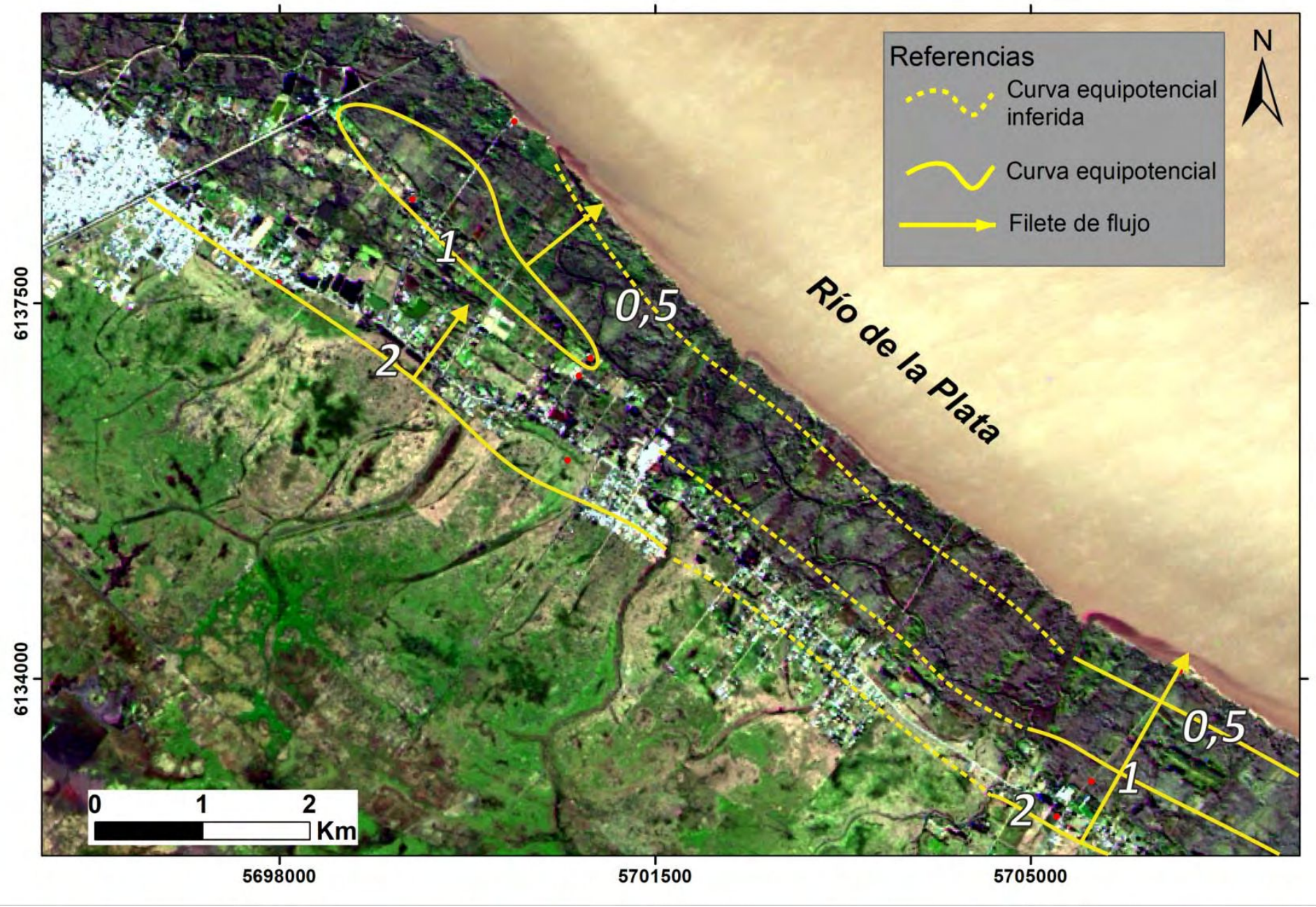

Figura 7. Mapa isofreático para julio de 2017. 


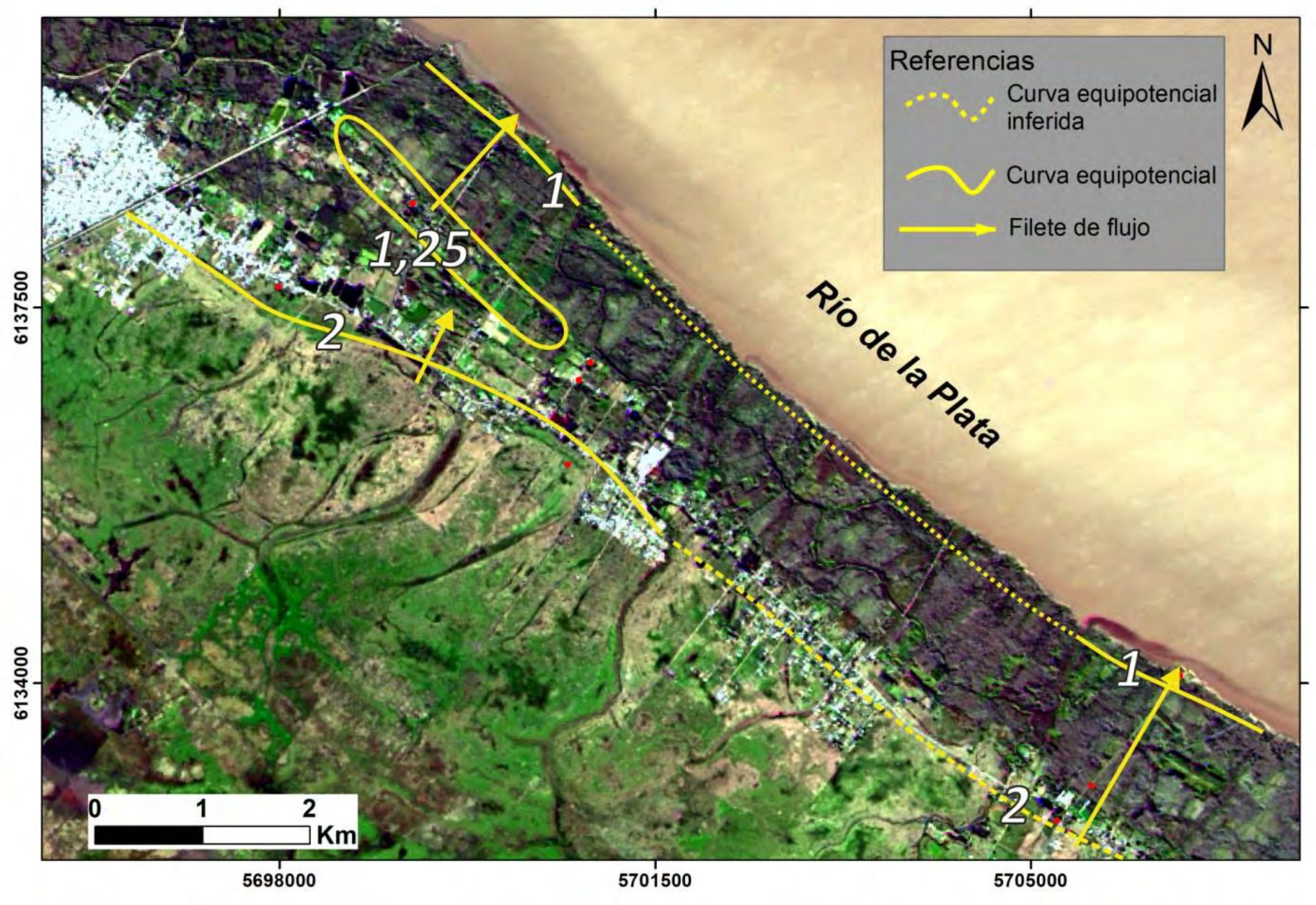

Figura 8. Mapa isofreático para septiembre de 2017. 


\section{Anexo 7}

\section{Protocolos}

\section{Análisis isotópicos}




\section{FORMULARIO DE RESULTADOS DE ENSAYOS - 16/05/2020}

Ensayo realizado: Medición de isótopos de oxigeno $\left(\delta^{18} \mathrm{O}\right)$ e hidrógeno $\left(\delta^{2} H\right)$ en Cliente: Silvina Carretero(Cátedra Hidrología Gral, Fac. Cs Nat. y Museo U. N. La Plata) Tel.- email: scarretero@fcnym.unlp.edu.ar -
Laboratorio GEA (Grupo de Estudios Ambientales)

Instituto de Matemática Aplicada San Luis UNSL - CONICET

Avenida Ejercito de los Andes 950 (San Luis) cp. 5700

Tel.: 0266 - 4520300 interno:3034

e-mail: silvinaballesteros@gmail.com/http://gea.unsl.edu.ar/servicios.php

\begin{tabular}{|c|c|c|c|c|c|c|c|}
\hline \multirow{2}{*}{$\begin{array}{l}\mathrm{N}^{\circ} \text { Identif. } \\
\text { Lab - GEA }\end{array}$} & \multirow[t]{2}{*}{ Rotulo muestra } & \multirow[t]{2}{*}{ Sitio } & \multirow[t]{2}{*}{ Procedencia } & \multirow{2}{*}{$\begin{array}{c}C \mathrm{CE} \\
\text { (us } / \mathrm{cm} \text { ) }\end{array}$} & \multicolumn{2}{|c|}{ Valores corregidos por deriva } & \multirow[t]{2}{*}{ Observaciones } \\
\hline & & & & & & $\delta^{2} \mathrm{H}$ & \\
\hline IE0351 & MT1 & Mar de Tuyú & & & -5.09 & -31.69 & \\
\hline IE0352 & MT2 & Mar de Tuyú & & & -4.76 & -27.75 & \\
\hline IE0353 & MT3 & Mar de Tuyú & & & -5.98 & -37.67 & \\
\hline IE0354 & MT4 & Mar de Tuyú & & & $\mid-3.97$ & -22.34 & \\
\hline IE0355 & MT5 & Mar de Tuyú & & & -6.34 & -41.30 & \\
\hline IE0356 & MT6 & Mar de Tuyú & & & -3.86 & -20.19 & \\
\hline IE0357 & MT7 & Mar de Tuyú & & & -4.71 & -27.28 & \\
\hline IE0358 & MT8 & Mar de Tuyú & & & -4.84 & -28.16 & \\
\hline IE0359 & MT10 & Mar de Tuyú & & & -4.46 & -24.23 & \\
\hline IE0360 & MT11 & Mar de Tuyú & & & -3.81 & -19.03 & \\
\hline IE0361 & MT12 & Mar de Tuyú & & & -4.41 & -25.05 & \\
\hline IE0362 & MT13 & Mar de Tuyú & & & -4.14 & -24.22 & \\
\hline IE0363 & MT14 & Mar de Tuyú & & & -4.14 & -23.64 & \\
\hline IE0364 & MT15 & Mar de Tuyú & & & -4.18 & -24.61 & \\
\hline IE0365 & MT16 & Mar de Tuyú & & & -3.89 & -22.06 & \\
\hline IE0366 & MT17 & Mar de Tuyú & & & -5.49 & -33.13 & \\
\hline IE0367 & MT18 & Mar de Tuyú & & & -4.77 & -27.87 & \\
\hline IE0378 & MT19 & Mar de Tuyú & & & -5.58 & -33.36 & \\
\hline
\end{tabular}

\begin{tabular}{|c|c|c|}
\hline REDACTO & REVISO & APROBO \\
\hline Silvina Ballesteros & María Poca & María Poca \\
& & \\
\hline
\end{tabular}




\section{FORMULARIO DE RESULTADOS DE ENSAYOS - 16/05/2020}

Ensayo realizado: Medición de isótopos de oxigeno $\left(\delta^{18} \mathrm{O}\right)$ e hidrógeno $\left(\delta^{2} H\right)$ en Cliente: Silvina Carretero(Cátedra Hidrología Gral, Fac. Cs Nat. y Museo U. N. La Plata) Tel.- email: scarretero@fcnym.unlp.edu.ar -
Laboratorio GEA (Grupo de Estudios Ambientales)

Instituto de Matemática Aplicada San Luis UNSL - CONICET

Avenida Ejercito de los Andes 950 (San Luis) cp. 5700

Tel.: 0266 - 4520300 interno:3034

e-mail: silvinaballesteros@gmail.com/http://gea.unsl.edu.ar/servicios.php

\begin{tabular}{|c|c|c|c|c|c|c|c|}
\hline \multirow{2}{*}{$\begin{array}{l}\mathrm{N}^{\circ} \text { Identif. } \\
\text { Lab - GEA }\end{array}$} & \multirow[t]{2}{*}{ Rotulo muestra } & \multirow[t]{2}{*}{ Sitio } & \multirow[t]{2}{*}{ Procedencia } & \multirow{2}{*}{$\begin{array}{c}\text { CE } \\
\text { (us } / \mathrm{cm} \text { ) }\end{array}$} & \multicolumn{2}{|c|}{ Valores corregidos por deriva } & \multirow[t]{2}{*}{ Observaciones } \\
\hline & & & & & $\delta^{18} \mathrm{O}$ & $\delta^{2} \mathrm{H}$ & \\
\hline IE0368 & $\mathrm{P} 1$ & Berisso & & & -4.41 & -23.81 & \\
\hline IE0369 & $\mathrm{P} 2$ & Berisso & & & -2.95 & -9.64 & \\
\hline IE0370 & $\mathrm{P3}$ & Berisso & & & -4.40 & -23.39 & \\
\hline IE0371 & P4 & Berisso & & & -4.39 & -23.73 & \\
\hline IE0372 & P5 & Berisso & & & -4.96 & -25.46 & \\
\hline IE0373 & P6 & Berisso & & & -5.03 & -26.94 & \\
\hline IE0374 & $\mathrm{P} 8$ & Berisso & & & -3.46 & -18.77 & \\
\hline IE0375 & $\mathrm{P9}$ & Berisso & & & -5.52 & -30.34 & \\
\hline IE0376 & P10 & Berisso & & & -3.35 & -18.66 & \\
\hline IE0377 & P11 & Berisso & & & -4.17 & -22.64 & \\
\hline
\end{tabular}

\begin{tabular}{|c|c|c|}
\hline REDACTO & REVISO & APROBO \\
\hline Silvina Ballesteros & María Poca & María Poca \\
& & \\
\hline
\end{tabular}




\section{Anexo 8}

\section{Balances}

hidrológicos diarios

Costa marítima

(Mar del Tuyú) 
Balance Hidrológico Diario

2016

Area De Estudio: MDT_2015_2018

ENERO
EXC. E.R.

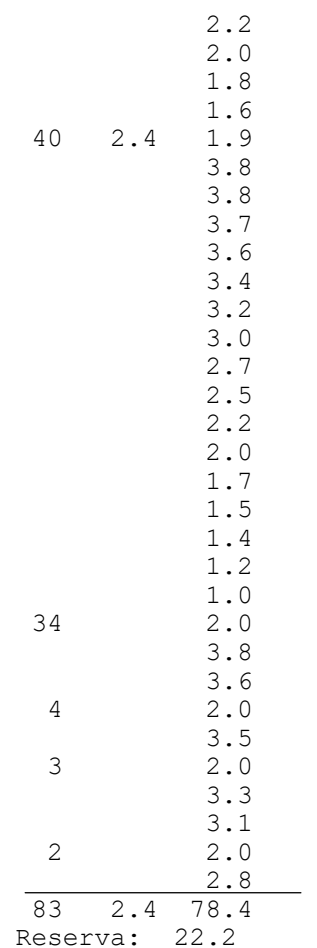

Reserva: 22.2

JULIO
$P$ EXC. E.R.

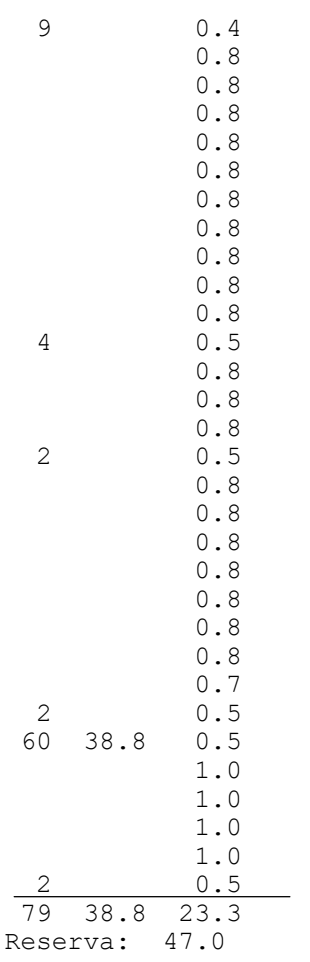

AGOSTO
$P \quad$ EXC. E.R.

P EXC. E.R.

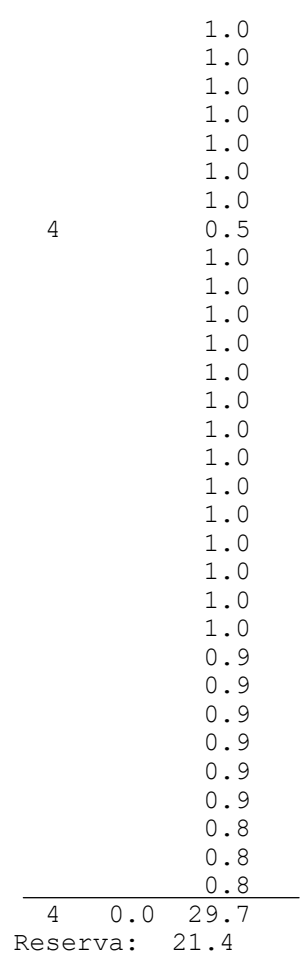

SEPTIEMBRE

Estación:

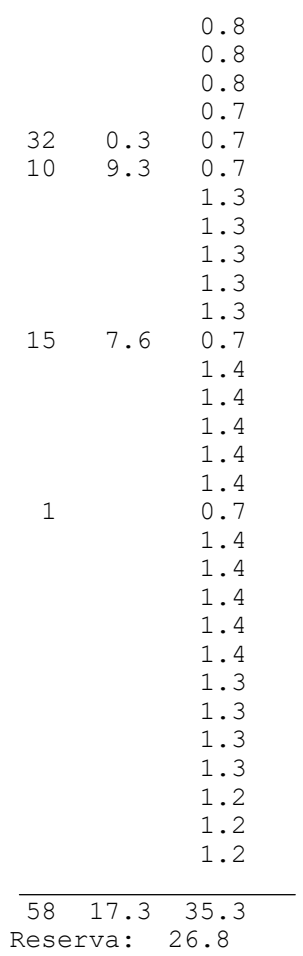

ABRIL
P EXC. E.R.

\begin{tabular}{|c|c|c|}
\hline \multirow{4}{*}{5} & & $\begin{array}{l}0.6 \\
0.5\end{array}$ \\
\hline & & 0.5 \\
\hline & & $\begin{array}{l}1.2 \\
0.7\end{array}$ \\
\hline & & 0.6 \\
\hline & & 0.6 \\
\hline \multirow[t]{5}{*}{2} & & 1.2 \\
\hline & & 0.6 \\
\hline & & 0.5 \\
\hline & & 0.5 \\
\hline & & 0.5 \\
\hline \multirow[t]{2}{*}{46} & 2.1 & 1.1 \\
\hline & & 2.2 \\
\hline \multirow[t]{4}{*}{11} & 7.6 & 1.1 \\
\hline & & 2.2 \\
\hline & & 2.1 \\
\hline & & 2.1 \\
\hline \multirow[t]{8}{*}{22} & 14.5 & 1.1 \\
\hline & & 2.1 \\
\hline & & 2.0 \\
\hline & & 2.0 \\
\hline & & 1.9 \\
\hline & & 1.9 \\
\hline & & 1.8 \\
\hline & & 1.8 \\
\hline \multirow[t]{4}{*}{1} & & 0.9 \\
\hline & & 1.7 \\
\hline & & 1.6 \\
\hline & & 1.5 \\
\hline 87 & 24.2 & 39.2 \\
\hline 30 & va: & .6 \\
\hline
\end{tabular}

OCTUBRE P EXC. E.R.

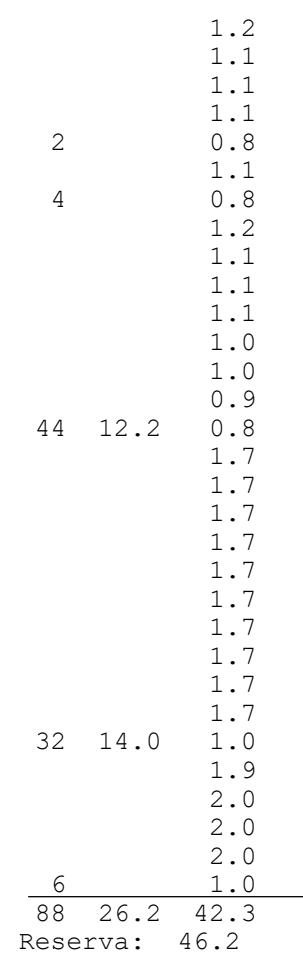

MAYO
P EXC E TUNIO
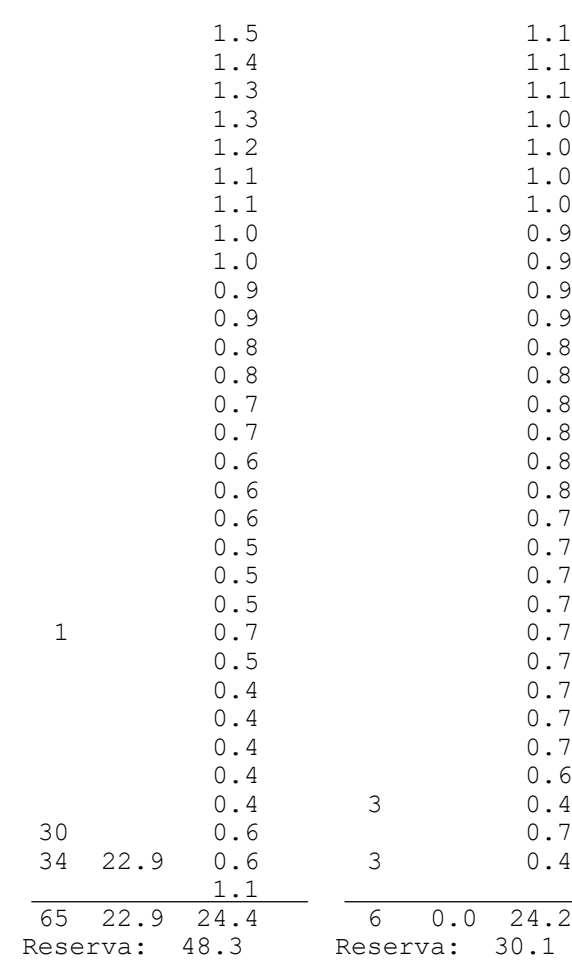

1.1

1.1

1.0

1.0

1.0

1.0

0.9

0.9

0.9

0.9

0.8

0.8

0.8

0.8

0.8

0.7
0.7

0.7

0.7

0.7

0.7

0.7

0.7

0.7

0.6
0.4

0.7

3

0.4

$\begin{array}{lll}6 & 0.0 & 24.2\end{array}$

Reserva: 30.1

NOVIEMBRE

P EXC. E.R.

DICIEMBRE

$\begin{array}{lll}2 & 1.0 & 1.0\end{array}$

$23 \quad 20.2 \quad 1.0$

2.1

2.1

2.1
2.1

2.1

2. 0

$6 \quad 1.1$

2.1

2.1

2.1

2.0

2.0

1.9

1. 9

1.2

5

22

0.9
0.8

0.8
-1.5

2.3

2. 2

2.1

1.9

1.8

1.7

1.5

$1 \cdot 4$

1.3
1.2

1.1

1.0

1.0
1.7

2.0
1.9

1.9
1.8
1.7

1.7

1. 6

1.6
1.5
1.5

1.5

1. 4

1. 3

1. 2

1.0

$\begin{array}{lll}36 & 20.2 & 51.0\end{array}$

Reserva: 11.1
1.2

1.1

1.0

1.2

1.0

1.8

1.6
1.5

1.3

1.2

$\begin{array}{lll}42 & 1.2 & 1.8\end{array}$

$81 \quad 1.2 \quad 42.7$

Reserva: 48.2 
Balance Hidrológico Diario

2017

Area De Estudio: MDT_2015_2018

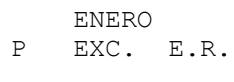

\begin{tabular}{|c|c|c|c|c|c|}
\hline 1 & & 1.9 & & & 0.6 \\
\hline & & 3.7 & & & 0.6 \\
\hline 88 & 77.9 & 1.9 & & & 0.5 \\
\hline & & 3.8 & & & 0.4 \\
\hline & & 3.8 & & & 0.4 \\
\hline & & 3.7 & 9 & & 1.9 \\
\hline & & 3.6 & & & 1.2 \\
\hline & & 3.4 & 6 & & 1.9 \\
\hline 6 & & 2.0 & & & 1.5 \\
\hline & & 3.5 & & & 1.3 \\
\hline & & 3.3 & & & 1.2 \\
\hline & & 3.0 & & & 1.0 \\
\hline & & 2.8 & & & 0.9 \\
\hline & & 2.5 & 4 & & 1.9 \\
\hline & & 2.3 & & & 1.0 \\
\hline & & 2.0 & & & 0.9 \\
\hline & & 1.8 & 16 & & 1.9 \\
\hline & & 1.6 & 20 & & 1.8 \\
\hline & & 1.4 & & & 3.4 \\
\hline 14 & & 2.0 & & & 3.3 \\
\hline & & 2.6 & & & 3.1 \\
\hline & & 2.3 & & & 2.8 \\
\hline & & 2.0 & 14 & & 1.8 \\
\hline & & 1.8 & & & 3.3 \\
\hline & & 1.6 & & & 3.1 \\
\hline & & 1.4 & 11 & & 1.7 \\
\hline & & 1.2 & 21 & 12.7 & 1.7 \\
\hline & & 1.1 & 3 & 1.3 & 1.7 \\
\hline & & 1.0 & & & \\
\hline & & 0.8 & & & \\
\hline & & 0.7 & & & \\
\hline & 77.9 & 70.3 & 104 & 14.0 & 46.9 \\
\hline $\operatorname{Res}$ & ra: & 5.2 & Res & rva: & 8.3 \\
\hline
\end{tabular}

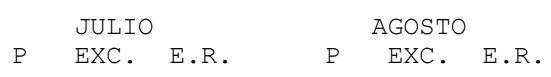

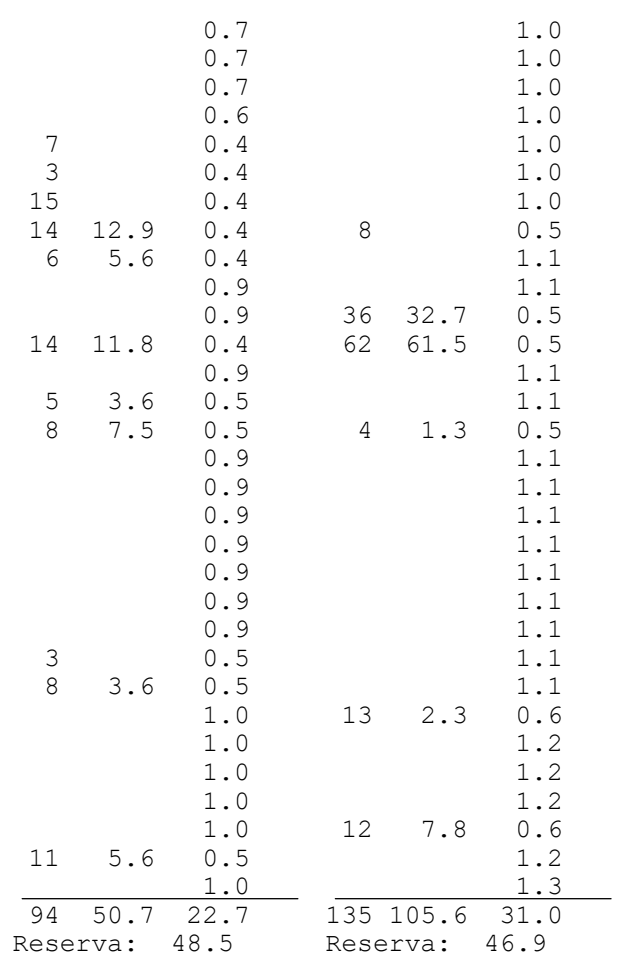

Estación:

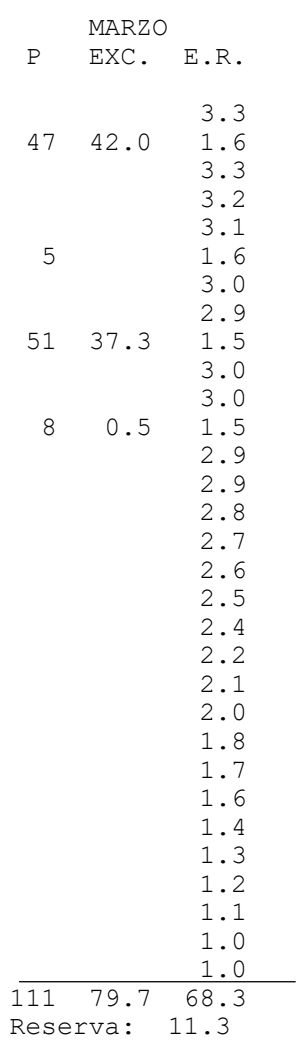

ABRIL
PXC. E.R.

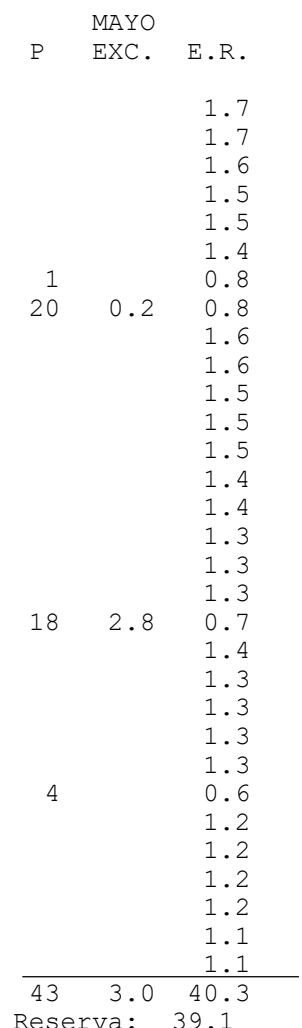

PUNIO

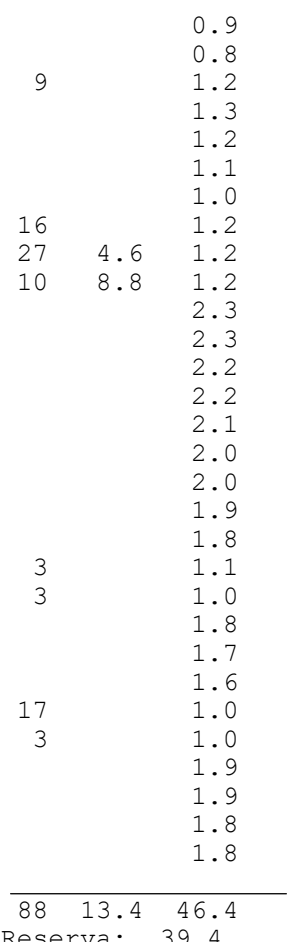

Reserva: 39.1

\begin{tabular}{cc}
\hline $11 \quad 0.0$ & 22.2 \\
Reserva: & 27.9
\end{tabular}
1.1

1.1

1.0
1.0

0.9

0.9

0.9

0.8

0.8

0.8

0.7

0.7

0.4

0.4

0.8

0.7
0.7

0.7

0.7

0.4
0.7

0.7

0.7

0.4

0.7
0.7

0.7 \begin{tabular}{ccc}
\multicolumn{2}{c}{ NOVIEMBRE } & \multicolumn{2}{c}{ DICIEMBRE } \\
$\mathrm{P}$ EXC. E.R. & $\mathrm{P}$ & EXC. E.R.
\end{tabular}

P EXC. E.R.
OCTUBRE $P$ EXC. E.R.

\section{DXC.}

\begin{tabular}{|c|c|c|}
\hline \multicolumn{2}{|l|}{20} & 0.8 \\
\hline \multirow[t]{7}{*}{1} & & 0.8 \\
\hline & & 1.5 \\
\hline & & 1.5 \\
\hline & & 1.4 \\
\hline & & 1.4 \\
\hline & & 1.4 \\
\hline & & 1.4 \\
\hline \multirow[t]{9}{*}{10} & & 0.8 \\
\hline & & 1.5 \\
\hline & & 1.5 \\
\hline & & 1.5 \\
\hline & & 1.5 \\
\hline & & 1.5 \\
\hline & & 1.4 \\
\hline & & 1.4 \\
\hline & & 1.4 \\
\hline 27 & 5.1 & 0.9 \\
\hline \multirow[t]{8}{*}{1} & 0.1 & 0.9 \\
\hline & & 1.8 \\
\hline & & 1.8 \\
\hline & & 1.8 \\
\hline & & 1.8 \\
\hline & & 1.8 \\
\hline & & 1.8 \\
\hline & & 1.8 \\
\hline \multirow[t]{2}{*}{1} & & 1.0 \\
\hline & & 1.8 \\
\hline 26 & 10.9 & 1.0 \\
\hline \multirow[t]{2}{*}{12} & 11.0 & 1.0 \\
\hline & & 2.0 \\
\hline 98 & 27.2 & 43.6 \\
\hline & va: & 7.0 \\
\hline
\end{tabular}

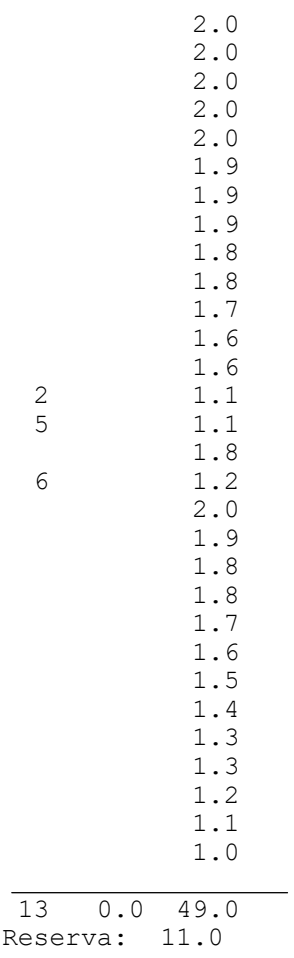

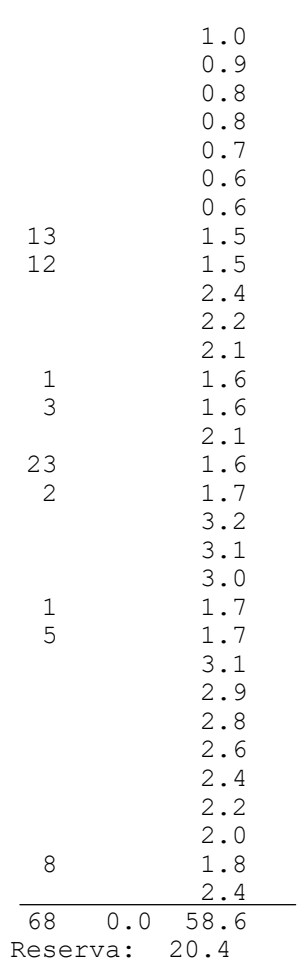

0.7

.6

.1

4

1.8
2.4

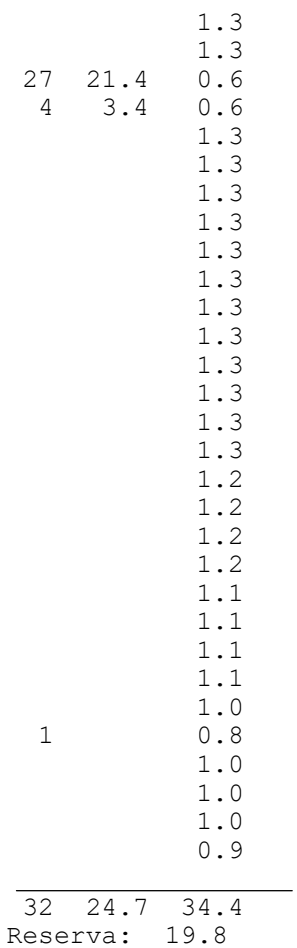

Reserva: 19.8 
Balance Hidrológico Diario

\section{8}

\section{Area De Estudio: MDT_2015_2018}

\begin{tabular}{|c|c|c|}
\hline \multirow[b]{2}{*}{$\mathrm{P}$} & \multicolumn{2}{|l|}{ ENERO } \\
\hline & $\mathrm{EXC}$ & E.R. \\
\hline & & 2.2 \\
\hline 1 & & 1.9 \\
\hline & & 1.9 \\
\hline 3 & & 1.9 \\
\hline 4 & & 1.9 \\
\hline & & 2.1 \\
\hline & & 1.9 \\
\hline & & 1.7 \\
\hline & & 1.5 \\
\hline & & 1.4 \\
\hline & & 1.2 \\
\hline & & 1.1 \\
\hline & & 1.0 \\
\hline 6 & & 2.0 \\
\hline & & 1.3 \\
\hline & & 1.2 \\
\hline & & 1.0 \\
\hline & & 0.9 \\
\hline & & 0.8 \\
\hline & & 0.7 \\
\hline & & 0.6 \\
\hline & & 0.5 \\
\hline & & 0.5 \\
\hline & & 0.4 \\
\hline & & 0.3 \\
\hline & & 0.3 \\
\hline & & 0.3 \\
\hline & & 0.2 \\
\hline & & 0.2 \\
\hline & & 0.2 \\
\hline & & 0.2 \\
\hline 14 & 0.0 & 33.3 \\
\hline e & & 1.1 \\
\hline
\end{tabular}

FEBRERO
P EXC. E.R.

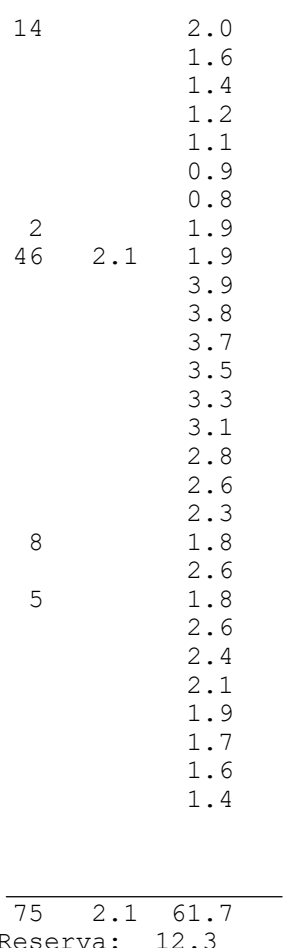

AgOSTO

P EXC. E.R.

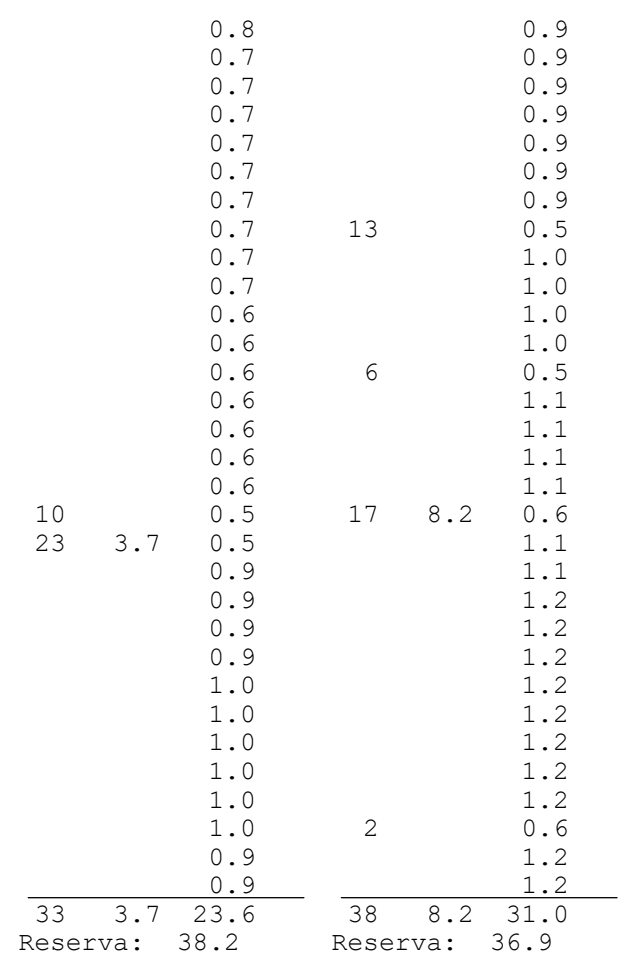

Estación:

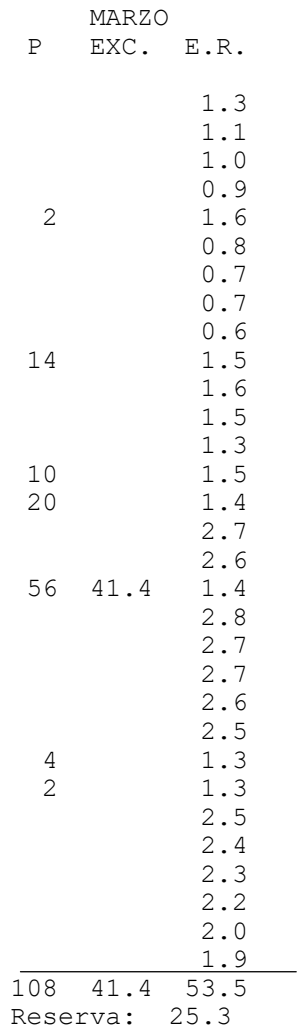

ABRIL
P EXC. E.R.

\section{8}

1.7
1.6

1.6
1.5

1.4

1.2

1.3

1.2

1.1

1.0
1.2

26
2

1.1

2.1

2.1

2.0

1.9

$\begin{array}{rrr}3 & & 1.1 \\ 39 & 20.3 & 1.1\end{array}$

1.1
2.1
2.1

2.1

2.0

2.0

1.9

1.9

1.8

1.0

1.9

0.9

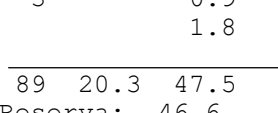

Reserva: 46.6

MAYO
$P \quad$ EXC.

E.R.

JUNIO

\begin{tabular}{|c|c|c|}
\hline & & 1.8 \\
\hline & & 0.9 \\
\hline \multirow[t]{6}{*}{3} & & 0.9 \\
\hline & & 1.7 \\
\hline & & 1.7 \\
\hline & & 1.7 \\
\hline & & 1.6 \\
\hline & & 1.6 \\
\hline \multirow[t]{2}{*}{16} & 4.8 & 0.8 \\
\hline & & 1.6 \\
\hline \multirow[t]{3}{*}{9} & 6.6 & 0.8 \\
\hline & & 1.5 \\
\hline & & 1.5 \\
\hline \multirow[t]{5}{*}{7} & 3.2 & 0.7 \\
\hline & & 1.5 \\
\hline & & 1.4 \\
\hline & & 1.4 \\
\hline & & 1.4 \\
\hline \multirow[t]{9}{*}{1} & & 0.7 \\
\hline & & 1.3 \\
\hline & & 1.3 \\
\hline & & 1.3 \\
\hline & & 1.2 \\
\hline & & 1.2 \\
\hline & & 1.2 \\
\hline & & 1.1 \\
\hline & & 1.1 \\
\hline 39 & 23.2 & 0.6 \\
\hline 13 & 12.4 & 0.6 \\
\hline \multirow[t]{2}{*}{17} & 16.4 & 0.6 \\
\hline & & 1.1 \\
\hline 06 & 66.5 & 37.8 \\
\hline
\end{tabular}

1.1

1.1

1.1

1.1

1.0

1.0
1.0

1. 0

.9

0.9

0.9
0.5

0.9

0.8

0.8

0.8

0.8

0.8

0.8

0.8

5

0.4

0.8

0.8
0.8

0.8

0.8

0.8

0.8
0.8

0.8

0.8

$10 \quad 0.0 \quad 25.7$ Reserva: 32.5

SEPTIEMBRE OCTUBRE NOVIEMBRE P EXC. E.R. P EXC. E.R. P EXC. E.R. DICIEMBRE

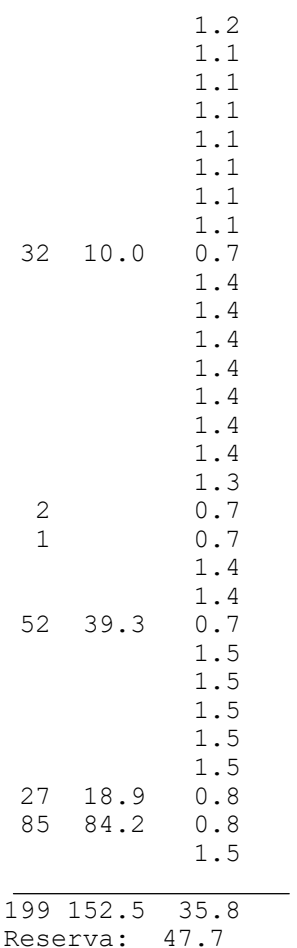

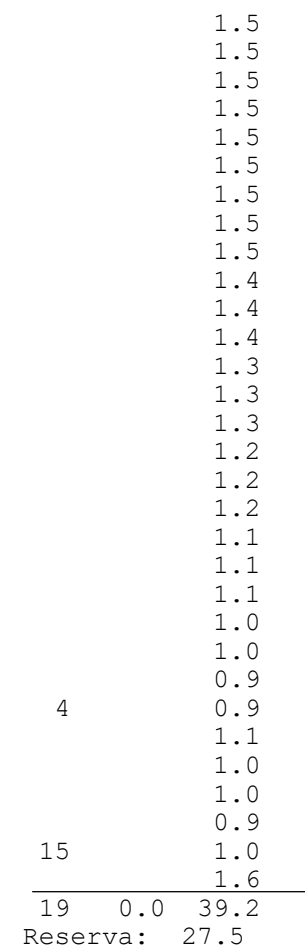

P EXC. E.R.

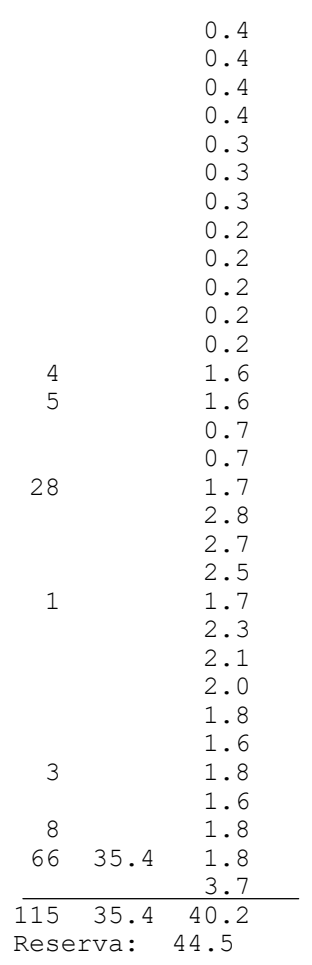

